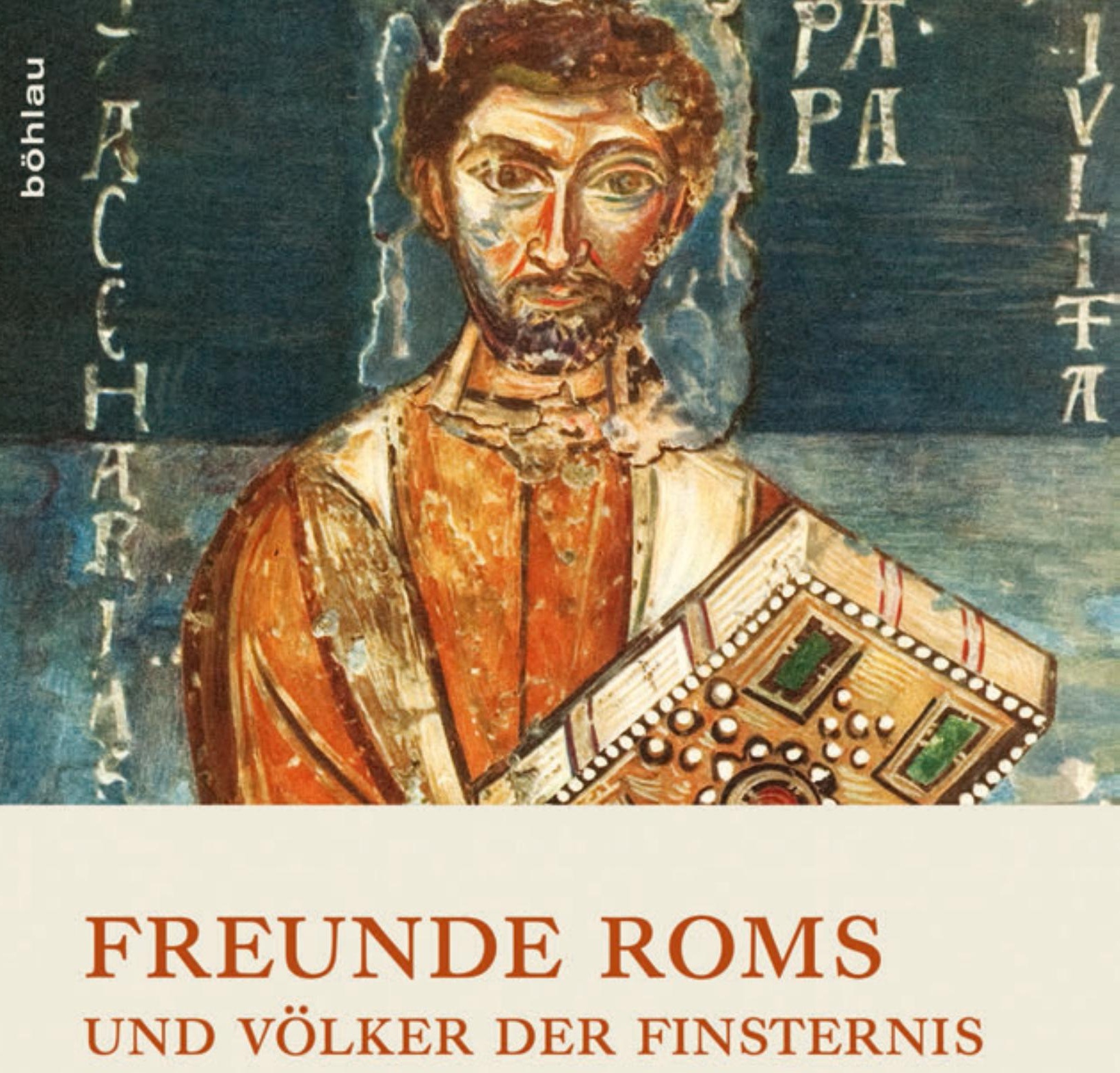

Die päpstliche Konstruktion von Anderen im 8. und 9. Jahrhundert

CLEMENS GANTNER 
böhlau 



\section{FREUNDE ROMS UND VÖLKER DER FINSTERNIS}

Die päpstliche Konstruktion von Anderen im 8. und 9. Jahrhundert

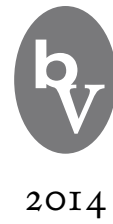

Böhlau Verlag Wien Köln Weimar 


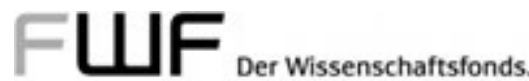

\section{Veröffentlicht mit Unterstützung des Austrian Science Fund (FWF): PUB 185-V21}

Bibliografische Information der Deutschen Nationalbibliothek:

Die Deutsche Nationalbibliothek verzeichnet diese Publikation in der Deutschen Nationalbibliografie; detaillierte bibliografische Daten sind im Internet über http://dnb.d-nb.de abrufbar.

Umschlagabbildung: Joseph Wilpert (Hg.), Die römischen Mosaiken und Malereien der kirchlichen Bauten vom IV. bis zum XIII. Jahrhundert, Band 4: Tafeln: Malereien, Seite I8 I a, Freiburg im Br. I 9 I 6 (C) Universitätsbibliothek Heidelberg

(C) 2014 by Böhlau Verlag Ges.m.b.H \& Co. KG, Wien Köln Weimar Wiesingerstraße I, A- го го Wien, www.boehlau-verlag.com

Alle Rechte vorbehalten. Dieses Werk ist urheberrechtlich geschützt.

Jede Verwertung außerhalb der engen Grenzen des Urheberrechtsgesetzes ist unzulässig.

Lektorat: Michael Suppanz, Klagenfurt

Umschlaggestaltung: Michael Haderer, Wien

Satz: Michael Rauscher, Wien

Druck und Bindung: Prime Rate kft., Budapest

Gedruckt auf chlor- und säurefrei gebleichtem Papier

Printed in the EU

ISBN $978-3-205-79593-3$ 


\section{Inhalt}

Abkürzungsverzeichnis . . . . . . . . . . . . . . . . 9

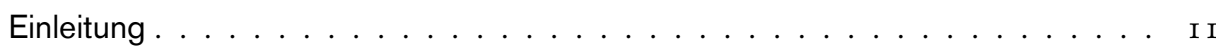

1. Zu den Quellen des achten und neunten Jahrhunderts . . . . . . . . . I6

I.I Der Liber Pontificalis . . . . . . . . . . . . . . . . . . . . I6

I.r.I Die Vorlagen und die ersten Versionen . . . . . . . . . . . . . . . . I6

I.r.2 Genre und Erstellung des Liber Pontificalis . . . . . . . . . . . . . . 2 I

I.I.3 Textvarianten des Liber Pontificalis im achten Jahrhundert . . . . . . . . 26

I.r.3.I Die zwei Versionen der Vita Gregors II. . . . . . . . . . . . . . . . . . . 26

I.I.3.2 Die Rezensionen des Liber Pontificalis im achten Jahrhundert unter besonderer Berücksichtigung der Vita Stephans II. . . . . . . . . . . . 28

I.2 Der Codex epistolaris Carolinus . . . . . . . . . . . . . 38

I.3 Weitere Quellen . . . . . . . . . . . . . . . . 43

I.3.I Die Collectio Britannica . . . . . . . . . . . . . . . . . 44

I.3.2 Das Register Johannes VIII. . . . . . . . . . . . . . . . 45

2. Das Papsttum und die Anderen: Theoretische Überlegungen . . . . . . . 48

2.I L'image de l'autre, Extimität und Othering . . . . . . . . . . . . . 48

2.2 Zur Verwendung der Begriffe „Fremde“ und „Andere“ - Disclaimer und Versuch einer Definition . . . . . . . . . . . . . 57

3. Voraussetzungen: Der Papst, Rom und das imperium . . . . . . . . . . . 6o

3.I Der Papst und Rom im achten Jahrhundert . . . . . . . . . . . . . . . . 60

3.2 Das imperiale und "griechische“ Rom: Die Ewige Stadt als Knotenpunkt am Mittelmeer . . . . . . . . . . . . . . . . . 68

3.2.I Zum Verhältnis Rom-Griechen aus postkolonialer Sicht . . . . . . . . . 68

3.2.2 Die „Griechen“ und der Lateinische Westen in historischer Perspektive seit dem sechsten Jahrhundert . . . . . . . . . . . . 70

3.2.3 Greci als kulturelle und soziale Kategorie . . . . . . . . . . . . 88

3.2.4 Die römischen Griechen . . . . . . . . . . . . . 9I 
4. Die päpstliche Darstellung und Wahrnehmung der Greci im achten Jahrhundert . . . . . . . . . . . . . . . . . . IOI

4.I Das Bild des Ostens im Liber Pontificalis, ca.700-ca. 757 . . . . . . I02

4.2 Papstbriefe bis 772: Das Auftauchen der Bezeichnung Greci . . . . . . о8

4.3 Der Pontifikat Hadrians I.: Die formale Loslösung Roms . . . . . . . I I 8

4.4 Rom und die Greci: Zusammenfassung . . . . . . . . . . ${ }_{\text {I36 }}$

5. Das Papsttum zwischen Langobarden und Franken . . . . . . . . . . . I 39

5.I Die Wahrnehmung der Langobarden in Quellen zu den Pontifikaten

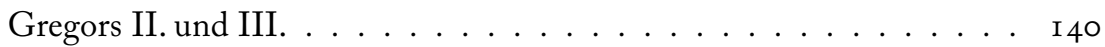

5.2 Zacharias, Liutprand und Ratchis . . . . . . . . . . . . . I 45

5.3 Stephan II. und die Langobarden . . . . . . . . . . . . . . . I 54

5.3.I Papst vs. Langobarden - Zusammenfassung der Vita Stephani . . . . . I 54

5.3.2 Die Langobarden bei Stephan II. - der Tiefpunkt? . . . . . . . . . . I ${ }_{5} 8$

$5.4 \quad$ Paul I. und Desiderius . . . . . . . . . . . . . . ${ }_{\text {I } 64}$

5.5 Stephan III. und der Codex Carolinus-Brief $45 \ldots \ldots$. . . . . . . 69

5.5.I Chaos in Rom: 767/768 und die Rolle des Desiderius . . . . . . . . 169

$5 \cdot 5.2$ Codex Carolinus Brief $45 \ldots \ldots \ldots \ldots$ I72

$5 \cdot 5 \cdot 3$ Der Besuch Bertradas und Stephans Kehrtwende . . . . . . . . . $\quad$ I82

5.5.4 Die Vita Stephans III. nach der Intervention Bertradas in Rom

(Frühling/Frühsommer 77r) . . . . . . . . . . . . . . . . . 83

5.6 Hadrian I. - Römische Ambivalenz . . . . . . . . . . . . . . ${ }_{\text {I } 85}$

5.6. I Die Vita Hadriani . . . . . . . . . . . . . . . . . I 85

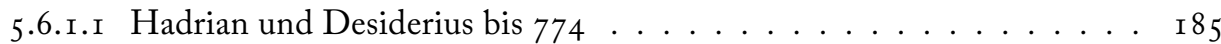

5.6.r.2 Ein differenziertes Langobardenbild . . . . . . . . . . . . . . . . I92

5.6.2 Der Codex Carolinus . . . . . . . . . . . . . . 997

5.6.2. I Die Briefe 50 und $5 \mathrm{I}$ und die Lage im langobardischen Tuszien . . . . $\quad$ I98

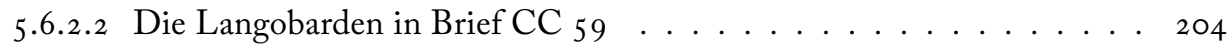

5.6.2.3 Langobardische Rebellionen? . . . . . . . . . . . . . . 207

5.6.2.4 Benevent und die Rückkehr des Adelchis . . . . . . . . . . . . . 2 Io

5.7 Die Wechselfälle der römischen Langobardenpolitik - Versuch einer

Zusammenfassung .................. 2 I 4

5.8 Die Franken: Freunde - Verbündete - Andere im achten Jahrhundert . 2 I 8

5.8. I Eine Sonderstellung der Franken? . . . . . . . . . . . . . 2 I9

5.8 .2 Die Franken als Andere? . . . . . . . . . . . . . . 228

6. Das neunte Jahrhundert und die sarazenische Bedrohung . . . . . . . . 244

6.I Die Päpste und die Sarazenen im achten und neunten Jahrhundert . 244 
6.2 Veränderung der Wahrnehmung: Das Umfeld des Papstes in Italien . . 257

6.3 Veränderung der Wahrnehmung: Krieg gegen Nichtchristen . . . . . . 264

6.4 Zusammenfassung: Der Einfluss der Sarazenen auf das Papsttum . . . 270

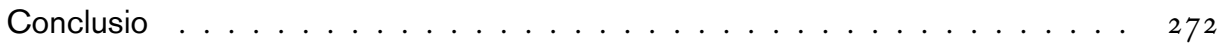

Tabellen-, Abbildungs-, Quellen- und Literaturverzeichnis . . . . . . . . . . . 282

Verzeichnis der Tabellen und Abbildungen . . . . . . . . . . . . . . 282

Tabellen. . . . . . . . . . . . . . . . . 282

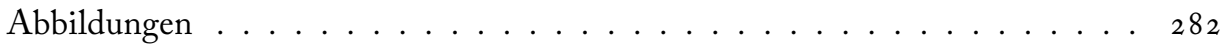

Verzeichnis der verwendeten Quellen . . . . . . . . . . . . . . . 282

Verzeichnis der verwendeten Literatur . . . . . . . . . . . . . . 285

Appendix: Die Textgruppen des Liber Pontificalis . . . . . . . . . . . . . 302

Die Textklassen und ihre wesentlichen handschriftlichen Textzeugen für das achte Jahrhundert . . . . . . . . . . . . . . . 302

Schematische Darstellung der wesentlichen Entwicklungen der

Handschriftenklassen . . . . . . . . . . . . . . 308

Die Entwicklung der Textklassen von Gregor II. bis Paul I. . . . . . . . . . . . 3 3 I3

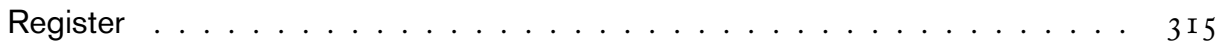

Personen, Orte und Sachen . . . . . . . . . . . . . 3 I5

Zitierte mittelalterliche Handschriften . . . . . . . . . . . . . 322 



\section{Abkürzungsverzeichnis}

Bibel

Für die Bücher der Bibel werden gängige deutsche Abkürzungen verwendet. Der Text der Vulgata folgt http://www.bibleserver. com, der deutsche Bibeltext stammt aus derselben Quelle und folgt dem Text der Einheitsübersetzung (EU).

BP The Book of Pontiffs (Liber Pontificalis): The Ancient Biographies of the First Ninety Roman Bishops to AD 7I5 (trans. Raymond Davis, Translated Texts for Historians, 6, Liverpool $\left.{ }^{2} 2000\right)$.

CC Codex epistolaris Carolinus (ed. Wilhelm Gundlach, MGH EE 3, Epistolae Merovingici et Carolini aevi I, Berlin r892) 469-657.

CC SL Corpus Christianorum, Seris Latina

CDL Codice Diplomatico Longobardo

Deutsches Archiv Deutsches Archiv für Erforschung des Mittelalters

$\mathrm{JE}^{2}$

LMA Lexikon des Mittelalters, 9 Bde. (München I980-I999).

LP Liber Pontificalis

LP I Le Liber Pontificalis: Texte, introduction et commentaire, Bd. I (ed. Louis Duchesne, Paris ${ }^{2}$ I955, ${ }^{1}$ I 886).

LP II Le Liber Pontificalis: Texte, introduction et commentaire, Bd. 2 (ed. Louis Duchesne, Paris ${ }^{2}$ I955, ${ }^{1}$ I 892).

LP III Bezeichnet den unter der Leitung von Cyrille Vogel erstellten Register- und Ergänzungsband, den dritten Band der Neuauflage von 1955: Le Liber Pontificalis: Texte, introduction et commentaire, Bd. 3: Additions et corrections de Mgr L. Duchesne (ed. Louis Duchesne/Cyrille Vogel, Paris ${ }^{2}$ I957).

LP 8 The Lives of the Eighth-Century Popes (Liber Pontificalis): The Ancient Biographies of Nine Popes from AD 7 I 5 to AD 8I7 (trans. Raymond Davis, Translated Texts for Historians, I3, Liverpool I992).

1 Die Ergänzungen zur ersten Ausgabe von 1851 wurden in der Ausgabe von 1885 von Ferdinand Kaltenbrunner (bis 590, JK²), Paul Ewald (bis 882) und Samuel Löwenfeld (bis 1198, JL2) vorgenommen. Für die vorliegende Arbeit ist ausschließlich der Bearbeitungsteil Ewalds von Relevanz. 
LP 9 The Lives of the Ninth-Century Popes (Liber Pontificalis): The Ancient Biographies of Ten Popes from AD 8I7 to AD 89I (trans. Raymond Davis, Translated Texts for Historians, 20, Liverpool 1995).

MGH Monumenta Germaniae Historica

AA Auctores Antiquissimi

EE Epistolae

SS Scriptores

SS rer. Germ. in us. schol. Scriptores rerum Germanicarum in usum scholarum separatim editi

SS rer. Lang.

Scriptores rerum Langobardicarum et Italicarum

MIÖG Mitteilungen des Instituts für Österreichische Geschichtsforschung

Neues Archiv Neues Archiv der Gesellschaft fürältere deutsche Geschichtskunde

PL

PmbZ Patrologia Latina, ed. Jacques Paul Migne

Prosopographie der mittelbyzantinischen Zeit, ed. Ralph Johannes Lilie/Friedhelm Winkelmann, et al., 6 Bde. (Berlin/New York 1999-200I).

RGA Reallexikon der Germanischen Altertumskunde, 2. Auflage.

VIÖG Veröffentlichungen des Instituts für Österreichische Geschichtsforschung 


\section{Einleitung}

Quae enim societas luci ad tenebras? - „Was haben denn Licht und Finsternis gemeinsam?“2

Papst Stephan III. stellte diese Frage im Jahr 770 Karl dem Großen und seinem Bruder Karlmann, beide damals seit etwa zwei Jahren Könige der Franken. Der Papst stellte mithilfe dieses Zitats aus dem Zweiten Brief an die Korinther die Franken den Langobarden gegenüber, wobei letztere den Part der Finsternis zugewiesen bekamen. Die beiden betroffenen gentes wurden somit buchstäblich in ein SchwarzWeiß-Schema gebracht. Der Brief wurde in einer diplomatischen Ausnahmesituation geschrieben, als das Papsttum fürchten musste, mit den Franken seinen letzten mächtigen Verbündeten zu verlieren - entsprechend nervös fiel die schriftliche Stellungnahme des Papstes aus. Doch allgemein wurden die Anderen und Fremden aus Sicht des Papsttums häufig auf die Seite der Finsternis gestellt - manche von Ihnen wurden grundsätzlich zu quasihomogenen Gruppen wie eben „den“ Langobarden oder „den“ Sarazenen zusammengefasst und konnten im Konfliktfall auf diese Weise rasch und einfach zu Völkern der Finsternis stilisiert werden. Im selben Schema sahen die Päpste sich selbst, „ihre“ Römer und ihre Freunde und Verbündeten wenig überraschend auf der Seite des Lichts. Genau ihren Status als Verbündete und Freunde mahnte Stephan III. bei den beiden Karolingerkönigen tatsächlich auch wenig später im selben Brief ein:

Denn es gebührt sich, Eure Exzellenz an Folgendes zu erinnern: So wie Ihr dem Heiligen Petrus und seinem bereits genannten Statthalter [Stephan II.], sowie auch dessen Nachfolgern geschworen habt, dass unsere Freunde auch Eure Freunde und unsere Feinde auch Eure Feinde sein sollen, gedenken auch Wir genauso an diesem Schwur festzuhalten. ${ }^{3}$

Die karolinigischen Franken waren Freunde Roms, die Langobarden hingegen Feinde, die mit der Finsternis identifiziert wurden. Dennoch waren aber beide, wie wir im Lauf dieses Buches sehen werden, aus römischer Sicht Andere, die zwar in

2 Codex Carolinus, Brief 45 (ed. Wilhelm Gundlach, MGH EE 3, Epistolae Merovingici et Carolini aevi 1, Berlin 1892) 560-563, hier 561. Zitat aus 2 Kor 6,14.

3 Codex Carolinus, Brief 45, ed. Gundlach 562: Nam et illud excellentiam vestram oportet meminere: ita vos beato Petro et praefato vicario eius vel eius successoribus spopondisse, se amicis nostris amicos esse et se inimicis inimicos; sicut et nos in eadem sponsione firmiter dinoscimur per manere. 
ein biblisches Schema eingepasst wurden, aber dennoch nicht zum Papst und den Römern gehörten.

Die Begegnung des Ich mit dem Anderen ist eine der wesentlichen Erfahrungen, die alle Menschen betrifft. Ebenso ist zumindest seit dem Entstehen menschlicher Zivilisation das Aufeinandertreffen der eigenen Gruppe (der in-group) mit einer fremden Gruppe (den Anderen, der out-group) Teil menschlichen Daseins. Es ist diese Kommunikation über und zwischen in- und out-group, mit der sich die vorliegende Arbeit auseinandersetzt.

Das frühmittelalterliche Papsttum ist für eine Untersuchung der Frage nach der Interaktion mit Anderen prädestiniert. Denn in Rom kam man täglich in verschiedensten Situationen mit Anderen in Kontakt. Einige dieser Anderen waren dem Papsttum sicher sehr vertraut, wie etwa griechische Mönche, die in Rom lebten, ja vielleicht sogar in Rom geboren waren. Doch es gab auch Andere, die sehr fremd wirkten, wie etwa die Sarazenen, mit denen sich Rom im neunten Jahrhundert auseinandersetzen musste.

Ein wesentlicher Aspekt war die Interaktion der Päpste mit großen, mehr oder weniger politisch definierbaren Kollektiven - wenig überraschend war es die Auseinandersetzung mit diesen größeren Gruppen, die in den Quellen besonders intensiv behandelt wird. Deshalb soll in der vorliegenden Arbeit der Fokus auf jene großen Gruppen gelegt werden, mit denen die Päpste in besonders lang anhaltendem und engem Kontakt standen. Bei diesen Gruppen, ob nun aus römischer Sicht gentes oder nicht, handelte es sich nicht um monolithische Blöcke von Menschen. In einigen Fällen waren sich die unter einem Gesichtspunkt zusammengefassten Individuen möglicherweise sogar selbst nicht bewusst, dass sie einer solchen Gruppe zugerechnet wurden. Aus Sicht der Päpste spielte das aber keine Rolle, denn von ihrer Warte aus existierten die von ihnen definierten Gruppen durchaus.

Kapitel I widmet sich der Beschreibung der verwendeten Quellen. Zuerst wird der römische Liber Pontificalis präsentiert. Besonderes Augenmerk wird dabei auf die Erstellung und Entwicklung des Textes im achten Jahrhundert gelegt, als der Liber Pontificalis gleich in drei verschiedenen Rezensionen und mehreren verschiedenen Kombinationen handschriftlich verfügbar war. Unterstützend werden diesem Unterkapitel weitere Technika zum Liber Pontificalis im Appendix zur Seite gestellt, wo eine Kurzvorsstellung der wesentlichen Handschriften ebenso enthalten ist, wie eine Tabelle, die die wichtigsten Textgruppen in den Viten des Liber Pontificalis bis zu Stephan V. (885-89I, dem letzten Papst, der im Frühmittelalter eine Liber Pontificalis-Vita erhielt) veranschaulichen soll. Tabelle 3 im Appendix enthält auch die Pontifikatsdaten der im Text genannten Päpste, welche daher in den meisten Fällen 
nicht angegeben werden. Darüber hinaus wird hier auch auf wesentliche Bruchstellen in der handschriftlichen Überlieferung des Liber Pontificalis hingewiesen.

In Kapitel I.2 wird der sogenannte Codex Carolinus vorgestellt, der eine Sammlung von Papstbriefen enthält, die zwischen 739 und 791 an karolingische Empfänger ergingen. Die Sammlung enthält mit 99 Briefen den größten Teil der für das achte Jahrhundert überlieferten Papstbriefe. Schließlich sollen auch noch andere Quellen kurz behandelt werden; nicht zuletzt werden die sogenannte Collectio Britannica und der Registerauszug Johannes VIII. kurz vorgestellt. Bei beiden handelt es sich um wichtige Sammlungen von päpstlichen Schreiben aus dem neunten Jahrhundert.

Danach widmet sich Kapitel 2 methodischen und theoretischen Überlegungen zu Alterität und Fremdheit. Dabei liegt das Augenmerk immer auf der speziellen Situation des Papsttums im Frühmittelalter, was es nötig macht, gängige Theorien für den Zweck der Arbeit so weit wie möglich zu adaptieren.

Kapitel 3.I stellt zunächst die Voraussetzungen der päpstlichen Herrschaft in Rom und dem Umland der Stadt dar. Kapitel 3.2 fragt dann nach der Situation Roms im immer noch existierenden Römischen Reich. Als wesentlicher Ansprechpartner der Kaiser im Westen aber auch als bedeutendes Zentrum ekklesiastischen Widerstands war Rom eine Schnittstelle zwischen lateinischer und griechischer Kultur. Das komplexe Verhältnis zum griechischen Kulturraum, zum Kaiser, aber auch zu den Griechen in Rom selbst soll hier für den Zeitraum zwischen 640 und etwa 750 beleuchtet werden, die Situation der „Griechen“, die in Rom selbst lebten, auch darüber hinaus.

Kapitel 4 ist den schwierigen Beziehungen der Päpste zum Kaiser und seinen Offiziellen sowie generell zu Vertretern des griechischen Kulturraums im achten Jahrhundert gewidmet. In drei chronologisch angeordneten Abschnitten wird dieses Verhältnis zunächst bis zur Mitte des achten Jahrhunderts, dann bis 772 und schließlich während des Pontifikats Hadrians I. analysiert. Das Hauptaugenmerk liegt dabei auf der Bezeichnung Greci beziehungsweise Griechen, die als Indikator für diese sehr komplexe Beziehung fungieren wird.

Kapitel 5 beschäftigt sich mit den Langobarden und Franken vom Pontifikat Gregors II. (715-73I) bis zu jenem Hadrians I. (772-795). Die Langobarden waren auf allen Seiten Nachbarn des römischen Dukats und als solche sehr stark mit der Entwicklung des Papsttums im achten Jahrhundert verbunden. Die Langobardenbeziehungen sind dabei auch untrennbar mit der Allianz der Päpste mit den Karolingern 
ab der Mitte des Jahrhunderts verknüpft, die in diesem Abschnitt auch immer wieder behandelt werden wird. Zudem werden die Frankenbeziehungen am Schluss des Kapitels gesondert analysiert.

Kapitel 6 ist den Sarazenen gewidmet und bietet somit einen Ausblick ins neunte Jahrhundert, wo die Beziehungen zu den verschiedenen in Italien vor allem militärisch tätigen Sarazenengruppen die Politik des Papsttums prägten. Hier wird zwar auch die Repräsentation dieser Anderen genau betrachtet, doch das Hauptaugenmerk liegt auf den Auswirkungen, die die Konfrontation mit diesen in mehrerlei Hinsicht Fremden auf die Päpste und das Papsttum hatte.

Daneben gäbe es allerlei Andere und Fremde, mit denen das Papsttum ebenfalls zu tun hatte, die in der vorliegeden Arbeit jedoch nicht im Detail berücksichtigt werden können (auch wenn von einigen Fällen die Rede sein wird). Als Beispiel seien all jene Kontakte genannt, welche die Päpste im Zuge der christlichen Mission mit Anderen hatten, im gewählten Zeitrahmen sind vor allem die Bemühungen des Bonifatius in der Germania und die Bulgarenmission unter Papst Nikolaus I. zu nennen. Auch Pilgerreisen nach Rom könnten thematisiert werden. Manche dieser Fragen plant der Verfasser anderswo zu behandeln. Eine große Gruppe, die in päpstlichen Quellen mitunter vorkommt, sind die Juden. Sie werden jedoch im Untersuchungszeitraum in allen Fällen nur als generische Andere (meist negativ) erwähnt, unter Rückgriff auf biblische Motive und ältere Berichte aus dem oströmischen Reich. Deshalb sind auch sie nicht Gegenstand dieses Buches.

Die in diesem Buch zitierten Quellenstellen wurden zum größten Teil ins Deutsche übersetzt, außer an Stellen, wo das nicht zweckmäßig gewesen wäre. Die Übersetzungen aus dem Liber Pontificalis basieren auf der englischen Übersetzung von Raymond Davis (The Lives of the Eighth Century Popes beziehungsweise The Book of Pontiffs). Auch zu anderen Quellen wurden bestehende Übertragungen genutzt und entsprechend vermerkt. Die meisten Übersetzungen stammen vom Verfasser, großer Dank gilt Cinzia Grifoni für die hervorragende fachliche Beratung.

Dieses Buch hätte ohne die freundliche Hilfe vieler Personen nicht in der vorliegenden Form erstellt werden können. Zunächst gilt mein Dank Walter Pohl, der die Arbeit nicht nur umfassend betreut hat, sondern mir mit meinem Disserationsprojekt bis Sommer 2010 auch die Mitarbeit an seinem Wittgenstein-Projekt „Ethnische Identitäten im frühmittelalterlichen Europa“ ermöglicht hat. Danach hatte ich die Gelegenheit, an Prof. Pohls H E R A Projekt „Cultural Memory and the Resources of the Past" mitzuwirken und im Zuge dessen auch das Buchmanuskript umzuarbeiten und fertigzustellen. 
Claudia Rapp hat die als Basis dieses Buches dienende Dissertation ebenfalls mit großem Engagement mitbetreut, dafür und für viele wertvolle Hinweise gebührt ihr großer Dank.

Ich bin auch Leslie Brubaker und John Haldon zu Dank verpflichet, die mir schon Anfang 20I0 Einblick in das Manuskript ihres im Jänner 20I I erschienen Buches „Byzantium in the Age of Iconoclasm: A History“ gewährt haben. Auch Rosamond McKitterick, Helmut Reimitz, Maya Maskarinec und Gerald Krutzler sei für die gewährte Einsicht in ihre in Manuskriptform vorliegenden Artikel gedankt.

Schließlich gilt mein Dank den Mitarbeiterinnen und Mitarbeitern und auch den Gästen der Frühmittelalterabteilung des Instituts für Mittelalterforschung der Österreichischen Akademie der Wissenschaften, die immer für die Diskussion von Problemen zur Verfügung gestanden sind, im Einzelnen Francesco Borri, Richard Corradini, Max Diesenberger, Nicola Edelmann, Andreas Fischer, Ingrid Hartl, Gerda Heydemann, Rutger Kramer Alexander O'Hara, Marianne Pollheimer, Roland Steinacher, Marco Stoffella, Veronika Wieser, Katharina Winckler, Bernhard Zeller sowie Helmut Reimitz, jetzt Universität Princeton. Auch mit Stefan Schima hatte ich viele erhellende Diskussionen. Viele gute Seiten dieses Buches gehen auf intensive Kommunikation mit den genannten Personen zurück, während ich für die möglicherweise enthaltenen Defizite ganz allein die Verantwortung trage.

Abschließend möchte ich auch meiner Familie danken, die mich immer sehr liebevoll unterstützt hat. 


\section{Zu den Quellen des achten und neunten Jahrhunderts}

\subsection{Der Liber Pontificalis ${ }^{4}$}

\subsubsection{Die Vorlagen und die ersten Versionen}

Der sogenannte „alte“5 Liber Pontificalis (in der Folge LP abgekürzt) ist eine der wesentlichen Quellen für das Papsttum im Besonderen und das frühe Mittelalter im Allgemeinen. Er ist aufgrund seiner Verbreitung als einer der „Bestseller“ des Mittelalters zu betrachten. ${ }^{6}$ Vor seinem Abbrechen am Ende des neunten Jahrhunderts wurde der römische LP vor allem in Italien und dem Frankenreich häufig kopiert und verteilt.

Das Konzept des LP war in seiner Ausprägung, die der Text im achten Jahrhundert annimmt, einige hundert Jahre alt. Im Mittelalter war der Grundstock des Werkes Papst Damasus zugeschrieben worden, was daran lag, dass sich am Beginn des Textes meist ein gefälschter Briefwechsel zwischen besagtem Papst und dem H1. Hieronymus fand. ${ }^{7}$ Danach wurde am Ausgang des Mittelalters Anastasius Bibliothecarius als Urheber des LP betrachtet. ${ }^{8}$ Diese Zuschreibung hielt sich bis tief in die Neuzeit, sogar in der Patrologia Latina von Jacques-Paul Migne wird dieser noch als Autor geführt. ${ }^{9}$

4 Dieses Kapitel basiert auf Kapitel 1.1 und 1.2 meiner der Langobardischen Rezension des Liber Pontificalis gewidmeten Abschlussarbeit des Magisterstudiums „Geschichtsforschung, Historische Hilfswissenschaften und Archivwissenschaft" am Institut für österreichische Geschichtsforschung der Universität Wien mit dem Titel „Studien zur handschriftlichen Überlieferung des Liber Pontificalis am Beispiel der so genannten Langobardischen Rezension“ aus dem Jahr 2009, es wurden aber neuere Erkenntnisse der Forschung eingearbeitet.

5 Diese Bezeichnung wird des Öfteren gewählt, um den bis Stephan V. im späten neunten Jahrhundert reichenden Text von seinen hoch- und spätmittelalterlichen Fortsetzungen und Bearbeitungen abzugrenzen. In der vorliegenden Arbeit ist im Folgenden ausschließlich von diesem frühmittelalterlichen Text die Rede.

6 Bernard Guenée, Histoire et culture historique dans l'Occident medieval (Paris 1980) 248-255.

7 Davis, LP 8, XIII.

8 Zur Geschichte dieser Zuschreibung, die sich zum Teil auch heute noch im Internet finden lässt, siehe Girolamo Arnaldi, Come nacque la attribuzione ad Anastasio del Liber Pontificalis, in: Bullettino dell'Istituto Storico Italiano per il Medio Evo e Archivio Muratoriano 75 (1963) 321-343.

9 PL 127 und 128: „Anastasii Bibliothecarii historiae de vitis romanorum pontificum.“ Schon Vignoli 
Am Ende des 19. Jahrhunderts wurde ausgiebig darüber diskutiert und polemisiert, wann man den Abfassungszeitpunkt des LP anzunehmen habe. Dabei wurden Entstehungshorizonte im frühen sechsten und frühen siebenten Jahrhundert gesehen. ${ }^{10}$ Zumindest in diesem Streitpunkt folgt die Forschung zuletzt der Theorie von Duchesne, die verkürzt wie folgt lautet: In den späten 53oer- oder frühen 540er-Jahren wurde die zweite Fassung ${ }^{11}$ des LP erstellt, die den Text beinhaltete, der sich schließlich durchsetzte und - nach einer weiteren Übergangszeit - ab dem frühen siebenten Jahrhundert kontinuierlich geführt wurde. ${ }^{12}$

Davor gab es noch einige andere Vorstufen des LP. Zunächst sind aus dem vierten Jahrhundert Texte erhalten, die angereicherten Papstlisten glichen, insbesondere ist der sogenannte Liberianische Katalog zu erwähnen, der bis zum Pontifikat des Liberius reicht und deshalb so benannt ist. ${ }^{13}$ Darüber hinaus gab es das sogenannte Laurentianische Fragment, das sich als Teil einer weiteren Papstchronologie aus dem frühen sechsten Jahrhundert erhalten hat - und im symmachischen Schisma recht deutliche Sympathien für Symmachus' im Endeffekt unterlegenen Gegenspieler Laurentius hegt. ${ }^{14}$ Aus demselben Streit heraus, aber mit Wohlwollen für Symmachus ausgestattet, entstand die erste Version des LP, auf der einige Zeit später die bereits erwähnte, heute gemeinhin einfach als LP bezeichnete zweite Stufe aufbaute. Diese Version ist heute allerdings nur noch in gekürzten Fassungen, den sogenannten Epitoma erhalten, von denen eine bis zum Pontifikat Felix IV. reicht und somit etwa dem Redaktionshorizont entspricht. Die andere hingegen wurde - weiter in gekürzter Form - bis zu Papst Conon im siebenten Jahrhundert fortgesetzt. ${ }^{15}$

Neben der gängigen Theorie, die die Abfassung des LP in das sechste Jahrhundert datiert, gibt es aber auch jene von Theodor Mommsen, der sich vor allem aufgrund

hatte Anastasius in seiner Edition allerdings, wohl absichtsvoll, nicht erwähnt. Vgl. Girolamo Arnaldi, Anastasio Bibliotecario, in: Dizionario biografico degli Italiani, Bd. 3 (Roma 1961) 25-37, hier 36.

10 Zur heutigen Lehrmeinung siehe Klaus Herbers, Zu frühmittelalterlichen Personenbeschreibungen im Liber Pontificalis und in römischen hagiographischen Texten, in: Von Fakten und Fiktionen. Mittelalterliche Geschichtsdarstellungen und ihre kritische Aufarbeitung, ed. Johannes Laudage (Köln/ Weimar/Wien 2003) 165-191, hier 169-171, bes. Anm. 15-17.

11 Von Duchesne „seconde édition“ genannt.

12 Duchesne, LP I, XXXIII-XLVIII.

$13 \mathrm{Zu}$ dieser und anderen chronologischen Quellen zum spätantiken Papsttum, die an dieser Stelle nicht aufgelistet werden können, siehe Duchesne, LP I, I-XXV und 1-42.

14 Der Text ist einfach zugänglich bei BP, ed. Davis 103-106. Siehe ebd., XIVf. Siehe Kommentar bei Duchesne, LP I, XXV-XXXII und 43-46. Zur Handschrift (und einer neuerlichen Transkription) siehe Ignazio Giorgi, Appunti su alcuni manoscritti del Liber Pontificalis, in: Archivio della società romana di storia patria 20 (1897) 247-312, hier 247-261.

15 Zu dieser ersten „Edition“, wie sie Duchesne nannte, siehe ders., LP I, XLIX-LXVII und ebd., 47113 (Texte). Zu den Texten siehe auch die Übersetzung, BP, ed. Davis 107-114 (nur bis Felix IV.). 
von linguistischen Argumenten für eine Abfassung im siebenten Jahrhundert aussprach. Seiner Position folgt neuerdings wieder Luciana Cuppo, die auf einen Brief Gregors des Großen hinweist, der tatsächlich nahelegen könnte, dass der berühmteste Papst des Frühmittelalters keine Kenntnis vom LP hatte - für Mommsen und Cuppo der Beleg, dass er noch nicht existierte. ${ }^{16}$ Die neueste Forschung geht aber in der überwältigenden Mehrheit von einer Abfassung des Textes im sechsten Jahrhundert aus. Hermann Geertman hat sogar mit inhaltlichen Argumenten das Jahr 535 wahrscheinlich machen können. ${ }^{17}$ Somit ist im Moment von einer Entstehung des LP im früheren sechsten Jahrhundert auszugehen. Mommsen und mit ihm Cuppo müssen deswegen mit ihrer linguistischen Argumentation nicht unbedingt unrecht haben, es ist keineswegs auszuschließen, dass der Text im siebenten Jahrhundert abgeschrieben und dabei auch sprachlich überarbeitet wurde. Allenfalls könnte man dieser Interpretation entgegen halten, dass der Text zu dieser Zeit bereits in mehreren Textvarianten vorgelegen haben könnte, was eine Bearbeitung nicht sehr wahrscheinlich machen würde. ${ }^{18}$ Dafür gibt es jedoch noch zu wenig schlüssige Erkenntnisse.

Wichtig ist es, für die Zwecke der vorliegenden Arbeit festzuhalten, dass zumindest ab der Mitte des siebenten Jahrhunderts die Papstviten des LP von Zeitgenossen verfasst wurden. ${ }^{19}$

Die Viten des LP folgen in ihrem Aufbau allesamt einem bestimmten Schema, dessen maximale Ausprägung wie folgt zusammengefasst worden ist: (I) Name, (2) Herkunft und Abstammung, (3) Dauer des Pontifikats, (4) Qualifikation als Märtyrer, (5) persönliche Charakteristik des Papstes, (6) historische Details, (7) (disziplinäre) Dekrete, (8) Stiftungen und Bautätigkeit, (9) Ordinationen, (ıo) Ort und Datum des

16 Siehe Luciana Cuppo, I pontifices di Costantinopoli nel Liber Pontificalis del settimo secolo: Note sul codice BAV, Vat. Lat. 3764, in: Rivista di storia e letteratura religiosa 44 (2008) 359-371, hier bes. 364f. Siehe Liber Pontificalis pars prior (ed. Theodor Mommsen, MGH SS Gesta pontificum romanorum 1, Berlin 1898) XVI und XXV. Verwendet wird dabei Gregor I., ep. 9, 148 an Sencundinus (ed. Dag Norberg, Gregorii magni registrum epistularum, 2 Bde., CC SL 140 und 140A, Turnhout 1982) Bd. 2, 698-704.

17 Siehe die Ausführungen von Herman Geertman, Documenti, redattori e la formazione del testo del Liber Pontificalis, in: Il Liber Pontificalis e la storia materiale, ed. ders. (Mededelingen van het Nederlands Instituut te Rom, 60-61, Assen 2003) 267-284, und ders., La genesi del Liber pontificalis romano. Un processo di organizzazione della memoria, in: Liber, Gesta, histoire. Écrire l'histoire des évêques et des papes, de l'Antiquité au XXIe siècle, ed. François Bougard/Michel Sot (Turnhout 2009) 37-108. Zur aktuellen Forschungsmeinung siehe zusammenfassend Rosamond McKitterick, Roman texts and Roman history in the early middle ages, in: Rome Across Time and Space: Cultural Transmission and the Exchange of Ideas, C.500-1400, ed. dies./Claudia Bolgia/John Osborne (Cambridge 2011) 19-33.

$18 \mathrm{Zu}$ den Textvarianten des LP siehe unten, Appendix.

19 Das scheint spätestens ab Papst Honorius (625-638) der Fall zu sein, vgl. Davis, BP XIII. 
Begräbnisses und (I I) Sedisvakanz. ${ }^{20}$ Diese Liste ist vor allem für die frühen Papstleben, also für jene, die vom Hersteller der „Zweiten Edition“ im sechsten Jahrhundert in einem Guss geschrieben worden sind, zutreffend. Im achten Jahrhundert scheint sie weniger praktikabel (aber nichtsdestotrotz anwendbar), vor allem weil einige Teile, wie etwa das Martyrium, nun nicht mehr vorkommen können, dafür aber zunächst die historischen Details und wenig später ganz besonders die Stiftungen sehr viel Platz einnehmen.

Schließlich scheint es noch wichtig, die bisher vorhandenen neuzeitlichen Editionen des LP zumindest kurz aufzuzählen, um auch die Geschichte der Beschäftigung mit dem Text ein wenig zu illustrieren. Die erste kritische Edition wurde ja, wie wir bereits gehört haben, von Louis Duchesne vorgelegt. Etwa zur gleichen Zeit, als Duchesne seine Arbeit begann, starteten auch die MGH ein Unternehmen, das den LP kritisch edieren sollte. Die Versuche der MGH trugen allerdings zunächst keine Früchte, da der mit der Aufgabe beauftrage Dr. Pabst nach einigen schon geleisteten Handschriftenstudien im Jahr I870 im Deutsch-Französischen Krieg ums Leben kam. Seine Ergebnisse wurden zwar von Georg Waitz im Neuen Archiv veröffentlicht, doch das Unternehmen hatte einen herben Rückschlag hinnehmen müssen. ${ }^{21}$ So dauerte es bis I898, als Theodor Mommsen seine Edition des LP unter dem Titel Gesta Episcopum Romanorum, Bd. I vorlegen konnte, ${ }^{22}$ die jedoch nur einen Teil des Textes bis inklusive Papst Konstantin umfasst. Zudem konnte gegenüber der schon vorliegenden Edition Duchesnes nur in Detailfragen ein nennenswerter Fortschritt erzielt werden. Tatsächlich wird heute in einigen Fragen auch die ältere Edition als die korrektere angesehen. Für das achte und neunte Jahrhundert wurde der LP von den MGH jedenfalls nicht weiter ediert und es ist auch fraglich, ob eine solche Edition der Mühe wert befunden werden kann, auch wenn die Duchesne-Edition im Detail durchaus Schwächen aufweist. Eher wäre für diese Fälle aber daran zu denken, diese Edition einer Überarbeitung zuzuführen und insbesondere fehlende Varianten nachzutragen.

Die Editionsgeschichte des LP beginnt aber schon weit vor Duchesne und es ist an dieser Stelle angebracht, sie kurz zusammenzufassen, da einige dieser Ausgaben auch

20 Michel Sot, Gesta episcopum, gesta abbatum (Typologie des sources du moyen âge occidental 37, Turnhout 1981) 32f., den der Verfasser in einem Punkt, der persönlichen Charakteristik, aus Klaus Herbers, Leo IV. und das Papsttum in der Mitte des 9. Jahrhunderts. Möglichkeiten und Grenzen päpstlicher Herrschaft in der späten Karolingerzeit (Päpste und Papsttum 27, Stuttgart 1996) 13, ergänzt hat. Zu einer etwas abgewandelten Liste kommt Walter Berschin, Biographie und Epochenstil im lateinischen Mittelalter 1: Von der Passio Perpetuae zu den Dialogi Gregors des Großen (Quellen und Untersuchungen zur lateinischen Philologie des Mittelalters 8, Stuttgart 1986) $271 \mathrm{f}$.

21 Dr. H. Pabst's Reise nach Italien 1869/70, ed. Georg Waitz, in: Neues Archiv, 2 (1877) 31-45.

22 Liber Pontificalis pars prior, ed. Mommsen. 
erhebliche Auswirkungen auf die modernen kritischen Editionen hatten. Bereits im Laufe des Mittelalters wurde der LP mehrere Male überarbeitet und in neue Textformen integriert. ${ }^{23} \mathrm{Im}$ I6. und I7. Jahrhundert wurden erste gedruckte Textversionen erstellt. ${ }^{24}$ I7 I8-I735 erschien schließlich die Edition von Francesco Bianchini. Hier wurden zum ersten Mal im größeren Stil Varianten verschiedener Handschriften präsentiert. Auch die besonders interessante Farnese-Handschrift $\left(\mathrm{E}^{5}\right)$, die zur Zeit Duchesnes leider bereits verloren war, wurde hier einbezogen. Diese Edition wurde später von Muratori für seine Scriptores rerum Italicarum verwendet und völlig unbearbeitet in Jacques-Paul Mignes Patrologia Latina aufgenommen. ${ }^{25}$ Schließlich brachte ab I724 Giovanni Vignoli den ersten Band seiner dreibändigen Edition heraus, in der versucht wurde, den Text nicht selbst zu emendieren, sondern anhand des vorhandenen Materials in den Handschriften vorzugehen - ein Novum für den LP. Die Grundlage der Edition bildeten hierbei vor allem die in der Biblioteca Vaticana vorhandenen Handschriften. Vignoli unterschied jedoch nicht zwischen späteren Hinzufügungen und ursprünglichen Teilen des Textes, sodass er nur eine Art ,Maximalvariante' lieferte. ${ }^{26}$ Von Vignoli wurde auch eine Gliederung in Textabschnitte eingeführt. Diese Abschnitte (oder Kapitel) hat Duchesne in seiner Edition wiedergegeben, um die Vergleichbarkeit zu erhöhen. In Raymond Davis' Übersetzung sind sie zur Gliederung des Textes und zum Vergleich mit Duchesne sehr wichtig. Auch in der vorliegenden Arbeit werden sie öfters zitiert. Sie sollen, auch ob ihrer praktischen Länge, einer besseren Orientierung im Text dienen.

Das war jedenfalls die Situation, wie sie Duchesne vorfand. Seit seiner eigenen Edition ist nur die erwähnte Teiledition Mommsens erschienen, darüber hinaus gibt es für den LP in der Fassung des frühen Mittelalters keine Neuerungen. ${ }^{27}$

23 Man denke hier nur an den Liber Floridus, vgl. Duchesne, LP I, CLXXXV-CLXXXVII, sowie die reichhaltigen Anmerkungen dazu in Duchesne, LP III, ed. Cyrille Vogel 63f., sowie ebd. 63-66 zu einer interessanten anderen Überarbeitung aus England zur Zeit Williams von Malmesbury.

24 Zunächst teilweise von Peter Crabbe, dann der Volltext, zunächst 1602 als sogenannte Mainzer Edition von Johannes Busaeus auf Basis einer Kopie des Vat. Lat. 3764 (Textklasse E1). 1649 wurde diese Edition von Charles Annibal Fabrot im Corpus Byzantiae historiae, Paris 1648-1711, neu herausgegeben. Dieser Text findet sich auch in anderen Werken des 17. Jahrhunderts. Lukas Holste versuchte um die Mitte desselben Jahrhunderts zu einer besseren Edition zu gelangen, konnte das Unternehmen aber nicht vor seinem Tod abschließen. Siehe hierzu Louis Duchesne, Etude sur le Liber Pontificalis, in: Bibliothèque des Ecoles françaises d'Athènes et de Rome 1 (Paris 1877) 115-118 und ders., LP II, LV-LVII (und dazu auch ders., LP III, ed. Vogel 116).

25 Siehe ausführlich Duchesne, Etude 118f. und 120f. Zur Handschrift $\mathrm{E}^{5}$ siehe unten, Kap. 1.1.3.

26 Duchesne, Etude 119f. und 122.

27 Allerdings gab es seitdem eine Edition der hochmittelalterlichen Version des Pietro Guglielmo: Liber Pontificalis nella recensione di Pietro Guglielmo e del card. Pandolfo, glossato da Pietro Bohier, vescovo di Orvieto, 3 Bde. (ed. Ulderico Prerovsky, Studia Gratiana 21-23, Rom 1978). 
Zum Schluss muss noch darauf hingeweisen werden, dass der LP in der modernen Forschungsliteratur auf eine Vielzahl von Arten zitiert wird. In der vorliegenden Arbeit wurde eine sehr schlichte Zitierweise gewählt, die nur den Band der Edition Louis Duchesnes und die entsprechende Seite nennt. Falls der Papst, dem die zitierte Vita gewidmet ist, nicht ohnehin aus dem Haupttext zweifelsfrei hervorgeht, wurde hinter der Seitenangabe in Klammer vermerkt, um wessen Vita es sich handelt. Es wäre auch möglich gewesen, die Leben mit ihrer jeweiligen Ordnungszahl zu zitieren, die auch in den Handschriften des LP geführt werden, doch erschwert diese Zitierweise den meisten Lesern die Lektüre, außer sie wird, wie häufig, inkonsequent angewandt, was aber zwangsläufig zu eher redundanten Ausdrücken wie „Leben 94 (Stephan II.)“ führt.

\subsubsection{Genre und Erstellung des Liber Pontificalis}

Prinzipiell scheint es zunächst nicht logisch, die beiden Aspekte - Genredefinition und Herstellungszusammenhänge - in einem Kapitel zu behandeln, letzteres würde man viel eher schon im vorhergehenden, ebenfalls einführenden Kapitel erwarten. Tatsächlich ist aber die Klärung der Frage des Genres eine wesentliche Komponente, die es überhaupt erst erlaubt, die Frage nach den Umständen der Herstellung des LP zu stellen.

Vielleicht ist es einfacher, schnell zu definieren, was der LP nicht ist: Er ist mit Sicherheit keine Hagiographie. Zwar gab es eine Vorstellung von einer Art ,Amtsheiligkeit' der Päpste, die schon im Frühmittelalter nachgewiesen werden kann, doch haben die Texte des LP keinerlei Züge einer Heiligenvita, ${ }^{28}$ am ehesten vielleicht noch die letzten Texte des LP im späten neunten Jahrhundert (Nikolaus I., Hadrian II. ${ }^{29}$ ), die

28 Berschin, Biographie, Bd. 1, 270-277, behandelt den Liber Pontificalis als Muster einer Reihenbiographie. Zur schwierigen Definition von Hagiographie siehe ebd., 17-22. Klaus Herbers, Zu Mirakeln im Liber Pontificalis des 9. Jahrhunderts, in: Mirakel im Mittelalter. Konzeptionen, Erscheinungsformen, Deutungen, ed. ders./Martin Heinzelmann/Dieter R. Bauer (Beiträge zur Hagiographie 3, Stuttgart 2002) 114-134, hier 119, spricht dem Liber Pontificalis gleichfalls hagiographische Züge ab. Vgl. auch ders., Leo IV., 13. Die Amtsheiligkeit der Päpste wurde allerdings erst viel später im Dictatus Papae Gregors VII. formuliert, siehe Klaus Herbers, Papst Leo IV. und seine Vita im Liber Pontificalis (um 850), in: Mirakelberichte des frühen und hohen Mittelalters, ed. ders./Lenka Jirouskova/Bernhard Vogel (Freiherr-vom-Stein-Gedächtnisausgabe, Ausgewählte Quellen zur deutschen Geschichte des Mittelalters 43, Darmstadt 2005) 118-123, hier 118, doch dennoch ist von einem solchen Konzept schon früher auszugehen, siehe François Bougard, Composition, diffusion et réception des parties tardives du Liber pontificalis romain (VIII--IX ${ }^{\mathrm{e}}$ siècles), in: Liber, Gesta, histoire. Écrire l'histoire des évêques et des papes, de l'Antiquité au XXIe siècle, ed. ders./Michel Sot (Turnhout 2009) 127-152, hier 132f.

29 Hadrian II. markiert den Bruch der Tradition des Liber Pontificalis, nach ihm klafft eine vier Päpste währende Lücke. Erst Stephan V. erhielt wieder einen Eintrag, der jedoch nicht mehr vollständig 
wahrscheinlich von Johannes Hymmonides, dem Hagiographen Gregors des Großen, verfasst wurden - und einen deutlichen Stilbruch im LP markieren. ${ }^{30}$

Trotzdem hat es sich in der Forschung heute weitestgehend eingebürgert, in Bezug auf die einzelnen Einträge des LP den Begriff Vita zu verwenden und so wird er auch im vorliegenden Text verwendet. Der Begriff birgt jedoch, wie schon angedeutet, irreführende Ungenauigkeiten: Schon in der Geschichtswissenschaft im Allgemeinen ist der Begriff Vita nicht erschöpfend definiert und daher eher unscharf gebraucht, was aber - positiv gesprochen - dazu beiträgt, dass die grundsätzliche, oft genreübergreifende Offenheit mittelalterlicher Texte quasi implizit mitkommuniziert wird. Und doch rückt die Bezeichnung einen Text sprachlich zumindest in die Nähe von Hagiographie.

Im Speziellen evoziert der Begriff jedoch darüber hinaus den Eindruck, dass es sich um die Beschreibung des Lebens einer Person handelt. Das ist im LP aber nicht der Fall, denn hier wird fast ausschließlich über die Taten einer bestimmten Person (und ihrer unmittelbaren Mitarbeiter) im Zuge der Ausübung eines Amtes, nämlich des Bischofs von Rom, berichtet. ${ }^{31}$ Es finden sich zwar häufig kurze Berichte über den Werdegang eines Papstes vor seiner Wahl, diese bleiben aber immer schematisch und sind eher als literarische Stilmittel zu interpretieren, die auf Dinge hinweisen, die später im Pontifikat der betreffenden Person noch eine Rolle spielen werden. Fast immer finden sich im achten Jahrhundert auch sprachliche Anklänge an bestimmte vorangegangene Viten des LP, womit möglicherweise eine programmatische Verknüpfung mit dem jeweiligen Vorgänger angezeigt werden sollte. Der Begriff Gesta, der auch in zeitnahen Quellen des Öfteren Verwendung fand, wäre für die Einträge des LP jedenfalls passender. ${ }^{32}$

Der Zweck der Herstellung des LP war also aller Wahrscheinlichkeit nach, einen Rechenschaftsbericht über einen abgelaufenen Pontifikat zu erstellen. Die Frage ist allerdings, an wen sich dieser Bericht richten sollte. Im Prinzip scheint zunächst ein

überliefert ist. Danach gibt es erst wieder im zwölften Jahrhundert eine Fortsetzung des Liber Pontificalis, die jedoch unter gänzlich veränderten Gesichtspunkten erfolgte.

30 Davis, LP 9, IX-XII. Siehe dazu Herbers, Personenbeschreibungen. Zu den Argumenten für die Urheberschaft des Johannes siehe François Bougard, Anastase le Bibliothécaire ou Jean Diacre? Qui a réécrit la Vie de Nicolas Ir et pourquoi, in: Vaticana et medievalia. Études en l'honneur de Louis Duval-Arnould, ed. Jean-Marie Martin/Bernadette Martin-Hisard/Agostino Paravicini Bagliani (Millennio Medievale 71, Strumenti e Studi 14, Florenz 2008) 27-40: Bougard argumentiert, dass Nikolaus I. implizit mit Gregor dem Großen, dessen hagiographische Vita sicher von Johannes stammt, gleichgesetzt werden sollte und somit einen anderen Grad an Heiligkeit erlangen sollte als seine Vorgänger.

31 Klaus Herbers, Das Bild Papst Leos III. in der Perspektive des Liber pontificalis, in: Erzbischof Arn von Salzburg, ed. Meta Niederkorn-Bruck/Anton Scharer (Wien/München 2004) 137-154, hier 138.

32 Herbers, Bild Papst Leos III. 138. Vgl. dazu Sot, Gesta, insbesondere 32f. zur Bedeutung des Liber Pontificalis für das Genre. 
römisches Publikum der primäre Adressat gewesen zu sein, wobei sich kaum nachweisen lässt, ob dieses nun nur aus der römischen Geistlichkeit bestand oder auch die weltliche Oberschicht mit einschloss. Doch im Lauf der Zeit dürfte sich das Zielpublikum erweitert haben, sodass in der Forschung schließlich von einer Funktion des LP als „offizielle“ beziehungsweise „halboffizielle“ Geschichtsschreibung der päpstlichen Verwaltung gesprochen wird. ${ }^{33}$ Im Prinzip ist die Darstellung einer Geschichte für nicht zum inneren Kreis des Lateran gehörende Leser jedoch nicht der alleinige, ja oft nicht einmal der vorrangige Daseinszweck des LP, weswegen wohl etwa Raymond Davis die zitierte einschränkende Variante gewählt hat, auch wenn dem LP sein offiziöser Charakter nicht abgesprochen werden soll. ${ }^{34}$ Tatsächlich veränderte sich der Verwendungszusammenhang aber im Lauf der Zeit immer wieder und im Fall der Vita Stephans II., die für die vorliegende Arbeit von großer Wichtigkeit ist, steht der offiziös-historiographische Charakter relativ stark im Vordergrund. ${ }^{35}$ Insofern wurde die Vita Stephans als offizielle Historiographie verwendet, Lidia Capo schreibt sogar von Propaganda. ${ }^{36}$ Später, im neunten Jahrhundert, gab es aber möglicherweise wieder andere Ansprüche und das Zielpublikum könnte wieder weniger weit gefasst gewesen sein.

Die Viten der einzelnen Päpste wurden ab der Mitte des siebenten Jahrhunderts von Zeitgenossen zumeist bald nach dem Ableben des Papstes fertiggestellt. ${ }^{37}$ Wahrscheinlich wurde zu diesem Zeitpunkt aber nicht immer der gesamte Eintrag in einem Guss verfasst. Thomas Noble meinte, im Beginn der Papstleben mit seinen schematisch-formelhaften Zügen möglicherweise das Schema der offiziellen Berichte über den Amtsantritt eines neuen Papstes, die etwa an den Kaiser versandt werden mussten, zu erkennen.

33 Walter Ullmann, A Short History of the Papacy (London $\left.{ }^{2} 1974\right) 30$ schrieb vom Liber Pontificalis als „perhaps, the first ,official' historiography“. Demgegenüber bezeichnet Klaus Herbers, Leo IV., 118 den Liber Pontificalis als „halboffiziell“. Der Ausdruck „semi-official“ wird auch als die Bezeichnung auf dem Klappentext von Davis, LP 9, verwendet. Diese Wortwahl findet sich im Kommentarteil nicht mehr, aber dennoch wird der Charakter als vor allem rombezogen und nicht tatsächlich historiographisch geschildert, vgl. ebd., XIf.

34 Herbers, Leo IV., 16.

35 Diesen Anstieg an politisch-historischer Information hat schon Erich Caspar, Geschichte des Papsttums von den Anfängen bis zur Höhe der Weltherrschaft, Bd. 2: Das Papsttum unter byzantinischer Herrschaft (Tübingen 1933) 774f. (Anm. zu Seite 315) hervorgehoben. Er sah hier im achten Jahrhundert einen Übergang der Aufgabe des Verfassens des Liber Pontificalis an die Kanzlei.

36 Vgl. Lidia Capo, Il Liber Pontificalis i Longobardi e la nascita del dominio territoriale della chiesa romana (Spoleto 2009) bes. 203-214, wo sie unglücklicherweise auch versucht, das Argument auf die Päpste ab Gregor II. auszuweiten, was aber nicht gut funkionieren kann, da deren LP-Viten noch viel mehr auf ein stadtrömisches Publikum abzielten.

37 Davis, BP, XLVII. 
Somit könnte der Beginn der Viten zumindest auf diesen offiziellen Schreiben, die etwa zum Kaiser nach Konstantinopel geschickt werden mussten, basiert haben. ${ }^{38}$ Allerdings lässt der erste, den Papst vorstellende Abschnitt trotz seiner Formelhaftigkeit fast immer Bezüge zum später geschilderten Wirken des Papstes erkennen. ${ }^{39}$ Somit können die Antrittsmitteilungen höchstens als Vorlagen für den Beginn der Viten gedient haben, sie wurden aber keinesfalls unverändert oder nahezu unverändert übernommen.

Aus diesen Beobachtungen heraus hat Noble argumentiert, dass der LP letztlich in der päpstlichen Kanzlei hergestellt worden sein dürfte. Der Ort der Herstellung ist allerdings bis heute umstritten. Einige Forscher sind vehement für eine Zuständigkeit des päpstlichen Vestarariums eingetreten, ${ }^{40}$ der Stelle, die für die Aufzeichnung der Ausgaben und damit auch der Bautätigkeit und Wohltätigkeit des Papstes zuständig war. ${ }^{41}$ Doch so einseitig dürfte es auf keinen Fall funktioniert haben. Deshalb hat François Bougard eine arbeitsteilige Lösung vorgeschlagen: Der Text wäre zunächst in der Kanzlei angelegt worden, um dann im Vestararium mit den Stiftungsinformationen angereichert zu werden und eventuell wiederum in der Kanzlei um historiographisches Material erweitert zu werden. Bougard räumt jedoch selbst ein, dass dieser ideale Ablauf gerade für das Leben Stephans II. nicht so funktioniert haben kann. Außerdem könnte in einigen Fällen ein und derselbe Autor für alle genannten Stufen verantwortlich gewesen sein. ${ }^{42}$

Die Frage ist also, ob man dieses Modell der Arbeitsteiligkeit für das achte Jahrhundert wirklich braucht. Denn in der noch relativ wenig ausgebildeten und bürokratisierten päpstlichen Verwaltung ${ }^{43}$ hätten die jeweiligen Stellen sicherlich verhält-

38 So eine Theorie von Bougard, Composition $135 f$.

39 Thomas F. X. Noble, A new Look at the Liber Pontificalis, in: Archivum historiae pontificiae, 23 (1985) 347-358, hier 351.

40 So Duchesne, LP I, CLXII und CCXLIII-CCXLV.

41 Herman Geertman, More Veterum. Il Liber Pontificalis e gli edifici ecclesiastici di Roma nella tarda antichità e nell'alto medioevo (Archaeologica Traiectina, Groningen 1975) 34: „Sotto la diezione del prior Vestiarii, chiamato anche vestararius e, nel Liber Pontificalis, vestiarius, venivano progettate e preparate, realizzate e registrate nei libri attività come fondazioni, costruzioni di nuovi edifici, restauri e donazioni.“ Der Vorsteher des Vestarariums war ein wichtiger Faktor in der päpstlichen Administration, unter Hadrian I. bekleidete etwa sein Nachfolger Leo III. diesen Posten, siehe ebd., 34f.

42 Bougard, Composition 130f. Jeweils ein einzelner Autor dürfte etwa wiederum für die Vita Stephans II. und für sowohl den historischen und den Schenkungsteil der Vita Hadrians I. verantwortlich gewesen sein. Zu Hadrian vgl. Florian Hartmann, Hadrian I. (772-795). Frühmittelalterliches Adelspapsttum und die Lösung Roms vom byzantinischen Kaiser (Päpste und Papsttum 34, Stuttgart 2006) 24.

43 Wie die Organisation der päpstlichen Verwaltung im Einzelnen funktioniert hat, kann für die Zeit vor den Reformen des elften Jahrhunderts nicht sicher gesagt werden. Auch die Ausprägung der 
nismäßig einfach auf das Material der anderen zugreifen können. ${ }^{44}$ Insofern scheint zunächst die plausibelste Lösung zu sein, von einer Herstellung des LP in der päpstlichen Kanzlei auszugehen, allerdings zum Teil unter weitgehenden Rückgriffen auf die Aufzeichnungen des Vestarariums. So erklärt sich etwa die recht deutliche Parteinahme des LP für den primicerius notariorum Christophorus in der Vita Stephans III. ${ }^{45}$ Als ehemaliger Leiter der Kanzlei hatte seine Partei auch nach seiner Ermordung, die zumindest mit Billigung des Papstes erfolgt sein dürfte, dort noch Anhänger. ${ }^{46}$

Dass die Vita Hadrians I. nach dem Jahr 774 nur noch aus Material des Vestarariums besteht, ist auch kein schlüssiger Beweis, dass der Text auch dort hergestellt worden sein muss, denn ein Individuum aus der Kanzlei hätte wohl auch Zugang zu diesen Aufzeichnungen haben können. ${ }^{47}$

Allerdings könnten sich die Bedingungen im neunten Jahrhundert wieder verkompliziert haben, wie die Geschichte des Anastasius Bibliothecarius lehrt. Dieser war unter Nikolaus I. zu dieser hohen Position gekommen, in der er wohl großen Teilen der päpstlichen Verwaltung und eben auch der Kanzlei vorstand. Davor war er aber unter Leo IV. verbannt und mit Anathem belegt worden. Daraufhin hatte er versucht, sich mithilfe des herrschenden Karolingerkaisers Ludwigs II. als Nachfolger Leos

päpstlichen Kanzlei ist umstritten. Walter Ullmann, The Growth of the Papal Government in the Middle Ages: A Study in the Ideological Relation of Clerical to Lay Power (London 1955) 327, hat gezeigt, dass ein cancellarius erst ab dem elften Jahrhundert belegt ist. Aber auch er spricht schon für die Päpste der Spätantike von einer Kanzlei (vgl. etwa ebd., 5, Anm. 4). Tatsächlich dürfte die Existenz einer recht ausgefeilten Verwaltung des Lateran im achten Jahrhundert kaum zu bestreiten sein, den Notaren stand eben ein primicerius vor, der sogar von einem secundicerius unterstützt wurde. Die Zahl der in der jeweiligen Verwaltungseinheit beschäftigten Mitarbeiter lässt sich jedoch nicht mehr nachvollziehen. Auch die Aufgabenverteilung ist - wie das Beispiel des Liber Pontificalis ja belegt nicht mehr genau eruierbar.

44 In der Zeit vor dem achten Jahrhundert dürfte das Vestararium allerdings tatsächlich großen Anteil an der Herstellung des Liber Pontificalis gehabt haben, vgl. Berschin, Biographie, Bd. 2, 115-117. Dass allerdings, wie Berschin, Biographie, Bd. 2, 116 meint, eine Erwähnung des Vestarariums in der Vita Papst Severinus (LP I, 328) für eine Abfassung ebendort spricht, ist zu bezweifeln, da der Übergriff der Armee auf die päpstlichen Ressourcen auch an anderer Stelle sicherlich für Aufsehen gesorgt hätte.

45 Siehe Noble, New look 355 f.

46 Abgesehen davon wurde die Vita Stephans III. wohl erst in der Zeit Hadrians I. verfasst, als die Gruppe der einstigen Anhänger des Christophorus wieder rehabilitiert gewesen zu sein scheint. Vgl. unten, Kap. 4.2 und insbesondere S. 116.

47 Es ist durchaus denkbar, dass man sich aus politischen Gründen entschied, nach 774 keine historiographischen Elemente mehr einzubauen, vielleicht wegen offener Streitpunkte mit den Karolingern, vielleicht wegen einer eventuell schwierigen Situation in Rom selbst. Zum schwierigen Verhältnis Hadrians mit Karl dem Großen vgl. Hartmann, Hadrian 197-265. 
durchzusetzen, war aber nach kurzer Zeit an Benedikt III., der wohl in Rom über einen starken Rückhalt verfügte, gescheitert. Diese Vorgehensweise hatte ihm einen sehr negativen Eintrag im LP beschert. ${ }^{48}$ Doch es gelang ihm nicht, den für ihn sehr ungünstigen Eintrag zu löschen oder umzuarbeiten, was darauf hindeutet, dass sein Zugriff auf den in Rom geführten Text (nicht zu reden von jenen Texten, die Rom bereits verlassen hatten) gering gewesen sein dürfte. ${ }^{49}$ Das ist besonders bemerkenswert, da sein Vertrauter Johannes Hymmonides später wahrscheinlich an den Leben Nikolaus I. und Hadrians II. arbeitete. ${ }^{50}$

So gesehen dürfte Bougards Idealvariante (Kanzlei $\rightarrow$ Vestararium $\rightarrow$ Kanzlei) auch für die Spätzeit des LP zum Teil durchaus noch anwendbar sein.

\subsubsection{Textvarianten des Liber Pontificalis im achten Jahrhundert}

\subsubsection{Die zwei Versionen der Vita Gregors II.}

Die Biographie Gregors II., unsere wesentlichste Quelle für seinen Pontifikat, hat sich in zwei verschiedenen Versionen erhalten - einer etwa zeitgenössischen und einer späteren Überarbeitung, in der vor allem mehr Material hinzugefügt wurde. Duchesne hat die Überarbeitung in die 75oer datiert. Das begründete er damit, dass die überarbeitete Version langobardenfeindlicher sei, was am besten in die Zeit nach Papst Zacharias und zur Vita Stephans II. passe. ${ }^{51}$ Das ist, wie wir sehen werden, anhand der tatsächlichen Überarbeitungen kaum belegbar - die Langobarden werden nicht wesentlich anders dargestellt. ${ }^{52}$ Demgemäß sieht neuerdings Bougard die Änderungen eher in den frühen 740er-Jahren, als zwischen Papst Zacharias und dem Langobardenkönig Liutprand relativ gutes Einvernehmen herrschte. ${ }^{53}$ Bougard bringt die Überarbeitung der Vita in der Folge auch mit der Erstellung der Vita

48 LP II, 141-144. Siehe zu seiner Person ausführlich Girolamo Arnaldi, Anastasio Bibliotecario, antipapa, in: Enciclopedia dei papi, Bd. 1 (Rom 2000) 735-746.

49 Das wird vielleicht auch durch eine Episode illustriert, die sich direkt nach dem Tod Nikolaus I. (867) zugetragen haben soll: Anastasius wurde wenig später, im Zuge seines zweiten Absetzungsverfahrens 868, vorgeworfen, versucht zu haben, die Dekrete der gegen seine Person gerichteten Synode von 853 und andere damit verbundene Schriftstücke zu entwenden. Siehe dazu die in Hinkmar, Annales Bertiniani (ed. Georg Waitz, MGH SS rer. Germ. in us. schol. [5], Hannover 1883) 94-96 inserierte Urkunde Hadrians II. Siehe auch Arnaldi, Anastasius 29. Insofern dürfte Anastasius auch als Nikolaus' Privatsekretär und später sogar als Bibliothecarius keinen uneingeschränkten Zugang zu allen im Lateran aufbewahrten Schriftstücken gehabt haben, also auch nicht zum Liber Pontificalis.

50 Davis, LP 9, 249.

51 Duchesne, LP I, CCXX-CCXXIII, siehe auch die Zusammenfassung in Davis, LP 8, $1 \mathrm{f}$.

52 Ganz im Gegensatz zur Vita Gregors III., siehe dazu jeweils unten, Kap. 5.1.

53 Bougard, Composition $137 f$. 
des Zacharias in Verbindung. Wir werden unten in Kapitel 5 auch sehen, dass im LP-Eintrag für Zacharias König Liutprand größtenteils in einem passablen Licht erscheint. ${ }^{54} \mathrm{Da}$ jedoch die handschriftliche Überlieferung der beiden Viten in vielen Fällen voneinander unabhängig ist, erscheint ein direkter Zusammenhang der Redaktion der beiden Viten eher nicht wahrscheinlich. ${ }^{55}$ In der Folge werden bei Bezugnahme auf die Vita Gregors II. ihre beiden Versionen in der Darstellung berücksichtigt.

Ein interessantes Detail der Überlieferung der Vita Gregors II. ist, dass sich bereits in der Chronica Maiora Bedas eindeutige Zitate daraus finden, obwohl diese als 725 fertiggestellt gilt. Da Gregor II. erst 73I starb, kann eine fertige Fassung seiner LP-Vita auch erst in diesem Jahr existiert haben, da seine Biographie seinen gesamten Pontifikat abdeckt. ${ }^{56}$ Somit ist es als zumindest wahrscheinlich anzusehen, dass seine Vita schon zu seinen Lebzeiten begonnen wurde und dass eine Vorabversion, die zumindest Ereignisse bis 717/718 enthielt, nach England gelangte. ${ }^{57}$ Uns liegt also wahrscheinlich zumindest in Teilen eine sehr nah am Geschehen festgehaltene Darstellung vor.

54 Siehe dazu unten, Kap. 5.2.

55 Mit an Sicherheit grenzender Wahrscheinlichkeit in einem libellus verbreitet wurde die sogenannte Langobardische Rezension der Vita Stephans II. Dieser libellus umfasste die Viten von Gregor II. bis Stephan II. Die Gregorsvita ist dabei allerdings in der älteren Fassung aufgenommen worden. Siehe dazu Clemens Gantner, Studien zur Überlieferung des Liber Pontificalis am Beispiel der so genannten Langobardischen Rezension (ungedr. Univ. Magisterarbeit, Wien 2009) 159-167, und Clemens Gantner, The Lombard Recension of the Roman Liber Pontificalis, in: Rivista di storia del cristianesimo, 10,1 (2013) 65-114, hier 72f.

56 Ganz im Gegensatz zur Vita Gregors III. und Zacharias, deren Bericht jeweils einige Zeit vor ihrem Tod endet. Vgl. Davis, LP 8, 18 und 29.

57 Der Sachverhalt wird oft erwähnt, vgl. dazu Duchesne, LP I, CCXXIIf. und Bougard, Composition 134, mit Anm. 15. Zum Textvergleich siehe Beda, Chronica maiora a. 725 et Chronica minora a. 703 (ed. Theodor Mommsen, MGH AA 13, Chronica minora saec. IV-VII, 3, Berlin 1898) 223-354, hier 227f. (Kommentar) und beispielsweise 319f. Fraglich bleibt aber letztlich, ob Beda die Arbeiten an seinem Text tatsächlich 725 vollständig abgeschlossen hat, auch wenn die Widmung an seinen Abt Hwaedberth offenbar auf dieses Jahr hindeutet (vgl. Anton von Euw, Anmerkungen zu Diözesan- und Dombibliothek Handschrift 103, in: Glaube und Wissen im Mittelalter, Katalogbuch zur Ausstellung [München 1998] 129-132) und zudem auch einige Berechnungen im Text einen Redaktionshorizont im Jahr 725 belegen (vgl. Faith Wallis, Bede: The Reckoning of Time [Translated Texts for Historians 29, Liverpool 1999] XVI, Anm. 4). Theoretisch hätten die Passagen aus dem Liber Pontificalis auch nach dem Tod Gregors II. noch nach England gelangt sein und dort eingearbeitet worden sein können. Warum dann aber diese Einarbeitung genau mit 717/718 (einer Überflutung Roms durch ein Hochwasser des Tiber) beendet worden wäre, lässt sich so tatsächlich nur schwer erklären. Insofern ist eher davon auszugehen, dass es circa 725 eine unfertige Fassung der Vita Gregors II. in Nordengland gab. 
1.1.3.2 Die Rezensionen des Liber Pontificalis im achten Jahrhundert unter besonderer Berücksichtigung der Vita Stephans II.

Es existieren heute gleich drei Versionen der Vita Stephans II., die jeweils in den Handschriftengruppen $\mathrm{C}^{34} \mathrm{E}, \mathrm{BD}$ und $\mathrm{AC}^{12} \mathrm{G}$ zusammengefasst werden können. ${ }^{58}$ Die letzte Gruppe ist die sogenannte Langobardische Rezension ${ }^{59}$, von der wir unten noch Genaueres hören werden. BD wird gemeinhin als „fränkische Rezension“ bezeichnet und unterscheidet sich von $\mathrm{C}^{34} \mathrm{E}$ dadurch, dass in $\mathrm{BD}$ dem Text einige Zusätze hinzugefügt wurden.

Zunächst stellt sich die Frage, ob nicht die BD-Rezension als früheste der drei großen Versionen des Lebens Stephans II. anzusehen ist. Denn die Handschriften dieser Textgruppe sind relativ früh (viele Exemplare stammen schon aus dem 9. Jh.) und sehr reich überliefert, während man das für die Handschriften, die den mutmaßlichen Originaltext repräsentieren $\left(\mathrm{C}^{34} \mathrm{E}\right)$, nicht uneingeschränkt sagen kann, denn nur die Leithandschrift von $\mathrm{C}^{3}$ stammt aus dem 9. Jahrhundert, $\mathrm{C}^{4}$ aus dem Io. und die E-Klasse ist überhaupt erst relativ spät erhalten. ${ }^{60}$

Die Handschriften der BD-Klasse sind jedoch nur nördlich der Alpen überliefert, während die gesamte E-Klasse für einen der wesentlichsten italienischen Überlieferungsstränge steht und nur $\mathrm{C}^{34}$ nördlich der Alpen verfasst wurden. Alleine schon dieses räumliche Argument spricht also gegen eine umgekehrte Abhängigkeit. Einschränkend muss man jedoch zugestehen, dass der Grundstock der beiden Klassen bis ins siebente Jahrhundert zweifellos aus Italien stammt. ${ }^{61}$ Dazu kommt, dass auch die ganze Handschriftenklasse $\mathrm{C}$ nur nördlich der Alpen überliefert ist und anders als D den im Prinzip gleichen textlichen Grundstock der frühen Papstleben wie B vorweisen kann. ${ }^{62}$ Insofern ist es also eher nicht gut möglich anhand der heutigen geographischen Verteilung von bestimmten Textvarianten alleine ein Argument festzumachen.

Dazu kommen nun im Fall der BD-Version aber noch inhaltliche Indizien, die alle Zweifel ausräumen dürften: Sie unterscheidet sich im Wesentlichen von der

58 Siehe auch die Graphik in Gantner, Lombard recension 72.

59 Siehe dazu Bougard, Composition 139-143, und zuletzt Capo, Liber Pontificalis, bes. 80f., die interessante Fragen aufwirft, aber schlussendlich leider die Langobardische Rezension als ursprüngliche Vita Stephans II annimmt, was zwar verlockend, aber wie wir noch sehen werden ziemlich unwahrscheinich ist. Siehe auch ausführlich Gantner, Studien und Clemens Gantner, Lombard recension.

60 Siehe unten, Appendix.

61 Siehe unten, Appendix.

62 Siehe unten, Appendix. 
$\mathrm{C}^{34} \mathrm{E}$-Gruppe nur durch einzelne längere und kürzere Textstellen, die sie zusätzlich enthält - und durch grammatikalisch oft deutlich besseres Latein. Die zusätzlichen Textstellen könnten zwar im Prinzip in einer anderen Version auch gezielt gekürzt worden sein, doch wenn man den Charakter dieser Stellen vergleicht, wird relativ schnell klar, dass hier der bestehende Text erweitert wurde und nicht ein längerer Text um diese Zusätze verkürzt wurde. ${ }^{63}$ Denn gleich einige dieser Hinzufügungen gleichen sich sprachlich und in ihrem Tenor auf außerordentliche Weise, heben sich jedoch vom restlichen Text merkbar ab. Gegen Kürzungen spräche außerdem, dass bei fast allen Viten erst in dieser Rezension die sonst üblichen Schlussformeln mit der Zahl der Ordinationen von Klerikern der römischen Kirche enthalten sind - etwas, das wohl kein Redaktor normalerweise weggekürzt hätte.

Auch inhaltlich ist in den meisten Fällen eine einheitliche Linie vorhanden, die auf ein planvolles Vorgehen hinweist. Daran knüpft sich sogleich die Frage, wie diese Überarbeitung des Textes zu bewerten ist. Rosamond McKitterick spricht von einer „fränkischen Rezension“ und charakterisiert diese so: „It serves to reinforce the associations of the Carolingians and the Franks with Rome and papal authority, and provides essential justification of the Frankish conquest of Italy. It incorporates, as I have stressed above, substantial additions, notably in the lives of the eighth-century Popes Gregory III and Stephen II (III), which are pertinent to Frankish affairs or which offer a Frankish dimension to papal affairs." ${ }^{64}$ Prinzipiell ist dieser Darstellung völlig zuzustimmen. Die Interpolation im Leben Gregors III. etwa fügte dem Text, in dem die Langobarden sonst nie erwähnt werden, eine aus Sicht der karolingischen Eroberer möglicherweise notwendige antilangobardische Komponente hinzu. ${ }^{65}$ Die wesentlich zahlreicheren Einschübe im Leben Stephans II. weisen ebenfalls in diese Richtung, insbesondere jene beiden, die über den Ausbau des von den Karolingern besonders geförderten Petronillakultes berichten. ${ }^{66}$ Auch der Hinweis auf die Verleihung des Palliums an Chrodegang von Metz muss wohl an ein fränkisches Publikum gerichtet gewesen sein. ${ }^{67}$

Die Frage ist nur, wer die Anpassungen für ein fränkisches oder frankophiles Publikum vornehmen ließ und wann diese Anpassungen erfolgt sind. Rosamond McKit-

63 In der modernen Forschung gibt es an dieser Richtung der Relation auch keinen Zweifel, vgl. etwa Rosamond McKitterick, History and Memory in the Carolingian World (Cambridge 2004) 146.

64 McKitterick, History 146.

65 Siehe LP I, 420, Anm. *.

66 LP I, 455. Siehe dazu McKitterick, History 146f. und V. Saxer, Petronilla, in: LMA, Bd. 6, 1951f., die darauf hinweist, dass der Petronillakult ursprünglich auf einer missverstandenen Inschrift beruhte, die sich auf eine vornehme Römerin und nicht auf die angebliche Tochter des Heiligen Petrus bezog. 67 LP I, 456. 
terick geht auf diese Frage in ihrem Buch History and Memory, das eine ausführlichere Darstellung enthält, nicht ein. ${ }^{68}$ Tatsächlich hat sie sich aus gutem Grund nie explizit festgelegt. Denn es finden sich ebenso auch Einträge, die auf Informationen aus erster Hand in Rom hinweisen und die nicht direkt auf ein spezifisches Interesse im Frankenreich zurückgeführt werden können, beispielsweise die zusätzlichen Einträge zur Ausstattung von Santa Maria Maggiore und dem Pantheon (Sancta Maria ad Marthyres), die mit hoher Wahrscheinlichkeit aus dem Register des Vestarariums stammen. ${ }^{69}$

Der Redaktor (beziehungsweise die Redaktoren) hatte also für seine Arbeit Zugang zu den schriftlichen Quellen des Lateran, insbesondere jenen des Vestarariums, die meisten der Einschübe beschäftigen sich mit offiziellen Akten des Papstes und mit Stiftungstätigkeit. Somit kommt als Ort für die Redaktion nur Rom, genauer der Lateran in Frage, da nur dort die Aufzeichnung des Vestarariums eingesehen werden konnten. Da die Einschübe auch fast alle demselben Muster folgen, ist eher anzunehmen, dass eine Person oder zumindest eine Gruppe, die einem gemeinsamen Plan folgte, sie vorgenommen hat. ${ }^{70}$

Doch es gibt auch für den Abfassungszusammenhang in Italien ein Gegenargument, nämlich einen Einschub, der sich nur in einem Teil der Handschriften findet, nämlich in $\mathrm{B}^{56} \mathrm{D}$. Berichtet wird - zum Haupttext nicht ganz passend - von einer Messe, die der Papst in Maurienne im Zuge seines Besuches im Frankenreich für Pippin zelebrierte. ${ }^{71}$ Dieser Einschub dürfte tatsächlich nicht mehr in Italien eingefügt worden sein, es sei denn, die für die Franken gedachte Version wäre dort ein weiteres Mal ergänzt worden. Insofern kann man in diesem einen Fall von einem Sonderfall sprechen, für die anderen Teile muss das keine Bewandtnis haben.

Man muss also von einer Erweiterung des Textes in mindestens zwei Stufen ausgehen, die wesentliche davon, in der wahrscheinlich fast alle Einschübe vorgenommen wurden, noch in Rom und eine weitere spätere Redaktionsstufe im Frankenreich. ${ }^{72}$

Interessanterweise wird erst in der erweiterten BD-Version der Tod des primicerius Ambrosius berichtet, der den Papst auf seiner Reise zu König Pippin begleitet hatte. ${ }^{73}$

68 An anderer Stelle setzt sie jedoch implizit voraus, dass die Anpassungen im Frankenreich erfolgt seien, wenn sie von einer „ninth-century Frankish version“ schreibt, siehe Rosamond McKitterick, Charlemagne. The Formation of a European Identity (Cambridge 2008) 67 und dies., History 67.

69 LP I, 443, Anm. ** und 444, Anm. *.

70 Siehe Gantner, Lombard recension 91f., auch Capo, Liber Pontificalis 67f. (mit Anm. 88!) hat sehr stark in diese Richtung argumentiert.

71 LP I, 450, Anm. * und zu Zeile 5.

$72 \mathrm{Zu}$ ähnlichen Schlüssen kommt auch Bougard, Composition 138.

73 LP I, 447, Anm. *. 
Zumindest dieser Einschub könnte aus dem Pontifikat von Stephans Nachfolger Paul stammen, denn sechs Jahre später wurden die Gebeine des Ambrosius nach Rom überstellt. ${ }^{74}$ Im Zuge dessen könnte das Interesse an seinem Tod wieder zugenommen haben. Inwieweit diese mögliche Datierung jedoch auf die anderen Einschübe übertragen werden kann, ist kaum festzumachen, die Pontifikate aller Nachfolgepäpste bis 774, vielleicht mit Ausnahme jenes des „Gegenpapstes“ Konstantin II. ${ }^{75}$, kommen für die Einschübe gleichermaßen in Frage, eine Datierung ist also schwer möglich. Es spricht aber einiges dafür, sie auf die Zeit nach $774 \mathrm{zu}$ datieren, als man durch einige der Einschübe die endgültige fränkische Intervention rechtfertigen wollte. ${ }^{76}$ Es scheint sogar möglich, dass als Vorlage für diese Textgruppe jene LP-Handschrift als Vorlage diente, die von Papst Leo III. übersandt wurde. ${ }^{77}$ Auch die Reise Leos ins Frankenreich im Jahr 804 käme hier als möglicher Übermittlungsweg in Betracht. ${ }^{78}$ Das frühe neunte Jahrhundert, auf das die ersten Handschriften der BD-Version des Liber Pontificalis datiert werden, bildet schließlich den endgültigen Abschluss des Zeitfensters.

Der Liber Pontificalis der B-Klasse wurde interessanterweise später als Element der fränkischen Historiographie verwendet, wie das Beispiel des Codex 473 der Österreichischen Nationalbibliothek (Liber Pontificalis Textklasse B ${ }^{6}$ ) zeigt. Hier diente der Liber Pontificalis als Aufmacher, ja als Grundstock für eine Reihe von darauffolgenden, originär fränkischen historiographischen Texten, nämlich den Liber historiae Francorum, die Continuationes Fredegarii und die Annales regni Francorum in ihrer nicht überarbeiteten Fassung ${ }^{79}$, die von der Vita Karoli Magni Einhards

$74 \mathrm{Im}$ Jahr 759, wie die beiden überlieferten Versionen seines Epitaphs berichten. Siehe Davis, LP 8, 62, Anm. 55 und Duchesne, LP I, 457f., Anm. 27 und ders., LP III, 103.

75 Zur Problematik des Begriffs "Gegenpapst“ im Fall Konstantins II. siehe unten, Kap. 5.5.1, sowie Klaus Herbers, Konkurrenz und Gegnerschaft. „Gegenpäpste“ im 8. und 9. Jahrhundert, in: Gegenpäpste. Ein unerwünschtes mittelalterliches Phänomen, ed. Harald Müller/Brigitte Hotz (Papsttum im mittelalterlichen Europa 1, Wien/Köln/Weimar 2012) 55-70, bes. 56-58 und 66f. Konstantin war in seiner Antszeit jedenfalls der einzige amtierende Bischof von Rom.

76 So sieht das auch Bougard, Composition 138.

77 McKitterick, History 122. Mary Garrison, The Franks as the New Israel? Education for an identity from Pippin to Charlemagne, in: The Uses of the Past in the Early Middle Ages, ed. Yitzhak Hen/ Matthew Innes (Cambridge 2000) 114-161, hier 127 mit Anm. 49.

78 Zum Besuch Leos im Frankenreich 804/805 siehe Paolo Delogu, Leone III, santo, in: Enciclopedia dei papi, Bd. 1 (Rom 2000) 695-704, hier 701: Delogu spekuliert hier auch, dass Leo im Zuge der Reise das Constitutum Constantiniani nach Norden gebracht haben könnte. Der Zeitpunkt der Fertigstellung dieser berühmten Fiktion aus dem Umkreis des Papstes ist aber weiterhin umstritten.

$79 \mathrm{Zu}$ den Fassungen der Annales regni Francorum siehe sehr präzise McKitterick, Charlemagne 31-43. Zur Überarbeitung siehe auch Roger Collins, The ,Reviser' revisisted. Another look at the alternative 
unterbrochen werden. Daran knüpfen sich noch zwei genealogische Texte zu den Karolingern. ${ }^{80}$

Doch auch diese Verwendung (wie Helmut Reimitz gezeigt hat wohl im oder kurz nach dem Jahr $869^{81}$ ) macht eine von Franken erstellte Version nicht wahrscheinlicher.

Insgesamt gibt es zwar hinreichende Gründe, die Bezeichnung „fränkische Rezension“ nicht zu verwerfen, vor allem wenn man vom intendierten und wohl auch erreichten Publikum ausgeht. ${ }^{82}$

Wesentlich schwieriger ist die Einordnung der sogenannten Langobardischen Rezension, enthalten in den Textklassen $\mathrm{AC}^{12} \mathrm{G}{ }^{83}$ Gleich als Erstes gilt es wieder, die Beziehung zur von Duchesne als Original identifizierten Version $\mathrm{C}^{34} \mathrm{E}$ zu klären. Kann die Langobardische Rezension nicht auch die Originalversion sein? Schließlich ist nicht auszuschließen, dass sie sogar früher überliefert ist, keine der Handschriften, die die langobardenfeindliche Version der Vita Stephans II. enthält, kann mit Sicherheit früher datiert werden als die Handschriften aus Lucca ( $\mathrm{A}^{1}$, um 8oo) und Leiden ( $\mathrm{C}^{1}$, etwa 790).

Es gibt tatsächlich keine zwingenden Beweise für eine Präzedenz der gemeinsamen Version der Klassen $\mathrm{C}^{34} \mathrm{E}^{84}$ vor $\mathrm{AC}^{12} \mathrm{G}$. Die von $\mathrm{AC}^{12} \mathrm{G}$ repräsentierte Langobardische Rezension scheint auf den ersten Blick zwar tatsächlich eine Überarbeitung des in der Duchesne Edition repräsentierten Textes zu sein. Es wurde aber vor kurzem von Lidia Capo postuliert, dass umgekehrt in der anderen Version die antilangobardische Prägung erst später hinzugefügt wurde..$^{85}$

Doch schon im Text selbst finden sich einige Indizien, die auf eine spätere Überarbeitung, die zur Langobardischen Rezension geführt hat, hindeuten. Allen voran zu

version of the Annales regni francorum, in: After Rome's Fall. Narrators and Sources of Early Medieval History. Essays presented to Walter Goffart, ed. Alexander C. Murray (Toronto 1998) 191-213.

$80 \mathrm{Zu}$ der Handschrift siehe ausführlich Helmut Reimitz, Ein karolinigisches Geschichtsbuch aus St.

Amand. Der Codex Vindobonensis palat. 473, in: Text - Schrift - Codex. Quellenkundliche Arbeiten aus dem Institut für Österreichische Geschichtsforschung, ed. Christoph Egger/Herwig Weigl (München 2000) 34-90 und McKitterick, History 120-132.

81 Reimitz, Geschichtsbuch.

82 So ist auch schon Duchesne in seiner Edition ähnlich vorsichtig vorgegangen.

83 Siehe dazu Gantner, Lombard recension.

84 Wenn man diese Version überhaupt so zusammenfassen will: $\mathrm{C}^{3}$ bricht in der Vita Stephans II. ab und ist daher nicht voll zu zählen. $\mathrm{C}^{4}$ entstammt dem zehnten Jahrhundert und die E-Handschriften sind überhaupt teilweise erst im späten Mittelalter geschrieben worden ( $\left.\mathrm{E}^{26}\right)$, die eine wichtige Ausnahme $\left(\mathrm{E}^{5}\right)$, die wahrscheinlich aus dem neunten Jahrhundert stammte, ist heute verloren, $\mathrm{E}^{1}$ und $\mathrm{E}^{4}$ entstammen dem 11. Jahrhundert. Die „Originalversion“ ist also erst ausgesprochen spät überliefert. 85 Siehe Capo, Liber Pontificalis $80 \mathrm{f}$. 
nennen ist hier der Umstand, dass die pejorativen Adjektive gegen Aistulf zunächst gleich beginnen, das heißt, dass Aistulf am Beginn der Vita noch nefandus sein kann und auch die übertrieben positive Attribuierung Stephans II. noch erfolgt und erst nach und nach reduziert wird. ${ }^{86}$ Dieser Befund spricht dafür, dass ab dieser Stelle ein Redaktor stärker in den Text eingegriffen hat und nicht dafür, dass ein Autor hier mit der negativen Darstellung aufgehört hätte und erst ein späterer Redaktor die antilangobardische Rhetorik fortgeführt hätte. ${ }^{87}$

Neben den inhaltlichen Argumenten liefern auch die ältesten Handschriften der Langobardischen Rezension wichtige Anhaltspunkte, die für eine Abhängigkeit dieser Version von $\mathrm{C}^{34} \mathrm{E}$ sprechen. Die Langobardische Version ist tatsächlich in zwei Untergruppen gespalten, denn während die Texte $A{ }^{1} \mathrm{G}$ einer weiteren Überarbeitungsstufe entstammen, ist bei $\mathrm{C}^{2}$ (repräsentiert durch den Codex Guelferbytanus, Io.I I Augusteus in quarto in Wolfenbütte ${ }^{88}$ ) eine deutlich höhere Anzahl an Übereinstimmungen mit $\mathrm{C}^{34} \mathrm{E}$ festzustellen. Das schließt schon drei der ältesten Handschriften dieser Rezension völlig als „Originalversion“ aus, aber $\mathrm{C}^{34} \mathrm{E}$ könnten so gesehen natürlich immer noch von $\mathrm{C}^{2}$ abhängen. Doch gibt es in der textlichen Überlieferung Elemente, die eine Abhängigkeit in diese Richtung praktisch ausschließen. Es sei hier nur auf die erste gemeinsame Variante der Gruppe $A C^{12} \mathrm{G}$ in der Vita Stephans II. verwiesen. Die vier ältesten Handschriften haben hier übereinstimmend eine Variante: Während $\mathrm{C}^{34} \mathrm{E}$ übereinstimmend die Worte intro venerabilem überliefern, hat $\mathrm{C}^{2}$ hier introierensens, die anderen Handschriften haben relativ ähnliche Formen. Es ist an dieser Stelle offenbar nahezu unmöglich gewesen, den Text von $\mathrm{C}^{34} \mathrm{E}$ aus jenem von $\mathrm{C}^{2}$ zu verbessern. Viel wahrscheinlicher ist es, dass es sich umgekehrt um eine Verschreibung aus dem Text von $\mathrm{C}^{34} \mathrm{E}$ handelt. Solche Stellen finden sich auch in $\mathrm{C}^{2}$ und viel mehr noch in $\mathrm{AC}^{1} \mathrm{G} .{ }^{89}$

Zusammen mit den inhaltlichen Argumenten ist Lidia Capo also zu widersprechen: Trotz der späteren Überlieferung ist weiterhin davon auszugehen, dass der Text, den $\mathrm{C}^{34} \mathrm{E}$ haben, ursprünglich der Text der Vita Stephans II. gewesen ist.

Neben der Frage der Präzedenz stellt sich ebenso die Frage, ob die Langobardische Rezension überhaupt eine „römische“ Variante des LP ist oder aber eine von Langobarden erstellte Überarbeitung, wie seit Duchesne eigentlich meist als sicher angenommen wurde - eine Frage, die sich als nicht beantwortbar erweist. François Bou-

86 So ist Aistulf bei LP I, 441, Z. 12 noch protervus ... rex, ebd. 442, Z. 10 ist er nequissimus und ebd., 443, Z. 8 ist er nefandus rex. (Und das obwohl sich schon ebd., 441, Z. 14 der erste sicher absichtliche Eingriff der Langobardischen Rezension findet, vgl. Gantner, SLombard recension 84f.)

87 Vgl. ausführlich Gantner, Studien 123-126 und 139-148 und Gantner, Lombard recension $91 \mathrm{f}$.

88 Siehe dazu Gantner, Studien 63-89.

89 Siehe dazu ausführlich Gantner, Studien 115-148, und ebd., Appendix 1, 181-194. 
gard hat sie mit guten Argumenten mit Lucca in Verbindung gebracht, von wo ja auch die wahrscheinlich zweitälteste Handschrift stammt. ${ }^{90}$ Mit viel Verve hat sich Lidia Capo hingegen dafür ausgesprochen, dass die Überarbeitung doch in Rom stattgefunden haben muss. ${ }^{91}$ Tatsächlich lässt sich keine dieser Interpretationen nachweisen und zwar weder im Text noch anhand der handschriftlichen Überlieferung, ${ }^{92}$ auch wenn man die Entstehung einiger sinnstörender Fehler einem römischen Redaktor fast nicht zutrauen möchte, von denen aber zumindest einige auch einem späteren Kopiervorgang zugeschrieben werden könnten.

Eine Überarbeitung in Rom mit dem Ziel einen den Langobarden gegenüber diplomatischeren Text zu erstellen, ist daher dennoch nicht auszuschließen. Dafür spricht auch, dass die Vita inhaltlich so gut wie nicht verändert wurde. In keiner Änderung lässt sich unzweifelhaft langobardischer Revisionismus nachweisen. König Aistulf etwa wird in beiden Versionen mehrmals Eidbruch vorgeworfen. Auch die Situation von 752, in der Aistulf zumindest aus Sicht der Langobarden aller Wahrscheinlichkeit nach gar keinen Vertrag verletzt hatte, wird in keiner Weise beschönigt. ${ }^{93}$ So gesehen wäre ein römischer Ursprung der Überarbeitung etwas wahrscheinlicher.

Was also geschah im Zuge der Redaktion mit dem Text der Vita Stephans II.? Ohne im Detail auf einzelne Änderungen einzugehen, lässt sich folgendes Fazit erstellen: Während das grundlegende Narrativ unangetastet blieb und weiterhin das Vorgehen Stephans II. und Pippins ohne Wenn und Aber legitimiert wird, wurde in den Ton der Vita entscheidend eingegriffen. Alle negativen Epitheta, die die Langobarden als Kollektiv angreifen, sowie auch eine Reihe von pejorativen Adjektiven, die nur König Aistulf zugedacht waren, wurden weggelassen oder (selten) zum Positiveren verändert. Zugleich wurden die in der Originalversion tatsächlich extrem häufig verwendeten positiven Adjektive und Bezeichnungen für Pippin und den Papst selbst fast gänzlich aus dem Text genommen. Der Text wurde dadurch kaum weniger papst- oder karolingerfreundlich, es scheint eher wahrscheinlich, dass das Original im Zuge der Redaktion als stilistisch wenig ansprechend empfunden wurde, insbesondere die exzessive Lobhudelei. Zum Stil der Originalversion sagte der Übersetzer Raymond Davis: „The writer's style is tedious, particularly in his repetitive use of epithets. Aistulf is never mentioned without being described, at the very least, as wicked; Pepin is always christianissimus. Both kings are given their regal titles at every

90 Bougard, Composition 139-143.

91 Capo, Liber Pontificalis 80.

92 Gantner, Studien 117-123.

93 Vgl. oben und siehe Ottorino Bertolini, Il primo „periurium“ di Astolfo verso la chiesa die Roma, in Miscellanea Giovanni Mercati, Studi e testi 125 (Vatikanstadt 1946) 160-205, ND in ders., Scritti Scelti di Storia Medievale, 2 Bde, ed. Ottavio Banti (Livorno 1968) Bd. 1, 125-169. 
mention; the pontiff and other clerics are always sanctissimus; anyone mentioned more than once becomes ,the aforesaid' (John the silentiary, mentioned once before, is ,the oft-mentioned'). Even so the writer's frequent changes of subject within a sentence create problems, and doubts result on who is the antecedent of possessive and reflexive adjectives and pronouns. ${ }^{\text {"94 }}$ Damit hat er im Prinzip auch Recht und mit hoher Wahrscheinlichkeit war genau dieses massive Auftreten der positiven und negativen Epitheta eine wesentliche Triebfeder für den oder die Redaktor(en) der Langobardischen Rezension.

Doch wenn man nur das holprige sprachliche Bild der Vita in Betracht zieht, greift man zu kurz. Die verwendeten Epitheta hatten nämlich sicherlich auch eine politische Dimension, und der Frankenkönig als wesentlicher Verbündeter Roms musste deshalb in dem Text entsprechend offiziös tituliert werden. Das geschah nun vor allem deshalb in dem durchaus exzessiven Ausmaß, weil sich die Vita eben auch nicht zuletzt an ein fränkisches Publikum richten sollte. Den Autor der Originalvita brachte also wahrscheinlich vor allem Sorge dazu, den Frankenkönig und den Papst so massiv mit Titeln zu versehen. ${ }^{95}$

Ein Beispiel illustriert besonders gut die Vorgehensweise bei der Erstellung der Langobardischen Rezension: Die Eingriffe der Rezension nähern sich an dieser Stelle schon ihrem Höhepunkt, den sie in LP I, 450, 3-I I [Var (49) in Gantner, Studien] finden. Diese im Folgenden in Abbildung I zitierte Variante spricht eigentlich weitestgehend für sich selbst. Gerade deshalb wurde sie hier als Vollzitat sogar in zwei Spalten wiedergegeben. Die linke Spalte enthält den Text der Edition Duchesnes (und daher der Textklasse $\mathrm{C}^{3}$ nach der Berner Handschrift), die rechte den Text der Langobardischen Rezension. Veränderungen und Hinzufügungen gegenüber dem Editionstext, der die Originalrezension der Vita repräsentiert, werden kursiv wiedergegeben, Auslassungen werden graphisch nicht extra ausgewiesen. Die gemeinsamen Varianten von $\mathrm{AC}^{1}$ beziehungsweise $\mathrm{AC}^{1} \mathrm{G}$ werden gegenüber der Schreibung von $\mathrm{G}$, die einige individuelle Varianten enthält, und gegenüber $\mathrm{C}^{2}$, die an den befußnoteten Stellen den Text der Edition hat, bevorzugt und mit den Fußnoten a-d einzeln ausgewiesen.

Sowohl inhaltlich als auch stilistisch wurden hier wohl die umfangreichsten Änderungen vorgenommen. Bougard hat deshalb die Vermutung geäußert, dass dem

94 Davis, LP 8, 52.

95 Zur Frage der politischen Verwendung von Titeln in frühmittelalterlichen Texten siehe Helmut Reimitz, Omnes Franci. Identifications and Identities of the early medieval Franks, in: Franks, Northmen, and Slavs: Identities and State Formation in Early Medieval Europe, ed. Ildar H. Garipzanov/ Patrick J. Geary/Przemyslaw Urbanczyk (Cursor Mundi, 5, Turnhout 2008) 51-69. 
Redaktor an dieser Stelle besonders viel gelegen haben könnte, ${ }^{96}$ dass es sich beim Redaktor also um jemanden gehandelt haben könnte, der entweder selbst in den Kampfhandlungen 754 involviert war, der im Auftrag von jemandem arbeitete, der ein besonderes Interesse an einer Abänderung dieser Stelle gehabt haben könnte, oder dass der Redaktor zumindest in einem Umfeld stand, das auf irgendeine Weise näher an den Kämpfen mit den Franken 754 beteiligt war. Es ist aber meines Erachtens nach nicht sicher, ob der Redaktor ein spezielles Interesse an der Stelle erkennen lässt oder ob er sich nur aufgrund des ihm vorliegenden Textes zu den Änderungen veranlasst sah. Dass die bereits erwähnte Stelle, die die Hilfe Christi für die Franken thematisiert, nicht wesentlich verändert wurde, zeigt, dass es dem Redaktor wie im restlichen Text vor allem darum ging, die sehr einseitige Version des Liber Pontificalis in eine fairere Variante zu verwandeln. Aus durchaus verständlichen Gründen sah er sich an der vorliegenden Stelle gezwungen, besonders stark einzugreifen, um eine ausgewogene Version herzustellen. So rechtfertigt er die Bereitschaft des langobardischen Heeres zum Kampf, ohne es auf die ferocitas Aistulfs zu schieben, ausnahmsweise wurde hier gleich der ganze Satz deutlich abgeändert, tatsächlich klingt er schlicht sachlicher. Auch der Rückzug der Langobarden nach Pavia wird geschildert, die ursprüngliche Schlussfolgerung, der König habe sich dorthin aus Furcht vor den Franken zurückgezogen, wird weggelassen und durch die Bemerkung ersetzt, dass er dort „mit den Seinen lebte“. Das alles ist vor allem dazu da, der Stelle ihre sogar für die Vita Stephans außergewöhnliche Schärfe zu nehmen. Man hat nicht den Eindruck, dass Aistulf hier besonders positiv dargestellt werden sollte, sondern nur realistisch und ohne allzu persönliche Angriffe.

Die zitierte Stelle zeigt darüber hinaus auch die besonders engen textlichen $\mathrm{Zu}$ sammenhänge zwischen den Textklassen $\mathrm{AC}^{1} \mathrm{G}$, die in Fußnoten extra ausgewiesen sind. Sie kann aber auch als Beispiel für die recht große Kohärenz der Handschriften der Langobardischen Rezension stehen. Der gegenüber der Edition unterschiedliche Satzanfang (recht unvermittelt mit dem Wort Ita, hier durch den großen kursiven Anfangsbuchstaben markiert) ist in allen Handschriften auf die eine oder andere Weise sichtbar, ${ }^{97}$ was darauf hindeutet, dass das auch in einer gemeinsamen Vorlage so gewesen sein könnte. ${ }^{98}$ Dazu gibt es auch noch weitere kleine Varianten, die allen

96 Bougard, Composition $140 f$.

97 Das soll nicht bedeuten, dass die Edition hier eine Art sakrosankte Version bieten würde und sich der beschriebene Satzanfang nicht auch in anderen Liber Pontificalis Handschriften auf ähnliche Weise finden könnte. Dennoch fällt die betreffende Stelle durch ihre Einheitlichkeit auf.

98 Zweifellos sind Satzanfänge bzw. Satzzeichen in mittelalterlichen Handschriften zumeist weit entfernt davon einem erkennbaren System zu folgen und daher alles andere als sichere Indikatoren. Dennoch hat die Untersuchung der vier Handschriften auffällige Gemeinsamkeiten ergeben, die in der 


\section{LPI, ed. Duchesne 450:}

Tunc fisus in omnipotentis Dei misericordia antefatus Pippinus Francorum rex iter suum profectus est, praemittens ante suum occursum aliquos ex suis proceribus et cum eis exercitales viros ad custodiendum proprias Francorum clusas; ibique coniungentes remoti residebant, proprii regis praestolantes adventum. Audiens itaque protervus ille Aistulfus parvos fuisse Francos illos qui ad custodiam propriarum advencrant clusarum, fidens in sua ferocitate, subito aperiens clusas, super eos diluculo cum plurimis irruit exercitibus. Sed iustus iudex dominus Deus et salvator noster Iesus Christus victoriam paucissimis illis tribuit Francis; et multitudinem illam Langobardorum superantes trucidaverunt, ita ut ipse Aistulfus, fugam arreptus, vix ab eorum evadere potuisset manibus et usque Papiam in civitatem absque armis fugam arripuisset; in qua et prae timore Francorum cum aliquantis se retrusit.

\section{Text der Langobardischen Rezension:}

Tunc Pippinus rex profectus est, promittens $^{\mathrm{a}}$ ante suum occursum aliquos ex suos et cum eis exercitales viros ad custodiendum proprias Francorum clusas; ibique coniungentes remoti residebant, regem sum expectantes. Audiens itaque Aistulfus rex parvum mumerum ex illis Francis adfuisse qui ad custodiendam propria advenerant, fidens in sua fortitutdine, subito aperiens clusas, super eosdem diluculo cum plurimis inruit ${ }^{e}$ exercitibus. Sed iustus iudex dominus Deus noster lesus Christus victoriam illis pancissimis tribuens Francis; et multitudinem illam Langobardorum superantes trucidaverunt, Ita ut ipse Aistulfus, fugam areptus ${ }^{\mathrm{d}}$, ab eorum evasit manibus et usque Papiam in civitatem fugam arripuisset; in qua se cum suis habitavit.

Abbildung I: Variante (49), LPI, 450, ll. 3-II (entnommen aus Gantner, Studien 146)

Handschriften eigen sind. Alleine für sich genommen wären sie nicht außergewöhnlich ${ }^{99}$, dadurch, dass sie sich aber in allen vier Handschriften auf die gleiche (oder fast die gleiche) Weise finden, werden sie dennoch bedeutsam.

Zuletzt bleibt noch zu klären, wann denn die Überarbeitung der Vita Stephans II. stattgefunden hat. Eine auch nur halbwegs akkurate Antwort ist schwierig. Duchesne

Form ihres Auftretens als überzufällig zu bewerten sind. Bestimmte Satzanfänge haben sich tatsächlich in allen vier Manuskripten als im jeweiligen Stil gekennzeichnete Stellen erwiesen, die auf eine ähnliche Gestaltung schon in einer frühen Vorlage hindeuten. Daher wird mit aller gebotenen Vorsicht in der vorliegenden Arbeit auf diese Stellen hingewiesen. Es sollte jedoch vermieden werden, ein Argument nur aufgrund dieser Indikatoren aufzubauen.

99 Und es sei darauf hingewiesen, dass sich in den einzelnen Handschriften noch einige weitere individuelle Varianten zu der zitierten Stelle finden, ganz besonders in Textklasse G. 
wollte die Abfassung noch vor 774 einordnen, ${ }^{100}$ denn er ging davon aus, dass eine solche Version nach dem Fall des Langobardenreichs nicht mehr möglich gewesen wäre. Hierin kann man ihm keinesfalls zustimmen, denn zum einen existierte das Reich ja weiter, zum anderen gab es auch noch lange Zeit nach 774 Menschen in Italien, die sich als Langobarden bezeichneten, am längsten sicherlich in Süditalien. Somit kann als terminus ante quem eigentlich nur die Datierung der ältesten Handschrift herangezogen werden. Es handelt sich dabei um den Leidener Codex Vossianus Lat. Q6o, der ursprünglich wohl im Kloster St. Amand oder dessen Umgebung entstanden ist und wohl noch vor 800 geschrieben wurde. ${ }^{101}$ Wenn wir etwas Zeit für die Verbreitung der Rezension veranschlagen, ist wohl davon auszugehen, dass sie zumindest bis 780 verfasst wurde. Wie wir noch sehen werden, gab es in der Zeit zwischen dem Tod Stephans II. 757 und 780 viele Zeiträume, in denen der Text auch in Rom verfasst worden sein könnte, im langobardischen Bereich kommt überhaupt der gesamte Zeitraum in Frage.

\subsection{Der Codex epistolaris Carolinus}

Neben dem LP ist der sogenannte Codex Carolinus (oder Codex epistolaris Carolinus, um Verwechslungen vorzubeugen, in der Folge $\mathrm{CC}$ abgekürzt) die wichtigste und reichhaltigste Quelle päpstlicher Texte für das achte Jahrhundert. Die Briefsammlung ist heute nur in einer mittelalterlichen Handschrift erhalten, dem Codex lat. 449 der Österreichischen Nationalbibliothek in Wien. Daneben gibt es eine Reihe von neuzeitlichen Abschriften, die sogar vom Herausgeber des Textes für die MGH, Wilhelm Gundlach in Betracht gezogen wurden. Doch letztlich gehen auch diese Abschriften nur auf den einen mittelalterlichen Codex zurück. ${ }^{102}$

Der einzige mittelalterliche Textzeuge des CC stammt aller Wahrscheinlichkeit nach aus Köln, wo die Abschrift in der zweiten Hälfte des neunten Jahrhunderts angefertigt wurde. Der Codex trägt einen Besitzvermerk des Kölner Erzbischofs Willibert, was dazu verleitet hat, die Erstellung auch in seinen Pontifikat zu datieren. Tatsächlich ist der Vermerk allerdings nur in die Handschrift eingeklebt, was eine genaue Zuweisung erschwert, auch wenn die Hand, die den Vermerk beschriftet hat, der anlegenden Hand des Vorworts des Codex zumindest stark ähnelt, wenn es sich nicht ohnehin

100 Duchesne, LP I, CCXXVI.

101 Siehe dazu vor allem Bernhard Bischoff, Die südostdeutschen Schreibschulen, Bd. 2, Die vorwiegend österreichischen Diözesen (Wiesbaden 1980) 65 und 102. Siehe auch McKitterick, History 212.

102 Achim Thomas Hack, Codex Carolinus. Päpstliche Epistolographie im 8. Jahrhundert, 2 Bde. (Päpste und Papsttum 35, 1-2, Stuttgart 2006-2007), Bd. 1, 87-90. 
um denselben Schreiber handelte. Doch selbst das würde eine ganz sichere Datierung nicht erlauben, da der Schreiber durchaus länger in Köln gewirkt haben könnte. ${ }^{103}$

Wichtig ist aber jedenfalls, festzuhalten, dass es sich bei der heute vorliegenden Überlieferung nicht um das Original der Sammlung aus dem späten achten Jahrhundert, sondern um eine fast hundert Jahre später hergestellte Kopie handelt.

Auf dieser Grundlage wurde der Text des CC also ediert. Die letztgültige Ausgabe von Gundlach ist, wie erwähnt, in die MGH, EE 3 (Berlin I892) 469-657, aufgenommen worden. Ihr Zustandekommen ist jedoch als recht problematisch zu bewerten. Denn es blieb Gundlach versagt, die Handschrift im Original zu begutachten, er hatte nur die Möglichkeit, Michael Tangl, der sein Kontaktmann in Wien war, eine lange Liste mit Fragen zu schicken, die er anhand einer ihm vorliegenden Abschrift der Handschrift, die Georg Heinrich Pertz I 820 angefertigt hatte, im Vergleich mit Philipp Jaffés Ausgabe erstellte. Somit musste sich Gundlach bei der Produktion seines Textes relativ stark auch auf die vorangegangene und zur Zeit seiner Bearbeitung erst wenige Jahrzehnte alte Edition Jaffés verlassen. ${ }^{104}$

Doch der CC bereitet für eine Edition sehr spezifische Probleme: Im frühen I7. Jahrhundert befasste sich der damalige Leiter der Kaiserlichen Hofbibliothek, Sebastian Tengnagel, eingehend mit dem Codex und wollte ihn für eine Edition durch Jakob Gretser aufbereiten. Da der vorhandene Text in seinen Augen sehr unzulängliches Latein enthielt, brachte er eine ganze Reihe von Korrekturen an, oft direkt über dem alten Buchstabenbestand. Das Problem ist, dass es ohne Ansicht des Originals an manchen Stellen tatsächlich fast unmöglich ist, zu entscheiden, wie der ursprünglich eingetragene Text lautete. ${ }^{105}$

Es verwundert angesichts dieser Faktenlage nicht, dass es bereits kurz nach Erscheinen der Edition massive Kritik daran gab, nicht zuletzt von Paul Fridolin Kehr, der gleich im Jahr nach der Veröffentlichung eine vernichtende Einschätzung der Edition abgab und kaum Fortschritte gegenüber der Vorgängeredition Jaffés zu er-

103 Siehe Codex epistolaris Carolinus, Österreichische Nationalbibliothek Codex 449 (Codices selecti, 3, Graz 1962) fol. $\mathrm{a}^{\mathrm{v}}$ (der eingeklebte Besitzvermerk) und $1^{\mathrm{R}}$ (zum Vergleich die Kapitalis der Praefatio). Vgl. Franz Unterkircher, Einleitung, in: Codex epistolaris Carolinus, Österreichische Nationalbibliothek Codex 449 (Codices selecti, 3, Graz 1962) I-XXVII, hier XX, zur Entstehungszeit des Codex, der auf die Unsicherheit der Zuweisung zum Pontifikat Williberts (870-889) hinweist. Paläographisch ist der Codex eher um die Mitte des neunten Jahrhunderts anzusiedeln. Siehe auch ebd., XIXf. zu den Rubriken.

104 Siehe dazu ausführlich Hack, Codex Carolinus, Bd. 1, 44-47. Zur Edition (und auch zur Person) Jaffés vgl. ebd., 39-42.

105 Unterkircher, Einleitung zum Faksimile von CVP 449, XXI. Siehe auch eine Schriftprobe Tengnagels, ebd., XIV, Abb. 7. Die „Korrekturen“ Tengnagels lassen sich im Faksimile auf fast jeder Seite deutlich erkennen. 
kennen vermochte. ${ }^{106}$ Einige Zeit später war es auch Kehr, der die Datierung und Anordnung, die Gundlach für die etwa 30 im CC enthaltenen Briefe Pauls I. vorgeschlagen hatte, korrigierte. ${ }^{107}$ Gundlach hatte schon vor der Kritik Kehrs eine lange Stellungnahme im Neuen Archiv verfasst, worin er seine Vorgehensweise erklärte und größtenteils verteidigte sowie auf seine Probleme bei der Produktion des Textes hinwies. ${ }^{108}$ Letztlich muss man festhalten, dass die aktuelle Edition zwar keineswegs unbenutzbar ist, aber dennoch nicht völlig zuverlässig.

Glücklicherweise gibt es seit I962 eine Faksimileedition der Wiener Handschrift, herausgegeben von Franz Unterkircher. Das Faksimile ermöglicht es, strittige Stellen in der MGH-Edition zu überprüfen.

Widmen wir uns nun dem CC selbst: Es handelt sich hier um eine Sammlung von Papstbriefen an verschiedene karolingische Empfänger, die ersten richteten sich noch an Karl Martell, der Großteil der Briefe ist aber an die Könige Pippin und Karl den Großen adressiert. Der CC enthält Briefe der Päpste Gregor III. (2 Stücke), Zacharias (I), Stephan II. (8), Paul I. (32), Stephan III. (5) und Hadrian I. (49) sowie nachgestellt zwei Briefe des am römischen Konzil von 769 abgesetzten Konstantin II. Der Zeithorizont ist dabei 739 bis 790/79I.

Die Sammlung wurde im Jahr 79r begonnen, wie aus dem Vorwort hervorgeht, das nun im Volltext zitiert wird, auch weil es später für die Argumentation noch wesentlich ist:

\footnotetext{
+ REgNANTE in PERPETUUM DOMino ET SAlvatore Nostro iesu Christo,

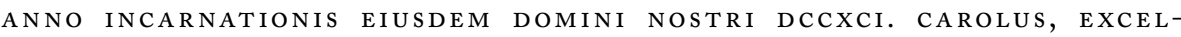
LENTISSIMUS ET A DEO ELECTUS REX FRANCORUM ET LANGOBARDORUM AC PATRICIOS ROMANORUM, ANNO FELICISSIMO REgNi IPSIUS XXIII., DIVINO NUTU INSPIRATUS, SICUT ANTE OMNES QUI ANTE EUM FUERUNT SAPIENTIA ET PRUDENTIA EMINET, ITA IN HOC OPERE UTILISSIMUM SUI OPERIS INSTRUXit INGENIUM, UT UNIVERS AS EPISTOLAS, QUE TEMPORE BONAE MEMORIAE DOMNI CAROLI AVI SUI NEC NON ET GLORIOSI GENITORIS SUI PIPPINI SUISQUE TEMPORIBUS DE SUMMA SEDE APOSTOLICA BEATI PETRI APOSTOLORUM PRINCiPIS SEU ETIAM DE IMPERIO AD EOS DIRECTAE ESSE NOSCUNTUR, EO QUOD
}

106 Paul Fridolin Kehr, Rezension von Wilhelm Gundlach (ed.), Codex Carolinus, in: Göttingische Gelehrte Anzeigen 155 (1893) 871-898. Siehe zu seiner Kritik und der folgenden Diskussion: Hack, Codex Carolinus, Bd. 1, 47-51.

107 Paul Fridolin Kehr, Über die Chronologie der Briefe Pauls I. im codex Carolinus, in: Nachrichten von der Königlichen Gesellschaft der Wissenschaften zu Göttingen, Philologisch-Historische Klasse, 2 (1896) 103-157.

108 Wilhelm Gundlach, Ueber den Codex Carolinus, in: Neues Archiv, 17 (1892) 525-566. 


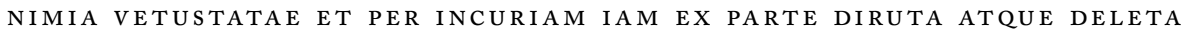
CONSPEXERAT, DENUO ME MORALIBUS MEMBRANIS SUMMO CUM CERTAMINE RENOVARE AC RESCRIBERE DECREVIT - INCIPIENS IGITUR, UT SUPRA DIXIMUS,

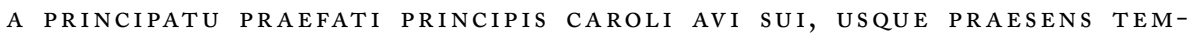
PUS ITA OMNIA EXARANS, UT NULLUM PENITUS TESTIMONIUM SANCTAE ECCLAESIAE PROFUTURUM SUIS DEESSE SUCCESSORIBUS VIDEATUR, UT SCRIPTUM EST: "SAPIENTIAM OMNIUM ANTIQUORUM EXQUIRET SAPIENS“ ET CETERA. ${ }^{109}$
\end{abstract}

Wahrscheinlich wurde die Sammlung in Regensburg in der Zeit des langen Aufenthalts des karolingischen Hofes in der ehemaligen agilolfingischen Hauptstadt zwischen August 79I und Herbst 793 fertiggestellt. ${ }^{110}$

Allerdings enthält der CC keineswegs alle Papstbriefe aus dem Zeitraum, den der $\mathrm{CC}$ abdeckt. Das zeigt sich schon in der Reihe von Fällen, die Achim Hack zusammengestellt hat. In Hacks Liste finden sich ausschließlich Papstbriefe, deren Existenz sich sicher aus Briefen des CC selbst erschließen lässt, insgesamt sieben Stücke. ${ }^{111}$ Doch damit nicht genug - es finden sich auch eine Reihe von Lücken in der Überlieferung, für die völlig klar sein muss, dass es in dieser Zeit Kommunikation gegeben hat. Das beste Beispiel sind die Briefe Hadrians I., die erst nach dem Fall Pavias im Spätsommer oder Herbst 774 einsetzen. Somit ist kein Brief aus den ersten zweieinhalb Jahren von Hadrians Pontifikat erhalten - obwohl der LP ganz klar belegt, dass Kommunikation mit den Franken und Karl dem Großen stattgefunden haben muss. ${ }^{112}$ Man könnte nun annehmen, dass Briefe weggelassen wurden, um bestimmte unangenehme Themen auszuklammern oder Unstimmigkeiten zwischen Papsttum und Karolingern zu verschleiern. Doch im CC sind, wie wir unten in Kapitel 5.6.2 sehen werden, Briefe enthalten, die von Spannungen zwischen dem Papst und den Karolingern berichten. Das reine Vorhandensein dieser Briefe ist ein starkes Indiz, dass zwar Briefe zur Gänze weggelassen wurden, das aufgenommene Material jedoch nicht verändert wurde. Dennoch ist aber nicht auszuschließen, dass die weggelassenen Stücke absichtlich nicht aufgenommen wurden - hier kommen aber mehrere Möglichkeiten in Frage: Die Briefe könnten inhaltlich zu heikel gewesen sein, um sie in den CC aufzunehmen, genauso wäre es aber denkbar, dass sie von ihrer Form her oder konkreter von ihrer Sprache her nicht den Gefallen des Königs oder eher des Kompilators fanden. Oder sie wurden als inhaltlich mittlerweile überholt betrachtet. Die letzte Möglichkeit ist schließlich,

109 CC, Praefatio, ed. Gundlach 476.

110 Hack, Codex Carolinus, Bd. 1, 80-82.

111 Hack, Codex Carolinus, Bd. 2, 952-956.

112 Vgl. LP I, 486-514 (Vita Hadrians I.). 
dass die fehlenden Briefe einfach in Regensburg nicht zur Verfügung standen, weil sie an einem anderen Ort aufbewahrt wurden oder bereits verloren oder zerstört worden waren. ${ }^{113}$ In Regensburg waren nämlich sicherlich nur jene Briefe vorhanden, die Teil des beweglichen Schatzes des fränkischen Hofes waren. ${ }^{114}$

Doch zu welchem Zweck wurde der CC überhaupt angelegt? Florence Close hat kürzlich dazu bemerkt: „Le roi entendait très manifestement immortaliser le souvenir de la relation qui unit sa famille à la papauté, en soulignant le rôle de défenseur de l'Église déjà assumé par ses ancêtres. Le Codex Carolinus (CC) n'est pas le fruit d'assemblage exhaustif mais le résultat d'une scrupuleuse collecte de documents entreprise à des fins propagandistes. "115 Trotz aller Meriten ihres Aufsatzes: Diese Einschätzung des CC führt wahrscheinlich zu weit. Erinnern wir uns, was im Vorwort der Sammlung geschrieben wurde: ... eo quod nimia vetustate et per incuriam iam ex parte diruta atque deleta conspexerat, denuo ... renovare ac rescribere decrevit. ${ }^{116}$ Als Grund wird vom Schreiber also angegeben, dass die alten Papstbriefe, die mit ziemlicher Sicherheit auf Papyrus geschrieben waren, ${ }^{117}$ sonst dem Zerfall anheim gefallen wären. Und diese Darstellung ist eigentlich ziemlich glaubwürdig. Dafür spricht etwa auch, dass der Text von $\mathrm{CC}_{1} 5^{118}$ nicht mehr rekonstruiert werden konnte und daher nur eine Zusammenfassung eingefügt wurde. Gegen eine Verwendung als Propagandainstrument spricht neben dem tatsächlichen Interesse an Konservation der Briefe auch die Tatsache, dass der CC nur in einer einzigen Handschrift überliefert ist (wiewohl es sich bei dieser um eine Kopie handelt). Sehr viele Exemplare können daher nicht in Umlauf gewesen sein. Man vergleiche das nun mit dem Befund tatsächlicher Propagandaschriften, etwa des LP oder der Vita Karoli Magni Einhards. ${ }^{119}$

Somit ist im Zweifel dem Vorwort also eher zu glauben: Die Briefe sollten vor allem erhalten werden, um sie weiter verwenden zu können. ${ }^{120}$ Der CC ist also vor

113 Dieser Ansicht neigt Hack, Codex Carolinus, Bd. 1, 65, zu.

114 Hack, Codex Carolinus, Bd. 1, 80.

115 Florence Close, De l'alliance Franco-Lombarde à l'allience Franco-Pontificale, in: Francia. Forschungen zur westeuropäischen Geschichte, 37 (2010) 1-24, hier 2. Auch Stefano Gasparri, The Fall of the Lombard Kingdom. Facts, Memory and Propaganda, in: 774: ipotesi su una transizione; atti del Seminario di Poggibonsi, 16-18 febbraio 2006, ed. ders (Turnhout 2008) 41-65, hier 43, hat ähnliche Ansätze, er bezeichnet den CC unter Einschränkungen auch als Ausdruck der päpstlichen Propaganda, doch er sieht schlussendlich das Ziel des Erhalts der Texte als zentral an.

116 CC, Praefatio, ed. Gundlach 476.

117 Hack, Codex Carolinus, Bd. 1, 65.

118 CC 15, ed. Gundlach 512, Text in Anm. a zu CC 15.

119 Siehe zum Beispiel Guenée, Histoire et culture 250.

120 So sieht das auch Hack, Codex Carolinus, Bd. 1, 67, der auch darauf hinweist, dass es sich sicher nicht um eine literarische Briefsammlung handelt, wie man sie sonst sehr häufig findet. 
allem als Sammlung zum politischen, antiquarischen und vielleicht kanzleimäßigen Gebrauch zu betrachten. So gesehen wäre es auch verständlicher, wieso nur ein Teil der Briefe als wichtig genug für die Sammlung erachtet wurde. Die anderen Stücke wurden einfach aus inhaltlichen oder stilistischen Gründen nicht mehr benötigt.

Abgesehen von dieser wichtigen Information zum Verwendungszusammenhang des CC liefert das Vorwort der Sammlung aber auch eine eher rätselhafte Information. Es ist nämlich davon die Rede, dass der Codex nicht nur die Briefe der Päpste, sondern auch jene der Kaiser enthalten sollte (de summa sede apostolica beati Petri apostolorum principis seu etiam de imperio, siehe Zitat oben). Doch in der aktuellen Fassung ist kein Brief der Kaiser aufgenommen worden. Johannes Haller hat de imperio so interpretiert, dass damit die Stadt Rom, die zur Abfassungszeit vieler Briefe ja tatsächlich noch zum Kaiserreich gehörte, gemeint sei. ${ }^{121}$ Dorine van Espelo hat in einem Aufsatz vor Kurzem Hallers Ansatz aufgegriffen und sehr überzeugend argumentiert, dass imperium in der Bedeutung „Herrschaft“ zu lesen ist und sich auf den Nutzen der Schreiben für die karolingische Machtentfaltung bezieht. ${ }^{122}$ Die Forschung ist heute also insgesamt pessimistischer denn je, ob Briefe des Kaisers je integriert wurden oder überhaupt aufgenommen werden sollten. Da unser einziger Textzeuge aber nur eine spätere Kopie ist, kann diese Frage letztlich nicht endgültig entschieden werden. ${ }^{123}$

\subsection{Weitere Quellen}

LP und CC sind die Hauptquellen der vorliegenden Arbeit. Während der LP noch dazu auch für das neunte Jahrhundert meist zumindest irgendwelche Angaben enthält - wenn auch manche der Viten durchaus enttäuschend sein mögen - reicht der CC nur bis 79I und auch in dieser Phase enthält er, wie wir gesehen haben, nur einen sehr spezialisierten Auszug aus der päpstlichen Korrespondenz, der allerdings gleichzeitig das Gros der erhaltenen Texte des achten Jahrhunderts darstellt. Papstbriefe finden sich jedoch noch in einer Vielzahl von anderen Werken überliefert, insbesondere wieder ab dem neunten Jahrhundert. Manche, wenn auch sehr wenige, sind noch heute im Original erhalten ${ }^{124}$, viele in anderen Texten überliefert oder in Cartularien

121 Johannes Haller, Quellen zur Geschichte der Entstehung des Kirchenstaates (Quellensammlung zur deutschen Geschichte, Leipzig/Berlin 1907) VIII.

122 Dorine van Espelo, A testimony of Carolingian rule? The Codex epistolaris carolinus, its historical context, and the meaning of imperium, in: Early Medieval Europe, 21,3 (2013) 254-82.

123 Hack, Codex Carolinus, Bd. 1, 64f.

124 Das älteste vollständig überlieferte Original einer Papsturkunde stammt aus dem Jahr 819, eine Urkunde Papst Paschalis I. Daneben existiert nur ein kleines Fragment eines Briefs Hadrians I. 
eingetragen. Wertvolle Quellen sind dabei die Kanonessammlungen der Kirchenrechtsgelehrten des hohen Mittelalters, in denen viele Texte erhalten geblieben sind, wenn auch in stark gekürzter Form und mit teilweise unsicheren Zuweisungen der Texte zu den einzelnen Päpsten. Ein besonders frühes und für die vorliegende Arbeit wichtiges Beispiel ist Collectio Britannica, die gleich in der Folge genauer beschrieben werden soll. Wichtig sind aber auch das sehr berühmte Dekret Gratians oder das Dekret und die Panormia Ivos von Chartres.

Daneben gibt es für die Papstbriefe auch die Möglichkeit, dass das Register, in das wohl ursprünglich die meisten der Briefe der Päpste mindestens seit dem sechsten Jahrhundert eingetragen worden waren, erhalten geblieben ist. Die berühmteste Registerabschrift, die allerdings nur einen Teil der Korrespondez dieses Papstes abdeckt, ist sogar in der hier betrachteten Zeit angefertigt worden: Unter Hadrian I. wurde eine umfassende Registerhandschrift der Briefe Gregors des Großen angefertigt, aus der heute die meisten Stücke stammen, die von diesem berühmtesten Papst des Frühmittelalters bekannt sind. ${ }^{125}$ Von allen Päpsten des achten und neunten Jahrhunderts sind aber nur von einem einige Teile des Registers erhalten geblieben und zwar von Johannes VIII. Dieses Teilregister wird unten noch genauer vorgestellt.

Abgesehen davon dominiert für die Briefe der Päpste des neunten Jahrhunderts die Mischüberlieferung: Sie sind in verstreuten Werken, oft lange Zeit nach ihrem Abfassungszeitpunkt, enthalten. Viele Briefteile finden sich etwa in kanonistischen Kompilationen. Ein Beispiel ist Papst Nikolaus I., von dem in der MGH-Edition I7o Briefe enthalten sind, die jedoch aus einer Vielzahl von Quellen stammen. ${ }^{126}$

\subsubsection{Die Collectio Britannica}

Die sogenannte Collectio Britannica ist eine Sammlung von Briefen, fast alle wurden von Päpsten verfasst, einige wenige stammen von anderen Autoren. ${ }^{127}$ Sie wurde wahrscheinlich in Rom in der zweiten Hälfte des elften Jahrhunderts zusammengestellt und stammt aus dem Umkreis der kanonistischen Forscher, die in der Stadt unter der Ägide von Papst Gregor VII. begonnen hatten, Kirchenrechtssammlungen

(JE22 2462). Siehe Harry Breslau, Handbuch der Urkundenlehre für Deutschland und Italien, Bd. 1 (Leipzig ${ }^{2}$ 1912) 72, mit Anm. 3.

125 Dag Norberg, Gregorii magni registrum epistularum, 2 Bde., CC SL 140 und 140A (Turnhout, 1982) Bd. 1, V.

126 Siehe Epistolae Nicolai I papae (ed. Ernst Perels, MGH EE 6) 257-690, bes. die Einleitung des Editors, 257-266, in der die gesamte in der Edition berücksichtigte Handschriftenüberlieferung aufgeführt ist.

127 Herbers, Leo IV., 50. 
herzustellen. ${ }^{128}$ Die Sammlung wird dabei etwa den Jahren Io9o-ro93 zugerechnet. ${ }^{129}$ Der Codex wurde Ende des 19. Jahrhunderts in der British Library von Edmond Bishop „wiederentdeckt“, das heißt in seinem Quellenwert neu eingeschätzt und in einer Abschrift den MGH in Berlin zur Verfügung gestellt. ${ }^{130}$

Die Collectio ist deswegen so wesentlich, weil sie für einige Päpste des neunten Jahrhunderts eine Reihe von Briefen überliefert, die sonst nicht anderweitig erhalten sind oder davor nur fragmentarisch (oder besser: noch fragmentarischer) bekannt waren. Klaus Herbers hat etwa gezeigt, dass sich die Zahl der bekannten Briefe Leos IV. durch die Collectio verdoppelt hat. ${ }^{131}$ Allerdings sind eine Reihe von Stücken aus verschiedenen Gründen in der Forschung als Fälschungen kritisiert worden. Von den 45 enthaltenen Fragmenten Leos IV. betrifft das immerhin acht. ${ }^{132}$ Glücklicherweise ist darunter nicht der für die vorliegende Arbeit besonders wichtige Brief Leos an das fränkische Heer (siehe unten, Kapitel 6.3), denn dieser ist auch in anderen Werken überliefert, die zwar ebenfalls der hochmittelalterlichen Kanonistik zuzordnen sind, aber nicht von der Collectio Britannica abhängen.

\subsubsection{Das Register Johannes VIII.}

Die Quellenlage für den Pontifikat Johannes' VIII. ist zwiespältig: Für ihn ist kein LP-Eintrag erhalten und es ist auch sehr zweifelhaft, dass jemals einer existierte. Doch gerade für diesen Papst ist dafür eine Abschrift seines Briefregisters erhalten, die einen sehr guten Einblick in seinen Pontifikat ermöglicht.

Der Teilauszug des Registers ist heute im Vatikanischen Archiv als Band I der Registra Vaticana erhalten. Die Handschrift stammt aus dem elften Jahrhundert und ist in sehr schmuckvoller Beneventana gehalten. Diese Schrift weist in ihrer Ausprägung darauf hin, dass der Registerauszug im elften Jahrhundert in Monte Cassino

128 Georg May, Kirchenrechtsquellen: Katholische, in: Theologische Realenzyklopädie, Band 19: Kirchenrechtsquellen, ed. Gerhard Krause/Gerhard Müller (Berlin/New York 1990) 1-44, hier 17.

129 Zur Datierung siehe Paul Fournier/Gabriel LeBras, Histoire des collections canoniques en Occident depius les fausses décrétales jusqu'au Decret de Gratien (2 Bde., Paris 1931-1932) Bd. 2, 55-99 und $155-163$.

130 Herbers, Leo IV., 49f. Die Handschrift befindet sich immer noch in der British Library, Ms. Add. 8873.

131 Herbers, Leo IV., 49. Ebd., Anm 1, illustriert Herbers das am Beispiel der Papstregesten Jaffés bzw. der überarbeiteten Fassung von Jaffé, Ewald, Löwenfeld und Kaltenbrunner, im betreffenden Fall $\mathrm{JE}^{2}$. Während die erweiterte Fassung nach dem „Fund“ der Collectio für Leo 65 Einträge aufweist, hatte die alte Version Jaffés nur 36.

132 Herbers, Leo IV., 57. Zur gesamten Forschungsdiskussion siehe ebd., 51-58. 
oder von einem dort ausgebildeten Schreiber angefertigt wurde. ${ }^{133}$ Dietrich Lohrmann hat argumentiert, dass die Abschrift tatsächlich in Santa Maria al Palladio, der Montecassineser Niederlassung in Rom, angefertigt wurde. ${ }^{134}$ Sicher ist jedenfalls, dass die Handschrift sich im I3. Jahrhundert in Monte Cassino befand, was ein Bibliotheksvermerk beweist. ${ }^{135}$ Die Handschrift ist eine Kopie einer Vorgängerhandschrift, die als der eigentliche Registerauszug anzusehen ist. ${ }^{136}$

Die Registerabschrift umfasst lediglich die Jahre 876 bis 882 , wobei vom erstgenannten Jahr ebenfalls ein großer Teil fehlt, da das Register (wie auch jenes Gregors des Großen) nach Indiktionsjahren gegliedert war. Die Briefe setzen somit erst am I. September 876 ein und reichen bis Ende August 882, das heißt, es fehlen auch die Briefe, die kurz vor dem Tod des Papstes am r6. Dezember 882 in der neuerlichen ersten Indiktion ab September verfasst wurden. Es ist in der Forschung bis heute umstritten, was mit den Briefen vor September 876 passierte, Spekulationen reichen von einem Verlust der Register für die ersten Jahre des Pontifikats bis zu einem Verlust der Abschrift vor der Erstellung der erhaltenen Kopie. ${ }^{137}$

Auch der heute erhaltene Teil des Registers wird unterschiedlich gesehen: Es ist immer noch umstritten, ob es sich bei dem erhaltenen Teil um eine vollständige Kopie des Registers für die enthaltenen sechs Indiktionen (I0., 876/877, bis I5., 88 I/882) handelt - die Frage ist wohl auch nicht eindeutig zu beantworten. Klar ist aber, dass Briefe und vor allem Privilegien Johannes' VIII. überliefert sind, die sich nicht in der Registerhandschrift finden. Das könnte aber auch daran liegen, dass schon bei der Registrierung eine Auswahl aus den Stücken getroffen wurde und/oder dass ein eigenes Privilegienregister existierte. ${ }^{138}$ Es ist aber dennoch möglich, dass der Kopist im elften Jahrhundert auch Briefe wegließ, wenn auch keinerlei Kriterium festgestellt werden kann, nach dem er vorgegangen sein könnte.

Kurz muss auch noch auf die Frage der Urheberschaft der in den in Kapitel I.2 und I.3 beschrieben Sammlungen enthaltenen Briefe eingegangen werden. Die Papst-

133 Erich Caspar, Studien zum Register Johanns VIII., in: Neues Archiv, 36 (1911) 77-156, hier $85 f$. Siehe auch ebd., I-III, Tafeln, die einige Blätter der Handschrift im Negativ zeigen.

134 Dietrich Lohrmann, Das Register Papst Johannes' VIII. (872-882). Neue Studien zur Abschrift Reg. Vat. 1, zum verlorenen Originalregister und zum Diktat der Briefe (Bibliothek des Deutschen Historischen Instituts in Rom, 30, Tübingen 1968) 102.

135 Caspar, Studien 86.

136 Caspar, Studien 92.

137 Die Positionen der Forschung hat Dorothee Arnold, Johannes VIII. Päpstliche Herrschaft in den karolingischen Teilreichen am Ende des 9. Jahrhunderts (Europäische Hochschulschriften, 797, Frankfurt am Main, et al., 2005) 37-45, gut zusammengefasst.

138 Siehe Arnold, Johannes VIII., 29-31. 
briefe weisen in so gut wie allen Fällen den Papst als Absender aus. Es ist aber davon auszugehen, dass der Papst nur in den allerwenigsten Fällen das Schriftstück selbst niedergeschrieben hat. Und auch für das Diktat der Briefe werden in vielen Fällen Mitarbeiter der Kanzlei verantwortlich gewesen sein. Wenn also in der Folge vom Papst als Verfasser des hier zu betrachtenden Briefes die Rede ist, sei hiermit auf mögliche andere tatsächliche Urheber hingewiesen. Es ist jedoch aus heutiger Sicht nicht mehr von großer Bedeutung, wer die Papstbriefe nun im Einzelnen verfasst hat. Die Handlung erfolgte wie die des Papstes selbst. Die betrauten Personen handelten wahrscheinlich mit dem Einverständnis der Päpste. Gerade für diplomatisch wichtige Kommunikation, um die es sich bei allen in der Arbeit behandelten Schriftstücken handelt, kann nahezu ausgeschlossen werden, dass sie überhaupt ohne Wissen und Einverständnis des Papstes durchgeführt werden konnte. 


\section{Das Papsttum und die Anderen: Theoretische Überlegungen}

\subsection{L'image de l'autre, Extimität und Othering}

"Je veux parler de la découverte que le je fait de l'autre. ${ }^{139}$ So begann Tzvetan Todorov sein Werk über ,La conquête de l'Amérique‘, das den für die hier geführten Betrachtungen bedeutsamen Untertitel ,La question de l'autre' trägt. Er legt auf den ersten Seiten seiner Einleitung dar, wie aktuell diese Frage nach der „Entdeckung“ und Eroberung Amerikas war und hat damit zweifellos recht, denn selten vor und nach dieser Zeit sind so regelmäßig derart verschiedene Kulturen aufeinandergestoßen, ohne vorhin in jeglichem Kontakt zueinander gestanden zu haben.

Die Begegnungen eines Ich mit einem Anderen bestimmen jegliches menschliche Dasein. Die Anderen werden in der vorliegenden Arbeit nicht genau im Sinne der Unterscheidung von (petit) autre beziehungsweise (grand) Autre durch Jacques Lacan verwendet, bei dem das große Andere schon bei den eigenen Eltern in der Kindheit, ja im Prinzip bei der eigenen Selbstrepräsentation im Sprechakt beginnt. ${ }^{140}$ Doch weil seine Sicht des Anderen jeder Auseinandersetzung auch mit dem Phänomen des Fremden zugrunde liegt und entsprechend häufig in der Theorie der Andersheit herangezogen wird, wird „Andere“ hier prinzipiell groß geschrieben, um zu signalisieren, dass es hier um das Andere außerbalb der in-group des Papstes geht, eine Gruppe, die in der Folge noch zu definieren sein wird.

Todorov definierte „anders“ in seinem Sinne folgendermaßen: „... lui être extérieur, une autre société donc, qui sera, selon les cas, proche ou lontain: des êtres que tout rapproche de nous sur le plan culturel, moral, historique“, um dann mit einer Definition der amerikanischen Ureinwohner als ultimativ Fremde fortzusetzen. ${ }^{141}$ In der vorliegenden Arbeit geht es jedoch um Andere, die man durchaus kannte. Einige

139 Tzvetan Todorov, La conquête de l'Amérique. La question de l'autre (Paris 1982) 11.

140 Vgl. das Lemma „Other“, in: Post-Colonial Studies. The Key Concepts, ed. Bill Ashcroft/Gareth Griffith/Hellen Tiffin (London/New York $\left.{ }^{2} 2000\right)$ 154-156. Jacques Lacan, Das Werk von Jacques Lacan. Das Seminar: Buch 3 (1955 - 1956). Die Psychosen, ed. Norbert Haas (Berlin/Weinheim 1997) z.B. 322. Siehe auch Elisabeth Roudinesco/Michel Plon, Wörterbuch der Psychoanalyse: Namen, Länder, Werke, Begriffe (Wien 2004, frz. Orig. 1997) 24-27 (Lemma „Andere (der)“).

141 Todorov, Conquête 11. 
Individuen, sozusagen Repräsentanten von fremden Gruppen, dürfte man in Rom in jedem der in den folgenden Abschnitten beschriebenen Fälle kennengelernt haben, wenn auch in unterschiedlichem Ausmaß: Während die Langobarden als an mehreren Grenzen direkte Nachbarn, die noch dazu stark romanisiert waren, ziemlich vertraute Andere waren, waren schon die Franken ein wenig weiter entfernt. Die fremdesten Anderen werden von den Sarazenen repräsentiert, aber auch sie waren immerhin Teil des poströmischen mittelmeerischen Kulturraumes, somit kein Vergleich mit den Fremden Todorovs, die für die iberischen Europäer völlig unbekannt waren, ja für die erst der Papst entscheiden musste, ob sie denn überhaupt als Menschen zu betrachten seien - und somit als Ziel der christlichen Mission, inklusive Anspruch auf eine menschenwürdige Behandlung. ${ }^{142}$

Im Europa des achten und neunten Jahrhunderts kannte man die meisten Fremden. Entweder stand man mit ihnen ohnehin in Kontakt, zumindest aber lagen ausreichend Texte bereit, um die betreffenden gentes (und nicht-gentes) einzuordnen. ${ }^{143}$ Mittels der antiken Ethnographie oder zumindest der Etymologien Isidors von Sevilla ließen sich alle der von den Päpsten beschriebenen Völker der Sphäre des Bekannten zurechnen. ${ }^{144} \mathrm{Zu}$ dieser wesentlichen Literatur gesellte sich in allen Gesellschaftsschichten auch die Darstellung der Bibel und in gehobenen Schichten ihre von kirchlichen Autoritäten erfolgte Auslegung.

Klar ist also, dass die uns überlieferten Beschreibungen der gentes nicht ohne den Diskurs, in dem sie entstanden sind, gesehen werden können. Dieser Diskurs der A1terität wurde nicht nur von der vorhandenen autoritativen Literatur geprägt, sondern auch von anderen wesentlichen Faktoren, nicht zuletzt der alltäglichen Wahrnehmung von fremden Pilgern und Händlern - denn Rom und seine drei Häfen Ostia,

142 Rechtsverbindlich bekräftigt wurde das durch Papst Paul III. 1537, siehe zum Beispiel Claudia Schnurmann, Europa trifft Amerika: Zwei alte Welten bilden eine neue atlantische Welt, $1492-$ 1783 (Münster 2009) 9 oder Matthias Gillner, Bartolomé de las Casas und die Eroberung des indianischen Kontinents. (Theologie und Frieden 12, Stuttgart/Berlin/Köln 1997), 42-55 (zur Situation der Mission in Mittelamerika), bes. 48 (zur Bulle Sublimis Deus).

143 Was nicht heißen soll, dass man an den Rändern Europas nicht sogar auf als monströs beschrieben Fremde treffen konnte, siehe Ian N. Wood, Where the wild things are, in: Visions of Community in the Post-Roman World. The West, Byzantium and the Islamic World, ed. Walter Pohl/Clemens Gantner/Richard Payne (Aldershot 2012) 531-542. Mit solchen Vorstellungen kommt man jedoch in den Quellen des Papsttums so gut wie nicht in Kontakt. Allenfalls vereinzelte Berichte von Missionaren, die am Rand der christlichen Welt agierten, drangen nach Rom. Im achten Jahrhundert sind besonders für Willbrord und Winfried-Bonifatius ausgezeichnete Kontakte nach Rom belegt.

144 Zur antiken Ethnographie siehe Greg Woolf, Tales of the Barbarians. Ethnography and Empire in the Roman West (Chichester/Malden, Mass. 2011). Siehe zukünftig auch Michael Maas, Roman Imperial Ethnography and the End of Antiquity (in Vorbereitung). 
Portus und Centumcellae/Civitavecchia waren nicht zuletzt auch ein wichtiger Verkehrsknotenpunkt am Mittelmeer. ${ }^{145}$

Teil des Diskurses waren aber auch die politischen Interessen Roms, im untersuchten Zeitraum soweit bekannt meist deckungsgleich mit jenen des Papsttums. Man sollte also nicht außer Acht lassen, dass sich in den für unser heutiges ebenso wie für das zeitgenössische Bild von frühmittelalterlicher Alterität wirkmächtigen päpstlichen Texten auch die politischen Interessen des Papsttums und der im Papsttum tätigen, nahezu immer anonymen Autoren widerspiegeln.

Alterität wurde also, im Rahmen des herrschenden Diskurses, auf verschiedene Weise wahrgenommen und dargestellt. In den meisten in der Folge zu behandelnden Fällen handelte es sich allerdings um eine Art „intimate alterity“, um Extimität, um hier einen weiteren Begriff Jacques Lacans zweckentfremdet, also ausdrücklich nicht in der Nachfolge des großen Psychoanalytikers anzuwenden. ${ }^{146}$ Denn die Fremden/ Anderen waren unzweifelhaft unterschiedlich von den Autoren unserer Quellen aus dem Umfeld des Papsttums (zu ihnen siehe Kapitel I), zugleich waren sie aber „discomfortingly familiar" ${ }^{147}$

Somit muss das Anders-Sein als ein Begriff gesehen werden, der keineswegs absolut in einem monochromen Schema angewandt werden kann. Vielmehr ist an eine Skala zu denken, an der gemessen manche Gruppen näher oder weiter weg von Rom oder der römischen Kirche eingeordnet werden konnten und mussten. In jedem dieser Akte der Ordnung der eigenen Umwelt war es für den jeweiligen Sprecher von Bedeutung, den eigenen Standpunkt zumindest implizit neu zu erfinden. Der Begriff der Extimität soll im vorliegenden Text dabei helfen, die unklaren, oft verzerrten und vor allem variablen Grenzen zwischen Identität (vielleicht eher im Sinne von Identisch-Sein/Gleichheit) und dem Anders-Sein auszudrücken, so wie ihn auch der

145 Michael McCormick, Origins of the European Economy. Communications and Commerce, AD 300-900 (Cambridge 2001) 618-630, zum neunten Jahrhundert siehe auch Paolo Delogu, L'importazione di tessuti preziosi e il sistema economico romano nel IX secolo, in: Roma medievale. Aggiornamenti, ed. ders. (Florenz 1998) 123-141.

146 Lacan spricht von extimité, was wie Jeffrey Jerome Cohen, Introduction: Midcolonial, in: The Postcolonial Middle Ages, ed. ders. (New York 2000) 1-17, hier 5, zusammenfasst: „characterizes whatever inassimilable remainder results when the raw Real of the world is transformed into the Symbolic structure of culture", siehe auch ebd., 16, mit Anm. 16. Siehe außerdem Jacques-Alain Miller, Extimité, in: M. Brachner, Lacanian Theory of Discourse: Subject, Structure, Society (New York 1994) 74-87, hier 77: Extimität ist das Äquivalent zum Unbewussten selbst, beschreibt aber auch die Beziehung des Analysten zum (in dieser Hinsicht eben nicht intimen) Analysierten.

147 Cohen, Introduction 5, der mit dem zitierten Ausdruck das Mittelalter und die mittelalterlichen Menschen an sich meint, aber zugleich eine perfekte Beschreibung für Verhältnisse zu jemand (ob nun scheinbar oder tatsächlich) Vertrautem liefert. 
Kunsthistoriker Francisco Prado-Villar verwendet: „The icon of the Virgin in the Moorish household ... signals, the presence of the Other and of its discourse at the very center of intimacy. “ 148 Bei aller Diversität findet sich gerade im engeren nachbarschaftlichen Umfeld oft auch vieles, das verbindet.

Ein wichtiger Teil der vorliegenden Arbeit wird sich damit beschäftigen, wie das Papsttum im achten und neunten Jahrhundert Unterschiede zu Anderen in seinen Texten herausstrich und Gemeinsamkeiten situationsbedingt einsetzte. Dabei geht es um eine ganze Reihe von Punkten, obschon die römischen Quellen von realpolitischen Fragen dominiert werden.

Die Wahrnehmung von Anderen unterlag aber immer auch gesellschaftlichen Spielregeln, einem ungeschriebenen Regelwerk dessen, was gesagt oder nicht gesagt werden konnte. Dieses Regelwerk ist ein Teil des Konzepts des „Diskurses“. Die wesentliche Begrifflichkeit und Theorie wurde von Michel Foucault formuliert. ${ }^{149}$ Eine treffende Definition, vor allem für die Anwendung in den Geschichtswissenschaften bietet Walter Pohl: „A complex and, to a large extent, implicit set of rules governs the way in which members of a given society can decide, not only what is true or false, but also what is possible or impossible, what exists and what is an illusion, what can be said and what cannot, what is desirable and what should be disapproved." ${ }^{150}$ Das Papsttum kann also nicht alleinstehend betrachtet werden, auch wenn es aufgrund seiner großen kulturellen und sozialen Macht, seines großen Prestiges vermochte, den in Rom herrschenden Diskurs zu einem großen Teil selbst zu gestalten.

Aber wer war überhaupt das bereits mehrfach genannte Papsttum? Für die vorliegende Arbeit ist es wohl am besten als päpstliche in-group, als die Eigenen des Papstes zu definieren. ${ }^{151}$ In Kapitel 3.I, das dem Umfeld des Papstes in der Stadt Rom im achten und neunten Jahrhundert gewidmet ist, wird die Zusammensetzung

148 Francisco Prado-Villar, The Gothic anamorphic gaze, in: Under the Influence. Questioning the Comparative in Medieval Castile, ed. Cynthia Robinson/Leyla Rouhi (Leiden 2005) 67-100, hier 69 (Miller, Extimité 77, interpretativ zitierend). Ibid., 69, Anm. 5: „In my analysis, extimacy works as an operative concept at two levels, both from a formal point of view - in relation to the „extroversion" of the visual configuration of Cantigas - and conceptually, in relation to the unstable boundaries of identity and otherness that characterize the work."

149 Grundlegend: Michel Foucault, L'ordre du discours (Paris 1972).

150 Walter Pohl, Introduction - Strategies of identification: A methodological profile, in: Strategies of Identification. Ethnicity and Religion in Early Medieval Europe, ed. Walter Pohl/Gerda Heydemann (Cultural Encounters in Late Antiquity and the Middle Ages 13, Turnhout 2013) 1-64, hier 29.

151 Zudem kann man auch argumentieren, dass das Papsttum neben einer Institution auch im frühen Mittelalter bereits eine Idee repräsentierte, die über den Einfluss des Patriarchats Rom noch hinaus ging. In diesem Buch soll aber das Hauptaugenmerk auf der institutionell-politischen Bedeutungsebene liegen. 
dieser Gruppe detailliert dargestellt werden. Das Papsttum war allerdings keine homogene Gruppe, die ein kollektives Ziel verfolgte, vielmehr gab es innerhalb dieser Institution durchaus divergierende Interessen. Amtsträger innerhalb der römischen Kirche verfolgten sehr oft ihre eigenen Interessen, nicht jene des Papsttums. Zudem waren die hierarchischen Strukturen zwar in der Theorie meist klar, die reale Macht eines Amtsträgers hing aber oft von der jeweiligen Person und ihrem Umfeld in der Stadt Rom ab. Einige dieser Individuen, die zum engsten Kreis des Papstes gehörten, werden in den folgende Kapiteln Erwähnung finden. Trotz aller Einschränkungen sind viele überlieferte Quellen jedoch dem Papsttum insgesamt zuzuordnen. Das gilt in besonderem Maß für den Liber Pontificalis, der ja wie oben in Kapitel I.I beschrieben nur unter begrenztem Einfluss des Papstes und seiner höchsten Beamten stand. Demgegenüber hatten die Päpste wahrscheinlich in fast allen Fällen direkten Einfluss auf die diplomatische Korrespondenz, die jedoch auch schlussendlich von der dem primicerius unterstehenden Kanzlei formuliert wurde.

Bislang haben wir uns mit der Frage der tatsächlichen Wahrnehmung des Fremden/Anderen durch die päpstliche in-group und den weiter gefassten peculiaris populus beschäftigt - beziehungsweise mit Möglichkeiten sich dieser Frage anzunähern. Daneben gibt es aber auch das aktive Gestalten des in der eigenen Kommunikation transportierten Bildes von Anderen. Dieser Faktor der Konstruktion des Anderen ist in unseren Quellen wesentlich leichter zu fassen. Zumeist finden wir aktive Versuche, ob nun absichtsvoll oder unabsichtlich, Andere auszugrenzen und sich selbst somit abzugrenzen. Diese Strategie wird als Othering bezeichnet. Gemeint ist damit eine Ausgrenzung und Marginalisierung von Anderen mit dem Ziel, die eigene Gruppe (hier die päpstliche res publica, das Papsttum, Rom und der päpstliche peculiaris populus ${ }^{152}$ ) von ihnen positiv abzusetzen. ${ }^{153}$ Der Begriff wurde von Gayatri Spivak zuerst für jenen Diskurs (explizit in der Tradition Foucaults) verwendet, in dem sich die imperialen Großmächte des i9. und 20. Jahrhunderts von ihren Kolonien abgrenzten. ${ }^{154}$

Ohne den Terminus zu verwenden, hat Edward Said dem Konzept in seinem berühmten Buch ,Orientalism' in den Human- und Sozialwissenschaften zum Durchbruch verholfen. ${ }^{155}$ Auch Said schrieb vor allem über die kolonialistische europäische

$152 \mathrm{Zu}$ diesen Konzepten siehe unten, Kap. 3.1.

153 Tobias Schwarz, Bedrohung, Gastrecht, Integrationspflicht: Differenzkonstruktionen im deutschen Ausweisungsdiskurs (Bielefeld 2010) 22.

154 Lemma: Othering, in: Post-Colonial Studies, ed. Ashcroft/Griffith/Tiffin 156-158.

155 Edward Said, Orientalism (London/New York 2003, ${ }^{1} 1978$ ) v. a. 1-30 und 49-73 zum Wandel des Bildes des „Ostens“ im „Westen“. Berechtigterweise wird Saids Buch jedoch für den Versuch kritisiert, die westlichen Vertreter des „Orientalismus“ weitestgehend homogen darzustellen und dabei 
Perspektive der Neuzeit und Moderne. Er zeichnete seinen Orientalismus als Diskurs, der dazu dient die Macht der imperialistischen europäischen Nationen (und später auch der USA) gegenüber dem als fundamental Anders wahrgenommenen „Orient“ soweit wie möglich aufrechtzuerhalten. Wichtig ist es aber zu betonen, dass Said hier keineswegs eine Verschwörung des „Westens“ gegen den Orient sehen wollte. Vielmehr charaktersierte er seinen Orientalismus folgendermaßen:

It is rather a distribution of geopolitical awareness into aesthetic, scholarly, economic, sociological, historical and philological texts; it is an elaboration not only of a basic geographic distinction (the world is made up of two unequal halves, Orient and Occident) but also of a whole series of ,interests' which, by such means as scholarly discovery, philological reconstruction, psychological analysis, landscape and sociological description, it not only creates but also maintains; it is, rather than expresses a certain will or intention to understand, in some cases to control, manipulate, even to incorporate, what is a manifestly different (or alternative and novel) world; it is, above all, a discourse that is by no means in direct corresponding relationship with political power in the raw, but rather is produced and exists in uneven exchange with various kinds of power, shaped to a degree by the exchange with power political (as with a colonial or imperial establishment), power intellectual (as with reigning sciences like comparative linguistics or anatomy, or any of the modern policy sciences), power cultural (as with orthodoxies and canons of taste, texts, values), power moral (as with ideas about what ,we' do and what ,they' cannot do or understand as ,we do). ${ }^{156}$

Diese Schlüsseldefinition von „Orientalism“ soll für die vorliegende Arbeit auch als nützliche Definition des Othering, der Konstruktion von Anderen, fungieren. Es gab einen herrschenden Diskurs, der in vielen Fällen, von denen wir einige kennen lernen werden, dazu zwang, Fremde durch Verfremdung zu definieren, ja zeitweise überhaupt als Andere zu erschaffen. ${ }^{157}$ Auch wenn in vielen Fällen eine bewusste Vorgehensweise des Papsttums anzunehmen ist, gibt es ebenso oft Fälle, in denen bei der Konstruktion des Anderen nicht zielgerichtet und planvoll vorgegangen wurde. Das Papsttum operierte, argumentierte und existierte schlichtweg als Teil eines Diskurses, der sich

individuelle Unterschiede völlig zu nivellieren, siehe z. B. Urs App, William Jones's Ancient Theology, in: Sino-Platonic Papers 191 (2009), bes. 11-19; zudem betrieb Said in vielen Fällen auch eine (zu) radikale Einschränkung auf einen Ost-West-Konflikt, siehe Daniel Martin Varisco, Reading Orientalism. Said and the Unsaid (Seattle/London 2007) z. B. 48.

156 Said, Orientalism 12.

157 Siehe dazu zum Beispiel Kap. 4.2 zu den Greci der Päpste Stephan II. und Paul I. und Kap. 5.5 zu Brief CC 45. 
aus vielen Quellen speiste. (Als wesentliche Elemente können kurz das antike römischgriechische Erbe, die moderne Realität des Imperiums und vor allem die christliche Kultur und die aktuelle verletzliche politische Lage Roms benannt werden.)

So verlockend aber der Bezug zu den Postcolonial Studies auch ist, er muss in zumindest einer ganz wesentlichen Hinsicht relativiert werden: Die Beziehung zu Anderen steht aus päpstlicher Sicht keineswegs immer in einem imperial-überlegenen Zusammenhang, was daran liegt, dass Rom häufig nicht aus einer Position der Stärke heraus sprechen konnte. ${ }^{158}$ Auch hier werden wir eine Reihe von Ausnahmen finden können, wobei, um bei Said zu bleiben, die Macht meist im kulturellen und moralischen Bereich verankert war, seltener im politischen und intellektuellen. Das ändert jedoch nichts daran, dass gerade im achten und neunten Jahrhundert die Position Roms im Verhältnis zu den verschiedenen Hegemonialmächten sogar noch komplizierter war als jene von Kolonien zum Mutterland und umgekehrt. ${ }^{159}$ Dennoch ging es auch im Rom dieser Zeit um Macht: Im achten Jahrhundert war das unausgesprochene politische Ziel der Ausbau der eigenen Handlungsautonomie (und später der faktischen Autonomie) und die Ausweitung des päpstlichen Einflussgebietes in allen Bereichen.

Alle bisher notwendigerweise vorgebrachten Relativierungen, insbesondere die Verwendung des Othering-Modells, sollen keinesfalls darüber hinwegtäuschen, dass den vom Papsttum niedergeschriebenen Unterscheidungen reale Differenzen zu Grunde lagen. Diese Differenzen lagen möglicherweise im Bereich der geographischen oder sozialen Herkunft einer Person oder Gruppe, in der religiösen Orientierung und in kulturellen und sprachlichen Unterschieden. Letztlich ist nicht davon auszugehen, dass die Päpste des gewählten Zeitraums völlig artifizielle Unterscheidungen fabrizierten, die ohne Verankerung in der Realität existiert hätten. Allenfalls ist es möglich, von einer Reduktion der komplexen erlebten Wirklichkeit in vereinfachte Denkmuster auszugehen. Die Schriften, die uns aus dem frühmittelal-

158 Auch die neueste historische Forschung, die postkoloniale Theorien anwendet, geht meist zwingend von einer realen imperialen Identität aus, der eine postkoloniale quasi antagonistisch gegenübersteht. Siehe als gutes Beispiel Cohen, Introduction, der jedoch zumindest zeigen kann, dass die postkoloniale Theorie auf das Mittelalter anwendbar ist, auch wenn die Entwickler der Theorie sich damit wohl nicht leicht identifizieren könnten. Es muss aber in Bezug auf die postkoloniale Theorie betont werden, dass eine klare Rollenverteilung in koloniale und postkoloniale Identitäten weder den mittelalterlichen noch den frühneuzeitlichen Verhältnissen entsprechen kann bzw. jemals entsprochen hat. Zur Kritik am ursprünglichen Konzept des Orientalismus Edward Saids zusammenfassend María do Mar Castro Varela/Nikita Dhawan, Postkoloniale Theorie. Eine kritische Einführung (Bielefeld 2005) 37-46, bes. 40-42 zur Vereinfachung und statischen Gliederung der Lager in kolonial und postkolonial.

159 Besonders interessant ist diese Frage in Bezug auf das Kaiserreich des achten Jahrhunderts („Byzanz"), siehe dazu in Bezug auf die postkoloniale Theorie Kap. 3.2.1. 
terlichen Rom erhalten geblieben sind, zeigen uns meist den Mainstream, manchmal aber wohl auch die Grenzen des Diskurses, der über verschiedene Andere in Rom beziehungsweise gemeinsam mit den Kommunikationspartnern der Päpste möglich war. Insofern zielte ein in Texten des Papsttums vorgenommenes Othering in einigen Fällen auch nicht primär auf das Umfeld des Papstes selbst ab, sondern richtete sich an die Kommunikationspartner: Die Anderen der Texte sollten also auch den Adressaten, dem intendierten Publikum ent-fremdet werden.

Angesichts einer real existierenden Diversität war die kommunikative Strategie, Differenzen aufzuzeigen, in vielen Fällen naheliegend. Man soll aber auch nicht verschweigen, dass es in dieser Hinsicht auch Gegenbewegungen gab: In Fällen, in denen es - aus welchen Gründen auch immer - nötig erschien, oder aber von vorherrschenden Meinungen nahegelegt wurde, konnte es auch zu Formen von „same-ing“, also zu bewussten und unbewussten Akten des Gleichmachens und der Identifizierung mit einem an sich Anderen kommen. Auch solche Fälle sollen als Beispiel des Umgangs mit Fremdem nicht übersehen werden, auch wenn sie in unserem Zeitraum deutlich seltener vorkommen. Der Ansatz stammt von Mohja Kahf, die spezifisch die Assimilierung sarazenischer Frauen in der hoch- und spätmittelalterlichen europäischen Literatur anspricht: „Since medieval European texts were not in the position to ,orientalize' the Orient, to create a system of knowledge about it, to delimit and differentiate it, their tendency is to do just the opposite: to make it the same.... Instead of distancing, othering, making Oriental, these texts are ,same-ing.' For one thing they assume that the Muslims are at least the equals of Europeans." ${ }^{160}$ Ähnliche Phänome gab es auch schon im Frühmittelalter, etwa als Beda Venerabilis den Umayyaden-Kalifen Mu'awiya in seiner Adaption von Adamnans De locis sanctis als christlichen König erscheinen ließ.161

Bei den Begriffen Othering und Saming (in der Folge aus praktischen Gründen nicht mehr in der Schreibweise Kahfs) handelt es sich um englischsprachige Neologismen. Es stellt sich die Frage, ob dieselben Vorgänge nicht auch mit einer deutschsprachigen Terminologie fassbar wären, welche dann zu bevorzugen wäre. Allerdings ist insbesondere der Begriff Othering in der Forschung bereits relativ gut eingeführt. Dasselbe kann für Saming zwar nicht behauptet werden, doch auch hier verwenden die einzig verfügbaren wissenschaftlichen Auseinandersetzungen den englischen Terminus. Abgesehen davon umfassen beide Begriffe, wie in der gleich folgenden

160 Mohja Kahf, Western Representations of the Muslim Woman. From Termagant to Odalisque (Austin, Texas 1999) 53.

161 Siehe John Victor Tolan, Saracens. Islam in the Medieval European Imagination (New York 2002) 72f. Tatsächlich wurden die Sarazenen aber meist eher als Fremde dargestellt, von den Päpsten sogar immer, siehe unten, Kap. 6. 
kurzen Zusammenfassung zu ihrer Bedeutung noch klar werden wird, ein größeres Spektrum an möglichen Aktivitäten den handelnden (im vorliegenden Fall vor allem schreibenden) Personen. So kann Othering sowohl Konnotationen in Richtung „Ausgrenzung“ als auch „Entfremdung“ transportieren. Ja seine Bedeutung im Sinne von „Anders machen“ oder „Anders darstellen“ kann zu der verfügbaren deutschen Begrifflichkeit sogar als übergordnete Bedeutungsebene gedacht werden. Man kann nun zu Recht kritisieren, dass diese Maßnahme die Genauigkeit der alternativen Terminologie vermissen lässt. Doch zugleich eröffnet sich so die Möglichkeit, das vorhandene methodische Instrumentarium auf eine größere Anzahl an Quellen gewinnbringend anzuwenden - insbesondere in der Rückschau auf das viele Jahrhunderte entfernte Frühmittelalter ein entscheidender Vorteil.

Zusammenfassend muss man Folgendes festhalten: In der vorliegenden Arbeit gilt es im untersuchten Zeitraum vor allem zwei Ebenen zu beachten, nämlich:

I. die tatsächliche Wahrnehmung von Fremden durch die Päpste und ihre unmittelbare Umwelt und deren Interpretation sowie

2. die Konstruktion und Manipulation eben dieser Wahrnehmungen von anderen Identitäten durch die Autoren unserer Quellen. Diese Arbeit am Bild eines bestimmten Fremden oder einer Gruppe von Anderen lässt sich grob in zwei Strategien einteilen:

a) Othering, das heißt die Betonung oder gar künstliche Schaffung von Merkmalen, die Andere von einem Ich oder Wir unterscheiden, wobei die Eigenperspektive je nach Bedarf wiederum entweder große oder kleine Personengruppen umfassen kann, von Wir, der Papst (nos, im Singular gedacht) bis hin zu Wir, die gesamte Christenheit. Von diesem Standpunkt aus werden jeweils Andere gezielt abgegrenzt, eben dem Othering unterworfen. Zudem wird Othering auch angewandt, um bestimmte Gruppen auch von Adressaten der Päpste abzugrenzen. Das Othering reichte dabei von einer leichten Betonung der in Punkt I aufgeführten Wahrnehmung von Andersartigkeit bis hin zu gezielten rhetorischen Kampagnen.

b) Sameing, als völlig entgegengesetzte Strategie, wurde ebenfalls angewandt. Hier werden Unterschiede nivelliert und negiert um ein Gemeinsamkeitsgefühl zu erschaffen. Dass dahinter ebenso wie beim Othering häufig leicht erkennbare politische Interessen standen und auch oft rhetorische Muster Anwendung fanden, ${ }^{162}$ bedeutet nicht, dass diese Argumentationsweisen nicht wirkmächtig

162 Siehe dazu Matthew Kempshall, Rhetoric and the Writing of History (Manchester 2011), bes. $147 \mathrm{f}$. zum Liber Pontificalis. 
wurden. Oft erfolgte Sameing gleichzeitig mit Othering gegenüber einer dritten Gruppe. Insgesamt ist Sameing zumindest im Untersuchungszeitraum seltener nachzuweisen als Othering. Dass das durchaus in der Situation Roms in dieser Zeit mitbegründet sein kann, wird in den folgenen Abschnitten der Arbeit offenkundig werden.

Wir sehen also in der vorliegenden Arbeit Andere von der Warte des Papsttums aus, durch seine Optik gebrochen. Die beiden herausgearbeiteten Bereiche Wahrnehmung und Konstruktion können allerdings nicht unabhägig voneinander betrachtet werden. Die Anderen waren in verschiedem Ausmaß der Interpretation der Päpste ausgesetzt. Dabei ist es unmöglich, das frühmittelalterliche Papsttum losgelöst von dem Alteritätsdiskurs, von dem sie geprägt worden waren und dessen Teil sie waren, zu sehen. Die Konstruktion von Identitäten muss zwangsläufig auf der dem sprechenden Individuum eigenen Wahrnehmung aufbauen, welche wiederum von der herrschenden kollektiven Wahrnehmung beeinflusst wird, ihr entweder zu einem gewissen Grad folgt oder sich gegen sie richtet. Das Problem ist jedoch, dass unsere schriftlichen und dinglichen Quellen zu keiner Zeit die ungebrochene Wahrnehmung von Anderen wiedergeben, sondern immer die Interpretation des Autors enthalten. Insofern ist es auch schwierig die konstruierten Elemente einer Darstellung genau einzuschätzen, aber in diesem Fall können immerhin durch den Vergleich der Quellenzeugnisse gewisse Tendenzen herausgearbeitet werden.

\subsection{Zur Verwendung der Begriffe „Fremde“ und „Andere“ - Disclaimer und Versuch einer Definition}

Im vorangegangenen Kapitel wurden die Begriffe „Fremde“ und „Andere“ nahezu austauschbar verwendet, wohl auch, weil sie in weiten Teilen der Literatur als Quasisynonyme verwendet werden. ${ }^{163}$ Und das obwohl sie genau das nicht sind. Streng

163 Eine kleine Google-Recherche zeigt das schon bei den Buchtiteln, es seien hier nur rein exemplarisch etwa folgende Sammelbände zitiert: Das Fremde im Selbst. Das Andere im Selben. Transformationen der Phänomenologie, ed. Matthias Flatscher/Sophie Loidolt (Orbis Phaenomenologicus Perspektiven, Neue Folge Bd. 19, Würzburg 2010) und Das Fremde und das Andere in der Kinderund Jugendliteratur, ed. Petra Bükler/Clemens Kammler (Weinheim/München 2003). Hier heißt es auch in der Einleitung auf Seite 7 unter Aufzählung verschiedenster Phänomene der Alterität: „Fremdheit und die Begegnung mit dem Fremden, mit dem „Anderssein des Anderen“, gehören zu den Grunderfahrungen des Menschen. Doch gerade gegenwärtig spielen Begriffe wie das Fremde, das Andere, Differenz und Alterität in den verschiedensten gesellschaftlichen Diskursen eine Rolle wie nie zuvor." Das soll keineswegs heißen, dass die genannten Bände unsauber mit den Begriffen 
genommen beginnt der oder die Andere schon beim jeweiligen Nächsten, in der Familie, beim engsten Mitarbeiterstab des Papstes oder beim Mitbruder im Kloster. Doch diese Personen könnte man nicht a priori auch als fremd bezeichnen, auch wenn manche davon einem durchaus fremd sein mögen - in diesem Fall bedarf es aber der spezifischen Definition. Die Fremden sind somit zweifellos eine Teilmenge der Anderen, der wesentlich inklusiveren Kategorie.

In der vorliegenden Arbeit geht es auf den ersten Blick eher um das Fremde beziehungsweise die Fremden, und doch trifft der Begriff nicht auf alle Fälle zu, um die es geht. Denn es ist zumindest fraglich, ob die römischen Zeitgenossen des achten und neunten Jahrhunderts einen Teil der untersuchten Gruppen und Einzelpersonen überhaupt ohne zu zögern als fremd eingestuft hätten. Die Rede ist vor allem von den in der modernen Literatur irreführend als „Byzantiner“ bezeichneten Menschen, denen unten Kapitel 3.2 und 4 gewidmet sind. Aber auch einige Langobarden und Franken standen den Päpsten durchaus nahe und sind nicht ohne weiteres als Fremde zu sehen.

Hans-Werner Goetz hat vor nicht allzu langer Zeit der Wahrnehmung von Fremden im Mittelalter einen Aufsatz gewidmet und dabei eine knappe, aber äußerst genaue Analyse vorgelegt, die sich den zeitgenössischen Begriffen für Fremde und das Fremde widmet, also Begriffen wie alienus, $-a$, exter(n)us, $-a$ und dergleichen. ${ }^{164}$ Die sehr schlüssige Studie ist für das in der vorliegenden Arbeit untersuchte Material leider kaum verwendbar, denn klare Bezeichnungen von einer Person oder einer Gruppe als fremd sind - in welcher lateinischen Form auch immer - in der päpstlichen Korrespondenz extrem rar. Das heißt nicht, dass es aus päpstlicher Sicht keine Individuen oder Gruppen gab, die als fremd eingestuft worden wären. Die Päpste identifizierten Andere zumeist mittels eines ihre geographische oder ethnische Herkunft betreffenden Begriffs. So gab es aus Sicht der Päpste also Langobarden, Franken, Griechen, aber auch Sizilianer, Syrer und Armenier und auf wieder einer anderen Ebene Sarazenen. Sie unterschieden sich von den Romani, der schwer zu definierenden Gruppe, mit der sich wahrscheinlich die Mehrheit der Einwohner Roms identifizierte. Auch wenn diese Anderen nicht pauschal als abstrakte mit einem der möglichen Ausdrücke als Fremde bezeichnet werden und auch nicht mit einem anderen vereinheitlichenden

umgehen, das ist nicht der Fall. Es soll nur zeigen, dass ein gewisses Verschwimmen der Begrifflichkeit ineinander bei aller Auseinandersetzung mit Alterität gerade in der deutschen Sprache nahezu unvermeidbar ist und das auch in Fächern, die an sich terminologisch meist trennschärfer argumentieren, als es in der Geschichtswissenschaft zumeist üblich ist.

164 Hans-Werner Goetz, „Fremdheit“ im frühen Mittelalter, in: Herrschaftspraxis und soziale Ordnung im Mittelalter und in der frühen Neuzeit, ed. Peter Aufgebauer/Christine van der Heuvel (Hannover 2006) 245-265. 
Begriff, wie etwa „Barbaren“, belegt wurden (werden konnten), so waren sie doch unzweifelhaft nicht zur eigenen ,in-group“ zu zählen.

Die Frage ist jedoch, wie gerade die bereits angesprochenen Oströmer oder Griechen oder auch die Armenier und Syrer definiert werden können. Besonders die in Rom oder zum Teil auch die in Italien befindlichen Individuen, Familien und größeren Gruppen, denen diese Gruppenbezeichnungen gegeben wurden, können in dieser Arbeit nicht leichthin als Fremde eingestuft werden und wären von der päpstlichen Administration wohl auch nicht einfach als fremd abgestempelt worden. Einige von ihnen gehörten unter bestimmten Gesichtspunkten sicherlich zur päpstlichen „ingroup“ - und doch hoben sie sich unter anderen Gesichtspunkten definitiv von den lateinischen Romani ab.

Somit ist es unmöglich, in der vorliegenden Arbeit ausschließlichen den Begriff „Fremde“ zu verwenden und es muss häufiger der Terminus „Andere“ Verwendung finden. Andere im Sinne der vorliegenden Studie waren all jene, die nicht zur päpstlichen „in-group“ im weiteren Sinne gehörten, also nicht zu jenen Menschen, die im LP mitunter sehr treffend als peculiaris populus bezeichnet wurden, ein Begriff, dem sich das nun folgende Kapitel 3.I noch näher widmen wird. ${ }^{165}$

165 Zum Konzept siehe Thomas F. X. Noble, The Republic of St. Peter. The Birth of the Papal State, 680-825 (Philadelphia 1984) 51. 


\section{Voraussetzungen: Der Papst, Rom und das imperium}

\subsection{Der Papst und Rom im achten Jahrhundert}

Dieser kurze Abschnitt der „Voraussetzungen“ ist dem unmittelbaren Umfeld gewidmet, in dem die Päpste agierten. Oft wird in der Historiographie der Einfachheit halber die Position des Papstes und des Papsttums pars pro toto für die ganze Stadt Rom gesehen, doch die Päpste agierten seit dem Entstehen des Amtes des Bischofs von Rom nicht in einem Vakuum, sondern waren eng mit den Geschicken der Stadt Rom verbunden. ${ }^{166}$

Für den großen Überblick über die Geschichte des Papsttums bis ins achte Jahrhundert hinein muss man immer noch auf Erich Caspar werweisen, der seine Geschichte des Papsttums 1933 vorgelegt hat. ${ }^{167}$ Caspar ist zwar in sehr vielen seiner Schlussfolgerungen und auch Nuancierungen zu widersprechen, und es wurde ihm in der Literatur schon vielfach widersprochen, doch von der Tiefe und Quellenkenntnis gibt es für die Zeit von ca. 480 bis 750 kein Werk, das an seines heranreicht. Er ist also immer noch als Grundlage zu benutzen.

Unbedingt erwähnt muss auch das Gesamtwerk des italienischen Historikers Ottorino Bertolini werden, schon deshalb, weil seine Schriften außerhalb Italiens viel zu selten verwendet werden. Besonders in seiner dankenswerterweise in den I96oerJahren von Ottavio Banti erstellten Aufsätzesammlung hat Bertolini eine Reihe von wesentlichen Entdeckungen veröffentlicht, die immer noch Gültigkeit besitzen. So ist er auch für viele Aspekte der Papstgeschichte des achten und neunten Jahrhunderts bis heute die maßgebliche Autorität. ${ }^{168}$

166 Wir dürfen dabei nicht vergessen, dass Rom im Frühmittelalter ein äußerst multifunktionales Konzept war. In diesem Buch wird aber von der päpstlichen und stadtrömischen Facette des Begriffs vorrangig die Rede sein, auch wenn alternative Konzepte hin und wieder diskutiert werden werden. Siehe dazu Stefano Gasparri, Roma e i longobardi, in: Roma nell'alto medioevo. Settimane di studio del centro italiano di studi sull'alto medioevo 48 (2001) 219-253, hier 222, und Walter Pohl, Conceptions of Ethnicity in Early Medieval Studies, in: Debating the Middle Ages - Issues and Readings, ed. Lester K. Little/Barbara H. Rosenwein (Oxford 1998) 15-24.

167 Erich Caspar, Geschichte des Papsttums von den Anfängen bis zur Höhe der Weltherrschaft, Bd. 2: Das Papsttum unter byzantinischer Herrschaft (Tübingen 1933).

168 So etwa für die Auseinandersetzungen in Rom im Jahr 771, siehe dazu unten, Kap. 5.5. Einige seiner wesentlichsten Aufsätze finden sich in Ottorino Bertolini, Scritti Scelti di Storia Medievale, 2 Bde., 
Die wichtigste, beste und immer noch recht neue Darstellung für den Zeitraum, mit dem sich die vorliegende Arbeit beschäftigt, ist sicherlich Thomas F. X. Nobles „Republic of St. Peter“169, ein Werk, das sowohl einen essenziellen Überblick über die Geschichte Roms und des Papsttums bietet als auch über die Funktionsweise dieser Institution im Zeitraum zwischen 680 und 825.

Noble ist es auch, der mit einer Beobachtung den Einstieg in diese kurze Beschreibung der Situation des Papstes liefert, denn er war es, der die Menschen, die zum päpstlichen Einflussbereich gehören, auf Englisch absichtlich zweideutig als „peculiar people“ bezeichnet hat. ${ }^{170}$ Die Aufmerksamkeit seines Lesers ist ihm sicher, wenn er erklärt, dass es sich hierbei um eine Quellenbezeichnung handelt, das häufig vorkommende peculiaris populus. Dieser populus war nun nicht „merkwürdig“ - heute die hauptsächliche Bedeutung des Wortes „peculiar“ - sondern es handelt sich um die Herde oder die Schäfchen des Papstes, abgeleitet von peculium, was das Eigentum eines Menschen bezeichnet und von pecus, dem Schaf/Herdentier. Der Papst bezeichnet sich somit als Hirte seiner Herde. Im Gegensatz zum Begriff res publica, der in zwei verschiedenen Bedeutungen in den päpstlichen Quellen vorkommt und wechselnd das Kaiserreich oder den päpstlichen Bereich Mittelitaliens bezeichnen konnte, ist die Bedeutung des peculiaris populus völlig klar. Doch wer gehörte zu diesem populus der Päpste des achten Jahrhunderts? Zunächst denken wir hier an die Stadt Rom. Um die Mitte des achten Jahrhunderts wurde diese fast völlig vom Papst und seinen Mitarbeitern dominiert. Die Kirche war zum Beispiel der wesentlichste Landbesitzer in Rom und dem Umland. Die kirchlichen Besitzungen wurden dabei im Wesentlichen von den römischen Diakonen verwaltet, die somit für das Einkommen des Papsttums sorgten. Das Kollegium der Diakone, dem der archidiaconus als dienstältestes Mitglied vorstand, war entsprechend bedeutend und spielte in der Papstnachfolge oftmals eine große Rolle. ${ }^{171}$ Zur Erhebung zum Bischof von Rom reichte der Weihegrad des Diakons damals aus, ja die Diakone waren den Priestern (siehe unten) im Rang in der römischen Kirche gleichgestellt. ${ }^{172}$

Die Einnahme des Papstes aus den Diakonien und den außerhalb gelegenen päpstlichen Patrimonien verwaltete der saccellarius, der päpstliche „Finanzminister“.

ed. Ottavio Banti (Livorno 1968). Zu erwähnen ist auch seine monumentale Monographie: ders., Roma di fronte a Bisanzio e ai Longobardi (Storia di Roma 9, Bologna 1941).

169 Thomas F.X. Noble, The Republic of St. Peter. The Birth of the Papal State, 680-825 (Philadelphia 1984).

170 Noble, Republic 51.

171 Die zeitweilig gerne geäußerte Meinung, das Amt des archidiaconus hätte eine Art Anwartschaft auf den Pontifikat bedeutet, wurde von Stefan Schima, Papsttum, Papstwahl und Nachfolgesouveränität. Oder: Inwiefern kann ein Papst seine Nachfolge beeinflussen?, in: Juridikum 4/2003, 180-183, hier 181, glaubhaft widerlegt.

172 Zu den Ämtern siehe Noble, Republic 212-255, zu den Diakonen bes. 213-218. Siehe auch R. Puza, Titelkirche, röm., in: LMA, Bd.8, 814f. 
Theoretisch ebenfalls in Zusammenhang mit der päpstlichen Güterverwaltung standen die defensores. Sie waren im Prinzip dafür zuständig, im Fall von Rechtsstreitigkeiten die am Grund lebenden Bauern gegen die Obrigkeit, meist andere Teile der päpstlichen Verwaltung, vor Gericht zu vertreten. ${ }^{173}$ Man darf daran zweifeln, ob dieses System in der Praxis gut funktioniert hat. Doch in ihrer Eigenschaft als Rechtsgelehrte waren die defensores wichtige Mitglieder auf vielen päpstlichen Missionen. Die Rechtsgelehrten waren wahrscheinlich eher nicht der höheren Geistlichkeit zuzuordnen, die ab dem Rang der Diakone begann. Das wichtigste Mitglied der päpstlichen Verwaltung, war der primicerius notariorum, der Vorsteher der päpstlichen Kanzlei und in dieser Funktion auch wesentliches Mitglied des in wechselnden Besetzungen informell existierenden päpstlichen diplomatischen Stabes. Die Hauptaufgaben des primicerius waren aber die Leitung der päpstlichen Kanzlei (des scriniums) sowie bis ins achte Jahrhundert hinein auch die Leitung des Archivs und der Bibliothek (Aufgaben, die zeitweise auch von einem eigens betrauten bibliothecarius übernommen wurden). Der primicerius gehörte nicht dem höheren Klerus an, er durfte nur niedrige Weihegrade bekleiden, maximal den Rang des Subdiakons, meist aber noch niedrigere, auch für Laien verwendete Weihegrade. Er war jedoch im Rang den Priestern und Diakonen gleichgestellt, war also salopp formuliert ehrenhalber Mitglied des Klerus. ${ }^{174}$ Das Amt war wahrscheinlich eine wesentliche Karrieremöglichkeit für dem Adel entstammende Personen, wie etwa auch der Fall des Onkels Papst Hadrians I. zeigt. ${ }^{175}$ Oft gab es in der Kanzlei noch einen weiteren hochrangigen Beamten, den secundicerius. Das allein zeigt, wie bedeutend die Zentrale der päpstlichen Textproduktion schon im Frühmittelalter gewesen sein muss, unabhängig vom tatsächlichen Personalstand der Kanzlei, über den wir nichts wissen. Doch es genügt, daran zu denken, dass die 854 erhaltenen Briefe Gregors des Großen möglicherweise nur einen Teil der in seinen 14 Jahren auf dem Stuhl Petri erwachsenen Schriftstücke darstellen, um zu sehen, dass die Textproduktion eine der wichtigsten Aufgaben in der päpstlichen Verwaltung war. ${ }^{176}$

173 Noble, Republic 222.

174 Vgl. Paul Hinschius, Das Kirchenrecht der Protestanten und Katholiken in Deutschland, Bd. 1: System des katholischen Kirchenrechts mit besonderer Rücksicht auf Deutschland (Berlin 1869) 381. Zum Amt selbst und dem römischen Notariat nach der Zeit Gregors des Großen siehe Breslau, Handbuch, Bd. 1, 195-200. Siehe auch Pierluigi Galletti, Del primicero della santa sede apostolica e di altri uffiziali maggiori del sacro palagio lateranese (Rom 1776).

$175 \mathrm{Zu}$ Theodotus siehe unten, Kap. 4.3.

176 Siehe John R. C. Martyn, The Letters of Gregory the Great. Translated, with introduction and Note, 3 Bde. (Medieval Sources in Translation, 40, Toronto 2004), 13f. 
Wie die Organisation der päpstlichen Verwaltung im Einzelnen funktioniert hat, kann für die Zeit vor den Reformen des elften Jahrhunderts nicht sicher gesagt werden. So ist etwa auch die Ausprägung der päpstlichen Kanzlei umstritten. Walter Ullmann hat gezeigt, dass ein cancellarius erst ab dem elften Jahrhundert belegt ist. ${ }^{177}$ Aber auch er spricht schon für die Päpste der Spätantike von einer Kanzlei. ${ }^{178}$ Tatsächlich dürfte die Existenz einer recht ausgefeilten Verwaltung des Lateran im achten Jahrhundert kaum zu bestreiten sein. Die Zahl der in der jeweiligen Verwaltungseinheit beschäftigten Mitarbeiter lässt sich jedoch in den meisten Fällen nicht mehr nachvollziehen. Auch die Aufgabenverteilung ist nicht mehr genau eruierbar.

Auf der Seite der Geistlichkeit war bereits von den Diakonen die Rede. Ihnen waren vom Rang im Prinzip die Priester (presbyteri) übergeordnet, tatsächlich nach ihrer Macht im Lateran aber höchstens gleichgestellt. Die Priester waren für die Seelsorge an den vielen Kirchen Roms zuständig und leiteten auch wechselnd die Gottestdienste in den wesentlichen Bischofskirchen der Stadt. Ihr Vorsteher war der archipresbyter. Ihm kam die wichtige Aufgabe zu, im Falle der Abwesenheit des Papstes gemeinsam mit dem archidiaconus und dem primicerius notariorum die Amtsgeschäfte in Rom weiterzuführen. ${ }^{179}$

Die Zentrale der päpstlichen Seelsorge und der päpstlichen Verwaltung lag im frühen Mittelalter im Lateranpalast und der Kathedrale San Giovanni, die in den Quellen ohne Ausnahme als basilica Constantiniana bezeichnet wird, als Kirche des Konstantin. Zwar war Alt-St. Peter liturgisch betrachtet für Rom wichtiger, doch die Lateransbasilika hatte unter anderem den Vorteil, innerhalb der alten aurelianischen Mauer gelegen zu sein. Wie gefährdet St. Peter im Verhältnis dazu lag, zeigte sich nicht nur beim sarazenischen Überfall $846^{180}$, sondern etwa auch 771, als der Langobardenkönig Desiderius von dort aus in die römische Politik eingriff - wenn er auch nach kurzer Zeit von Papst Stephan III. selbst unterstützt wurde. ${ }^{181}$

Neben der kirchlichen Verwaltung existierte zunächst noch eine weltliche Verwaltung in Rom, auch wenn es der Kirche - wir brauchen nur an die defensores zu denken - gelang, viele Bereiche des täglichen Lebens zu ihrer Aufgabe zu machen. Über

177 Ullmann, Growth 327.

178 Ullmann, Growth 5, Anm. 4

179 Martin I., ep. 15 ad Theodorum, PL 87, col. 199-202, hier 201A (JE2 2079): ... quia in absentia pontificis archidiaconus et archipresbyter et primicerius locum praesentant pontificis. Vgl. auch JE 2077 und Johann Baptist Sägmüller, Die Entwicklung des Archipresbyterats und Dekanats bis zum Ende des Karolingerreichs (Tübingen 1898) 21, mit Anm. 1. Zu den Priestern und der Entwicklung ihrer Aufgaben seit dem fünften Jahrhundert siehe auch Noble, Republic 214-216.

180 Diesem Angriff und seinen Folgen widmet sich Kap. 6.

181 Siehe dazu unten, Kap. 5.5.4. 
die weltliche Verwaltung ist, aufgrund des Umstandes, dass wir nur über aus dem geistlichen Umfeld stammende Quellen aus Rom verfügen, relativ wenig bekannt. Noch im achten Jahrhundert muss es eine Art weltliche Strafgerichtsbarkeit gegeben haben, wie wir noch aus der Vita Papst Hadrians I. erfahren, als eine Übergabe von Mördern an den prefectus urbis berichtet wird. ${ }^{182}$ Doch muss man einschränkend bemerken, dass der oberste weltliche Beamte Roms, der $d u x$, zu diesem Zeitpunkt bereits vom Papst ernannt wurde.

Das Amt des dux war im Laufe der ersten Hälfte des achten Jahrhunderts unter päpstliche Kontrolle geraten, ${ }^{183}$ es ist durchaus vorstellbar, dass das als Resultat des Steuerstreits der späten 720 or-Jahre und der damit verbundenen bewaffneten Auseinandersetzungen geschehen war. ${ }^{184}$ Ursprünglich (und de iure vielleicht bis in die 770er-Jahre) war der $d u x$ ein kaiserlicher Beamter, der in seiner Hand die zivile und militärische Verwaltung eines kleineren geographischen Bereichs vereinheitlichte. Im Fall des dux von Rom war das der sogenannte Dukat von Rom. Dieser war wahrscheinlich in der zweiten Hälfte des siebenten Jahrhunderts als untergeordneter Teilbereich des Exarchats von Ravenna gegründet worden. Dieser Bereich wurde sehr bald de facto vom Papst und seiner Verwaltung dominiert, der vom Kaiser eingesetzte $d u x$ konnte hingegen zu keinem Zeitpunkt seine ihm nominell zukommende Machtfülle im Dukat und der Stadt entfalten. ${ }^{185}$ Wahrscheinlich ist es der Dukat von Rom, wenn im LP von der Romanorum provincia die Rede ist, ${ }^{186}$ wenn nicht ohnehin, wie in der Vita Papst Zacharias', direkt vom Dukat geschrieben wird. ${ }^{187}$ Diese Vita kann uns auch gleich die Problematik des Begriffs Romani vor Augen führen: Er wurde durchaus auch um die Mitte des achten Jahrhunderts noch in Bezug auf das Kaiser-

182 LP I, 490. Siehe Duchesne, LP I, 515, Anm. 12, und Davis, LP 8, 128f., Anm. 20. Ob dieses Amt noch mit jenem von Justinian geschaffenen identisch ist, wissen wir nicht. Davis spekuliert sogar, dass Hadrian es neu geschaffen haben könnte.

183 Hartmann, Hadrian 39f. diskutiert die Entwicklung des Amtes nach der Übernahme durch den Papst.

184 Siehe dazu unten, Kap. 3.2.2 und Kap. 5.1.

185 Zur Entstehung des Dukats von Rom siehe den sehr detaillierten und gründlichen, wenn auch ein wenig zu optimistischen Artikel von Bernard Bavant, Le duché byzantin de Rome: Origine, durée et extension géographique, in: Mélanges de l'École française de Rome: Moyen-Age, Temps modernes, 91, 1 (1979) 41-88. Siehe außerdem Thomas S. Brown, Gentlemen and Officers: Imperial Administration and Aristocratic Power in Byzantine Italy, A.D. 554-800 (Hertford 1984) 53-56; Ullmann, Growth 58, mit Anm. 3, und, am neuesten und besonders wichtig, Paolo Delogu, Il passaggio dall'antichità al medioevo, in: Storia di Roma dall'antichità a oggi, Bd. 2, Roma medievale, ed. André Vauchez (Rom/Bari 2001) 3-40, hier $20 f$.

186 So zum Beispiel LP I, 444 (Vita Stephans II.).

187 LP I, 426-435. 
reich verwendet, wie wieder die Vita des Zacharias belegt. ${ }^{188}$ Wenn also zweifelsfrei von der Stadt oder dem Einzugsbereich geredet werden sollte, musste man Romana urbs oder eben ducatus Romanus schreiben.

Der Bereich des Dukats stand zunächst auch ganz besonders in engem Zusammenhang mit dem von den Päpsten des achten Jahrhunderts verwendeten Ausdruck peculiaris populus, wenn dieser Ausdruck zeitweise auch eine gewisse Ausweitung auf Ravenna und die Pentapolis erfahren haben könnte. ${ }^{189}$

Ravenna war neben Rom die zweite wichtige Stadt in Mittelitalien und in der kaiserlichen Verwaltung Rom übergeordnet. Spätestens ab 584 bis zum Fall Ravennas im Jahr 75 I war sie der Sitz des Exarchen, des Vertreters des Kaisers in Italien. ${ }^{190}$ Auch der Papst war im Prinzip dem Exarchen unterstellt, von dem jeder neu gewählte Papst auch die Zustimmung zur Weihe einholen musste. ${ }^{191}$ Der steigende Einfluss der Päpste in Mittelitalien führte besonders in den 720er-Jahren sogar zu bewaffneten Auseinandersetzungen ${ }^{192}$, aus denen Papst Gregor II. jedoch gestärkt hervorging.

Deshalb konnte der Papst nun auch den Dukat von Rom selbst kontrollieren, was schließlich dazu führte, dass man um die Mitte des achten Jahrhunderts im Lateran begann, den eigenen Herrschaftsbereich und nicht mehr das Kaiserreich als res publica zu bezeichnen, wie die Vita Stephans II. deutlich belegt: Wenn der LP ... causam beati Petri et reipublice Romanorum gleichsetzt, geht es nur mehr um das Gebiet des Papstes. ${ }^{193}$

Was also war Rom aus Sicht des Papstes? Auf diese Frage gibt es aus römischen Quellen leider kaum eine Antwort, auch wenn etwa der LP und die Papstbriefe immer wieder vereinzelte Hinweise auf die Selbstsicht der Autoren bieten, doch auch hier steht so gut wie immer die ecclesia im Vordergrund.

188 LP I, 428: diversis provinciis Romanorum.

189 Der Ausdruck wird zwar nicht verwendet, als Papst Zacharias im LP I, 429f., als Retter in Ravenna einzieht, doch findet sich hier eine ganz massive Hirte-Herde-Rhetorik, die durchaus in diese Richtung führen sollte.

190 Zum Exarchat siehe Salvatore Cosentino, Storia dell'Italia bizantina (VI-XI secolo): Da Giustiniano ai Normanni (Bologna 2008) 135-137: sicher belegt ist das Amt 584 durch einen Brief Papst Pelagius' II. Siehe auch Francesco Borri, Duces e magistri militum nell'Italia esarcale (VI-VIII secolo), in: RM Reti Medievali Rivista, 6 (2005/2) 1-42, bes. 10-12.

191 Vgl. u. a. das Formular zur Meldung der erfolgten Wahl an den Exarchen aus dem Liber Diurnus, V60=C59 (ed. Hans Förster, Liber Diurnus Romanorum Pontificum, Bern 1958) 114-117. Siehe auch unten, Kap. 4.2, bes. Anm. 388.

192 Siehe dazu unten, Kap. 3.2.2 und 5.1.

193 LP I, 447f. Siehe dazu Davis, LP 8, 63, mit Anm. 62 und 63: Davis sieht das Gebiet Ravennas bereits eingeschlossen. Siehe auch Noble, Republic 81, der jedoch in der Folge schon die Sezession des Papsttums vom Imperium sehen will, was vielleicht zu weit geht. 
Rom war für die Päpste des achten Jahrhunderts jedoch mehr als nur die Kirche: Die neu gewonnene Handlungsfreiheit der Päpste in Mittelitalien ab den 73oer-Jahren schlug sich im Versuch nieder, den römischen Einflussbereich noch auszuweiten. Im Zuge dessen bekommen wir vielleicht den besten Einblick, was die Bedeutung Roms aus Sicht der Päpste - abgesehen vom peculiaris populus und dem unmittelbaren Herrschaftsgebiet - gewesen sein könnte. Die Päpste versuchten spätestens seit Gregor II., das reiche kulturelle Kapital Roms im Westen vorteilhaft zu „vermarkten“. Gregor selbst hatte zum Beispiel gute Kontakte zum fränkischen dux Aquitaniens, Eudo. Das erfahren wir aus dem LP, wo von geistlicher Unterstützung der aquitanischen Truppen gegen die sarazenischen Angreifer berichtet wird. Im LP sind es die vom Papst übersandten geweihten Schwammbrote, deren Verzehr den Franken im Jahr 72 I den (tatsächlich bedeutenden) Sieg in der Schlacht von Toulouse ermöglicht. ${ }^{194}$ Es liegt auf der Hand, dass das Papsttum vor allem auf kirchlich-religiöser Ebene seine Stärken hatte. So erscheint es nur logisch, dass Stephan II. in seinen Verhandlungen mit dem neu gekrönten Frankenkönig Pippin vor allem den Schutz des Heiligen Petrus für die Franken als Belohnung in Aussicht stellte. ${ }^{195}$ Religiöse Argumente wurden aber nicht nur den Franken gegenüber eingesetzt, auch die Verhandlungen zwischen Zacharias und dem Langobardenkönig Liutprand zu Beginn der 740erJahre waren davon geprägt. ${ }^{196}$

Doch die Päpste beschränkten sich nicht nur auf ihre religiöse Kernkompetenz. Als tatsächliche Herren Roms konnten sie offenbar auch auf die reichen kaiserlichen Identifikationsmuster der Stadt zurückgreifen. Das bekannteste Beispiel ist hier sicherlich die Vergabe des patricius Romanorum-Titels an Pippin und seine Söhne Karl und Karlmann durch Stephan II. ${ }^{197}$ In der Forschung ist bis heute umstritten, welche Bedeutung dieser Titel nun wirklich hatte. Es wurde behauptet, der Papst habe den Titel erfunden ${ }^{198}$ - doch tatsächlich handelt es sich bei dem Titel um einen eher un-

194 LP I, 401. Siehe unten, Kap. 5.8.1 mit Anm. 756.

195 Siehe zum Beispiel Stephans Brief an ,alle Franken“: CC 5, ed. Gundlach 487f. und vgl. CC 10, ebd., 501-503, in dem die Papstkanzlei nicht im Namen des Papstes, sondern im Namen des Apostels Petrus schreibt.

196 Siehe dazu unten, Kap. 5.2.

197 Annales mettenses priores (ed. Bernhard von Simson, MGH SS rer. Germ. in us. schol. [10], Hannover 1905) 45f. und die sogenannte Clausula de unctione Pippini (ed. Alain J. Stoclet, La „clausula de unctione Pippini regis“: mises au point et nouvelles hypthèses, in: Francia 8 [1980]) 1-42, hier $2 f$. Siehe auch den umfangreichen Kommentar Stoclets.

198 Der Proponent dieser Meinung war Werner Ohnsorge, Der Patricius-Titel Kaiser Karls des Großen, in: Byzantinische Zeitschrift 53 (1960) 300-321, der sogar in Abrede stellte, dass Pippin diesen Titel jemals vom Papst erhielt. Dagegen siehe schon Josef Deér, Zum Patricius-Romanorum-Titel Karls des Großen, in: Archivum Historiae Pontificiae 3 (1965), 31-86, ND in: Zum Kaisertum 
typischen, aber doch durchaus nachzuweisenden kaiserlichen Ehrentitel, abgeleitet

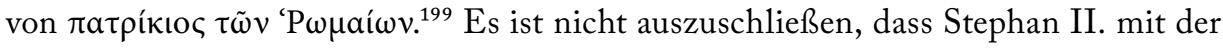
Verleihung des Titels sogar von den kaiserlichen Amtsträgern, die kurz zuvor in Rom weilten, oder dem Kaiser selbst beauftragt worden war. ${ }^{200}$ Klar ist aber in jedem Fall, dass der Papst hier eine Mischung aus imperialem Erbe und aktuellen kaiserlichen Vorrechten zu seinen Gunsten einsetzen konnte.

Die Päpste positionierten sich mit einem Vorgehen wie diesem als „cultural brokers“201 für den Lateinischen Westen und zwar sowohl im geistlichen wie im weltlichen Bereich. ${ }^{202}$ Vor allem im Zuge dessen verraten sie durch ihr Vorgehen auch, wie sie zu Rom standen. In erster Linie waren der Dukat und die Stadt das Herrschaftsgebiet des Papstes, in dem auch die Menschen lebten, um die sich der Lateran letztendlich zu kümmern hatte. Doch der Papst fühlte sich auch in allgemeinerer Weise für die Menschen Mittelitaliens bis hinauf nach Venedig verantwortlich, auch wenn hierbei Herrschaftsansprüche eine wesentliche Rolle spielten. Rom war für die Päpste aber noch mehr. Es war die Stadt der Apostelfürsten Petrus und Paulus (des ersteren mehr als des letzteren), einer Reihe christlicher Märtyrer und schlussendlich der Sitz der westlichen Christenheit, ein Umstand den man nicht müde wurde zu betonen. Darüber hinaus war Rom aber auch fest im alten Römischen Reich verankert und für die längste Zeit auch im achten Jahrhundert noch Teil des aktuellen Kaiserreichs.

Karls des Großen. Beiträge und Aufsätze, ed. Gunther Wolf (Darmstadt 1972) 240-308 (in der Folge danach zitiert).

199 Siehe Deér, Patricius-Romanorum-Titel und Noble, Republic 278-280.

200 Dagegen spricht sich zwar Noble, Republic 279 aus, doch letztendlich ist eine Beteiligung der kaiserlichen Gesandten eben nicht auszuschließen. Weiters dagegen auch Peter Classen, Karl der Große, das Papsttum und Byzanz, in: Karl der Große. Lebenswerk und Nachleben, Bd. 1, ed. Helmut Beumann/Wolfgang Braunfels u. a. (Düsseldorf 1965) 537-607, hier 552, und François Louis Ganshof, Note sur les origines byzantines du titre „Patricius Romanorum“, in: Annuaire de l'Institut de Philologie de l'Histoire orientales et slaves 10 (1950) 261-282, hier 268f. und 274f. Einen Mittelweg bietet Herwig Wolfram, Intitulatio, Bd. 1: Lateinische Königs- und Fürstentitel bis zum Ende des achten Jahrhunderts (Graz/Wien/Köln 1967) 230-232, indem er argumentiert, dass der Titel vom Kaiser zumindest nachträglich anerkannt wurde, zuvor aber vom Papst frei ausgestaltet wurde, allerdings wahrscheinlich ebenfalls mit dem grundsätzlichen Einverständnis der kaiserlichen Beamten.

201 Zum Konzept siehe Helmut Reimitz, Cultural brokers of a common past: history, identity and ethnicity in Merovingian historiography, in: Strategies of Identification. Ethnicity and Religion in Early Medieval Europe, ed. Walter Pohl/Gerda Heydemann (Cultural Encounters in Late Antiquity and the Middle Ages 13, Turnhout 2013) 257-301.

202 Unter dem Titel „Learning Empire“ lief von 2010-2013 ein HERA Forschungsprojekt als Teil des internationalen Projekts „Cultural Memory and the Resources of the Past" in Wien, das sich unter anderem mit der Rolle des Papstes bei der Kulturvermittlung zwischen Ost und West und imperialer Vergangenheit und der Gegenwart des achten Jahrhunderts beschäftigt. 
3.2 Das imperiale und "griechische" Rom: Die Ewige Stadt als Knotenpunkt am Mittelmeer ${ }^{203}$

\subsubsection{Zum Verhältnis Rom-Griechen aus postkolonialer Sicht}

Die Postkoloniale Theorie, die schon in Kapitel 2 mit Einschränkungen als geeignete theoretische Grundlage für die Wahrnehmung des Anderen vorgestellt worden ist, geht in ihren Grundlagen von einer unweigerlichen Dichotomie zwischen einer kolonial-imperialistischen Identität auf der einen Seite und einer postkolonial-subalternen auf der anderen Seite aus. Das wurde zwar auch vonseiten der Proponenten dieser Theorie mit deutlicher Einschränkung vertreten, ${ }^{204}$ eine koloniale Identität aber dennoch immer vorausgesetzt. Auf die Problematik der Anwendung dieser Theoreme im Hinblick auf das frühmittelalterliche Rom wurde daher oben bereits deutlich hingewiesen. Dennoch beschäftigen wir uns mit der römischen Identität vielleicht mit der imperialen Identität schlechthin. Einer der Meilensteine auf Roms Weg zum das Mittelmeer umspannenden Imperium war die Machtübernahme im heutigen Griechenland und Kleinasien im Laufe des zweiten Jahrhunderts vor Christus. Nachdem bereits im frühen dritten Jahrhundert vor Christus die Graecia Magna in Süditalien erobert worden war, kam sukkzessive der gesamte hellenische Kulturbereich unter die Kontrolle Roms. Rom war in allen diesen Gegenden zweifellos eine Kolonialmacht. Das Verhältnis zur kulturell überlegenen Kolonie wurde zwar von römischer Seite oft auch in schönen Farben gezeichnet, gleichzeitig war es von Vorurteilen durchsetzt. Zudem wurden griechische Sklaven im großen Stil nach Mittelitalien importiert, was zwar einerseits sicher den Kulturkontakt förderte, andererseits sicherlich Roms Kolonialismus nur noch anfachte. ${ }^{205}$ In Anlehnung an Edward Saids Orientalism könnte man aus römischer Sicht wohl von einer Art Graecism ausgehen, einem verklärt-überheblichen Bild vom Osten.

Auch als in der Spätantike zwei Reichsteile geschaffen wurden, war die politische Elite des Ostens zunächst noch lateinisch geprägt. Zur Ausbalancierung der Situation könnte jedoch beigetragen haben, dass das immer stärker ins Zentrum rückende

203 Einige Abschnitte des vorliegenden Kapitels sind in etwas veränderter Form als Teil des Artikels Clemens Gantner, The label "Greeks" in the papal diplomatic repertoire in the eighth century, in: Strategies of Identification. Ethnicity and Religion in Early Medieval Europe, ed. Walter Pohl/ Gerda Heydemann (Cultural Encounters in Late Antiquity and the Middle Ages 13, Turnhout 2013) 303-349, erschienen.

204 Siehe Castro Varela/Dhawan, Postkoloniale Theorie 55-58 zu den Grundlagen der Theorie Gayatri Spivaks, die sehr deutlich festgehalten hat, dass solch ein „bipolares“ System nicht existiert.

205 Zum Verhältnis Griechen - Römer im antiken Rom siehe ausführlich Ronald Mellor, Graecia capta. The confrontation between Greek and Roman identity, in: Hellenisms: Culture, Identity, and Ethnicity from Antiquity to Modernity, ed. Katerina Zacharia (Aldershot 2008) 79-126. 
Christentum eher griechisch dominiert war. Auch die Elite des Kaiserreichs wurde dann immer stärker gräzisiert, viele spätere Kommentatoren wollten in Kaiser Maurikios (582-602) den ersten "griechischen Kaiser" erkennen. ${ }^{206}$

Spätestens im 6./7. Jahrhundert hatte sich das Blatt also völlig gewendet: Die beim Imperium bzw. bei der res publica verbliebenen Teile des Westens (bald nur noch Teile Mittelitaliens, Süditalien und Nordafrika) sahen nun wie Kolonien des Machtzentrums in Kleinasien aus und wurden zum Teil auch entsprechend behandelt.

Diese Dominanz aus dem Osten wurde jedoch wiederum für die Stadt Rom im Laufe des späten siebenten und der ersten Hälfte des achten Jahrhunderts stetig ausgehöhlt - das allerdings unter der Führung kulturell griechischer Päpste (zum Konzept „kulturell griechisch“ vgl. unten, Kapitel 3.2.3), was die ganze Komplexität der Beziehung Roms zu Konstantinopel noch einmal unterstreicht.

Somit war Rom im achten Jahrhundert auf sehr widersprüchliche Weise postkolonial mit dem Imperium verbunden. Einerseits repräsentierte Rom selbst noch immer die alte, lateinische römisch-imperiale Identität wie kein zweiter Ort und auch einige Bewohner des nunmehrigen Dukats von Rom werden sich wohl noch mit derartigen Ideen identifiziert haben. ${ }^{207}$ Man fühlte sich in Rom also unter anderem als Vertreter und vielleicht Hüter der „wahren“ imperialen Identität.

Auf der anderen Seite nahm man die Welt aber selbst wahrscheinlich zugleich aus einer subalternen postkolonialen Perspektive wahr, die in der die beiden vorigen Jahrhunderte andauernden Oberherrschaft aus dem Osten begründet lag (siehe dazu besonders Kapitel 3.2.2).

Wenn Rom sich also mit den griechischsprachigen Vertretern des (immer noch von seiner gesamten Ideologie her römischen) Imperiums beschäftigte, dann fand eine solche Auseinandersetzung zugleich aus einer kolonialen wie auch einer postkolonialen Perspektive statt. Wenn man noch in Betracht zieht, dass die kom-

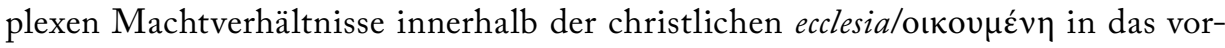
liegende Modell noch gar keinen Eingang gefunden haben, kann man vielleicht

206 So etwa Paulus Diaconus, Historia Langobardorum, 3, 15 (ed. Ludwig Bethmann/Georg Waitz, MGH SS rer. Lang.) 12-187, hier 100: Quo defuncto, Mauricius indutus purpura, redimitus diademate, ad circum processit, adclamatisque sibi laudibus, largita populo munera, primus ex Grecorum genere in imperio confirmatus est. Siehe dazu Maya Maskarinec, Who were the Romans? Shifting scripts of Romanness in early medieval Italy, in: Walter Pohl/Gerda Heydemann, Post-Roman Transitions. Christian and Barbarian Identities in the Early Medieval West (Cultural Encounters in Late Antiquity and the Middle Ages 14 (Turnhout 2013) 297-363.

207 Auch außerhalb Roms wurden entsprechende Fragen diskutiert, so fertigte Paulus Diaconus im Auftrag Adelpergas (Ehefrau Prinzeps Arichis II. von Benevent und Tochter des Langobardenkönigs Desiderius) auf Basis der Historia Romana Eutrops eine eigene Römische Geschichte an. Siehe dazu Maskarinec, Who were the Romans? 
ermessen, wie unendlich komplex das Verhältnis der Stadtrömer mit Ostrom ${ }^{208}$ geworden war.

Sehr aufschlussreich ist im Hinblick auf dieses Dilemma der päpstliche Umgang mit dem Begriff Greci (die Griechen), dem sich Kapitel 4 widmet.

\subsubsection{Die "Griechen" und der Lateinische Westen in historischer Perspektive seit dem sechsten Jahrhundert}

Im frühmittelalterlichen Lateinischen Westen scheint es zunächst absolut üblich gewesen zu sein, die Einwohner und insbesondere die Repräsentanten des verbliebenen Teils des Römischen Reichs (des, jeweils anachronistisch, als oströmisch oder byzantinisch bezeichneten Reichs) Griechen, Greci, zu nennen. Nur nebenbei sei bemerkt, dass in der Folge Greci ohne Diphtong (also -ae-) geschrieben werden wird, außer wenn es in der Quelle definitiv anders geschrieben wird, oder wenn es sich um eine Quelle handelt, die der karolingischen Correctio zuzurechnen ist. Die italienischen Quellen schreiben den Diphtong in der Regel nicht.

Die Bezeichnung „Griechen“ scheint sich jedenfalls im Laufe des siebenten Jahrhunderts weitgehend durchgesetzt zu haben - jedoch nicht in der Stadt Rom, die zu dieser Zeit bereits von den Päpsten dominiert wurde. In der Ewigen Stadt hatte man ein völlig anderes Verhältnis zu den nach der arabischen Expansion verbliebenen das Imperium gänzlich beherrschenden Provinzen. Und zumindest de iure war Rom auch tatsächlich ein Teil dieses Reichs. Entsprechend schwer fiel es offenbar, die Bezeichnung „Griechen“ zu verwenden, eine Frage, der sich Kapitel 4.I noch eingehend widmen wird.

Zunächst müssen wir uns als Vorbedingung die Frage stellen, wie die „Griechen“ in der modernen Mittelalterforschung gesehen werden: Das Lexikon des Mittelalters (LMA) wird hierfür als Beispiel verwendet. Es finden sich dort Einträge für „Griechenland [das nur den Verweis auf die mehr oder weniger im heutigen Griechenland gelegenen themata der Zeit enthält], Griechische Buchschrift, Griechische Indiktion, Griechische Kanzlei- und Geschäftsschrift, Griechische Kursive, Griechische Literatur, Griechische Sprache, Griechischer Stil and Griechisches Feuer“. ${ }^{209}$ Doch es gibt keinen Eintrag für „Griechen“, auch wenn die Existenz eines solchen „Volkes“ quasi implizit vorausgesetzt wird.

Stattdessen findet sich im LMA allerdings eine lange Sektion zu „Byzantinischem“, beginnend mit dem Lemma „Byzantinische Kunst“ und dominiert von dem

208 Zur Verwendung dieser Bezeichnung siehe in der Folge Kap. 3.2.2.

209 LMA, Bd. 4, Sp. 1703-1712. 
langen Lemma zum „Byzantinischen Reich“.210 Der Terminus „Byzanz“ ist für die vorliegende Arbeit jedoch zu irreführend, um ihn leichten Herzens verwenden zu können. Zwar hätte man im Rom des achten Jahrhunderts (und auch lange davor und

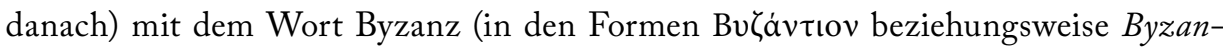
tium) aller Wahrscheinlichkeit nach durchaus etwas anfangen können. Man hätte darin jedoch den alten Namen von Konstantinopel erkannt, der auch in zeitgenössischen griechischen Texten nicht selten für die Hauptstadt verwendet wurde. Dane-

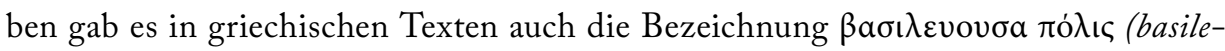
uousa polis $)^{211}$ - so wie auch in lateinischen päpstlichen Texten Constantinopolis selten so genannt wird, hier wurde oft regia urbs bevorzugt, was eine wörtliche Übersetzung des zitierten griechischen Ausdrucks gewesen sein könnte. ${ }^{212}$

Auch der Begriff Ostrom ist ein Hilfsbegriff, ebenfalls aus der Rückschau entstanden. Tatsächlich verstand sich das Reich als das Römische Reich und wurde von den Zeitgenossen auch als solches wahrgenommen. Der Begriff ist vielleicht etwas weniger irreführend als „Byzanz“, weil er eine stärkere Kontinuität vermittelt und wird daher in der Folge zur immer wieder notwendigen sprachlichen Abgrenzung des Ostens vom Westen bisweilen werwendet werden.

Wichtiger als die moderne Wissenschaftssprache ist jedoch die Selbstsicht der Zeitgenossen, der wir uns nun kurz annähern wollen. Die Greci des Frühmittelalters hätten sich nie selbst auf diese Weise bezeichnet, ihre Identifikation erfolgte

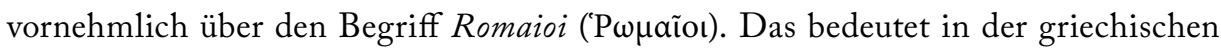
Sprache schlichtweg „Römer“, also Einwohner des Römischen Reichs. Aus dem griechischen Wort hat wiederum die deutschsprachige Historiographie den Begriff „Rhomäer" geschaffen, der jedoch wie sein sehr verwandter Begriff „Byzantiner“ ein reiner Kunstbegriff ist. ${ }^{213}$ In der englisch- und französischsprachigen Forschung gibt es einen solchen Terminus nicht.

Neben Romaioi gibt es noch die Bezeichnungen Graikoi und Hellenes, die für eine Eigendefinition der „Oströmer" in Frage kommen. Doch beide wurden spätestens seit dem sechsten Jahrhundert so gut wie nicht verwendet. ${ }^{214}$ Hellenes war im frühen

210 LMA, Bd. 2, Sp. 1169-1327, davon 1227-1327 „Byzantinisches Reich“.

211 Giorgio Vespignani, Costantinopoli Nuova Roma come modello della urbs regia tardoantica, in: Reti Medievali Rivista, XI - 2010/2 (luglio-dicembre), http://www.retimedievali.it (Stand 26.4.2011) 1 und 5. Siehe auch Guglielmo Cavallo, The Byzantines (Chicago 1997) 239.

212 Vielleicht wird in diesem Fall sogar ein besonders gutes Verständnis des Papsttums für die im Osten angewandte Wortwahl deutlich.

213 Johannes Koder, Rhomaioi, in: LMA, Bd. 7, Sp. 797.

214 Vgl. Johannes Koder, Byzanz, die Griechen und die Romaiosyne - eine „Ethnogenese“ der „Römer“?, in: Typen der Ethnogenese unter besonderer Berücksichtigung der Bayern, Berichte des Symposiums der Kommission für Frühmittelalterforschung, 27. Bis 30. Oktober 1986, Stift Zwettl, 
Mittelalter sehr ungebräuchlich, weil der Begriff seit dem frühen Christentum als Synonym für „Heiden“ verwendet worden war und noch immer als solcher galt. ${ }^{215}$ Erst im Laufe des neunten Jahrhunderts wurde die Bezeichnung wieder in isolierten Fällen verwendet, insbesondere in literarisch äußerst gebildeten Kreisen. ${ }^{216}$

Graikoi ist überhaupt ein sehr komplizierter Begriff. Es sind nur vereinzelte Fälle bekannt, in denen er als Selbstbezeichnung gedient haben könnte. Diese Fälle stammen vom Balkan aus einer griechisch-slawisch gemischten Bevölkerung, vom absoluten Rand der oströmischen Einflusssphäre. ${ }^{217}$ Allerdings werden wir ihm später noch einmal in einem ganz besonderen Zusammenhang begegnen. ${ }^{218} \mathrm{Im}$ frühen Mittelalter dürfte das wenig benutzte Wort mit ziemlicher Sicherheit ein Lehnwort aus dem Lateinischen gewesen sein. ${ }^{219}$ Überhaupt dürfte das Wort nicht griechischen (bzw. hellenischen) Urpsrungs sein: Граıкó ৎ war niemals eine Selbstbezeichnung, sondern stammt von dem lateinisch/italischen Begriff Graecus, der in Italien schon vorkam, aber nicht ursprünglich in Latein zunächst für das illyrische Volk der Grais (Г $\rho \tilde{a} \varepsilon \varsigma)$ verwendet worden war. Von dort wurde der Name auf die aus italischer Sicht ebenfalls aus dem Osten stammenden Ionier/Hellenen übertragen. Schon in der Antike hatte die Bezeichnung Graeci in den lateinischen Quellen meist einen abwertenden Charakter (auch wenn es durchaus Bewunderung für die kulturellen Leistungen gab ${ }^{220}$ ) und wurde auch von den so bezeichneten Menschen als abwertend verstanden. ${ }^{21}$

Eine Quelle ist besonders prädestiniert, um das Verhältnis zwischen Romaioi und Greci zu demonstrieren, nämlich die sogenannte Apokalypse des Pseudo Methodius. Dieser Text präsentiert sich als eine Geschichte der Welt mit einem großen prophetischen Teil und gibt vor, im 4. Jahrhundert von Methodius von Olympus in Lykien

Niederösterreich, I, ed. Herwig Wolfram/Walter Pohl (Veröffentlichungen der Kommission für Frühmittelalterforschung, 12, Wien 1990) 103-111.

215 Für Details siehe Claudia Rapp, Hellenic identity, romanitas and Christianity in Byzantium, in: Hellenisms: Culture, Identity, and Ethnicity from Antiquity to Modernity, ed. Katerina Zacharia (Aldershot 2008) 127-147, bes. 136-144, und Johannes Koder, Griechische Identitäten im Mittelalter. Aspekte einer Entwicklung, in: Byzantium: State and Society: In memory of Nikos Oikonomides, ed. Anna Avramea, Angeliki Laiou and Evangelos Chrysos (Athen 2003) 297-319, bes. $299 f$. Siehe auch Warren Treadgold, A History of the Byzantine State and Society (Stanford 1997) 136.

216 Koder, Griechische Identitäten, bes. 307-316 für die Entwicklungen nach 800.

217 Koder, Romaiosyne, und ders., Griechische Identitäten 305.

218 Siehe weiter unten in diesem Kapitel zu Maximos Confessor.

219 Koder, Romaiosyne, bes. 104.

220 Mellor, Graecia capta.

221 Michel Dubuisson, GRAECVS, GRAECVLVS, GRAECARI: L'emploi péjoratif du nom des Grecs en latin, in: 'E $\lambda \lambda \varepsilon v ı \sigma \mu o \varsigma$. Quelques jalons pour une histoire de l'identité grecque. Actes du Colloque de Strasbourg, 25-27 octobre 1989, ed. Suzanne Said (Leiden/New York/Kopenhagen/Köln 1991) $315-335$, bes. $316-317,323$ und 329-334. 
verfasst worden zu sein. Tatsächlich wird die Abfassung des Textes heute in der Forschung fast einhellig in die 69oer-Jahre datiert. Die Originalsprache der Revelationes des Pseudo Methodius war Syrisch, eine der wesentlichsten Vorlagen war die sogenannte Schatzhöhle, eine syrische Weltgeschichte. Der Text wurde daraufhin sehr schnell ins Griechische übersetzt und auf der Grundlage dieser Übersetzung auch ins Lateinische. ${ }^{222}$ Es gibt Spekulationen, wo diese Übersetzungen angefertigt worden sein könnten, die griechische wird öfters mit den Klöstern am Sinai in Verbindung gebracht, Beweise gibt es aber für keine der Theorien.

Was die Quelle für einen Vergleich einzigartig macht, ist der Umstand, dass die Versionen in drei Sprachen in relativ kurzer Zeit entstanden.

In der syrischen Version der Revelationes findet sich eine sehr aufschlussreiche Definition, und zwar an der Stelle, als der anoyme Autor die ersehnte Rückeroberung der nun arabisch beherrschten Gebiete durch den Kaiser ansetzt ${ }^{223}:$ „.. und es wird gegen sie ausziehen der König der Griechen in großem Zorn, und er wird aufgeweckt werden wie ein Mann, der seinen Wein abgeschüttelt hat, den sie für tot hielten." ${ }^{\text {"24 }}$

Der Kaiser ist an dieser Stelle also eigentlich der „König der Griechen“ - so konnte er jedenfalls im Syrien des späten siebenten Jahrhunderts gesehen werden. In der griechischen Übersetzung, die etwa um die Jahrhundertwende zum achten Jahrhun-

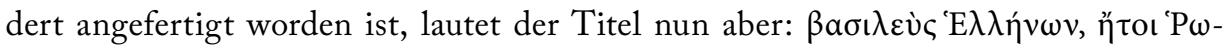
$\mu$ aíwv (basileus Hellenon, etoi Romaion). Das ist nun tatsächlich sehr bemerkenswert. Erstens übersetzte der unbekannte Übersetzer das syrische Yawnaye mit Hellenon,

222 Siehe Die Apokalypse des Pseudo-Methodius: Die ältesten griechischen und lateinischen Übersetzungen (ed. Willem J. Aerts/Georg A. A. Kortekaas, 2 Bde., Corpus Scriptorum Christianorum Orientalium; Subsidia, 97 und 98, Louvain 1998) Bd. 1, 15-35. Siehe auch Wolfram Brandes, Die Belagerung Konstantinopels 717/718 als apokalyptisches Ereignis. Zu einer Interpolation im griechischen Text der Pseudo-Methodios-Apokalypse, in: Byzantina Mediterranea: Festschrift für Johannes Koder, ed. Klaus Belke/Ewald Kislinger/Andreas Külzer/Maria A. Stassinopoulou (Wien/ Köln/Weimar 2007) 65-91, hier 68.

223 Siehe Hannes Möhring, Der Weltkaiser der Endzeit: Entstehung, Wandel und Wirkung einer tausendjährigen Weissagung (Mittelalterforschungen, 3, Stuttgart 2000) 54-104, bes. 82-88: Die Revelationes haben eine starke Verbindung zur Alexanderlegende, wobei Alexander (vielleicht das „role model“ schlechthin für einen basileus Hellenon?) mit dem zeitgenössischen Kaiser Justinian II. in Verbindung gebracht wird.

224 Die syrische Apokalypse des Pseudo-Methodius, 13, 11 (ed. Gerrit J. Reinink, Corpus Scriptorum Christianorum Orientalium, 541, Scriptores Syri, 221 [der syrische Text findet sich in den Bänden 540 bzw. 220], Louvain 1993) 62. Auf Syrisch lautet der Titel des „Königs der Griechen“: bnawby $d$-malka d-yawnaye; yawnaye bedeutet Griechen und kommt möglicherweise von der Bezeichnung Ionier. Martin Lang (Innsbruck) sei für die Transskription dieser Passage gedankt. Siehe im Allgemeinen Robert G. Hoyland, Seeing Islam as Others saw it: A Survey and Evaluation of Christian, Jewish and Zorotastrian Writings on Early Islam (Princeton/NJ 1997) 263-267 und 295-297. 
doch sah er sich offenbar gezwungen, diesen Terminus nicht ohne Erklärung stehen zu lassen. Er erläuterte seinen Lesern also, dass es sich eigentlich um den basileus Romaion handelte. ${ }^{225}$ So bedeutsam dieser Nebensatz auch ist, es ist ebenso auffällig, dass der Übersetzer nicht Romaion für die direkte Übersetzung aus dem Syrischen hielt, sondern eben Hellenon. Es zeigt, wie schwierig es für Menschen, die von außen betrachtet als „Griechen“ gegolten hätten, war, sich zu definieren.

Die lateinische Fassung aus den ersten beiden Dekaden des achten Jahrhunderts gibt den zitierten Titel schließlich als rex Gregorum sive Romanorum an. ${ }^{226}$ Er übersetzte also Hellenon mit Gregorum (Grecorum) und gab dann auch die Spezifizierung an, so wie sie sich schon in seiner griechischen Vorlage fand.

Das Beispiel zeigt, dass die Außenbezeichnungen für die Menschen, die im Rest des Imperiums, vor allem in seinem Kerngebiet im westlichen Kleinasien, lebten, sich jeweils stark von der Innensicht unterschieden. Auf Lateinisch war die Bezeichnung „Griechen“ gebräuchlich während auf Griechisch der Terminus „Römer“ bevorzugt wurde. ${ }^{27}$

Und nüchtern betrachtet war das Oströmische Reich, abgesehen vielleicht von einigen weit vom Zentrum entfernt gelegenen Provinzen, im Grunde „griechisch“, wenn man kurz von der heutigen Sicht der Dinge auf Deutsch ausgehen möchte. ${ }^{228}$ Diese Einschätzung umfasst sowohl die dominierende Sprache, die, auch wenn sie vor der arabischen Expansion vielleicht nicht einmal die Muttersprache der Mehrheit gewesen sein mag, als Hauptverkehrssprache und endgültig seit dem sechsten Jahrhundert auch als Verwaltungssprache unangefochten war. Das „Griechische“ umfasste daneben aber auch das kulturelle und historische Erbe des Oströmischen Reichs, siehe dazu unten, Kapitel 3.2.3. Die „Gräzisierung“ des Kaiserreichs und insbesondere der kaiserlichen Verwaltung wird oft mit der Herrschaft der Kaiser Phokas und Herakleios verbunden ${ }^{229}$, aber es scheint angebrachter, hier einen Prozess zu sehen, der bereits im fünften Jahrhundert seinen Anfang nahm und sich bis ins achte Jahrhundert fortsetzte. ${ }^{230}$

225 Aerts/Kortekaas, ed., Die Apokalypse des Pseudo-Methodius, Bd. 2, 50, sind der Meinung, dass diese Erklärung eingefügt wurde, um eine mögliche Missinterpretation der Hellenes als „Heiden“ zu vermeiden. Siehe dazu auch Koder, Romaiosyne 106.

226 Pseudo-Methodius, Revelationes, 13, 11 (ed. Ernst Sackur, Sibyllinische Texte und Forschungen: Pseudo-Methodius, Adso und die Tiburtinische Sibylle, Halle/Saale 1898, 22006) 1-96, hier 89.

227 Weitere Beispiele aus dem Frühmittelalter finden sich in Koder, Romaiosyne und ders., Griechische Identitäten.

228 Auf Griechisch wäre auch die moderne Entsprechung im Prinzip „hellenisch“, doch dieser Begriff ist in der deutschsprachigen Historiographie völlig anders besetzt und würde hier nur verwirren.

229 Siehe zum Beispiel Georg Ostrogorsky, Geschichte des Byzantinischen Staates (Handbuch der A1tertumswissenschaft 12,1,2, München 1968) 70-91, bes. 89.

230 Koder, Griechische Identitäten 300. 
Im Lateinischen Westen hatte sich spätestens am Begin des achten Jahrhunderts die Meinung durchgesetzt, dass Greci in den verbliebenen östlichen Teilen des Römischen Reichs (das allerdings meist nur als imperium ohne zusätzliche Hinweise bezeichnet wurde) lebten. So verwendete man im Frankenreich, also dem Gebiet, aus dem der Löwenanteil der erhaltenen Quellen des achten Jahrhunderts stammt, den Terminus Graeci einfach für die Bewohner des Kaiserreichs. ${ }^{231}$ Es sei darauf hingewiesen, dass dieser Terminus noch im achten Jahrhundert offenbar gemeinhin ohne negative Konnotationen verwendet wurde. Im neunten Jahrhundert entwickelte er aber einen negativen Klang, so kritisierten zum Beispiel die Fuldaer Annalen den Karolingerkaiser Karl III. (den Dicken) dafür, dass er sich mit Grecas glorias geschmückt habe. ${ }^{232}$

Doch es gab im lateinisch dominierten Bereich Europas eine Region, in der diese vorherrschende Sichtweise nicht oder nicht so stark vorkam: Mittel- und Süditalien sowie die gesamte Adriaküste. Denn in diesen Bereichen Italiens war die Herrschaft des Kaisers entweder ungebrochen oder doch noch sehr nahe, was wohl großen Anteil an der veränderten Haltung hatte. Wir müssen nur an Ravenna, die alte kaiserliche Hauptstadt und langjähriger Sitz des Exarchen, an Venedig und Neapel denken. Nicht unerwähnt sollen auch die langobardischen Dukate Süditaliens, insbesondere jener von Benevent, bleiben, die auch über besondere Beziehungen zum Kaiserreich verfügten. Dazu kommt noch, dass besonders Sizilien, aber auch Teile Kalabriens und Apuliens spätestens seit dem siebenten Jahrhundert zum griechischen Kulturbereich des Mittelmeers zu rechnen sind. ${ }^{233}$

Auch Rom unterschied sich schon von den Voraussetzungen her vom größten Teil des Lateinischen Westens, was sich zweifellos auch auf die Wahrnehmung des Kernbereichs des Kaiserreichs im Osten auswirkte. Schließlich war Rom am Beginn des achten Jahrhunderts immer noch Teil des Römischen Reichs und die Bewohner der Stadt waren Untertanen des Römischen Kaisers, auch wenn dieser nun offiziell die griechische Version dieses Titels führte. Die Quellen der Zeit vermitteln den Eindruck,

231 Andreas Mohr, Das Wissen über die Anderen: Zur Darstellung fremder Völker in den fränkischen Quellen der Karolingerzeit (Münster/New York/München/Berlin 2005) 44-47. Siehe auch Franz Tinnefeld, Abendland und Byzanz: ein Europa?, in: Byzanz: das andere Europa, ed. Peter Segl, in: Das Mittelalter, 6, 2 (Berlin 2001) 19-38, hier 21. Und siehe Gerald Krutzler, Die Wahrnehmung fremder Völker in der Merowingerzeit, in: Walter Pohl/Gerda Heydemann, Post-Roman Transitions. Christian and Barbarian Identities in the Early Medieval West (Cultural Encounters in Late Antiquity and the Middle Ages 14 (Turnhout 2013) 487-547.

232 Annales Fuldenses, a. 876 (ed. Friedrich Kurze, MGH SS rer. Germ. in us. schol. [7], Hannover 1891, ND 1993) 86.

233 Siehe Cosentino, Italia bizantina und Vera von Falkenhausen, Chiesa greca e chiesa latina in Sicilia prima della conquista Araba, in: Archivio Storico Siracusano, 5 (1978-79/1985) 137-155. 
dass man sich im Dukat von Rom ${ }^{234}$ immer noch als Teil des Imperiums betrachtete. Die Bewohner des Dukats verband ein gemeinsamer historischer Hintergrund mit den Menschen im Rest des Reichs, nämlich das Erbe des Römischen Reichs aus der Zeit, als es noch unangefochten über das ganze Mittelmeer geherrscht hatte.

Im sechsten Jahrhundert wurde Kaiser Justinian (527-565) von seinen Zeitgenossen im Osten für seine renovatio imperii gepriesen. So schrieb Johannes Lydos, der Kaiser habe „Rom zurückgegeben, was Rom gehört.“235 Rom war auch im frühen Mittelalter noch „eine Stadt und eine Idee“.236

Doch seit dem sechsten Jahrhundert hatten sich die Zeiten geändert, die Verwaltung wurde immer "griechischer“. Als Beispiel soll das römische Recht dienen, das in der Theorie die Kulturräume innerhalb des Reichs verband - das Corpus Iuris Civilis. ${ }^{237}$ Zunächst muss man allerdings zugeben, dass nicht gesichert ist, dass diese Form des Rechts im Lateinischen Westen überhaupt angewandt wurde. In weiten Bereichen etwa könnten noch der Codex Theodosianus (also der Vorgänger des CIC) oder regionalere Rechtsbücher wie die Lex Romana Visigothorum in Verwendung gewesen sein. Für Rom gibt es zwischen 603 und 866 abgesehen von einer Reminszenz in der LP-Vita Papst Leos III. keine Beweise, dass das CIC angewandt wurde. Doch es gibt auch keinen Hinweis, dass ein anderes Römisches Recht in Rom verwendet wurde, weshalb eher davon auszugehen ist, dass das CIC in Kraft war. ${ }^{238}$ Das CIC ist somit als verbindendes Element zwischen Ost und West zu sehen, auch wenn im Westen oftmals auch der Codex Theodosianus noch in Verwendung gewesen sein könnte. ${ }^{239}$ Im Osten gab es inoffizielle griechische Übersetzungen des CIC und die allermeisten Novellen lagen ohnehin in griechischem Originaltext vor. Doch 74I wurde das CIC für den Osten von Kaiser Leon III. außer Kraft gesetzt und

234 Zur Erklärung des Begriffs siehe oben, Kap. 3.1.

235 Mischa Meier, Das andere Zeitalter Justinians: Kontingenzerfahrung und Kontingenzbewältigung im 6. Jahrhundert n. Chr. (Göttingen 2003) 168-170, bes. 169, wo er Johannes Lydos zitiert.

236 Hans-Georg Beck, Konstantinopel: das neue Rom, in: Gymnasium: Zeitschrift für Kultur der Antike und humanistische Bildung, 71 (1964) 166-173, hier 167. Siehe auch Antonio Carile, Roma vista da Constantinopoli, in: Roma fra oriente a occidente (Settimane di studio del Centro italiano di studi sull'Alto Medioevo, 49, Spoleto 2002) 49-99, und Heinz Hofmann, Roma caput mundi? Rom und imperium romanum in der literarischen Diskussion zwischen Spätantike und dem 9. Jahrhundert, in: Roma fra oriente a occidente (Settimane di studio del Centro italiano di studi sull'Alto Medioevo, 49, Spoleto 2002) 493-559, dem jedoch in seinen Theorien nur bedingt zuzustimmen ist.

237 Siehe Tinnefeld, Abendland und Byzanz 36.

238 Othmar Hageneder, Das crimen maiestatis, der Prozeß gegen die Attentäter Papst Leos III. und die Kaiserkrönung Karls des Großen, in: Aus Kirche und Reich. Studien zu Theologie, Politik und Recht im Mittelalter. Festschrift für Friedrich Kempf, ed. Hubert Mordek (Sigmaringen 1983) 5579, bes. 61-64.

239 Hageneder, Crimen maiestatis. 
durch ein neues Gesetzteswerk ersetzt, die Ecloga. ${ }^{240}$ Zwar waren die griechischen Übersetzungen des Codex Justinianus noch bis ins neunte Jahrhundert weiterhin in Gebrauch, ${ }^{241}$ dennoch war die Proklamation der Ecloga ein wesentlicher Schritt weg von der Idee eines einheitlichen Römischen Reichs, ja von der Idee von Rom an sich.

Im politischen und rechtlichen Bereich gab es, wie wir auch unten noch ausführlich sehen werden, also immer weniger Gemeinsamkeiten zwischen Ost und West, das Imperium lebte hier vielmehr von der Erinnerung an glorreiche frühere Tage.

Im achten Jahrhundert war das entscheidende verbindende Element des Römischen Reichs in Ost und West demgegenüber das Christentum als gemeinsame Religion. ${ }^{242}$ Diese Gemeinsamkeit blieb viel länger erhalten, sodass sich eine stark unterschiedliche Entwicklung in verschiedenen Bereichen zeigt: auf der einen Seite die schnell geringer werdenden persönlichen und politischen Kontakte und Kooperationen, auf der anderer Seite die weit stärkeren Kontakte auf der religös-ekklesiastischen Ebene. Thomas Noble hat diesen Unterschied wie folgt ausgedrückt: „... Rome had constant and copious access to Greek Christian thought. Greek secular thought was a closed book to early medieval Rome, ..."243

Entscheidende Ereignisse, die das Verhältnis der Menschen in Rom zum Kaiser und seinen Beamten nachhaltig erschütterten, waren vor allem im siebenten Jahrhundert passiert.

Kaiser Herakleios hatte 638 das neue Dogma des Monotheletismus in der sogenannten Ekthesis verkündet und sein Nachfolger Konstans II. hatte 648 in dem unter dem Namen Typos bekannt gewordenen kaiserlichen Befehl nämlich jegliche Diskussion über den Willen Christi/den Willen Christi verboten. Zunächst hatte auch Papst Honorius dieser umstrittenen Lehre teilweise zugestimmt, der zufolge Christus zwar eine menschliche und eine göttliche Natur gehabt habe, jedoch nur einen göttlichen Willen. ${ }^{244}$ Doch die Nachfolger des Honorius lehnten diese Lehre ab. Nach der Publikation des Typos berief Papst Theodor das große römische Konzil von 649 ein, dem jedoch nicht mehr er selbst, sondern sein Nachfolger Martin I.

240 Leslie Brubaker/John Haldon, Byzantium in the Iconoclast Era, c. 680-850 - A history (Cambridge 2011) 78f. Siehe Ecloga (ed. Ludwig Burgmann, Ecloga: Das Gesetzbuch Leons III. und Konstantinos' V., Forschungen zur byzantinischen Rechtsgeschichte, 10, Frankfurt am Main 1983) bes. 1-12.

241 Koder, Identitäten 303.

$242 \mathrm{Zu}$ diesen Gemeinsamkeiten siehe Judith Herrin, The Formation of Christendom (Princeton, NJ 1987) 15-89 und Andrew J. Ekonomou, Byzantine Rome and the Greek Popes: Eastern Influences on Rome and the Papacy from Gregory the Great to Zacharias, A.D. 590-752 (Lanham, Maryland 2007) 300.

243 Thomas F. X. Noble, The declining knowledge of Greek in eighth and ninth century Papal Rome, in: Byzantinische Zeitschrift, 78 (1985) 56-62, hier 60.

244 Siehe Antonio Sennis, Onorio I, in: Enciclopedia dei papi, Bd. 1 (Rom 2000) 585-589, hier bes. $586 f$. 
vorstand. Die wesentlichen Beiträge zum Konzil kamen allerdings nicht vom Papst, sondern von dem Mönch Maximos Homologetes, dem distinguiertesten Gegner des Monotheletismus, und seinem Kreis. ${ }^{245}$

Durch diese Vorgehensweise hatte Papst Martin sich jedenfalls in direkte Opposition zum Kaiser gesetzt. Im Jahr 652 rebellierte auch noch der Exarch von Ravenna Olympios und versuchte, sich im Westen zum Kaiser ausrufen zu lassen. Er starb jedoch wenig später auf einem Feldzug nach Süditalien oder Sizilien, der angeblich gegen dort aufgetauchte Sarazenen geführt wurde, tatsächlich aber wohl um sich gegen die kaiserlichen Truppen im Süden abzusichern. ${ }^{246}$

Im Jahr 653 kamen Truppen des Kaisers nach Rom. Sie umstellten die Lateransbasilika. Martin ergab sich freiwillig und wurde als Gefangener nach Konstantinopel geführt und dort vor Gericht gestellt. ${ }^{247}$ Erst im Gerichtsverfahren erfuhr er, dass die Anklage gegen ihn ausschließlich auf Hochverrat für die Unterstützung Olympios' lautete - jegliche Diskussion von religiösen Inhalten während des Prozesses war offenbar nicht vorgesehen, auch wenn der Papst immer wieder versuchte, die Argumentation in diese Richtung zu lenken. Daneben leugnete er jegliche freiwillige Beteiligung am Putsch Olympios' und gab an, dessen Usurpation nur unter Druck akzeptiert zu haben. Seiner Argumentation verleiht zumindest Gewicht, dass einige Jahre später auch Maximos mit sehr konstruiert wirkenden Vorwürfen des Hochverrats angeklagt wurde. Martin wurde jedenfalls verurteilt und starb $655 \mathrm{im}$ Exil in Cherson auf der Krim. ${ }^{248} \mathrm{Zu}$ diesem Zeitpunkt war bereits sein Nachfolger Eugenius I. im Amt, der jedoch vom römischen populus daran gehindert wurde, Ekthesis und Typos zu ratifizieren. ${ }^{249}$

245 Vgl. Gilbert Dagron, Byzantinische Kirche und byzantinische Christenheit zwischen Invasionen und Ikonoklasmus (von der Mitte des 7. bis zum Beginn des 8. Jahrhunderts), in: Die Geschichte des Christentums, Mittelalter, Bd. 1: Bischöfe, Mönche und Kaiser (642-1054), ed. Gilbert Dagron, Pierre Riché und André Vauchez (Freiburg/Basel/Wien 2007) 3-96, hier 40-50.

246 Andreas N. Stratos, The exarch Olympius and the supposed Arab invasion of Sicily in AD 652, in: Jahrbuch der Österreichischen Byzantinistik, 25 (1976) 63-73. Stratos hat wahrscheinlich zu Recht die angeblichen Übergriffe der Sarazenen 652 in Zweifel gezogen. Sein Fazit, ebd. 73, enthält allerdings haarsträubende faktische Fehlinterpretationen der Überlieferung des Liber Pontificalis - er möchte die Vita Martins I. ins 9. oder gar 10. Jahrhundert datieren, leider in Unkenntnis des Faktums, dass die Vita spätestens (!) ab dem 8. Jahrhundert handschriftlich überliefert ist. Aus diesem Grund ist seiner Theorie letztlich nur eingeschränkt zuzustimmen.

$247 \mathrm{Zu}$ den Ereignissen in Rom siehe LP I, 336-338.

248 Meine Zusammenfassung folgt der ausführlichen Erörterung von Wolfram Brandes, „Juristische“ Krisenbewältigung im 7. Jahrhundert? Die Prozesse gegen Papst Martin I. und Maximos Homologetes, in: Fontes Minores X (Forschungen zur byzantinischen Rechtsgeschichte, 22, 1998) 141-212. Siehe dort für eine Fülle weiterer Details.

249 LP I, 341. 
Im Kontext dieser Ereignisse finden sich zwei interessante griechisch geschriebene Quellen, die den Begriff Graikoi verwenden. Zunächst fällt er in den Akten des römischen Konzils von 649, die zunächst auf Griechisch verfasst wurden und dann erst ins Lateinische übertragen wurden (was viel über den Einfluss kulturell griechischer Mönche und Priester auf dem Konzil aussagt). In den Akten werden die Hegumenoi von Klöstern aus Jerusalem, Afrika und Rom erwähnt:

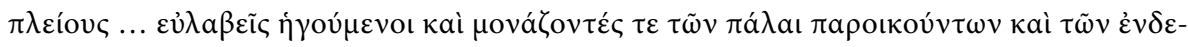

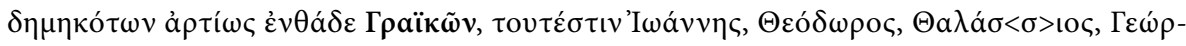

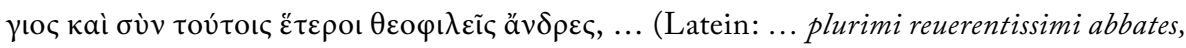
presbiteri et monachi Greci, tam per annos habitantes in hac Romana ciuitate, nec non in praesenti aduentantes, id est Iohannes, Theodorus, Thalassius, Georgius et cum ipsis alii uenerabiles uiri, ..... ${ }^{250}$

Jean-Marie Sansterre geht an dieser Stelle sogar davon aus, dass es sich bei der Bezeichnung Greci bzw. Граїкоเ um eine Selbstbezeichnung der Äbte handelte. Doch gerade davon ist nicht auszugehen, da wir diese Einstufung eben nur durch die Akten des Konzils überliefert haben.

Damit verbunden ist der Bericht über den Prozess Maximos' im Jahr 655, der von einem seiner Anhänger in der sogenannten Relatio motionis inter Maximum et principes aufgezeichnet wurde. ${ }^{251}$

Bei seiner Verhandlung wurde Maximos gefragt: „Warum liebst du die Römer und hasst die Griechen (hier: Граıкоúৎ, Graikous)?“, worauf der Mönch antwortete, er liebe die Römer, da sie für dieselbe Sache einstünden, er liebe aber auch die Griechen, da ihre Sprache auch die seine sei (homoglossous). ${ }^{252}$

250 Concilium Lateranense a. 649 (ed. Rudolf Riedinger, Acta conciliorum oecumenicorum, Series 2, Bd. 1, Berlin 1984) 48-49 (markierte Wörter durch mich). Siehe zu der Stelle: Jean-Marie Sansterre, Les moines grecs et orientaux à Rome aux époques byzantine et carolingienne (milieu du VI ${ }^{\mathrm{e}} \mathrm{s}$. - fin $\mathrm{du} \mathrm{IX}^{\mathrm{e}} \mathrm{s}$.), 2 Bde. (Académie royale de Belgique, Mémoires de la classe des lettres, Collection in- $8^{\circ}$, $2^{\mathrm{e}}$ série, 66, 1 [1983]), Bd. 1, 10-11 und 78. Zu den im Text erwähnten Personen siehe die PmbZ, Iohannes \# 3402, Bd. 2, 384 (,Ioannes [!], Abt der Sabaslaura bei Jerusalem'), Theodoros \# 7302, Bd. 4, 360f. (,Abt einer afrikanischen Sabas-Laura'), Thalassios \# 7253, Bd. 4, 328f. (,Abt des armenischen Klosters St. Renati in Rom') und Georgius \# 2284, Bd. 2, 26f. (,Abt des Kilikierklosters [Ad aquas Salvias] in Rom').

251 Relatio motionis inter Maximum et principes (ed. Pauline Allen/Bronwen Neil, Maximus the Confessor and his companions: documents from exile, Oxford Early Christian Texts, Oxford 2004) 48-74. Siehe Brandes, Krisenbewältigung, bes. 155, Anm. 90 und 92.

252 Sansterre, Moines, Bd. 1, 62-63 und Bd. 2, 115, Anm. 2. 
Es ist zu bezweifeln, dass die Relatio den genauen Wortlaut des Verfahrens wiedergibt, ja Wolfram Brandes hat sogar in Zweifel gezogen, ob der Text überhaupt auf der Grundlage eines Augenzeugenberichts oder gar von einem Augenzeugen selbst angefertigt wurde. ${ }^{253}$ Maximos Anhänger stammten wahrscheinlich hauptsächlich aus Ägypten und Afrika, also liegt hier in keinem Fall eine Verwendung des Begriffs als Selbstbezeichnung vor.

In beiden Fällen wurde Graikos offenbar vor allem verwendet, um in schwierigen Situationen Faktionen und Loyalitäten innerhalb des Römischen Reichs besser bestimmen zu können. Auch das intendierte Publikum der Relatio muss hier in Betracht gezogen werden: die Hochburgen der antimonotheletischen Bewegung lagen im Osten des Reichs (Syrien, Palästina), Nordafrika mit Ägypten und in Italien, allesamt Regionen, in denen ein Leser durchaus eher den Begriff Graikoi erwarten könnte als ein Leser aus dem Kerngebiet des Reichs in Kleinasien. Klar ist aber in jedem Fall, dass entsprechende Unterschiede durchaus wahrgenommen wurden, die auf diese Weise in dieser speziellen Situation offenbar am besten ausgedrückt werden konnten.

Die Affäre um Papst Martin I. stellte für das siebente Jahrhundert den Tiefpunkt der Beziehungen zwischen Rom und Konstantinopel dar - und sie wurde lange nicht vergessen, wie Quellenmaterial aus dem achten und neunten Jahrhundert klar belegt. Besonders interessant ist dabei ein umstrittener Brief Papst Gregors II. an Kaiser Leon III. Im Zuge der römischen Steuerrevolte schrieb der Papst:

Du terrorisierst uns indem Du sagst: ,Ich werde jemanden schicken, der das Bildnis des Heiligen Peter zerstört und ich werde Gregor, der dort Bischof ist, als Gefangenen fortführen lassen, so wie Konstantin [Konstans II. ${ }^{254}$ ] es mit Martin getan hat.' ... Wenn Du uns aber weiterhin trotzen solltest, so wie Du es sagst, und uns bedrohst, dann haben Wir keine andere Wahl, als gegen Dich zu kämpfen. Der Bischof von Rom wird sich nur drei Meilen zurückziehen, in die Kampanía, und dann - Viel Glück! - jage [in Rom] dem Wind nach. Bischof Martin, unser Vorgänger, hat eine Versammlung abgehalten und versuchte, Frieden zu stiften. Außerdem wurde er von dem verirrten Geist Konstantins, der sich im Irrtum bezüglich der Dogmen der Heiligen Dreifaltigkeit und im Fahrwasser der herätischen Bischöfe, der genannten Sergios, Paul und Pyrrhos befand, gefangen genommen

253 Brandes, Krisenbewältigung 155.

254 Kaiser Konstans II., der als Herakleios getauft worden war, trug eigentlich den offiziellen Thronnamen Konstantinos, auch seine Gesetze erließ er in diesem Namen. Konstans war lediglich sein Rufname, mit dem er aber in der Historiographie bezeichnet wurde. Vgl. Constans 2, in: Prosopography of the Later Roman Empire, ed. Arnold Hugh Martin Jones (3 Bde., Cambridge 1971-1992) Bd. 3,1, 333, und Ostrogorsky, Geschichte des Byzantinischen Staates 95. 
nach Byzanz gebracht, und, nachdem er dort in vielfacher Weise misshandelt worden war, ins Exil verbracht. ${ }^{255}$

Die beiden Briefe Gregors an Kaiser Leon sind stark interpoliert worden, doch einiges spricht dafür gerade die zitierte Passage aus dem ersten Brief als zeitgenössischen Textteil der $720 e r-J a h r e ~ z u$ betrachten. ${ }^{256}$ Insbesondere für eine Echtheit der Passage spricht, dass der Papst explizit davon ausgeht, dass ein Rückzug ins Gebiet des Dukats von Benevent eine ernsthafte Option ist. Das wiederum wäre nur in der speziellen Situation in den 720er- und 73oer-Jahren möglich gewesen. ${ }^{257}$

Auch im neunten Jahrhundert verschwand Martin nicht aus den Gedanken wichtiger Personen in Rom. Der berühmte Anastasius Bibliothecarius stellte ein umfangreiches Dossier zu ihm zusammen. ${ }^{258}$ Es existiert zudem auch eine auf Griechisch verfasste Vita Martins, die möglicherweis im Rom des achten Jahrhunderts verfasst wurde, eine genaue Einordnung scheint jedoch nicht möglich. ${ }^{259}$

Nach der Affäre rund um Papst Martin blieb das Verhältnis zwischen Rom und Kaiser Konstans II. gespannt. Der Kaiser kam schließlich 663 in den Westen und besuchte Rom. Es ist nicht völlig klar, wie freudig er dort empfangen wurde, aber er ordnete dort die Entfernung von einer Reihe kirchlicher Wertgegenstände an, unter anderem der Kupferschindeln vom Dach des Pantheon. Somit dürfte er auch den Rest seines Ansehens in Rom verspielt haben. ${ }^{260}$

Unter Konstans' Nachfolger Konstantin IV. wurde jedoch der Monotheletismus auf dem sechsten ökumenischen Konzil in Konstantinopel 680/68I verworfen, ja

255 Deutsche Übersetzung durch den Autor auf der Basis der französischen Übersetzung: Erster Brief Gregors II. an Leon III. (ed. Jean Gouillard, Aux origins de l'iconoclasme: Le témoignage de Grégoire II?, in: Traveaux et memoires, Centre de recherché d'histoire et de civilisation byzantines, 3 [1968]), 243-307, hier 294f., 11. 236-238 und 241-248.

256 Hans Grotz, S. I., Beobachtungen zu den zwei Briefen Papst Gregors II. an Kaiser Leo III., in: Archivum Historiae Pontificiae, 18 (1980) 9-40; und ders., Weitere Beobachtungen zu den zwei Briefen Papst Gregors II. an Kaiser Leo III., in: Archivum Historiae Pontificiae, 24 (1986) 365-375. Helmut Michels, Zur Echtheit der Briefe Papst Gregors II. an Kaiser Leon III., in: Zeitschrift für Kirchengeschichte, 99 (1988) 376-391, bringt eine Reihe diskussionswürdiger Bedenken vor, doch bis jetzt ist es nicht als bewiesen anzusehen, dass die oben zitierte Passage nicht aus der Zeit der Steuerrevolte stammt und dann für den gefälschten Brief wieder verwendet wurde. Michels, ebd., geht davon aus, dass die Fälschung im späten achten Jahrhundert entstand.

257 Siehe dazu ausführlicher unten, Kap. 5.1. mit Anm. 486.

258 Siehe Bronwen Neil, Seventh-Century Popes and Martyrs: The Political Hagiography of Anastasius Bibliothecarius (Studia Antiqua Australiensia, 2, Turnhout 2006). Ihre Ausgabe ist allerdings von Wolfram Brandes, in: Byzantinische Zeitschrift, 102, 2 (2010) 794-803, zu Recht kritisiert worden. 259 Neil, Seventh-Century Popes 106-109.

260 LP I, 343 (Papst Vitalian, 657-672). 
mehr noch, in den Akten des Konzils nahm der Papst den ersten Rang ein und auch seine Suffragane wurden sehr günstig gereiht. Als Wermutstropfen bliebt zwar, dass auch Papst Honorius als Unterstützer des Monotheletismus bezeichnet und mit Anathem belegt wurde, doch alles in allem war nun ein (letzter) Höhepunkt in den Beziehungen zu Konstantinopel erreicht. ${ }^{261}$

Doch zur großen Enttäuschung in Rom folgte schon 691/692 unter Justinian II. die sogenannte Trullanische Synode, die auch Quinisextum genannt wird, weil es ihr Ziel war, das fünfte und das sechste ökumenische Konzil vor allem um disziplinäre Kanones zu ergänzen. Da die Beschlüsse jedoch teilweise für Rom und den Westen inakzeptabel waren, weil sie der dortigen Praxis widersprachen, weigerte sich Papst Sergius I. (687-70I), die Akten zu unterzeichnen, ja er weigerte sich sogar, sie offiziell in Empfang zu nehmen. ${ }^{262}$ Daraufhin versuchte der Kaiser, den Papst wiederum festnehmen zu lassen, doch diesmal mit weit geringerem Erfolg:

Hierauf sandte er [Justinian II.] seinen brutalen protospatarius mit dem Befehl, den genannten Bischof ebenso in die kaiserliche Stadt zu bringen. Doch Gottes Barmherzigkeit kam ihm zuvor und der Heilige Petrus, Apostel und Apostelfürst, half ihm und rettete seine Kirche unversehrt. Die Herzen der ravennatischen Miliz wurden aufgeregt, und auch jene der Pentapolitani und der umliegenden Gebiete; sie wollten nicht erlauben, dass der Bischof des apostolischen Stuhls in die kaiserliche Stadt gehe. Als also von allen Seiten eine große Schar von Milizionären zusammenkam, erschrak der spatharius Zacharias sehr und weil der fürchtete, dass er von der Menschenmasse getötet werden könnte, schlug er vor, die Tore der Stadt zu schließen und den Bischof festzuhalten. Er selbst aber suchte vor lauter Furcht Zuflucht im Schlafgemach des Bischofs und bat diesen unter Tränen, sich seiner zu erbarmen und nicht zuzulassen, dass jemand sein Leben nähme. Die ravennatische Armee drang bewaffnet beim Peterstor in die Stadt ein, kam zum Bischofssitz in den Lateran, und brannte darauf, den Bischof zu sehen, denn es ging das Gerücht um, dass dieser bereits bei Nacht herausgeschmuggelt worden sei und auf ein Schiff gebracht worden sei. Da sowohl das obere als auch das untere Tor des Patriarchats geschlossen waren, drohten sie, beide niederzureißen, wenn sie nicht schnell geöffnet würden. In großer Furcht und

261 Siehe zum Beispiel Judith Herrin, Constantinople, Rome and the Franks in the seventh and eighth centuries, in: Byzantine Diplomacy: Papers from the Twenty-fourth Spring Symposium of Byzantine Studies, ed. Jonathan Shepard/Simon Franklin (Aldershot, 1992) 91-107, hier 97, und ead., Formation 275-280.

262 Noble, Republic 20-21. Siehe Concilium Quinisextum (ed. Heinz Ohme, Fontes Christiani, 82, Turnhout 2006) bes. die ausführliche Einleitung, sowie Heinz Ohme, Das Concilium Quinisextum und seine Bischofsliste: Studien zum Konstantinopeler Konzil von 692 (Arbeiten zur Kirchengeschichte 56, Berlin/New York 1990) bes. 1-76. 
verzweifelter Todesangst kroch der spatharius Zacharias unter das Bett des Bischofs um sich zu verstecken, gerade so, als ob er außer sich wäre und den Verstand verloren hätte. Der Heilige Papst tröstete ihn und sagte ihm, dass er nichts zu befürchten habe. ${ }^{263}$

Es ist ein unglaublich starkes Bild, das der LP hier transportiert: Die Milizen der mittelitalienischen Gebiete eilen dem Papst zur Hilfe, sodass sich der Spatharius Zacharias zunächst in die Gemächer des Papstes flüchten muss. Als die papstfreundlichen Truppen schließlich den Lateran erreichen, versteckt sich der Vertreter des Kaisers sogar, vor Angst ganz von Sinnen, unter dem Bett des Pontifex. Doch Sergius tröstet ihn und kann schließlich in der Folge auch verhindern, dass sich die Meute an Zacharias vergreift. Diese Episode zeigt, wie sehr sich das Blatt in Italien seit der Gefangennahme Martins gewendet hatte - sie begründet aber zugleich auch die Anspannung, die der Papst immer gegenüber dem Kaiser zeigte.

Die Kanones des Trullanums wurden trotz weiterer Verhandlungen auch unter den folgenden Päpsten in Rom wahrscheinlich nie voll akzeptiert, jedenfalls aber nicht zur Anwendung gebarcht. ${ }^{264}$ Das siebente Jahrhundert endete somit mit Streitigkeiten betreffend der religiösen Praxis, nachdem es auch politisch viel neues Misstrauen gegenüber dem Imperium gebracht hatte.

Die 72oer-Jahre brachten schließlich eine weitere wesentliche Entwicklung. Leon III. war seit 7 7 Kaiser. Es war ihm gelungen, die Belagerung Konstantinopels durch die umajjadischen Truppen zu beenden und die unmittelbare militärische Bedrohung für den Westen Kleinasiens abzuwenden, doch das Reich war dennoch einer

263 LP I, 373f.: Deinde Zachariam, inmanem suum protospatarium, cum iussione direxit ut praedictum pontificem similiter in regiam deportaret urbem. Sed misericordia Dei praeveniente beatoque Petro apostolo et apostolorum principe suffragante, suamque ecclesiam inmutilatam servante, excitatum est cor Ravennatis militiae, ducatus etiam Pentapolitani et circumquaque partium, non permittere pontificem apostolociae sedis in regiam ascendere urbem. Cumque ex omni parte multitutdo militiae conveniret, Zacharias spatarius perterritus et trepidans ne a turba militiae occideretur, portas quidem civitati claudi et teneri pontificem postulabat. Ipse vero in cubiculo pontificis tremebundus refugiit, depraecans lacrimabiliter ut sui pontifex miseretur nec permitteret quemquam eius animae infestari. Exercitus autem Ravennatis ingressus per portam beati Petri apostoli cum armis et tuba, in Lateranense episcopio venit, pontificem videre aestuans quem fama vulgante per nocte sublatum et in navigio missum fuisse cognoverunt. Dumque fores patriarchii, tam inferiores quamque superiores, essent clause, et has in terra, nisi citius aperirentur, mittere minarentur, prae nimia timoris angustia et vite disperatione, Zacharias spatarius sub lecto pontificis ingressus sese abscondit, ita ut mente excederet et perderet sensum. Quem beatissimus papa confortavit, dicens nullomodo timere.

264 Judith Herrin, The Quinisext Council (692) as continuation of Chalcedon, in: Chalcedon in Context. Church Councils 400-700, ed. Richard Pryce/Mary Whitby (Translated Texts for Historians, Contexts 1, Liverpool 2009) 148-168, bes. 160-163, geht davon aus, dass Papst Konstantin I die Kanones des Quinisextums bei seinem Besuch in Konstantinopel 710 weitestgehend akzeptiert hat. Demgegenüber geht Noble, Republic 20f. eher von einem für beide Seiten tragbaren Kompromiss aus. 
massiven Bedrohung ausgesetzt. In dieser Situation beschloss der Kaiser, die nicht von den Angriffen der Sarazenen betroffenen Gebiete höher zu besteuern. Doch diese Steuer wollte Papst Gregor II. nicht akzeptieren, schließlich hatte Rom in Zeiten der Bedrohung in den letzten Jahren auch nicht auf die Hilfe der kaiserlichen Truppen zählen können. Gregor kann man dabei nicht als besonders kaiserfeindlich einstufen. Er war einer der wichtigsten Berater seines Vorgängers Konstantin gewesen und hatte im Zuge dessen auch der Delegation angehört, die 7 ro in Konstantinopel mit Kaiser Justinian ein Übereinkommen getroffen hatte. ${ }^{265}$ Kaiser Leon wurde in Rom zudem zunächst sehr positiv gesehen - zumindest wesentlich besser als Philippikos Bardanes, der der kurzzeitige Vorvorvorgänger Leons als Kaiser gewesen war (7 I I713) und versucht hatte den Monotheletismus wiederzubeleben, weshalb er von Rom ausdrücklich nicht anerkannt worden war. ${ }^{266}$ Im Zuge der Unstimmigkeiten sprach sich Gregor auch deutlich gegen die Erhebung eines Usurpators in Italien aus. ${ }^{267}$

Der Versuch, Rom stärker zu besteuern, führte jedenfalls zu offenem Widerstand des Papstes, der auch Briefe versandte, in denen er andere Untertanen des Kaisers in Italien dazu aufrief, es ihm gleichzutun. ${ }^{268}$ Dieses Verhalten zog nun physische Auseinandersetzungen nach sich. ${ }^{269}$ Zunächst wurden diese in Rom selbst geführt, wo ein Versuch unternommen wurde, den Papst gefangenzunehmen, oder, wenn wir dem LP glauben wollen, ihn sogar zu töten:

Einige Zeit später fassten der dux Basilius, der chartularius Jordannes und der Subdiakon Johannes, genannt Lurion, den Plan den Bischof zu töten. Der imperiale spatharius Ma-

265 LP I, 389: Gregorius diaconus. Siehe Kommentar von Duchesne, LP I, 394, n. 9.

266 LP I, 391f.

267 LP I, 408, in der jüngeren Version der Vita Gregors II. Zu den Versionen der Vita Gregors II. siehe oben, Kap. 1.1.3.1.

268 So der LP I, 404, wo diese Vorgehensweise allerdings schon (anachronistsisch) mit dem Ikonoklasmus in Verbindung gebracht wird.

269 Die beste Darstellung des Steuerstreits findet sich in Wolfram Brandes, Finanzverwaltung in Krisenzeiten: Untersuchungen zur byzantinischen Administration im 6.-9. Jahrhundert (Forschungen zur byzantinischen Rechtsgeschichte 25, Frankfurt am Main 2002) 368-384. Paul Speck, Kaiser Leon III., die Geschichtswerke des Nikephoros und des Theophanes und der Liber Pontificalis: Eine

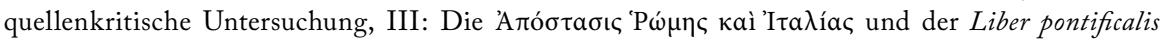
(Bonn 2003) 553-571, hat die Auseinandersetzungen sogar als „Römischen Steuerkrieg“ bezeichnet, was vielleicht sogar passend wäre, angesichts der bewaffneten Auseinandersetzungen, die folgten. Specks Arbeit ist allerdings als äußerst umstritten zu bezeichnen und sollte nur mit erhöhter Vorsicht benutzt werden, besonders wenn er sich über die Vorgänge im Westen äußert. Konkret neigte er dazu, die vorhandenen Quellen in Bausch und Bogen als Fälschungen zu bezeichnen oder in spätere Zeiten zu datieren. Belege dafür blieb er aber weitgehend schuldig, in manchen widerlegt ihn sogar die handschriftliche Überlieferung von Quellen. 
rinus, der von der kaiserlichen Stadt mit einem ebensolchen Befehl des Kaisers [nach Rom] geschickt worden war und den Rang des $d u x$ von Rom innnehatte, stimmte dem Plan zu. Doch sie konnten nicht den richtigen Zeitpunkt dafür finden. ... Später wurde der patricius Paul als Exarch nach Italien geschickt und wieder dachten sie darüber nach, das Verbrechen auszuführen. ${ }^{270}$

Obwohl Offizielle in Rom, einer davon, Johannes Lurion, sogar Mitarbeiter im Lateran, den Papst zu töten planen, lässt der LP keinen Zweifel daran, von wem dieser Plan sanktioniert wurde - von den Vertretern des Kaisers. Der Spatharius Marinus hat sogar den Auftrag des Kaisers, den Papst ermorden zu lassen. Der Plan wird jedoch aufgedeckt, Johannes und Iordannes werden hingerichtet und der $d u x$ Basilius ins Kloster geschickt. ${ }^{271}$

In der Folge versucht der neue Gesandte des Kaisers, der patricius und ehemalige Exarch Eutychius, militärisch gegen Rom vorzurücken, scheitert jedoch am Widerstand der Langobarden, die den Dukat von Rom verteidigen. ${ }^{272}$ Dann jedoch geling es Eutychius, den Langobardenkönig Liutprand auf seine Seite zu ziehen, der auch nach Rom vorrückt, dort jedoch nicht militärisch vorgeht, sondern in Verhandlungen mit Gregor II. erreicht, dass sich dieser wiederum zu Verhandlungen mit dem patricius bereit erklärt. ${ }^{273}$

Tatsächlich verhielt sich Gregor II. 729 wieder loyal zum Kaiser - es dürfte also eine Art Übereinkommen getroffen worden sein, mit dem beide Seiten zufrieden sein konnten. ${ }^{274}$

Sehr häufig wird angenommen, der Kaiser habe dem Papst im Zuge der Auseinandersetzung die Patrimonien auf Sizilien entzogen, doch jüngste Studien argumen-

270 LP I, 403, hier zitiert in der älteren Fassung der Vita: Post aliquod Basilius dux, Iordannes chartularius et Iohannis subdiaconus cognomento Lurion consiliuum inierunt ut pontificem interficerent; quibus assensum Marinus imperialis spatharius qui Romanum ducatum tenebat a regia missus urbe, imperatore mandante hoc, praebuit. Sed tempus invenire non poterunt... Postmodum Paulus patricius exarchus missus in Italia; qui denuo ut scelus perficerent mediabat. Zu den genannten kaiserlichen und päpstlichen Beamten siehe Brown, Gentlemen, Basilius ${ }^{2}$, Iordanes, Marinus ${ }^{2}$ und Paulus ${ }^{1}$, sowie 180; Salvatore Cosentino, Prosopografia dell'Italia bizantina (493-804), Bd. 1 (Bologna 1996), Basilius ${ }^{22}$, 204; ebd., Bd. 2 (Bologna 2000), Iohannes ${ }^{274}$,Lurion', 203, Iordannes ${ }^{1}$, 221, Marinus ${ }^{14}$, 336; PmbZ, Basilius \# 978, Bd. 1, 320, Marinus \# 4817, Bd. 3, 174 und Paulos \# 5815, Bd. 3, 531f.

271 LP I, 403.

272 LP I, 405f. Zur Verwicklung der Langobarden in den Steuerstreit siehe unten, Kap. 5.1. Zu Eutychius siehe Brown, Gentlemen, Eutychius ${ }^{1}$ und vor allem Cosentino, Prosopografia, Bd. 1, 427-429: Eutychius?.

273 LP I, 407f., wobei es hier hilfreich ist, die jüngere Version der Vita (in der rechten Spalte gedruckt) zu benutzen.

274 Brandes, Finanzverwaltung 375. 
tieren, dass diese Güter erst in den 75oer-Jahren entzogen wurden. Möglicherweise waren sie sogar Teil eines Abkommens zwischen Papst Stephan II. und Kaiser Konstantin V., das die Streitigkeiten rund um Ravenna beilegen sollte. ${ }^{275}$ Das heißt, dass wohl nicht die Übergabe von Sizilien den Streit beigelegt haben kann. Doch im achten Jahrhundert verlor der Papst auch die kirchliche Oberhoheit über die Provinz Illyricum, die dem Patriarchen von Konstantinopel unterstellt wurde. Hier ist eine Datierung auf spätere Zeiten weniger leicht zu belegen, man könnte also spekulieren, dass eine Übergabe dieser Gebiete einen Teil des Ausgleichs mit dem Kaiser ausgemacht haben könnte.

Doch bereits kurze Zeit, vielleicht wenige Monate später kamen neue unangenehme Nachrichten aus dem Osten. Dort war eine Kontroverse über die Rolle der Bilderverehrung ausgebrochen und der Kaiser spielte darin eine Rolle. ${ }^{276}$ In Rom dürfte man überhaupt nur über diffuse Informationen verfügt haben. Die LP-Vita Gregors II. beschreibt schon das Auftreten des Papstes gegen diese Vorgänge, vermischt aber zweifellos Ereignisse des Steuerstreits, den der Autor nur sehr ungern erwähnt, mit dem offenbar als viel edler angesehenen päpstlichen Vorgehen gegen die dogmatischen Unstimmigkeiten. ${ }^{277}$ Die Vita Gregors II. wurde zwar zweifellos schon zu seinen Lebzeiten begonnen, sie wurde aber wahrscheinlich, wie fast alle Viten des LP, erst unter seinem Nachfolger fertiggestellt. ${ }^{278}$ Und die beiden Briefe Gregors II. an den Kaiser wurden zumindest sehr stark interpoliert und dürften ursprünglich

275 Siehe Brandes, Finanzverwaltung 368-384 und Albrecht Graf Finck von Finckenstein, Rom zwischen Byzanz und den Franken in der ersten Hälfte des 8. Jahrhunderts, in: Festschrift für Eduard Hlawitschka zum 65. Geburtstag, ed. Karl Rudolph Schnith/Roland Pauler (Münchner historische Studien, Abteilung Mittelalterliche Geschichte, 5, München 1993) 23-36, hier 26-30. Die Chronik des Theophanes Confessor ist die einzige Quelle, die die Wegnahme der Partimonien schon in die frühen 730er-Jahre datiert. Speck, Leon III, Bd. 3, 529-551, hat die Darstellung der Ereignisse durch Theophanes in fast jeglicher Hinsicht in Zweifel gezogen und könnte in diesem Fall durchaus Recht behalten. Siehe auch Wolfram Brandes, Pejorative Phantomnamen im 8. Jahrhundert: Ein Beitrag zur Quellenkritik des Theophanes und deren Konsequenzen für die historische Forschung, in: Zwischen Polis, Provinz und Peripherie. Beiträge zur byzantinischen Geschichte und Kultur, ed. Lars M. Hoffmann/Anuscha Monchizadeh (Mainzer Veröffentlichungen zur Byzantinistik, 7, Wiesbaden 2005) 93-125, hier 121f., mit Anm. 102.

276 In der neuesten Darstellung von Brubaker/Haldon, Byzantium, kommen die Autoren zu dem Schluss, dass tatsächlich etwas in Konstantinopel und Kleinasien passiert war und dass sich die Diskussion um die Rolle der Bilder in den Kirchen drehte. Demgegenüber gab es aber keinen organisierten Ikonoklasmus (also eine systematische Zerstörung von Bildern), was bisher meist angenommen wurde.

277 LP I, 404-410.

278 Zur Vita Gregors II. vgl. oben, Kap. 1.1.3.1. 
nichts mit dem Ikonoklasmus zu tun gehabt haben. ${ }^{279}$ Der damit verbundene Brief, den der Papst angeblich an den Patriarchen Germanos schickte, gilt überhaupt als gefälscht beziehungsweise als fälschlich Gregor II. zugeschrieben. ${ }^{280}$

Doch Gregor III. reagierte jedenfalls auf den beginnenden Ikonoklasmus, indem er am r. November 73I eine Synode in Rom einberief. Die Akten sind nicht überliefert, aber alles deutet darauf hin, dass auf der Synode Aktionen gegen die Bilderverehrung verdammt wurden. ${ }^{281}$ Der Papst versuchte mehrmals die Entscheidungen dem Kaiser zustellen zu lassen, seine Gesandten wurden jedoch laut LP immer wieder aufgehalten. ${ }^{282}$

Nach dieser ersten aufgeregten Phase beruhigten sich zunächst noch einmal die Gemüter. Doch 754 berief Konstantin V., der 74I seinem Vater nachgefolgt war und seit 743 unangefochten regierte, das Konzil von Hiereia (ein Vorort Konstantinopels auf der asiatischen Seite des Bosporus) ein, auf dem die ikonoklastische Theorie formuliert wurde. Auch danach wurden aber nicht im Wortsinn Bilder verbrannt, sondern es wurden allzu prominent platzierte Ikonen verdeckt, einige allerdings auch übermalt. Einige Mosaiken wurden entfernt. Auch die Zahl der Menschen, die im Zuge der Auseinandersetzungen ums Leben kamen, ist zumindest als sehr niedrig einzuschätzen. ${ }^{283}$

Zur Zeit herrscht in der Forschung der durchaus berechtigte Trend, die Auswirkungen des ersten Ikonoklasmus ${ }^{284}$ im achten Jahrhundert als relativ gering einzustufen. Doch für die Päpste war das Konzil von 754 der letzte nötige Schritt, der die Beziehungen zum Kaiser endgültig zum Schlechten wendete. Zusammen mit der andauernden Ineffektivität des kaiserlichen Schutzes in Italien führte die Situation der 75 oer zu einer gründlichen Neubewertung der Beziehungen unter den Bruderpäpsten Stephan II. und Paul I., wie unten in Kapitel 4 ausgeführt wird. Auch vonseiten Konstantinopels scheinen sich die Beziehungen abgekühlt zu haben. ${ }^{285}$

279 Vgl. oben in diesem Kapitel zur Rezeption Papst Martins in dem Brief und bes. Anm. 256.

280 Zur Thematik ausführlich Gouillard, Aux origines, der jedoch auch die beiden Briefe an Leon III. als völlig gefälscht betrachtet und somit nicht wie Grotz (oben, Anm. 256) von einer tatsächlich zeitgenössischen aber verfälschten Grundlage dieser beiden Briefe ausgeht.

281 Siehe Thomas F. X. Noble, Images, Iconoclasm and the Carolingians (Philadelphia 2009) $118 f$.

282 LP I, $416 f$.

283 Noble, Images 60-68.

284813 kam es zu einer Neuaufnahme der ikonoklastischen Lehren durch Kaiser Leon V., die bis 843 andauerte. Daher spricht man vom ersten Ikonoklasmus vor dem Konzil von Nicäa und vom zweiten Ikonoklasmus im neunten Jahrhundert.

285 Die durchaus kargen Quellen zeigen, dass die Kommunikation zwischen Konstantin V. und den Päpsten ab den 750ern deutlich zurückging. Siehe Regesten der Kaiserurkunden des oströmischen Reichs, 1, 1, ed. Franz Dölger/Andres E. Müller (München ${ }^{2} 2009$ ) 165-176. Nach ebd., 170, Nr. 


\subsubsection{Greci als kulturelle und soziale Kategorie}

Nachdem nun die Ausgangslage zwischen Konstantinopel und Rom und die gegenseitige Wahrnehmung bereits angesprochen wurde, sollte eine genaue Analyse der Situation im päpstlichen Rom des achten Jahrhunderts selbst erfolgen. Doch bevor dieser sehr spezielle Fall genau untersucht werden kann, ist es unabdingbar, das dafür benötigte Instrumentarium zu schärften. Zu diesem Zweck gilt es zu klären, welche Art von Kategorie „Griechen“, also Greci und auch „griechisch“ im Westen und in Rom selbst sein konnte.

Zunächst scheint es logisch, vor allem von der griechischen Sprache als entscheidendem Faktor auszugehen, so wie interessanterweise etwa Jean-Marie Sansterre in seiner meisterlichen Studie über die "griechischen“ Klöster ${ }^{286}$ immer wieder, allerdings implizit, angenommen hat. ${ }^{287}$ Und tatsächlich ist die griechische Sprache ein wesentliches Unterscheidungsmerkmal, so wie Sprache generell ein wesentliches Element bei der Bildung von Identitäten darstellt. ${ }^{288}$ Und wir haben ja oben in Kapitel 3.2.2 auch einen Fall gefunden, als in der sogenannten Relatio motionis, einer Quelle aus dem Umfeld des Maximos Homologetes, explizit die Sprache als wesentliches Element der "Gräzität" des angeklagten Maximos herangezogen wurde.

Und doch ist die Sprache, wie wir sehen werden, nur eines von einer Vielzahl von Elementen, die die griechische Identität ausmachten - ganz besonders was das frühmittelalterliche Italien betrifft. Thomas Granier nachgewiesen, dass im Neapel des zehnten Jahrhunderts eine ostentative griechische Seite der Identität von Individuen vor allem dafür verwendet wurde, einen bestimmten sozialen Status auszudrücken. So gibt es eine Vielzahl von Urkunden, auf denen eine Reihe von Subskribenten, manchmal sogar alle von ihnen, in Griechischer Unziale unterfertigten. Nebenbei sei bemerkt, dass diese Schrift zu dieser Zeit im Osten bereits von der neuen griechischen Minuskelschrift abgelöst worden war. ${ }^{289}$ Das Interessante an diesen griechischen

318, ist überhaupt kein Beweis einer direkten Kommunikation mehr erhalten, bis schließlich 784 die berühmte Kontaktaufnahme Kaiserin Eirenes mit Papst Hadrian zum Zweck der Planung des zweiten Konzils von Nicäa verzeichnet ist, ebd., 180f., Nr. 343 und 344.

$286 \mathrm{Zu}$ einer Definition hiervon kommen wir dann in Kap. 3.2.4.

287 Sansterre, Moines: es ist kaum möglich hier eine spezielle Seite anzugeben, dieser Eindruck bezieht sich auf das Gesamtwerk, besonders Band 1.

288 Walter Pohl, Telling the difference: Signs of ethnic identity, in: Strategies of Distinction. The Construction of Ethnic Communities, 300-800, ed. Walter Pohl/Helmut Reimitz (The Transformation of the Roman World, 2, Leiden/Boston/Köln 1998) 17-69, bes. 64.

289 Über diese Schrift siehe Cyril Mango, L’origine de la minuscule, in: La paléographie greque et Byzantine (Colloques Internationales du Centre Nationale de la Recherche Scientifique [CNRS] 559, Paris 1977) $175-180$. 
Unterschriften in der antiquierten Schrift ist aber, dass die so unterzeichnenden Individuen offenbar in so gut wie allen Fällen kaum Griechisch konnten. Sie machten auffällige Fehler, bisweilen finden sich sogar gänzlich lateinische Ausdrücke einfach in griechischen Buchstaben wiedergegeben. Die griechische Schrift war daher in Neapel keineswegs ein Ausdruck davon, dass die Muttersprache dieser Personen das Griechische gewesen ist, vielmehr war die Verwendung der griechischen Schrift ein Ausdruck einer bestimmten Identität. So war es für Mönche in bestimmten Klöstern und für Personen auf bestimmten Machtpositionen unabdingbar, auf Griechisch zu unterschreiben. ${ }^{290}$

Nun ist es aus methodischen Gründen nur schwer möglich, die Ergebnisse Graniers für das zehnte Jahrhundert auf das achte zu übertragen. Wir können bei aller Vorsicht eher davon ausgehen, dass die griechische Sprache in Neapel zweihundert Jahre zuvor noch eine wesentlich wichtigere Rolle gespielt hatte. Noch schwieriger ist es dann, die Ergebnisse aus Neapel auf Rom zu übertragen, doch man muss sicherlich in Betracht ziehen, dass Greci auch in Rom eine soziale Kategorie gewesen sein könnte. Es ist sogar wahrscheinlich, dass der Terminus auch diese Form der Identifizierung miteinschloss. Doch kann diese Art von Kategorie im Prinzip ausschließlich für aus Italien stammende, möglicherweise sogar nur für schon länger in Rom verwurzelte "Griechen“ gegolten haben. Doch als „Griechen“ wurden, wie wir in Kapitel 4 sehen werden, auch die Menschen bezeichnet, die im Osten, in den Kernregionen des Oströmischen Reichs, lebten. Insbesondere wurden dabei auch Repräsentanten des Kaisers miteingeschlossen, der Kaiser selbst allerdings höchstens implizit - es gab keinen imperator Grecorum. Es gab also aus römischer Sicht zwei Arten von Griechen, nämlich erstens die „Italo-Griechen“ und zweitens die Greci aus Kleinasien. Diese beiden Gruppen waren wechselseitig wahrscheinlich nicht völlig exklusiv, wenn wir etwa an Sizilien denken oder an die vielen neu nach Westen gekommenen Menschen aus dem Osten. Dennoch wird man die beiden Gruppen immer wieder unterscheiden müssen, da sie in den Quellen meist unterschiedlich behandelt wurden. Auch ihre eigenen Identitätsressourcen waren durchaus unterschiedlich.

Wir können uns dieser Frage wieder über das Element der Sprache annähern. Für beide Gruppen gilt, dass die Sprache ein wesentliches Unterscheidungsmerkmal darstellte. Eine unterschiedliche Muttersprache oder zumindest eine unterschiedliche

290 Thomas Granier, Les moines „grecs“ de Saints-Serge-et-Bacchus et Saints-Théodore-et-Sébastien dans la société napolitaine des VII ${ }^{\mathrm{e}}-\mathrm{XII} \mathrm{e}^{\mathrm{e}}$ siècles, in: Vivre en société au Moyen Âge. Occident chrétien $\mathrm{VI}^{\mathrm{e}}-\mathrm{XV}$ e siècle, ed. Claude Carozzi/Daniel Le Blévec/Huguette Taviani-Carozzi (Aix-en-Provence 2008) 197-218. 
Kultursprache war zweifellos ein wesentliches Merkmal. ${ }^{291}$ Doch die linguistische Differenz alleine reicht wohl nicht aus, um die Unterschiede zwischen lateinischsprachigen Römern Mittelitaliens und den Greci zu erklären.

Die Quellen des achten Jahrhunderts zeigen viel mehr eine kulturelle Bruchlinie zwischen dem Westen und dem Osten beziehungsweise zwischen Lateinischsprachigen und „Griechen“. Diese Trennung existierte auch schon vor der kulturellen „Byzantinischen Renaissance“292 des ausgehenden achten und neunten Jahrhunderts, als die Lektüre der griechischen Klassiker wieder mehr geschätzt und stärker forciert wurde. Schon im achten Jahrhundert hatten ein Romaios aus Konstantinopel und ein Romanus aus Rom sehr unterschiedliche kulturelle Hintergründe. Es mag sogar sein, dass es heute nicht mehr möglich ist, das volle Ausmaß dieser Bruchlinie zu ermessen. ${ }^{293}$ Dieser Unterschied wurde in der ekklesiastischen Sphäre wohl am deutlichsten, wo es zunächst unterschiedliche Liturgien gab. Zudem war auch die Literatur unterschiedlich, in dem Sinne, dass es etwa unterschiedliche maßgebliche Kirchenväter und generell einen anderen Kanon von Texten gab, die ein gut ausgebildeter Kleriker kennen musste.

Klar ist, dass diese Unterscheidung nur in geringerem Ausmaß für die Italo-Griechen gegolten haben kann. Für sie können wir von einer Art „Mischform“ ausgehen, die zwar etwa eine griechisch geprägte Bildung, aber dafür einen „römischeren“ Zugang zum täglichen Leben bedeutet haben mag. ${ }^{294}$ Wiederum können wir davon

291 Sansterre, Moines, Bd. 1, 62-76. Der Faktor Sprache könnte jedoch in einem monastischen Umfeld eine bedeutendere Rolle gespielt haben als etwa unter Weltklerikern oder Laien.

292 Der Terminus bezieht sich hier auf die kulturelle Aufbruchsbewegung, vor allem im Zentrum des Reichs in Kleinasien, die bereits im achten Jahrhundert begann und im neunten Jahrhundert eng mit dem Patriarchen Photios verknüpft ist.

293 Im neunten Jahrhundert war besonders in der literarischen Elite des Ostens der kulturelle Hintergrund und der historische Hintergrund (zumindest so wie er wahrgenommen wurde) sehr griechisch, siehe die pointierte Zusammenfassung von Demetrios J. Constantelos, Christian Hellenism and How the Byzantines Saw Themselves, in: The National Herald, 12. September 2004: „... the history they remembered and the history they studied was that of the ancient Greeks ..., the image they possessed of themselves had been molded by the language they spoke, the literature they read ... and the physicians and scientists they studied ... from ancient times to their times." Siehe auch Demetrios J. Constantelos, Christian Hellenism: Essays and Studies in Continuity and Change (Studies in the social and religious history of the mediaeval Greek world, 3, New Rochelle 1998) und Tinnefeld, Abendland.

294 So waren etwa auch im ekklesiastischen Bereich tätige kulturell griechische Menschen bis zu einem gewissen Grad den Regelungen des Papstes unterworfen. Und dennoch wurden sie als Andere wahrgenommen: Sansterre, Moines, Bd. 1, 111, schreibt über die griechischen Mönche in Rom: „Différentes par leurs coutumes, leurs rites et surtout leur langue, les cénobites ,grecs‘ furent séparés de leurs confrères latins sur le plan institutionnel, très vraisemblablement dès le VII e s." Unglücklicherweise geht er nicht auf den von ihm vorgebrachten unterschiedlichen Habit ein, klar ist aber dass sich die "Griechen“ in vielerlei Hinsicht unterschieden. 
ausgehen, dass die griechische kulturelle Prägung von in Rom lebenden Menschen im monastischen Bereich höher gewesen sein dürfte als in anderen Lebenswelten.

Die kulturelle Trennung umfasste, wie gezeigt, neben der linguistischen Ebene eine ganze Reihe von Bildungsfeldern und Elementen des täglichen Lebens sowie des persönlichen Erfahrungshorizonts. Diese Trennung war der wesentliche Faktor in der päpstlichen Prägung des Begriffs Greci. Aus diesem Grund wird in der vorliegenden Arbeit auch häufig die Bezeichnung „kulturell griechisch“ verwendet. Dieser etwas sperrige Hilfsausdruck soll zeigen, dass der Terminus „Griechen“ eine Vielzahl von Personen mit verschiedensten individuellen Hintergründen zusammenfassen muss.

Im Folgenden widmet sich die vorliegende Arbeit den „Griechen“ in der Stadt Rom. In dem Abschnitt wird von Griechen die Rede sein, und zwar nunmehr ohne Anführungszeichen. Dennoch sei noch einmal darauf verwiesen, dass es sich bei diesen Griechen um „Menschen aus dem Osten des Reichs beziehungsweise aus dem Süden der italienischen Halbinsel“ handelte, die aus sehr unterschiedlichen Regionen stammten. Sie konnten und können aber als Griechen in einem kulturellen Sinn bezeichnet werden. ${ }^{295}$

\subsubsection{Die römischen Griechen ${ }^{296}$}

Wir haben bereits gesehen, dass die Ereignisse des siebenten Jahrhunderts die Beziehungen zwischen Rom und Konstantinopel deutlich verkompliziert hatten. Es ist umso interessanter, dass just in dieser kritischen Phase das römische Bischofsamt zumeist von zumindest nominell aus dem griechischen Bereich des Reichs stammenden Männern bekleidet wurde. Schon Mitte des siebenten Jahrhunderts gab es mit Papst Theodor I. (642-649) einen wesentlichen Papst, der vom LP als natione Grecus eingestuft wird, aber aus Jerusalem stammte ${ }^{297}$ - ein weiterer Beleg, dass Grecus sich zumindest nicht auf eine regionale Herkunft bezog. Theodor war immerhin Vordenker des gegen den Montheletismus gerichteten Laterankonzils, wenn er auch

295 Sansterre, Moines, Bd. 1, 13, schreibt bezüglich des Klosters, das in den Quellen Renati genannt wird: „Bien qu'ils fuissent rangés parmi les Гpaıko - une appellation générique en l'occurrence - les nouveaux occupants étaient des Arméniens.“ Siehe auch McCormick, Origins 224: „The Greek population in Rome was a very cosmopolitan group indeed."

296 In Gantner, Greeks, verwendet der Verfasser an dieser Stelle den Hilfsausdruck Easterners, der zwar anachronistisch ist, aber die Heterogenität in Rom gut zum Ausdruck bringt. Die deutsche Entsprechung „Ostler“ wirkt jedoch unpassend.

297 Siehe dazu auch Duchesne, LP I, 333, Anm. 1: Die Formulierung des LP ist an dieser Stelle verwirrend, es könnte auch gemeint sein, dass der Vater Theodors, der denselben Namen trug, aus Jerusalem stammte. 
die Durchführung nicht mehr erlebte. In den Jahren 678 bis $75 \mathrm{I}$ kam es schließlich zu einer fast vollständigen Dominanz „östlicher“ Päpste. Von 683/684 bis 685 gab es mit Benedikt II. einen aus Rom stammenden Papst und von 715-73I herrschte Gregor II., vom LP ebenfalls als natione romanus eingestuft. Daneben gab es im genannten Zeitraum von über 7o Jahren noch i I Päpste aus dem griechischen Kulturbereich, die jedoch nach Herkunft aufgeschlüsselt wurden (siehe Tabelle I). Es finden sich darunter vier Syrer, drei Greci und zwei Sizilianer. Dazu kommt noch Papst Conon, über den berichtet wird, sein Vater sei Thraker gewesen, er aber auf Sizilien aufgewachsen. Auch nicht klar zuordenbar ist Papst Sergius, der vielleicht wesentlichste Papst des ausgehenden siebenten Jahrhunderts. Er wird als Syrus aus der Gegend von Antiochia bezeichnet, der aber auf Sizilien aufgewachsen sei. Wie wir aus diesen Kategorisierungen leicht erkennen können, war die Zugehörigkeit zu einer dieser Gruppen, vor allem was Syrer und Sizilianer betrifft, keineswegs trennscharf. Das Ende dieser langen Reihe kam 752, als nacheinander die „lateinischen“ Römer Stephan II. und Paul I. auf den Papstthron kamen. Danach folgte für ein Jahr der später nicht anerkannte Konstantin II., bevor Stephan III. Papst wurde. Er wird als natione Siculus bezeichnet ${ }^{298}$, ist also wohl auch der "griechischen“ Fraktion zuzuordnen.

Kurz zu Sizilien: Die Insel wurde spätestens im Lauf des siebenten Jahrhunderts stark gräzisiert, unter anderem durch Zuwanderer aus dem Osten, die entweder vor der arabischen Expansion oder vor den religiösen Repressionen in Kleinasien geflohen waren. Die Insel zählte auch von der Verwaltung her größtenteils zur griechischen Sphäre des Mittelmeers. Allerdings gab es zunächst noch große Besitzungen der römischen Kirche auf Sizilien und sicherlich noch eine Minderheit unbestimmter Größe mit lateinischer Muttersprache. ${ }^{299}$ Doch man muss nur den Umstand in Betracht ziehen, dass die Gräzisierung Kalabriens im neunten und zehnten Jahrhundert fast ausschließlich von Sizilien aus erfolgte, um erahnen zu können, wie "griechisch“ die größte Insel des Mittelmeers dann war. ${ }^{300}$ Alles in allem kann man also davon ausgehen, dass die sizilianischen Päpste einen kulturell griechischen Hintergrund hatten. In diesem Sinne wäre Stephan III. wahrscheinlich der letzte "griechische“ Papst und nicht Zacharias, von dem das immer wieder behauptet wird. ${ }^{301}$

298 LP I, 468.

299 Cosentino, Italia bizantina 72-75.

300 Cosentino, Italia bizantina 327.

301 Auch Sansterre, Moines, Bd. 1, 81 und Filippo Burgarella, Presenze greche a Roma. Aspetti culturali e religiosi, in: Roma fra oriente a occidente (Settimane di studio del Centro italiano di studi sull'Alto Medioevo, 49, Spoleto 2002) 943-992, hier 945, kommen zu diesem Schluss. 
Tabelle I: natione-Kategorie des Liber Pontificalis, 625-795

\begin{tabular}{|c|c|c|}
\hline Papst & Pontifikat & Herkunft nach LP; I 323-386 und II I. \\
\hline Honorius I. & $625-638$ & natione Campanus \\
\hline Severinus & 640 & natione Romanus \\
\hline Johannes IV. & $640-642$ & natione Dalmata \\
\hline Theodor I. & $642-649$ & natione Grecus, ex patre Theodoro episcopo de civitate Hierusolima ${ }^{302}$ \\
\hline Martin I. & $649-653 / 5$ & de civitate Tuderina provincie Tuscie ${ }^{303}$ \\
\hline Eugenius I. & $654-657$ & natione Romanus, de regione prima Aventinense \\
\hline Vitalian I. & $657-672$ & natione Signensis, provincia Campania \\
\hline Adeodatus & $672-676$ & natione Romanus \\
\hline Donus & $676-678$ & natione Romanus \\
\hline Agatho & $678-68 \mathrm{I}$ & natione Sicula \\
\hline Leo II. & $68 \mathrm{I}-683$ & natione Sicula \\
\hline Benedikt II. & $683 / 4-685$ & natione Romanus \\
\hline Johannes V. & $685-686$ & natione Syrus \\
\hline Conon & $686-687$ & oriundus patre Thraceseo, edocatus apud Siciliam \\
\hline Sergius I. & $687-701$ & natione Syrus, Antiochiae regionis, ortus ... in Panormo Siciliae \\
\hline Johannes VI. & $701-705$ & natione Grecus \\
\hline Johannes VII. & $705-707$ & natione Grecus \\
\hline Sisinnius & 708 & natione Syrus \\
\hline Konstantin I. & $708-715$ & natione Syrus \\
\hline Gregor II. & $715-73 \mathrm{I}$ & natione Romanus \\
\hline Gregor III. & $73 \mathrm{I}-74 \mathrm{I}$ & natione Syrus \\
\hline Zacharias & $74 \mathrm{I}-75^{2}$ & natione Grecus \\
\hline Stephan II. & $75^{2-757}$ & natione Romanus \\
\hline Paul I. & $757-767$ & natione Romanus \\
\hline $\begin{array}{l}\text { Konstantin II. } \\
\text { (später nicht } \\
\text { anerkannt) }\end{array}$ & $767-768$ & $\begin{array}{l}\text { Keine Vita im LP. Stammte aus Nepi (im Norden des römischen } \\
\text { Dukats), hätte im achten Jh. vermutlich als Romanus gezählt. }\end{array}$ \\
\hline Stephan III. & $768-77^{2}$ & natione Siculus \\
\hline Hadrian I. & $772-795$ & natione Romanus \\
\hline Leo III. & $795-8 \mathrm{I} 6$ & natione Romanus \\
\hline
\end{tabular}

302 Siehe hierzu Duchesne, LP I, 333, Anm. 1.

303 Martin I. ist einer der wenigen Päpste, bei denen die natione Formel variiert wurde. Es fehlt auch der Name seines Vaters. 
Somit könnte man vielleicht zusammenfassen, dass in der Zeit zwischen 678 und 772 immerhin I2 von I6 Päpsten aus dem griechischen Kulturraum stammten.

Doch die Griechen dominierten nicht nur das höchste Amt des römischen Dukats, es ist sicher, dass sie auf allen Ebenen der ekklesiastischen und monastischen Hierarchie Roms in beträchtlicher Zahl vertreten waren, auch wenn nicht mehr ermessen werden kann, wie groß diese Zahl gewesen ist.

Ekonomou schätzt, dass das Verhältnis zwischen Griechen und Lateinern im römischen Klerus in der Zeit von 70I-752 sogar 3,5 zu I (sic!) betragen habe ${ }^{304}$, doch diese extrem hoch angesetzte Zahl steht auf tönernen Füßen. So hat er jeden unsicheren Fall (und davon gibt es sehr viele) den „Easterners“ zugeschlagen. Auch seine Methoden sind sehr zweifelhaft. Er argumentiert, von der I3 Personen unfassenden Entourage des (syrischen) Papstes Konstanin I. auf seiner Reise nach Konstantinopel seien I I östlicher Herkunft gewesen. Doch diese Behauptung stützt er lediglich auf den Befund der Namen in der LP-Vita Konstantins. ${ }^{305}$ Ekonomou gibt die Namen (und einige Ämter) in seinem Buch sogar in ihrer griechischen Form wieder, obwohl sie im LP in ihrer lateinischen Form enthalten sind. ${ }^{306}$ In diesem Zusammenhang sei darauf hingewiesen, dass Zuordnungen zu einer bestimmten Personengruppe lediglich auf Basis eines Namens ausgesprochen problematisch sind. Demgegenüber misst Jörg Jarnut dem Namensmaterial allerdings viel Bedeutung zu (allerdings im Hinblick auf gentes der Völkerwanderungszeit): „... naming of children makes it possible to draw conclusions about the self-classification of the parents in gender assigned groups and also about their expectations and wishes for the future of the child.“" ${ }^{307}$ Der Befund von Namensmaterial kann sogar in einer sehr gemischten Bevölkerung wie in Rom wichtig sein, aber keinesfalls als einziges Kriterium. Zudem sollte dieses Material nicht zur Erstellung von Statistiken verwendet werden.

304 Ekonomou, Byzantine Rome 245.

305 LP I, 389: Hisdem temporibus misit suprafatus imperator [Justinian II.] ad Constantinum pontificem sacram per quam iussit eum ad regiam ascendere urbem. Qui sanctissimus vir iussis imperatoris obtemperans ilico navigia fecit parari, quatenus iter agrederetur marinum. Et egressus a porto Romanodie $V$ mens. octob., indictione VIIII, secuti sunt eum Nicetas episcopus de Silva Candida, Georgius episcopus Portuensis, Michaelius, Paulus, Georgius presbiteri, Gregorius diaconus, Georgius secundicerius, Iohannes defensorum primus, Cosmas sacellarius, Sisinnius nomenclator, Sergius scriniarius, Dorotheus subdiaconus et Iulianus subdiaconus et de reliquis gradibus ecclesiae clerici pauci.

306 Ekonomou, Byzantine Rome 273, Anm. 13

307 Jörg Jarnut, Nomen et gens. Political and linguistic aspects of names between the third and the eighth century - Presenting an interdisciplinary project from a historical perspective, in: Strategies of Distinction. The Construction of Ethnic Communities, 300-800, ed. Walter Poh1/Helmut Reimitz (The Transformation of the Roman World, 2, Leiden/Boston/Köln 1998) 113-116, hier 116. 
Griechen (im kulturellen Sinn) waren also spätestens ab der Mitte des siebenten Jahrhunderts ein wesentliches Element in der römischen Kirche. Sie wurden zweifellos schon allein wegen ihrer liturgischen und sprachlichen Kenntnisse auch dringend gebraucht - so wie sie selbst umgekehrt auch Rom als (relativ) sicheren Zufluchtsort brauchten. ${ }^{308}$

Doch Menschen aus dem Osten und Süden waren nicht nur im kirchlichen Bereich, in der päpstlichen Administration und in den Klöstern vertreten, sie scheinen generell einen beträchtlichen Teil der Bevölkerung der Stadt ausgemacht zu haben. ${ }^{309}$ Man muss hier auch bedenken, dass die Päpste schließlich vom Klerus und den höchsten Repräsentanten der Laien in Rom gewählt wurden. ${ }^{310}$ Es existieren Schätzungen, denen zufolge bis zu $40 \%$ der Bevölkerung Ravennas Griechen in unserem Sinne gewesen sein könnten und man kann mit Thomas Noble davon ausgehen, dass der Bevölkerungsanteil in Rom nicht wesentlich geringer gewesen sein dürfte. ${ }^{311}$

Es ist leicht, sich der Illusion hinzugeben, dass die römischen Greci loyaler zum Kaiser gewesen sein könnten als ihre „lateinischen“ Nachbarn. Doch dem war nicht so. In vielen Fällen wird man sogar umgekehrt davon ausgehen können, dass die römischen Griechen den Griechen in Kleinasien gegenüber noch kritischer eingestellt waren. Nach der zweifachen Proklamation des Monotheletismus (und dem Verbot jeglicher Diskussion über die Frage der Naturen und der Willen Christi) wurde die Gruppe der Griechen in Rom viel mehr mit Dissidenten aus dem Osten, sowohl aus Syrien als auch aus Kleinasien, aufgestockt. Diese Dissidenten hatten ihre Hochburgen in jenen Klöstern Roms, die dem griechischen Ritus folgten. ${ }^{312}$ Das soll nicht heißen, dass nur Personen nach Rom flohen, die zuvor der religiös-politischen Opposition im Osten angehörten, aber man muss sich vor Augen führen, dass auch jene kulturell griechischen Kleriker und Mönche, die selbst aus dem Osten nach Rom immigriert waren, sehr häufig eine sehr römische Sicht der Dinge hatten und auch eine sehr römische Politik verfolgten. Einige mögen sogar antikaiserlicher eingestellt gewesen sein als die Lateiner im Lateran. ${ }^{313}$

308 Burgarella, Presenze 960.

309 In dieser Position waren sie seit dem Ende des siebenten Jahrhundert, siehe zum Beispiel Ekonomou, Byzantine Rome 212.

310 Ekonomou, Byzantine Rome 247. Wiederum geht es wohl zu weit, davon auszugehen, dass die „Easterners“ in Rom sogar in der Mehrheit gewesen seien, wie es Ekonomou tut, doch sie müssen zweifellos einen große Gruppe innerhalb der Bevölkerung gebildet haben.

311 Noble, Republic 4.

312 Siehe auch oben, Kap. 3.2.2 zum Konzil von 649 und Maximos.

313 Marios Costambeys/Conrad Leyser, To be the Neighbour of St. Stephen: Patronage, Martyr, Cult, and Roman Monasteries, c. 600 - c. 900, in: Religion, Dynasty and Patronage in Early Christian Rome, 300-900, ed. Kate Cooper/Julia Hillner (Cambridge 2007) 262-287, hier 272: „... in gene- 
Ein Indiz für diese Behauptung ist zum Beispiel, dass die Klöster griechischen Ritus' sich im Untersuchungszeitraum als treu Verbündete der jeweils herrschenden päpstlichen Administration erwiesen: Ausnahmslos alle Gefangenen des Papstes, von denen wir im Zuge der Wirren der zweiten Hälfte des achten Jahrhunderts erfahren, wurden in griechischen Klöstern inhaftiert. ${ }^{314}$

Im Jahr 806/807 gab es mindestens sieben griechische Klöster in Rom, nämlich die Klöster sancti Sabe, beati Anastasii, sancti Andree ... in Clibus Scauri, beatae Agathae martyris, sancti Erasmi ... in Caelio monte, sancti Silvestri und beati Laurentii martyris, qui appellatur Pallacini. ${ }^{315}$ Die griechischen Monasterien hatten seit dem siebenten Jahrhundert steten Zulauf von kulturell griechischen Mönchen aus dem Osten erhalten, der erst im neunten Jahrhundert deutlich geringer wurde. ${ }^{316}$ Die meisten dieser Mönche kamen aus griechischen Gemeinschaften in Italien südlich von Rom, wie prosopographische Erhebungen gezeigt haben. ${ }^{317}$

Doch was bedeutete es überhaupt, ein Kloster als griechisch zu bezeichnen? Der LP liefert uns hier ein interessantes Beispiel. Papst Paul I. gründete ein Kloster in einem Haus, dass zu seinem Familienbesitz gehörte und legte fest, dass ... grece modulationis psalmodie cynovium esse ..., dass es also ein Kloster sein solle, in dem die Psalmen auf Griechisch gesungen werden sollten. ${ }^{318}$ Diese etwas komplizierte Ausdrucksweise deutet wohl auf die sogenannten griechischen Riten hin, die sich deutlich von den in lateinischen Klöstern verwendeten unterschieden. Es ist wichtig zu betonen, dass auch die griechischen Klöster dabei keiner einheitlichen Regel,

ral the Greek monks were keen to assimilate to the liturgical and devotional life of the city and to demonstrate their loyalty to the papacy.“ Auch die ,griechischen“ Päpste verfolgten eine sehr auf die Stadt Rom bezogene Politik, wie Ekonomou, Byzantine Rome 247f. zeigt.

314 Für Details siehe Sansterre, Moines, Bd. 1, 98-100. Bei den Gefangenen handelte es sich um den abgesetzten „Gegenpapst“ Konstantin II., seinen vizedominus und einen seiner Brüder (768/9), den primicerius Christophorus und seinen Sohn, den secundicerius Sergius (771/2, zu ihnen siehe unten, Kap. 5.5), sowie Papst Leo III. (799).

315 LP II, 22. Siehe dazu ausführlich Sansterre, Moines, 1, 32-39 und Geertman, More Veterum 115119. Siehe auch Costambeys/Leyser, Neighbour 272.

316 Jean-Marie Martin, Greeks in Italy, in: The Papacy: an encyclopedia, Bd. 2, ed. Philippe Levillain, trans. John W. O’Malley (New York/London 2002) 638f. (Originalversion: Dictionnaire historique de la papauté, 1994).

317 McCormick, Origins 213-236, bes. 223 und 235, mit Anm. 57, sowie Sansterre, Moines, Bd. 1, 45. 318 LP I, 465. Es existiert auch der Text der Gründungsurkunde, allerdings ist er erst in einer Handschrift aus dem 16. Jahrhundert überliefert, siehe Concilium Romanum a. 761 (ed. Albert Werminghoff, MGH LL Concilia 2, 1, Concilia aevi Karolini (742-842), Hannover/Leipzig 1906) 64-71. Zur Bedeutung dieses Dokuments siehe Sansterre, Moines, Bd. 1, 36 und Bd. 2, 90-91, Anm. 257. Siehe auch Paolo Delogu, Paolo I, santo, in: Enciclopedia dei papi, Bd. 1 (Rom 2000) 665-669, hier 667: Das Kloster ist heute S. Silvestro in Capite. 
einheitlichen Gebräuchen oder einer einheitlichen Liturgie folgten, auch hier gab es sehr unterschiedliche Ausformungen. ${ }^{319}$ Man kann jedoch zumindest davon ausgehen, dass die Liturgie in griechischer Sprache ausgeführt wurde. ${ }^{320}$

Es scheint gesichert, dass die griechischen Klöster Roms ausschließlich von kulturell griechischen Mönchen bevölkert wurden. ${ }^{321}$ Aus diesem Befund können jedoch keinerlei Rückschlüsse auf Mitglieder des Klerus oder die Laienbevölkerung Roms gezogen werden. In diesen Bereichen können wir von weit stärkerer Interaktion zwischen den verschiedenen Kulturgruppen ausgehen. Es ist also anzunehmen, dass sich die griechischen Römer hinsichtlich ihrer Zugehörigkeit zu Weltklerus, Mönchtum und Laienstand wesentlich unterschieden. Es sei hier noch einmal ausdrücklich darauf hingewiesen, dass es Immigration auch im Bereich der Laienbevölkerung in beträchtlichem Ausmaß gab. ${ }^{322}$

Doch damit nicht genug: die Greci unterschieden sich zudem auch nach ihrer Herkunft. Interessant sind hier schon die Akten des römischen Konzils von 649: hier werden vier Äbte griechischer Klöster genannt, davon zwei aus Rom, bezeich-

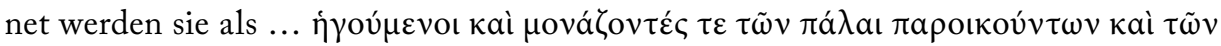

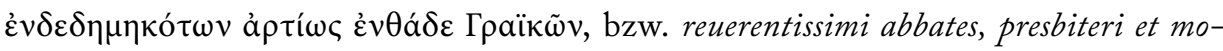
nachi Greci. ${ }^{323}$ Doch die beiden genannten Äbte römischer Klöster, Thalassios, „Abt des armenischen Klosters St. Renati“ und Georgius, Abt des Kilikierklosters (Ad aquas Salvias)", standen laut Prosopographie der mittelbyzantinischen Zeit gar nicht "Griechen" vor, sondern vielmehr Armeniern beziehungsweise Kilikiern, als welche sie auch in den Konzilsakten wenig später ausgewiesen sind. ${ }^{324}$ Diese Diskrepanz in der Einstufung kann eigentlich nur so gedeutet werden, dass es, wie wir oben

319 Sansterre, Moines, Bd. 1, 88-90: Die griechische Regel wird oft mit jener des Basilius gleichgesetzt, die jedoch erst im Hochmittelalter für griechische Klöster im Westen verpflichtend vorgeschrieben war. In der Zeit davor gab es nur gewisse Richtlinien und jedes Kloster folgte im Prinzip seiner eigenen Regel.

320 Zur griechischen Liturgie im Mittelalter siehe Demetrios J. Constantelos, Liturgy and liturgical daily life in the medieval Greek world - the Byzantine Empire, in: The Liturgy of the Medieval Church. Second edition, ed. Thomas J. Heffernan/E. Ann Matter (Kalamazoo 2005) 97-128. Die Psalmen waren ein entscheidender Bestandteil der damaligen Liturgie; siehe zum Beispiel Sansterre, Moines, Bd. 1, 87 und 97. Zur griechischen Liturgie in Italien siehe Cosentino, Italia bizantina 321-334. Eine sehr interessante Fallstudie zu Neapel im neunten und zehnten Jahrhundert bietet Granier, Moines 213f.

321 Sansterre, Moines, Bd. 1, 81, 87 und 107.

322 Burgarella, Presenze 952, beschreibt den Fall einer östlichen Familie, die sich in Rom wahrscheinlich über einen längeren Zeitraum nachweisen lässt.

323 Concilium Lateranense a. 649, ed. Riedinger 48f.

324 PmbZ, Thalassios \# 7253, Bd. 4, 328-329 und Georgius \# 2284, Bd. 2, 26-27 und Sansterre, Moines, Bd. 1, 10-13. 
in Kapitel 3.2.3 schon herausgearbeitet haben, innerhalb der kulturell als griechisch eingestuften Gruppe noch eine Reihe von Untergruppen gab, die sich nach geographischer und/oder ethnischer Herkunft unterschieden. Die Bezeichnung von einer Person als Armenier ist dabei am ehesten ethnisch zu verstehen. ${ }^{325}$ Ein paralleler Schluss für die oben auch genannten Kilikier ist, obwohl ihr Ursprung wohl nicht weit von Armenien zu suchen ist, allerdings nicht zulässig. Sehr kompliziert stellt sich schließlich die syrische Identität dar: Sie war im siebenten und achten Jahrhundert erst im Begriff sich zu einer ethnischen Identität zu entwickeln, weshalb diese Bezeichnung in Rom vor allem auf die geographische Herkunft eines Individuums oder seiner Vorfahren abzielen könnte - wobei nicht einmal klar sein kann, wie dieser Bereich umrissen werden kann. ${ }^{326}$

Wir haben jetzt sehr deutlich gesehen, dass Rom im siebenten und achten Jahrhundert auch eine griechische Stadt war, dass vor allem im kirchlichen Bereich viele Menschen tätig waren, die zumindest unter bestimmten Gesichtspunkten als Greci gesehen werden konnten, und das, obwohl sie in anderem Zusammenhang auch Syrer, Armenier, Sizilianer oder gar einfach Römer sein konnten (wobei auch diese genannten Identitäten wechselseitig keineswegs exklusiv zu verstehen sind).

Es wird häufig attestiert, dass der griechische Charakter Roms nach dem Tod Papst Zacharias' unter Stephan II. und Paul stark abgenommen habe. Wie wir noch sehen werden, war der Pontifikat Stephans II. tatsächlich in vielerlei Hinsicht ein Wendepunkt, auch was die Wahrnehmung von und den Umgang mit Anderen betrifft. ${ }^{327} \mathrm{Ab}$ der Zeit Stephans waren auch die wichtigen Positionen in der päpstlichen Verwaltung zum Großteil in der Hand von lateinischen Römern (wobei wir in einigen Fällen nur nach den Namen der genannten Personen gehen können).

Doch die Griechen verschwanden 752 nicht plötzlich von der Bildfläche, sie blieben eine Gruppe von großem Einfluss in der Stadt. Nach Paul I. und dem kurzen

325 Siehe Cosentino, Italia bizantina 39. Die Kategorie „Armenier“ hatte zudem sicherlich eine geographische Komponente, möglicherweise sogar eine sprachliche, wobei wir nicht mehr feststellen können, welche Sprache die armenischen Mönche in Rom tatsächlich verwendet haben. In diesem Fall mit hoher Wahrscheinlichkeit auszuschließen ist hingegen eine religiöse Komponente dieser Bezeichnung, die sonst im oströmischen Bereich gegenüber den hauptsächlich monophysitischen Armeniern sicher eine Rolle gespielt hat. Die Mönche in Rom waren aber ziemlich sicher chalzedonisch.

326 Siehe dazu Bas ter Haar Romeny/Naures Atto/Jan J. van Ginkel/Mat Immerzeel/Bas Snelders, The Formation of a Communal Identity among West Syrian Christians: Results and Conclusions of the Leiden Project, in: Church History and Religious Culture, 89, 1-3 (2009) 1-52, und vgl. Bas ter Haar Romeny, Ethnicity, Ethnogenesis, and the Identity of Syriac Orthodox Christians, in: Visions of Community in the Post-Roman World. The West, Byzantium and the Islamic World, 300-1100, ed. Walter Pohl/Clemens Gantner/Richard Payne (Aldershot 2012) 183-204.

327 Siehe unten, Kap. 4.2, 5.3 und die Conclusio. 
Intermezzo des umstrittenen Konstantin II. kam der schon genannte Stephan III. auf den Stuhl Petri. Er ist, wie bereits erörtert, dem kulturell griechischen Bevölkerungsteil zuzuordnen. Geboren wurde er auf Sizilien, kam aber in jungen Jahren nach Rom, wo er Mönch im Kloster St. Chrysogonus wurde. Es gibt Forscher, die vermuten, dass es sich hierbei um ein griechisches Kloster handelte. ${ }^{328}$ Der LP überliefert jedoch, dass das Offizium in diesem Kloster in der selben Weise gehalten worden sei wie in Alt St. Peter. Insofern dürfte St. Chrysogonus eher einen lateinischen Ritus verwendet haben. ${ }^{329}$ Stephan durchlief jedoch ohnedies eine recht untypische Karriere für einen hochrangigen Kleriker Roms: Er wurde von Papst Zacharias direkt aus dem Kloster in die päpstliche Administration übernommen. ${ }^{330}$

Abgesehen vom letzten Griechen im höchsten römischen Amt gab es in Rom, wie wir ja bereits gesehen haben, auch weiterhin eine Reihe von griechischen Klöstern, die auch weiterhin Zulauf aus dem Osten zu verzeichnen hatten. Dabei handelte es sich vor allem um Mönche die vor Repressionen im Osten geflohen waren. Diese Repressionen erlitten sie allerdings in den meisten Fällen wahrscheinlich vor allem aufgrund der ausgesprochen antimonastischen Politik Konstantnins V. und weniger aufgrund etwaiger Opposition gegen die ikonoklastische Politik des Kaisers, wobei die beiden genannten Beweggründe keinesfalls als wechselseitig exklusiv zu betrachten sind. ${ }^{331}$

Es wurden in Rom auch im achten und neunten Jahrhundert noch neue griechische Klöster gegründet. Adeodatus gründete St. Erasmus, Gregor. II. St. Agatha, Paschalis I. St. Prassede und Leo IV. St. Stephan und Cassius. ${ }^{332}$ Im frühen neunten Jahrhundert weilte sogar Methodios, der spätere Patriarch von Konstantinopel, als Mönch in Rom, wohin er offenbar vor der Wiederaufnahme des Ikonoklasmus geflohen war. ${ }^{333}$ Für seinen Aufenthalt kommen laut Albert Ehrhard die Jahre 815-82 I „in Betracht". Er veranlasste offenbar in Rom die Erstellung eines zweibändigen Martyrologiums, das heute noch erhalten ist (Paris BNF Cod. Grec I470 und I476), mög-

328 Noble, Knowledge 59.

329 LP I, 468 und LP I, 418: letztere Stelle berichtet über die Gründung des Klosters durch Gregor III. Siehe Davis, LP 8, 24, Anm. 32. Die Schenkungsliste aus der Vita Leos III. für das Jahr 806/807 enthält zwar das Kloster, jedoch nicht im Block mit den zweifelsfrei griechischen Klöstern. Sansterre, Moines, Bd. 1, 34 und 81, präsentiert Stephan als den einzigen bekannten Griechen, der in einem lateinischen Kloster Mönch war. (Siehe auch ebd., 107).

330 LP I, 468. Es war generell ungewöhlich für Mönche, auch eine Karriere in der päpstlichen Administration zu machen. Siehe Sansterre, Moines, Bd. 1, $107 \mathrm{f}$.

331 Noble, Images 64-68.

332 Sansterre, Moines, Bd. 1, 49.

333 Siehe zum Beispiel Warren Treadgold, The prophecies of the patriarch Methodius, in: Revue des études byzantines, 62 (2004) 229-237, hier 229. 
licherweise ist einer der Abschnitte vom späteren Patriarchen selbst verfasst worden. Die Handschrift zeigt jedenfalls, dass die „Griechen“ in Rom auch weiterhin kulturschaffend tätig waren. ${ }^{334}$

Blicken wir zurück ins achte Jahrhundert: Von der Klostergründung Pauls I. war oben schon die Rede. Unter demselben Papst gab es auch eine Anfrage des fränkischen Hofes, wo offenbar griechische Bücher benötigt wurden. Paul beantwortete diese Bitte indem er eine beträchtliche Zahl an griechischen Werken ins Frankenreich sandte. ${ }^{335}$ Dieser Vorgang ist ein Indiz dafür, dass Kenntnisse und auch Wertschätzung des Griechischen auch unter „lateinischen“ Römern verbreitet waren. ${ }^{336}$

Alle unsere Quellen deuten also darauf hin, dass das „griechische“ Bevölkerungselement auch nach $75^{2}$ und bis ins neunte Jahrhundert hinein noch beträchtlichen Einfluss in Rom und auf das Papsttum hatte, seine Vorherrschaft war jedoch gebrochen. Die Immigration von Mönchen (und Laien) aus nunmehr islamisch dominierten Gebieten, insbesondere aus Syrien, hatte um 700 ihren Höhepunkt überschritten, doch es gab dafür regen Zulauf aus Kleinasien, der erst im neunten Jahrhundert zurückging. ${ }^{337}$

334 Siehe ausführlich Albert Ehrhard, Überlieferung und Bestand der hagiographischen und homiletischen Literatur der griechischen Kirche von den Anfängen bis zum Ende des 16. Jahrhunderts, Erster Teil: Die Überlieferung, Bd. 1 (Texte und Untersuchungen, 50, Leipzig 1937) 22-24 und 258-266 (zur Sammlung selbst). Siehe außerdem Henri Omont, Inventaire sommaire des manuscrits grecs de la Bibliothèque Nationale, Seconde Partie (Paris 1888) 55f. (BNF Gr. 1470) und 57f. (BNF Gr. 1476). Beide Handschriften wurden im Jahr 890 von einem Anastasius als Kopie einer verlorenen Vorlage in der vorliegenden Form angefertigt.

335 CC 24, ed. Gundlach 529.

336 Noble, Knowledge 58.

337 Sansterre, Moines, Bd. 1, 50. 


\section{Die päpstliche Darstellung und Wahrnehmung der Greci im achten Jahrhundert ${ }^{338}$}

Im vorigen Kapitel haben wir die Verhältnisse in Rom beschrieben und dabei ein besonderes Augenmerk auf die in der deutschsprachigen Mediävistik oft übersehene oder manchmal gar heruntergespielte griechische Seite Roms gelegt. Hier schließt nun auch gleich Kapitel 4 an, es ist der päpstlichen Wahrnehmung und Konstruktion von Greci gewidmet. Dabei wird die Frage der Verwendung dieses Begriffes einen Rahmen bilden, innerhalb dessen sich auch andere Fragestellungen entfalten sollen, so etwa nach der politischen Situation zwischen Rom und dem Kaiser beziehungsweise seinen Repräsentanten und zum Verhältnis der Religionspolitik zur allgemeinen Politik. Der Hintergrund letzterer Fragestellung ist die immer wieder geäußerte Vermutung, die Päpste hätten ihre Religionspolitik vor allem nach der Nützlichkeit der jeweiligen Position für die Emanzipation Roms ausgerichtet.

Diese Fallstudie versucht, die Frage nach dem päpstlichen Verhältnis zu „Griechen" und zum Kaiser nicht an modernen Vorstellungen davon auszurichten, was alles als „byzantinisch“ oder oströmisch anzusehen ist. Wie wir in Kapitel 3.2.2 gesehen haben, standen solche Kategorien den Zeitgenossen nicht zur Verfügung - umso interessanter ist es jedoch, zu sehen, wie ähnlich sich das lateinische Othering mittels des Begriffs Greci in der modernen Forschung über die genannten Kategorien fortgesetzt hat.

Die Untersuchung wird - abgesehen von dieser Konzentration auf den Begriff Greci - zeitlich auf das achte Jahrhundert eingeschränkt. Es soll nicht verhehlt werden, dass das auch aus Gründen der Ökonomie geschieht, denn im neunten Jahrhundert gäbe es auch eine Fülle von hochinteressantem, wenn auch in der Vergangenheit viel analysiertem Material. Man braucht nur an die päpstliche Intervention im Dauerstreit zwischen den Patriarchen Photios und Ignatios zu denken. ${ }^{339}$ Doch in der

338 Einige Abschnitte des vorliegenden Kapitels sind in etwas veränderter Form als Teil des Artikels Clemens Gantner, The label "Greeks" in the papal diplomatic repertoire in the eighth century, in: Strategies of Identification. Ethnicity and Religion in Early Medieval Europe, ed. Walter Poh1/ Gerda Heydemann (Cultural Encounters in Late Antiquity and the Middle Ages 13, Turnhout 2013) 303-349, erschienen.

339 Klaus Herbers, Papst Nikolaus I. und Patriarch Photios. Das Bild des byzantinischen Gegners in lateinischen Quellen, in: Die Begegnung des Westens mit dem Osten. Kongreßakten des 4. Sympo- 
Folge wird versucht werden, zu zeigen, dass die entscheidenden Weichenstellungen auf der päpstlichen Seite bereits im achten Jahrhundert erfolgten.

\subsection{Das Bild des Ostens im Liber Pontificalis, ca. 700 - ca. 757}

Schon Kapitel 3.2 hat gezeigt, wie schwierig es für Rom war, eine funktionierende Kommunikation über und mit dem Kernbereich des Kaiserreichs und insbesondere mit seinen Eliten im Osten aufzubauen. Diese allgemeine Unsicherheit, wie mit dem östlichen Gegenüber, das einem vertraut und fremd zugleich erschien, umzugehen war, findet auch ihren Niederschlag in den päpstlichen Texten. Hier zeigt sie sich bereits in Bezug auf die Bezeichnungen Grecus und Greci, die die Päpste beziehungsweise ihre Textgestalter im achten Jahrhundert zunächst kaum verwendeten. Es ist also vor allem bemerkenswert, wie selten wir diesen Begriffen in der ersten Hälfte des achten Jahrhunderts begegnen. Nun kann man berechtigterweise anmerken, dass der Begriff „Griechen“ ja gar nicht die einzige Möglichkeit gewesen wäre, die Menschen aus dem Osten zu klassifizieren. Wir haben aber bereits in Kapitel 3.2.2 gesehen, dass der Terminus im größten Teil des Lateinischen Westens zu Beginn des achten Jahrhunderts die Normbezeichnung gewesen sein dürfte. ${ }^{340}$ Wir haben allerdings auch gesehen, dass Rom sich in dieser Hinsicht wesentlich vom Frankenreich oder vom spanischen Westgotenreich unterschied - vor allem im Hinblick auf den unmittelbaren Zugang zu jenen Menschen, die von Autoren, die in weniger häufigem Kontakt mit ihnen standen, leichthin als Greci tituliert wurden. Insofern ist in römischen Quellen durchaus ein differenzierterer Zugang zu erwarten. Das bedeutet jedoch nicht, dass der Ausdruck Greci in Rom unbekannt war, denn wir haben ja oben ebenfalls gesehen, dass die Griechen schon in der klassischen Antike konsequentem Othering unterworfen waren, nicht zuletzt auch unter Verwendung dieses Begriffs. ${ }^{341}$

Widmen wir uns nun kurz der LP-Vita Gregors II., die in ihrer ursprünglichen Fassung wahrscheinlich aus den $730 e r-J a h r e n$ stammt. ${ }^{342}$ Daneben gibt es, wie wir

sions des Mediävistenverbandes in Köln aus Anlaß des 1000. Todesjahres der Kaiserin Theophanu, ed. Odilo Engels/Peter Schreiner (Sigmaringen 1993) 51-74; ders., Rom und Byzanz im Konflikt. Die Jahre 869/870 in der Perspektive der Hadriansvita des Liber Pontificalis, in: Die Faszination der Papstgeschichte. Neue Zugänge zum frühen und hohen Mittelalter, ed. Wilfried Hartmann/Klaus Herbers (Forschungen zur Kaiser- und Papstgeschichte des Mittelalters, Regesta Imperii, Beiheft 28, Köln/Weimar/Wien 2008) 55-70.

340 Siehe oben, Seite 75, bes. Anm. 231.

341 Siehe oben, Kap. 3.2.2, bes. Anm. 221.

342 Damals wurde aus der Rückschau einiger Jahre wahrscheinlich der Ikonoklasmus erst in dieser Intensität in die Vita gebracht. Da Gregor II. am 11. Februar 731 starb, ist es eher unwahrscheinlich, 
gesehen haben, auch eine spätere, überarbeitete Version, die jedoch in Bezug auf den Kaiser und seine Beamten keine wesentlichen Änderungen enthält. ${ }^{343}$ Die Vita enthält viele Informationen über die Probleme Gregors mit Kaiser Leon III. (7I7-74I). Dennoch enthält der Text an keinem Punkt (und auch in keiner der Versionen) den Terminus Greci. Generell bekommt man in der Vita den Eindruck, dass die Herkunft der handelnden Personen als sekundär betrachtet wurde. Wichtig war vielmehr, auf welcher Seite des Konflikts zwischen Papst und Kaiser (zuerst im Steuerstreit, dann im Streit um die Bilder) sich jemand befand. Ausgenommen von dieser Sichtweise sind jedoch die Langobarden, die immer ethnisch identifiziert und definiert werden. Das geschah, obwohl die verschiedenen Gruppen innerhalb der langobardischen gens im Steuerstreit eine entscheidende Rolle spielten. Die rund um Rom gelegenen Dukate griffen offenbar sogar zugunsten des Papstes in den Konflikt ein. ${ }^{344}$ Der plausibelste Grund dafür ist, dass sie, im Gegensatz zu den anderen wichtigen Personen der Vita, nicht der Elite des Römischen Reichs zugerechnet werden konnten. Das würde bedeuten, dass die Repräsentanten des Kaisers in gewissem Sinne immer noch als Teil der eigenen in-group gesehen wurden. Das gilt auch für die Verschwörer, die laut LP versucht haben sollen, Gregor II. zu ermorden: Der $d u x$ Basilius, der chartularius Jordannes, der Subdiakon Johannes Lurion und der kaiserliche spatharius Marinus werden allesamt nur über ihre jeweilige Position (ihr Amt oder ihren Rang) in der imperialen oder päpstlichen Verwaltung definiert und nicht über ihre Herkunft. Selbiges gilt für den Exarchen Paulus und den ehemaligen Exarchen Eutychius, die in der Affäre ebenfalls eine Rolle spielten. ${ }^{345}$

Die Vita Gregors III. bietet in dieser Hinsicht ein sehr ähnliches Bild: Menschen, die wahrscheinlich aus dem Osten kommen, werden über ihr jeweiliges Amt definiert, aber abgesehen von ihren Personennamen gibt es keinerlei Hinweis, der ihren griechischen kulturellen und/oder sozialen Hintergrund mit Sicherheit belegen würde. Die Personennamen reichen schon deshalb nicht aus, weil (ursprünglich) griechische Namen sich bei der gesamten Bevölkerung Roms in dieser Zeit relativ großer Beliebtheit erfreuten. ${ }^{346}$ Auch bei Gregor III. spielt der Ikonoklasmus eine bedeutende Rolle, aber er wird dem Kaiser persönlich zur Last gelegt, nicht unper-

dass er gegen die neue Bilderpolitik im Osten, die dort nach neueren Erkenntnissen erst ab 730 diskutiert wurde, noch selbst so weitgehend protestierte, wie es sein Biograph sich gewünscht hätte. Vgl. Brubaker/Haldon, Byzantium 82-84.

$343 \mathrm{Zu}$ den Versionen der Vita siehe oben, Kap. 1.1.3.1.

344 Siehe dazu unten, Kap. 5.1.

345 LP I, 403-405. Zu den Personen siehe oben, Anm. 270 und 272.

346 Sansterre, Moines, Bd. 1, 86 hält fest, dass griechische Namen sich auch unter lateinischen Römern schon länger großer Beliebtheit erfreuten. 
sönlichen Greci. ${ }^{347}$ Obwohl Gregor III. also von seinem Biographen als natione Syrus eingestuft wird, setzte er die Politik seines Vorgängers, der als Romanus bezeichnet wird, ohne jegliche Bruchlinien fort. Wiederum zeigt sich, dass es eine allgemeine päpstlich-römische Politik gab, bei der alle Mitglieder der päpstlichen Verwaltung an einem Strang zogen. In dieser Hinsicht ist es auch interessant, dass wir im frühen achten Jahrhundert keine Berichte über Unzufriedenheit mit dem Papst oder gar über umstrittene Papstwahlen haben - und das obwohl sowohl Gregor II. als auch Gregor III. immer wieder unter hohen Druck von außen gerieten. ${ }^{348}$

Interessant ist noch die Person Gregors III. Von ihm wird im LP dezidiert berichtet, dass er hervorragende Sprachkenntnisse in Griechisch und Latein besaß. ${ }^{349}$ Man könnte deshalb annehmen, dass er sich in dieser Hinsicht von seinem Vorgänger unterschied, was es überhaupt für den Autor der Vita als wesentlich erscheinen ließ. Doch gerade für Gregor II. scheint es ausgesprochen wahrscheinlich, dass er des Griechischen sehr gut mächtig war. ${ }^{350}$

Der Hinweis auf die Bilingualität Gregors III. kann auch nicht direkt mit seiner Herkunft (wie natione wahrscheinlich zu übersetzen ist) in Verbindung gebracht werden, denn es wäre zumindest theoretisch möglich, dass seine Muttersprache Syrisch war - auch wenn wir daran mit ebensoviel Recht zweifeln dürfen. Gregor könnte direkt aus Syrien nach Rom eingewandert sein, doch es ist zumindest gleich wahrscheinich, dass seine Vorfahren schon seit einigen Generationen auf der italienischen Halbinsel lebten. ${ }^{351}$ In letzterem Fall bestünden wiederum mehrer Möglichkeiten: seine Familie könnte in Rom selbst, in Mittelitalien (dem Exarchat und der Pentapolis) oder im noch wesentlich griechischeren Süden gelebt haben. ${ }^{352}$

Die wichtigste Information, die wir aus dem kurzen Hinweis des LP auf die Bilingualität Gregors III. beziehen können, ist, dass die Kenntnis der griechischen Sprache offenbar sehr hochgeschätzt wurde, insbesondere aber die Zweisprachigkeit in den beiden in Rom relevanten Sprachen Griechisch und Latein. Nach allem was wir bisher über die Situation in Rom im achten Jahrhundert festgestellt haben, können solche guten Sprachkenntnisse aber eigentlich nicht besonders rar gewesen sein. ${ }^{353}$

347 Siehe LP I, $415 f$.

348 Das sollte sich ab der Mitte des Jahrhunderts radikal ändern.

349 LP I, 415: ... greca latinaque lingua eruditus, ...

350 Siehe Noble, Knowledge 57. Gregor II. war Mitglied der Delegation die 710/711 Konstantinopel besuchte und es ist schwerlich anzunehmen, dass er ohne gute Griechischkenntnisse dafür ausgewählt worden wäre.

351 Siehe Noble, Republic 185-188.

352 Siehe oben, Kap. 3.2.4, bes. bei Anm. 322.

353 Noble, Knowledge. 
Vielleicht war aber echte Bilingualität wiederum nicht ganz alltäglich ${ }^{354}$ und möglicherweise war Gregor III. in dieser Hinsicht besonders herausragend.

Mit Sicherheit hatte Gregors Nachfolger Zacharias hervorragende Sprachkenntnisse, schließlich fertigte er eine Übersetzung der Dialogi Gregors des Großen an, eine Aufgabe, die nur zu bewältigen war, wenn man auch über sehr gute Lateinkenntnisse verfügte. ${ }^{355}$ Zacharias schätzte selbst auch Zweisprachigkeit als ein sehr hohes Gut, wie er in einem Brief an Winfried-Bonifatius betont. In dem Schreiben rühmt der Papst den römischen Beitrag zur Entwicklung der Kirche Englands. Dabei hebt er besonders den Heiligen Theodor hervor, den er für seine zweisprachige philosophische Ausbildung lobt. ${ }^{356}$

Zacharias selbst wird in seinem LP-Eintrag wie folgt eingeführt: Zacharias, $n a-$ tione Grecus, ex patre Polichronio, ... ${ }^{357}$ Diese Stelle wird in der Literatur recht häufig zitiert und Zacharias wird häufig zum letzten griechischen Papst erklärt. Wir haben oben schon gesehen, dass dieses Attribut wahrscheinlich eher Stephan III. zusteht. ${ }^{358}$

Die natione Nennung im LP des achten Jahrhunderts bezieht sich am ehesten auf relativ ungenau definierte Weise in irgendeiner Form auf die Herkunft oder den Ursprung des jeweiligen Papstes. Es gibt keinerlei Hinweise, dass sich die LP-Autoren zu dieser Zeit an irgendwelche Richtlinien diesbezüglich gehalten hätten. ${ }^{359}$ Es gilt jedoch als wahrscheinlich, dass die Päpste gerade auf die ersten Absätze ihrer Biographie einen gewissen Einfluss ausübten. Denn dieser Abschnitt könnte sogar als eine Art Visitenkarte für die Päpste nach ihrer Weihe fungiert haben. Deshalb ist

354 Sansterre, Moines, Bd. 1, 76.

355 LP I, 435, Davis, LP 8, 50, Anm. 103 und Paolo Delogu, Zaccaria, santo, in: Enciclopedia dei papi, Bd. 1 (Rom 2000) 656-659, hier 656.

356 Zacharias, ep. ad Bonifatium, ep. 80 (ed. Michael Tangl, Die Briefe des Heiligen Bonifatius und Lullus, MGH EE sel., 1, Berlin 1916) 173: ... Theodorus, Greco-Latinus ante philosophus et Athenis eruditus, Romae ordinatus ... Hierbei handelt es sich nebenbei bemerkt um den einzigen Papstbrief im gesamten Corpus der Bonifatiusbriefe, der das Wort "griechisch“ (auf die Sprache bezogen) enthält; daneben gibt es in der Sammlung nur noch einen weiteren Brief, der dieses Wort enthält. Theodor von Canterbury wurde in Tarsos geboren. Vgl. zu seiner Person: Klaus-Peter Todt, Theodor von Canterbury, in: Biographisch-bibliographisches Kirchenlexikon, Bd. 11 (1996) 869-871.

357 LP I, 426.

358 Siehe oben, Kap. 3.2.3 und 3.2.4.

359 Die natione-Kategorie im LP wäre ein lohnendes Gebiet für eine vertiefende Studie, die jedoch bislang ausständig ist. Die Angabe einer natio war jedenfalls ein traditionelles Element, das schon in der Entstehungszeit des LP im sechsten Jahrhundert vorhanden war. Es ist jedoch davon auszugehen, dass sich die Kritertien, nach denen die natio eines Papstes bestimmt wurde, bis ins achte Jahrhundert hin verändert hatten. Das zeigt sich auch oben in Tabelle 1, aus der zum Beispiel deutlich wird, dass einige Autoren der Leben des siebenten Jahrhunderts wesentlich mehr auf Details bedacht waren als ihre Nachfolger im achten. 
mit erhöhtem Interesse der neugewählten Päpste an ihrer Repräsentation an dieser Stelle zu rechnen. ${ }^{360}$ Somit können wir zumindest davon ausgehen, dass Zacharias mit seiner Zuordnung einverstanden war.

Sehr fraglich ist, was mit Grecus überhaupt ausgedrückt wurde. Es wäre am einfachsten, seinen Geburtsort in einer Gegend zu suchen, die im siebenten oder achten Jahrhundert als Grecia bezeichnet werden konnte. Der einzige mittelalterliche Autor, der das auch ausdrücklich getan hat, ist Konstantin Porphyrogennetos, der behauptete, Zacharias habe aus Athen gestammt. ${ }^{361}$ Moderne Historiker sind meist einem anderen Hinweis gefolgt, der belegen soll, dass Zacharias aus Kalabrien kam, ${ }^{362}$ auch wenn seine Verbindung mit Siberena/Santa Severina glaubwürdiger Beweise entbehrt: Es handelt sich lediglich um eine lokale Tradition, die noch dazu sehr spät überliefert ist. ${ }^{363}$

Das einzige, was wir aus der Bezeichnung Grecus herauslesen können, ist, dass Zacharias in eine kulturell griechische Familie geboren wurde. Er könnte deshalb von überall zwischen Rom ${ }^{364}$ und dem östlichen Anatolien gestammt haben, einzig Sizilien können wir mit hoher Wahrscheinlichkeit deshalb ausnehmen, da Päpste von dort immer als natione Siculus identifiziert wurden. Ebenso scheidet Syrien aus, das wohl generell die ehemaligen östlichsten Gebiete des Reichs bezeichnet - eine Herkunft aus dieser Region wäre nämlich sonst wahrscheinlich ebenfalls, wie bei Gregor III. und einigen seiner Vorgänger, eigens ausgewiesen worden (siehe oben, Tabelle r).

Wir wissen jedenfalls, dass die „griechische“ Herkunft des Papstes vom Autor seiner Vita zweifelsfrei festgehalten wurde, so wie das für jeden Papst des LP immer vorgenommen wurde. Dennoch dürfte das reine Faktum seiner Herkunft für seine Zeitgenossen sonst nicht von sehr hoher Bedeutung gewesen sein.

360 Siehe Bougard, Composition 134-136.

361 Konstantin Porphyrogennetos, De administrando imperio, 27 (ed. Gyula Moravcsik/Romilly J. H.

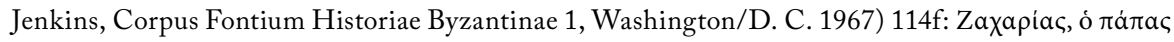
AAnvaĩoc. Siehe Burgarella, Presenze (aber auch Sansterres Antwort in der folgenden Diskussion, ebd., 989, ist durchaus zu beachten).

362 Siehe zum Beispiel Giorgio S. Marcou, Zaccaria (679-752): L'ultimo papa greco nella storia di Roma altomedievale. Note storico-giuridiche, in: Apollinaris, 50 (1977) 274-289, hier 274. Der Topos der kalabrischen Herkunft Zacharias' findet sich in fast allen ihn betreffenden Lexika-Einträgen (so etwa PmbZ, Bd. 5, \#8614).

363 Sansterre, Moines, Bd. 2, 75f., Anm. 112, und Burgarella, Presenze 944f., der den Versuch, Zacharias' Herkunft in Süditalien zu suchen damit erklärt, dass versucht wurde, ihn so in Beziehung zu seinen Vorgängern am Papstthron zu setzen. Darin ist ihm schon deshalb nicht zu folgen, weil die Herkunft der meisten dieser Päpste ebenso im Dunkeln liegt.

364 Delogu, Zaccaria 656, schreibt: „... apparteneva probabilmente ad una delle numerose famiglie che si trasferirono dall'Oriente a Roma tra la fine del VII secolo ed i primi decenni dell'VIII ...", doch leider gibt es auch dafür keine Beweise. Möglich ist seine Herkunft aus Rom selbst aber allemal. 
Die Bezeichnung Grecus und die Erwähnung der Kenntnisse lingua greca betrifft jedenfalls immer nur Individuen, die dem römischen Klerus zuzuordnen sind. In keinem Fall wird in den Quellen der Zeit eine ganze Gruppe als Greci bezeichnet.

Die Strategie für den Umgang mit kulturellen Griechen, speziell mit mutmaßlich oder erwiesenermaßen aus dem Osten kommenden Amtsträgern, wurde im LP für die Leben Zacharias' und Stephans II. fortgesetzt. Besonders in letzterem Fall ist das durchaus bemerkenswert, wie wir bei der Analyse der Briefe des Codex Carolinus noch sehen werden. Selbst in der Vita Pauls I. kann keine Änderung festgestellt werden, was aber daran liegt, dass dieser LP-Eintrag überhaupt äußerst knapp und inhaltsleer gehalten worden ist. Stephan II. war besonders am Beginn seines Pontifikats in intensivem Kontakt mit kaiserlichen Offiziellen. Er setzte sich persönlich, vor allem aber über Gesandte, für die Rückgabe Ravennas und des Exarchats an den Kaiser ein. Doch tatsächlich hatte der Langobardenkönig Aistulf nicht nur den Exarchat eingenommen, er bedrohte auch den letzten verbliebenen (nominellen) Herrschaftsbereich des Imperiums in Mittelitalien. Nach einigen Versuchen lässt der Autor der LP-Vita Stephan II. zu folgendem Schluss kommen: „Mit jenem [Aistulf] erreichte er nichts, und er erkannte im Besonderen auch, dass von der kaiserlichen Macht keine Hilfe kommen würde.“365

Der Autor drückt sich hier sehr umständlich aus. Mit der relativ sperrigen und für den LP absolut untypischen Konstruktion ${ }^{366} a b$ imperiale potentia vermeidet er möglicherweise ab Grecis zu schreiben. Das Wort Greci ist in der gesamten Vita nicht zu finden - wieder werden die Vertreter der kaiserlichen Administration, die sicherlich aus dem Osten kamen, nur mittels ihres Ranges identifiziert. Man kann nun die Frage stellen, ob das Wort Greci an dieser Stelle überhaupt zu erwarten wäre. Dieses Problem kann nicht vollständig gelöst werden, da wir aufgrund des vorhandenen Textes nur ex silentio argumentieren und also letztlich nur spekulieren können. Wir werden aber im folgenden Kapitel 4.2 sehen, dass der Terminus fast zeitgleich (in pejorativem Zusammenhang) in das diplomatische Repertoire des Papsttums aufgenommen wurde und somit auch hier angewendet hätte werden können.

Die offizielle Darstellungsweise des LP änderte sich jedoch erst während des Pontifikats Hadrians I., zunächst in der Vita Stephans III., die wir später in Kapitel 4.3 noch genauer analysieren werden.

365 LP I, 444: ... et dum ab eo nibil hac de re optineret, cernens praesertim et ab imperiale potentia nullum esse subveniendi auxilium;...

366 Bemerkenswert ist, dass genau dieser Ausdruck gleich in einer Reihe früher LP-Handschriften falsch kopiert wurde, vgl. Gantner, Studien 129 und $183 \mathrm{f}$. 
Im LP vor 772 konnten also sowohl griechische Päpste als auch griechische Institutionen, konkret Klöster, vorkommen, die auch mit dem Epithet Grecus versehen wurden. Doch das Kerngebiet des Kaiserreichs in Kleinasien, die dortigen Beamten und der Kaiser selbst, wurden niemals mit diesem Terminus bedacht. Dafür gibt es zwei mögliche, wechselseitig nicht exklusive Erklärungen: Zum einen könnte die Gruppe von Klerikern, die für die Produktion des LP zuständig war und die nicht kulturell griechisch war ${ }^{367}$, Rücksicht auf die römischen Griechen genommen haben. Zum anderen können wir den Quellen wohl eine sehr ausgeprägte Vorsicht in Bezug auf die richtigen Bezeichungen attestieren - und Greci wäre zwar eine sicherlich bekannte, vielleicht aber doch als zu pauschal und abwertend empfundene Variante gewesen.

\subsection{Papstbriefe bis 772: Das Auftauchen der Bezeichnung Greci}

Der Codex Carolinus enthält die meisten Papstbriefe, die wir bis 772 zur Verfügung haben, insgesamt sind es in dieser Sammlung 5o Stück (wenn man das lange Regest $\mathrm{CC} 5^{368}$ mitzählt). Daneben haben wir auch einige Papstbriefe aus anderen Quellen, von denen einer hier von Interesse ist: Es handelt sich um die Einladung zur antiikonoklastischen Synode in Rom am r. November 73I, die von Papst Gregor III. an Erzbischof Antoninus von Grado geschickt wurde. ${ }^{369}$ Hierin gelingt es dem Papst,

367 Die Herstellung des LP wurde sicherlich von „lateinischen“ päpstlichen Beamten vorgenommen. Der genaue Ablauf der Textproduktion wird seit mehr als 100 Jahren diskutiert, siehe oben, Kap. 1.1.2.

368 Siehe CC 15, ed. Gundlach 512, Text in Anm. a zu Brief 15.

369 Epistolae Langobardicae Collectae, 13, Gregorius III. papa Antonino Gradensi, (ed. Wilhelm Gundlach, MGH EE 3, Epistolae Merowingici et Karolini aevi, Berlin 1892) 703. Die Authentizität dieses Briefes ist zuletzt in Zweifel gezogen worden, vor allem, weil er ein Vorgehen von ungenannten Personen in Konstantinopel gegen Bilder erwähnt. Speck, Leon III, III, 586f., hat den Brief wegen seiner sicherlich anachronistischen Intitulatio als unecht eingestuft. Tatsächlich kann diese, die den Papst Gregorius tertius pontifex nennt, so nicht in dem Brief gestanden sein. Doch das alleine kann keinesfalls ausreichen, den ganzen Text zu verwerfen, es ist ebenso möglich, dass der Kopist den Beginn zum besseren Verständnis seiner Zeitgenossen veränderte. Auffällig ist, wie vorsichtig der Papst seine Worte wählte. Eine spätere Fälschung hätte wesentlich deutlichere Wort gegen den Ikonoklasmus gefunden, wie wir oben schon in Bezug auf die verfälschten Briefe Gregors II. gesehen haben (vgl. oben, Anm. 256). Paul Fridolin Kehr, Italia Pontificia, 7, 2, Nr. 17 (Berlin 1925) 36f., hat den Brief nicht als gefälscht markiert. Pietro Conte, Regesto delle lettere dei papi del secolo VIII (Milano 1984) 200f., sieht den Brief nicht als echt an, er ist aber ohnehin der Historizität der Synode von 731 gegenüber zu kritisch eingestellt. Brubaker/Haldon, Byzantium 119f., mit Anm. 169, integrieren den Brief mit äußerster Vorsicht in ihre Argumentation. Zusammenfassend kann man nicht von der Hand weisen, dass Vorsicht im Umgang mit diesem Brief angebracht ist, allerdings nicht deswegen, weil er den Bilderstreit erwähnt, sondern aufgrund der sehr späten Überlieferung - 
aus seiner Sicht gefährliche Vorgänge in Konstantinopel anzuprangern, die die Bilder betreffen, ohne dabei das Wort Greci zu verwenden. Besonders bemerkenswert ist, dass auch der Kaiser und seine Administration nicht erwähnt werden. Gregor schrieb schlicht: „Denn es herrscht in der regia urbs und einigen Provinzen [des Reichs] ein nutzloser Irrglaube (impietas), wie Ihr, wie wir glauben, bereits gehört habt. ${ }^{\text {“370 }}$ Es ist also nur von einer nutzlosen impietas die Rede, die es in Konstantinopel und einigen anderen Provinzen gibt. Der Papst vermeidet somit, den Kaiser direkt anzugreifen, möglicherweise, weil er zu diesem Zeitpunkt über sehr ungenaue Informationen verfügte oder weil sich Leon III. nicht klar deklariert hatte. ${ }^{371}$ Der Brief passt mit seiner Wortwahl jedoch perfekt zu jenem Befund, den wir im LP ausmachen konnten. Auch dort hat sich schon eine gewisse Unsicherheit im Zusammenhang mit dem Bilderstreit gezeigt.

Die ersten zehn Briefe des CC bleiben überhaupt still und erwähnen nichts, was den Osten betrifft. Zwar sind alle Briefe an Karolinger bzw. Franken adressiert und so gesehen wäre es den Päpsten leicht möglich gewesen, den Terminus Greci zu verwenden. Wir müssen in Betracht ziehen, dass es in diesen zehn Briefen überhaupt nicht im Interesse der Päpste lag, den Kaiser zu erwähnen, schließlich strebte man ein Bündnis zwischen dem Papst beziehungsweise dem H1. Petrus und den Franken an. In den Briefen ging es meist um die Gefahr, die von den Langobarden für den Papst ausging. Somit erschien es den Päpsten wohl sinnvoll, den Kaiser aus dem Spiel zu lassen. Die Briefe der Päpste Gregor III. und Zacharias stammen zudem aus einer Phase in der höchstens sehr geringe Spannungen mit dem Kaiser zu bemerken sind. Die Situation änderte sich jedoch in den 75oern, ganz besonders mit dem Konzil von 754, das die Päpste als Affront auffassten. Außerdem wurde immer klarer, dass Kaiser Konstantin V. nicht willens oder nicht in der Lage war, militärisch in Italien zu intervenieren. In dieser Situation wurde die päpstliche Sprache sehr viel deutlicher. Der erste Hinweis auf diese veränderte Situation findet sich in Brief I I des CC. ${ }^{372}$

Dabei handelt es sich um den letzten Brief Stephans II. an König Pippin. Der Papst starb ungefähr ein bis zwei Monate danach, sein Nachfolger wurde sein Bruder Paul I.

es sei allerdings darauf hingewiesen, dass viele als wesentlich erachtete Quellen zur Byzantinischen Geschichte ebenfalls erst in Handschriften des späten Mittelalters erhalten sind.

370 Epistolae Langobardicae Collectae, 13 (Gregorius III. papa Antonino Gradensi), ed. Wilhelm Gundlach, MGH EE, 3 (Berlin 1892) 691-715, hier 703: Est enim infelix impietas apud regiam urbem, ut-credimus - notum habetis, et per diversas provincias, ...

371 Zur unsicheren Situation aus römischer Sicht siehe neuerdings auch Brubaker/Haldon, Byzantium 84-86.

372 Zur Nennung von Greci in den Briefen des CC siehe unten, Tabelle 2 in Kap. 4.3. 
In CC II versuchte Stephan, die von ihm selbst geschmiedete Allianz mit den Franken zu stärken, ein Anliegen, das in allen seinen Briefen an die Franken eine große Rolle spielt, wenn es in seinen früheren Briefen ( $\left.\mathrm{CC}_{4-\mathrm{IO}}\right)$ auch häufig von akuten Problemen mit den Langobarden flankiert wird. Im Zuge seiner „Invokation“ des Bündnisses findet sich folgende Passage:

Und das fordern wir unablässig von Deiner hervorragenden Güte [Pippin]: dass Du, inspiriert von Gott und seinem Apostelfürsten St. Peter, den Befehl geben mögest, die Dinge mit der Fraktion der Griechen zu ordnen, damit durch Dich der heilige katholische und apostolische Glaube in Ewigkeit ganz und unversehrt bleibe; und dass die heilige Kirche Gottes auch von ihrer [der Griechen] unheilbringenden Bosheit befreit werde, so wie sie auch von anderen befreit worden ist, und ihre Sicherheit zurückgegeben werde; sie möge auch alle ihre Besitzungen zurückerhalten, ... ${ }^{373}$

In diesem Absatz legte Stephan die Grundlage für die Argumentationslinie, der sein Bruder in den kommenden zehn Jahren folgen würde. Die Probleme mit dem Kaiser werden mit einer unpersönlichen Gruppe verknüpft, die nun tatsächlich Greci genannt wird. Es ist ein bedeutender Strategiewechsel in der Kommunikation des Papstes, der hier stattfand: Nunmehr wurden nicht mehr spezifische Personen genannt - konkret der Kaiser und mit ihm verbundene Beamte beziehungsweise auch Personen aus der kirchlichen Hierarchie des Ostens - sondern die Vorwürfe bezogen sich nun (anscheinend) auf alle Greci.

Zweifellos ist es möglich, dass hier auch eine gewisse Rücksicht darauf genommen wurde, dass Pippin 756/757 in engem diplomatischem Kontakt mit kaiserlichen missi stand und der Papst sich deshalb entschied, ein abstrakteres Bild des Gegners zu zeichnen.

Aber es steckt wohl mehr hinter diesem Wechsel der Wortwahl als diplomatische Feinheiten. Die Beziehungen des Papstes zu Konstantinopel waren mittlerweile zweifellos angespannt, einerseits, wie wir gesehen haben, weil der Bilderstreit mittlerweile auf eine völlig neue Ebene gehoben worden war, andererseits wegen der Patrimonien des Papstes auf Sizilien, Kalabrien und in Illyricum, die Konstantin V. dem Patriarchen von Konstantinopel zugeschlagen hatte. Es ist zwar nicht unwahrscheinlich, dass diese Übertragung quasi im Austausch für den Exarchat erfolgte, doch

373 CC 11, ed. Gundlach 506: Et hoc obnixe postulamus praecelsam bonitatem tuam: ut inspiratus a Deo et eius principe apostolorum beato Petro ita disponere iubeas de parte Grecorum, ut fides sancta catholica et apostolica per te integra et inconcussa permaneat in eternum et sancta Dei ecclesia, sicut ab aliis, et ab eorum pestifera malitia liberetur et secura reddatur atque omnia propriaetatis suae percipiat,... 
dennoch scheint man in Rom nicht ganz einverstanden gewesen zu sein. Stephan spricht diese Umstände möglicherweise sogar an, wenn er schreibt: et secura reddatur atque omnia propriaetatis suae percipiat, ... ${ }^{374}$

Aus diesen beiden Gründen entwickelte Stephan II. das Thema der malitia Grecorum.

Ausgehend von dieser Basis schrieb Paul I. mehrmals an Pippin von der impia hereticorum Grecorum malitia. Exakt dieser Ausdruck findet sich in den Briefen $\mathrm{CC}_{3} 8$ und 32, die beide vor allem das prinzipielle Einverständnis zwischen Papst und Frankenkönig betonten. ${ }^{375}$ Es fällt auf, wie selbstverständlich, ja fast beiläufig wirkend der Papst die doch sehr harte Formulierung verwendet. Die Briefe sind vom Herausgeber des CC, Wilhelm Gundlach, beide auf das Jahr 760 datiert worden, doch wie so oft wurde Gundlach auch in diesem Fall korrigiert, sodass nun CC 38 auf den Jahreswechsel $759 / 760, \mathrm{CC}_{32}$ ungefähr auf $760 \mathrm{zu}$ datieren ist. ${ }^{376}$

Es sind dies die einzigen Papstbriefe des achten Jahrhunderts, in denen die „Griechen" ausdrücklich als Häretiker gebrandmarkt werden. Generell verwendeten die Päpste eine solche Einstufung nicht häufig, meist schreckten sie eher davor zurück. Doch auch ohne die asudrückliche Bezeichnung der Greci als Häretiker zu verwenden, konnte Paul seine Ansicht sehr deutlich transportieren. Im Jahr 759 sandte er $\mathrm{CC}$ 30, wo sich folgende Formulierung findet: nefandissimi Greci, inimici sanctae ecclesiae et orthodoxae fidei expugnatores. Er kommt in dem Brief sogar noch ein zweites Mal darauf zu sprechen. ${ }^{377}$

Es zeigt sich hier, dass der Ikonoklasmus von den Bruderpäpsten als hauptsächlicher Angriffspunkt der Greci ausgemacht worden war, was auch wenig verwunderlich ist, denn das Konzil von 754 hatte offenbar keinen Raum für Ambiguitäten gelassen. In seinen Briefen versuchte Paul, die Franken von der römischen Sicht der Dinge zu überzeugen. Das tat er in Reaktion auf die immer noch anhaltenden Versuche des Kaisers, eine eigene Allianz mit den Franken zu bilden, die möglicherweise sogar den Papst ausschließen sollte.

Interessant ist, dass Paul sich nicht veranlasst sah, die Verfehlungen der Greci in seinen Schreiben zu diskutieren. Er entschied sich, aus seiner Position als Haupt der Kirche die Theologie in Konstantinopel als unorthodox zu erklären. ${ }^{378}$ Wichtig ist es

374 In CC 11, ed. Gundlach 506. Siehe Brandes, Finanzverwaltung 374f., mit Anm. 771, und oben, Kap. 3.2.2.

375 Siehe CC 32, ed. Gundlach 538f. und CC 38, ebd. $550 f$.

$376 \mathrm{Kehr}$, Chronologie 113-117.

377 CC 30, ed. Gundlach 536 (gleich zwei Attacken auf die Greci).

$378 \mathrm{Zu}$ den Bemühungen des Papstes, sich als einziges Maß der Orthodoxie zu präsentieren vgl. Sebastian Scholz, Politik - Selbstverständnis - Selbstdarstellung: Die Päpste in karolingischer und ottonischer Zeit (Historische Forschungen 26, Stuttgart 2006) 72-74. 
jedoch, zu betonen, dass die Griechen keine absolute Priorität für Paul I. besaßen, das hatten die Meinungsverschiedenheiten mit dem Langobardenkönig Desiderius, in denen den Franken seit 754 eigentlich eine Art Schiedsgerichtposition zugekommen wäre.

In CC I7 aus dem Jahr $75^{379}$ geht es um ein gemeinsames Vorgehen Desiderius' mit kaiserlichen Truppen gegen den langobardischen $d u x$ von Benevent. Die politische Auseinandersetzung mit Desiderius wird unten noch ausführlich besprochen. ${ }^{380}$ Der Kern des Briefes im Quellentext:

Und er ging sofort nach Neapel, wohin König Desiderius den kaiserlichen missus Georgius rief, der zu Euch in die Francia geschickt worden war. Mit diesem sprach er heimlich in böser Absicht. Er schloss mit ihm einen Pakt und sandte auch einen Brief an den Kaiser, in dem er diesen aufforderte, seine kaiserlichen Armeen in die Provinz Italien zu entsenden. ${ }^{381}$ Desiderius selbst schwor mit dem gesamten populus der Langobarden, dem kaiserlichen Heer Verstärkung zu gewähren - was Gott verhindern möge - damit sie gemeinsam, von der einen Seite das kaiserliche Heer, von der anderen Seite Desiderius mit dem gesamten populus der Langobarden, die Stadt Ravenna einnehmen könnten, und der imperator dort die Macht haben solle wie es ihm beliebte. Und es wurde auch mit jenem Georgius abgemacht, dass die Schiffsflotte Siziliens nach Otranto geschickt werden sollte, damit Griechen und Langobarden sie gemeinsam belagern und einnehmen könnten; diese sollte mit allen Bewohnern und darin befindlichen Gütern dem Kaiser übergeben werden, lediglich der $d u x$ [Liutprand von Benevent] selbst und dessen Ratgeber [oder Regent] Johannes sollten dem König zurückgegeben werden. ${ }^{382}$

379 Hier handelt es sich um einen der wenigen Briefe, bei dem der MGH-Editor Gundlach und Paul Fridolin Kehr übereinstimmen (vgl. Kehr, Chronologie), wobei in den allermeisten Fällen bis heute Kehr zu folgen ist.

380 Siehe unten, Kap. 5.4.

381 Es ist unklar, wer den Brief senden sollte. McCormick, Origins 872, Nr. 164, geht davon aus, dass Desiderius den Brief sandte.

382 CC 17, ed. Gundlach 515: Et confestim dirigens Neapolim, isdem Desiderius rex accersivit Georgium imperialem missum, qui ad vos Franciam directus fuerat. Cum quo nefariae clam locutus est, iniens cum eo consilium atque suas imperatori dirigens litteras, adhortans eum, ut suos imperiales dirigat exercitus in hanc Italiam provintiam. Et ipse Desiderius cum universo Langobardorum populo professus est, Deo sibi contrario, auxilium prelatis imperialibus exercitibus inpertire, quatenus - ex una parte ipse inperatoris exercitus et ex alia isdem Desiderius cum universo Langobardorum populo - utrique dimicantes Ravennantium civitatem conprehendere queant, suamque imperator, quod Dominus non permittat, adimplere valeat in quodcumque voluerit voluntatem. Nam et hoc cum eodem Georgio imperiali misso constituit, ut dromonorum Siciliae stolum in Otorantina civitate dirigatur, ut tam Greci quamque Langobardi ipsam opsidentes conprehendere valeant civitatem; eamque concedat imperatori cum hominibus et facultatibus quae in ea consistunt; et tantummodo ducem illum atque eius nutritorem Iohannem praedicto regi restituant. $\mathrm{Zu}$ 
Auch in diesem Brief kommen Greci vor, wenn von der Fraktion des Kaisers im Allgemeinen die Rede ist. Auffällig ist aber, dass er ohne besondere negative Epitheta auskommt, obwohl die Situation für den Papst politisch eher unerfreulich war. Generell zeigt Paul aber die Vertreter des Kaisers als intrigant-konspirativ, so wie auch den Langobardenkönig. Auch wenn keine pejorativen Adjektive verwendet werden, ist die Darstellung klar kritisch. Paul schildert sogar das Schreckensszenario, dass sich die Allianz zwischen Langobarden und Griechen nach Tarent auch gegen das nun päpstliche Ravenna richten könnte, „und dem Kaiser alle seine Wünsche erfüllt würden - was der Herr nicht erlauben möge!“. Mit dieser Aussage wird Konstantin V. sogar fast auf eine Stufe mit Desiderius gestellt, dem das hier parallel zu sehende, klassisch-antilangobardische Deo sibi contrario zur Seite gestellt wird.

Wir müssen also festhalten, wie leicht es Stephan II. und Paul I. fiel, den Terminus Greci ins päpstliche diplomatische Repertoire aufzunehmen. Sie verbanden den Begriff meist mit dem Ikonoklasmus, den Paul bei mehreren Gelegenheiten am Beginn seines Pontifikats sogar ausdrücklich als Häresie beziehungsweise unorthodox anprangerte.

Das kurzfristige Ziel dieser rhetorischen Offensive war möglicherweise, eine weitgehende Allianz zwischen den Franken und dem Kaiser zu verhindern. Doch um dieses Ziel zu erreichen, hätte es der neuen Rhetorik nicht bedurft, denn man hätte auch die Strategie der Vorgängerpäpste bis Zacharias verfolgen können und die Kritik an den Kaisern oder ihren Amtsträgern festmachen können. Und es ist auch nicht so, dass diese Möglichkeit nicht genutzt worden wäre, wie CC I7 klar belegt: Hier finden wir gleich mehrmals die Worte imperialis und imperaror(is).

Greci wurde also nicht verwendet, um einen direkten Bezug auf oströmische Offizielle bis hin zum Kaiser zu vermeiden und die Berichte allgemeiner zu gestalten. Die Bruderpäpste nutzten den Terminus vielmehr, um das ganze östliche Imperium mitsamt seiner Einwohner zu diffamieren. ${ }^{383}$ Dabei wurde möglicherweise sogar in Kauf genommen, einen Teil des eigenen römischen Klerus zu verstören. Denn der prominente Fall Papst Zacharias hat ja gezeigt, dass es Menschen in Rom gab, die sich als Greci fühlten und bezeichneten. Allerdings müssen wir in Betracht ziehen, dass es sich dabei durchaus um eine Minderheit innerhalb der großen kulturell griechischen Minderheit Roms gehandelt haben kann.

Liutprand von Benevent und der Rolle des nutritor Johannes siehe Stefano Gasparri, I duchi longobardi (Studi storici 109, Rom 1978) 96-98.

383 Eine ähnliche verallgemeinernde Strategie verfolgte die Vita Stephans II. im LP im Hinblick auf die Langobarden. Siehe unten, Kap. 5.3 und 5.4. 
Es ist zumindest nicht auszuschließen, dass gewisse Ressentiments gegen die römischen Griechen bei der Wortwahl der Päpste eine Rolle gespielt haben könnten. Dass es solche Ressentiments der „lateinischen“ Mehrheit gegen die einflussreichen Griechen gab, ist jedenfalls sehr wahrscheinlich. ${ }^{384}$ Doch Stephan und Paul waren unter dem Syrer Gregor III. in die schola im Lateran gekommen, waren von Zacharias zu Diakonen geweiht worden und waren somit Teil des Systems dieser beiden Päpste, in dem die Griechen immer noch eine beträchtliche Rolle spielten. ${ }^{385}$

Tatsächlich waren Formen von Grecus die einzige gangbare Möglichkeit, auf allgemeine Weise die Kerngebiete des Kaiserreichs und die Menschen von dort zu benennen. Denn sobald sie stattdessen imperium verwendet hätten, hätten sie sich zumindest in ihren eigenen Augen und bis zu einem gewissen Grad auch sich selbst miteinbezogen. Rom war immer noch Teil des Römischen Reichs! Die maßgeblichen Amtsträger im Lateran müssen ab 757 gefühlt haben, dass die alte Taktik, sich nicht dezidiert über die Unterschiedlichkeit innerhalb des Imperiums, über die Andersartigkeit der Romaioi im Osten zu äußern, nicht ausreichte, um das Papsttum vom Kaiser abzuheben. Ohne also auf umständliche Umschreibungen, wie imperiale potentia in der Vita Stephans II. zurückgreifen zu müssen, war nur die Bezeichnung Greci praktikabel.

Indem sie also die Bezeichnung „Griechen“ verwendeten, verfolgten die Päpste ihre eigene „strategy of distinction“386. In der großen Menge der römischen Bürger, der Romani, gab es nun auf der einen Seite das Papsttum und ihren peculiaris popu$l u s^{387}$ im Dukat von Rom und generell in weiten Teilen Mittelitaliens und auf der anderen Seite die Greci, die auch für den Kern des Imperiums im Osten und die Proponenten von dessen kirchlicher und weltlicher Verwaltung standen. Moderne Historiker - und Byzantinisten - versuchen diese Diskrepanz über den Hilfsausdruck „Byzanz“ zu vermitteln.

Die neue Sitaution stellte sich also so dar: Das kaiserliche Heer verteidigte den Dukat von Rom nicht mehr und die Häresie der Kirchen im Osten war durch ein

384 Ekonomou, Byzantine Rome 247, liefert ein Beispiel aus dem siebten Jahrhundert.

385 LP I, 463: Hic [Paulus] ab ineunte etate in Lateranensi patriarchio cum proprio seniore germano Stephano, predecessore eius pontifice, pro eruditione ecclesiastice discipline traditus est, temporibus domni Gregorii secundi iunioris pontificis; et postmodum a domno Zaccharia beatissimo papa in diaconii ordine pariter cum antelato suo germano consecratus est.

386 Siehe dazu Walter Pohl, Introduction, in: Strategies of Distinction: The Construction of Ethnic Communities, 300-800, ed. Walter Poh1/Helmut Reimitz (The Transformation of the Roman World 2, Leiden/Boston/Köln 1998) 1-15 und ders., Telling the Difference, bes. 22-27 über Sprachen.

387 Noble, Republic 51 hat aus diesem Terminus, der spätestens in der LP-Vita des Zacharias vorkommt (LP I, 427), auf Englisch den Begriff „peculiar people“ geprägt. 
Konzil bestätigt worden - wenn auch nicht für den äußersten Osten und auch in Anatolien nicht allumfassend. Diese Situation zwang die Päpste, sich von Kaiser und Reich zu distanzieren, was sie dadurch erreichten, dass sie ihre Antagonisten im Reich pauschal als Greci bezeichneten.

Zum ersten Mal im achten Jahrhundert betrieben die Päpste um die Mitte des achten Jahrhunderts also gezieltes Othering gegen die „Griechen“. Sie verwendeten Sprache und Kultur dabei als herausragendste Anzeichen und nahmen offenbar bewusst die eigentlich unzureichende Trennschärfe ihrer neuen Rhetorik in Kauf.

Wir müssen allerdings klar festhalten, dass die Päpste ihre diplomatische Sprache aller Wahrscheinlichkeit nach nicht jener ihrer Adressaten, der Franken, anpassten. Dafür nämlich schätzten sie ihre eigenen althergebrachten Formen viel zu sehr: So setzte Paul I. in seiner Kommunikation mit Pippin erwiesenermaßen Elemente aus dem sogenannten Liber Diurnus ein, die eigentlich für den diplomatischen Verkehr innerhalb des Imperiums entwickelt worden waren. ${ }^{388}$

Die Päpste passten also nicht unbedingt ihre Rhetorik ihren Adressaten an, sondern drückten nun deutlicher als zuvor die schon längere Zeit veränderte Situation im Römischen Reich aus.

Paul I. starb am 28. Juni 767 und schon in den letzten Monaten seiner Regierungszeit, als sich sein Tod offenbar schon abzeichnete, hatten sich Wirren angekündigt. ${ }^{389}$ Der lokale Machthaber Toto von Nepi rückte direkt nach dem Ableben des Papstes in Rom ein und setzte innerhalb von kurzer Zeit seinen Bruder als Papst Konstantin II. ein. Dieser durchlief dabei die Weihen in sehr schneller Folge und blieb wohl in Rom relativ umstritten. Der mächtige primicerius notariorum Christophorus und sein Sohn und secundicerius Sergius widersetzten sich seiner Herrschaft, schafften es aber, Rom, unter dem Vorwand ins Kloster zu gehen, zu verlassen. Mit langobardischer Hilfe gelang es ihnen jedoch, wieder in Rom einzurücken und im August 768 ihren Kandidaten, Stephan III., zum Papst erheben zu lassen. Zu den Ereignissen in Rom siehe ausführlicher unten, Kapitel $5 \cdot 5 \cdot{ }^{390}$

388 CC 12, ed. Gundlach 507f. Siehe Hack, Codex Carolinus, Bd. 1, 641f., Anm. 763 und ebd., 391, mit Anm. 209. Siehe auch Liber Diurnus, V60=C59, ed. Förster 114-117.

389 LP I, 468 (Vita Stephans III.)

390 Im Kapitel zu den Langobarden wird diese Situation ausführlicher analysiert, da vor allem die Beteiligung König Desiderius' für starke Emotionen sorgte. Für grundlegende Informationen über den Pontifikat Stephans III. siehe LP I, 468-480, und Ottorino Bertolini, La caduta del primicerio Cristoforo (771) nelle versioni dei contemporanei, e le correnti antilongobarde e filolongobarde in Roma alla fine del pontificato di Stefano III (771-772), in: Rivista di Storia della Chiesa in Italia, 1, n. 2-3 (1947) 227-289, ND in ders., Scritti Scelti di Storia Medievale, 2 Bde, ed. Ottavio Banti (Livorno 1968) Bd. 2, 615-677 (im Folgenden benutzte Version), sowie Noble, Republic 113-116. 
Stephan III. kam, wie bereits ausführlich erörtert, aus dem stark gräzisierten Sizilien, ${ }^{391}$ war aber seit jungen Jahren im römischen Klerus tätig und zum Zeitpunkt seiner Erhebung Kardinalpriester von Santa Cecilia. Er wird in seiner LP-Vita als Vertrauter Pauls I. beschrieben, der ihm auch an seinem Sterbebett zur Seite gestanden ist (und deshalb nach seinen eigenen Angaben nicht am Staatsstreich Totos beteiligt gewesen sein kann). ${ }^{392}$

Die LP-Vita wurde aber dennoch nicht von einem Anhänger der Politik dieses Papstes geschrieben. Wie die meisten Viten des LP wurde sie erst unter dem nachfolgenden Papst, in diesem Fall Hadrian I., fertiggestellt, es spricht aber sogar einiges dafür, dass die Vita in der vorliegenden Form überhaupt erst im Pontifikat Hadrians geschrieben wurde. Der Text wirkt sehr wie eine Art Vorgeschichte für den ersten Teil der Vita Hadrians und wurde aller Wahrscheinlichkeit nach vom selben Autor verfasst. Doch damit nicht genug: Raymond Davis, der Übersetzer des LP, hat die Vita Stephans III. mit einigem Recht als verkappte Vita Christophori bezeichnet, denn der mächtige primicerius ist in vielerlei Hinsicht der eigentliche Held der Erzählung. Sein Name wird öfter genannt als jener des Papstes und nachdem er im Jahr 77I in Ungnade fällt und an den Folgen seiner Blendung stirbt, bricht die Vita sehr unvermittelt ab und schildert die letzten Monate des Pontifikats nicht mehr. ${ }^{393}$ Insofern kann die Vita für den Pontifikat Stephans nur unter erhöhter Vorsicht als Quelle herangezogen werden - für das „Griechen“-Bild ist sie als Zeugnis aus dem Pontifikat Hadrians zu betrachten. ${ }^{394}$

Daneben existieren aus dem Pontifikat Stephans III. noch fünf Briefe, die allesamt im CC überliefert sind ( $\mathrm{CC}_{44}$ bis 48 ) und an verschiedene karolingische Adressaten gerichtet sind.

Schon aus diesem kleinen Sample lässt sich jedoch sagen, dass sich Stephan nicht der Rhetorik seiner Vorgänger angeschlossen hat. Klar ist, dass sich die Briefe vor allem mit der schwierigen Situation in Rom, die seinen ganzen Pontifikat lang anhalten sollte, beschäftigen.

In Stephans Briefen findet sich auch $\mathrm{CC}_{45}$, das Paradebeispiel, wie antilangobardische Ressentiments in den 77oer-Jahren in Rom instrumentalisiert werden konnten. ${ }^{395}$

In diesem Brief kommt auch die Sprache auf einen früheren Heiratsplan zwischen den Karolingern und dem Kaiser: Der Mitkaiser Leon IV., Sohn von Kaiser Kon-

391 Siehe oben, Kap. 3.2.3 und 3.2.4.

392 LP I, 468.

393 Siehe Davis, LP 8, 87 und 107. LP I, 480.

394 Siehe Hartmann, Hadrian 8.

395 CC 45, ed. Gundlach 560-563. Der Brief zielte darauf ab, eine geplante Heiratsallianz zwischen den herrschenden Karolingern, Karl dem Großen und Karlmann, und einer Tochter des Langobardenkönigs Desiderius zu verhindern. Siehe dazu unten, Kap. 5.5.2. 
stantin V., hätte die Tochter König Pippins heiraten sollen, doch die Heirat wurde abgesagt. In diesem Beispiel jedoch griff Stephan III. auf die alte Strategie der Päpste vor Stephan II. zurück:

Und ich bitte euch daher auch, euch folgendes ins Gedächtnis zu rufen: - denn auch wenn der Kaiser Konstantin [V.] versuchte, euren gnädigen Vater seligen Angedenkens zu überreden, seinen Sohn [Leon IV.] mit eurer Schwester, der edelsten Gisela, zu verheiraten, und dass es euch nicht erlaubt sein solle, euch mit [Frauen] anderer Herkunft zu verbinden - dass ihr dies jedoch nicht gegen den Willen der Bischöfe des apostolischen Stuhls in irgendeiner Weise durchführen sollt. ${ }^{396}$

Kaiser Konstantin und sein Sohn werden zwar eindeutig als von den Franken alienigeni behandelt, doch es wird in für das vorliegende Schreiben geradezu frappierend untypischer Weise auf diesen Umstand nicht ausdrücklich hingewiesen. Konstantin wird wieder nur als imperator bezeichnet, sein Sohn namentlich nicht einmal genannt. Beide kommen aber ohne jegliches Epithet aus. Ungefähr so hatten auch die päpstlichen Darstellungen des frühen achten Jahrunderts geklungen.

Ein noch wesentlich klareres Bild bieten die Akten des Konzils, das Stephan III. im Jahr 769 einberief und zu dem auch eine Reihe von fränkischen Bischöfen gekommen war. ${ }^{397}$ Das Hauptziel des Konzils war zweifellos, die Herrschaft Stephans zu legitimieren und verbindliche Regeln für die Papstnachfolge zu schaffen, die vor allem die römischen Laien von der Wahl ausschließen sollten und somit Probleme wie 767 vermeiden helfen sollten. ${ }^{398}$

In der vierten Actio beschäftigte sich das Konzil jedoch auch mit der Frage der Bilder. Die Kanones sind erst im elften Jahrhundert in der kanonistischen Sammlung des Kardinals Deudedit überliefert, in der Forschung wird sein Text trotz des zeitlichen Abstandes aber als durchaus glaubwürdig gesehen. ${ }^{399}$ Es ist jedenfalls auffällig, wie allgemein die Bestimmungen des Konzils gehalten sind:

396 CC 45, ed. Gundlach 562 (leicht verändert wiedergegeben, siehe Anm. 624): Itaque et hoc, peto, ad vestri referre studete memoriam: eo quod, dum Constantinus imperator nitebatur persuadere sanctae memoriae mitissimum vestrum genitorem ad accipiendum coniugio filii sui germanam vestram nobilissimam Ghisylam neque vos aliae nationi licere copulari, sed nec contra voluntatem apostolicae sedis pontificum quoquo modo vos audere peragere.

397 Die Liste der Teilnehmer findet sich in einer einzigen LP Handschrift, nämlich Leiden, Vossianus Lat. Q. 41 (B4 nach Duchesne). Siehe Duchesne, LP I, 482, Anm. 28.

398 Concilium Romanum a. 769 (ed. Albert Werminghoff, MGH LL Conc. 2, 1, Concilia aevi Karolini (742-842), Hannover/Leipzig, 1906) 74-92. Siehe dazu auch Hartmann, Hadrian 60f. und 66-69.

399 Concilium Romanum a. 769, ed. Werminghoff 87-88. Siehe Hartmann, Hadrian 67, mit Anm. 165, der darauf hinweist, dass der Text stilistisch gut ins achte Jahrhundert passt. Auch anhand des 
Item. Es ist zu befürchten, dass im Zuge des Streits um die Bilder sich die Lage der bösen Lehrmeinungen noch verschlechtert und dass es verboten wird, die Körper der Heiligen und die Reliquien der Märtyrer als Glieder des Herren anzubeten und zu verehren.

$[\ldots]$

Item. Wenn jemand sich weigert, die heiligen Bilder unseres Herrn Jesus Christus und seiner Mutter, sowie aller Heiligen nach den Erlässen der heiligen Väter, zu verehren, so ist er zu exkommunizieren (anathema sit). ${ }^{400}$

Wir sehen, dass sich die Beschlüsse des Konzils weder an eine bestimmte Person noch an eine bestimmte Region richten. Auch Verstöße werden im Prinzip nicht genau definiert, es wird nur auf die „Heiligen Väter“ verwiesen.

Im Jahr 769 war es wohl nicht besonders opportun, den Kaiser direkt anzugreifen, und doch würde man erwarten, etwas über die Urheber und die geographische Verbreitung des Ikonoklasmus lesen zu können. Doch offenbar vermied man es absichtlich, konkreter zu werden. Das Material, das dem Pontifikat Stephans III. zugeordnet werden kann, ist zwar karg, es besteht aber doch die Möglichkeit, dass Rom sich zwischen 768 und 772 wieder an die alten, sehr zurückhaltenden Kommunikationsregeln gehalten haben könnte.

\subsection{Der Pontifikat Hadrians I.: Die formale Loslösung Roms}

Nach dem Tod Stephans III. Anfang des Jahres 772 wurde Hadrian I. zum römischen Bischof gewählt. Die Wahl erfolgte verdächtig rasch und es ist absolut möglich, dass schon weniger als drei Jahre nach dem Konzil von 769 gegen dessen Bestimmungen verstoßen wurde. ${ }^{401}$

Hadrian war in vielerlei Hinsicht der ideale Kandidat der römischen Oberschicht: Er stammte aus einer adeligen Familie, aber war auch in der päpstlichen Administration gut verankert. Bekannt ist vor allem sein Onkel Theodotus. Dieser trug zwar

dezidierten Hinweises auf die Situation im Umland Roms meint Hartmann einen größeren Eingriff in den Text durch Deusdedit ausschließen zu können. Auch der LP überliefert eine Zusammenfassung des Konzils, auch zu Actio 4 (LP I, 476f.), doch dort wird eine auffällig andere Terminologie verwendet - wie wir unten in Kap. 4.3 noch genauer sehen werden.

400 Concilium Romanum a. 769, ed. Werminghoff 87: Item. Pavendum est, ne sub iconarum occasione ad peiora sese status male assertionis erigat et corpora sanctorum et reliquias martyrum adorari tanquam membra Domini ac venerari prohibeatur.

Item. Si quis sanctas imagines domini nostri Ihesu Christi et eius genitricis atque omnium sanctorum secundum sanctorum patrum statuta venerari noluerit, anathema sit.

401 Hartmann, Hadrian 63-69. 
einen griechischen Namen, es kann aber kein Zweifel bestehen, dass er zur Elite der lateinischen Mehrheit Roms gehörte. Er hielt im achten Jahrhundert eine Reihe von bedeutenden Posten. In der weltlichen Verwaltung brachte er es bis zum höchsten Amt, dem dux, das er unter Zacharias bekleidete. Es dürfte recht klar sein, dass auch dieser Teil der Verwaltung der Stadt in den 740ern de facto vom Lateran kontrolliert wurde. ${ }^{402}$ Danach kam Theodotus auch in der päpstlichen Verwaltung noch an den wichtigen Posten des primicerius defensorum. Er diente unter den Päpsten Zacharias, Stephan II. und Paul I. ${ }^{403}$ Theodotus war mit seinem Haus in der Via Lata sogar ein Nachbar der Bruderpäpste. Theodotus schaffte es sogar in die visuelle Repräsentation Roms Einzug zu halten, was sehr deutlich seinen Einfluss und seinen Reichtum belegt: Als er das Amt des primicerius defensorum innehatte, ließ er unter Zacharias eine Kapelle in St. Maria Antiqua errichten, in der sowohl der Papst als auch Theodotus selbst abgebildet sind. ${ }^{404}$

Sein Neffe Hadrian war relativ früh zum Vollwaisen geworden und somit oblag seinem Onkel seine Förderung. Er dürfte ihm eine gute Erziehung ermöglicht haben und dafür gesorgt haben, dass der junge Mann im römischen Klerus einen raschen Aufstieg nahm..$^{405}$

Die Quellenlage zu Hadrian I. ist an sich hervorragend, von ihm sind mehr Briefe überliefert als von allen Päpsten des achten Jahrhunderts vor ihm zusammen. Auch die Vita im LP ist zumindest sehr lang, ihr historischer Teil reicht jedoch lediglich bis zum Sommer 774. Wahrscheinlich wurde dieser Teil der Vita vom selben Autor verfasst, der quasi als Vorgeschichte die Vita Stephans III. geschrieben hatte. ${ }^{406}$ Nach dem Jahr 774 klafft, jedenfalls was die politische Geschichte betrifft, ein Loch im LP, doch die Briefe kompensieren uns in gewisser Weise dafür. Die Briefe Hadrians, von denen wieder der Großteil im CC überliefert ist, setzen jedoch erst im Herbst oder Spätsommer des Jahres 774 ein, davor haben wir also wieder hier eine Lücke von fast zweieinhalb Jahren. Das ist umso beklagenswerter, als der LP für genau diese

402 Wahrscheinlich konnten Gregor II. oder III. die weltliche Verwaltung unter ihre Kontrolle bringen, nachdem Gregor II. aus dem Steuerstreit der 720er als faktischer Sieger hervorgegangen war.

$403 \mathrm{Zu}$ seiner Person siehe Hartmann, Hadrian 37-42 und Bavant, Duché 76-78.

404 Siehe dazu ausführlicher Hartmann, Hadrian 40-42.

405 Brown, Gentlemen 172 und 185f. und Hartmann, Hadrian 60-62. Zu den spärlichen Informationen über Hadrians Ausbildung, siehe ebd., 293f. Traditionellerweise wird aber davon ausgegangen, dass Hadrian eine herausragende Ausbildung erhielt, siehe Noble, Knowledge 61. Angesichts seines familiären Hintergrunds und des Faktums, dass er schon in jungen Jahren im Lateran ausgebildet wurde, ist auch tatsächlich davon auszugehen. Hartmann, Hadrian 293f. zweifelt jedoch an, dass das auch bedeuten muss, dass er eine sehr gute theologische Ausbildung hatte. Tatsächlich tat sich Hadrian in seinem Pontifikat eher als Politiker und Administrator hervor.

406 Davis, LP 8, 85 und 107. 
Zeit eine Darstellung liefert, die mit Sicherheit aus der Rückschau frühestens 775 geschrieben wurde. ${ }^{407}$

Im Jahr 774 veränderte sich die politische Situation in Italien auf entscheidende Weise. Karl der Große marschierte auf Bitte Hadrians in der Poebene ein, setzte schließlich den Langobardenkönig Desiderius ab und machte sich selbst zum König. Dadurch entledigte er den Papst der bei weitem größten Bedrohung für die territoriale Intergrität des römischen Dukats und für die faktische Autonomie des Laterans innerhalb seines Herrschaftsgebiets. Diese wesentliche Veränderung verschaffte Hadrian einen im Vergleich zu seinen Vorgängern geradezu komfortablen politischen Spielraum. Diesen nutzte der Papst, um Rom und das Papsttum de iure vom Kaiser loszulösen. Das Jahr 78I stellt eine Art terminus ante quem für dieses Vorgehen dar, denn in diesem Jahr ist die erste päpstliche Urkunde erhalten, die nicht nur nicht mehr nach den Regierungsjahren des Kaisers datiert wurde, sondern nach den Pontifikatsjahren Hadrians selbst sowie den Inkarnationsjahren (AD-Datierung). Die letzte Urkunde davor ist allerdings bereits 772 überliefert, in ihr wurden die Regierungsjahre Konstantins V. verwendet. ${ }^{408}$ Man muss nun in Betracht ziehen, dass bereits das Konzil von 769 nicht mehr nach dem Kaiser datierte, doch hier wurde ausschließlich die Inkarnationsdatierung verwendet, was vielleicht so gerechtfertigt wurde, dass es in dem Konzil um kirchliche Belange gegangen sei. ${ }^{409}$ Die Verwendung der Regierungsjahre des Papstes ließ dann 78 I wirklich keinen Zweifel mehr an der neuen Rechtslage aus Sicht Roms.

Erst kürzlich wurde von Hartmann sehr überzeugend argumentiert, dass Hadrian die formale Sezession Roms bereits 775 oder 776 durchführte. Etwa um diese Zeit begann der Papst, seine eigenen Münzen zu prägen, die sich nicht mehr an das Vorbild aus Konstantinopel hielten. Die erste Serie trug dabei das Bildnis des Heiligen Petrus, die zweite schon jenes Hadrians - der ultimative Ausdruck des päpstlichen Herrschaftsanspruchs. ${ }^{410}$

Die Situation 775 war für ein entsprechendes Vorgehen des Papstes auch tatsächlich äußerst günstig: Nicht nur die Bedrohung des Dukats von Rom durch die

407 Siehe dazu ausführlicher unten, Kap. 5.6.

408 Siehe Hartmann, Hadrian $157 f$.

409 Siehe Concilium Romanum a. 769, ed. Werminghoff 75: Eisque in hanc Romanam urbem coniungentibus mense Aprile, indictione septima, protinus antedictus Stephanus sanctissimus papa adgregans diversos episcopos Tusciae atque Campaniae et aliquantos istius Italiae provinciae, ... Es sei aber darauf hingewiesen, dass es sich hier möglicherweise gar nicht um die offizielle Datierung der Akten des Konzils handelt, da diese nirgendwo im Volltext überliefert, geschweige denn im Original erhalten sind.

410 Hartmann, Hadrian 173, siehe Philip Grierson/Mark Blackburn, Medieval European Coinage. The Early Middle Ages (500-1000) (Cambridge 1986, 2007) $259 \mathrm{f}$. 
Langobarden war weggefallen, auch in Konstantiopel gab es Umwälzungen: Nach etwa 32 Jahren uneingeschränkter Herrschaft war 775 Konstantin V. verstorben und ihm folgte sein Sohn Leon IV., über den überraschend wenig in den Quellen berichtet wird, in den päpstlichen gar nicht. Es ist davon auszugehen, dass in Rom der neue Kaiser einfach nicht anerkannt wurde. Hartmann geht sogar, allerdings ohne Beweise, davon aus, dass der formale Akt der Nichtanerkennung dadurch gesetzt wurde, dass die Übernahme des Kaiserbildnisses oder zumindest seine Aufstellung im Palast am Palatin verweigert wurde. Achim Hack hat demgegenüber, ebenfalls ohne Beweise, eine Fortführung der Tradition der Bildeinholung für wahrscheinlich erachtet. Es wäre allerdings aus der römischen Perspektive unlogisch gewesen, das Bild einzuholen und aufzustellen und gleichzeitig den Kaiser nicht mehr anzuerkennen, was Hartmanns Position wahrscheinlicher wirken lässt. ${ }^{411}$ Aus Konstantinopel gibt es im Übrigen keinerlei Nachricht über die Loslösung des Papstes. ${ }^{412}$

Doch selbst wenn wir davon ausgehen, dass dieser demonstrative Akt unterlassen wurde: Es spricht alles dafür, dass sich Hadrian 775 oder 776 formal vom Römischen Reich lossagte. Dass Rom zuvor schon faktisch unabhängig gewesen war, mag stimmen und doch war es schon allein psychologisch für beide Seiten ein entscheidender Schritt. Dieser war für den Papst umso leichter zu rechtfertigen, als die Religionspolitik des verstorbenen Kaisers als häretisch eingestuft worden war und auch der nunmehrige Nachfolger nominell daran beteiligt gewesen war und sich auch nicht anschickte, die Beschlüsse von Hiereia abzumildern. ${ }^{413}$

Doch wir dürfen nicht davon ausgehen, dass ein derartiger Einschnitt in die rechtliche Situation Roms unwidersprochen vonstattengehen konnte. Wir haben oben in Kapitel 3.2.2 gesehen, wie stark Rom personell und vor allem ideell mit dem Osten verbunden war. Besonders der Gedanke des Römischen Reichs war in der Stadt Rom nicht so einfach loszuwerden: War denn Rom ohne das Imperium überhaupt denkbar (und umgekehrt)?

Die Sezession vom Kaiser brachte also zweifellos wesentlich mehr Reibungsenergie, als man zunächst vermuten könnte. Insofern war Hadrian gezwungen, sich, das

411 Hartmann, Hadrian 164-171, dagegen Achim Thomas Hack, Bildaussendung und Bildeinholung im 7. und 8. Jahrhundert, in: Saeculum, 54 (2003) 147-177, hier 165-169.

412 Siehe Regesten, ed. Dölger/Müller 174-178, bes. 177: Es gibt überhaupt keine relevanten Dokumente für die Regierung Leons IV.

413 Zum Bruch mit Konstantinopel 775/76 siehe Hartmann, Hadrian 164-172. Hageneder, Crimen maiestatis 72 hat zuvor ebenfalls bereits in diese Richtung argumentiert und ist von einem Zeitpunkt kurz nach 774 ausgegangen. Siehe auch Thomas F. X. Noble, Topography, Celebration and Power: The Making of Papal Rome in the Eighth and Ninth Centuries, in Topographies of Power in the Early Middle Ages, ed. Frans Theuws/Mayke de Jong (The Transformation of the Roman World 6, Leiden/Boston/Köln 2001) 45-91, hier 73. 
Papsttum und Rom so stark wie möglich vom Kaiser abzugrenzen. Er verwendete dafür, wie schon Stephan II. und Paul I., den Begriff Greci, die größtmögliche Form des Othering gegen den Kaiser und das Imperium, allerdings mit verstärkter Frequenz: Hatten die Bruderpäpste noch in ihren zusammen 40 CC-Briefen den Begriff Greci sieben Mal in sechs Briefen verwendet ${ }^{414}$, so tat Hadrian das in 49 Briefen derselben Sammlung $22 \mathrm{Mal}$ in acht Briefen, wie aus Tabelle 2 ersichtlich wird.

Tabelle 2: Codex Carolinus Briefe, die den Terminus Greci enthalten ${ }^{415}$

\begin{tabular}{|c|c|l|l|l|c|}
\hline CC Nr. (MGH) & MGH, S. & von Papst & Adressat & Datierung & Anzahl \\
\hline II & 506 & Stephan II. & Pippin III. & 757 & I \\
\hline I7 & 5 I5 & Paul I. & Pippin III. & 758 & I \\
\hline 30 & 536 & Paul I. & Pippin III. & Ende 759 ? & 2 \\
\hline 32 & 539 & Paul I. & Pippin III. & $760 ?$ & I \\
\hline 37 & 549 & Paul I. & Pippin III. & Ende 766 & I \\
\hline 38 & 55 I & Paul I. & Pippin III. & $759 / 760$ & I \\
\hline 57 & 582 & Hadrian I. & Karl d. Große & Februar 776 & I \\
\hline 59 & 585 & Hadrian I. & Karl d. Große & 776 & 5 \\
\hline 63 & 590 & Hadrian I. & Karl d. Große & $776-780$ & 2 \\
\hline 64 & $59 \mathrm{I}$ & Hadrian I. & Karl d. Große & 780 & 2 \\
\hline 80 & 613 & Hadrian I. & Karl d. Große & 787 & 2 \\
\hline 82 & 616 & Hadrian I. & Karl d. Große & $787 / 788$ & I \\
\hline 83 & $617 f$. & Hadrian I. & Karl d. Große & $787 / 788$ & 6 \\
\hline 84 & 620 & Hadrian I. & Karl d. Große & $787 / 788$ & 3 \\
\hline
\end{tabular}

414 Hier wird die eine spezifische Erwähnung der Griechischen Sprache nicht mitgerechnet, die sich in CC 24 findet: Greco eloquio. Derselbe Ausdruck wird auch in CC 99, dem zweiten Brief von „Gegenpapst“ Konstanin II., verwendet. Es handelt sich in beiden Fällen um eine generische Bezeichnung der Sprache, die nicht mit bestimmten Individuen verknüpft ist. In CC 24 geht es um griechische Bücher, in CC 99 um einen Brief aus den östlichen Patriarchaten, den Konstantin II. ins Frankenreich auf Griechisch und Latein weiterleitete.

415 Die Datierung für die Briefe Pauls I. folgt Kehr, Chronologie, ausgenommen CC 37, der von Michael McCormick, Textes, images et iconoclasme dans la cadre des relations entre Byzance et l'occident Carolingien, in: Testo e imagine nell'alto medioevo (Settimane di studio del Centro italiano di studi sull'Alto Medioevo, 41, Spoleto 1994) 95-162, hier 116-122, noch überzeugender datiert werden konnte. CC 11 von Stephan II. ist aus dem Text heraus zweifelsfrei zu datieren. Zu Hadrians Briefen: Zu CC 57 und 64 siehe Ottorino Bertolini, Carlomagno e Benevento, in: Karl der Große, Bd. 1, Persönlichkeit und Geschichte, ed. Wolfgang Braunfels/Helmut Beumann (Düsseldorf 1965) 609-671, hier 615, Anm. 28 und 622, Anm. 75. Zu CC 80-82 siehe Hack, Codex Carolinus 615-624, und Bertolini, Carlomagno 637f. Für CC 59 und 63 wird die Datierung aus Gundlachs MGH-Edition angegeben. 
Dazu müssen wir auch noch in Betracht ziehen, dass Stephan und Paul ihre MalitiaGrecorum-Vorwürfe unter dem Eindruck des Konzils von Hiereia entwickelten. Dazu kamen dann noch die Versuche des Kaisers, direktere Kontakte zu den Franken zu knüpfen: Besonders Paul I. musste sein ganzes diplomatisches Können gegen diese Bedrohung aufbieten.

Hadrian I. stand zunächst nicht vor so entscheidenden Differenzen mit dem Osten, also war er an sich nicht gezwungen, den Franken die päpstliche Politik in derselben Intensität anzupreisen wie seine Vorgänger. Doch wie diese fürchtete auch er das Auftreten einer oströmischen Armee in Mittelitalien. Schon in CC 57, der von Ende 775 stammt, findet sich diese Sorge, die sich tatsächlich erst über ein Jahrzehnt später als begründet erweisen sollte. Hier berichtet Hadrian unter anderem darüber, dass eine Rückkehr des ehemaligen langobardischen Mitkönigs Adelchis aus seinem Exil in Konstantinopel bevorstehe und dass dieser von ,griechischen“ Truppen unterstützt werde. ${ }^{416}$ Der Papst befürchtet sogar einen Angriff dieses Heeres auf Rom - insofern scheint es möglich, dass die formale Trennung vom Kaiser bereits erfolgt war, auch wenn dieser Schluss nicht zwingend notwendig ist.

Gegen Gottes Willen werden sie sich kommenden März mit einer Schar von Griechen und Adelchis, dem Sohn des Desiderius, vereinen, zu Wasser und zu Land über uns herfallen und uns in der Absicht bekämpfen, die Stadt Rom einzunehmen, alle Kirchen Gottes zu plündern, das ciborium über dem Grab Eures Gönners, des Heiligen Petrus, zu stehlen, uns selbst, was Gott verhindern möge, als Gefangenen abzuführen, wieder einen König der Langobarden einzusetzen und Eurer königichen Macht Widerstand zu leisten. ${ }^{417}$

Auch in einem weiteren Brief weist Hadrian Karl auf die Möglichkeit eines langobardischen Umsturzes und auf mögliche Angriffe auf Rom hin. ${ }^{418}$

Die moderne Historiographie neigt zumeist dazu den zugegebenermaßen sehr dramatischen Worten Hadrians keinen Glauben zu schenken. Ihm wird vorgeworfen, Panik verursachen zu wollen, um mit militärischer Hilfe der Franken doch noch die Kontrolle über die südlichen langobardischen Dukate erlangen zu können. Als an-

416 Siehe dazu ausführlicher unten, Kap. 5.6.2.3, wo auch der Brief detaillierter besprochen wird.

417 CC 57, ed. Gundlach 582: ... Deo eis contrario proximo Martio mensae adveniente utrosque se in unum conglobent cum caterva Grecorum et Athalgibs Desiderii filium et terrae marique ad dimicandum super nos irruant, cupientes hanc nostram Romanam invadere civitatem et cunctas Dei ecclesias denudare atque ciborium fautoris vestri, beati Petri, abstollere vel nosmet ipsos, quod avertat divinitas, captivos deducere nec non Langobardorum regem redintegrare et vestrae regali potentiae resistere. Die Übersetzung folgt teilweise Hartmann, Hadrian $217 f$.

418 CC 56, ed. Gundlach 580f. 
dere Möglichkeit wird angegeben, dass Hadrian am Spoletiner dux Hildebrand hätte Rache nehmen wollen, denn dieser hatte sich 773 zunächst dem Papst unterworfen, nur um im Laufe des Jahres 775 auf die Seite Karls des Großen zu wechseln. ${ }^{419}$ Nur einige wenige Forscher haben dem Schreiben hohe Glaubwürdigkeit attestiert, allen voran Ottorino Bertolini. ${ }^{420}$ Und tatsächlich sollten wir den Inhalt bei aller Rhetorik des Papstes nicht von der Hand weisen. Denn wenig später fand tatsächlich die Rebellion des Friauler dux Rotcaus statt, die zwar von den Franken sehr rasch niedergesschlagen wurde, aber wohl nur in der Retrospektive verharmlost werden kann - Hadrian konnte diese Entwicklung einige Wochen zuvor nicht vorhersehen. Klar ist also, dass es Unzufriedenheit unter den immer noch mächtigen langobardischen Großen gab. Insofern kann man dem Papst durchaus glauben, dass Gesandte dieser Potentaten in Spoleto zusammenkamen. Und dass dabei über für den Papst und die Karolinger wenig ersprießliche Optionen debattiert worden sein könnte, ist kaum auszuschließen. ${ }^{421}$

Was aber war die Rolle der Greci in diesen Entwicklungen? Wie real Hadrians Befürchtungen hier waren, lässt sich kaum noch ermessen, schließlich passierte 776 zunächst in Süditalien nichts. Doch erstens hatte er mit der langobardischen Rebellion durchaus recht, und zweitens versuchte Adelchis ja tatsächlich ein Jahrzehnt später (vergeblich) noch einmal in Italien Fuß zu fassen ${ }^{422}$ - und es ist nicht sehr wahrscheinlich, dass er tatsächlich vorhatte so lange zu warten und dass der Versuch 788 spontan erfolgte.

Papst Hadrian, der gerade dabei war, formal die kaiserliche Herrschaft abzuschütteln, mag das Treffen in Spoleto und Adelchis' Möglichkeiten in deren unmittelbarem Bedrohungspotential zunächst ein wenig überschätzt haben, doch seine Worte in $\mathrm{CC}_{57}$ waren alles andere als unbegründet.

Schon kurze Zeit später hatte Hadrian tatsächlich Probleme mit oströmischen Offiziellen. In CC 63 beschwerte er sich über "griechische" Einflussnahme in Istrien: Der Bischof Mauritius war von den Greci abgesetzt und geblendet worden. ${ }^{423}$

Richtig bedrohlich wurde die Situation jedoch auch in direkter Nähe Roms, wie wir aus CC 64 erfahren. Nach Auseinandersetzungen mit dem Beneventaner dux Arichis hatte Hadrian 778 die erste offensive Militäraktion des Papsttums befohlen, die Besetzung der Stadt Terrecina. Dabei war es auch zu Zerwürfnissen mit Reprä-

419 Hartmann, Hadrian 217f., mit Anm. 79 bietet einen Überblick über die relevante Literatur. Hartmann selbst bezeichnet ebd. den Brief als ,übertrieben“.

420 Bertolini, Carlomagno 617-620.

421 Siehe dazu unten, Kap. 5.6.2.3.

422 Siehe dazu unten, Kap. 5.6.2.4.

423 CC 63, ed. Gundlach 590. 
sentanten des Imperiums in der Region gekommen, insbesondere mit dem strategos von Sizilien. ${ }^{424}$

Somit grüßen wir eure allertriumphalste Güte [Karl d. Gr.] und durch unser Schreiben bringen wir, noch unverblümter als zuvor, Euch aus diesen Gegenden [Mittelitalien] zur Kenntnis, dass die unaussprechlichen Napolitaner gemeinsam mit den Gott verhassten Griechen, dem schlechten Rat des Arichis, dux von Benevent, folgend, zur Stadt Terracina gekommen sind, welche wir zuvor dem Dienst am Heiligen Petrus, sowie an uns und an Euch unterworfen hatten; die Stadt ist nun wegen schlechten Rats wieder von den genannten unaussprechlichen Napolitanern gemeinsam mit den falsch[gläubig]en (perversi) Griechen eingenommen worden. ${ }^{425}$

Auffällig ist zunächst die Unterscheidung zwischen den Neapolitanern und den Greci. Die große Mehrheit der Einwohner Neapels waren „kulturell lateinisch“; auch wenn sie Untertanen des Kaisers waren, wurden sie somit von Hadrian separat dargestellt. ${ }^{426}$ Dennoch waren sie Feinde des Papstes, wie das Adjektiv nefandissimi ganz klar illustriert.

Im vorliegenden Abschnitt ist aber vor allem von Interesse, wie massiv die Greci, bei denen es sich hier klar um Vertreter des Kaisers handelt, verbal attackiert werden. Sie sind immerhin Deo odibiles und perversi ${ }^{427}$ ! Diese Bezeichnungen waren bis dahin

424 Siehe Scholz, Politik 96; Noble, Republic 163f., und Bertolini, Carlomagno 620-623. Zu dem namentlich nicht genannten strategos von Sizilien (im Rang eines patrikios) siehe PmbZ, Anonymus \# 10976, Bd. 5, 390.

425 CC 64, ed. Gundlach 591: Quatenus salutantes triumphatorissime erga vos benivolentiae vestrae, per hos nostros affatus enucleatius vobis de partibus istis insinuamus, qualiter nefandissimi Neapolitani una cum Deo odibiles Grecos, praebente maligno consilio Arighis duce Beneventano, subito venientes Terracinensem civitatem, quam in servitio beati Petri apostolorum principis et vestro atque nostro antea subiugavimus, nunc autem invalido [Edition: in valido] consilio iterum ipsi iam fati nefandissimi Neapolitani cum perversis Grecis invasi sunt.

426 Zum dominanten lateinischen Element in Neapel schon im achten Jahrhundert siehe Granier, Moines 198: „Toutes les sources, sauf donc quelques inscriptions, sont en latin et signalent parfois l'origine grecque (italogreque le plus souvent) de certains personnages, ainsi bien distingués des $\mathrm{Na}$ politains: sinon de véritables étragers, en tous cas des gens présentés comme différents." Das schließt allerdings keinesfalls aus, dass oströmische Offizielle von der Stadt aus operieren konnten. So residierten zumindest bei einer Gelegenheit im achten Jahrhundert, 788, hochrangige "griechische“ Offiziere in Neapel wie CC 84, ed. Gundlach 620, belegt.

427 Es sei darauf hingewiesen, dass dieser Ausdruck nicht allein die heute gültigen Konnotationen transportieren muss, sondern „verirrt“ in jeder möglichen Schattierung des Wortes bedeuten kann. Wahrscheinlich handelt es sich um eine Anspielung auf den Ikonoklasmus. 
im achten Jahrhundert für die Langobardenkönige quasi „reserviert“ gewesen ${ }^{428}$ und sollten im neunten Jahrhundert vor allem den Sarazenen vorbehalten sein. ${ }^{429}$

Es waren Passagen wie diese, die Florian Hartmann dazu bewogen haben dürften, von „Hadrians bisweilen irrationale[r] Graecophobie“ zu schreiben. ${ }^{430}$ Davon kann aber keine Rede sein: Zugegeben, wir finden im vorliegenden Schreiben, ebenso wie in einigen anderen Briefen, zum Teil überraschend harte Rhetorik. Doch müssen wir auch an Beispiele wie den frühen Brief CC 57 denken: Es zeigt sich, dass die antigriechische Rhetorik Hadrians nicht nur situationsabhängig war (in CC 64 etwa stand für den Papst und den Dukat von Rom viel auf dem Spiel), sondern weit davon entfernt irrational oder ungewollt zu sein: Hadrian verwendete die Angriffe auf diffuse aber bedrohliche Greci absichtsvoll, um seine Feinde einem möglichst effektiven Othering unterziehen zu können.

Der Kern der Strategie Pauls I. wurde somit von seinem ehemaligen Günstling und Nachbarn übernommen, doch Hadrian verwendete eine deutlich schärfere Sprache und modifizierte die Taktik im Hinblick auf die Sachlage in seinem Pontifikat. Das führte zu einem wesentlichen Unterschied: In Hadrians Schreiben finden sich kaum noch Anspielungen auf den Bilderstreit. ${ }^{431}$ Das mag daran liegen, dass sich die Auseinandersetzung seit 754 durchaus abgekühlt haben könnte. Mit dem Tod Konstantins V. fiel übrigens der Proponent der Bilderfeinde weg und wenn von seinem Sohn Leon IV. kein Abrücken von den Beschlüssen in Hiereia bekannt ist, so scheint er doch kaum mehr Druck auf die auch im Osten immer noch starke ikonodule Opposition ausgeübt zu haben. ${ }^{432}$

Möglich ist aber auch, dass die Theologie nicht unbedingt das bevorzugte Metier Hadrians war, der sich in der Realpolitik und der Verwaltung wesentlich mehr zuhause fühlte. ${ }^{433}$

Zweifellos war Hadrian ein sehr begabter und effektiver Politiker, der sehr genau wusste, wie er mit den Franken, seinen wesentlichsten Verbündeten, in Bezug auf seine Feinde kommunizieren konnte. Wenn er also Kaiser, Reich und vor allem die

428 Siehe dazu unten, Kap. 5, wobei besonders die LP-Vita Stephans II. hierfür interessant ist.

429 Siehe zum Beispiel LP II, 81 (Gregor IV.).

430 Hartmann, Hadrian 172.

431 Das perversi in CC 64 könnte allerdings auf eine religiöse Irrlehre gemünzt sein und somit in diese Richtung weisen.

432 Brubaker/Haldon, Byzantium 248-250 und 262.

433 Hartmann, Hadrian 267-294, argumentiert das sehr schlüssig (siehe besonders sein Fazit, ebd., 300). Es mag allerdings sein, dass er Hadrian im Hinblick auf seinen möglichen Mangel an Gelehrsamkeit etwas zu negativ beurteilt. Klar ist, dass Hadrian sich eher als Staatsmann als als Theologe profilieren konnte, wenn man vielleicht vom römischen Beitrag zum zweiten Konzil von Nicäa absieht, an dem sein persönlicher Anteil nicht mehr ermessen werden kann. 
diffusen Greci immer wieder beschuldigte und pejorativ schilderte, so geschah das durchaus mit Kalkül.

Noch einmal müssen wir die politische Situation in Betracht ziehen: Spätestens 776 ist davon auszugehen, dass Rom sich formell vom Imperium gelöst hatte. Wahrscheinlich geschah das, indem man die „Gunst der Stunde“ nutzte und Leon IV. als Nachfolger Konstantins V. schlicht nicht mehr anerkannte. Niemals hatte ein Papst also bessere Gründe, Rom und Mittelitalien von den „Griechen“ abzugrenzen, als sie Hadrian hatte. Er musste seine trotz aller schon geschehenen Entfremdung immer noch revolutionäre Politik gegenüber seinen Zeitgenossen verteidigen; insbesondere in Rom muss es wichtig gewesen sein, die eigenen Schritte möglichst drastisch zu kommunizieren, und es ist doppelt schade, dass der LP zu diesen Aktionen nichts mehr zu berichten weiß. Es ist jedoch davon auszugehen, dass die formelle Sezession Roms besonders in der Stadt nicht auf ungeteilte Zustimmung gestoßen ist - es gab sicherlich Gruppen, die den Schritt für nicht günstig, vielleicht für verfrüht hielten. Es mag Loyalisten gegeben haben, die aus prinzipiellen Gründen nicht an ein Rom ohne Reich denken wollten, doch genau das war es, was Hadrian anstrebte. Es sei nur nebenbei bemerkt, dass, auf der Grundlage der Analyse in Kapitel 3.3 und 3.4, nicht davon auszugehen ist, dass die kulturell griechischen Römer die einzigen waren, die Kritik hätten üben können, oder dass sie Hadrians Politik geschlossen skeptisch gegenüber gestanden wären.

In Reaktion auf Hadrians Schritte operierten 778-780 jedenfalls südlich von Rom im Terracina-Konflikt oströmische Truppen offen gegen päpstliche Kontingente, was die Situation natürlich weiter eskalieren ließ (und sicher beiden Seiten in Rom Material für ihre Argumentation lieferte). ${ }^{434}$

Ein, wenn nicht der entscheidende Moment in Hadrians Politik war also die Sezession vom Kaiser Ende 775 oder im Lauf des Jahres 776. Er schlug sich in der Rhetorik nieder, die in den Papstbriefen ab CC 63 zu finden ist. ${ }^{435}$ Der einzige Brief, der vor dem Politikwechsel verfasst wurde, ist $\mathrm{CC}_{57}$, den wir oben schon im Detail gesehen haben. Und tatsächlich hielt sich Hadrian hier noch mit seiner Rhetorik zurück, und das, obwohl er ein relativ drastisches Schreckensszenario vom Fall Roms an Adelchis und seine griechischen Hilfstruppen entwarf. ${ }^{436}$

Problematisch ist allerdings, dass wir für den Pontifikat Hadrians nur über relativ wenige Texte verfügen, die die Zeit vor den entscheidenden Vorgängen zwischen 774 und 776 behandeln. Zweifellos kommen hier die LP-Einträge von Stephan III. und

$434 \mathrm{Zu}$ den wahrscheinlichen Spannungen in Rom siehe auch Hartmann, Hadrian 172 und 175.

435 Wahrscheinlich noch davor wurde CC 59 verfasst, der aber einen absoluten Ausnahmefall darstellt und unten gesondert behandelt wird.

436 Hartmann, Hadrian 172. 
Hadrian in Betracht: Die Vita Stephans wurde sicherlich während Hadrians Pontifikat geschrieben, wahrscheinlich vom selben Autor, der dann auch den ersten Teil der Vita Hadriani verfasste. Man kann sie sogar als eine Art Prolog für die zweite Vita verstehen. Der politische Teil der Vita Hadriani selbst wurde wahrscheinlich am Beginn des Jahres 776 verfasst und umfasst die ersten beiden Pontifikatsjahre Hadrians bis zum Fall Pavias im Frühsommer $774 .{ }^{437}$

Nach dieser Darstellung bietet die Vita Hadrians leider bis auf ganz kurze Einwürfe nur noch eine detaillierte Auflistung der Stiftertätigkeit des Papstes, was, trotz der Bedeutung dieser Liste für die Stadt- und Baugeschichte Roms, angesichts der historischen Bedeutung des Pontifikats nur bedauert werden kann.

In den beiden narrativen Sektionen des LP, die unter Hadrian entstanden sind, finden sich keine Greci, allerdings wird in beiden Texten je einmal der Ausdruck Greciae partes verwendet, der hier einer genaueren Erklärung bedarf. Raymond Davis hat ihn in seiner sonst beinahe fehlerlosen Übersetzung des LP als „districts of Greece" übersetzt, was aber leider äußerst verwirrend ist. ${ }^{43}$ Denn tatsächlich sind damit zweifellos die Kernregionen des Kaiserreichs gemeint, was Davis zwar nicht ausdrücklich in Abrede stellt, aber dennoch kann seine Übersetzung leicht falsch aufgefasst werden.

Der erste dieser Fälle findet sich im Zuge einer Zusammenfassung der Akten des römischen Konzils von 769, von dem ja oben bereits die Rede gewesen ist. Der Autor der Vita Stephans III. sagt, dass das Konzil von Hiereia 754 in eben dieser Gegend stattgefunden habe: ,jene abscheuliche Synode, die vor Kurzem in den Grecie partes abgehalten worden ist. ${ }^{439}$ Damit ist völlig klar, wo für den Autor die Grecie partes liegen. Es handelt sich hier um einen Zusatz zu den sonst zusammenfassend referierten Akten des römischen Konzils, die sich über den Ikonoklasmus nur in einem allgemeineren Ton und ohne genaue geographische Zuschreibung äußerten. ${ }^{440}$ Es handelt sich hier um die einzige erhaltene Stellungnahme gegen den Ikonoklasmus aus den ersten Pontifikatsjahren Hadrians I.

Die zweite Stelle, die den Ausdruck Greciae partes beinhaltet, stammt aus Hadrians Vita. Der cubicularius Paulus Afiarta, der unter Stephan III. nach dem Fall des primicerius Christophorus für kurze Zeit beträchtlichen Einfluss auf die Politik des Papstes nehmen hatte können, sollte wegen seiner Verwicklung in die Morde an eben

437 Der erste Teil der Vita Hadrians ist LP I, 486-499, Kapitel 1-44. Eine kurze und prägnatne Analyse zum Autor der Viten Stephans III. und Hadrians I. bietet Davis, LP 8, 107-119; zur Datierung siehe auch Hartmann, Hadrian 21-28 und 216-221. Siehe ausführlicher unten, Kap. 5.6.

438 LP 8, trans. Davis 100.

439 LP I, 477: execrabilem illam synodum quae in Grecie partibus nuper facta est.

440 Siehe dazu oben, Kap. 4.2. 
jenem Christophorus und an dessen Sohn und secundicerius Sergius angeklagt werden. Die Vita Hadrians gibt an, dass der Papst diese Art der Strafgerichtsbarkeit nicht selbst ausüben und Paulus deshalb zum Kaiser schicken wollte. Er sollte also für sein Gerichtsverfahren Greciae partibus geschickt werden. ${ }^{41}$ Nebenbei sei bemerkt, dass Paulus nie nach Osten eingeschifft wurde, angeblich widersetzte sich der Erzbischof von Ravenna aus persönlichen Gründen dem Befehl des Papstes, jedenfalls ließ er den cubicularius hinrichten. ${ }^{42}$ Wiederum ist mit dem etwas verwirrenden Ausdruck ganz klar das Kerngebiet des Reichs gemeint, hier sogar spezifisch Konstantinopel.

Mit ihrer Formulierung stechen beide Texte heraus, eine ähnliche geographische Verwendung findet sich davor (und danach) im päpstlichen Material des achten Jahrhunderts nicht. Die Verwendung des Ausdrucks passt aber zu den Tendenzen der päpstlichen Kanzlei in den ersten Jahren von Hadrians Pontifikat. In beiden Fällen ist die Bezeichnung zwar als sicherlich unfreundlich, aber verglichen mit der späteren Wortwahl als relativ neutral aufzufassen, auch wenn im Fall des LP-Berichts über das Konzil in der Sache durchaus hart argumentiert wurde. Insofern passt der Befund der LP-Viten sehr gut zu Brief CC 57.

Bemerkenswert ist, dass noch in der zweiten genannten Passage, jener aus der Vita Hadrians, der Kaiser zumindest theoretisch als maßgebliche Gerichtsinstanz für in Rom nur schwer verhandelbare Fälle galt. Zweifellos müssen wir damit rechnen, dass Hadrian über Paulus' Ableben nicht sehr betrübt gewesen sein dürfte, ja man möchte daran zweifeln, dass es je einen Befehl gab, diesen nach Osten zu schaffen. Dennoch: Der Autor der Vita anerkannte mit seiner Formulierung im Prinzip immer noch die Oberhoheit des Kaisers. Doch nur kurze Zeit später, jedenfalls 776, sagte sich der Papst formell vom Osten los. Schon vor diesem Schritt waren die wenigen erhaltenen Texte alles andere als griechenfreundlich, doch danach wurde die päpstliche Rhetorik zweifellos deutlicher - aus den genannten Gründen. Der Terminus Greci war nun fraglos mit der schwammigen Bedeutung „Leute des Imperiums“ beziehungsweise „Kernland des Kaiserreichs“ etabliert, wobei allerdings auch die kulturellen Griechen aus Italien und von anderswo weiterhin so bezeichnet werden konnten.

Der Terminus wurde ab 776 üblicherweise zusammen mit pejorativen Epitheta oder zumindest in negativem Kontext verwendet, was mit den neu geschaffenen politischen Realitäten einherging.

Eine gewisse Vorsicht ließ aber auch Hadrian in seinem diplomatischen Umgang walten, was wahrscheinlich nicht zuletzt daran lag, dass das griechische Element in Rom weiterhin einflussreich war und zudem auch dringend gebraucht wurde.

441 LP I, 490.

442 LP I, $490 f$. 
Gleich zu Beginn seines Pontifkikats stand Hadrian in fortwährenden Verhandlungen mit dem Langobardenkönig Desiderius. In Kapitel 2I seiner Vita wird von einer der diplomatischen Missionen berichtet, die in diesem Zusammenhang standen: Ihr Leiter war Pardus, der Abt von St. Saba, dem vielleicht prominentesten "griechischen“ Klosters Roms. Sein Titel wird in der Vita interessanterweise sogar mit egumenus wiedergegeben, einer leicht latinisierten Form des griechischen ịjoú$\mu \varepsilon v o \varsigma$, hegoumenos. ${ }^{443}$ Einer der Nachfolger des Pardus war ebenfalls an einer der wichtigsten Missionen der Zeit Hadrians beteiligt. 786/87 wurde Abt Petrus gemeinsam mit dem römischen Erzpriester desselben Namens zum Koleiter der römischen Delegation beim zweiten Konzil von Nicäa ernannt. ${ }^{444}$ Klarerweise war es eine kluge Entscheidung einen aller Wahrscheinlichkeit nach griechischsprachigen Abt als Vertreter Roms zu dem Konzil zu schicken, auf dem ausschließlich auf Griechisch verhandelt wurde. Dennoch zeigt auch die Betrauung des Abtes mit dieser so wichtigen Aufgabe, wie stark die griechische Bevölkerung Roms in den 78 oerJahren noch integriert gewesen sein muss und dass gute Kontakte in den Lateran weiterhin aufrecht erhalten wurden.

Das Konzil von Nicäa markierte zweifellos den Höhepunkt in den Beziehungen zwischen Hadrian I. und Konstantinopel - was fraglos dem Umstand geschuldet war, dass Hadrian einen theologischen Erfolg sehr gut gebrauchen konnte, während für Kaiserin Eirene und ihren Patriarchen Tarasios die möglichst enge Einbindung des Papstes den Erfolg des Konzils gewährleisten sollte. ${ }^{445}$ Hadrians berühmte Briefe an Kaiser Konstantin VI. und seine Mutter sowie an Tarasios wurden entsprechend in die Akten des Konzil aufgenommen, zunächst offenbar sogar im etwa gegenüber Tarasios durchaus kritischen Volltext. ${ }^{446}$ Die Bezeichnung Greci findet sich in den

443 LP I, 493.

444 Siehe Noble, Images 74 und 160. Noble hat spekuliert, dass auch das Faktum, dass die beiden Delegationsleiter den bedeutungsvollen Namen Petrus trugen, mit zu ihrer Ernennung beigetragen haben könnte - geschadet haben dürfte es sicherlich nicht.

445 Siehe Brubaker/Haldon, Byzantium 260-276; ebd., 275 wird darauf hingewiesen, dass als einer der wichtigsten Punkte, um das Konzil von Hiereia als nicht ökumenisch zu definieren, die Absenz päpstlicher Gesandter angeführt wurde.

446 Beide Briefe wurden in der zweiten Sitzung des Konzils verlesen und angenommen, siehe Zweites Konzil von Nicäa, 2. Sitzung (ed. Erich Lamberz, Concilium Universale Nicaenum secundum, concilii actiones I-III, Acta Conciliorum Oecumenicorum, Series 2, Bd. 3, 1, Berlin/New York 2008) 112-221: Die Edition enthält auch die längere (wahrscheinlich authentische) Version der Briefe, so wie sie Anastasius Bibliothecarius in seiner Übersetzung im neunten Jahrhundert wiedergab. Siehe zu diesen Veränderungen Erich Lamberz, „Falsata Graecorum more“? Die griechische Version der Briefe Papst Hadrians I. in den Akten des VII. Ökumenischen Konzils, in: Novum Millennium. Studies on Byzantine History and Culture Dedicated to Paul Speck, ed. Claudia Sode/Sarolta Takács (Aldershot 2001) 213-229, der gezeigt hat, dass Hadrians Briefe wahrscheinlich in der Vollversion 
Akten wenig überraschend nicht, auch nicht in den Briefen Hadrians und wir können getrost annehmen, dass es aus päpstlicher Sicht einfach nicht sinnvoll gewesen wäre, sie zu verwenden, weil sich die angesprochenen Menschen nicht als Griechen verstanden und die Bezeichnung zudem durchaus als beleidigend hätten verstehen können, ganz abgesehen davon, dass der Terminus ohnehin recht unpräzise und daher ungeeignet war.

Insgesamt war die Kommunikation zwischen der Kaiserin und dem Papst von auffällig konstruktivem und wohlgesonnenem Ton geprägt, so sehr, dass wir, wenn nicht die dinglichen Quellen der 77oer-Jahre eine klare Aussage zuließen, daran zweifel müssten, ob sich Rom tatsächlich nur ein Jahrzehnt zuvor vom Kaiserreich losgesagt hatte.

Diese Beobachtung muss jedoch deutlich eingeschränkt werden: Das Konzil und all die Ereignisse rundherum sind ausschließlich der kirchlichen Sphäre zuzuordnen. Auf diesem Gebiet der Beziehungen stellte das Nizänum auch tatsächlich den Normalzustand wieder her und Rom betrachtete den Osten nun wieder als orthodox. Der Tradition der ökumenischen Konzile folgend hatte Rom auf dem Konzil auch den höchsten Rang inne, die päpstlichen Gesandten werden in den Akten bei jeder Gelegenheit an erster Stelle genannt. ${ }^{447}$ Hadrian verteidigte die Beschlüsse des Konzils auch vehement gegenüber den skeptischen Franken, wie der Hadrianum genannte, lange Brief in der Sache an Karl den Großen zweifelsfrei belegt. ${ }^{448}$

Und die verbesserten Beziehungen auf der religionspolitischen Ebene fanden möglicherweise auch in den Briefen Hadrians ihren Niederschlag: Ungefähr 788 beginnen die Briefe im $\mathrm{CC}$ wieder, den Kaiser zu erwähnen, was zuvor das letzte Mal in CC 58 Mitte der 770er-Jahre der Fall gewesen war. ${ }^{449}$ Dazwischen wurden nur diffus-negative Greci erwähnt. Das ist zwar ein recht schwacher Indikator, doch er könnte darauf hinweisen, dass der Papst eine Verbesserung der Beziehungen auch in den Briefen an Karl den Großen ausdrückte.

des Anastasius verlesen wurden und erst im Laufe des neunten Jahrhunderts in einer in Konstantinopel erstellten neuen griechischen Abschrift der Akten um unliebsame Punkte gekürzt wurden.

447 Siehe Zweites Konzil von Nicäa, ed. Lamberz. Hadrian I. wurde von Eirene und Tarasios von Beginn an in die Vorbereitungen des Konzils miteinbezogen. Siehe auch Carile, Roma 72, der darauf hinweist, dass auch Theophanes Confessor in seiner Chronik den Päpsten eine führende Rolle im Kampf gegen den Ikonoklasmus zugestand und sie generell sehr positiv darstellte.

448 Hadrian I., Hadrianum (ed. Karl Hampe, MGH EE 5, Epistolae selectae pontificum Romanorum Carolo Magno et Ludowico Pio regnantibus scriptae, 2, Berlin 1899) 5-57.

449 CC 58 wurde von Gundlach auf die Zeit nach dem 7. Februar 776 datiert. Die Briefe CC 60, 70, 72 und 82 erwähnen zwar Kaiser, aber immer in der Vergangenheit. Der regierende Kaiser wird wieder in CC 83 genannt (nur das Amt, nicht sein Name). Siehe CC, ed. Gundlach 585-587, 599-601, 602f., 615f. und 617-619. 
Doch die realpolitische Situation zwischen Rom und Konstantinopel blieb davon so gut wie unberührt. ${ }^{450}$ Hadrian war prädestiniert dafür, die Bereiche Politik und Religionspolitik nicht zu vermischen.

Und tatsächlich kam es auch 788 zu neuerlichen Auseinandersetzungen, die, auch wenn die römische Miliz diesmal nicht eingriff, durchaus für den Papst bedrohlich waren.

Wieder entwickelten sich die Probleme im Süden Italiens. Der Langobardenkönig Adelchis, Sohn des Desiderius, traf mit einer "griechischen“ Streitmacht im nunmehrigen Prinzipat von Benevent ein und versuchte offenbar dort die Macht an sich zu bringen. Die Truppen dafür müssen ihm von oströmischen Amtsträgern zur Verfügung gestellt worden sein. Adelchis in Benevent hätte eine ernste Bedrohung für den Papst bedeutet. Karl der Große schickte Adelchis jedoch dessen Neffen Grimoald, den Erben seines kürzlich verstorbenen Vaters Arichis von Benevent, entgegen, der seinen Onkel auch tatsächlich in die Flucht schlagen konnte und so auch gleich die Bedrohung für Rom abwenden konnte. ${ }^{451}$

Klar ist aber, dass die Involviertheit oströmischer Truppen vom Papst als nichts anderes als ein unfreundlicher Akt aufgefasst werden konnte. Somit verwundert es nicht, dass sich in den Briefen CC 80 und 82-84, die diesen Fall betreffen, wieder eine ähnlich scharfe Rhetorik findet, wie sie zuvor in den Briefen zu finden war, die den Terracina-Konflikt betrafen.

Ein Bild der Einstellung Hadrians I. zu den Greci wäre allerdings nicht vollständig, wenn nicht auch der eine Brief bearbeitet würde, der in der Überlieferung deutlich heraussticht. Es handelt sich um CC 59 , einen Brief der im Prinzip nicht genau datiert werden kann, aber nicht vor 776 abgefasst wurde. ${ }^{452}$ Der Papst antwortet hier auf leider in karolingischen Quellen nicht erhaltene Vorwürfe Karls des Großen mit folgender Passage:

Wir antworten hiermit auf Eure honigsüßen Schreiben betreffend den Verkauf von Sklaven, welche (wie Ihr sagt) von unseren Römern an die unaussprechliche gens der Sarazenen

$450 \mathrm{Zu}$ diesem Schluss kommt auch Peter Classen, Karl der Große, das Papsttum und Byzanz: Die Begründung des karolingischen Kaisertums (Sigmaringen ${ }^{21985)}$ 37, in seinem kurzen aber richtigen Fazit: Auf der politischen Ebene war der Papst nicht mehr treuer Untertan des Kaisers.

451 Siehe dazu unten ausführlicher, Kap. 5.6.2.4. Siehe auch Noble, Republic 178-180 und die wesentlich detailliertere, aber recht parteiische Darstellung von Ludo Moritz Hartmann, Geschichte Italiens im Mittelalter, Bd. 2, 2 (Gotha 1903) 306-313. Bertolini, Carlomagno 639-655 hat mit Recht darauf hingewiesen, dass diese Ereignisse zum völligen Verlust jeglichen Einflusses führten, den der Papst im Prinzipat von Benevent gehabt hatte.

452 Siehe die Diskussion dieser Frage unten, Kap. 5.6.2.2. 
verkauft worden sein sollen. Doch bis jetzt sind wir, was Gott verhindern möge, nicht so tief gesunken, um ein solches Verbrechen zu begehen; und wenn es begangen wurde, so wäre es ohne unsere Zustimmung geschehen. Jedoch segeln immer unaussprechliche Griechen an der langobardischen Küste, die diese familiae dann kauften; ${ }^{453}$ sie haben auch einen Vertrag (amicitia) mit den Langobarden [dieser Gegend] geschlossen und von diesen Langobarden die Sklaven erhalten.

$\mathrm{Zu}$ dieser Frage haben wir daraufhin auch dem dux Allo geschrieben, dass er mehr Schiffe bereitstellen müsse und die genannten Griechen festnehmen und ihre Schiffe mit Feuer verbrennen solle; doch er wollte unseren Forderungen nicht Folge leisten, weil „wir weder Schiffe noch Seeleute haben, die jene festnehmen könnten.“ Trotzdem haben wir für Gott so gut wir konnten Zeugnis abgelegt, weil wir danach einen großen Kampf ausgefochten haben um zu erreichen, dass dieses Verbrechen verhindert wird; deshalb haben wir die Schiffe der griechischen gens im Hafen unserer Stadt Centumcellae [später Civitavecchia] verbrennen lassen und jene Griechen für lange Zeit im Kerker festgehalten.

Doch von den Langobarden, von denen wir schon geschrieben haben, sind weitere familia verkauft worden, weil sie Armut und Hunger dazu zwangen; andere von diesen Langobarden besteigen sogar aus eigenem Willen die Schiffe der Griechen, weil sie alle Hoffnung $\mathrm{zu}$ überleben aufgegeben hatten. ${ }^{454}$

453 Es ist unklar, was familia (in der Handschrift im Singular und falschen Fall) hier bedeutet. Wahrscheinlich ist familias gemeint. Der Papst will wohl vermitteln, dass die Langobarden ihre eigenen Haushaltsangehörigen in die Sklaverei verkaufen mussten. Siehe dazu auch McCormick, Origins $877 f .$, Nr. 186.

454 CC 59, ed. Gundlach 585: Repperimus enim in ipsas vestras mellifluas apices pro venalitate mancipiorum, ut quasi per nostris Romanis venundati fuissent in gentem necdicendam Saracenorum. Et numquam, quod absit, in tale declinavimus scelus, aut per nostram volontatem factum fuisset; sed in litoraria Langobardorum semper navigaverunt necdicendi Greci et exinde emebant ipsa familia et amicitia cum ipsis Langobardis fecerunt et per eosdem Langobardos ipsa suscipiebant mancipia. In quibus et direximus exinde Alloni duci, ut preparare debuisset plura navigia et comprehenderet iam dictis Grecis et naves eorum incendio concremaret; sed noluit nostris obtemperare mandatis, quia nos nec navigia habemus nec nautas, qui eos conprehendere potuissent. Tamen, in quantum valuimus, Domino proferimus teste, quia magnum exinde habuimus certamen cupientes hoc ipsud scelus vetare; qui et naves Grecorum gentis in portu civitatis nostrae Centumcellensium comburi fecimus et ipsos Grecos in carcere per multa tempora detinuimus. Sed a Langobardis, ut praefati sumus, plura familia venundata sunt, dum famis inopia eos constringebat; qui alii ex eisdem Langobardis propria virtutae in navigia Grecorum ascendebant, dum nullam habebant spem vivendi. Siehe zu CC 59 auch unten, Kap. 5.6.2.2 und 6.1, sowie Clemens Gantner, New Visions of Community in ninth-century Rome. The impact of the Saracen threat on Papal thought, in: Visions of Community in the Post-Roman World: The Latin West, Byzantium and the Islamic World, 300-1100, ed. Walter Pohl/Clemens Gantner/Richard Payne (Aldershot 2012) 403-421, hier 403-405. 
Karl der Große hatte offenbar angedeutet, dass der Papst und seine Untertanen in Sklavenhandel mit der gens necdicenda Saracenorum verwickelt seien. Dem widersprach der Papst jedoch vehement und wies darauf hin, dass es in Wirklichkeit Langobarden aus Tuszien seien, die Sklaven an necdicendi Greci verkauften. Das negative Adjektiv überrascht mit Blick auf Hadrians sonstige Korrespondenz nicht, doch man muss in diesem Zusammenhang vorsichtig sein, denn der Papst setzte den Ausdruck ganz klar parallel zu den ebenso bezeichneten Sarazenen. Die Erwähnung der Sarazenen wirkt nun wiederum so, als ob sie direkt aus Karls Schreiben zitiert worden sei, weswegen man nicht sagen kann, inwiefern hier nicht einfach nur aus der Antwortsituation heraus der Ausdruck gewählt wurde. Denn generell scheint der Brief im Stile der rhetorischen correctio mit den Ausdrücken des Königs zu spielen: Das Gesagte soll symbolisch zurückgewiesen werden und dadurch die „Wahrheit“"werden. ${ }^{455}$

Hier interessiert aber zunächst vor allem die spezielle Rolle der Greci (zu jener der Langobarden und der Sarazenen siehe unten, Kapitel 5.6.2.2 und 6.I): Wir müssen in Betracht ziehen, dass es sich bei ihnen aller Wahrscheinlichkeit nach nicht um von Konstantinopel oder lokalen Offiziellen des Reichs kontrollierte Schiffe handelte. Die Sklavenhändler operierten wahrscheinlich auf eigene Rechnung und ohne Deckung durch imperiale Offizielle. Vielleicht erklärt diese spezielle Situation auch die zweite Nennung der "Griechen“ in dem Brief. Hadrian berichtet dort, dass er einiger Sklavenhändler durch Zufall habhaft geworden ist und sie im vom Papst kontrollierten Hafen Centumcellae, dem heutigen Civitavecchia, festgehalten hat: naves Grecorum gentis in portu civitatis nostrae Centumcellensium comburi fecimus et ipsos Grecos in carcere per multa tempora detinuimus. ${ }^{456}$ Es handelt sich hier um das einzige Mal, dass ein Papst des achten Jahrhunderts von einer gens Grecorum schreibt, ganz im Gegensatz zu Franken, Langobarden und Sarazenen, die permanent als gens definiert wurden. ${ }^{457}$ Diese Nennung spiegelt, dem rhetorischen Aufbau des Briefes folgend, die wahrscheinlich von Karl übernommene necdicenda gens Saracenorum wider und erschien wohl deshalb der päpstlichen Kanzlei sinnvoll.

Doch anlässlich dieser Passage muss man die Frage stellen, ob Greci nicht doch auch eine ethnische Bezeichnung sein konnte. Zunächt muss in dieser Hinsicht mit Nachdruck darauf hingewiesen werden, dass wir im achten Jahrhundert über keinen Hinweis auf eine Gruppe verfügen, die sich selbst als Greci definierte, wir haben nur den Fall von Papst Zacharias und zwei weiteren Päpsten, die sich möglicherweise als Einzelperson so definierten.

455 Kempshall, Rhetoric 7f.

456 CC 59, ed. Gundlach 585.

457 Vgl. die entsprechenden Kapitel der vorliegenden Arbeit. 
Demgegenüber war Greci vor allem ein Etikett, das anderen Personen zugeschrieben wurde. Somit kann der für eine ethnische Deutung so wichtige Punkt eines Gefühls der Zugehörigkeit für das achte Jahrhundert nicht nachgewiesen werden. ${ }^{458}$ Doch die Greci hätten zumindest aus der Außensicht durch den Papst als eine ethnisch zu unterscheidende Gruppe definiert werden können. Und diese Option wurde ja auch tatsächlich genutzt, wenn auch nur dieses eine Mal unter sehr besonderen Umständen. Dennoch war diese Möglichkeit schon im achten Jahrhundert ganz klar vorhanden: Ähnlich wie die romanitas hatte auch Greci ein „verstecktes ethnisches Potential“ ${ }^{459}$ Der entscheidende Unterschied war jedoch, dass Romani sehr häufig als Selbstbezeichnung verwendet wurde, Graikoi hingegen nur in sehr isolierten Fällen. ${ }^{460}$ Dennoch ist eine gewisse Vergleichbarkeit gegeben, und zwar insofern, als eine Vielzahl an Facetten und Konnotationen, die mit den Begriffen Romani und Greci verbunden waren, es nahezu unmöglich machten, alle potenziellen Bedeutungen in der jeweiligen Situation zu erfassen. Die Begriffe blieben zu offen, um in den meisten Fällen als „ethnic marker" dienen zu können. ${ }^{461}$

Hadrian I. starb im Jahr 795. Sein Nachfolger wurde Leo III., der unter Hadrian das Amt des vestararius ausgeübt hatte. Er war also der für Stiftungen und Bauten zuständige Beamte gewesen, was angesichts der regen Bautätigkeit Hadrians kein unbedeutendes Amt gewesen sein kann. ${ }^{462}$

Leo III. wird in der Literatur des Öfteren als von griechischer oder gar arabischer Herkunft eingestuft, als Argument dient der ungewöhnliche Name seines Vaters, Atzuppius. ${ }^{463}$ Abgesehen davon scheint Leo auch über keinerlei Rückhalt unter den Laien Roms verfügt zu haben. Der LP allerdings überliefert, dass Leo natione Romanus gewesen sei. Es handelt sich hier um die einzige ausdrückliche Information einer zeitgenössischen Quelle, weswegen sie nicht von der Hand gewiesen werden sollte. ${ }^{464}$

458 Siehe Walter Pohl, Geschichte und Identität im Langobardenreich, in: Die Langobarden - Herrschaft und Identität, ed. ders./Peter Erhard, Forschungen zur Geschichte des Mittelalters 9 (Wien 2004) 555-566, hier 565 und ders., Archaeology of Identity: Introduction, in: Archäologie der Identität, ed. ders./Matthias Mehofer, Forschungen zur Geschichte des Mittelalters 17 (Wien 2010) I-V, hier III.

459 Siehe Pohl, Conceptions of ethnicity 21, zum „hidden ethnic potential“ der romanitas.

460 In späteren Jahrhunderten entfaltete das Griechentum genau dieses Potential auf dem Balkan, siehe dazu Koder, Romaiosyne.

461 Walter Pohl, Invasions and Ethnic Identity, in: Italy in the Early Middle Ages, 476-1000, ed. Cristina La Rocca (Oxford 2001) 11-33, hier 11.

462 Noble, Republic 226.

463 Noble, Republic 187f., n. 14, er folgt hier offenbar Ohnsorge.

464 Herbers, Bild Papst Leos III., 141f. Siehe LP II, 1 (Beginn der Vita Leos III.). 
Unglücklicherweise verfügen wir über keine Zeugnisse aus dem Pontifikat Leos, die sich der Zeit vor 800 zuordnen lassen und sich mit Konstantinopel oder den Greci beschäftigen. In den danach verbliebenen Schriftstücken geht es mehrmals nebenbei um Greci und Leo verwendet den Begriff ohne zu zögern. ${ }^{465}$ Allerdings finden sich nun keine negativen Epitheta mehr, was einerseits ein Zeichen ist, dass sich die etwas ruhigeren Beziehungen nach 787 fortgesetzt haben könnten. Andererseits zeigt sich hier auch, dass Leo es nicht mehr nötig hatte, gegen den Osten auf Othering zu setzen, da die Loslösungsstrategie seiner Vorgänger zweifellos von Erfolg gekrönt gewesen war.

\subsection{Rom und die Greci: Zusammenfassung}

Schon früh während des Pontifikats Hadrians I. war die römische Verwendung des die Differenz betonenden Begriffs Greci vollständig besiegelt. Das Wort verlor keineswegs seinen pejorativen Charakter, den es spätestens seit Stephan II. aufwies, obschon die offenen Feindseligkeiten nach 788 vorerst beendet waren und weitgehend gutes Übereinkommen mit Konstantinopel herrschte. Das Wort Greci war immer noch ambivalent, denn es konnte viele verschiedene Gruppen von Personen unter ganz unterschiedlichen Umständen meinen. Auch in Rom gab es noch eine große Minderheit von Menschen, die zumindest unter einem gewissen Blickwinkel als Griechen erschienen, ja einige mögen sich persönlich sogar so bezeichnet haben.

Die Beziehungen zum Osten und zu Kaiser beziehungsweise Kaiserin waren nach Hadrians Regierung völlig gespalten. Auf der einen Seite herrschte nun wieder relativ umfassendes Übereinkommen auf der ekklesiastischen Ebene, auf der anderen Seite ging man politisch nunmehr getrennte Wege.

Es ist auffällig, wie wenig Einfluss auf diese Situation die Krönung Karls des Großen zum Kaiser der Römer durch Leo III. im Jahr 800 eigentlich hatte. Während die Vorgänge die Beziehungen zwischen Konstantinopel und den Franken für lange Zeit, ja eigentlich die ganze Zeit des weiteren Bestehens des Oströmischen Reichs hindurch beeinflussten, ja eigentlich belasteten, hatten sie auf die Beziehungen zum Papsttum zunächst keine heute noch erkennbaren Auswirkungen. Es scheint vielmehr, als seien die wesentlichen Schritte in dieser Beziehung bereits früher gesetzt worden, wie das vorliegende Kapitel versucht hat zu skizzieren. Der Begriff Greci hat sich dabei für die Ost-West-Beziehungen des Papsttums, trotz der ihm eigenen

465 Leonis III. papae epistolae X, epp. 5, 6 und 8 (ed. Karl Hampe, MGH EE 5, Berlin 1899) 85-104, hier 94, 96f. und 99. 
Problematik als idealer Indikator erwiesen, sofern man den aus den zeitgenössischen Quellen von den Forschern der letzten Jahrzehnte mühsam herausdestillierten historischen Hintergrund des jeweiligen päpstlichen Schriftstücks in Betracht zieht.

Für Rom war schon alleine bemerkenswert, dass der Begriff Greci in der spezifischen, von Stephan II. und Paul I. geprägten Form überhaupt entstehen konnte und dass er derart offen auf pejorative Weise eingesetzt werden konnte. ${ }^{466}$ In dieser Hinsicht ist zweifellos von hoher Wichtigkeit, in Betracht zu ziehen, dass Rom im Grund auch eine griechische Stadt war, in der es vor allem eine dem Lateran, also dem eigentlichen Machtzentrum der Stadt, sehr nahe stehende Elite von griechischen Klerikern und Mönchen gab. Fakt ist, dass der Einfluss dieser Griechen ab der Mitte des achten Jahrhunderts auffällig zurückging. Die Gründe dafür müssen im Dunkeln bleiben, denn auf Seiten der griechischen Minderheit sind zu diesem Zeitpunkt keinerlei Verfallserscheinungen feststellbar. Somit überrascht es nicht, dass kulturell griechische Menschen noch längere Zeit in wesentlichen Positionen, nun vor allem temporärer Natur, zu finden sind.

Unter diesen Umständen in der Ewigen Stadt ist die Entscheidung der Bruderpäpste, ihre oströmischen Feinde der malitia Grecorum zu bezichtigen, besonders bemerkenswert. Die Verwendung des Begriffs war aus Sicht der Zeitgenossen wahrscheinlich durchaus verständlich, denn die Kernregionen des Kaiserreichs waren ja in sprachlicher, kultureller und sozialer Hinsicht zweifellos „griechisch“. Doch durch den bewussten Schritt, diese Greci nur in einem negativen Licht, gespickt mit Anspielungen auf ihr religiöses Fehlverhalten zu porträtieren, machten die Päpste einen deutlichen Schritt über diese in weiten Teilen des Lateinischen Westens unumstrittene Greci-Titulierung der Oströmer hinaus. Das geschah aus dem dringenden Bedürfnis heraus, das Papsttum und Rom möglichst deutlich vom Kern des Römischen Reichs abzuheben. Das Othering funktionierte in diesem Fall, wie sonst auch immer, in beide Richtungen, beeinflusste sowohl die Wahrnehmung des Papstes als auch die des oströmischen Bereichs des Reichs in der lateinischen Welt. Die päpstliche Taktik scheint insofern aufgegangen zu sein, als es wenige Anzeichen in der lateinischen Literatur der Zeit gibt, die Rom als Teil des Kaiserreichs benennen - die Stadt wurde so gut wie ausschließlich mit dem Papsttum und dem heiligen Petrus in Verbindung gebracht.

Eine wichtige Beobachtung ist hier allerdings noch zu diskutieren: Der Terminus Greci im Sinne des gezielten Othering gegen den Kaiser und die Oströmer ist nur in

466 Chris Wickham, Framing the Early Middle Ages: Europe and the Mediterranean, 400-800 (Oxford 2005) 9, schreibt von Quellen, die belegen, dass bestimmte Sichtweisen überhaupt möglich waren. Die erhaltenen Quellen stecken in gewissem Sinne den Bereich dessen ab, was "gesagt werden konnte." 
Quellen von Päpsten zu finden, die im LP als Romani bezeichnet wurden. Besonders sticht hier Stephan III. heraus, in dessen Schriften sich die Bezeichnung nicht findet. Es ist sicherlich in Betracht zu ziehen, dass das an der sehr geringen Anzahl an erhaltenen Quellen zu seinem Pontifikat liegt. Ebenso muss aber zumindest die Möglichkeit erwogen werden, dass der wahrscheinlich kulturell griechisch geprägte Sizilianer Stephan in dieser Hinsicht auch einen etwas vorsichtigeren Zugang favorisiert haben könnte, der eher mit jenem seiner Vorgänger von 752 zu vergleichen wäre.

Nach dem kurzen Intermezzo (wenn es ein solches überhaupt gab) setzte Hadrian I. allerdings die rhetorische Strategie Pauls I. fast ungebrochen fort. Wir müssen hier auch daran denken, dass sein Onkel, Vormund und Förderer Theodotus, der um die Mitte des achten Jahrhunderts eine Reihe wesentlicher Funktionen in Rom und für die Päpste innehatte, durchaus an der Entwicklung dieser Strategie beteiligt gewesen sein könnte.

Hadrian kam die Vorarbeit der Bruderpäpste zweifellos gelegen, als er kurz nach dem Fall von Pavia und dem Tod Konstantins V. die Gelegenheit ergriff, sich und Rom vom Kaiser loszusagen. Der Papst hatte dadurch sicherlich in- und außerhalb Roms Erklärungsbedarf - und er reagierte sehr deutlich, indem er Rom nun fast noch deutlicher, jedenfalls aber noch entschlossener vom Reich absetzte. Die „griechischen“ Offiziellen Italiens spielten ihm dabei bei mehreren Gelegenheiten eigentlich in die Karten, man möge nur an die Auseinandersetzung um Terracina denken. Zweifellos kommunizierte Hadrian Karl dem Großen in vielen Fällen aber auch durchaus sehr reale Bedrohungspotenziale.

Diese entschlossene diplomatische Position hinderte Hadrian allerdings nicht daran, mit Kaiserin Eirene und Patriarch Tarasios auf der großen religionspolitischen Bühne zu kooperieren, selbstverständlich zu beiderseitigem Nutzen. Im kirchlichen Bereich kam es im neunten Jahrhundert zu Auseinandersetzungen, bei denen vor allem die Frage des Vorrangs zwischen Konstantinopel und Rom eine entscheidende Rolle spielte. Der tatsächliche Bruch auf dieser Ebene kam aber erst viel später mit dem großen Schisma von I054. Auf der politischen Ebene war der Bruch jedoch nicht umzukehren und dazu hatte die rhetorische Wende der 75 oer den Grundstein gelegt. 


\section{Das Papsttum zwischen Langobarden und Franken}

Der Befund des päpstlichen Materials zwischen 568 und dem späten 8. Jahrhundert zeigt, wie leicht es war, die Langobarden als Andere oder Fremde zu sehen. Gregor der Große hatte die Basis der päpstlichen Rhetorik bereits entwickelt, indem er fast durchgehend das Attribut nefandissimi für sie gebrauchte - und zwar sowohl in seinen literarischen Werken als auch in seinen Briefen. ${ }^{467}$ Damals waren die meisten Langobarden von der römischen Mehrheitsbevölkerung der Halbinsel wohl besser unterscheidbar: bei der Tracht ${ }^{468}$, in der Sprache ${ }^{469}$ und der Religion. Die Langobarden waren zum Teil arianische Christen, manche dürften auch noch Heiden gewesen sein. ${ }^{470} \mathrm{Im}$ siebten Jahrhundert folgte eine Phase, in der sich die Päpste in den spärlich erhaltenen Quellen überhaupt nicht zu den neuen Nachbarn äußerten - vielleicht

467 Siehe Walter Pohl, Gregorio Magno e il regno dei Longobardi, in: Gregorio Magno, l'impero e i regna ed. Claudio Azzara (Florenz 2008) 15-28.

468 So bei Paulus Diaconus, Historia Langobardorum, 4, 22, ed. Bethmann/Waitz 124: Paulus weist besonders auf die auffällige Haartracht hin. Die Kleidung hingegen muss sich nicht wesentlich von jener der spätrömischen Militärelite unterschieden haben, siehe Guy Halsall, Barbarian Migrations and the Roman West, 376-568 (Cambridge 2007) 104 und 110.

469 Zur Sprache der Langobarden siehe etwa: Maria Giovanna Arcamone, Die langobardischen Personennamen in Italien: nomen und gens aus der Sicht der linguistischen Analyse, in: Nomen et gens: zur historischen Aussagekraft frühmittelalterlicher Personennamen, ed. Dieter Geuenich/Wolfgang Haubrichs/Jörg Jarnut (RGA Erg. Bd. 16, Berlin/New York 1997) 157-175, und Wolfgang Haubrichs, Amalgamierung und Identität - Langobardische Personennamen in Mythos und Herrschaft, in: Die Langobarden - Herrschaft und Identität, ed. Walter Pohl/Peter Erhart (Forschungen zur Geschichte des Mittelalters, 9, Wien 2005) 67-99.

470 Walter Pohl, Deliberate ambiguity - the Lombards and Christianity, in: Christianizing Peoples and Converting Individuals, ed. Gyuda Armstrong/Ian N. Wood (Turnhout 2000) 47-58. Siehe weiterführend Stephen C. Fanning, Lombard Arianism Reconsidered, in: Speculum 56,2 (1981) 241-258, Thomas S. Brown, Lombard religious policy in the late sixth and seventh centuries: The Roman dimension, in: The Langobards Before the Frankish Conquest. An Ethnographic Perspective, Giorgio Ausenda/Paolo Delogu (Woodbridge 2009) 289-308, und Gasparri, Roma e i longobardi 226f. Gasparri betont dabei, dass lediglich drei Langobardenkönige, Authari, Arioald und Rothari, mit Sicherheit Arianer waren. Zu Rotharis Politik und Stellung siehe Paolo Delogu, Kingship and the shaping of the Lombard political body, in: The Langobards Before the Frankish Conquest: an Ethnographic Perspective, ed. ders./Giorgio Ausenda (Woodbridge 2009) 251-288, hier 255-260. 
weil die Beziehungen nun im Großen und Ganzen gut waren ?471 Und bei genauerem Hinsehen hat auch Gregor bereits gute Kontakte zu den Langobarden gepflegt, insbesondere zu Königin Theodelinda. ${ }^{472}$

Sicher hatte sich die Situation völlig verändert, als die Langobarden um das Jahr 700 wieder in römischen Texten auftauchen: Die Führungsschicht war seit längerer Zeit katholisch, die Langobarden sprachen nun zunehmend das Latein der Mehrheitsbevölkerung und falls ihre Tracht sich je von jener anderer Militärverbände unterschieden hatte, hatten sie sie ebenfalls längst aufgegeben. Die Langobarden hatten sich also in Italien fast vollständig assimiliert, sich lediglich eine distinkte politische Identität bewahrt, etwa ihre eigenen Herrschaftsbereiche oder ihr eigenes Recht. ${ }^{473}$ Ihr Herrschaftsgebiet hatten sie sukzessive ausgebaut, sodass im Norden nur noch sehr kleine Gebiete unter der Herrschaft des Kaiserreichs standen. Im Süden beherrschte der Dukat von Benevent den größten Teil des Festlandes, wiederum waren Konstantinopel nur kleine Enklaven geblieben, die es mehr oder weniger direkt beherrschte. ${ }^{474}$

Die stärkere Assimilation der Langobarden brachte die Päpste dazu, sie nun gezielt als Andere darzustellen. Dieses Unterfangen war auch im achten Jahrhundert nicht besonders schwierig, es fanden sich leicht Punkte, die man nutzen konnte, um Othering durchzuführen, wenn auch vor allem im politischen Bereich. Und im Gegensatz zu den „Griechen“475 fand man sich selbst nicht in einer zwiespältigen Position wieder, es war leicht sich abzusetzen. Die Realität war trotzdem komplexer, wie die detaillierte Untersuchung der Quellen des achten Jahrhunderts zeigen wird.

5.1 Die Wahrnehmung der Langobarden in Quellen zu den Pontifikaten Gregors II. und III.

Für die Konstruktion der langobardischen Identität und für unsere Untersuchung der Wahrnehmung der Langobarden ist die Vita Gregors II. im Liber Pontificalis der ideale Ausgangspunkt. Denn dieser Eintrag war der erste Text nach fast roo Jahren,

471 Siehe Capo, Liber Pontificalis 225-240, und unten, Anm. 476.

472 Vgl. Walter Pohl, Theodelinde, in: RGA, 2. Aufl, Bd. 30 (2005) 412f. Siehe auch Ross Balzaretti, Theodelinda, ,Most Glorious Queen'. Gender and Power in Lombard Italy, in: The Medieval History Journal, 2 (1999) 183-207.

473 Siehe Gasparri, Roma e i longobardi 232.

474 Noble, Republic 1f. und map 1. Barbara M. Kreutz, Before the Normans. Southern Italy in the Ninth and Tenth Centuries (Philadelphia 1991) 1-5.

475 Vgl. oben, Kap. 4. 
der die Langobarden wieder ausführlicher in die Narration einbezog. ${ }^{476}$ Diese Beobachtung gilt für beide erhaltenen Fassungen. ${ }^{47}$

Die Langobarden treten in der Vita zunächst durch Übergriffe auf das Territorium des Dukats von Rom in Erscheinung, so etwa Romuald II. von Benevent in Kapitel $7^{478}$ oder König Liutprand in Kapitel $13 .{ }^{479}$ Interessant ist, dass die verschiedenen Machtbereiche der Langobarden nicht unterschieden werden.

Doch der große Auftritt der Langobarden folgte später, im Zuge der römischitalischen Steuerrevolte, von der wir bereits in anderem Zusammenhang gehört haben. ${ }^{480}$ In den späten $720 e r n$ war die Beziehung Roms zum Kaiser und seinem Exarchen auf dem Tiefpunkt, sodass der patricius Eutychius versuchte, Rom mit den Truppen des Exarchats anzugreifen. Ihm stellten sich nun die Langobarden entgegen, und zwar, wie der LP zu berichten weiß, sowohl der König als auch die duces. Als Eutychius die Langobarden zu bestechen versucht, finden die Langobarden eine klare Antwort: „Sie schrieben ihm zurück und drückten ihre Verachtung für den verabscheuungswürdigen Verrat des Mannes aus. Römer und Langobarden verbanden sich wie Brüder im Band des Glaubens. “481 Gemeinsam wehrten sie die militärische Intervention des Eutychius ab. Die Langobarden erscheinen hier als rechtgläubige Brüder der Stadtrömer sehr positiv. Interessant ist aber, dass ihr König nicht namentlich genannt wird.

Es folgt allerdings die Schilderung eines langobardischen Angriffs auf Sutri 727/28 sowie für 729 eines Angriffs König Liutprands auf Rom. Diese Übergriffe wurden beiden LP-Versionen zufolge im Einvernehmen mit Eutychius durchgeführt, dem es gelungen war, Liutprand auf seine Seite zu ziehen. ${ }^{482}$ Nach Verhandlungen und gemeinsamem Gebet mit dem Papst erreicht Liutprand, dass Eutychius Rom friedlich

476 Zwischen den 630er-Jahren und ca. 720 werden die Langobarden in den päpstlichen Quellen kaum er-wähnt, siehe Capo, Liber Pontificalis 225-40. Die einzige Ausnahme bildet der Angriff Gisulfs I. von Benevent auf den römischen Dukat, siehe ebd., 217f. und 225, Anm. 267; LP I, 383 (Vita Papst Johannes' VI.).

$477 \mathrm{Zu}$ den Fassungen siehe oben, Kap. 1.1.3.1.

478 LP I, 400: Neapel eroberte Cuma von Romuald II. wieder zurück. Zu Romuald siehe Gasparri, I duchi $91 \mathrm{f}$.

479 LP I, 403.

480 Siehe ausführlicher mit der aktuellen Forschungsdiskussion in Kap. 3.2.2.

481 LP I, 406 (beide Versionen gleich): Qui rescriptis detestandam viri dolositatem dispicientes, una se quasi fratres fidei catena constrinxerunt Romani atque Longobardi ...

482 Um die weitgehend unabhängigen Dukate Spoleto und Benevent unter Kontrolle zu bringen, wie vor allem die ältere Version der LP-Vita deutlich macht. Siehe Walter Pohl, Das Papsttum und die Langobarden, in: Der Dynastiewechsel von 751. Vorgeschichte, Legitimationsstrategie und Erinnerung, ed. Matthias Becher/Jörg Jarnut (Münster 2004) 147f. zur Rolle König Liutprands. 
betreten kann - der König ist schließlich auch im LP derjenige, der eine gütliche Einigung ermöglicht.

Die Darstellung der Langobarden in der Vita oszilliert zwischen der üblichen Kennzeichnung als Feinde, die es auf das Territorium der Römer abgesehen haben, und jener als heldenhafte Verbündete des Papstes gegen die kaiserlichen Amtsträger. Das starke Bild der im Glauben wie Brüder verbundenen Römer und Langobarden ist in der Forschung zum achten Jahrhundert bisher kaum rezipiert worden. Der Papst hatte zumindest mit einigen langobardischen Dukaten gute Kontakte, darunter auch mit jenen von Tuszien oder Chiusi, die im Gegensatz zu Spoleto und Benevent besser vom König kontrolliert werden konnten. Besonders tragfähig dürfte aber das Bündnis mit dem Dukat von Spoleto gewesen sein, welches mehrfach positiv erwähnt wird. Mit dem mächtigen König Liutprand überwog allerdings auch schon unter Gregor II. der Konflikt.

Neben dem LP gibt es für den Pontifikat Gregors II. relativ wenige Quellen, doch eine sehr umstrittene ist für die Langobardenbeziehungen von Interesse. Es handelt sich dabei um den ersten der beiden zusammen überlieferten griechischen Briefe, die Gregor - angeblich unter dem Eindruck des beginnenden Ikonoklasmus - an Kaiser Leon III. richtete. ${ }^{483}$

Der Brief ist zweifellos in der jetzigen Form als Fälschung zu bezeichnen, doch diese wurde wahrscheinlich auf der Grundlage eines Originals aus den 720 orn erstellt. ${ }^{484}$ Der Brief ist oben in Kapitel 3.2.2 bereits länger zitiert, es findet sich darin der Satz:

Wenn Du uns aber weiterhin trotzen solltest, so wie Du es sagst, und uns bedrohst, dann haben wir keine andere Wahl, als gegen Dich zu kämpfen. Der Bischof von Rom wird sich nur drei Meilen zurückziehen, in die Kampanía, und dann - Viel Glück! - jage [in Rom] dem Wind nach. ${ }^{485}$

Der hier zitierte Abschnitt gehört zu jenen Teilen, die wahrscheinlich den 720 ern und daher der Zeit der römischen Steuerrevolte entstammen. Mit dem Ikonoklasmus hatte das nichts zu tun. Man muss wohl davon ausgehen, dass der Papst sich außerhalb des römischen Dukats in Sicherheit bringen wollte. Mit den drei Meilen wäre also eher die Grenze des Dukats gemeint, als die Stadtgrenze. Der als Kampa-

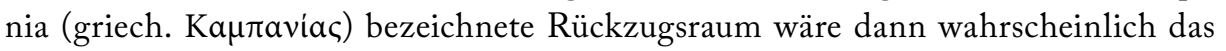

483 Siehe Gouillard, Aux origins.

484 Siehe zu diesem Brief oben, Kap. 3.2.2, bes. Anm. 256.

485 Erster Brief Gregors II. an Leon III., ed. Gouillard 294-295, 11. 241-248. 
Gebiet des Dukats Benevent südlich von Rom. ${ }^{486}$ Somit passt diese Passage perfekt zu Kapitel I9 der LP-Vita Gregors II. Nur in einem Bündnis mit den Langobarden würde es für den Papst Sinn haben, sich in deren Gebiet zurückzuziehen. Dort hätte der Kaiser seiner aller Voraussicht nach tatsächlich nicht habhaft werden können. Der erste Brief an Leon III., so problematisch die Quelle auch ist, ist somit ein weiteres Zeugnis für die guten Beziehungen, die das Papsttum zu den Langobarden unterhielt. Das Vertrauen in manche der Nachbarn war so groß, dass man sich, wenn man dem Brief trauen kann, sogar nicht scheute, dem Kaiser gegenüber auf deren zu erwartende Unterstützung anzuspielen. Die Langobarden wurden aus der Sicht des Papsttums dadurch zwar keineswegs zu Eigenen, sie waren immer deutlich von den Römern abgesetzte Andere, doch kann man zumindest in der LP-Stelle, an der sie zu Brüdern im Glauben stilisiert werden, einen Akt des Sameing sehen, nicht im Sinne von "gleichmachen“ sondern eher von ,angleichen“.

Für den Pontifikat Gregors III. haben wir weniger Nachrichten als für jenen seines Vorgängers. Die Langobardenbeziehungen sind da keine Ausnahme. Sicher ist aber, dass Gregor ein Bündnis mit den Dukaten Spoleto und Benevent unterhielt und - wohl eben dadurch - in Konflikt mit König Liutprand geriet. Die beiden südlichen langobardischen Dukate waren die meiste Zeit seit ihrer Entstehung in den 570er-Jahren vom langobardischen Königtum unabhängig gewesen. Allerdings war es ein Ziel jedes im Norden halbwegs gefestigten Königs gewesen, auch die südlichen Langobarden unter Kontrolle zu bringen. Die römischen Besitzungen in Mittelitalien, darunter auch der Dukat von Rom, insbesondere aber der Exarchat waren den Königen dabei im Weg. Deswegen wurden Ravenna und Rom in diese Auseinandersetzungen miteinbezogen, so auch in der Regierungszeit Liutprands. ${ }^{487}$

Der LP schweigt darüber in der Originalversion seiner Vita. Erst in einer Interpolation, die nur in der oft „fränkisch“ genannten BD-Rezension ${ }^{488}$ der Viten des achten Jahrhunderts enthalten ist, kommt Liutprand vor. In Worten, die an Deutlichkeit wenig zu wünschen übrig lassen, berichtet der Interpolator von einem großangelegten Angriff Liutprands auf das Umland Roms und vom deshalb erfolgten Hilfegesuch des Papstes an Karl Martell. Der Bericht kann aber kaum als Quelle für Gregors Zeit herangezogen werden, er wurde fast sicher erst nach der Mitte des Jahrhunderts abgefasst. ${ }^{49}$

486 Im sechsten Jahrhundert gehörte diese Region zur oströmischen Eparchie Kampanía, siehe Bavant, Duché 49f. Es ist anzunehmen, dass diese Bezeichnung, besonders auf Griechisch, auch im achten Jahrhundert noch auf diese Gegend Anwendung fand.

487 Gasparri, Roma e i longobardi 223, sieht zu Recht vor allem Ravenna als Ziel der Langobarden.

$488 \mathrm{Zu}$ dieser Fassung siehe oben, Kap. 1.1.3.2.

$489 \mathrm{Zu}$ dem Einschub siehe ausführlicher unten, Kap. 5.5 (zu den Haartrachtstellen des LP). 
Erhalten sind außerdem zwei Briefe Gregors, die er an Karl Martell sandte. Nach einem kurzen Ausloten der Möglichkeiten im ersten Brief ${ }^{490}$, enthält der zweite, der Stellung zur politischen Involviertheit des Papstes nimmt, eine sehr interessante Sachverhaltsdarstellung:

Mein Sohn, bitte glaube nicht den lügnerischen Anwürfen und Überredungen dieser Könige [Liutprand und Hildeprand]. Denn sie wollen Dich lauter Falschheiten glauben lassen, indem sie ausweichend schreiben: dass nämlich ihre duces, jene von Spoleto und Benevent sich irgendetwas gegen sie zuschulden kommen lassen haben; doch das sind alles Lügen. Denn - möge Dir die Wahrheit genügen, mein Sohn - sie verfolgen die duces nur aus einem Grund, nämlich dass sie uns im vorangegangenen Jahr nicht von ihrem Territorium aus angreifen wollten, so wie es jene [die Könige] getan haben, als sie den Besitz der Heiligen Apostel zerstörten und die ihnen anvertrauten Menschen (den peculiaris populus) ausplünderten. Denn so sprachen die duces: „Denn wir führen keinen Krieg gegen die Heilige Kirche Gottes und die ihr anvertrauten Menschen, weil wir mit ihnen einen Friedensvertrag haben und von jener Kirche den Glauben erhalten haben." Und deswegen wütete ihr eigenes Schwert gegen sie. Denn die genannten duces sind, dem alten Herkommen folgend, bereit, ihnen [den Königen] zu gehorchen. Doch jene, die wegen des zuvor Berichteten immer noch zornig waren, wollen die hervorragende Gelegenheit nutzen, diese und uns zu zerstören und anzugreifen, deswegen, erzählen sie Eurer Güte falsche Dinge, während sie uns beide [uns und die duces] verfolgen, damit sie auch jene edelsten duces absetzen und ihre eigenen schlechten Leute an deren statt zu duces ernennen können; dadurch könnten sie noch viel mehr [als bisher] täglich und auch von allen Seiten die Kirche Gottes erobern, die Sachen des Heiligen Apostelfürsten Petrus entwenden und seinen peculiaris populus gefangen nehmen. Dennoch, damit die Wahrheit Euch dargelegt werde, allerchristlichster Sohn, mögest Du befehlen, nach der Heimkehr dieser Könige einen sehr treuen missus, der nicht bestochen werden kann, zu entsenden, damit er mit eigenen Augen die gegen uns gerichtete Verfolgung, die Erniedrigung der Kirche Gottes, die Verwüstung ihres Besitzes und die Tränen der Flüchtlinge sehen kann und Deiner Güte alles berichten kann. ${ }^{491}$

490 CC 1 , ed. Gundlach 476f.

491 CC 2, ed. Gundlach 477-479, hier 478: Non credas, fili, falsidicis suggestionibus ac suasionibus eorundem regum [Liutprand und Hildeprand]. Omnia enim false tibi suggerunt, scribentes circumventiones: quod quasi aliquam culpam commissam habeant eis eorum duces, id est Spolentinus et Beneventanus; sed omnia mendacia sunt. Non enim pro alio - satisfaciat te veritas, fili-eosdem duces persequitur capitulo nisi pro eo, quod noluerunt praeterito anno de suis partibus super nos inruere et, sicut illi fecerunt, res sanctorum apostolorum destruere et peculiarem populum depraedare, ita dicentes ipsi duces:, Quia contra eclesiam sanctam Dei eiusque populum peculiarem non exercitamus, quoniam et pactum cum eis habemus et ex ipsa eclesia fidem accepimus. Ideoque mucro eorum desevit contra eos. Nam ipsi predicti duces parati fuerunt et sunt, secundum antiquam consuetudinem eis hobedire. Sed illi, retinentes iram pro eo quod superius diximus, 
Der Papst war also in den Verhandlungen mit dem Karolinger damit konfrontiert worden, dass er sich schließlich mit den duces verbündet habe, was die Reaktion Liutprands auf den Plan gerufen habe. Im Vergleich zu späteren Schriften ist auffällig, wie sachlich der Papst versucht, die römische Position zu argumentieren. Die Langobardenkönige Liutprand und Hildeprand werden völlig wertfrei und ohne herabsetzende Epitheta dargestellt. Ihnen wird jedoch vorgeworfen, Lügen zu verbreiten. Denn die duces von Spoleto und Benevent würden jetzt nur deshalb angegriffen, weil sie sich geweigert hätten, Rom und die Kirche selbst anzugreifen und sich auf ein Bündnis mit Rom berufen hätten. Außerdem wird ihnen zu Gute gehalten, schließlich den Glauben zu verteidigen.

Der Appell an den fränkischen Hausmeier zeigt, dass die Situation für den Papst bedrohlich erschien. Das umso mehr, als Karl Martell als Verbündeter Liutprands galt. Vielleicht auch aus diesem Grund ist der zweite Brief verhältnismäßig vorsichtig formuliert. Er fordert jedoch die Franken deutlich zur Parteinahme für den Papst auf. Karl Martell kam dieser Forderung allerdings soweit wir wissen nie nach, Liutprand setzte seine Politik in Mittelitalien ungehindert fort.

Auch wenn die Quellenlage nicht ideal ist, kann doch festgehalten werden, dass sich die Beziehung des Papsttums zum langobardischen Königreich während des Pontifikats Gregors III. deutlich verschlechtert hatte - immerhin kam es nun zu handfesten militärischen Auseinandersetzungen. Das langobardische Königreich zählte nun wieder zweifelsfrei zu den Feinden Roms. Umso auffälliger ist es, dass auch unter Gregor III. noch nicht der Versuch unternommen wurde, gezieltes Othering gegen den König zu betreiben. Es wurde aber zwischen feindlichen und freundlichen Langobarden unterschieden: Die bedrohten Dukate waren noch zu jenen ehrenwerten Verbündeten zu zählen, die die Kirche sogar verteidigten.

\subsection{Zacharias, Liutprand und Ratchis}

Der Pontifikat Zacharias' wird in der Literatur gemeinhin unter einem einzigen Gesichtspunkt gesehen: Er war der letzte „griechische“ Papst - was das zu bedeuten hatte,

\footnotetext{
per exquesitam occasionem volentes illos et nos destruere et invadere, ideo, utrosque persequentes, vestre bonitati suggerunt falsa, ut et duces illos nobilissimos degradent et suos ibidem pravos ordinent duces et multo amplius cotidie et ex omni parte Dei eclesiam expugnent et res beati Petri principis apostolorum dissipent atque populum peculiarem captivent. Tamen ut rei veritas vobis declaretur, christianissime fili, iubeas post ipsorum regum ad propria reversionem tuum fidelissimum missum, qui non a premiis corrumpatur, dirigere, ut propriis oculis persecutionem nostram et Dei ęclesię bumiliationem et eius rerum dissolationem et peregrinorum lacrimas conspiciatur et tue bonitati omnia pandantur.
} 
ist bereits an anderer Stelle erörtert worden. ${ }^{492}$ Tatsächlich ist die historische Bedeutung von Zacharias nicht an seiner Herkunft festzumachen, seine Politik erwies sich für das Papsttum als wegweisend und sein oft als revolutionär betrachteter Nachfolger Stephan II. war, wie wir noch sehen werden, stark seinem Vorgänger verpflichtet.

Als Quelle für Zacharias' Langobardenpolitik kann ausschließlich seine Vita aus dem Liber Pontificalis dienen, denn entsprechender diplomatischer Schriftverkehr ist - im Gegensatz vor allem zu seinen Nachfolgern - wenig erhalten. Dafür spielen die Langobarden die zentrale Rolle in der Vita, die erste Hälfte des Textes wird fast völlig von diesem Thema dominiert. Die Vita des Zacharias bietet glücklicherweise ein sehr zeitgenössisches Bild, sie scheint von einer Person verfasst worden zu sein, die den Papst auf einigen seiner Reisen selbst begleitet hat und daher die Ereignisse als Augenzeuge schildern konnte. ${ }^{493}$ Der Bericht scheint dabei in weiten Teilen relativ ausbalanciert und verhältnismäßig fair, auch wenn er natürlich die päpstliche Position vertritt - ganz besonders auffällig ist das im Vergleich mit der darauffolgenden Vita Stephans II.

In den ersten Absätzen der Vita wird vor allem das letzte Pontifikatsjahr Gregors III. geschildert, das in dessen Vita nicht mehr enthalten war. Der Grund dafür ist, dass der Dukat von Rom beim Tod Gregors in einer äußerst schwierigen Position war. Rom hatte, wie wir auch aus dem bereits besprochenen Brief Gregors III. wissen, die duces von Spoleto und Benevent gegen König Liutprand unterstützt. Die Chronologie ist durchaus umstritten ${ }^{494}$, etwa $739 / 40$ hatte aber Liutprand ganz klar die Oberhand gewonnen. Der Spoletiner $d u x$ Transamund II. musste in Rom Zuflucht suchen. ${ }^{495}$ Wahrscheinlich als Reaktion darauf - auch wenn Gregor III. das vehement bestritt ${ }^{496}$ - nahm Liutprand vier befestigte Orte des römischen Dukats ein, Amelia (zeitgen. „Ameria“), Orte, Bomarzo und Blera. ${ }^{497}$ Auch ein neuerliches, vom Papst gefördertes Aufbegehren Transamunds verlief wenig zufriedenstellend, und das, obwohl Liutprand abwesend war, da er Karl Martell auf seinem Feldzug gegen die Sarazenen unterstützte. ${ }^{498}$

492 Siehe oben, Kap. 4.1.

493 Davis, LP 8, 29f. und 39, n. 36. Letztere Stelle bezieht sich auf Kap. 10 der Vita (LP I, 428), wo sehr persönlich über ein gemeinsames Mahl von Zacharias und Liutprand berichtet wird und der LP-Autor schreibt, Liutprand habe gesagt, er könne sich nicht erinnern, jemals so viel gegessen zu haben. Davis bezeichnet das als „perhaps the LP's most extraordinary example of eyewitness reporting!“

494 Für die immer noch glaubwürdigste Darstellung siehe Noble, Republic 44-48.

495 Siehe Gasparri, I duchi $77 f$.

496 Siehe oben in Kap. 5.1 das ausführliche Zitat aus CC 2.

497 LP I, 426.

498 Siehe dazu J. Insley, Septimanien, in: RGA, Bd. 28 (2004) 185-194, hier 190. Paulus Diaconus, 
Die Reaktion des neu gewählten Papstes Zacharias war ein veritabler renversement des alliances. Er unterstützte nun König Liutprand, der so binnen kürzester Zeit Transamunds habhaft werden konnte. Dafür sollte der König die vier Besitzungen des Dukats von Rom zurückgeben. ${ }^{499}$

Als diese Rückgabe nach der Übergabe Spoletos nicht erfolgte, entschloss sich Zacharias, den Langobardenkönig selbst zu treffen. Das Ereignis war auch insofern epochal, als nun zum ersten Mal ein Papst mit einem Langobardenherrscher außerhalb des beim Römischen Reich verbliebenen Gebiets zusammentraf. ${ }^{500}$ Das Treffen in Terni wird als äußerst amikal geschildert. Es wurde ein Friedensvertrag auf 20 Jahre zwischen Rom und dem Langobardischen Königreich geschlossen, wobei der genaue geographische Geltungsbereich des Vertrages offenbar ungeklärt blieb oder von den beteiligten Parteien unterschiedlich ausgelegt werden konnte. Allerdings wurden der römischen Kirche entfremdete Patrimonien zurückgegeben, darunter auch die umstrittenen vier Orte. ${ }^{501}$ Der Nutzen für Liutprand lag zunächst im Bruch der Allianz zwischen den duces und Rom. Außerdem könnte er sich von dem Arrangement mit dem Papst freie Hand gegen den Exarchat versprochen haben. ${ }^{502}$ Der Papst kehrte jedenfalls triumphal nach Rom zurück, besonders ausführlich wird auch der Umritt geschildert, den er zur Rückgabe der vier „Städte“ gemeinsam mit Vertretern des Königs unternahm. ${ }^{503}$

Nach der Kritik an Liutprand darf der König in diesen Passagen also glänzen, jedoch nur für kurze Zeit. Schon im folgenden Jahr greift er Ravenna an und nimmt zunächst das castrum Cesena ein, was die dortigen Machthaber und bemerkenswerterweise sogar den Exarchen selbst dazu bringt, an den Papst zu appellieren, welcher sogleich nach Ravenna aufbricht. Auf der Reise wird er in einer erwei-

Historia Langobardorum 6, 54, ed. Bethmann/Waitz 183, berichtet, dass Liutprand persönlich an dem Feldzug gegen Narbonne teilnahm: Tunc Carolus legatos cum muneribus ad Liutprandum regem mittens, ab eo contra Sarracenos auxilium poposcit; qui nibil moratus cum omni Langobardorum exercitu in eius adiutorium properavit.

499 LP I, 426f.

500 Noble, Republic 52. Diplomatische Missionen waren jedoch für Päpste generell nichts Außergewöhliches, Papst Konstantin I. etwa hatte 710 selbst eine Mission nach Konstantinopel angeführt. Gregor II. wiederum war bereits mit Liutprand zusammengetroffen, jedoch vor den Mauern Roms. Schon unter Gregor dem Großen hatte es rege diplomatische Kontakte gegeben und Gregor war auch mit dem Langobardenkönig Agilulf zusammengetroffen, allerdings eben nicht auf langobardischem Territorium, siehe Stefano Gasparri, Italia longobarda. Il regno, i Franchi, il papato (Rom/ Bari 2012) 75-77.

501 LP I, 427f.

502 Noble, Republic 52 und 54.

503 LP I, $428 f$. 
terten (oder doch eher vollständigen?) Version der Vita durch biblische Anklänge sogar eindeutig zum Neuen Moses erhoben. ${ }^{504}$ Als Grund der erneuten Mission des Papstes wird im LP der Einsatz für seine Schafe angegeben, die er als Guter Hirte nicht im Stich lassen kann. In der ersten Hälfte des achten Jahrhunderts hatte das Papsttum aber auch handfestes politisches Interesse am Bereich des Exarchats. Außerdem fühlte man sich in Rom dem imperium zweifellos noch verbunden, und der Papst verhandelte sehr oft eben auch im Auftrag des Kaisers mit den Langobarden. Stadtrömische und kaiserliche Interessen spielten im Fall Ravennas also zu gleichen Teilen eine Rolle. ${ }^{505}$

Von Ravenna aus brach Zacharias nun nach Pavia (in der Vita des Zacharias konsequent mit dem antiken Namen Ticinum bezeichnet) auf, um Liutprand zu treffen. Doch diesmal gestaltete sich schon die Reise schwieriger als die gesamte Mission nach Terni im Jahr davor. Zacharias hatte den primicerius Ambrosius und einen presbyter Stephan ${ }^{506}$ vorausgeschickt, um den Besuch vorzubereiten. Die beiden ließen ihm nun die Nachricht zukommen, dass die langobardischen Machthaber in der Nähe von Ravenna den Papst nicht nach Nordwesten reisen lassen wollten. Der Papst machte sich dennoch auf den Weg. Sein Biograph im LP betont dabei die Lebensgefahr, in der er durch die Entscheidung geschwebt habe - zweifellos eine Übertreibung, denn die lokalen Gastalden hätten sicherlich den diplomatischen Eklat gescheut. Tatsächlich gelang es Zacharias offenbar ohne Probleme bis Pavia vorzudringen. Dort jedoch weigerte sich der König offenbar zunächst, die „Vorhut“ der päpstlichen Entourage zu treffen. Der Papst selbst wurde dann jedoch sehr wohl von langobardischen Würdenträgern empfangen. Zacharias zelebrierte zunächst am 28. Juni eine Messe in der Basilika von Pavia, die dem Heiligen Petrus geweiht und von Liutprand selbst wiederaufgebaut worden war. ${ }^{507}$ Am folgenden Tag feierte der Papst dann gemeinsam mit dem König die Festlichkeiten zum Peter-und-Paul-Tag. ${ }^{508} \mathrm{Za}$ charias rückte bei seinem Besuch in Pavia seine Rolle als Nachfolger und Stellvertreter Petri also in den Vordergrund. Einerseits setzte er Liutprand damit unter Druck,

504 Eine schattenspendende Wolke erleichtert die Reise des Papstes. Siehe dazu Gantner, Studien $109 f$. 505 Vgl. dazu auch oben, Kap. 3 und 4, bes. Kap. 3.2.2. Sehr gut werden die Motive des Papsttums in Bertolini, Il primo „periurium“, dargestellt.

506 Es ist unklar, ob es sich hier um einen der zwei Päpste (Stephan [II.] und III.) handelt, die in den folgenden Jahren diesen Namen tragen sollten und zuvor Priester waren. Stephan II. war vor seiner Wahl Diakon und kann daher hier nicht gemeint sein. Stephan III. allerdings wurde just von Zacharias zum Kardinalpriester von St. Cecilia ernannt.

507 Davis, LP 8, 42, Anm. 54: Die St. Peters Kirche hatte vor 600 bereits existiert. Liutprand ließ sie wieder aufbauen und fügte ein Kloster hinzu. Siehe Paulus Diaconus, Historia Langobardorum, 6, 58, ed. Bethmann/Waitz 186.

508 LP I, 429f. 
andererseits konnte dieser bei positivem Ausgang der Verhandlungen mit dem Papst auch erhebliches Prestige gewinnen. ${ }^{509}$

Am Tag nach dem Hochfest gelang es Zacharias nach, wie der LP bemerkt, zähen Verhandlungen, Liutprand zur Rückgabe der meisten Gebiete Ravennas zu bewegen. Des Weiteren wurde auch Cesena mit zwei Dritteln seiner Güter dem Exarchat zurückgegeben. Ein Drittel der Güter sollte zurückgehalten werden, bis (mit Stichtag I. Juni 744?) eine Gesandtschaft aus Konstantinopel zurückgekehrt sei (regia reverterentur urbe). Wiederum hatte sich Zacharias durchgesetzt und wieder wurde der König, der sich zunächst multa duritia widersetzt hatte, in seine Schranken gewiesen. ${ }^{510}$ Zacharias' Erfolg dürfte wohl vor allem auf ausgeklügeltem religiösem Druck basiert haben. So betrachtet kann sein Eintreffen am Vortag des Hochfestes der wichtigsten mit Rom verbundenen Heiligen kein Zufall gewesen sein. Der alternde König Liutprand wollte sich offenbar auch aufgrund religiöser Gefühle nicht gegen den höchsten kirchlichen Würdenträger stellen ${ }^{511}$ - und dieser wusste seine Position in dieser Hinsicht voll auszunutzen. ${ }^{512}$ Vielleicht war sich Liutprand auch bewusst, dass ein Angriff auf den Papst dem Ansehen des Langobardenreichs schaden würde - wie sich ja wenige Jahre später auch unter König Aistulf zeigen würde.

Abgesehen von religiös-politischem Druck hatte Zacharias wohl aber auch eine Menge an symbolischem Kapital zu bieten, auf das Liutprand nicht verzichten wollte. Es ist bezeichnend, dass der Papst bei beiden Zusammentreffen mit dem König auch eine groß angelegte Messe zelebrierte. In Terni weihte er zudem auch einen Bischof für einen Ort im langobardischen Herrschaftsbereich. ${ }^{513}$ Und in Pavia feierte er mit dem König eines der wesentlichsten römischen Kirchenfeste. Er konnte Liutprand in beiden Fällen also relativ wertvolles symbolisches Kapital bieten, dieser konnte die Treffen zur Eigenwerbung nutzen. Selbst sein Nachgeben konnte Liutprand als pietas gegenüber der Kirche ausgelegt werden. Auch im klugen Einsatz des nahezu unerschöpflichen symbolischen Kapitals erwies sich Zacharias als Lehrmeister seiner Nachfolger, insbesondere Stephan II. sollte genau dadurch das Bündnis mit den Karolingern gelingen - auch etwas, das Zacharias bereits vorbereitet hatte, auch wenn die Beziehungen mit den Franken in seiner LP-Vita keine Erwähnung finden. ${ }^{514}$

509 Siehe dazu bald Gantner, Papacy as cultural broker.

510 LP I, 430 f.

511 Noble, Republic 55: „The king was also a man of sincere religious sentiments and he did not relish having to make war on the pope."

512 Pohl, Papsttum 145-161, hier 149-151.

513 Der Ort selbst ist in der Forschung umstritten, der LP hat das wahrscheinlich verschriebene „Cosinensis“. Siehe dazu Davis, LP 8, 39, Anm. 35.

514 Der Grund dafür ist wohl darin zu sehen, dass diese Beziehungen erst aus der Rückschau nach 754 
Vor diesem Hintergrund ist es überraschend, wie sich der Autor unseres Textes wenig später über das Ableben Liutprands äußerte:

Als er mit seinem gesamten Gefolge nach Rom zurückgekehrt war und Gott dafür dankte, feierte er erneut das Fest der Heiligen Apostel Petrus und Paulus mit dem gesamten Volk. Und er widmete sich dem Gebet, in dem er den allmächtigen Gott um Gnade und Trost für das ravennatische und das römische Volk vor dem hinterhältigen Verfolger Liutprand bat. Gottes Barmherzigkeit verachtete sein Gebet nicht und berief den König vor der vereinbarten Zeit ${ }^{515}$ von dieser Welt ab. Und die ganzen Verfolgungen kamen zu einem Ende, es war Freude nicht nur bei den Römern und Ravennaten, sondern auch bei der gens der Langobarden; denn diese verjagten auch [Liutprands] Neffen Hildeprand, der diesem als böswilliger König nachgefolgt war, aus dem Königtum und wählten Ratchis, der zuvor dux gewesen war, als König. ${ }^{516}$

Zuvor wird Liutprand meist in neutralen Worten geschildert und kooperiert schlussendlich immer mit dem Papst. Zacharias ist zwar der unumstrittene Held der Darstellung, doch auch der König erscheint zumindest als ordentlicher christlicher Herrscher, der auf den rechten Weg zurückgeführt werden kann. Doch bei seinem Tod ist alles anders.

Schwang hier noch ein Revanchegedanke mit, der sich auf Liutprands gegen Rom gerichtetes Bündnis von 729 oder seine (allerdings selbst aus römischer Sicht wohl vertretbaren) Aktionen gegen Gregor III. bezogen haben könnte? Oder musste man sich von Liutprand abgrenzen, um in Rom ein tragfähiges Feindbild aufrechtzuerhalten? Tatsache ist, dass an dieser Stelle Othering gegen Liutprand und seine Herrschaft betrieben wurde und das obwohl sich die Darstellungsweise eigentlich mit der vorhergehenden Erzählung nicht deckt.

wichtig wurden und die Vita da längst abgefasst war - ihr politischer Teil wurde wahrscheinlich schon zu Lebzeiten des Papstes in seiner jetzigen Form abgeschlossen, vgl. Davis, LP 8, 29. Zu den Franken siehe unten, Kap. 5.8.

515 Davis, LP 8, 43, Anm. 62, vermutet, dass hier der vereinbarte Zeitpunkt einer Rückgabe Cesenas an den Langobardenkönig gemeint ist.

516 LP I, 431: Regressus autem in urbe Romana cum omnibus qui secum erant, gratias agentes Deo, denuo natale beatorum principum apostolorum Petri ac Pauli cum omni populo celebravit, et sese in orationibus dedit, petens ab omnipotenti Deo misericordiam et consolationem feri populo Ravennantium et Romano ab insidiatore et persecutore illo Liutprando rege. Cuius preces non dispiciens divina clementia eundem regem ante constitutum de hac subtraxit luce. Et quievit omnis persecutio, factumque est gaudium non solum Romanis et Ravennianis, sed etiam et genti Langobardorum; quoniam et Hilprandum nepotem suum quem ipse reliquerat, regem malivolum, proiecto de regno, Ratchisum qui fuerat dux sibi Langobardi elegerunt in regem. 
Davis schließt aus der harschen Kritik an Liutprands Herrschaft jedenfalls, dass der Autor den Bericht sehr zeitnah niederschrieb, weil er in Kenntnis der späteren Politik Aistulfs milder geurteilt hätte. ${ }^{517}$ Die Beziehungen Roms zum noch 744 zum König erhobenen Ratchis waren zu Beginn allerdings tatsächlich wesentlich besser als zu Liutprand und seinem kurzzeitigen Nachfolger Hildeprand. Man könnte aber auch umgekehrt argumentieren, dass der verbale Ausfall gegen die Langobarden besser in die Regierungszeit Stephans II. passen würde, so wie etwa auch der Zusatz zur Vita Gregors III. oft in diese Zeit datiert wird. ${ }^{518}$ Die harten Worte waren vielleicht aber auch schon Ausdruck eines beginnenden Antagonismus zwischen Rom und dem langobardischen Königtum noch zu Lebzeiten Zacharias'.

Ein weiterer Punkt, den man nicht außer Acht lassen sollte, ist das Narrativ der Vita selbst, das ganz auf Zacharias zugeschnitten ist. Alle anderen Protagonisten haben darin vor allem die Aufgabe, die Rolle des Papstes als „neuer Prophet“ zu unterstreichen. Liutprands Handeln folgt somit in unserer Quelle nicht so sehr den historischen Ereignissen als vielmehr literarischen Topoi: Er fungiert im Text zunächst als Sünder (Vertragsbrecher), den nur der heilige Mann bekehren kann. Bei seinem Tod jedoch erschien dem Autor offenbar das Bild des mit der Hilfe Gottes überwundenen Feindes passender. Liutprand wechselt also im Text die Rolle, vor allem um der Figur des Papstes mehr Konsistenz zu verleihen. Wahrscheinlich haben also sowohl narrative Überlegungen als auch die aktuelle politische Situation die Bewertung Liutprands beeinflusst.

Für Ende 744 liefert der LP jedenfalls ein äußerst harmonisches Bild. Denn Ratchis bestätigte den auf 20 Jahre angelegten Friedensvertrag von Terni ${ }^{519}$ Er tat dies ob reverentiam principis apostolorum, aus Wertschätzung für den Apostelfürsten, er wurde also in der Narration des LP-Autors zweifellos als positive Figur eingeführt. ${ }^{520}$ Wir begegnen ihm erst fünf Jahre später wieder, als er die Pentapolis angreift und unter anderem Perugia belagert. Diese Gegend gehörte aller Wahrscheinlichkeit nach zum Gebiet des Exarchats und war daher aus langobardischer Sicht vom Friedensvertrag nicht betroffen. Dennoch musste seit der Intervention Zacharias' 743 klar sein, dass Rom die Sache anders sah. Warum also ließ sich Ratchis auf eine Konfrontation ein? Es wurde spekuliert, dass der Papst oder der Exarch den Frieden gebrochen

517 Davis, LP 8, 43, Anm. 61.

518 Siehe dazu oben, Kap. 5.1.

519 Eigentlich ist nur von einem Friedenvertrag auf 20 Jahre die Rede. Noble, Republic 56, schließt jedoch glaubhaft aus der eigentümlichen Formulierung, dass wohl der bestehende Vertrag bestätigt wurde.

520 LP I, 431. 
hätten, ${ }^{521}$ doch gibt es dafür keinerlei Anhaltspunkte in den Quellen. Möglich ist auch, dass Ratchis von kriegerischen langobardischen Großen gedrängt wurde, gegen den Exarchat vorzugehen. ${ }^{522}$ Das erscheint schon realistischer, doch es gibt noch eine wahrscheinlichere Erklärung: Der König musste, um seine Position zu sichern, die Oberhoheit Pavias über Spoleto und Benevent wiederherstellen, denn sonst wäre er gegenüber Liutprand an Prestige deutlich abgefallen. Um dauerhafte Kontrolle zu sichern, bedurfte es eines ebenso dauerhaften Zugriffs auf den Süden, der nun bei Perugia an der schmalsten Stelle der Besitzungen des Reichs in Mittelitalien hergestellt werden sollte. Dazu kam, dass der tatsächliche Machtzuwachs und der nachdrücklichere Machtanspruch des Papsttums spätestens unter Zacharias für die Langobardenkönige bedrohlich wurden. Ratchis war sich auch aus diesem Grund sicher bewusst, dass er mit seinem Vorgehen gegen Ravenna ein beträchtliches Risiko einging. Tatsächlich machte sich Zacharias sofort auf den Weg. Er schaffte es, Ratchis, laut LP durch finanzielle Mittel und Predigt zur Aufgabe der Belagerung zu bewegen.

Doch damit nicht genug, für den LP war der Triumph des Papstes vollkommen:

Er predigte ihm heilbringende Dinge und mit Gottes Hilfe gelang es ihm, seine Seele hin zu geistlichen Studien zu lenken. Nach einigen Tagen entsagte Ratchis seiner Königswürde und wandte sich unterwürfig mit seiner Frau und seinen Kindern zur Schwelle des Heiligen Apostelfürsten Petrus. Er unterwarf sich dort der erwähnten Predigt des heiligen Papstes, wurde zum Kleriker gemacht und legte mit seiner Frau und seinen Kindern den Mönchshabit an. ${ }^{523}$

Der Langobardenkönig wählte mit seiner Familie auf die Predigt des Papstes hinauf also ein geistliches Leben. Tatsächlich ist es wahrscheinlicher, dass Druck seines machtbewussten Bruders Aistulf zu dieser Entscheidung wesentlich beigetragen hat. ${ }^{524}$ Der LP jedenfalls machte aus diesem Ereignis einen Triumph des Papstes, der es schafft, das verlorene Schaf durch seine heilsspendende Predigt sogar für ein geistliches Leben zu gewinnen. Folgerichtig befasste sich der Autor der Vita von

521 Hartmann, Geschichte Italiens im Mittelalter, Bd. 2, 2, 149.

522 Noble, Republic 56.

523 LP I, 434: Cui et salutifera praedicans, Deo auctore, valuit animum eius spiritali studia inclinare. Et post aliquantos dies isdem Ratchis rex, relinquens regalem dignitatem, devote cum uxore et filiis ad beati Petri principis apostolorum coniunxit limina, acceptaque a praelato sanctissimo papa oratione clericusque effectus, monachico indutus est habitu cum uxore et filiis.

524 Siehe ausführlich Pohl, Papsttum 151-153, der auch die schwache Position Ratchis deutlich herausstreicht. 
dieser Stelle an nicht mehr mit dem Langobardenreich, obwohl Zacharias noch zwei weitere Jahre lebte und dabei auch erleben musste, dass mit Aistulf nun ein König in Pavia saß, der nicht gewillt war, mit ihm über Ravenna zu verhandeln und den Exarchat auch tatsächlich bald einnehmen konnte.

Was bleibt also von Zacharias' Pontifikat für die Langobardenbeziehungen? Wir sehen in der Vita einen Papst, der gut mit den langobardischen Machthabern umgehen konnte, der das hohe kulturelle und religiöse Kapital seines Amtes in die Waagschale zu werfen wusste. Walter Pohl hat diese Vorgehensweise treffend als „Machtpolitik ohne Waffen“ bezeichnet. ${ }^{525}$ Der Papst agierte dabei zeitweise sogar offiziell im Auftrag des Kaisers, war aber im Zuge dessen auch bestrebt, die Macht des Papsttums südlich der Poebene weiter auszubauen. Dabei dürfte auch für die langobardischen Herrscher ein Mehrwert entstanden sein, der eine nachgiebige Position vorteilhaft erscheinen ließ. Die freundliche Politik gegenüber den Langobarden scheiterte aber daran, dass der von den Päpsten gebotene religiös-ideologische Mehrwert von einigen Vertretern des Hofes als zu gering angesehen wurde, vor allem im Verhältnis zur steigenden politischen Macht des Papsttums. Diese Bewertung rief Aistulf mit seiner harten Gangart auf den Plan und ließ Zacharias' Politik im Endeffekt scheitern - auch wenn der LP davon nichts wissen wollte. Das führte wohl auch dazu, dass Stephan II. den Franken wenige Jahre später noch weit mehr religiöses, römisches und imperiales Kapital zu geben bereit war.

In der Erzählung der Vita des Zacharias erscheinen die Langobarden jedenfalls bis auf wenige Ausnahmen nicht besonders negativ, vor allem wenn man die Darstellung mit jener der folgenden Viten vergleicht. Das liegt einerseits daran, dass es neben Konflikten durchaus auch zu Kooperation kam. Andererseits war es für die Dramaturgie des Textes wichtig, das Agieren des Papstes als erfolgreich darzustellen, ${ }^{526}$ weswegen auch auf eine Erwähnung der Übergriffe des neuen Königs Aistulf auf den Exarchat verzichtet wurde. Der Triumph des Zacharias nicht über sondern eigentlich gemeinsam mit König Ratchis sollte nicht getrübt werden. An Ratchis sehen wir eine Spielart des Sameing mit religiösen Mitteln. Durch seinen Übertritt zum Mönchtum an der Schwelle der Apostel wird er gleichsam integriert - auch wenn diese Integration nicht vollständig sein konnte, wie sein erneutes Auftauchen als langobardischer Königskandidat gegen Ende der Vita Stephans II. belegt. ${ }^{527}$

525 Pohl, Papsttum 151.

526 Siehe dazu zukünftig: Clemens Gantner, The papacy as cultural broker in the eighth century, in: ders./Rosamond McKitterick/Sven Meeder, Cultural Memory and the Resources of the Past in the Early Middle Ages (Cambridge, in Vorbereitung).

527 LP I, 454. 


\subsection{Stephan II. und die Langobarden}

Wie in den Beziehungen zu den Greci, stellte der Pontifikat Stephans II. auch in der Langobardenpolitik und der damit einhergehenden Repräsentation dieser Anderen in päpstlichen Schriften einen Wendepunkt dar. Zum besseren Verständnis ist es zunächst nötig, die für die politische Geschichte äußerst reichhaltige LP-Vita Stephans zu analysieren.

\subsubsection{Papst vs. Langobarden - Zusammenfassung der Vita Stephani ${ }^{528}$}

Die LP-Edition Louis Duchesnes folgt fast ausschließlich der Rezension $\mathrm{C}^{34} \mathrm{E}$ der Vita Stephans, alle anderen Lesarten werden im Variantenapparat aufgeführt. Dieser Version folgt nun auch diese kurze Einführung, auf die Varianten der anderen Rezensionen wird im folgenden Kapitel eingegangen.

Die Vita ist für die Verhältnisse des Liber Pontificalis von stark überdurchschnittlicher Länge, allerdings setzt sie nur einen Trend zu ausführlicheren Schilderungen fort, der spätestens mit dem Leben Gregors II. eingesetzt hatte. ${ }^{529}$ Somit war die Vita Stephans zum Zeitpunkt ihrer Abfassung die zweitlängste Vita des Liber Pontificalis, sie wurde nur noch von der (vor allem aufgrund der umfangreichen Schenkungslisten) extrem langen Vita Silvesters I. übertroffen. ${ }^{530}$ Was dieses Leben aber besonders auszeichnet - und auch in dieser Hinsicht wurde ein allgemeiner Trend des frühen achten Jahrhunderts noch verstärkt - ist der besonders narrative Charakter des Textes, nur wenig wurde mit Registermaterial angereichert. In der Vita gibt es auch keine Trennung zwischen Ereignisgeschichte und Stiftungstätigkeit des Pontifikats, ${ }^{531}$ sondern die Bautätigkeit und andere Spenden an Kirchen wurden anscheinend chronologisch in den Text eingebaut.

Der von biblischer Sprache stark beeinflusste Stil der Vita des Zacharias ist hier nicht zu erkennen. Liest man den lateinischen Text des einen Lebens direkt nach dem anderen, dann ist der Bruch in der Sprache ziemlich deutlich wahrnehmbar.

528 Der folgende Abschnitt enthält überarbeitetes Material aus Gantner, Studien, Kapitel 3.

529 Auch davor gab es vielleicht schon einen Trend in diese Richtung. Zwar sind die Viten von Johannes VII. und Konstantin eher kurz geraten, doch jene von Papst Sergius I. ist durchaus auch schon zu den ausführlicheren zu zählen. Zu den Viten des späten siebenten Jahrhunderts siehe Duchesne, Etude 206f.

530 Allerdings war die Vita Hadrians I. vier Jahrzehnte später wiederum deutlich länger als jene Stephans. Die Vita Leos III. schließlich übertraf sogar jene Papst Silvesters an Länge.

531 Eine Trennung, die noch bei den Vorgängerpäpsten recht deutlich versucht wurde (wobei etwa bei Zacharias der Fokus noch manchmal zur Politik zurückwechselt) und ab der Vita Hadrians I. zeitweise fast exzessive Züge annehmen konnte (besonders zu nennen ist hier die Vita Hadrians selbst und jene von Leo IV., in beiden Fällen wurde offenbar seitenweise aus dem Register des päpstlichen Vestarariums übertragen). 
Inhaltlich dominiert im Text die Außenpolitik des Papstes - es geht vor allem um die Auseinandersetzung des Papsttums und des römischen Dukats mit dem Königreich der Langobarden, vertreten durch den ehrgeizigen König Aistulf, der seinen wesentlich konzilianteren Bruder Ratchis 749 abgelöst hatte, und um das radikal neu gestaltete Verhältnis zum Königreich der Franken. Der Geschichte dieses Antagonismus sind abgesehen von vier Abschnitten ${ }^{532}$ am Beginn und zwei am Ende des Textes nur drei weitere Abschnitte nicht gewidmet. Insgesamt beschäftigen sich also nur neun Abschnitte von 53 nicht in irgendeiner Form mit der päpstlichen Außenpolitik gegenüber Franken und Langobarden. Selbst in Abschnitt II, der mit der Erwähnung der Acheropsita-Ikone ${ }^{53}$ als klarer Seitenhieb auf das ikonoklastische Byzanz gedacht ist, werden die gesetzten liturgischen Akte schlussendlich mit den Langobarden in Verbindung gebracht.

Zunächst mag dieser Fokus vielleicht nicht überraschen, weil ja auch die Viten der Vorgänger Stephans (Zacharias und Gregors II.), durchaus auf Ereignisgeschichte ausgerichtet waren. ${ }^{534}$ Doch ist dort das Augenmerk, vielleicht auch aus faktischen Gründen, stärker auf mittelitalische Angelegenheiten konzentriert. Besonders auffällig ist jedoch der Kontrast zur Vita von Stephans Bruder und Nachfolger Paul I., in der die Außenpolitik auffällig ausgeklammert wird. Das mag auch daran liegen, dass die Politik Pauls als wesentlich weniger erfolgreich empfunden wurde als jene Stephans. Die generelle Informationsarmut der Vita Pauls deutet darauf hin, dass hier vor allem versucht wurde, bestimmte Informationen nicht zu vermitteln.

Am Beginn der Stephansvita steht - nach der seit langem etablierten Einleitung aller Liber Pontificalis-Viten ${ }^{53}$ - zunächst ein kurzer Bericht über die Wahl und das plötzliche Ableben Stephans (II.), des direkten Vorgängers des Protagonisten der Vita $(2)^{536}$. Dieser wird in offiziellen Papstlisten zumeist nicht geführt, da er, wie die

532 Die Zählung wurde im 18. Jahrhundert von Vignoli eingeführt. Zu seiner Edition siehe Duchesne, Etude 119-123.

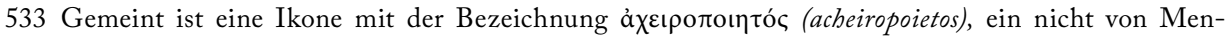
schenhand geschaffenes Bildnis. Siehe dazu Martin Büchsel, Das Christusporträt am Scheideweg des Ikonoklastenstreits im 8. und 9. Jahrhundert, in: Marburger Jahrbuch für Kunstwissenschaft, 25 (1998) 7-52, besonders 38 .

534 Ganz im Gegensatz dazu die Vita Gregors III., in deren ursprünglicher Version die Langobarden nicht erwähnt werden. Dieser Text konzentriert sich ganz auf die innerrömischen Vorgänge und die Beziehnungen zu Byzanz.

535 Das heißt Stephanus natione Romanus ex patre Constantino ... und so weiter.

$536 \mathrm{Im}$ Folgenden werden in Klammer die Zahlen der Abschnitte angegeben, so wie sie in der Edition Vignolis verwendet wurden. Sie ermöglichen eine leichte Orientierung sowohl in der Edition Duchesnes, wo sie am Rand als römische Zahlen angegeben sind, als auch in der Übersetzung von Davis, der sie überhaupt als wesentlichstes Ordnungsmittel verwendet. 
Vita Stephani zu berichten weiß, noch vor erfolgter Bischofsweihe an einer plötzlichen schweren Krankheit verstarb. ${ }^{537}$ Seine Wahl hat aber dazu geführt, dass es bei den Päpsten mit Namen Stephan zu Problemen mit den Ordnungszahlen gekommen ist, denn jene, die den nur zwei oder drei Tage amtierenden Papst mitzählen, führen den hier wesentlichen Stephan II. als III. Wenn in der Folge aber von Stephan II. die Rede ist, ist jener Papst gemeint, dem auch die LP-Vita gewidmet ist.

Nach dem plötzlichen Tod des Papstelekten wird Stephan II. gewählt, wobei von einer unumstrittenen Wahl berichtet wird, die allerdings in Santa Maria Maggiore durchgeführt wurde. ${ }^{538}$ Eigentlich hätte die Wahl nach den römischen Gepflogenheiten der Zeit in der Lateransbasilika (in den Quellen Constantiniana) stattfinden sollen. Allerdings war das achte Jahrhundert von Ausnahmen geprägt, entscheidend war erst die nach der Wahl erfolgende feierliche Einführung in den Lateranspalast, die so abgehalten werden musste. ${ }^{539}$ Es werden keine Gründe für den Ortswechsel angegeben, da Santa Maria Maggiore aber in der Vita sehr häufig genannt ist, kommt eine besondere Beziehung des Papstes zu dieser Kirche in Betracht. Möglich wäre auch eine amtliche Verbindung Stephans zu dieser Titelkirche, worüber aber in den Quellen nichts berichtet wird.

Bald schwenkt die Erzählung hin zum eigentlichen Thema der Vita, dem alle anderen Informationen untergeordnet werden - dem Konflikt mit den Langobarden und insbesondere mit ihrem König Aistulf. Schon der Beginn des Pontifikats war offenbar von Verhandlungen des Papstes mit dem Langobardenkönig geprägt, es ist gleich von drei Gesandtschaften die Rede. Mindestens eine davon wurde auch in Kooperation mit dem kaiserlichen Gesandten Johannes und damit letztlich im Auftrag des Kaisers durchgeführt, da die Verhandlungen sich auch um Ravenna und zusätz-

537 Der Autor der Vita schildert wahrscheinlich einen Schlaganfall, vgl. Davis, LP 8, 53, Anm. 3. Doch ist die Darstellung fast schon zu deutlich, um beim Leser nicht Zweifel zu wecken - auch ein politischer Mord lässt sich keineswegs ausschließen.

538 Basilika sanctae Dei genetricis ad praesepem.

539 Nikolaus Gussone, Thron und Inthronisation des Papstes von den Anfängen bis zum 12. Jahrhundert. Zu Beziehungen zwischen Herrschaftszeichen und bildhaften Begriffen, Recht und Liturgie im christlichen Verständnis von Wort und Wirklichkeit (Bonner historische Forschungen 41, Bonn 1978) 148f.: Gute Erkenntnisse liefert dabei vor allem der Bericht über die Einsetzung des nur ganz kurz amtierenden, nie anerkannten Philipp im Jahr 768 in der Vita Stephans III. Zu Stephan II. vgl. ebd., 147. Tatsächlich scheint ein ritueller adventus im Lateran im achten Jahrhundert verpflichtend gewesen zu sein, siehe Susan Twyman, Papal Ceremonial at Rome in the Twelfth Century (Henry Bradshaw Society Subsidia IV, London 2002) 41-52 und besonders 59-64. Philip Daileader, One will, one voice and equal love. Papal elections and the Liber Pontificalis, in: Archivum Historiae Pontificiae, 31 (1993) 11-31, hat die Berichte des Liber Pontificalis über Papstwahlen gründlich untersucht, der Ort der Wahl spielt in seinem Untersuchungszeitraum vom siebenten bis zum neunten Jahrhundert zumindest in den Texten keine Rolle. 
liche Gebiete drehten, die direkt zum Exarchat gehörten $(5-9){ }^{540}$ Schon hier wirft die päpstliche Historiographie Aistulf massiv Vertrags- und Eidbruch vor - doch Bertolini hat schon 1946 gezeigt, dass der angeblich auf 40 Jahre abgeschlossene Friedensvertrag wohl vorbehaltlich eines für die Langobarden positiven Ergebnisses der direkten Verhandlungen mit Kaiser Konstantin V. zu verstehen war. ${ }^{51}$

Nach einem kurzen Exkurs zu römischen Angelegenheiten, insbesondere zur Stiftertätigkeit des Papstes ( ( 2-I4), wird die Geschichte der Außenpolitik fortgesetzt. Mit Unterstützung der fränkischen Gesandten reist der Papst nun zunächst nach $\mathrm{Pa}-$ via (19-23), um von dort aus nach gescheiterten Verhandlungen seine Reise ins Frankenreich fortzusetzen. Diese Reise bildet dramaturgisch gesehen den Höhepunkt der Vita (23-29). Hier gelingt es Stephan, ein längerfristiges Bündnis mit dem ersten Karolingerkönig Pippin zu schließen, das die Sicherheit und die territoriale Unversehrtheit des päpstlichen Machtbereichs garantiert. Direkt im Anschluss wird der Restaurationsversuch von Pippins Bruder Karlmann ebenfalls Aistulf zur Last gelegt (30). Nun folgt die erste Intervention Pippins in Italien, die im ersten Friedensvertrag von Pavia endet $(3 \mathrm{I}-38)$. Durch einen Bruch des Friedensvertrages durch Aistulf ${ }^{54}$ kommt es zur zweiten Intervention Pippins und dem zweiten Friedensvertrag von $\mathrm{Pa}$ via, der den Päpsten zumindest de iure die Herrschaft über das Gebiet des Exarchats einbringt (39-47). Im letzten Kapitel dieser Schilderung werden die für den Papst relevanten Gebietsgewinne ${ }^{543}$ sehr genau notiert, wohl um in der Zukunft keinen Zweifel am Umfang der Gebietsübergabe aufkommen zu lassen. Schließlich wird der Tod Aistulfs und die päpstliche Hilfe bei der Wahl seines Nachfolgers Desiderius als eine Art Epilog geschildert (48-5 I).

Raymond Davis hat die Sprache der Originalversion der Vita als ausschweifend oder auch ermüdend bezeichnet. ${ }^{544} \mathrm{Zu}$ sehr hängt der Autor am Gebrauch von Titeln und Eigenschaftswörtern. Die Titel waren jedoch aus diplomatischer Sicht wahrscheinlich wichtig, wie wir oben bereits gesehen haben. ${ }^{545}$ Der Frankenkönig wird fast nie ohne seinen Herrschertitel erwähnt, auch fehlt ihm und dem Langobardenkönig fast nie ein zusätzliches Adjektiv. Pippin ist dabei zumeist christianissimus,

540 Siehe Noble, Republic 72-74: Noble weist darauf hin, dass Stephan II. wohl nicht darauf aus war, die Gebiete tatsächlich für das Imperium zurückzugewinnen, sondern eher für das Papsttum.

541 Bertolini, Periurium, z. B. 150.

542 In der Langobardischen Rezension lässt es der Redaktor wie ein Missverständnis aussehen.

543 Die Frage ist, ob sie als solche auch wahrgenommen wurden. Denn möglicherweise erfolgte ein Gebietstausch, im Zuge dessen die sizilianischen Patrimonien des Papstes an den Kaiser gingen. Vgl. oben, Kap. 3.2.2, bes. Anm. 275.

544 Davis, LP 8, 52.

545 Siehe oben, Kap. 1.1.3.2, und unten, Kap. 6.2. 
kann aber auch andere positive Adjektive bekommen, Aistulf wird hingegen bei jeder Nennung mit einem negativen Beiwort versehen, von denen nefandissimus, das generell für alle offen angegriffenen Feinde des Papstes verwendet wurde, noch zu den weniger aggressiven zu zählen ist. ${ }^{546}$ Schon in der Wortwahl wird deutlich, wie sehr sich der Autor bemühte, den Langobardenkönig immer als feindlichen Anderen zu markieren.

\subsubsection{Die Langobarden bei Stephan II. - der Tiefpunkt?}

Die schiere Anzahl an Überarbeitungen und Varianten der Vita Stephans II., die wir bereits oben in Kapitel I.I.3.2 kennengelernt haben, zeigt, dass der Text bereits im achten Jahrhundert und auch im neunten Jahrhundert von außergewöhnlicher politischer Bedeutung und auch Brisanz war und daher besondere Aufmerksamkeit genoss. So überrascht es auch nicht, dass ein beträchtlicher Teil der heute erhaltenen LP-Handschriften genau mit diesem Text endet - wir können hier sowohl ein spezifisches Interesse als auch einen Hinweis auf eine besonders intensive Verbreitung des bis zu diesem Text reichenden LP in den Jahren nach dem Ableben Stephans erkennen. ${ }^{547}$ Und insbesondere die Beschäftigung mit der sogenannten Langobardischen Rezension hat eines erwiesen: Auch schon im achten Jahrhundert wurde die Originalversion als offen langobardenfeindlich eingestuft, ob nun von einer der monastischen Gemeinschaften Mittelitaliens oder doch von päpstlichen Schreibern selbst. Und tatsächlich: Die Attacken auf die Langobarden erreichten hier eine neues Niveau:

Seine Vorgänger, die Herren Gregor, Gregor und Herr Zacharias, allerheiligste Bischöfe seeligen Angedenkens, hatten Karl, König [sic] der Franken hervorrangenden Angedenkens, Nachrichten gesandt, um ihn um Hilfe zu bitten gegen die Unterdückung und Invasionen, welche auch sie vonseiten der unaussprechlichen gens der Langobarden in dieser Provinz der Römer zu erdulden gehabt hatten. Auf dieselbe Weise sandte nun auch dieser verehrungswürdige Vater [Stephan II.], inspiriert von Gottes Gnade, seine Briefe heimlich durch einen Pilger an Pippin, den König der Franken ... ${ }^{548}$

546 Zur Verwandlung des Wortes in ein politisches „label“ siehe Gasparri, Fall 46f. Der Begriff war von Gregor dem Großen auf die neu angekommenen Langobarden gemünzt worden, siehe Walter Pohl, Gregorio Magno.

547 Bougard, Composition 144.

548 LP I, 444: tunc quemadmodum praedescessores eius beate memoriae domni Gregorius et Gregorius atque domnus Zacharias beatissimi pontifices Carolo excellentissime memorie regi Francorum direxerunt, petentes sibi subveniri propter oppressiones ac invasiones quas et ipsi in hac Romanorum provincia a nefanda 
Dieser Angriff auf die Langobarden markiert im Übrigen auch den eigentlichen Beginn der konsequenten Eingriffe in der Langobardischen Rezension. Die Stelle zeigt, dass der Autor nicht davor zurückschreckte, die Langobarden als gesamte gens ${ }^{549}$ mit pejorativen Adjektiven zu bedenken, etwas, das im Vergleich mit seinen Vorgängern heraussticht und seit der Zeit Gregors des Großen so nicht mehr vorgekommen war. Die Stelle ist auch deswegen interessant, weil sie eine konstante Politik der Päpste in der Langobardenfrage suggerieren will, die schon lange auf ein Eingreifen der Franken abgezielt habe. Oben wurden ja auch schon die beiden Briefe Gregors III. an den hier in der Vita wieder genannten Karl Martell analysiert. Ob bereits Gregor II. mit ähnlichen Anliegen mit dem Hausmeier in Kontakt getreten ist, wissen wir nicht, doch auszuschließen ist es nicht. ${ }^{550} \mathrm{Klar}$ ist aber, dass sowohl Gregor II. und Gregor III. als auch Zacharias zeitweise mit langobardischen Gruppen zusammenarbeiteten und keineswegs mit allen Langobarden in dauerhaftem Gegensatz standen. Aus diesem Grund musste der Autor der Vita Stephans II. an dieser Stelle besonders intensiv argumentieren, wieso dem Papst keine andere Möglichkeit blieb als gegen Aistulfs Langobarden vorzugehen. $\mathrm{Zu}$ diesem $\mathrm{Zweck}$ wurden die Langobarden nun nicht mehr nach Regionen aufgeteilt gezeigt, sondern möglichst einheitlich negativ dargestellt. Ein eindimensionales Feindbild sollte die Handlungen Stephans für die Leser folgerichtig erscheinen lassen.

Darüber hinaus musste der Autor der Vita außerdem erklären, warum auf ein weiteres Hilfegesuch an den Kaiser verzichtet wurde und Stephan bereit war, gänzlich auf die Franken als Schutzmacht zu vertrauen. Die oben zitierte Passage steht am Ende eines Abschnitts, der aufzeigen sollte, dass aus Konstantinopel nicht nur keinerlei Unterstützung für Rom zu erwarten war. Umgekehrt war das Kaiserreich immer stärker auf die diplomatische Unterstützung des Papstes angewiesen, um Ravenna vielleicht doch wieder zurückbekommen zu können.

Konsequent war die päpstliche Politik allerdings nur insofern, als unentwegt versucht wurde, Bündnispartner zu finden, die, wie wir oben gesehen haben, nicht mit dem Kaiser verbündet sein sollten. ${ }^{551}$ In Betracht kamen zunächst Franken, Aquita-

Langobardorum gente perpessi sunt, ita et modo et ipse venerabilis pater, divina gratia inspirante, clam per quendam peregrinum suas misit litteras Pippino, regi Francorum, ...

549 Zur Entwicklung des Konzepts der gens bei den Langobarden und zur entscheidenden Bedeutung des Königtums für diesen Prozess siehe Jörg Jarnut, Gens, Rex and Regnum of the Lombards, in: Regna and Gentes. The Relationship between Late Antique and Early Medieval Peoples and Kingdoms in the Transformation of the Roman World, ed. Hans-Werner Goetz/Jörg Jarnut/Walter Pohl (The Transformation of the Roman World, 13, Leiden/Boston 2003) 409-427. Siehe auch Gasparri, Roma e i Longobardi $220 \mathrm{f}$.

550 Siehe oben, Kap. 5.1, und unten, Kap. 6.

551 Siehe dazu oben, Kap. 3.2.2 und 4.2. 
nier und Bayern, zu Beginn aber eben auch noch langobardische Gruppen. Erst unter Stephan II. legte sich das Papsttum auf die Karolinger als wichtigste Verbündete fest. ${ }^{52}$ Und der Autor der Vita Stephani zeigt ja selbst auf, dass Stephan zunächst versuchte, die Situation in Zusammenarbeit mit dem Kaiser zu bereinigen und erst die Franken ansprach, als ab imperiale potentia nicht mehr ernsthaft mit militärischer Hilfe spekuliert werden konnte. ${ }^{553}$ Das Ziel der Vita ist die Rechtfertigung der Politik Stephans als einzige mögliche Vorgehensweise des Papstes. Das soll nun nicht bedeuten, dass der LP ein völlig unrealistisches Szenario entwarf. Aistulf verfolgte eine Politik in Mittelitalien, die den päpstlichen und kaiserlichen Interessen deutlicher entgegengesetzt war als jene seiner Vorgänger. Deshalb war es Stephan II. nicht möglich, sich unter Aufbietung des ganzen diplomatischen Repertoires des Papsttums gegen ihn durchzusetzen, etwas, was Zacharias gegen Ratchis noch gelungen war. ${ }^{554}$ Doch man muss im Hinterkopf behalten, dass der Autor der Vita die Langobarden in einer bestimmten Rolle brauchte und das beeinflusste ihn sicher in seiner Darstellung der Ereignisse. Dass Aistulf in der Narration ein geradezu idealtypischer Bösewicht ist, haben wir auch schon oben im Zuge der Analyse der Retouchen durch den Redaktor der Langobardischen Rezension sehen können. ${ }^{555}$ Noch einmal sei auf die oben bereits zitierte Stelle verwiesen:

Als der schamlose Aistulf hörte, dass nur eine geringe Zahl von Franken als Besatzung der clusae [befestigte Engstellen in Alpentälern] angekommen war, vertraute er auf seine Wildheit, öffnete plötzlich die clusae und fiel zu Tagesanbruch mit einer großen Streitmacht über sie her. Aber der gerechte Richter, unser Herr und Erlöser Jesus Christus, sprach jenen sehr wenigen Franken den Sieg zu; ...556

Der schamlose (protervus) Aistulf vertraut also auf seine eigene Wildheit/seinen Übermut und greift die (eigentlich ja auf sein Territorium vorrückenden) Franken an. Aber Gott und Jesus Christus stellen sich auf die Seite der Franken, deren Zahl,

552 Diese Einschätzung teilt etwa auch Pohl, Papsttum 149, zum Ende des Pontifikats Gregors III.: „Die fränkische Option bekam erst aus viel späterer Perspektive mehr als episodische Bedeutung.“ Siehe auch unten, Kap. 6.

553 LP I, 444.

554 Gasparri, Roma e i longobardi 237, weist folgerichtig auch darauf hin, dass Stephan im Prinzip ähnliche diplomatische Muster wie Zacharias verwendete.

555 Siehe Abbildung 1 und Kommentar, oben S. 35-37.

556 LP I, 450: Audiens itaque protervus ille Aistulfus parvos fuisse Francos illos qui ad custodiam propriarum advenerant clusarum, fidens in sua ferocitate, subito aperiens clusas, super eos diluculo cum plurimis irruit exercitibus. Sed iustus iudex dominus Deus et salvator noster Iesus Christus victoriam paucissimis illis tribuit Francis; ... 
ganz dem verwendeten Topos folgend, natürlich geringer sein muss. In der Niederlage erweist sich Aistulf schlussendlich auch noch als Feigling, als er sich aus Furcht vor den Franken nach Pavia zurückzieht. Daneben ist er, wie wir ebenfalls schon oben gesehen haben, bereits zu Beginn der Vita ein Meineidiger - auch wenn wir mit Bertolini davon ausgehen können, dass der König $75^{2}$ gar keinen Vertrag mit Rom gebrochen hatte, da der Friedensvertrag wohl an Verhandlungen mit Konstantinopel geknüpft war, die wenig zufriedenstellend verlaufen sein dürften. ${ }^{557}$ Diese Charakteristik legt er auch im Verlauf des Textes nicht ab. Denn nach dem ersten Friedensschluss von Pavia (754) weiß der Autor zu berichten: „Danach trennten sie sich voneinander und wie üblich wurde dieser untreue Langobardenkönig Aistulf meineidig (in periurii reatum), indem er aufschob zurückzugeben, was er geschworen hatte zurückzugeben. ${ }^{558}$ Rom wurden also Gebiete entgegen den Vereinbarungen des Vertrags zunächst nicht restituiert. Und das obwohl Aistulf zuvor den Vertrag cum universis suis iudicibus sub terribili et fortissimo sacramento bestätigt und beschworen hatte. ${ }^{59}$ Die Hintergründe des angeblichen Vertragsbruchs kennen wir nicht. Der Autor der Vita greift an dieser Stelle jedenfalls sein weiter vorne bereits angelegtes Bild des Königs wieder auf, der sich wie üblich (solite) des Eidbruches schuldig macht.

Eine weitere Stelle muss in Bezug auf Aistulf noch erwähnt werden, um das von ihm gezeichnete Bild abzurunden: Gleich zu Beginn der Vita wird beschrieben, wie Aistulf versucht, Rom durch Drohungen unter seine Gewalt zu bringen. Die Passage räumt beim Leser die letzten Zweifel aus, ob mit diesem Langobardenkönig nicht doch eine vernünftige Verhandlungslösung gefunden werden kann.

In der Zwischenzeit geriet der bereits erwähnte allergrausamste König der Langobarden, der nicht von seiner Bösartigkeit abgekommen war, in großen Zorn. Brüllend wie ein Löwe ${ }^{560}$, sandte er immer wieder Drohungen an die Römer, in denen er ankündigte, sie alle mit einem Schwert zu töten, wenn sie sich nicht, wie bereits berichtet, seinem Willen unterwerfen wollten. ${ }^{561}$

557 LP I, 441: At vero isdem protervus Langobardorum rex, antiqui hostis invasus versutia, ipsa foedera pacis post pone IIII menses, in periurii incidens reatu, disrupit; ... Siehe dazu oben, Kap. 5.3.2, und Bertolini, Periurium.

558 LP I, 451: Et post hoc ab invicem segregati, solite in periurii reatum infidelis ille Aistulfus Langobardorum rex incidens, quod iureiurando promisit reddere distulit.

559 LP I, 451.

560 Oder möglicherweise „mit den Zähnen knirschend wie ein Löwe“, wie Davis, LP 8, 57, Anm. 20 mit Bezug auf ebd. 61 mit Anm. 41 vorschlägt. Im Gegensatz zur zweiten Stelle (LP I, 446) muss sich der Autor hier aber nicht im Verb geirrt haben.

561 LP I, 442: Inter haec vero, permanens in sua pernicie praelatus atrocissimus Langobardorum rex, exarsit 
Interessant ist aber, dass der Verfasser der Vita auch die gesamte langobardische gens mit wenig schmeichelhaften Adjektiven bedachte, besonders mit dem Epithet nefanda, das - wie wir bereits oben gesehen haben ${ }^{562}$ - für politische Feinde des Papsttums „reserviert“ war. Der Text hob somit die literarische Auseinandersetzung mit den Langobarden auf ein für den LP neues Niveau. Umso auffälliger wird das, wenn man miteinbezieht, dass in dieser Vita auch die großen langobardischen Dukate Spoleto und Benevent nicht mehr eigens erwähnt werden, sondern in der Gesamtheit subsummiert werden. Zwar standen die Dukate tatsächlich unter der Herrschaft Aistulfs, aber die päpstlichen Texte des achten Jahrhunderts hatten zuvor auch in Fällen der Dominanz aus dem Norden die Dukate stets als separate Herrschaftsgebiete behandelt.

Die Vita Stephans II. stellt sich somit als eine Art politische antilangobardische Schrift dar, die ganz eindeutig den Diskurs auch außerhalb Roms in eine bestimmte Richtung lenken will. Der LP mit dieser Vita als Schlusspunkt wurde besonders stark verbreitet, und zwar sowohl in Italien als auch im Frankenreich. ${ }^{563}$

Es wurde in bisher ungekanntem Ausmaß versucht, durch gezieltes Othering der Langobarden die Meinung der italischen und fränkischen Eliten zugunsten des Papstes zu beeinflussen.

Dieselbe Vorgehensweise findet sich auch in den erhaltenen Briefen Stephans II. an Pippin. Alle, die sich ausdrücklich mit den Langobarden beschäftigen, stammen aus der Zeit nach 754, also nach dem ersten Friedensvertrag von Pavia. Die CCBriefe 6 bis ro berichten von Verstößen Aistulfs gegen Auflagen des Friedens und Brief 8 von der auch im LP enthaltenen Belagerung Roms. ${ }^{564}$ Immer wieder finden sich auch Wendungen, die die Verzweiflung des Papstes hervorstreichen sollen, etwa in CC Nummer 8, wo, wie öfter in Stephans Briefen, sogar die Steine mit dem Papst das Los Roms beklagen:

Denn auch unschuldige Kleinkinder trennten sie von den Brüsten ihrer Mütter, welche sie vergewaltigten und umbrachten. Und sie taten so viel Böses in dieser römischen Provinz, wie es sicherlich nicht einmal heidnische Völker irgendwann verursacht haben, sodass sogar, wenn man es so sagen kann, auch die Steine selbst, da sie die Verzweiflung der Unsrigen sehen, gemeinsam mit uns wehklagen. ${ }^{565}$

furore vehementi, et fremens ut leo, pestiferas minas Romanis dirigere non desinebat, asserens omnes uno gladio iugulari, nisi suae, ut praelatum est, sese subderent dicioni.

562 Siehe Kap. 5.3.1, Anm. 546.

563 Vgl. oben, Kap. 5.3.2 bei Anm. 547.

564 CC, ed. Gundlach 488-503.

565 CC 8, ed. Gundlach 495: Nam et innocentes infantulos a mamillis matrum suarum separantes, ipsasque vi 
Wieder sind es die "gottlosen“ Langobarden, die die Säuglinge von den Brüsten ihrer Mütter fortreißen - ein bekannter antibarbarischer literarischer Topos. ${ }^{566}$ Es ist bezeichnend, dass er an dieser Stelle Verwendung findet. Nicht einmal heidnische gentes, so schreibt der Papst, seien mit der Umgebung Roms jemals so verfahren. Diese pathetische Darstellung der Langobarden trägt bereits fast Züge jener Appelle, die die Päpste des neunten Jahrhunderts mit dem Aufruf zur Hilfeleistung gegen die Sarazenen an die fränkischen Machthaber schickten. ${ }^{567}$ Der Name König Aistulfs wurde in diesen Briefen im Übrigen konsequent als Haistulf wiedergegeben, die Endung also nicht latinisiert, wie es sonst etwa bei Pippinus oder anderen Machthabern üblich war. Handelte es sich hierbei vielleicht auch um absichtliches Othering?

Interessant ist, dass die Päpste erst ab 755 derart deutliche Darstellungen an die Franken schickten, denn noch in den CC Briefen 4 und 5 hatte Stephan Pippin beziehungsweise alle Franken zwar auch um Hilfe ersucht, ohne jedoch die Langobarden oder ihren König auch nur zu nennen. ${ }^{568}$ In den kurzen Aufrufen hatte der Papst ausschließlich auf eine nicht näher definierte missliche Lage Roms verwiesen, ohne aber konkret zu werden. Für die Franken hatte sich ihr Bündnis mit den Langobarden durchaus bewährt, so hatte etwa König Liutprand Unterstützung gegen die Sarazenen in Südfrankreich gewährt. ${ }^{569}$ Aus diesem Grund bat der Papst auf Rat des in Rom präsenten fränkischen Abts und Diplomaten Droctegang von Jumièges die fränkischen Großen einfach um Unterstützung für den Papst und den Heiligen Petrus - was diese nicht leichthin ausschlagen konnten, auch wenn die Konsequenzen erwartbar waren.

Insgesamt sah der Pontifikat Stephans II. eine massive Verschärfung der gegenüber den Langobarden angewandten Sprache. Es ist fraglich, wie realistisch die Darstellung der Gefahr war, die von den Langobarden für den Papst ausging. Und es mag sein, dass der Dukat von Rom weniger bedroht war, als in der Forschung seit

polluentes, interemerunt ipsi impii Langobardi. Et tanta mala in hac Romana provintia fecerunt, quanta certe nec pagane gentes aliquando perpetrate sunt, quia etiam, si dici potest, et ipsi lapides, nostras dissolationes videntes, ululant nobiscum.

566 Beispielsweise findet er sich in der Apokalypse des Pseudo-Methodius, XI, 18, ed. Aerts/Kortekaas, Bd. 1, 155. Zu Pseudo-Methodius siehe zum Beispiel Clemens Gantner, Hoffnung in der Apokalypse? Die Ismaeliten in den älteren lateinischen Fassungen der Revelationes des Pseudo-Methodius, in: Abendländische Apokalyptik. Kompendium zur Genealogie der Endzeit in der europäischen Kultur, ed. Veronika Wieser/Christian Zolles/Martin Zolles/Leo Schlöndorff/Catherine Feik (Berlin 2013) 521-548, mit weiterführender Literatur.

567 Siehe unten, Kap. 6.

568 CC 4 und 5, ed. Gundlach 487f.

569 Hartmann, Geschichte Italiens II,2, 137. 
Jahrhunderten als sicher angenommen wurde. ${ }^{570}$ Die Heftigkeit der Reaktion des Papstes entsprach aber wohl realistischen Befürchtungen, dass Aistulf seine Expansionspolitik fortsetzen könnte. Mehrfach stand für Rom sehr viel auf dem Spiel. Wäre Stephan II. etwa im Winter 753 im Frankenreich verstorben, wer weiß, ob die Franken für Rom interveniert hätten.

Im Jahr 757 hatte der Papst aber, so schien es, gesiegt. Aistulf war angeblich bei einem Unfall verstorben und der neue Langobardenkönig Desiderius war als Kandidat des Papstes und des fränkischen Gesandten Fulrad von St. Denis an die Macht gekommen. ${ }^{571}$ Er hatte noch dazu weitgehende territoriale Konzessionen zumindest angekündigt. Rom auf der anderen Seite hatte den Exarchat nun selbst mehr oder weniger unter Kontrolle.

\subsection{Paul I. und Desiderius}

Stephan II. verstarb am 26. April 757, und sogleich wurde sein Bruder, der Diakon Paulus, im Lateran zum Papst gewählt. Es gab auch einen Gegenkandidaten, den archidiaconus Theophylakt, der jedoch, wie der LP deutlich macht, weniger Rückhalt unter den Römern gehabt haben dürfte. Noble vermutet, dass vor allem die Unterstützung des römischen Adels für Paul, der ja selbst dieser Oberschicht entstammte, den Ausschlag gegeben hat. ${ }^{572}$ Demgegenüber stützt sich die alte Annahme, dass Theophylakt einer pro-,,griechischen“ Gruppierung angehört haben könnte ${ }^{573}$, ausschließlich auf den Namen des Erzdiakons und ist daher zurückzuweisen. Nach einmonatiger Unsicherheit gelang es Paul jedenfalls, sich durchzusetzen, Ende Mai 757 wurde er zum Papst geweiht.

Die ersten Jahre seines Pontifikats waren von einer eher unsicheren politischen Situation geprägt. Vor allem mit dem Langobardenkönig gab es immer wieder Reibereien, die zwar nicht an die Auseinandersetzungen mit Aistulf heranreichten, aber dennoch zu ernsthaften diplomatischen Verstimmungen führten.

Umsomehr verwundert es zunächst, dass die LP-Vita Pauls die Langobarden gar nicht erwähnt. Überhaupt ist die Vita sehr enttäuschend, sie umfasst nur knapp 3

570 Siehe dazu Pohl, Papsttum.

571 Gasparri, Roma e i longobardi 242. Auch die Karolinger sahen Desiderius damals als ihren Kandidaten, siehe Continuationes Fredegarii, 39 (ed. Bruno Krusch, MGH SS rer. Merov., 2, Fredegarium et aliorum chronica. Vitae sanctorum. Hannover 1888) 186.

572 Noble, Republic 194.

573 Kehr, Chronologie 132 und Noble, Republic 194 verweisen auf derartige Theorien, wobei sich besonders Noble deutlich dagegen ausspricht. 
Folioseiten in der Edition Duchesnes, verglichen mit den über I6 Seiten Stephans II. Wir erfahren so gut wie nichts über politische Ereignisse, und auch über die Stiftertätigkeit des Papstes wird relativ wenig berichtet. Wahrscheinlich wurde Pauls Pontifikat kurz nach seinem Tod in Rom nicht besonders positiv gesehen. Wie wir noch sehen werden, riss mit Toto von Nepi ein Gegner des sterbenden Papstes und seiner Beamten zunächst sogar die Macht an sich. Aber auch unter Stephan III., als wieder einige Proponenten der Regierung Pauls an die Macht kamen, sah sich offenbar niemand veranlasst, die Vita zu verbessern.

Dass die Langobarden nicht erwähnt wurden, kam wohl auch daher, dass man nicht eine so klar besetzte spannende Erzählung bieten hätte können, wie es für Stephan II. möglich gewesen war. Denn die Situation war komplex und man konnte mit Desiderius durchaus zu Kompromissen kommen. Eine antilangobardische Geschichte hätte so wahrscheinlich nicht glaubwürdig funktionieren können. Dafür war es später für den Pontifikat Stephans III. umso leichter wieder einen ähnlichen Text wie für seinen Namensvorgänger zu konstruieren.

Über Paul I. erfahren wir mehr aus seinen überlieferten Briefen. Aus seinem Pontifikat stammen die CC-Briefe I2 bis 43, nach Hadrian I. sind das bei weitem die meisten. Alle bis auf einen haben Paul als Absender, nur CC I3 stammt von omnis senatus atquae universa populi generalitas a Deo servate Romanae urbis. ${ }^{574}$ Dieser Brief steht im Zusammenhang mit der gerade erfolgten Erhebung Pauls und sollte dem Frankenkönig wohl suggerieren, dass nun nach kurzen Streitigkeiten alle Bürger Roms hinter dem neuen Papst standen.

Bezüglich der Langobarden bieten die Briefe Pauls ein wesentlich ausgewogeneres Bild, als es sich noch bei seinem Bruder Stephan zeigt. Es finden sich viele Hinweise auf harte Verhandlungen, und immer wieder versuchte Paul (offenbar mit bescheidenem Erfolg), für diese die Unterstützung der Franken zu gewinnen.

Nur zwei Briefe stechen hier wirklich heraus, zunächst CC 17 aus dem Jahr $75^{575}$. Der Brief wurde im Zuge der größten diplomatischen Krise des Pontifikats Pauls geschrieben. Desiderius hatte die nun zum direkten päpstlichen Einflussbereich gehörende Pentapolis durchzogen und dabei den Widerstand der örtlichen Milizen mit Waffengewalt gebrochen. Danach hatte er den Dukat Spoleto unterworfen und dort persönlich die Herrschaft übernommen. Daraufhin war er, so der päpstliche Bericht, gegen Benevent vorgerückt und hatte den dortigen $d u x$ Liutprand zur Flucht nach Otranto gezwungen. ${ }^{576}$ Doch damit nicht genug. In der Folge habe er sich mit

574 CC 13, ed. Gundlach 508f.

575 Siehe zu diesem Schreiben auch oben, Kap. 4.2.

576 Zur Person siehe Gasparri, I duchi 96-98. 
dem kaiserlichen Gesandten Gregorios in Neapel getroffen und ein gemeinsames Vorgehen gegen Otranto ausgehandelt. Und tatsächlich erhielten die Oströmer die Stadt zurück, während Desiderius des flüchtigen $d u x$ habhaft wurde. Paul berichtet außerdem davon, dass das Bündnis gegen die päpstliche Herrschaft in Ravenna gerichtet gewesen sei, doch tatsächlich kam nie ein Angriff auf Ravenna zustande - und angesichts der weiteren Ereignisse ist auch zweifelhaft, ob Ravenna jemals Gegenstand des langobardisch-oströmischen Abkommens war. Ja es ist sogar alles andere als sicher, dass es das Bündnis zwischen Langobarden und Byzantinern in der vom Papst beschriebenen Form überhaupt gab. ${ }^{577}$ Es scheint zumindest zweifelhaft, dass der Langobardenkönig den bedeutenden Hafen Otranto nur für einen flüchtigen $d u x$ eingetauscht hätte. Der $d u x$ könnte für Desiderius eher eine Art Trostpreis gewesen sein. Die Darstellung im Brief sollte jedenfalls ein negatives Bild des Langobardenkönigs transportieren, um die Bedrohung Roms zu unterstreichen.

Nach der militärischen Operation in Süditalien zog Desiderius jedenfalls nach Rom und verhandelte dort mit dem Papst. Er war jedoch nicht bereit, die 757 versprochenen Orte Imola, Bologna, Osimo und Ancona zu übergeben. Viel mehr forderte er vom Papst Unterstützung bei seinem Bemühen, die Rückkehr der nach dem Frieden von 756 gestellten langobardischen Geiseln aus dem Frankenreich zu erreichen. ${ }^{578} \mathrm{Im}$ Zuge dessen sandte Paul auch tatsächlich einen Brief mit der entsprechenden Bitte an Pippin, nämlich CC I6, nur um im nach der Abreise des Desiderius verfassten CC I7 dem Frankenkönig von der Rückgabe der Geiseln abzuraten, sofern nicht die Gebiete übergeben seien, die Desiderius Stephan II. für dessen Unterstützung versprochen hatte. ${ }^{579}$

Analysieren wir den Brief nun im Einzelnen:

Aber, hervorragendster Sohn und geistlicher compater ${ }^{580}$, Du mögest erkennen, worauf wir Deine Vortrefflichkeit früher schon durch apostolische Briefe hingewiesen haben, nämlich dass in dieser Gegend vom Langobardenkönig Desiderius gottlose Taten verübt und grausam abgeschlossen worden sind. Als wir seine Schandtaten gesehen haben, haben wir es

577 Francesco Borri, L'Adriatico tra Bizantini, Longobardi e Franchi. Dalla conquista di Ravenna alla pace di Aquisgrana (751-812), in: Bulletino dell'istituto storico italiano per il medioevo, 112 (2010) 1-56, hier 15-18. Claudio Azzara, Spoleto e Benevento e il regno longobardo d'Italia, in: I Longobardi dei ducati di Spoleto e Benevento. Atti del XVI Congresso internazionale di studi sull'alto medioevo (Spoleto, 20-23 ottobre 2002), (Spoleto 2003) 105-123, hier 120.

578 CC 17, ed. Gundlach 515f.

579 Eine eingehende Analyse bietet Kehr, Chronologie 135-137.

580 Compater beschreibt hier das Verhältnis des Taufpaten (Paul) zum Vater des getauften Kindes (Pippin). Siehe dazu J. F. Niemeyer/ C. van der Kieft/J. W. J. Burgers, Mediae Latinitatis Lexicon minus, 2 Bde. (Darmstadt $\left.{ }^{2} 2002\right)$ Bd. 1, 296 (Lemma compaternitas). 
für richtig gehalten, Euren hier anwesenden allertreuesten missus Rodbertus bei uns aufzuhalten, damit er durch seine Anwesenheit erkennen und bezeugen möge, was die Pläne des genannten König Desiderius und die Bosheit des langobardischen populus hervorbringen, und das Eurer vortrefflichen Exzellenz versichern möge.

Und so wie bisher weisen wir Eure von Gott beschützte hervorragende Exzellenz darauf hin, dass der genannte Langobardenkönig, die Städte der Pentapolis, die Ihr zum großen Nutzen für Eure Seele dem Heiligen Petrus übergeben habt, durchzogen hat und alle Feldfrüchte, die zur Ernährung der Menschen benötigt werden, mit Feuer und Schwert vernichtet hat. Ebenso hat er die Gebiete von Spoleto und Benevent, welche sich unter Eure von Gott beschützte Macht begeben hatten, unter Verspottung eurer königlichen Macht verheert und mit Feuer und Schwert die Dukate beider, Orte und Städte, verwüstet. Und er hat Alboin, den $d u x$ von Spoleto, und seine Getreuen, die sich im Glauben an den Heiligen Petrus und im Eid an Euch als treu erwiesen haben, gefangen genommen, ihnen schlimme Verletzungen zugefügt und sie in Ketten gelegt. Als er sich dann Benevent näherte, ergriff der $d u x$ von Benevent sofort die Flucht nach Otranto. Und als es schon lange bevorstand, dass er den $d u x$ überzeugen könnte, die eigene Stadt zu verlassen, setzte er einen mit Namen Arichis als $d u x$ von Benevent ein. ${ }^{581}$

Der zentrale Vorwurf ist, dass die Langobarden das Gebiet des Papstes verletzt haben und auch gegen Pippin selbst gehandelt haben, indem sie seinen angeblich gewährten Schutz für die langobardischen Dukate südlich des päpstlichen Machtbereichs missachtet haben. Die Sprache erinnert auffällig an die Dokumente der Zeit Stephans II., während dort allerdings Aistulf selbst regelmäßig impius ist, sind hier nur die Taten des Desiderius so charakterisiert, nicht der König selbst. Der König verwüstet jeden-

581 CC 17, ed. Gundlach 515: At vero, excellentissime fili et noster spiritalis compater agnoscas, nos pridem per apostolicas litteras eximiaetati tuae innotuisse, quae in his partibus a Desiderio Langobardorum rege impie peracta sunt atque crudeliter perpetrata. Igitur dum tam perniciosam eius operationem cerneremus, aptum prospeximus, praesentem fidelissimum vestrum missum Rodbertum bic apud nos detinere, quatenus, quid cepta iam fati Desiderii regis vel Longobardorum populi malitia pareret, praesentialiter agnoscens atque conspiciens vestram certiorem reddidisset eximiam praecellentiam. Etenim sicut pridem, ecce et nunc innotescimus a Deo servate excellentiae vestrae, quod praefatus Langobardorum rex, Pentapolensium per civitates transiens, quas beato Petro pro magna anime vestrae mercede contulistis, ferro et igne omnia sata et universa, quae ad sumptus hominum pertinent, consumpsit. Sicque Spolaetinus et Beneventanus, qui se sub vestra a Deo servata potestate contulerunt, ad magnum spretum regni vestri desolavit atque ferro et igne eorundem ducatum, loca et civitates, devastavit. Et conprehensum Alboinum ducem Spoletinum cum eius satrapibus, qui in fide beati Petri et vestra sacramentum prebuerunt, infixis in eis pessimis vulneribus, in vinculis detinet. Adpropinquante autem eo Benevento, ilico dux Beneventanus fugam arripuit in Otorantinam civitatem. Et dum diu immineret, ut ex ipsa sua civitate eundem ducem suaderet, [...] constituit ducem alium in eodem Beneventano ducatu nomine Argis. 
falls die Pentapolis und auch den Dukat von Spoleto mit Feuer und Schwert. Interessant ist, dass sich der Papst wieder als Fürsprecher der unabhängigen duces erweist, eine Funktion, die im achten Jahrhundert nur Stephan II. nicht eingenommen hatte.

Wichtig ist aber, dass hier noch einmal die Langobarden als Gesamtheit negativ dargestellt werden, wenn sich der fränkische missus nicht nur von der Schlechtigkeit ihres Königs, sondern des gesamten populus überzeugen soll. Es ist auch auffällig, dass hier die Langobarden tatsächlich einmal keine gens sondern eben ein populus sind. Eine mögliche Interpretation wäre, dass die Unterscheidung deshalb erfolgte, weil in der gens auch die Langobarden der Dukate inbegriffen gewesen wären, während der populus im Verhältnis zum König gedacht wurde. Doch da Vergleichsstellen gänzlich fehlen, lässt sich dieser Verdacht nicht erhärten. Halten wir aber fest, dass die Langobarden kollektiv als böse oder boshaft eingestuft werden.

In der direkt auf die zitierte Stelle folgenden Passage ist vom Bündnis des Langobardenkönigs mit Ostrom die Rede. Interessanterweise fehlen hier die starken pejorativen Worte, abgesehen davon, dass Desiderius als Deo sibi contrario bezeichnet wird. Diese Wendung findet sich im Übrigen häufig in der LP-Vita Stephans II.

Ein Absatz aus einem späteren Brief enthält weitere interessante Informationen über die römische Darstellung der Langobarden. Es handelt sich um CC 22, der von Kehr mit Vorbehalten ins Jahr 760 datiert wird. ${ }^{82}$ Er wurde in einer wesentlich weniger heiklen politischen Situation geschrieben. Fränkische Gesandte waren offenbar in Italien anwesend, um endlich die Übergabe der versprochenen Gebiete an den Papst zu überwachen. In dem Brief findet sich aber folgende Warnung Pauls:

Denn Euch ist [folgendes] bekannt geworden: Weil Ihr mitgeteilt habt, dass Ihr Eure hier anwesenden missi deshalb geschickt habt, damit Ihr durch sie herausfinden könnt, ob uns von Seiten der Langobarden die Güter vollständig zurückgegeben worden sind oder nicht, haben sie alles über den Stand des Falles in Erfahrung gebracht und haben die schlaue Verschlagenheit und die gewohnheitsmäßige Falschaussage unserer beider Rivalen erkannt. Und wenn sie mit Gottes Hilfe zu Euch zurückkehren, werden sie es Euch zu Gehör bringen. Denn wir haben auf jede einzelne Frage geantwortet, die Ihr ihnen aufgetragen hattet, uns zu stellen und haben ihnen in den Mund gelegt, was sie Eurer Exzellenz mitteilen sollen. Wir hoffen von Eurer Exzellenz dadurch eine Reaktion zu erhalten. ${ }^{583}$

$582 \mathrm{Kehr}$, Chronologie $149 \mathrm{f}$.

583 CC 22, ed. Gundlach 525f., hier 526: Quia vero innotuistis ob hoc vos praesentes direxisse missos, ut agnoscere per eos valuissetis, utrum nobis a parte Langobardorum plenariae facte fuissent iustitiae an non, ipsi omnino cause meritum comperti sunt et callidam versutiam atque solite falsiloquam propositionem eorumdem vestrorum nostrorumque emulorum agnoverunt, eisque ad vos revertentibus Deo propitio, vestris propalabunt in auribus. Eis denique de singulis quae a vobis iniuncta habuerunt nobis referentibus, singillatim 
Der Papst warnt also die Franken vor der „schlauen Verschlagenheit“ und der „gewohnheitsmäßigen Falschaussage" der Langobarden. Interessant ist wiederum, dass sich die Vorwürfe nicht allein gegen den König, sondern gegen alle Langobarden gleichermaßen richten.

Wir sehen also, dass auch in der Frühzeit des Pontifikats Pauls noch pauschale Anschuldigungen gegen die Langobarden ebenso möglich waren wie pejorative und polemische Darstellungen der Politik des Desiderius. Dieser hatte sich allerdings auch tatsächlich nicht an seine früheren Zusagen gehalten. Der Durchmarsch durch päpstliches Territorium nur zwei Jahre nach dem Frieden von Pavia und nur ein Jahr nach der eigenen Machtübernahme, die mithilfe des Papstes und der Franken erfolgt war, zeigt, dass er die politischen Möglichkeiten des langobardischen Königtums ebenso ausschöpfen wollte (und musste) wie seine Vorgänger.

Die Auseinandersetzungen, auch in der Frage der Territorien, ebbten jedenfalls spätestens 760 deutlich ab und somit wurden auch Nennungen in den Briefen Pauls spärlicher. Eigentlich kommen die Langobarden nur noch im Titel des Desiderius vor, welcher nun gänzlich ohne pejorative Epitheta auskommen durfte. Zur Entspannung dürfte auch beigetragen haben, dass Paul auf einen Teil seiner Forderungen verzichtete. ${ }^{54} \mathrm{Im}$ Pontifikat Pauls wurden die unter Stephan II. entwickelten Strategien des Othering, die gegen „alle“ Langobarden gerichtet waren, zunächst weiterverwendet. Durch die komplexen Verhandlungen veränderte sich das Bild jedoch im Laufe der Zeit und ließ dann Raum für realistischere und ausgewogenere Berichte auch auf päpstlicher Seite.

\subsection{Stephan III. und der Codex Carolinus-Brief 45}

\subsubsection{Chaos in Rom: 767/768 und die Rolle des Desiderius}

Der Pontifikat Pauls I. war auch vom Aufstieg eines päpstlichen Beamten gekennzeichnet: Christophorus, der schon unter Stephan II. wichtige Ämter innegehabt hatte. 757 war er an den Verhandlungen mit dem damaligen dux Desiderius beteiligt. Von Paul I. wurde er spätestens im Jahr 760 zum primicerius notariorum gemacht. ${ }^{585}$ In sei-

de omnibus responsum reddentes, in eorum posuimus ore, quae vestrae excellentiae suggerere debeant; effectum ex hoc a vestra adhipisci obtantes excellentia.

$584 \mathrm{Kehr}$, Chronologie 138-145. Zu den reduzierten Gebietsforderungen siehe Delogu, Paolo I, 666f.

585 Vgl. die Argumentation von Galletti, Del primicero 42-51, bes. 42 (Galletti benutzte Cennis Zählung der CC Briefe, nach der Gundlach-Ausgabe bezog er sich hier auf CC 19, der von Cenni noch ins Jahr 764 datiert wird, von Kehr, Chronologie 157, jedoch auf April 760). Zum Amt des primicerius siehe oben, Kap. 3.1. 
ner neuen Position konnte er seine Macht ausbauen, etwa indem er seinen Sohn Sergius zum Amt des secundicerius verhalf, was diesen zu seinem direkten Stellvertreter machte.

Die folgende Darstellung stützt sich in erster Linie auf die Vita Stephans III., ${ }^{586}$ die jedoch in einer völlig veränderten politischen Situation unter Hadrian I. niedergeschrieben wurde. ${ }^{587}$

Papst Paul starb im Jahr 767, zu einer Zeit, als er selbst und sein führender Beamter Christophorus durch eine andere Fraktion unter der Führung von Toto von Nepi massiv unter Druck geraten waren. Tatsächlich schaffte es diese Gruppe mithilfe von Truppen aus dem römischen Umland (v. a. aus dem römischen Tuszien), die Macht in Rom an sich zu reißen. Der militärische Befehlshaber Roms, der dux Gregorius, wurde von den Aufständischen getötet, Christophorus' und Sergius' konnten sie allerdings nicht habhaft werden. Im Anschluss wurde der Laie Konstantin zum neuen Papst gewählt. Die Erteilung der drei nötigen Weihen (Subdiakon, Diakon, Bischof von Rom $)^{588}$ erfolgte dabei nicht nach den kanonischen Bestimmungen, insbesondere nicht, da eine bestimmte Zeit vorgesehen war, die zwischen den Weihegraden liegen musste. Die Wahl Konstantins war somit eine äußerst umstrittene. Häufig wird heute davon ausgegangen, Konstantin sei deshalb von den Karolingern nicht anerkannt worden ${ }^{59}$ - was sich vor allem darauf stützt, dass er in seinen beiden Briefen im Codex Carolinus relativ unverhohlen um Anerkennung und Unterstützung heischte und ebendiese Briefe in der Sammlung an den Schluss gerückt sind. ${ }^{590}$ Letzteres Indiz ist tatsächlich stark, allerdings nur dafür, wie sein Pontifikat aus der Rückschau von 79I gesehen wurde. Da sich Konstantin II. aber in einigen karolingischen und postkarolingischen Papstkatalogen aus dem heutigen Frankreich findet, ist es ebenso möglich, dass er doch von Pippin anerkannt wurde. ${ }^{591}$

Christophorus und Sergius konnten in einer Unterredung mit dem neuen Papst die Erlaubnis zum Verlassen der Stadt erreichen, vorgeblich um im Umland von Spoleto in ein Kloster einzutreten. Tatsächlich begaben sich die beiden direkt nach Spoleto und - nachdem sie die Zustimmung des Langobardenherzogs erlangt hatten - an den Hof des Langobardenkönigs Desiderius, den sie ohne größeren Aufwand zu einer gemeinsamen Intervention in Rom bewegen konnten.

586 LP I, 468-480.

587 Siehe dazu auch oben, Kap. 4.2 und 4.3.

588 Zur Erhebung zum Bischof von Rom reichte der Weihegrad des Diakons damals aus, siehe oben, Kap. 3.1.

589 Davis, LP 8, 85.

590 CC 98 und 99, ed. Gundlach 649-653.

591 Duchesne, LP I, LIV, LVI und CCIII für zwei Papstkataloge aus dem neunten und zwölften Jahrhundert. Siehe auch Scholz, Politik 75 und Herbers, Konkurrenz 56-58. 
Es mag nun ziemlich naiv vonseiten Konstantins erscheinen, die beiden einfach so ziehen zu lassen, aber aus verschiedenen Gründen war die drohende Gefahr kaum vorauszusehen. Einerseits hatten die beiden keinerlei Unterstützung von Pippins Franken zu erwarten, da der Karolinger seine Kräfte zu dieser Zeit in Aquitanien gebunden hatte und auch schon seit über einem Jahrzehnt nicht mehr aktiv in Italien eingegriffen hatte. Ja möglicherweise war Konstantin sogar von den Franken anerkannt worden. ${ }^{592}$ Andererseits konnte niemand damit rechnen, dass gerade Christophorus, der maßgeblich an der antilangobardischen Politik Roms in den 75oer-Jahren mitgewirkt hatte, tatsächlich mit Desiderius paktieren und dadurch die mögliche Stärkung des langobardischen Einflusses in Rom in Kauf nehmen würde. ${ }^{593}$

Mit langobardischen Truppen zogen Christophorus und Sergius wieder nach Rom, Sergius selbst beteiligte sich dann an der Erstürmung der Stadt. Auf langobardischer Seite wird als Anführer der Priester Waldipert genannt, der nach erfolgreicher Übernahme der Macht sofort - Christophorus und wahrscheinlich auch Sergius übergehend - den Abt Philipp aus seinem Kloster St. Vitus ${ }^{594}$ holen ließ und zum Papst ausrufen ließ. Dabei stieß er jedoch auf erbitterten Widerstand der römischen Bevölkerung, sodass der herbeigeeilte Christophorus die Situation rasch unter Kontrolle bringen konnte. Unter seiner Führung wurde nun der Priester Stephan zum Papst gewählt.

Nach den Wirren standen sich Christophorus und Desiderius aufgrund der angeblich eigenmächtigen Aktion der langobardischen Truppen und der wenig später erfolgten Ermordung Waldiperts noch viel feindseliger gegenüber als vor 767.595 Stephan III., der auf Betreiben des Christophorus an die Macht gekommen war, unterstützte den primicerius zunächst.

Im Jahr 769 begann sich die politische Situation Roms erneut drastisch zu verändern. Ein Jahr zuvor war König Pippin gestorben und hatte das Reich unter seinen Söhnen Karlmann und Karl aufgeteilt, wobei der jüngere Karlmann die ,geopolitisch' - weitaus leichter zu regierenden Reichsteile erhalten hatte, die zudem noch einen sehr abgerundeten Komplex bildeten, während Karl sehr viele problematische Grenzen zu verteidigen hatte. Nach ihrem ersten Regierungsjahr

592 Scholz, Politik 75.

593 Diese Einschätzung teilen auch Noble, Republic 115, und Davis, LP 8, 90, Anm. 11.

594 Eigentlich wohl das als de Sardas bezeichnete Kloster, bei San Vito, siehe Ferdinand Gregorovius/ Waldemar Kampf, Geschichte der Stadt Rom, Bd. 1: Vom Beginn des V. Jahrhunderts bis zum Untergange [Untergang ?] des westlichen Reichs i. J. 476 (Darmstadt 1978) 481.

595 Es kann also keine Rede davon sein, dass Stephan durch die Langobarden an die Macht gekommen war und diesen daher zu Beginn positiv gegenüberstand, wie Scholz, Politik 76, schreibt. 
begann der Streit zwischen den Brüdern, ein Streit, der auch die Position des Papstes empfindlich schwächte und diesen dazu veranlasste, die beiden zur Versöhnung aufzurufen. ${ }^{596}$

Tatsächlich wurde aber eine Heiratsallianz zwischen Karl dem Großen und Desiderius geschlossen. Die meisten Forscher nehmen an, dass das Ziel eine Art „Einkreisung" Karlmanns war. ${ }^{597}$ Vor kurzem hat sich jedoch Rosamond McKitterick dagegen ausgesprochen, hierin ein Indiz für schwerwiegende Differenzen zwischen Karl und Karlmann zu sehen. Ja sie zweifelt sogar daran, dass es je zu dieser Eheverbindung kam und nimmt an, dass Einhard, der 50 Jahre später schrieb, schlicht einem Irrtum aufsaß. ${ }^{598}$ Anhand der vorhandenen Quellen ist es heute unmöglich, sichere Schlüsse über die Situation im Frankenreich zu ziehen. So wäre es, wie McKitterick bemerkt, sogar möglich, dass tatsächlich Karlmanns Frau Gerberga die Tochter des Langobardenkönigs war, wofür zumindest spräche, dass die junge Königin nach dem Tod Karlmanns sofort nach Norditalien floh. ${ }^{599}$ Auch dagegen spricht letztlich vor allem Einhard. Die Flucht Gerbergas zeigt allerdings, dass wir den päpstlichen Quellen durchaus glauben können, wenn sie von einer unsicheren Situation zwischen den Karolingerbrüdern berichten.

\subsubsection{Codex Carolinus Brief 45}

Die Heiratsverhandlungen zwischen Franken und Langobarden bedeuteten aus Sicht Stephans III. eine ernsthafte Bedrohung. In dieser Phase entstand ein Brief, der für die vorliegende Arbeit von außerordentlicher Wichtigkeit ist: CC 45. Hierbei handelt es sich um ein Schreiben Stephans III. aus dem Jahr $770^{600}$ an die Frankenkönige Karl und Karlmann.

596 CC 44, ed. Gundlach 558-560. Siehe auch unten, Kap. 5.8.

597 Zur Lage im Frankenreich vgl. konzis: Rudolf Schieffer, Die Karolinger (Stuttgart/Berlin/Köln ${ }^{42006)}$ 70-73. Siehe auch Janet L. Nelson, Making a difference in eighth century politics: The daughters of Desiderius, in: After Rome's Fall: Narrators and Sources of Early Medieval History, ed. Alexander Callander Murray (Toronto 1998) 171-190, und Jörg Jarnut, Ein Bruderkampf und seine Folgen. Die Krise des Frankenreiches, in: ders. Herrschaft und Ethnogenese im Frühmittelalter (Münster 2002) 235-246.

598 Siehe McKitterick, Charlemagne 75-88. Siehe Einhard, Vita Karoli, c. 18 (ed. Georg Waitz, MGH SS rer. Germ. in us. schol. [25], Hannover/Leipzig 1911) 22.

599 McKitterick, Charlemagne 87f., zeigt sich allerdings sehr skeptisch. Zu Gerberga siehe auch: Nelson, Making a difference.

600 In der Edition Gundlachs ist das Schreiben mit 770/771 datiert. Eine Datierung auf das Jahr 771 ist jedoch bei genauerer Betrachtung der vorhandenen Quellen und der dadurch bekannten Chronologie auszuschließen. Vgl. Noble, Republic 121-123. 
Fraglich ist - wie im Falle aller Papstbriefe - der tatsächliche Grad der Autorschaft des Papstes. Viele Forscher sehen Christophorus als eigentliche treibende Kraft hinter dem Brief. ${ }^{601}$ Tatsächlich scheint die Argumentation relativ schlüssig: Der besonders antilangobardische Christophorus habe unter hohem Druck im unter seiner Leitung stehenden scrinium die Marschrichtung des Textes entscheidend vorgegeben. Auch wenn Stephan III. das Schreiben kaum an Christophorus vorbei in Auftrag geben konnte, ist es aber unwahrscheinlich, dass der Papst in einen derart wichtigen diplomatischen Vorgang nicht eingebunden wurde. Selbst wenn die Formulierungen nicht die seinen waren, ist davon auszugehen, dass Stephan hinter der römischen Außenpolitik stand.

Thomas Noble hat CC 45 als einen der „most exquisitely intemperate letters ever written“602 bezeichnet. Politisch gesehen stellt der Brief so etwas wie eine Sackgassenentwicklung dar, die schlussendlich durch das Eingreifen der Königsmutter Bertrada in Rom entschärft wurde. Der Brief könnte aber durchaus Einfluss auf die spätere Heiratspolitik der Karolinger ${ }^{603}$ und generell auch auf die unmittelbare politische Entwicklung gehabt haben.

Dennoch ist im Folgenden eine detaillierte Analyse von Nöten, denn der Brief sagt einiges darüber aus, wie man in Rom im Jahr 770 das langobardische Königreich und insbesondere König Desiderius sehen konnte und, viel wichtiger, wie weit man in der Darstellung der Langobarden gehen konnte. Somit kann man durchaus auch von einem gewichtigen Ausdruck eines in Rom vorhandenen Diskurses sprechen.

\section{Gegen die Langobarden}

Das Kernstück des Briefes steht fast zu Beginn. Es spricht das Hauptproblem auf sehr offene und auch deutliche Weise an, ohne dabei mit markigen Adjektiven zu geizen: ${ }^{604}$

Und so ist uns die Nachricht überbracht worden, was wir mit starken Schmerzen im Herzen sagen: nämlich, dass der Langobardenkönig Desiderius eure Exzellenzen überredet

601 So etwa auch Noble, Republic 121.

602 Noble, Republic 121.

603 Siehe dazu Walter Pohl, Alienigena coniuga: Bestrebungen zu einem Verbot auswärtiger Heiraten in der Karolingerzeit, in: Die Bibel als politisches Argument: Voraussetzungen und Folgen biblizistischer Herrschaftslegitimation in der Vormoderne, ed. Andreas Pečar/Kai Trampedach (Historische Zeitschrift, Beihefte, Neue Folge, 43, München 2007) 159-188, hier 167, und zukünftig ders., Why not marry a foreign woman: Stephen III's letter to Charlemagne, in: Rome and Religion in the Early Middle Ages (Festschrift Thomas F. X. Noble), ed. Owen Phelan/Valerie Garver (in Vorbereitung), sowie Nelson, Making a Difference.

604 Die auffällige Offenheit thematisiert auch Pohl, Alienigena coniuga $169 f$. 
haben soll, seine Tochter einem von euch Brüdern in der Ehe zu verbinden. Wenn das tatsächlich so ist, so ist das sicherlich eine Einmischung des Teufels und nicht als eine Eheverbindung sondern vielmehr als eine Verbindung der schändlichsten Ideen zu betrachten, weil wir viele kennen, wie uns die Heilige Schrift lehrt, die durch eine unrechte Verbindung zwischen fremden Völkern (nationes) gegen Gottes Gebot verstoßen haben und damit eine große Sünde begangen haben. Es ist nämlich eine so große Dummheit, hervorragendste Söhne und große Könige, dass es überhaupt erlaubt ist darüber zu reden, dass eure hervorragende fränkische gens, die alle anderen gentes überragt, und ebenso eure edelste königliche Macht, was nicht geschehen möge, von verräterischen Nachkommen und der stinkendsten langobardischen gens beschmutzt werden sollten. Denn diese gens wird keineswegs zu den gentes gezählt, sondern aus ihrem Ursprung entstammt sicherlich auch die Art der Leprösen. Niemand, der bei klarem Verstand ist, könnte auch nur einen Verdacht hegen, dass er solch berühmte Könige einer derart abstoßenden und verachtenswerten Ansteckung bezichtigen würde; denn: Was haben Licht und Finsternis gemeinsam?' Oder: ,Was hat ein Gläubiger mit einem Ungläubigen gemeinsam?‘ $\left[2\right.$ Kor 6, I4f. ${ }^{605}$

Der Papst schreibt den beiden Karolingerkönigen, dass ihm ihre Heiratspläne mit den Langobarden zu Ohren gekommen seien. Sein Ziel ist es, die Heiratsallianz mit den Langobarden auf mehreren Ebenen als unmöglich darzustellen. In der zitierten Stelle sollen die Langobarden im wahrsten Sinne des Wortes ,verteufelt' werden. Desiderius wird sehr negativ gezeichnet, einer Heiratsverbindung wird der Rang einer christlichen Ehe abgesprochen (consortium nequissimae). Doch der Papst geht noch einen Schritt weiter und erklärt nun eine solche Heirat zu einer Gefährdung der ,Reinheit` der fränkischen gens. ${ }^{606}$ Die Karolinger wären im Fall der Heirat beschmutzt durch

$605 \mathrm{CC}$ 45, 561, Z. 4-18: Itaque nostrae perlatum est notioni, quod certe cum magno cordis dolore dicimus: eo quod Desiderius Langobardorum rex vestram persuadere dinoscitur excellentiam, suam fliam uni ex vestra fraternitate in conuvio copulari. Quod certe si ita est, haec proprie diabolica est immisio et non tam matrimonii coniunctio, sed consortium nequissimae adinventionis esse videtur, quoniam plures comperimus, sicut divinae scripturae historia instruimur, per aliae nationis iniustam copulam a mandatis Dei deviare et in magno devolutos facinore. Quae est enim, praecellentissimi flii, magni reges, talis desipientia, ut penitus vel dici liceat, quod vestra praeclara Francorum gens, quae super omnes gentes enitet, et tam splendiflua ac nobilissima regalis vestrae potentiae proles perfidae, quod absit, ac foetentissima Longobardorum gente polluatur, quae in numero gentium nequaquam conputatur, de cuius natione et leprosorum genus oriri certum est! Nullus enim, qui mentem sanam habet, hoc vel suspicari potest, ut tales nominatissimi reges tanto detestabili atque abhominabili contagio implicentur; , quae enim societas luci ad tenebras? aut quae pars fideli cum infidelae?"

606 Die Implikationen, die eine solche Argumentation aus der heutigen Sicht mit Blick auf das 20. Jahrhundert haben muss, sind aus der Betrachtung der Zeit heraus wohl noch nicht auf diese Weise zu verstehen. Klar wird somit jedenfalls, dass verquere Ideen die Tendenz haben immer wieder - allerdings unter verschiedenen Gesichtspunkten - zu entstehen. 
die übelriechendste gens der Langobarden (foetentissima Langobardorum gente). Die Sprösslinge (proles) wären somit verräterisch (perfidae), eine Anspielung auf die Eidbrüchigkeit die den Langobarden vom Papsttum seit Längerem vorgeworfen wurde. Die Langobarden seien außerdem nicht zu der Zahl der Völker zu zählen, sondern stammten aus demselben Ursprung wie die Aussätzigen. Auch könne niemand, der bei klarem Verstand sei, diese Problematik übersehen.

Einige Punkte sind hier besonders interessant. Zunächst ist der antithetische Aufbau bemerkenswert, durch den die Franken und die Langobarden gegeneinander aufgewogen werden. Die Langobarden sind für den Papst die ,umgekehrten' Franken, während diese nämlich als ein hervorragendes Volk bezeichnet werden, das über die anderen gentes zu stellen ist, sind sie nicht etwa das böseste aller Völker, sie sind überhaupt kein Volk, sondern gleichen eher einer Krankheit. Diese Antithese findet sich nicht nur in der vorliegenden Stelle, sondern ist im gesamten Brief präsent. So finden wir wenige Zeilen später: „... und wer aus Eurer edelsten Art hat sich entschlossen, sich mit der schrecklichen gens der Langobarden zu beschmutzen oder zu vermischen und wie ihr euch jetzt einredet, sich mit dieser fürchterlichen gens zu verschmutzen (was der Herr verhindern möge) ? “607

Bedeutsam ist in diesem Zusammenhang aber auch, dass der Autor hier von einer diabolica immisio schreibt - eine unmissverständliche Dämonisierung der Langobarden. An dieser Stelle wurde also das gesamte rhetorische Repertoire, das dem Papst zum Zwecke des negativen Othering zu Gebote stand, eingesetzt. Dabei wurden zweifellos auch auf rhetorische Modelle zurückgegriffen, die bereits seit der Antike in Gebrauch waren - was nebenbei bemerkt ein besseres Licht auf die in Rom im achten Jahrhundert verfügbare Bildung wirft. Man muss also, wie wir bereits gesehen haben, davon ausgehen, dass hier absichtlich ein schwarz-weißes Bild von Anderen gezeichnet wurde, um den maximalen Effekt beim intendierten Publikum, den Franken, zu erzielen. ${ }^{608}$ Doch das schmälert nicht die Tragweite der gewählten Worte und Vergleiche.

Die Frage ist, wieso den Langobarden in $\mathrm{CC}_{45}$ sogar abgesprochen wird, eine gens zu sein. Es muss für den Papst eine Argumentationsgrundlage geben, durch welche es ihm denkmöglich ist, eine solche Behauptung aufzustellen, denn diese konnte sich nicht außerhalb des etablierten Diskurses bewegen, ohne Gefahr zu laufen, von den Addressaten und auch in Rom selbst nicht ernst genommen zu werden. ${ }^{609}$

607 CC 45, 561, 26-29: et quis de vestro nobilissimo genere se contaminare aut conmiscere cum horrida Langobardorum gente dignatum est, ut nunc vos suademini, quod avertat Dominus, eidem horribili genti pollui? 608 In der Rhetorik spricht man seit Cicero hier von einer invectiva oder invectio, siehe Kempshall, Rhetoric 134 und 205.

609 Vgl. dazu Walter Pohl, Introduction - Strategies of Identification. 
Dazu muss man sich in Erinnerung rufen, dass die Langobarden zu diesem Zeitpunkt bereits seit über zweihundert Jahren auf der Apenninenhalbinsel sesshaft waren und große Teile davon beherrschten. Die Landnahme war zwar auf für die Bevölkerung relativ dramatische Weise erfolgt $t^{610}$, jedoch schon sehr lange her. Zudem waren die Langobarden nun seit sehr langer Zeit Christen und seit geraumer Zeit endgültig zum Katholizismus übergetreten. ${ }^{611}$ Somit mussten sie ohne jeden Zweifel als christlich gelten. Bezeichnend ist, dass der Papst sich durch seine vorgenommene Einstufung so weit wie nur möglich vom Gedanken eines einzigen populus Christianus entfernt. Es ist ihm sogar möglich, die Langobarden aus dem Kreis der Völker auszuschließen, obwohl sie christlich sind. Somit stellt sich die Frage, ob der Papst auf diese Weise den Langobarden sogar die Zugehörigkeit zur Christenheit abspricht. Auf welcher Grundlage basierte eine derartige Ausgrenzung? Isidor von Sevilla etwa, dessen Etymologien immerhin als „Realenzyklopädie“ des frühen Mittelalters gelten können, kann defintiv nicht die Grundlage für die Argumentation des Papstes gewesen sein. Er schließt die Langobarden ohne jeden Vorbehalt in seine (lange) Liste der Völker ausdrücklich mit ein. ${ }^{612}$ Auch in den erhaltenen Völkerkatalogen des Frühmittelalters finden sich die Langobarden. ${ }^{613}$ All diese Völkerlisten stehen aber mit dem christlichen Heilsversprechen in Verbindung. Das Hauptziel der Erklärung der Langobarden zur Nicht-gens dürfte gewesen sein, sie außerhalb der Gemeinschaft der (rechtgläubigen) Christen zu verorten. ${ }^{614}$ Als Indiz, dass die Langobarden an dieser Stelle als Nichtchristen verunglimpft werden, ist etwa das am Ende des hier zitierten Textes gewählte Bibelzitat aus dem zweiten Korintherbrief (quae enim societas luci ad tenebras? aut quae pars fideli cum infidelae?) zu werten. Das Bibelzitat liest sich in der Einheitsübersetzung folgendermaßen (zur Vollständigkeit erweitert): „[2 Kor 6, I4] Beugt euch nicht mit Ungläubigen unter das gleiche Joch! Was haben denn Gerech-

610 Siehe dazu Walter Pohl, Die Völkerwanderung. Eroberung und Integration (Stuttgart/Berlin/Köln 2002) 196-199.

611 Unter König Cunicpert wurde 698 das Dreikapitelschisma für den langobardischen Bereich beendet. Danach gab es nur noch zweifelsfrei katholische Langobardenkönige. Siehe Pohl, Alienigena coniuga 171, und Walter Pohl, Heresy in Secundus and Paul the Deacon, in: The Crisis of the Oikumene. The Three Chapters and the Failed Quest for Unity in the Sixth-Century Mediterranean, ed. Celia Chazelle/Catherine Cubitt (Studies in the Early Middle Ages 14, Turnhout 2007) 243-264.

612 Isidor, Etymologiae, IX, 2, 95f. (ed. Wallace M. Lindsay, Oxford 1911). Siehe auch Pohl, Alienigena coniuga 170.

613 So etwa in der sogenannten Fränkischen Völkertafel, siehe Walter Goffart, The supposedly ,Frankish 'Table of Nations: an edition and study, in: ders., Rome's Fall and After (Bristol 1989) 133-166, und Arno Borst, Der Turmbau von Babel. Geschichte der Meinung über Ursprung und Vielfalt der Sprachen und Völker, Bd. 2,1: Ausbau (München $\left.{ }^{2} 1995\right)$ 461f.

614 Vgl. auch Pohl, Alienigena coniuga 170. 
tigkeit und Gesetzwidrigkeit miteinander zu tun? Was haben Licht und Finsternis gemeinsam? [2 Kor 6, 15 ] Was für ein Einklang herrscht zwischen Christus und Beliar? Was hat ein Gläubiger mit einem Ungläubigen gemeinsam?“

Es ist davon auszugehen, dass das Zitat mit seinem Kontext gemeint war, welcher den entscheidenden Personen im Lateran ebenso wie den Adressaten im Frankenreich ohne Zweifel bekannt war. Es handelt sich um einen bewussten Angriff auf die Langobarden, der wiederum im Zusammhang mit ihrer Dämonisierung zu sehen ist.

Die Langobarden werden an dieser Stelle aber nicht nur aus dem populus Christianus ausgeschlossen, sie sind sogar einer speziellen Gruppe von Ausgestoßenen zuzurechnen. Lassen wir die entscheidende Passage dafür noch einmal Revue passieren: ... foetentissima Longobardorum gente polluatur, quae in numero gentium nequaquam conputatur, de cuius natione et leprosorum genus oriri certum est. Die Langobarden stammen also „aus demselben Ursprung, aus dem auch die Art der Leprösen/Aussätzigen zweifellos herstammt." Die Lepra war im Lateinischen Westen spätestens seit Gregor dem Großen eine bekannte Metapher für die Häresie. ${ }^{615}$ Es ist somit nicht unwahrscheinlich, dass die Häresieanspielung, die wahrscheinlich auf die arianische Vergangenheit der Langobarden gemünzt war, an den Karolingerhöfen verstanden wurde. Wir können also davon ausgehen, dass die Langobarden an dieser Stelle auf subtile Weise mittels einer Anspielung auf ihre „Neigung zur Häresie“ aus der Gemeinschaft der Christen ausgeschlossen werden sollten. Sie sind eine foetentissima (extrem übelriechende) und horrida (schreckliche/widerliche) gens.

Eines der weiteren Argumente des Papstes in $\mathrm{CC}_{45}$ ist, dass es schlecht sei, sich mit Frauen aus einer fremden gens einzulassen. ${ }^{616} \mathrm{Im}$ Gegensatz zu den scharfen Attacken gegen die Langobarden selbst wirkt dieses wesentlich schlüssiger, denn dafür, dass fremdländische Frauen als problematisch zu betrachten waren, finden sich im Alten Testament eine erkleckliche Anzahl an Beispielen, die Grundlagen dafür sind von Walter Pohl in seinem Artikel über das Verbot auswärtiger Heiraten aufgeführt worden. ${ }^{617}$ Im Zusammenhang mit dieser Argumentation stehen auch die vielfach

615 Gregor I., Moralia in Iob I,v,28 (ed. Marc Adrien, CC SL 143, Moralia in Iob Libri I-X, Turnhout 1979) 237: Leprosi itaque haereticos exprimunt quia dum rectis praua permiscent, colorem sanum maculis aspargunt. Siehe dazu Saul Nathaniel Brody, The Disease of the Soul. Leprosy in Medieval Literature (Ithaca/London 1974), bes. $124 \mathrm{f}$.

616 CC 45, 561, Z. 9f. und 29-32.

617 Pohl, Alienigena coniuga 161-165. Als Beispiele seien an dieser Stelle etwa die Vorgehensweise der Priester Pinchas (Num 25,1-8) und Esra (Esra 10) genannt: Nach der Rückkehr aus Babylon unter Artaxerxes spricht Esra unter anderem folgende Worte: „Der Priester Esra stand auf und sagte zu ihnen: Ihr habt dem Herrn die Treue gebrochen; ihr habt fremde Frauen genommen und so die Schuld Israels noch größer gemacht.“ (Esra 10,10). 
enthaltenen Ermahnungen im Hinblick auf Eheschließungen, die sich in drei verschiedene Gruppen gliedern lassen:

I. Die Vorfahren der beiden Könige haben keine Frauen aus einer anderen gens geheiratet $^{618}$ : Diese Beobachtung scheint korrekt zu sein.

2. Die Karolinger dürfen ihre aktuellen Frauen nicht verstoßen, das ist unchristlich. ${ }^{619}$ Hierzu ist zu bemerken, dass Karl der Große wohl mit Himiltrud verheiratet war, die Legitimität dieser Verbindung aber als zumindest zweifelhaft gelten muss. ${ }^{620}$

3. Die Vorfahren haben generell den Anordnungen der Päpste Folge geleistet.

Der letzte Punkt leitet bereits zu einem Thema über, das einen sehr großen Teil des Briefes einnimmt, und zwar die Betonung des Bündnisses der Franken mit dem Papst. Öfters wird dabei auf die Vorgehensweise König Pippins und Papst Stephans II. verwiesen. ${ }^{621}$ Diese Hinweise sind immer wieder durchsetzt mit Aufforderungen, diesen Weg nicht zu verlassen. Sie gipfeln zunächst in dem Matthäus/Lukas-Zitat: Qui vos recipit, me recipit; et qui vos spernit, me spernit. ${ }^{622}$ Mit höchstmöglicher Autorität wird somit den karolingischen Königen die Tragweite einer Zuwiderhandlung deutlich gemacht.

Schlussendlich wurde für die Langobarden auch noch das klassische und wohl realistischste Feindbild bemüht, nämlich jenes der (militärisch-politischen) ,Feinde Roms': „Und wie könnt ihr es wagen, gegen Eure Seelen zu handeln und mit unseren Feinden eine Verbindung eingehen zu wollen? Denn jene meineidige langobardische gens, die fortwährend die Kirche Gottes bekämpft und in unsere römische Provinz einfällt, ist bekanntermaßen unser Feind.“" ${ }^{23}$ Im Zuge dieser Darstellungsweise, die den zweiten Teil des Briefes dominiert, wird auch wieder der Gebietsstreit zwischen Rom und Pavia angesprochen, der den Pontifikat Pauls I. besonders zu Beginn dominiert hatte.

618 CC 45, 561, Z. 25f.

619 CC 45, 561, Z. 19-22 und 33-37.

620 Vgl. Jan T. Hallenbeck, Pavia and Rome. The Lombard Monarchy and the Papacy in the Eighth Century (Transactions of the American Philosophical Society, New Series, 72,4, Philadelphia 1982) 119. Schieffer, Karolinger 71 und 81, spricht in diesem Zusammenhang nur von einer, Verbindung؛

621 CC 45, 561, Z. 40f.; ebd. 562.

622 CC 45, 562, Z. 18. Siehe Mt. 10,40 und Luc. 10,16. Stephan III. betont hiermit auch seine Stellung in der Nachfolge der Apostel.

$623 \mathrm{CC}$ 45, 562, Z. 6-9: Et quomodo nunc contra animas vestras agere contenditis et cum nostris inimicis coniunctionem facere vultis, dum ipsa periura Langobardorum gens, semper ecclesiam Dei expugnantes et hanc nostram Romanorum provintiam invadentes, nostri esse conprobantur inimici? Siehe auch ebd. Z. 39 und 563, Z. 16-20. 


\section{Verbindung zu Ostrom}

Neben dem Hauptthema, dem heftigen Einspruch gegen eine Verbindung der Franken - gleich welcher Fraktion - mit den Langobarden, findet sich auch eine weitere entscheidende Information in dem Brief Stephans III., und zwar der Hinweis, dass auch eine Heirat mit einem Sohn des Kaisers Konstantin V. nicht als passend angesehen werden würde (bzw. wurde):

Und ich bitte euch daher auch, euch folgendes ins Gedächtnis zu rufen: - denn auch wenn der Kaiser Konstantin [V.] versuchte, euren gnädigen Vater seligen Angedenkens zu überreden, seinen Sohn [Leon IV.] mit eurer Schwester, der edelsten Gisela ${ }^{624}$, zu verheiraten, und dass es euch nicht erlaubt sein solle, euch mit [Frauen] anderer Herkunft zu verbinden - dass ihr dies jedoch nicht gegen den Willen der Bischöfe des apostolischen Stuhls in irgendeiner Weise durchführen sollt. ${ }^{625}$

Offenbar hatte sich das Papsttum schon unter der Herrschaft Pippins eingeschaltet, um eine Ehe von Gisela, der Schwester Karls und Karlmanns, mit dem Sohn des Kaisers zu verhindern. Ein solcher Vorgang ist leider anderweitig nicht bezeugt. Es ist auch nicht klar, um welchen der Vorgänger Stephans es sich gehandelt haben könnte. Es kann aber davon ausgegangen werden, dass Stephan auf einen tatsächlichen Vorfall rekurriert, mit der Erfindung eines Ereignisses der jüngeren Vergangenheit hätte er sich sonst an den beiden fränkischen Höfen nur lächerlich machen können. ${ }^{626} \mathrm{In}$ teressant ist zudem, dass die Stelle suggeriert, der Kaiser habe versucht exogame Heiraten der Söhne Pippins als Teil des angedachten Ehevertrages zu untersagen. An-

624 An dieser Stelle fügt Gundlach in seiner Edition einen Hinweis auf Textverlust ein. Auch wenn der Satz eine eigenartige grammatikalische Struktur aufweist, ist doch in der einzigen erhaltenen Handschrift an der Stelle keine Lücke zu finden (vgl. Wien Nationalbibliothek Ms CVP 449, fol. 50v, beziehungsweise die Faksimileedition Unterkirchers). Alle späteren Überlieferungen beruhen jedoch auf diesem einen Exemplar. Insofern kann durch die Lücke in den humanistischen Überlieferungen höchstens ein späterer (also neuzeitlicher) Zusatz wieder verloren gegangen sein. Die Schwierigkeiten Gundlachs - der ja das Original des Codex Carolinus nie zu Gesicht bekam - bei seiner Edition werden hier besonders deutlich.

$625 \mathrm{CC} 45$, ed. Gundlach 562 (leicht verändert wiedergegeben, siehe Anm. 624): Itaque et hoc, peto, ad vestri referre studete memoriam: eo quod, dum Constantinus imperator nitebatur persuadere sanctae memoriae mitissimum vestrum genitorem ad accipiendum coniugio flii sui germanam vestram nobilissimam Ghisylam neque vos aliae nationi licere copulari, sed nec contra voluntatem apostolicae sedis pontificum quoquo modo vos audere peragere.

626 Siehe dazu Pohl, Alienigena coniuga 173. Ein Konnex zu Christophorus, wie ihn Pohl vermutet, ist tatsächlich möglich. Die Verhandlungen über eine Heirat könnten sich tatsächlich zur Zeit Pauls I. zugetragen haben - ebenso möglich wäre aber schon der Pontifikat Stephans II. 
gesichts der realen Machtverhältnisse zwischen Kaisertum und Papsttum erscheint das zunächst wenig wahrscheinlich, abgesehen davon, dass das Latein an der Stelle verworren und daher schwierig zu übersetzen ist. Falls ein derartiger Passus in Verhandlungen zwischen den Gesandten Konstantins V. und den Karolingern im Raum stand, wäre das zumindest bemerkenswert.

Die kurze Anschweifung zu den ehemaligen Heiratsplänen rund um Gisela war für den Papst jedoch aus einem anderen Grund wichtig: auf diese Weise konnte er nämlich sein Argument auf eine allgemeinere Ebene heben. Ihm musste nämlich klar sein, dass sein Wettern gegen die Langobarden im Frankenreich nicht bei allen maßgeblichen Personen auf Verständnis stoßen würde, denn schließlich hatte es schon gegen die Kriege Pippins gegen Aistulf massive Opposition gegeben. Deswegen erschien es wohl sinnvoll, darauf hinzuweisen, dass auch Gisela Leon IV. letztlich nicht geheiratet hatte. ${ }^{627}$

Am Ende des Briefes kommt noch einmal die Sprache auf Gisela. Es sollte also auch eine Art „Kompensationsehe“ Giselas mit Adelchis, dem Sohn des Desiderius, ausgeschlossen werden: ${ }^{628}$

Auf keine Weise soll einer von euch Brüdern daran denken, eine Tochter des genannten Langobardenkönigs Desiderius zu ehelichen, und auch umgekehrt sollt ihr eure edelste Schwester, die von Gott geliebte Gisela, nicht dem Sohn des oft genannten Desiderius übergeben. Auch sollt ihr es nicht wagen, auf irgendeine Weise eure Ehefrauen zu verstoßen. ${ }^{629}$

\section{Schlussfolgerung und Drohung}

Bemerkenswert ist an Brief $\mathrm{CC}_{45}$ auch das Ende, in dem der Papst den karolingischen Brüdern bei Nichtbefolgen seiner Anordnungen Folgendes in Aussicht stellt:

Und wenn [einer von euch], was wir nicht hoffen wollen, es wagen sollte, gegen diese Liste unserer Entscheidungen und Ermahnungen zu handeln, so soll er wissen, dass er dann

627 Das bedeutet jedoch nicht, dass die Vermeidung eines Bündnisses der Franken mit Ostrom nicht eine der wichtigsten Agenden der Päpste war, wie die Analyse in Kapitel 4 gezeigt hat.

$628 \mathrm{Zu}$ Adelchis vgl. Helmut Zielinski, Adelchis, 1. König der Langobarden, in: LMA, Bd. 1, $144 f$. Siehe auch Ottorino Bertolini, Adelchi, re dei Longobardi, in: Dizionario biografico degli Italiani, Bd. 1 (1960) http://www.treccani.it/enciclopedia/re-dei-longobardi-adelchi_\%28Dizionario-Biogra fico\%29/ (Stand 12.6.2014).

629 CC 45, 563: ... ut nullo modo quisquam de vestra fraternitate praesumat filiam iam dicti Desiderii Langobardorum regis in coniugium accipere, nec iterum vestra nobilissima germana Deo amabilis Ghysila tribuatur flio saepe fati Desiderii, nec vestras quoquo modo coniuges audeatis dimettere. 
Kraft meines Herrn, des Heiligen Apostelfürsten Petrus, mit den Fesseln des Anathemas gebunden wäre und dem Königreich Gottes fremd sein soll und mit dem Teufel und seinen grausamsten Eitelkeiten und anderen unheiligen ewigen Feuern zur Verbrennung bestimmt wäre. ${ }^{630}$

Diese Drohung mit dem Anathem ist außergewöhnlich, Vergleichbares ist in der päpstlichen Korrespondenz mit den Franken sonst nicht zu finden. Sie zeigt vielleicht eindrucksvoller als alle bisher zitierten Stellen, mit welchem Einsatz der Papst hier spielte. Wie sehr unterscheidet sich doch der Ton von jenem der Briefe Stephans II. und Pauls, wo immer wieder das Bündnis mit den Franken beschworen wird. Trotz der Anathemadrohung fand die Hochzeit wahrscheinlich statt. Zur Verhängung des Anathemas kam es allerdings nicht, denn die politischen Vorzeichen hatten sich bereits geändert.

Oberflächlich betrachtet stellt CC 45 eine Anomalie dar, denn wirkmächtig wurde er nicht. Er zeigt jedoch zum einen, wie entscheidend eine Veränderung der karolingischen Bündnispolitik das Papsttum treffen konnte. Zum anderen - und das ist für die vorliegenden Betrachtungen entscheidend - sehen wir hier eine rhetorische Extremposition, die man in Rom sowohl den Langobarden als auch den fränkischen Verbündeten gegenüber einnehmen konnte. Die Frage ist also nicht, ob der Brief wirkmächtig wurde, es ist alleine schon von Bedeutung, dass den Karolingern mit Anathema gedroht wurde. Und es ist auch nicht so wichtig, ob die Langobarden in Rom wirklich so gesehen wurden, wie sie am Beginn des Briefes geschildert werden, als eine häretisch-aussätzige Nicht-gens. Bedeutsam ist schon allein, dass es im römischen Diskurs der frühen 77oer möglich war, eine solche Position nicht nur zu formulieren, sondern auch im diplomatischen Schriftverkehr mit den Franken zu verwenden, die man, wie jedem der inneren und äußeren Unterstützer und Kontrahenten Stephans III. klar sein musste, als Verbündete dringend brauchte. Wichtig ist es, noch einmal festzuhalten, dass der Text der Codex Carolinus Briefe nicht von den karolingischen Schreibern verändert wurde - $\mathrm{CC}_{45}$ ist dafür einer der besten Belege. ${ }^{631}$

Der Brief zeigt, dass sich der Papst ziemlich sicher sein musste, mit seinen Worten in Rom und bei seiner Zielgruppe nicht völlig über das Ziel hinauszuschießen, sondern vielleicht mit der einen oder anderen verbalen Attacke das eigene Anliegen zu

$630 \mathrm{CC}$ 45, 563: Et si quis, quod non optamus, contra huiusmodi nostrae adiurationis et exhortationes seriem agere praesumserit, sciat se auctoritate domini mei, beati Petri apostolorum principis, anathematis vinculo esse innodatum et a regno Dei alienum atque cum diabolo et eius atrocissimis pompis et ceteris impiis aeternis incendiis concremandum deputatum.

631 Siehe dazu ausführlicher oben, Kap. 1.2. 
untermauern. Das zeigt auch, wie aggressiv der antilangobardische Diskurs und das manchmal bis an seine Grenzen betriebene Othering sein konnten.

\subsubsection{Der Besuch Bertradas und Stephans Kehrtwende}

Die Position von $\mathrm{CC}_{45}$ erwies sich als kurzlebig, denn bald nach der Abfassung von CC 45 und 47 traf Bertrada in Rom ein und schaffte es, den Papst - nicht aber Chistophorus! - auf ihre Seite zu ziehen. Bertrada versicherte, dass Karl den Schutz Roms weiterhin garantieren könne, sogar besser als zuvor. Das konnte dieser auch noch im Jahr 770 beweisen, als er erfolgreich zugunsten Roms in Ravenna und in Benevent intervenieren ließ.

Das Einzige, was Stephan dafür tun musste, war, Desiderius als politischen Mitspieler zu akzeptieren und ihm gegenüber eine wohlwollende Politik zu verfolgen. ${ }^{632}$ Das war für Stephan in Ordnung, nicht aber für Christophorus, der aufgrund der Ereignisse von 768 persönlich mit Desiderius verfeindet war.

77 I erschien der Langobardenkönig in St. Peter, um mit Stephan III. zu verhandeln. Inwieweit sich Stephan und Desiderius zuvor abgestimmt hatten, ist unklar. Es kam zum Konflikt mit mächtigen Vertretern der päpstlichen Verwaltung. Zunächst musste Stephan zu Desiderius nach St. Peter (zur Erinnerung: Alt-St. Peter lag damals außerhalb der Mauern Roms) fliehen, auch weil sich Dodo, der Gesandte Karlmanns, offenbar auf die Seite Christophorus' geschlagen hatte. Doch von dort aus schaffte es der Papst über seine Verbindungsleute, in Rom hohen diplomatischen Druck auf Christophorus und Sergius aufzubauen, sodass diese, auch angesichts der starken militärischen Übermacht des Desiderius, recht bald aufgeben mussten. Sie zogen hinaus nach St. Peter, von wo aus sie wieder in die Stadt gebracht und dort schwer verstümmelt wurden. Christophorus starb wenig später, Sergius überlebte noch einige Zeit, bis er kurz vor dem Tod Stephans III. ermordet wurde. Das geschah wohl auf Veranlassung des neuen starken Mannes im Lateran, des cubicularius Paulus Afiarta. Er wird auch von der Historiographie bislang als neuer Herr Stephans III. gesehen. ${ }^{633}$ Vielleicht ist diese Einschätzung zwar zu weitreichend, jedenfalls konnte

632 Noble, Republic 122-124.

$633 \mathrm{Zu}$ den Ereignissen siehe am Besten Bertolini, La caduta del primicerio Cristoforo. Hier werden mehrere Versionen der Ereignisse gegenübergestellt und zwar die Rechtfertigung Stephans III. in seinem Brief CC 48, die Sicht des LP und eine ausführliche Schilderung, die jedoch erst im frühen 16. Jahrhundert in Randnotiz des Autors in Johannes Aventinus, Annales ducum Boiariae (ed. Sigmund von Riezler, Matthias Lexer, Annales ducum Boiariae, Bd. 1: Buch 1-4, München 1882) 410, Anm. 1, erhalten ist. Bertolini geht von einer sehr zeitnahen Quelle aus, doch es scheint hier wesentlich mehr Vorsicht geboten. 
Paulus eine nicht unbeträchtliche Macht anhäufen. Es wäre deshalb falsch, ihn als rein prolangobardisch einzuschätzen, ihm ging es wohl um seinen persönlichen Aufstieg. ${ }^{634}$ Er scheiterte jedenfalls nach dem Tod Stephans kläglich, als sich wieder eine den Langobarden negativ gegenüberstehende Gruppe des römischen Adels durchsetzen konnte.

In dieser völlig veränderten Situation in Rom sandte Stephan III. den als CC ${ }_{4} 8$ erhaltenen Brief an Karl den Großen und Bertrada, nicht jedoch an Karlmann, an dessen Gesandtem Dodo er heftig Kritik übt. Darin wird auch die päpstliche Kehrtwende gegenüber Desiderius deutlich: Desiderius ist plötzlich wieder excellentissimus filius noster und damit auf demselben Rang in der päpstlichen Gunst wie Karl, während Karlmann nur als germanus tuus, Carlomannus rex vorkommt. ${ }^{635}$ Direkte Anschuldigungen gibt es gegen Karlmann zwar nicht, aber klar ist, dass der Brief ausschließlich an Karl geht und eben nicht an seinen Bruder, der zuvor als Hoffnungsträger von Stephans Diplomatie gegolten hatte. ${ }^{636}$

Beeindruckend ist jedenfalls der Wechsel in der päpstlichen Darstellung des Desiderius, der zunächst höchste Wertschätzung genießt, dann lange sehr kritisch gesehen wird, schließlich unter Stephan III. sogar übelst verunglimpft wird, nur um 77 I wieder in der Gnade des Papstes zu stehen. Wie lange dieser Zustand andauerte, kann nicht zweifelsfrei festgestellt werden. In der Vita Hadrians I. wird, wie wir noch sehen werden, behauptet, Stephan habe sich vor seinem Tod wieder enttäuscht vom Langobardenkönig abgewandt. Diese Wechselfälle hat Noble perfekt durch den Titel des vierten Kapitels in seiner Republic of St. Peter ausgedrückt: „Our beloved son Desiderius ... that foul and pestiferous Lombard.“637

\subsubsection{Die Vita Stephans III. nach der Intervention Bertradas in Rom (Frühling/ Frühsommer 771)}

Stephan III. wird meist als Diener verschiedener Herren dargestellt. Dieses Bild eines schwachen Papstes beruht jedoch zum größten Teil auf seiner Vita im Liber Pontificalis.

Die Vita Stephans III. stammt, wie oben (Kapitel 4.2 und 4.3) schon erwähnt, nicht nur aller Wahrscheinlichkeit nach aus dem Pontifikat Hadrians I., sondern

634 Noble, Republic 126: „Finally, there were unsavoury characters like Paul Afiarta whose only allegiance was devoted to the advancement of their own careers."

635 CC 48, ed. Gundlach, 566.

636 Siehe CC 47, ed. Gundlach 565f., in dem der Papst ihm zur Geburt seines Sohnes gratuliert und sich als Taufpate anbietet.

637 Noble, Republic 99-137, siehe besonders 125. 
dürfte aus der Rückschau knapp nach der Niederlage des Desiderius 774 abgefasst worden sein. Ihr Autor war höchstwahrscheinlich identisch mit jenem des politischen Teils der Vita Hadrians I. ${ }^{638}$ Er war mit der Politik des Papstes ab 77I nicht einverstanden, wollte oder konnte Stephan III. in seinem Text jedoch nicht offen kritisieren. ${ }^{639}$ Dem Autor war daran gelegen, die Haltung des Papsttums Desiderius gegenüber vollkommen einheitlich und stringent als kritisch bis vollkommen ablehnend darzustellen, ${ }^{640}$ ohne aber, wie wir noch sehen werden, die Langobarden kollektiv zu verdammen. Die neuen Mächtigen, an ihrer Spitze nun ohne Zweifel Papst Hadrian selbst, standen hingegen den ermordeten Christophorus und Sergius zumindest nahe. In seiner Vita wird Stephan daher nur sehr selten als handelnd dargestellt, und zwar nur dann, wenn seine Politik immer noch gebilligt wurde. In den sonstigen Fällen wird seine Rolle bei den Ereignissen heruntergespielt oder verschwiegen. So musste der zum Zeitpunkt der Abfassung schon gestürzte Desiderius gemeinsam mit Paulus Afiarta als Sündenbock herhalten. ${ }^{641}$

Tatsächlich kommt Desiderius nur auf negative Weise vor, sein erster Auftritt im Liber Pontificalis nach den im Abschnitt über CC 45 beschriebenen Vorfällen findet im Zuge seines Eingreifens in die Nachfolgefrage des Bistums Ravenna statt. Hier wird auch durch Unterstützung des Langobardenkönigs der „falsche“ Kandidat, nämlich Michael anstatt des von Rom bereits abgesegneten Leo, zum Bischof erhoben. ${ }^{642}$ Zwar wird hier Desiderius' Rolle nicht allzu stark betont, der König findet sich jedoch erwartungsgemäß wieder auf der Seite der Bösen. Die Situation wird schließlich auf Befehl Karls des Großen bereinigt, der in der Liber Pontificalis-Darstellung vollständig positiv besetzt ist. Am Ende der Vita Stephans spielt Desiderius schließlich eine der bestimmenden Rollen. Er ist federführend an der brutalen Ausschaltung des Christophorus und Sergius beteiligt. Das Fazit des Autors zu seiner Rolle fällt entsprechend düster aus: „All dieses Unheil passierte durch das bösartige Anstiften des bereits genannten Langobardenkönigs Desiderius. ${ }^{\text {"43 }}$ Mit dieser Feststellung

638 Siehe Davis, LP 8, 85-87, der jedoch auch die Vita Pauls I. einbezieht und auch meint sie sei als Vorgeschichte gedacht gewesen. Dazu passt jedoch die inhaltliche Ausrichtung dieser Vita gar nicht, Desiderius etwa, der Antagonist der Viten Stephans III. und Hadrians I., kommt darin überhaupt nicht vor.

639 Generell war es eher die Tendenz des LP, die Päpste nicht offen zu kritisieren, auch wenn Kritik durchaus vorkommt. Das eindruckvollste Beispiel findet sich im Leben Sergius' II., von dem später in Bezug auf den Überfall auf Rom von 846 noch ausführlich die Rede sein wird, siehe unten, Kap. 6.1.

640 Davis, LP 8, 85-87, hier 87 und 107-122, hier 107.

641 Davis, LP 8, 87.

642 LP I, $477 f$.

643 LP I, 480: Haec vero omnia mala per iniquas inmissiones iamdicti Desiderii Langobardorum regis provenerunt. Vgl. Niemeyer, Mediae Latinitatis Lexicon minus, Bd. 1, 667 (Lemma immissio). 
endet auch die Vita, die somit die letzten Monate des Pontifikats Stephans III. bis Anfang 772 nicht mehr berichtet. Aus erzählerischer Sicht ist auch alles gesagt: Der Hauptschuldige ist der Langobardenkönig, seine iniquas inmissiones sind es, die zu den furchbaren Zuständen in Rom geführt haben. Die Wortwahl gemahnt in diesem Fall eigentlich wenig überraschend an die Vita Stephans II.

Auffallend ist, wie sehr die Verantwortung für die Ereignisse von Stephan III. abgeschoben wird und Desiderius als Drahtzieher in den Mittelpunkt gestellt wird. Einschränkend muss man jedoch bemerken, dass Paulus Afiarta trotzdem konsistent noch ein wenig negativer dargestellt wird als der Langobardenkönig. Er ist es auch, der schlussendlich für die Ermordung des Christophorus und (wie wir im Leben Hadrians noch erfahren werden) des Sergius verantwortlich gemacht wird. Desiderius erscheint unter diesem Eindruck nicht mehr als ultimativer Feind, so wie noch in $\mathrm{CC}_{45}$, sein Handeln wird vielmehr in Relation zu dem verräterischen Verhalten des Paulus gesetzt. Dennoch wird Desiderius in der Vita dem Othering unterworfen. Während er sich wohl selbst ab 77I als Verbündeten des Papstes sah, wird er im LP als gegen ganz Rom agierend gezeigt und alleine dadurch den Römern ent-fremdet.

\subsection{Hadrian I. - Römische Ambivalenz}

\subsubsection{Die Vita Hadriani}

\subsubsection{Hadrian und Desiderius bis 774}

Im LP-Eintrag Hadrians setzt sich das Desiderius-Bild nahtlos fort. Gleich nach der Einführung Hadrians als Bischof von Rom wird vom Autor der Vita das Verhältnis zu Desiderius abgesteckt, und zwar mit einem langen Monolog, in dem Hadrian den Gesandten des Langobardenkönigs die Haltung des Papsttums erklärt:

Sofort nach der Weihe seiner Heiligkeit sandte der Langobardenkönig Desiderius seine Gesandten, Theodicius, $d u x$ von Spoleto, Tunno, $d u x$ von Ivrea, und seinen vestararius Prandulus mit einer Nachricht zu ihm, die ihn überzeugen sollte, sich mit ihm im Band der caritas zu verbinden. Ihnen antwortete der allerheiligste Bischof folgendermaßen: „Ich möchte Frieden mit allen Christen halten, sogar mit eurem König Desiderius; ich werde versuchen, mich an jenen Friedensvertrag zu halten, der zwischen Römern, Franken und Langobarden geschlossen worden ist. Doch wie kann ich eurem König trauen, nach den Details, die mein Vorgänger, der Herr Papst Stephan, mir über seine betrügerische Treue (fraudulenta fides) berichtet hat. Er sagte mir, dass er ihn bei allen Versprechungen die Rechte der Heiligen Kirche betreffend, die er ihm vor dem Körper des Heiligen Petrus schwörend gemacht hatte, belogen hat. Mit seiner ungerechten Darstellung ist er soweit 
gegangen, dem primicerius Christophorus und seinem Sohn, dem secundicerius Sergius, die Augen ausstechen zu lassen und befriedigte so seine Wünsche gegenüber diesen beiden Würdenträgern der Kirche. Dadurch fügte er uns Schaden zu; keineswegs förderte er damit die apostolische Sache. Aus der Liebe heraus, die er für mich als sein Kind hatte, erzählte mein Vorgänger mir auch, dass als er ihm später seine Gesandten Anastasius, den ersten defensor, und den Subdiakon Gemmulus schickte, um ihn dazu zu ermahnen die Versprechungen, die er persönlich dem Heiligen Petrus gemacht hatte, zu erfüllen, er die Gesandten mit folgender Antwort zurückschickte: ,Ich habe bereits genug für den Apostolicus getan, als ich Christophorus und Sergius entfernte, die ihn zuvor beherrscht haben. Daher braucht er nicht nach seinen Rechten zu fragen. Denn es ist sicher, dass wenn ich dem Apostolicus nicht helfe, ihm großes Unheil widerfahren wird. Karlmann, König der Franken, war nämlich ein Freund der genannten Christophorus und Sergius und um ihren Tod zu rächen, ist er bereit mit seinem Heer nach Rom zu kommen und den Bischof selbst gefangen zu nehmen.' Das zeigt euch, wie es um die Treue eures Königs Desiderius bestellt ist und mit wieviel Zuversicht ich ihm Glauben schenken kann. “644

Wichtig ist, dass die Langobarden nicht kollektiv angegriffen werden. Als Brecher des Friedens wird immer nur Desiderius dargestellt, Stephan III. hingegen hat keinen Anteil daran. Erinnern wir uns zum Vergleich an den Brief CC 45, wo die Langobarden als Kollektiv angegriffen werden, obwohl die Attacken auch dort im Prinzip

644 LP I, 487: Itaque in ipso exordio consecrationis eius direxit ad eius beatitudinem suos missos Desiderius Langobardorum rex, id est Theodicium, ducem Spolitinum, Tunnonem, ducem Eburegias et Prandulum, vestararium suum, suasionis per eos mittens verba, sese quasi cum eo in vinculo caritatis velle colligandum. Quibus ita ipse beatissimus pontifex respondit, dicens: "Ego quidem cum omnibus christianis pacem cupio habere, etiam et cum eodem Desiderio rege vestro; in ea foederis pace quae inter Romanos Francos et Langobardos confirmata est studebo permanendum. Sed quomodo possum credere eidem regi vestro, in eo quod subtilius mibi sanctae recordationis praedecessor meus domnus Stephanus papa de fraudulenta eius fide referuit, inquiens quod omnia illi mentitus fuisset que ei in corpus beati Petri iureiurando promisit pro iustitiis sanctae Dei ecclesiae faciendis, et tantummodo per suum iniquum argumentum erui fecit oculos Christophori primicerii et Sergii secundicerii filii eius, suamque voluntatem de ipsis duobus proceribus ecclesiae explevit. Unde damnum magis et detrimentum nobis intulit; nam nullum profectum in causis apostolicis inpertivit. Sed et hoc isdem meus praedecessor, pro dilectione quam erga me suum pusillum habuit, mibi retulit, quia dum ad eum postmodum suos missos direxisset, videlicet Anastasium primum defensorum et Gemmulum subdiaconum, adortans eum ut ea quae praesentaliter beato Petro pollicitus est adimpleret, taliter ei per eosdem missos direxit in responsis: ,Sufficit apostolico Stephano quia tuli Christophorum et Sergium de medio, qui illi dominabantur, et non illi sit necesse iustitias requirendum. Nam certe si ego ipsum apostolicum non adiuvavero, magna perditio super eum eveniet. Quoniam Carulomannus, rex Francorum, amicus existens praedictorum Christophori et Sergii, paratus est cum suis exercitibus, ad vindicandum eorum mortem, Roma properandum ipsumque capiendum pontificem. ' - Ecce qualis est fides Desiderii regis vestri, et qua fiducia illi credere possim." 
Desiderius und seiner Familie galten. Der Autor der LP-Vita gesteht den Langobarden (und selbst Desiderius) im Übrigen auch die Zugehörigkeit zur Christenheit am Beginn der direkten Rede Hadrians explizit zu.

Die Rede stellt eine neuerliche Revision der Ereignisse des Jahres $77 \mathrm{I}$ dar. ${ }^{645}$ Zweifellos hatte Stephan III. seine Position gegenüber Karl dem Großen verändert und somit auch Desiderius als politischen Partner akzeptiert. Als dieser in Rom eingreifen wollte, bediente sich Stephan selbst des Königs, um sich von Christophorus zu befreien. Im Zuge der Verhandlungen mit Desiderius könnte dieser nun der vorliegenden Darstellung zufolge zunächst auch Restitutionen von ehemals römischen oder aber dem Exarchat zugehörigen Gebieten angekündigt haben, vielleicht in dem im Frieden von Pavia 756 vereinbarten Ausmaß. Durch das wohl durchaus riskante Eingreifen zugunsten Stephans (immerhin stand Karlmann auf der Seite des Christophorus) dürfte nun Desiderius andere Konzessionen zunächst zurückgestellt haben. In $\mathrm{CC}_{4} 8$, dem einzigen erhaltenen Brief Stephans an Karl den Großen (und Bertrada), der nach den umwälzenden Ereignissen verfasst wurde, werden vom Papst auch tatsächlich keinerlei Forderungen mehr erhoben.

Im Lichte dieser Ereignisse erscheint auch die Antwort des Desiderius an Stephan III., aus der der Autor der Vita Hadrian hier zitieren lässt, ziemlich logisch und folgerichtig. Sie zeigt auch eine andere realpolitische Situation, als sie noch in der LP-Vita Stephans dargestellt wird. Interessant ist die Wiedergabe in Form der Rede des Hadrian. Die Schilderung der Situation ist insgesamt als eine Kritik an seinem Vorgänger zu verstehen, der sich Desiderius gegenüber freundlich gezeigt habe, aber betrogen worden sei, auch wenn eben die zitierte Antwort des Desiderius der realistischste Teil der ganzen Rede zu sein scheint. Man kann davon ausgehen, dass sich Desiderius für Stephan III. als wenig verlässlicher politischer Partner erwiesen hatte, ganz einfach deswegen, weil er meist in der stärkeren Verhandlungsposition war und daher territoriale Konzessionen von vornherein unwahrscheinlich waren.

Die Langobarden werden in der zitierten Textpassage als Gruppe fast komplett ausgeklammert ${ }^{646}$, wodurch der Effekt der literarischen Rede vielleicht noch verstärkt werden soll. Im Einklang mit der Vita Stephans III. wird in dieser Passage gleich am Anfang der Hadriansvita abgesteckt, wer als Bösewicht für die Probleme Roms verantwortlich ist, nämlich der Langobardenkönig. Tatsächlich wurde so eine Einschätzung für den Pontifikat Stephans III. erst nachträglich konstruiert. Erinnern wir uns an

$645 \mathrm{Zu}$ den verschiedenen Versionen vgl. Bertolini, La caduta.

646 Allerdings sind sie als Vertragspartei von 754 und 756 genannt, vielleicht auch deswegen ausdrücklich, weil Desiderius zu dem Zeitpunkt nicht König und somit als langobardischer $d u x$ eben nur einer von vielen Vertragspartnern war. 
Brief CC 48 von Stephan III. von 771, gerichtet an Karl den Großen und Bertrada, jener Brief, in dem Desiderius auch als excellentissimus filius noster bezeichnet wird. Darin erfahren wir, dass es eine Zusammenarbeit gab, die zumindest dem Frankenkönig gegenüber als zufriedenstellend dargestellt werden konnte, wenn auch der Liber Pontificalis sicher nicht die Unwahrheit überliefert, wenn von Spannungen berichtet wird, die sich wie seit einigen Jahrzehnten immer wieder um die strittigen Gebiete in Mittelitalien drehten. Aus den ersten zwei Jahren von Hadrians Pontifikat sind keine Briefe im Codex Carolinus überliefert. Diese Lücke ist auffällig, sie ist sicher nicht darauf zurückzuführen, dass es in den fast zweieinhalb Jahren zwischen der Inthronisation Hadrians und Brief CC 50 vom Herbst 774 keinerlei Kontakte gegeben hat. ${ }^{647}$ Die Kommunikation dieser Zeit wurde aber nicht in die Sammlung aufgenommen. Dafür kann es eine Reihe von Gründen gegeben haben. Zunächst kommt in Betracht, dass die Briefe aus stilistischen Gründen nicht den Gefallen der Hersteller der Sammlung fanden. Ebenso ist möglich, dass die Schreiben inhaltlich nicht so bedeutend waren und daher den Aufwand nicht rechtfertigten. Gegen diese Form der Auslese spricht jedoch, dass sogar ein fast zerstörter Brief Pauls I. (CC I5) in die Sammlung aufgenommen wurde, auch wenn nur noch eine Inhaltsangabe angefertigt werden konnte. Und inhaltlich ist der $\mathrm{CC}$ auch zu heterogen, als dass man sagen könnte, dass die Auswahl nach der Wichtigkeit der Stücke erfolgt sei. Möglich ist, dass die Stücke an einem anderen Ort eingelagert waren und daher in Regensburg 79I nicht vorhanden waren. ${ }^{648}$

Wahrscheinlicher erscheint im vorliegenden Fall allerdings, dass die ersten Briefe Hadrians im CC bewusst weggelassen wurden. Man möchte meinen, dass das vor allem für Stücke zugetroffen haben müsste, die aus Sicht Karls des Großen 79r politisch nicht genehm waren. Doch es gibt eine Reihe von Briefen, in denen heftige Kritik am Karolingerkönig geübt wird, am auffälligsten ist der oben ausführlich besprochene Brief CC $45^{649}$, auch unten in Kapitel 5.6.2 werden wir noch einige solcher Passagen sehen. Es wäre also bei aller gebotenen Vorsicht anzunehmen, dass eine Reihe von Briefen, darunter die frühesten Hadrians, nicht aufgenommen wurden, weil sie für den König unangenehm und in der aktuellen politischen Situation außerdem überholt oder nicht mehr opportun waren. ${ }^{650}$ Die erwähnten im CC enthaltenen Briefe, die von Spannungen zwischen dem Papst und Karl berichten, sind nebenbei

647 CC 49 ist nach CC 50 und 51 zu datieren. Siehe Hartmann, Hadrian 200, Anm. 10, der sich vor allem auf Kehr, Rezension von Gundlach (ed.), Codex Carolinus, 895-897, stützt.

$648 \mathrm{Zu}$ dieser Frage siehe Kap. 1.2.

649 Der Brief könnte jedoch aus der Sicht von 791 durchaus als mögliche Rechtfertigung für die Auflösung (bzw. möglicherweise einen nie erfolgten Vollzug) der Ehe mit der Tochter des Desiderius betrachtet werden und daher von Wichtigkeit sein.

650 Siehe dazu Gasparri, Italia longobarda 147. 
bemerkt ein guter Beleg dafür, dass zwar Briefe ganz weggelassen wurden, das aufgenommene Material jedoch nicht verändert wurde.

Schon aufgrund der merkwürdigen Lücke im CC am Beginn des Pontifikats kann anhand der Vita Hadriani allein nicht automatisch davon ausgegangen werden, dass die Politik des Papstes aber gegenüber dem Langobardenkönig konsequent ablehnend gewesen ist. Sicher ist, dass Desiderius und Karl der Große schon im Dezember des Jahres 77I wieder Feinde waren und das auch bis 774 blieben. Die Rolle des Papstes bis 774 ist aber unklar, zumal ja auch die LP-Vita aus der Rückschau verfasst wurde.

König Desiderius bleibt also wie schon in der Vita Stephans III. der Sündenbock, auch für ein mögliches politisches Lavieren des Papstes. Wichtig ist, zu erwähnen, dass auch innerhalb Roms massiv gegen Paulus Afiarta und seine Unterstützer vorgegangen wurde. Es ist hier nicht der Platz, den langen Prozess gegen Paulus und seine Helfer wegen der angeblich von Paulus in Auftrag gegebenen Ermordung des ehemaligen secundicerius Sergius genau zu untersuchen. ${ }^{61}$ Stephan III. wird bei diesen Vorgängen selbst nicht erwähnt, wohl aber sein Bruder Johannes und mit Paulus einer seiner engsten Mitarbeiter - somit kann man wohl von einer Beteiligung des verstorbenen Papstes ausgehen, allenfalls könnte dieser schon gesundheitlich zu stark angegriffen gewesen sein, um noch handlungsfähig gewesen zu sein, was am Ende der Vita Stephans zumindest angedeutet wird. ${ }^{62}$ In der Vita Hadriani wird festgehalten, dass der Mord acht Tage vor dem Tod des Papstes verübt wurde. ${ }^{653}$ Es war also die Absicht des Autors, den Mord noch klar der Regierung Stephans zuzuweisen, der auch nicht exkulpiert werden sollte. Sowohl am Ende der Vita Stephans als auch in der Vita Hadrians wird Paulus Afiarta als Handlanger des Langobardenkönigs dargestellt, ${ }^{654}$ in der Vita Hadriani in folgender Passage:

Der genannte superista Paul weilte noch immer bei Desiderius und gab diesem das feste Versprechen, dass der allerheiligste Papst zu ihm gebracht werde: „Auch wenn ich ein Seil um seine Füße binden muss, ich werde ihn so gut zu dir bringen, wie ich kann.“655

Der cubicularius und superista des Papstes verspricht also dem König, ihm seinen Herrn, der wie wir noch sehen werden, aus gutem Grund ein Treffen verweigert, zur

651 Siehe dazu LP I, ed. Duchesne 489-491.

652 LP I, 480.

653 LP I, 489.

654 LP I, $479 f$.

655 LP I, 489: Praenominatus siquidem Paulus superista, adhuc apud eundem Desiderium existens, firmiter ei promittebat seipsum beatissimum papam ad eum deduci, dicens: "Quia si etiam funem in eius pedibus me adhibere convenerit, eum qualiter potuero ad tui deducam presentiam." 
Not an den Füßen gefesselt heranzuschaffen - ein Akt des Hochverrats. Allerdings scheint es unwahrscheinlich, dass Paulus tatsächlich eine solche Aussage im Beisein der anderen päpstlichen Gesandten gemacht hat. Der Satz ist vom Autor aufgenommen worden, um den Lesern die Illoyalität des Paulus und Machtdünkel möglichst drastisch vor Augen zu führen. Außerdem wird auf diese Weise auch Desiderius mit dem Missverhalten des päpstlichen Beamten in Verbindung gebracht.

Nun kurz zu den weitere Verfehlungen des Desiderius, wobei hier keine Vollständigkeit angestrebt wird, sondern nur das Bild analysiert werden soll, das der LP vom Langobardenkönig vermittelt. Gleich nachdem seine Boten, denen Hadrian seine Rede vorgetragen hat, abgereist sind, und noch bevor Boten des Papstes den König erreichen können, fällt Desiderius in den Exarchat ein. Und das, obwohl er dem Papst mittels seiner Gesandten feierlich Frieden versprochen hatte:

Nicht einmal zwei Monate waren vergangen seit dieser allerheiligste Mann den Gipfel des Pontifikats erreicht hatte, als jener allergrausamste Desiderius dieselben Städte [Faenza, die

Dukate von Ferrara und Comacchio] raubte und Ravenna von allen Seiten einschloss, ... ${ }^{656}$

Wir sehen hier das typische Muster der negativen Darstellung des Langobardenkönigs, die sich nicht wesentlich von jener Aistulfs zwei Jahrzehnte zuvor unterscheidet. Auch Desiderius wird nun mit Adjektiven wie etwa dem oben genannten atrocissimus bedacht, an anderen Stellen ist er auch protervus. ${ }^{657}$ Und auch Desiderius wird als vertrags- und eidbrüchig dargestellt. Das war schon in der langen Rede Hadrians am Beginn der Vita so, als moniert wurde, dass der König sich nicht an die Vereinbarungen mit Stephan III. gehalten hat. Auch jetzt ist das in seinem Namen gegebene Versprechen seiner Gesandten Hadrian gegenüber nichts wert. Wie nahe die Darstellung an der Realität liegt, kann nicht mehr festgestellt werden. Es dürfte unumstritten sein, dass sich Desiderius ab 769 in Angelegenheiten Ravennas einmischte und dabei für jenen Erzbischofskandidaten Partei ergriff, der nicht von Rom favorisiert wurde. Aus Sicht des Papstes stellte ein solcher Eingriff sicherlich einen Affront dar. Allerdings war es den Päpsten seit Stephan II. noch nicht gelungen, Ravenna unter ihre vollständige Kontrolle zu bringen, eine Kontrolle die nicht zuletzt von den Ravennaten selbst wenig herbeigesehnt wurde. ${ }^{658}$ Aus Sicht des Desiderius war Ravenna

656 LP I, 488: Nec enim duo menses praeterierunt quod ipse sanctissimus vir pontificatus culmen adeptus est, ita isdem atrocissimus Desiderius easdem abstulit civitates, constringens ex omni parte civitatem Ravennantium ...

657 LP I, 488.

658 Ravenna war spätestens seit dem frühen siebenten Jahrhundert im weltlichen und kirchlichen Bereich Rivalin Roms, siehe zum Beispiel Herrin, Formation 191 und 265. 
überhaupt getrennt vom päpstlichen Kernbereich zu betrachten, eine Auffassung, die er ja auch schon gegenüber Paul I. recht erfolgreich vertreten hatte. ${ }^{659}$

Neben Ravenna gab es aber für Hadrian eine wesentlich verzwicktere und unklarere politische Frage, nämlich jene der Erben des verstorbenen Karolingerkönigs Karlmann:

In diesen Tagen flüchteten die Frau und die Söhne Karlmanns, vormals König der Franken, gemeinsam mit Autchar zum Langobardenkönig; Desiderius setzte sich dafür ein und strebte sehr danach, dass diese Söhne Karlmanns das Königreich der Franken erhalten sollten. Deshalb versuchte er den allerheiligsten Bischof dazu zu verführen zu ihm zu kommen, damit er dort die Söhne des ehemaligen Königs Karlmann selbst zu Königen salbe. Er wünschte dadurch eine Teilung im Frankenreich herbeizuführen, den allerheiligsten Bischof selbst von der caritas und der Wertschätzung seiner Exzellenz Karl, König der Franken und patricius Romanorum, zu trennen und die Stadt Rom und ganz Italien seinem Königreich der Langobarden Untertan zu machen. ${ }^{660}$

Gerberga, die Witwe Karlmanns, war, wie wir bereits gehört haben, zu Desiderius geflohen. Über die Motive dafür kann nur spekuliert werden, da zu wenig über Gerberga selbst bekannt ist. Es gibt ja sogar die Theorie, dass sie selbst die berühmte namenlose Tochter Desiderius' gewesen sein könnte, was ihr Handeln noch verständlicher machen würde. ${ }^{661}$ Doch auch ohne diese Beziehung ist ihr Verhalten nachvollziehbar. Denn ihre Söhne stellten eine Bedrohung für das Machtstreben ihres Schwagers Karl dar. Bezeichnend ist, dass mit dem dux Autchar ein wichtiger ehemaliger Mitstreiter König Pippins, der 753 Stephan II. bei seiner Reise nach Norden begleitet hatte, die junge Witwe begleitete. ${ }^{662}$ Es ist bemerkenswert, wie offen und zunächst unparteiisch der Liber Pontificalis diese Situation schildert. Desiderius erkannte jedenfalls, dass die jungen Karolinger eine Gefahr für Karl den Großen darstellten, und bemühte sich, sie durch Hadrian salben zu lassen. Wie wir oben gesehen haben, versuchte er möglicherweise sogar über Paulus Afiarta Druck auf den Papst

659 Siehe oben, Kap. 5.4.

660 LP I, 488: In ipsis vero diebus contigit uxorem et filios quondam Carulomanni regis Francorum ad eundem regem Langobardorum fugam arripuisse cum Autcario; et nitebatur ipse Desiderius atque inianter decertebat quatenus ipsi filii eiusdem Carulomanni regnum Francorum adsumpsissent; et ob hoc ipsum sanctissimum praesulem ad se properandum seducere conabatur ut ipsos antefati quondam Carulomanni filios reges ungureret, cupiens divisionem in regno Francorum inmittere ipsumque beatissimum pontificem a caritate et dilectione excellentissimi Caruli regis Francorum et patricii Romanorum separare, et Romanam urbem atque cuncta Italia sub sui regni Langobardorum potestate subiugare.

661 Siehe oben, Kap. 5.5.1, und McKitterick, Charlemagne 87f.

662 McKitterick, Charlemagne 87. 
auszuüben. Interessant ist, dass der Liber Pontificalis den Langobardenkönig an dieser Stelle sogar ohne negatives Epithet erwähnt, eine Seltenheit. Die Entscheidung des Papstes für oder gegen Desiderius und die Söhne Karlmanns war offenbar nicht so klar, wie sie rückblickend dargestellt wurde. Der LP ist auffällig neutral formuliert, sodass wir durchaus spekulieren können, dass Hadrian ernsthaft mit Desiderius und Gerberga oder Autchar verhandelt haben könnte. ${ }^{663}$

Wir sehen an dieser Stelle einen Desiderius, der zwar den Papst unter Druck setzt, aber nicht so sehr als Bösewicht erscheint wie in den anderen gezeigten Passagen oder in der thematisch stark verbundenen Vita Stephans III. Da dort schon das grundlegende Othering gegen den König durchgeführt worden war, war es in der Vita Hadrians nicht mehr notwenig. Neben Desiderius wird im Jahr 773 auch sein Sohn Adelchis erwähnt, der ja als Nachfolger bereits aufgebaut war und der 788 noch als Protagonist des letzten langobardischen Restaurationsversuchs in Erscheinung treten sollte.

\subsubsection{Ein differenziertes Langobardenbild}

Desiderius und seine Verwandten spielen im LP eine doppelte Rolle. Zum einen sind sie Repräsentanten der Langobarden schlechthin, zum anderen werden sie als Individuen fassbar - namentlich genannt werden ausschließlich der König und sein Sohn Adelchis. In der zweiten Form ist ihre Darstellung meist negativ, auch wenn es graduelle Unterschiede gibt. Insbesondere Desiderius ist nicht zu trauen: Egal wem auch immer er was auch immer verspricht, es ist davon auszugehen, dass er seine Zusagen nicht einhält - wieder wird der bereits etablierte Topos der langobardischen Eidbrüchigkeit bemüht. ${ }^{664}$ Desiderius kommt also die Rolle des Antagonisten zu, gemeinsam mit Paulus, dem ja recht explizit vergeworfen wird, versucht zu haben, Rom den Langobarden in die Hände zu spielen.

Ganz anders sieht es mit den Langobarden als Kollektiv aus: Hier ist die zugewiesene Identität trotz der Repräsentantenstellung der Königsfamilie nicht konsequent durchgezogen: Es gibt neben den bösen Langobarden auch gute Langobarden, die bereit sind mit dem Papst zusammenzuarbeiten und sich diesem teils auch zu unterstellen. Auf ihr Schicksal wird in der Vita Hadrians mehrmals hingewiesen, ebenso auch darauf, dass zumindest die Dukate Spoleto und Benevent zur Einflusssphäre des Papstes gehören sollten. Tatsächlich hatte sie Desiderius jedoch schon um 758

663 Siehe dazu Noble, Republic 129-131.

664 Siehe oben, Kap. 5.3.2. 
unter seine Kontrolle gebracht, wie wir oben gesehen haben. ${ }^{665}$ Das heißt, dass sich die Bevölkerung dieser Bereiche in den Augen unseres Autors nicht aufgrund eigenen Fehlverhaltens, sondern wegen der Unterdrückung durch Desiderius nicht ihrem eigentlichen Herren, Petrus, anschließen kann. 773 muss Desiderius sein Heer aus Mittelitalien abziehen, um Karl dem Großen entgegenzutreten. Doch selbst als sich ein Teil der langobardischen Elite dem Papst unterwirft, äußert der LP-Autor noch Verständnis für jene, die diesen Schritt noch nicht wagen:

Alle anderen aus dem Dukat Spoleto waren ebenfalls begierig, sich dem Dienst an St. Peter und der Heiligen Römischen Kirche zu unterwerfen. Doch weil sie ihren König fürchteten, wagten sie es nicht, das zu tun. ${ }^{666}$

Aus Furcht vor dem König wagt ein Teil der Spoletiner Langobarden also nicht, zu widersprechen. Jene Langobarden, die zum Papst übergelaufen sind, werden erwartungsgemäß noch positiver dargestellt. In einer feierlichen Zeremonie in St. Peter wird Hildebrand von Hadrian als neuer $d u x$ von Spoleto eingesetzt. ${ }^{667}$ Hier handelt es sich um eine entscheidende Stelle der Vita: Der neue Anführer wird vom Papst bestätigt und damit auch dessen Oberhoheit über Spoleto anerkannt. ${ }^{668}$ Desiderius war zu diesem Zeitpunkt weder abgesetzt noch von den Franken geschlagen worden. Für beide Seiten stand also für den Fall, dass sich der Langobardenkönig doch noch behaupten sollte, viel auf dem Spiel. Auszuschließen war das mit Blick auf die Interventionen König Pippins in den 75oer-Jahren im Herbst 773 sicherlich noch nicht. ${ }^{669}$

Die Unterwerfung der Spoletiner Großen erfolgt in der Erzählung des LP auf noch vollkommenere Weise als nur durch die Einsetzung ihres neuen Herzogs in St. Peter - die Spoletiner Langobarden unterwerfen sich durch eine öffentliche Veränderung ihrer Haartracht:

Nachdem sie den Eid geleistet hatten, wurden sie alle nach römischer Sitte geschoren und der dreifach heiligste gute Hirte und Vater freute sich mit ihnen und ratifizierte ihnen den

665 Siehe oben, Kap. 5.4 zu Paul I.

666 LP I, 495: Etiam et reliqui omnes ex eodem ducatu Spolitino inianter desiderabant se tradendum in servitio beati Petri sanctaeque Romanae aeclesiae. Sed metuentes suum regem hoc nequaquam ausi sunt perpetrare. 667 LP I, $495 f$.

668 Diese währte jedoch nicht lange, Hildebrand unterstellte sich wahrscheinlich schon 776 Karl dem Großen. Davis, LP 8, 113, siehe auch Hartmann, Hadrian 210-221.

669 Siehe zu diesem wichtigen Punkt auch Ottorino Bertolini, Le relazioni politiche di Roma con i ducati di Spoleto e di Benevento nel periodo del dominio Longobardo, in: Atti del I congresso internationale di studi longobardi, Spoleto, 27-30 settembre 1951 (Spoleto 1952), 37-49, hier 47-49, ND in ders., Scritti Scelti di Storia Medievale, 2 Bde, ed. Ottavio Banti (Livorno 1968) Bd. 2, 679-692. 
$d u x$, den sie sich nach ihrem eigenen Willen gewählt hatten, nämlich den nobelsten Hildebrand, der zuvor mit den anderen zum apostolischen Stuhl geflohen war. ${ }^{670}$

Der Papst bestätigt in einer öffentlichen Zeremonie Hildebrand als neuen $d u x$ von Spoleto, ein eindeutiger Akt des Sameing. Nicht weniger als das scheint nämlich mit dem Wechsel der Haartracht intendiert zu sein. Interessant ist, dass einige Zeit früher im LP genau der umgekehrte Vorgang zu beobachten ist: Nach Eroberungen Liutprands im Bereich des ehemaligen Exarchats in der Zeit Gregors III. wird nämlich berichtet, dass danach die „römische“ Bevölkerung nach langobardischer Sitte geschoren worden sei:

Und die Provinz unter römischer Kontrolle wurde von den unaussprechlichen Langobarden und deren König Liutprand unterworfen. Als er nach Rom kam, schlug er sein Zelt auf dem Campus Neronis auf. Er plünderte das Umland der Stadt (campania) und kleidete und schor dort viele noble Römer nach Art der Langobarden. Deshalb war der Mann Gottes überall von Schmerzen geplagt, nahm die heiligen Schlüssel von der Confessio des Heiligen Petrus und schickte sie durch seine Gesandten, den allerheiligsten Mann, Bischof Anastasius und den Priester Sergius, mit dem Schiff nach Francia zu Karl, dem sehr weisen Mann, der damals das Reich der Franken regierte, um ihn zu bitten, sie von der großen Unterdrückung durch die Langobarden zu befreien. ${ }^{671}$

Bei dem Text handelt es sich um einen Einschub in der Vita Gregors, der nur in den Handschriftenklassen BD enthalten ist, der sogenannten fränkischen Rezension des LP. ${ }^{672}$ Duchesne hat den Nachtrag in die Zeit Stephans II. datiert und sich dabei vor allem auf die äußerst langobardenfeindliche Sprache des Abschnittes gestützt. ${ }^{673}$ Die Forschung ist ihm bisher in dieser Einschätzung gefolgt. ${ }^{674}$ Und sie hat auch etwas

670 LP I, 496: Tunc praesitum sacramentum omnes more Romanorum tonsorati sunt, et confestim ipse ter beatissimus bonus pastor et pater cum omnibus eultans constituit eis ducem quem ipsi propria voluntate sibi elegerunt, scilicet Hildiprandum nobilissimum, qui prius cum reliquis ad apostolicam sedem refugiam fecerat.

671 LP I, 420, Anm. *: Concussaque est provincia Romane dicionis subiecta a nefandis Langobardis seu et rege eorum Liutprando. Veniensque Romam in campo Neronis tentoria tetendit, depraedataque campania multos nobiles de Romanis more Langobardorum totondit atque vestivit. Pro quo vir Dei undique dolore constrictus sacras clavas et confessione beati Petri apostoli accipiens, partibus Franciae Carolo sagacissimo viro, qui tunc regnum regebat Francorum, navali itinere per missos suos direxit, id est Anastasium, sanctissimum virum, episcopum, necnon et Sergium presbyterum, postulandum ad praefato excellentissimo Carolo ut eos a tanta oppressione Langobardorum liberaret.

672 Siehe hierzu oben, Kap. 1.1.3.2.

673 Duchesne, LP I, CCXXIII.

674 Siehe Davis, LP 8, 26f., Anm. 46. 
für sich - die Darstellung der Langobarden und die Sprache würden tatsächlich sehr gut zum Autor der Vita Stephani, also in die Frühzeit des Pontifikats Pauls I., passen. Da Handschriften der BD-Rezension erst Anfang des neunten Jahrhunderts erhalten sind, wäre aber auch denkbar, dass die Stelle erst gleichzeitig mit oder nach der Abfassung dieses Teils der Vita Hadrians in den LP gekommen ist. Wahrscheinlicher ist aber, dass die Betonung der Scherungen in der Vita Hadriani auf Kenntnis der Interpolation bei Gregor III. zurückgehen und nicht umgekehrt. Eine Übereinstimmung des Autors der beiden Haartrachtpassagen des LP kann aufgrund des unterschiedlichen Stils nicht angenommen werden.

Haartracht und rituelles Haarescheren hatten im Frühmittelalter hohe politische Bedeutung. ${ }^{675}$

Was bedeutete es, nach Art der Langobarden beziehungsweise der Römer geschoren zu werden? Die einzige Information dazu liefert Paulus Diaconus. Er berichtet in der Historia Langobardorum, dass die Langobarden Nacken und Hinterkopf rasiert hatten, die Haare dafür vorne lang an der Seite des Gesichts - doch dieser Bericht bezieht sich auf ein Bild, das die längst vergangene Zeit Agilulfs und Theodelindas darstellte und das von Paulus selbst als offenbar nicht mehr den Gepflogenheiten seiner Zeit entsprechend geschildert wird. ${ }^{676}$ Wie die Langobarden ihr Haar im achten Jahrhundert trugen, ist nicht bekannt. Bei den Römern ist möglicherweise davon auszugehen, dass sie ihr Haar kurz trugen. ${ }^{67}$ In diesem Fall wäre es allerdings schwierig zu verstehen, wie eine Kurzhaar- noch zu einer langobardischen Frisur hätte geschoren werden können.

Überhaupt könnte man bezweifeln, dass Langobarden und Römer sich im achten Jahrhundert sehr stark in ihrer äußeren Erscheinung unterschieden - gäbe es nicht die zitierten Stellen im LP. Allerdings muss man wieder die Ebene des Othering mitdenken. Es ist möglich, dass sich nach der „Strategy of distinction“ die Langobarden von den Römern unterscheiden sollten, auch wenn das im alltäglichen Umgang miteinander keine Rolle mehr spielte.

Gemeinsam ist den LP-Stellen jedenfalls, dass es um die Frage der Unterwerfung einer Region geht. ${ }^{678}$ Dabei ist allein schon bemerkenswert, dass in Rom überhaupt

675 Siehe dazu ausführlich Maximilian Diesenberger, Hair, sacrality and symbolic capital in the Frankish kingdoms, in: The construction of communities in the early middle ages: Texts, resources and artefacts, ed. ders./Richard Corradini/Helmut Reimitz (Transformation of the Roman World 12, Leiden 2003) 173-212, bes. 185.

676 Paulus Diaconus, Historia Langobardorum, IV, 22, ed. Bethmann/Waitz 124. Siehe Pohl, Telling the Difference 56f. Siehe außerdem Halsall, Barbarian Migrations 104 und 110: Wahrscheinlich unterschied sich das Erscheinungsbild der Langobarden des späten sechsten Jahrhunderts kaum von jenem der römischen Armee ihrer Zeit.

677 Pohl, Telling the Difference 52.

678 Siehe zum Beispiel Hallenbeck, Pavia and Rome 162. 
mit dem Ändern der Haartracht argumentiert werden konnte! Es ist denkbar, dass der LP auf ein übernommenes Ritual der Langobarden hinweist und vor allem in der Vita Hadriani versucht, die Wirksamkeit der Unterwerfung dadurch noch zu betonen. An ihrer Öffentlichkeit lässt er ebenso keine Zweifel. Wir können daraus folgern dass in der Hadriansvita an dieser Stelle Othering und Sameing gleichzeitig angewandt wurden, die Langobarden als Andere gezeichnet wurden, die aber nichtsdestoweniger zugleich eingemeindet werden sollten. Dass der Text dadurch trotzdem nicht widersprüchlich wirkt, liegt in der Strategie des Autors begründet, der die Langobarden näher intergrieren aber zugleich auf sicherer Distanz halten möchte, was ihm in seiner Erzählung auch gelingt.

Noch ein weiterer Aspekt in der Darstellung des Autors des Lebens Hadrians ist auffällig. Der Akt des Haareschneidens wird in den beiden betroffenen kurzen Kapiteln der Vita nicht weniger als fünfmal erwähnt, immer wieder schwören die Langobarden dem Papst die Treue und immer erhalten sie in Verbindung damit den „römischen“ Haarschnitt. Diese Wiederholungen deuten auf eine weit weniger klare Rechtssituation hin - ein Hinweis darauf, dass die Vita zu einem Zeitpunkt verfasst wurde, als die päpstliche Oberherrschaft von Spoleto nicht mehr anerkannt wurde. Der ausufernd affirmative Aspekt der Darstellung verrät die Intentionen des Verfassers - es soll eine politische Konstellation beschworen werden, wie sie zumindest zur Zeit der Abfassung des Textes entweder nicht mehr existierte oder zumindest stark bedroht war. ${ }^{679}$

Diese Interpretation hat auch Konsequenzen für eine Datierung des Liber Pontificalis-Teileintrags, der die politische Geschichte des Pontifikats Hadrians bis zum Fall Pavias im Sommer 774 behandelt (danach verschwindet die Ereignisgeschichte so gut wie vollständig aus der Vita). Noch im Dezember 775 datierte Hildebrand von Spoleto eine Urkunde mit: Temporibus domni Adriani pontificis et universalis pape, et Hildebrandi gloriosi ducis ducatus Spoletani ... ${ }^{680}$ Die Frage ist, ob es nicht trotz der öffentlichen Unterordnung Hildebrands schon Anzeichen gegeben haben könnte, die in Rom Beunruhigung auslösten. Schon in der zweiten Hälfte des Jahres 775 dürfte nämlich Karl der Große direkte Kontakte zum dux von Spoleto geknüpft haben unter bewusster Umgehung des Papstes. Die Situation eskalierte schließlich noch gegen Ende desselben Jahres, als Hadrian Karl eindringlich vor einer Rebellion mit Beteiligung Hildebrands warnte. ${ }^{681}$ Die Abfassung des historischen Teils der Vita

679 Hartmann, Hadrian 26-28, spricht sich aus ähnlichen Gründen deutlich für eine relativ späte Datierung des Teils der Vita auf 775 aus.

680 CDL, Bd. 5, Nr. 64 (ed. Herbert Zieliniski, CDL, 5, Fonti per la storia d'Italia, 66, Rom 1986) 224-227, hier 226.

681 Siehe unten, Kap. 5.6.2.3, sowie CC 57, ed. Gundlach 582, und Hartmann, Hadrian 214-219. 
Hadriani dürfte somit angesichts der Ausdrucksweise nicht vor der zweiten Hälfte des Jahres 775 erfolgt sein, ja wenn man die Entwicklung in Spoleto berücksichtigt, erscheint sogar das Jahr 776 wahrscheinlicher.

Man muss auch die Frage stellen, ob eine solche politische Situation, wie sie in der „Unterwerfungsstelle“ des Liber Pontificalis beschworen wird, je real vorhanden war, das heißt, ob sich Hildebrand von Spoleto jemals überhaupt derart formell dem Papst unterworfen hat. Dass jedoch eine Art päpstliche Oberherrschaft in Spoleto anerkannt worden war, ist angesichts der Urkunde Hildebrands belegt. Somit ist die Darstellung des Liber Pontificalis zumindest in dieser Hinsicht glaubwürdig. Ein sicher detailliert choreographiertes - Unterwerfungsritual fand wahrscheinlich statt. Dabei handelte es sich unter anderem auch um einen Akt des Sameing, der einer öffentlichen teilweisen Integration dieser Langobarden dienen sollte.

Die Narration rund um den Dukat von Spoleto zeigt deutlich: Die Langobarden als monolitisch-böses Kollektiv, wie sie seit der Vita Stephans II. im Liber Pontificalis und bisweilen im CC dargestellt wurden, gab es in der Vita Hadriani nicht mehr. Vielmehr finden wir auch kooperative Langobarden, die sogar so weit gehen und sich dem Papst unterstellen. Wie vom Autor impliziert, zählten sie damit theoretisch sogar kurz zum populus des Papstes, auch wenn die Erzählung dem intendierten $\mathrm{Pu}-$ blikum zugleich berechtigte Zweifel mitgibt. Die Möglichkeit einer Integration wird aber nichtsdestotrotz vermittelt.

Dieses Bild der guten und schlechten Langobarden findet sich auch in den Briefen des CC, die nach der Eroberung Pavias durch Karl den Großen wieder einsetzen.

\subsubsection{Der Codex Carolinus}

Die Briefe Hadrians I. bilden den größten Bestand der im CC erhaltenen Briefe. Und dennoch ist nur ein Teil der Kommunikation dieses Papstes mit dem Frankenreich erhalten. Auch nach der großen und beklagenswerten Lücke bis Herbst 774 finden sich immer wieder Schreiben, die die Existenz anderer, nicht erhaltener Briefe voraussetzen. $^{682}$

Ein nicht unbeträchtlicher Teil der Briefe Hadrians beschäftigt sich mit Fragen, die Langobarden betreffen. Nicht alle von ihnen sind für unser Thema aussagekräftig. Sehr viele der Briefe betreffen gleichzeitig die Beziehungen Hadrians zu bestimmten Langobarden und seine Beziehung zu Karl dem Großen. Sie zeigen deutlich, wie häufig der Papst mit seinem fränkischen Verbündeten in Konflikt geriet.

682 Siehe oben, Kap. 1.2. 
5.6.2.1 Die Briefe 50 und 51 und die Lage im langobardischen Tuszien

Gleich die ältesten überlieferten Briefe Hadrians I. sind in Bezug auf die päpstliche Wahrnehmung von Langobarden nach der Übernahme des langobardischen Königreichs durch Karl den Großen wichtig. Es geht um komplexe Auseinandersetzungen rund um einen Langobarden namens Gausfrid, der vom Papst Unterstützung bei Restitutionsforderungen erhält. ${ }^{683} \mathrm{CC} 50$ enthält die folgende Passage, die das Engagement des Papstes für den Pisaner Gausfrid erklärt:

Das berichtete uns nämlich Gausfrid: Als er von Euch [Karl d. Gr.] entlassen, zurückgekehrt war, beabsichtigte der dux Allo, ihn umzubringen. Als deshalb Gausfrid wieder zu Euch zurückkommen wollte, stellte Allo Spione und Meuchelmörder am Wegesrand auf, die ihn töten sollten. Als er das bemerkte, floh er zu uns. Und weil er dann darum bat, zu Euch gesandt zu werden und weil wir unseren missus Anastasius gerade zu Euch schicken wollten, haben wir ihn zusammen mit diesem unserem missus entsandt. Wir bitten Euch, dass ihr ihn aus Liebe zum Heiligen Petrus und auf unser Antragen gutmütig empfangt und ihm die Gunst Eures Schutzes und Eurer Unterstützung zuteilwerden lasst; zudem bitten wir auch, dass dieser die Ländereien, die Ihr ihm zugesagt habt, durch die Großzügigkeit Eurer Autorität auch in Besitz nehmen kann. ${ }^{64}$

Gausfrid hatte also, seinem eigenen Bericht an Hadrian zufolge, bereits eine Bestätigung Karls über seinen Besitz erhalten, der zuständige dux Allo hatte diese aber nicht anerkannt und sogar das Leben Gausfrids bedroht, woraufhin dieser sich, da er nicht direkt zu Karl gelangen konnte, an den Papst wandte. So lautet jedenfalls die Version, die Hadrian Karl glaubhaft machen wollte. Es ist sehr schwer zu eruieren, was wirklich vorgefallen ist. Sicher scheint, dass einige hochgestellte Langobarden in Tuszien 774 zumindest teilweise enteignet wurden und bestimmte hohe Repräsentanten, wie wir gleich sehen werden, von politischen und religiösen Funktionen ferngehalten wurden. Gausfrid wandte sich in seiner Sache an den Papst, der ihm Unterstützung zusagte.

683 Siehe Hartmann, Hadrian 202-209.

684 CC 50, ed. Gundlach 570: Ipsae referuit nobis siquidem Gausfridus: dum a vobis absolutus reversus est, voluit eum interficere Allo dux; unde, dum vellet ipse Gausfredus ad vestra denuo reverti vestigia, posuit exploratores atque insidiatores in itinere, qui eum interficerent; quo cognito, apud nos refugium fecit. Et dum se petisset ad vestra absolvi vestigia, dum iam aderatum habuimus Anastasium nostrum missum ad vestram excellentiam dirigendum, eum ad vestram presentiam cum ipso nostro misso absolvimus. Quem, petimus, ut pro amore beati Petri et nostra postulatione benigne suscipere et protectionis atque favoris vestri opem illi inpertire dignemini, deprecantes et hoc: ut masas illas, quas ei concessistis, per vestram auctoritatis largitatem possideat. Die Übersetzung folgt weitgehend Hartmann, Hadrian 201. 
Aber möglicherweise agierte Gausfrid nicht nur in eigener Sache. Der Papst forderte von Karl nämlich außerdem:

Und auch dies bitten wir und verlangen wir dringend, dass Ihr die Bischöfe von Pisa, Lucca und Reggio zu den ihnen anvertrauten Sitzen, Kirchen und Gemeinden zurückkehren lasst, weil es so Deiner Seele, guter König, gelingen wird, dass jene Bischöfe auf ihren eigenen Sitzen wieder eingesetzt werden. ${ }^{685}$

Hadrian setzte sich also auch für abgesetzte langobardische Bischöfe ein, die durch Franken oder fränkische Parteigänger ersetzt worden waren und nun im fränkischen Exil festgehalten wurden. Es ist durchaus denkbar, dass hier auch eine Verbindung zu Gausfrid bestand.

Wieso setzte sich Hadrian so eindeutig auf die Seite der langobardischen Oberschicht? Erstens waren die Beziehungen in den letzten Jahren Stephans III. durchaus ambivalent, eine solche Politik könnte sich unter Hadrian fortgesetzt haben, auch wenn im Liber Pontificalis anderes berichtet wird. Zweitens hat Hadrian offenbar versucht, auf die politischen (und mittelbar auch auf die wirtschaftlichen) Vorgänge in der Nachbarregion Einfluss zu gewinnen. Und drittens können wir annehmen, dass der karolingische Einfluss in Mittelitalien dem Papst deutlich zu weit ging. Schließlich hatte man in dem Gebiet eigene politische Interessen.

Der folgende Brief CC 51, der wahrscheinlich 775 verfasst wurde ${ }^{686}$, liefert zusätzliche Informationen. $C_{5}$ I weist in der Gundlach Edition zunächst drei lange Absätze auf, in denen der Papst sein Verhältnis zu Karl sehr wortreich lobt. Doch dann kommt Hadrian zum Wesentlichen:

Weil Ihr uns über unseren missus Anastasius berichtet habt, dass er irgendwelche unanständigen Worte, die sich nicht gehören, an Euch gerichtet habe, Ihr deshalb sehr traurig gestimmt worden wäret und ihn daher bei Euch festhieltet, deshalb brennt unsere Seele sehr. Denn die Langobarden und Ravennaten sagen schon, dass ein König keinsefalls in Liebe zum Papst stehen könne, wenn er dessen missus bei sich festhielte. Aber es

685 CC 50, ed. Gundlach, 570: Sed et hoc nimis quesumus atque postulamus [vestram] benignitatem: ut episcopos illos, id est civitatis Pissinae seu Lucanae et Regio, ad proprias sedes adque ecclesias et plebes eis commissas absolvere iubeatis revertendum, quia ita, bone rex, excellentissime fili, animae tuae expedit, ut ipsi episcopi propriis sedibus restituantur (nicht übersetzt: omnesque Dei ecclaesiae suis praesulibus ornatae consistant et cunctus Dei populus in magna laetitia vestris felicissimis temporibus degere valeat vobisque hoc respiciat at aeternam mercedem). Die Übersetzung folgt Hartmann, Hadrian 201.

686 Zumindest gab es bisher keinen Widerspruch gegen die Datierung Gundlachs, siehe Hack, Codex Carolinus, Bd. 2, 1077. 
ist auch seit Beginn der Welt kein Fall bekannt, wo ein missus Deines Beschützers, des Heiligen Petrus, sei er groß oder unbedeutend, von irgendeiner gens fetsgehalten wurde. Also sollt Ihr ihn in Eurem Zorn zu uns schicken lassen, und wir werden ihn nach sorgfältiger Untersuchung bestrafen, wie es die Schuld erfordert, die wir an ihm finden. Doch jetzt zu dem Langobarden Gaidifrid, der mit diesem unserem missus Anastasius zu Euch gereist ist; über ihn habt Ihr berichtet, dass er, als er in Eurem palatium gewesen sei, Betrug gegen Euch begangen und darüber hinaus auch Euren Notar überredet habe, falsche Urkunden zu verfassen, durch die er uns in einen Streit mit Euch habe verwickeln wollen, was die Göttlichkeit abwenden möge. Denn es gibt keinen Menschen, der uns auf irgendeine Weise gegen Euch in Zorn versetzen könnte. Aber Gott, der die Geheimnisse der Menschen kennt, ist unser Zeuge: Durch keinen Anhaltspunkt haben wir diesen Mann als jemanden kennengelernt, der gegen Euch untreu gewesen wäre. ${ }^{67}$

Tatsächlich ist die Kommunikation mit dem König mittlerweile von gegenseitigen Vorwürfen geprägt: Der päpstliche missus Anastasius wird im Frankenreich festgehalten, weil er Karl den Großen beleidigt haben soll. Die Anschuldigungen registriert der Papst mit Verwunderung, beansprucht aber das Recht für sich, über Anastasius zu urteilen. Hadrian protestiert vor allem aus prinzipiellen Gründen gegen die Festnahme seines Gesandten, die seiner Meinung nach einen Verstoß gegen die diplomatischen Gepflogenheiten darstellt. Eine Gefangennahme des päpstlichen missus ist, wie er schreibt, zuvor noch nie und nirgends auf der Welt passiert. ${ }^{68}$ Für den Papst ist die Situation umso heikler, weil er fürchten muss, dass seine Position in Mittelitalien gegenüber den verbliebenen langobardischen Fürstentümern und dem Kaiser geschwächt werden könnte - genau dieses Problem spricht er in dem Brief auch

687 CC 51, ed. Gundlach 572: Illud vero, quod de Anastasium missum nostrum nobis indicastis, quod aliqua inportabilia verba, que non expediaebat, vobis locutus fuisset, unde valde tristi effecti fuistis et pro hoc adhuc apud vos eum detinetis, nimis noster fraglat animus; dum Langobardi et Raviniani fatentur inquientes, quia nullo modo rex in apostolico permanet caritate, dum eius missum apud se detinet. Sed neque ab ipsis mundi exordiis cognoscitur evenisse, ut missum protectoris tui, beati Petri, magnus vel parvus a quacumque gente detentus fuisset; sed iubeat nobis eum vestra sollicitudo dirigere, et, severissimae eos sciscitantes, iuxta noxam ei repertam eum corripiemus. Nam de Langobardo illo, qui cum eodem Anastasio misso nostro apud vos properavit nomine Gaidifridus, unde nobis significastis, ut, dum vestro fuisset palatio, fraudem agebat adversus vestram regalitatem, insuper et vestrum suasisset notarium falsasque fecisset litteras, per quas nos cupiebat in scandalum vobiscum immittere, quod avertat divinitas: neque invenitur homo, qui nos possit per quovis modum adversus vos in iracundiam provocare; sed testis nobis est Deus, qui hocculta hominum cognoscit: per nullum argumentum eum infidelem vestrum cognovimus. Die Übersetzung folgt Hartmann, Hadrian 201f.

688 Dass päpstliche missi sehr wohl von kaiserlichen Autoritäten festgehalten wurden, haben wir oben in Kap. 3.2.2 bereits gesehen, wir haben es hier also eher mit Hadrians rhetorischem Überschwang zu tun. 
ausdrücklich an: dum Langobardi et Raviniani fatentur inquientes, quia nullo modo rex in apostolico permanet caritate, dum eius missum apud se detinet. ${ }^{689}$

Von besonderem Interesse ist für uns der Langobarde „Gaidifridus“, der als Teil der päpstlichen Mission zu Karl dem Großen versucht haben soll, am Karolingerhof Urkunden fälschen zu lassen, nachdem der König sein persönliches Gesuch abgelehnt hatte. Hier ist die Situation für Hadrian verständlicherweise um einiges heikler als bei seinem eigenen missus. Da er die genauen Sachverhalte nicht kennen kann, riskiert er hier keinen Einspruch, sondern rechtfertigt sich nur insofern, als er versichert, dem Langobarden in gutem Glauben Unterstützung gewährt zu haben.

$\mathrm{CC}_{50}$ und $5 \mathrm{I}$ zeigen zwei Tendenzen: Zum einen waren die Beziehungen zwischen Papst und Frankenkönig bereits 774 wesentlich komplizierter, als es meist dargestellt wird und als uns die meisten Quellen vordergründig glauben machen. Zum anderen scheint klar, dass Hadrian schon kurz nach dem Fall Pavias als mögliche Anlaufstelle für in Ungnade gefallene Langobarden auftrat. Dieser Frage müssem wir uns nun im Detail widmen: Wir haben in den beiden Briefen Langobarden namens Gausfridus und Gaidifridus kennengelernt. In der Forschung wird ihre Identität fast einhellig angenommen - und inhaltlich spricht in den beiden Briefen auch relativ viel dafür. ${ }^{690}$ Gundlach, der an dieser Stelle Jaffé folgte, argumentierte in der Edition zudem damit, dass der betreffende Langobarde beide Male mit dem päpstlichen missus Anastasius zu Karl reiste. ${ }^{691}$ Letztlich ist von einer Person namens Gausfrid auszugehen, die uns in beiden Briefen begegnet. Dieser Langobarde wurde bemerkenswert ausdrücklich gegenüber dem verbündeten Frankenkönig in Schutz genommen.

Im Hinblick auf Gausfrid ist auch das überlieferte Kopfregest des Briefes 50 in der Handschrift des Codex Carolinus, welches in der Edition unter der Bezeichnung "Lemma“ in den Fußnoten wiedergegeben worden ist, interessant. ${ }^{692}$ Der Eindruck, den die Edition von den „Lemmata“ vermittelt, ist irreführend, weil diese Kopfregesten (als die sie Achim Hack völlig zu Recht identifiziert ${ }^{693}$ ) sehr prominent gestaltet in Maiuskelschrift fast allen Briefen vorangestellt wurden. Hier das Regest aus der Handschrift selbst:

689 CC 51, ed. Gundlach 572.

690 Hartmann, Hadrian, 200, Anm. 11. Vgl. ähnlich auch Hack, Codex Carolinus, Bd. 1, 470f. und Bd. 2, 1000 .

691 Gundlach, Codex Carolinus, 572, Anm. 6.

692 CC 50, ed. Gundlach 569, Anm. a zu Nr. 50.

693 Hack, Codex Carolinus, Bd. 1, 69. 
Item exempl[ar $]^{694}$ epistolae ad domnum Carolum ${ }^{695}$ regem direct(ae) per Gausfridum abbatem, in qua continetur de victoria ipsius predicti regis et de episcopis Pissano et Lucano, ut ad proprias sedes adque ecclesias pro sua pietate remeare concederet. ${ }^{696}$

Von der Petition Gausfrids selbst ist nicht die Rede, dafür wird dieser als Überbringer ${ }^{697}$ des Briefes ausgewiesen und als Abt angesprochen. Es ist ein Fehler des Kopisten von 791/93 zwar nicht auszuschließen, dennoch macht die Formulierung zumindest stutzig und wirft ein neues Licht auf CC 50. Entweder wusste der Kopist mehr als die heutige Forschung oder aber man hatte 79I gar keine Ahnung mehr, worum es I7 Jahre zuvor eigentlich gegangen war, was aber im Lichte des diplomatischen Eklats um den missus Anastasius eher unwahrscheinlich ist. Das Regest wurde auch nicht erst von dem Kölner Kopisten am Ende des 9. Jahrhunderts (oder in einer Zwischenstufe) verfasst. Aufgrund des Wortlautes des Regestes zu Brief I5 (der Brief selbst wurde nicht im Volltext kopiert) kann nämlich mit Sicherheit davon ausgegangen werden, dass die Regesten schon in der ursprünglichen Zusammenstellung enthalten waren. ${ }^{698}$

Wer also war Gausfrid? Um sich dieser Frage anzunähern bringt ein Vergleich mit dem Codice diplomatico Longobardo einige Ergebnisse: Ein Gausfridus ist in zwei Urkunden genannt, und zwar in den Nummern II, 250 und 25I. Beide Urkunden (verschiedenen Typs) stammen aus Lucca und sind auf das Frühjahr 77 I (März bzw. April) datiert. In der Carta Nummer 250 geht es um die Übergabe von Land an die Kirche des H1. Petrus in Castiglione, in der Umgebung von Lucca. Hierin ist von einer terra Gausfridi die Rede: ... latere uno est tenente in terra Gausfridi et de flii quondam Autperti ... ${ }^{69}$.

Die zweite Urkunde, eine Notitia vom 5. April 77ı, führt einen Gausfrid als Zeugen, bei dem es sich wahrscheinlich um dieselbe Person handelt. Die Notitia steht auf demselben Stück Pergament wie die Charta und enthält eine Korrektur der dort

694 Verschreibung: nach dem gekürzten exempl. steht ein relativ unschön gestrichener Buchstabe, wahrscheinlich sollte dieser ein „P“ werden, der Bogen ist jedoch nicht deutlich genug ausgeführt.

695 Verdoppelung von „rolum“. Vom Korrektor getilgt.

696 CVP 449, 59v, siehe auch die Faksimile Ausgabe (ed. Unterkircher) in den Codices selecti.

697 per $X$ et $Y$ seu $Z$ directa ist in den Briefen des CC als Ausweis des Überbringers zu verstehen, vgl. Hack, Codex Carolinus, Bd. 1, 70, der darauf hinweist, dass ein solcher Ausweis nur erfolgt, wenn der Überbringer des Schreibens explizit im Text genannt ist. Zudem erfolgte eine solche Hilfestellung für den Benutzer des Textes nur bis Brief 53, danach nicht mehr.

698 Siehe Gundlach, Ueber den Codex Carolinus 529, Anm. 2. Auch Hack, Codex Carolinus, Bd. 1, 69, folgt Gundlach in dieser Argumentation.

699 CDL, Bd. 2, Nr. 250 (ed. Luigi Schiaparelli, CDL, 2, Fonti per la storia d'italia 63, Rom 1933) 330. Die terra Gausfrids wird genannt, um den Schenkungsgegenstand abzugrenzen. 
aufgeführten Bestimmungen. ${ }^{700}$ Gausfrid trägt dabei keinen Titel, während drei Geistliche explizit als solche genannt sind, nämlich die presbyteri Rachiprand und Gumpert sowie der Diakon Osprand. Allerdings erfolgt diese genaue Bezeichnung nur in den Signaturen, im Text kommen die drei Kleriker nicht vor, wohl aber in der Notitia, CDL Nummer 25 I, wo auch noch der ausführende Filippus clericus sich selbst nennt. ${ }^{701}$ Dieser Befund schließt nicht aus, dass Gausfrid zu dem Zeitpunkt einem niedrigen geistlichen Weihegrad angehörte und auch nicht, dass er zu einem späteren Zeitpunkt in den geistlichen Stand übertrat, es macht jedoch unwahrscheinlicher, dass er bereits im Jahr 774/75 die Würde eines Abtes erlangt haben konnte. Unmöglich ist es allerdings nicht. So könnte Gausfrid etwa ein Kloster auf seinem Besitz gegründet und sich selbst zum Abt gemacht haben, um sein Erbe in den unsicheren Zeiten nach der Machtübernahme der Franken zu schützen. ${ }^{702}$ Simone Collavini hat es zuletzt sogar für möglich gehalten, Gausfrid mit Gumfred, dem ersten Abt des Klosters Monteverdi, gleichzusetzen - doch auch hier gibt es letztlich für eine Identifizierung keinen konkreteren Hinweis. ${ }^{703}$

Gausfrid trägt auffälligerweise auch niemals eine weitere regionale Bezeichnung, gleichzeitig wird jedoch seine terra nach ihm benannt. Er dürfte also durchaus jemand gewesen sein, den man in der Region um Lucca kannte. Durch die kurze Notitia wird Gausfrid darüber hinaus auch in das Umfeld des Bischofs Peredeo von Lucca gerückt, der nicht auf einer Durchführung des umstrittenen Passus der Urkunde besteht. Die Abänderung geschieht, wie der Text uns sagt, mit seinem Willen, gemeint ist das Einverständnis des Bischofs. ${ }^{704}$ Peredeo ist, wie wir bereits gesehen haben, einer der tuszischen Bischöfe, die durch päpstliche Vermittlung in der Mission von Anastasius und Gausfrid wieder in ihre alten Ämter eingesetzt werden sollen. Gausfrid schien für diese Mission wohl auch wegen seines Naheverhältnisses zum Bischof geeignet.

Fassen wir also zusammen: Über Gausfrid wissen wir, dass er ein hochgestellter Langobarde aus der Umgebung von Pisa war, der über eine eigene terra verfügte, mit der es 774 wahrscheinlich Probleme gab. Vor allem befand er sich in einem Konflikt mit dem für die Region zuständigen $d u x$ Allo. Sicher stand er auch der Kirche von

700 In der Carta war der Aussteller derselben auch als Person der Kirche übergeben worden, was offenbar niemals intendiert war. Vgl. CDL, Bd. 2, Nr. 251, ed. Schiaparelli 331.

701 CDL, Bd. 2, Nr. 250 und 251, ed. Schiaparelli $330 f$.

702 Herzlichen Dank an Walter Pohl für Diskussion zu Gausfrids Möglichkeiten.

703 Simone M. Collavini, Des Lombards aux Carolingiens: L'évolution des élites locales, in: Le monde Carolingien: Bilan, perspectives, champs de recherché. Actes du colloque international de Poitiers, Centre des Études supérieurs de Civilisation medieval, 18-20 novembre 2004, ed. Wojciech Falkowski/Yves Sassier (Culture et société médievale 18, Turnhout 2009) 263-300, hier 271f.

704 CDL, Bd. 2, Nr. 251, ed. Schiaparelli 331. 
Lucca in irgendeiner Form nahe, es ist möglich, dass er selbst in der Nähe Abt war, wie man zumindest 79r/793 in Regensburg geglaubt haben dürfte.

Das angesprochene Eintreten Hadrians für die abgesetzten Bischöfe war in der heiklen Situation Tusziens kurz nach dem Machtwechsel für das Papsttum riskant. Desiderius war dort $d u x$ gewesen, bevor er nach dem endgültigen Aus für Aistulf König der Langobarden geworden war (und zwar mit beträchtlicher Unterstützung Papst Stephans II.). Folgerichtig besetzte Karl der Große gerade dort einige Schlüsselpositionen neu, wahrscheinlich waren einige Würdenträger dem gestürzten König ganz besonders verpflichtet. Die Unterstützung Gausfrids mag noch aus verschiedenen Gründen erklärbar sein, aber mit dem Einsatz für die drei abgesetzten Bischöfe nahm der Papst die Konfrontation mit Karl dem Großen in Kauf, obwohl es unwahrscheinlich war, dass dieser die Forderungen des Papstes erfüllen würde. Aus der rein politischen Sicht ist also die Vorgehensweise Hadrians unverständlich. Wenn man jedoch die kirchenrechtlichen Aspekte betrachtet, wird einiges klarer: Der Bischof von Rom betrachtete sich als Metropolit als für Tuszien zuständig. Daher musste Hadrian auf eigenmächtige Umbesetzungen Karls (in seiner Funktion als Langobardenkönig) reagieren, gerade weil die Päpste außerhalb ihres unmittelbaren Machtbereichs seit der langobardischen Eroberung nicht mehr sehr viel realen Einfluss besessen hatten. Hadrian musste daran gelegen sein, die Situation zugunsten der Päpste zu verbessern, solange Karl noch nicht lange im Amt war. Er musste also danach trachten, sich zumindest für die Besetzung der geistlichen Ämter Mittelitaliens ein Mitspracherecht zu sichern. Zu diesem Zwecke wurden langobardische Große in dieser Region sprachlich an das Papsttum gebunden, was einem leichten Grad unserer Definition von Sameing entspricht. Es wurde aber auch klar gemacht, dass der Einfluss der Franken in ebendieser Gegend nicht besonders erwünscht war. Die mittelitalischen Bischöfe kehrten im Übrigen etwa 777 wieder in ihre Ämter zurück. ${ }^{705}$

\subsubsection{Die Langobarden in Brief CC 59}

Eine der interessantesten Nennungen von Langobarden im gesamten achten Jahrhundert findet sich in CC 59, einem Brief, der bereits oben in Kapitel 4.3 im Hinblick auf die Rolle der Griechen besprochen wurde. Hartmann zweifelt an der Datierung Gundlachs auf 776, ${ }^{706}$ der eine inhaltliche Verbindung zur Notitia Italica gesehen

705 Siehe dazu Hans Martin Schwarzmaier, Lucca und das Reich bis zum Ende des 11. Jahrhunderts. Studien zur Sozialstruktur einer Herzogsstadt in der Toskana (Bibliothek des Deutschen Historischen Instituts in Rom 41, Tübingen 1972) $79 f$.

706 Hartmann, Hadrian, 185, v. a. Anm. 132. 
hat $^{707}$, die jedoch möglicherweise schon ins Jahr $774 \mathrm{zu}$ datieren sein könnte und in diesem Fall nichts mit CC 59 zu tun hätte. ${ }^{708}$ Eine weiter gefasste Datierung ist also wohl nötig. Daher wird hier im Folgenden von einer Abfassung wohl zwischen $776^{709}$ und den frühen 78 oer-Jahren auszugehen sein.

Die entscheidende Passage des Briefes lautet:

Wir antworten hiermit auf Eure honigsüßen Schreiben betreffend den Verkauf von Sklaven, welche (wie Ihr sagt) von unseren Römern an die unaussprechliche gens der Sarazenen verkauft worden sein sollen. Doch bis jetzt sind wir, was Gott verhindern möge, nicht so tief gesunken, um ein solches Verbrechen zu begehen; und wenn es begangen wurde, so wäre es ohne unsere Zustimmung geschehen. Jedoch segeln immer unaussprechliche Griechen an der langobardischen Küste, die diese familiae dann kauften; ${ }^{710}$ sie haben auch einen Vertrag (amicitia) mit den Langobarden [dieser Gegend] geschlossen und von diesen Langobarden die Sklaven erhalten.

$\mathrm{Zu}$ dieser Frage haben wir daraufhin auch dem dux Allo geschrieben, dass er mehr Schiffe bereitstellen müsse und die genannten Griechen festnehmen und ihre Schiffe mit Feuer verbrennen solle; doch er wollte unseren Forderungen nicht Folge leisten, weil „wir weder Schiffe noch Seeleute haben, die jene festnehmen könnten. “Trotzdem haben wir für Gott so gut wir konnten Zeugnis abgelegt, weil wir danach einen großen Kampf ausgefochten haben um zu erreichen, dass dieses Verbrechen verhindert wird; deshalb haben wir die Schiffe der griechischen gens im Hafen unserer Stadt Centumcellae [später Civitavecchia] verbrennen lassen und jene Griechen für lange Zeit im Kerker festgehalten.

Doch von den Langobarden, von denen wir schon geschrieben haben, sind weitere familia verkauft worden, weil sie Armut und Hunger dazu zwangen; andere von diesen Langobarden besteigen sogar aus eigenem Willen die Schiffe der Griechen, weil sie alle Hoffnung zu überleben aufgegeben hatten. ${ }^{711}$

707 Gundlach, Codex Carolinus, 551, Anm. 1.

708 McKitterick, Charlemagne 111-114.

709 Der Grund dafür ist die sprachliche Einordnung der Greci, vgl. Hartmann, Hadrian 172. Siehe dazu McCormick, Origins 877f., Anm. 186, der den Brief mit Karls Legislation gegen Sklavenhandel im Februar 776 in Verbindung bringt, was möglich, aber keineswegs belegbar ist. Eher handelt es sich um einen terminus post quem. Zur Lossagung des Papstes vom Kaiserreich siehe oben, Kap. 4.3.

710 Es ist unklar, was familia (in der Handschrift im Singular und falschen Fall) hier bedeutet. Wahrscheinlich ist familias gemeint. Der Papst will wohl vermitteln, dass die Langobarden ihre eigenen Haushaltsangehörigen in die Sklaverei verkaufen mussten. Siehe dazu auch McCormick, Origins 877f., Nr. 186.

711 CC 59, ed. Gundlach 585. Siehe zu CC 59 auch oben, Kap. 4.3 (lateinischer Text in Anm. 454) und unten, 6.1, sowie Gantner, New Visions 403-405. 
Welche Identität die Sklavenhändler auch immer gehabt haben mögen, Hadrian bestreitet jedenfalls jegliche Kooperation, im Gegenteil: die Sklaven seien ihnen von Langobarden aus Tuszien verkauft worden. Interessant ist dabei die Darstellung der Situation dieser Langobarden. Ihnen wird zwar die Zusammenarbeit mit Sklavenhändlern vorgeworfen, der Papst nimmt sie aber in Schutz. Er gesteht ihnen zu, unter großem ökonomischen Druck zu stehen: Einige der Langobarden übergaben sich laut Hadrian sogar selbst den Händlern, dum nullam habebant spem vivendi. Dieses Motiv könnte aus einem Brief Gregors des Großen stammen, ${ }^{712}$ was umso wahrscheinlicher ist, als unter Hadrian auch eine der wesentlichsten Sammlungen der Briefe Gregors angelegt wurde. ${ }^{713}$ Es wäre also nicht verwunderlich, wenn der Papst auf Motive seines berühmten Vorgängers zurückgegriffen hätte.

Auch in diesem Fall stellt sich Hadrian also faktisch auf die Seite der tuszischen Langobarden, wie auch schon im „Fall Gausfrid“ und bei den langobardischen Bischöfen. Die schlechten Lebensbedingungen jener Langobarden, die im Brief nur kurz erwähnt werden, haben vor allem zwei Menschen zu verantworten, nämlich der für das langobardisch-fränkische Tuszien zuständige dux Allo und Karl der Große selbst als sein König. Dieser Umstand wird hier zwar nicht ausdrücklich angesprochen, doch die Klage über das Elend der Tuszier kann zweifellos als Kritik an Karl und seinem Geschäftsträger verstanden werden. ${ }^{714}$ Der Papst weist außerdem darauf hin, dass Allo sich einer Zusammenarbeit mit Rom verschließe. Die Sklavenhändler sind zwar durch die päpstliche Miliz im Hafen von Centumcellae (heute Civitavecchia) festgenommen worden, es gibt aber offenbar andere, die an ihre Stelle treten. Hadrian betont, dass Allo auf ein Hilfegesuch des Papstes nicht reagiert hat. Der $d u x$ gab offenbar an, keine Schiffe zum Zwecke einer wirksamen Überwachung der Küstenregionen zur Verfügung zu haben. Es zeigt sich, dass die Zusammenarbeit mit Karl dem Großen und seinen Amtsträgern offenbar nicht gut funktionierte. ${ }^{715}$ Darauf deutet auch hin, dass, wie wir oben in Kapitel 4.3

712 Gregor I., ep. 5, 38, ed. Norberg, Bd. 1, 312-314, hier 312f.: Corsica vero insula tanta niemitate exigentium et gravamine premitur exactionum, ut ipsi qui in illa sunt eadem quae exiguntur complere vix filios suos vendendo sufficiant. Unde fit ut, derelicta pia republica, possessores eiusdem insulae ad nefandissimam Langobardorum gentem cogantur effugere. Quid enim gravius, quid crudelius a barbaris pati possunt, quam ut constricti atque compressi suos vendere filios compellantur?

713 Siehe Gasparri, Fall 47f. und Hartmann, Hadrian 176 mit Anm. 100.

$714 \mathrm{Zu}$ diesem Schluss kommt auch McCormick, Origins 877f., Nr. 186. Allo war wahrscheinlich von Karl dem Großen selbst eingesetzt worden.

715 Hartmann, Hadrian, 203, Anm. 17, geht von einer Kooperation zwischen Allo und Hadrian aus, tatsächlich dürfte hier aber genau das Gegenteil eingetreten sein. Von entspannten Beziehungen zum dux Tusziens kann eigentlich keine Rede sein. 
schon gesehen haben, Brief CC 59 ein Schreiben Karls rhetorisch korrigieren sollte (correctio). ${ }^{716}$

Eine weitere Facette kommt hinzu, wenn man die im Brief angesprochene Vorgeschichte miteinbezieht: Karl der Große hatte offenbar Hadrian wegen der Problematik angeschrieben, war jedoch von einer ganz anderen Version ausgegangen, nämlich, dass jemand aus dem päpstlichen Einflussbereich (nostri Romani) mit Sarazenen Sklavenhandel getrieben hätte. Diese Version weist Hadrian zurück. Eine Verwicklung römischer Untertanen in die Affäre kann aber nicht ausgeschlossen werden, denn offenbar verfügte Karl der Große über Informationen, die darauf hindeuteten. Eine solche Beteiligung von Römern könnte durchaus ein Grund für die apologetische Haltung Hadrians gewesen sein.

Doch darauf lässt sich Brief 59 nicht reduzieren. Das Papsttum förderte ja in Tuszien lokale Potentaten ohne Verbindung zu den Karolingern, sicher auch um deren Einfluss ein wenig zurückzudrängen. Der vorliegende Fall zeigt sogar, dass diese Förderung wohl auch in etwas tiefere soziale Schichten ausgriff. Das Papsttum formulierte in einigen Briefen in den 77oer-Jahren einen begrenzten Herrschaftsanspruch für die langobardischen Herrschaftsgebiete rund um Rom, sicher auch, um die eigene Kontrolle rund um den Dukat zu erhöhen. Besonders ausgeprägt ist diese Politik im kirchlichen Bereich, aber auch in weltliche Angelegeheiten wie jene Gausfrids oder die Ernährungssituation der Menschen im Allgemeinen mischte sich Hadrian ein. Der Papst fühlte sich also für die Bewohner Tusziens verantwortlich, wenn auch in begrenztem Maße. Hadrian anerkannte deshalb nun auch positive Seiten an vielen Mitgliedern seiner neuen „Zielgruppe“. In dem Brief wird kein Sameing betrieben, ja die Langobarden werden sogar sehr deutlich von den Römern unterschieden. Sie sind kein Teil des peculiaris populus. Dennoch finden sich Anzeichen von Versuchen Roms, den nördlichen Teil Tusziens stärker zu intergrieren, auch wenn diese Bemühungen schließlich nicht immer von Erfolg gekrönt waren.

\subsubsection{Langobardische Rebellionen?}

Im Gegensatz zum bisher Gesehenen finden sich in der Korrespondenz Hadrians aber auch ausgesprochen negativ dargestellte Langobarden - besonders dann, wenn eine Restauration des Königreichs unter einem Langobarden im Raum stand, so etwa in $\mathrm{CC} 57$ von Ende 775 :

716 Vgl. oben, Kap. 4.3 mit Anm. 455. 
Unser missus hat, als er zu ihm [Hildebrand] kam, ihn in großem Aufstand vorgefunden, denn die missi der duces Arichis von Benevent, Rotcaus von Friaul und Reginbald von Chiusi traf er in Spoleto mit dem genannten Hildebrand an, als sie gerade gegen uns einen verderblichen Plan schmiedeten: nämlich dass sie sich gegen Gottes Willen kommenden März mit einer Schar von Griechen und Adelchis, dem Sohn des Desiderius, vereinen werden, zu Wasser und zu Land über uns herfallen und uns in der Absicht bekämpfen werden, die Stadt Rom einzunehmen, alle Kirchen Gottes zu plündern, das ciborium über dem Grab Eures Gönners, des Heiligen Petrus, zu stehlen, uns selbst, was Gott verhindern möge, als Gefangenen abzuführen, wieder einen König der Langobarden einzusetzen und Eurer königichen Macht Widerstand zu leisten. ${ }^{717}$

Hadrian berichtet in dem Brief, dass sich in Spoleto Gesandte der langobardischen duces Arichis von Benevent, Rotcaus von Friaul und Reginbald von Chiusi mit Hildebrand getroffen hätten, um eine Rebellion zu planen, im Zuge derer mithilfe von "griechischen“ Truppen der nach Konstantinopel geflohene Adelchis, Desiderius' Sohn und Arichis' Schwager in Italien restauriert werden sollte. Darum sah Hadrian auch eine ernsthafte Bedrohung für Rom. Der Ton des Briefes wirkt sehr aufgeregt, was vielleicht dazu beigetragen hat, dass in der Forschung oft von einer Verschwörungstheorie des Papstes ausgegangen wurde, die jedoch nicht eine reine Angstphantasie aus Rom gewesen sei. Vielmehr habe es sich um eine Intrige gegen Hildebrand gehandelt, der sich zu dieser Zeit der päpstlichen Herrschaft zu entzie-

717 CC 57, ed. Gundlach 582 (nur zweiter Teil übersetzt): Reminiscere consideramus a Deo protectam excellentiam vestram: sepius vobis innotuendum direxissemus de Hildibrandum Spoletinum ducem seu Arighisidem [griechisch dekliniert] Beneventanum ducem atque Rodcausum Foroiulanum de sevisimum consilium, quod erga nos atque vos gerendum non differunt. Nunc vero dum fidelissimi vestri missi, re vera sanctissimus frater noster Possessor episcopus atque Rabigaudus religiosus abbas, a Benevento repedantes, per praedictum Hildibrandum apud nos properati sunt, nimis nos obsecrantes pro prenominati Hildibrandi noxa, ut ei veniam tribuissemus, adserentes, ut apud eum nostrum indiculum et obsides pro sua dubitatione [mitteremus] et Hildibrandus nostris se pressentasset optutibus: nos quippe secundum fidelissimi missi vestri dictum illuc usque Spoletio direximus Stephanum nostrum fidelissimum dudum saccellarium, qui cum eum affatus fuisset et tunc nostros ibidem destinassemus obsides.

[Übersetzung ab hier:] Ipse nempe noster missus, cum apud eum coniunxisset, in magna eum invenit protervia, eo quod missi Arigisi Beneventani ducis seu Rodcausi Foroiulani nec non et Reginbaldi Clusinae civitatis ducum in Spoletio cum praefatum reperit Hildibrandum, adibentes adversus nos perniciosum consilium: qualiter, Deo eis contrario, proximo Martio mensae adveniente utrosque se in unum conglobent cum caterva Grecorum et Athalgibs Desiderii filium et terrae marique ad dimicandum super nos irruant, cupientes hanc nostram Romanam invadere civitatem et cunctas Dei ecclesias denudare atque ciborium fautoris vestri, beati Petri, abstollere vel nosmet ipsos, quod avertat divinitas, captivos deducere nec non Langobardorum regem redintegrare et vestrae regali potentiae resistere. Die Übersetzung folgt teilweise Hartmann, Hadrian 217f. 
hen versuchte. ${ }^{718}$ Der Brief vermittelt zugegebenermaßen den Eindruck, dass sich Hadrian vom Frankenkönig im letzten Jahr zu wenig beachtet fühlte. Auch im kurz zuvor abgefassten CC 56 wird diese Sichtweise sehr deutlich. ${ }^{719}$ Tatsache ist jedoch, dass Rotcaus, der $d u x$ von Friaul, schon wenig später (Anfang 776) rebellierte, auch wenn er letztlich schon bald scheiterte. ${ }^{720}$ Zwar ist über eine Unterstützung seines Plans durch die südlichen Dukate nichts bekannt, aber es ist plausibel, dass es davor zumindest Gespräche über ein gemeinsames Vorgehen gab. Und Arichis II. von Benevent (dort seit 774 der selbst ernannte erste princeps Langobardorum), dessen Vertreter laut dem päpstlichen Schreiben ebenfalls an den Gesprächen teilnahmen, kann zu keinem Zeitpunkt seiner Herrschaft als treuer Untertan Karls des Großen gesehen werden. ${ }^{721}$ Somit kann also die Darstellung Hadrians nicht völlig von der Hand gewiesen werden - auch angesichts dessen, dass Adelchis ja einige Jahr später tatsächlich wieder in Italien erschien.

Was sagt uns der Brief über die Langobarden? Auffällig ist, wie wenig sie vorkommen, nur als Hadrian zum Abschluss des Zitats darauf hinweist, dass Adelchis wieder als König der Langobarden eingesetzt werden soll, kommt er nicht umhin, diesen bei seinem kurzen Titel zu nennen. Die duces werden jedoch nicht als Langobarden identifiziert. Nun kann man einwenden, dass Karl der Große dieser Information auch sicher nicht bedurft hätte, um die genannten Personen einordnen zu können. Und doch zeigt allein schon die Wortwahl, wie sehr sich die Haltung des Papsttums zu Langobarden geändert hatte, wenn man etwa den Vergleich mit den Briefen Stephans II., Pauls und Stephans III. zieht. Es findet sich im vorliegenden Text, so eindringlich er die Gefahr auch darzustellen versucht, nicht einmal ein negatives Epithet für die duces oder Adelchis.

Dennoch haben wir es in diesem Fall mit negativ besetzten Langobarden zu tun, was zeigt, dass Hadrian nach 774 keineswegs nur langobardenfreundlich agierte. Das verdeutlich auch eine weitere Beschwerde über den $d u x$ von Chiusi in $\mathrm{CC}_{5} 8$ :

Reginbald, einstmals Gastalde in Città di Castello, und nun dux von Chiusi: durch seine bösartigen Machenschaften ${ }^{722}$ hat er nicht davon abgelassen, Eurer geistlichen Mutter, der Heiligen Kirche, und uns viele Übel zuzufügen, indem er sich bemüht hat, all jene, die

718 Die verschiedenen Theorien finden sich bei Hartmann, Hadrian, 218, Anm. 79.

719 CC 56, ed. Gundlach 581.

720 Siehe Harald Krahwinkler, Friaul im Frühmittelalter: Geschichte einer Region vom Ende des fünften bis zum Ende des zehnten Jahrhunderts (VIÖG, 30, Wien u. a. 1992) 119-143, bes. 119-126.

721 Siehe H. H. Kaminsky, Arichis II., in: LMA, Bd. 1, 930f. Über Arichis' Bedeutung und seine Beziehungen zu Karl dem Großen und Byzanz siehe: Kreutz, Before the Normans 5-9.

722 Vgl. Niemeyer, Mediae Latinitatis Lexicon minus, Bd. 2, 1302 (Lemma submissio). 
dem Heiligen Petrus von Eurer Exzellenz zum Lohn für Eure Seele geschenkt wurden, zu seinen eigenen bösartigen Zwecken zu stehlen; er wünscht jene in seinem eigenen Dienst zu haben. Deshalb ist er selbst mit einem Heer zu unserer Stadt Città di Castello geeilt und hat ihre Bewohner entführt. ${ }^{723}$

Der $d u x$ ist also, grob gesprochen, auch ein Dieb, was wenig schmeichelhaft ist, aber eine völlig andere Qualität an Vorwürfen, als wir sie zwischen 750 und 770 gesehen haben, auch wenn mit iniquus immerhin wieder eines der typischen pejorativen Adjektive vorkommt.

\subsubsection{Benevent und die Rückkehr des Adelchis}

Deutlich aggressiver wird die Wortwahl des Papstes wieder 780 in CC 64, wo es um die militärischen Auseinandersetzungen des Papstes mit Ostrom, Benevent und Neapel um die Stadt Terracina geht.

Doch wir haben ohne Euren Ratschlag weder die Geiseln noch die Stadt selbst zurückgegeben, weil wir die Geiseln für den Dienst an Euch festhalten wollten, weil ihre bösen Ratschlüsse keine anderen sind, als mit dem untreuesten Arichis, dux von Benevent, zu paktieren. Und täglich empfängt Arichis missi des unaussprechlichen patricius von Sizilien, wodurch er alleine das Hindernis aufbaut, damit wir keine Geiseln von den genannten Napolitanern erhalten, weil er jeden Tag [zur Hilfe] bei diesem Verbrechen den Sohn des unaussprechlichen Desiderius, einstmals unaussprechlicher König der Langobarden, erwartet, damit er gemeinsam mit diesem uns an Eurer statt erobern kann. ${ }^{724}$

Arichis wird hier immerhin als infidelissimus bezeichnet. Möglicherweise ist damit seine theoretische Abhängigkeit von Karl dem Großen gemeint. Denkbar ist auch,

723 CC 58, ed. Gundlach 583f.: Raginaldum, dudum in castello Felicitatis castaldium, qui nunc in Clusinae civitate dux esse videtur: eo quod plurima mala per suas iniquas summissiones spiritalis matris vestrae, sanctae Dei ecclesiae, et nobis ingerendum non desinit, dum omnino ea, quae beato Petro principi apostolorum a vestra excellentia pro animae vestre mercede offertae sunt, per suum iniquum argumentum abstollere anhelat et in suo proprio servitio eos habere desiderat; unde et per semet ipsum cum exercitu in eandem civitatem nostram, castello Felicitatis, properans, eosdem castellanos abstulit.

724 CC 64, ed. Gundlach 591f.: Sed nos sine vestro consilio neque obsides neque ipsam civitatem reddere habuimus, eo quod pro vestro servitio ipsos obsides apprehendere cupiebamus, quia eorum malignum consilium aliud non est, nisi una cum infidelissimo Arigibs duce Beneventano tractantes. Et cotidie missos nefandissimi patricii Sicilie ipso Arighis suscipiente, impedimentum iam fatus Arighis solus fecit, ut minime nos obsides a iam dictis Neapolitanis reciperemus, quia cotidie ad istam perditionem filium nefandissimi Desiderii, dudum necdicendi regi Langobardorum, expectat, ut una cum ipsum pro vobis nos expugnent. 
dass Hadrian insinuiert, der $d u x$ von Benevent sei dem Papsttum gegenüber untreu, zumal dieses prinzipiell eine Oberhoheit über Benevent und Spoleto anstrebte. Dagegen spricht jedoch, dass 780 schon klar war, dass realpolitisch davon nicht auszugehen war - und wir haben Hadrian ja in Kapitel 4.3 vor allem als begabten Politiker mit einem Gespür auch für das politisch Machbare kennengelernt.

Arichis kommt allerdings mit freundlicheren Worten davon als der patricius von Sizilien, der in diesem Zusammenhang nefandissimus geheißen wird, und somit mit einem Wort bedacht wird, das einige Zeit davor noch exklusiv für die Langobarden benutzt wurde. Daneben gibt es noch eine weitere negative Figur, nämlich den namentlich nicht genannten Adelchis. Arichis erwartet täglich perditionem filium nefandissimi Desiderii in Süditalien. Auf der politischen Ebene versuchte Hadrian, Karl den Großen mittels des Hinweises auf die immer noch größte Bedrohung für Karls langobardisches Königtum zu einem militärischen Eingreifen südlich von Rom zu bewegen. Dass Adelchis nicht namentlich genannt, aber umso eindeutiger identifiziert wird, verstärkt - sozusagen auf der emotionalen Ebene - den despektierlichen Charakter der Stelle. Denn eigentlich hätte das Epithet nefandissimus für Desiderius gereicht, um die Positionen klar zu machen. Es sei darauf hingeweisen, dass hier zudem noch mit der Bezeichnung filius perditionis gespielt wird, einer gängigen Bezeichnung für den Antichrist, und Adelchis' angebliche Rückkehr damit sogar in einen eschatologischen Zusammenhang gerückt wird.

Es passt hier gut ins Bild, dass Hadrians Biograph, wie wir oben gesehen haben, im LP ebenfalls seine geballte rhetorische Kraft auf Desiderius und seine Familie konzentrierte. Das schließt auch die Angriffe auf Arichis II. mit ein, der schließlich Schwiegersohn beziehungsweise Schwager des jeweiligen Proponenten dieser Familie war. So verwundert es auch nicht, dass Arichis in der Folge auch in CC 65 und CC 78 immer noch als Übeltäter in verschiedenen Auseinandersetzungen genannt ist. ${ }^{725}$ Doch bei alledem darf man nicht aus den Augen verlieren, dass, so sehr die Langobarden hier auch Feinde Roms sein mögen, die „Griechen“ in den Briefen wesentlich negativer dargestellt werden - in CC 64 werden die Amtsträger des Kaisers in Süditalien sogar als Deo odibiles und perversi bezeichnet. ${ }^{726}$

Nach der hitzigen und kriegerischen Situation des Jahres 780 glätteten sich die Wogen zunächst noch einmal, mit der tatsächlichen Intervention Adelchis' 788 erreichte die Auseinandersetzung aber ihren Höhepunkt. Die Situation in Benevent war kompliziert: Arichis II. war im August 787 verstorben, einen Monat nach seinem Sohn Romuald, der als sein Nachfolger vorgesehen gewesen war. Damit sollte nun

725 CC 65, ed. Gundlach 592f. (von 779/80), CC 78, ed. Gundlach 610 (von 781-786).

726 Siehe unten, Kap. 4.3. 
sein anderer Sohn Grimoald nachfolgen, der jedoch als Geisel am Hof Karls des Großen festgehalten wurde. Somit kontrollierte Adelperga, Arichis' Witwe, Benevent. In dieser Situation erschien ihr Bruder Adelchis wieder auf der politischen Bühne Italiens. Als Reaktion entließ Karl Grimoald unter der Bedingung, seinen Onkel zurückzuschlagen, was dieser mithilfe Spoletiner und anderer, fränkischer Truppen auch tatsächlich bewerkstelligte. Hadrian hatte entschieden vor dieser Vorgehensweise gewarnt, ohne jedoch negative Epitheta zu verwenden. ${ }^{727}$ Tatsächlich sagte sich Grimoald kurze Zeit danach, spätestens 790, gänzlich von der fränkischen Oberhoheit los. ${ }^{728}$

In $\mathrm{CC} 80$, der um den Jahreswechsel $787 / 788$ abgefasst wurde, berichtet Hadrian, dass Adelchis sich im oströmisch kontrollierten Teil Kalabriens nicht weit von Benevent aufhalte:

Eure treuesten missi, nämlich der Kaplan Roro und Betto, sind zu uns gekommen und haben, nachdem sie uns über Euer bestes königliches Wohl unterrichtet haben, bei uns über den unaussprechlichen Adelchis, den Sohn des gewalttätigen Königs Desiderius, nachgefragt: sie wollten wissen, ob es tatsächlich so sei, dass er, gegen Gott, nach Italien gekommen sei. Wir haben neulich nicht vergessen Euch durch Euren treuen missus, den comes Aruinus, mitzuteilen, was wir über jenen dreisten Adelchis gehört haben, weil auf wir keine Weise etwas vernachlässigen, wenn es mit Gottes Hilfe um Euren königlichen Sieg geht. Wir haben Eurer strahlendsten Exzellenz zeigen wollen, dass Eure außerordentliche königliche Umsicht mit dem Beistand Gottes und dem Geleit des Heiligen Apostelfürsten Petrus, sich klug um Eure und unsere Rettung kümmern soll. Folgendes ist uns nämlich über den genannten schändlichen Adelchis berichtet worden: dass er sich wirklich, gegen Gott, mit kaiserlichen missi in Kalabrien ${ }^{729}$ aufhält, nahe der Grenze zum Dukat von Be-

727 CC 80, ed. Gundlach 613: Quapropter nimis poscentes quaesumus vestram prerectissimam excellentiam, ut nullo modo pro causa Grimualdi filii Arichisi credere plus cuiquam iubeatis quam nobis; nam pro certo sciatis, quia, si ipsum Grimualdum in Benevento miseritis, Italiam sine conturbatione habere minime potestis, eo quod Leo episcopus secreta nobis sic fatus est: quia Adalberga relicta Arigibs tale habet consilium, ut, dum ipse Grimualdus filius eius Beneventanis finibus introierit, ingeniose cupit duas filias suas secum deferri et quasi orationis causa in Sanctum Angelum in Gargariopergere et deinde in Tarantu, ubi et thesauros suos reconditos habet, quia tantum octoginta milia distat a Sancto Angelo usque Taranto. Zu Gargario: Gemeint ist der Monte Gargano, in der Handschrift, CVP 449, 85v, steht tatsächlich eher -ri- (in Ligatur), der Schreiber könnte aber auch beim Versuch ein -n- zu schreiben abgerutscht sein, oder die Ligatur, die seinem -n- ähnlich sieht, schon als ausreichende Verbesserung seines Fehlers gesehen haben.

728 Noble, Republic 178f. Siehe Bertolini, Carlomagno e Benevento, bes. 638f. und zu den Folgen ebd. 655-671. Siehe außerdem Hartmann, Geschichte Italiens II,2, 307-312.

729 Kalabrien schloss damals wahrscheinlich das heutige Apulien noch mit ein. 
nevent. Über seine nichtsnutzige Ankunft hat uns Campulus, Bischof der Stadt Gaeta, in seinen Schreiben unterrichtet; und auf ähnliche Weise wurde uns auch aus der Pentapolis über die Anmaßung des Adelchis berichtet. Also haben wir wegen Eurer reichen Liebe neben anderen auch die an uns gerichteten Berichte aus Gaeta und der Pentapolis weitergeschickt. Denn wir wissen sicher, dass jener böse und falsche (perfidus) Adelchis zu keinem anderen Zweck in diese Gegend gekommen ist, als sich uns und Euch entgegenzusetzen. Also wäre es angebracht, dass sich Eure hervorragende königliche Exzellenz befleißigen möge, eine starke Truppe zu entsenden, damit wir dank Eures königlichen Beistands wie bisher überall unversehrt bleiben können. ${ }^{730}$

Hadrian wendete hier wieder jene rhetorische Linie an, die seine Vorgänger gegen Aistulf und Desiderius geprägt hatten: Adelchis ist perfidus, nequissimus, protervus und, wenig überraschend, nefandissimus und somit auf einer Stufe mit seinem Vater. Darüber hinaus ist er noch ein Werkzeug der Rom feindlich gesonnenen „Griechen“ (hier nur missi imperatoris), er ist also auf der ganzen Linie dem Othering des Papstes unterworfen, er ist der Darstellung des Papstes nach im Italien der $780 e r$ ein Fremder.

Das sehr negative Bild des langobardischen Südens blieb ebenso wie der Angriff Adelchis' auf 788 beschränkt, auch wenn sich die Beneventaner Angelegenheiten für Hadrian äußerst ungünstig entwickelten. ${ }^{731} \mathrm{Nach} 788$ ist im CC überhaupt nicht mehr von Benevent oder von anderen Langobarden die Rede, es scheint, als hätten sich die Wogen in dieser Hinsicht endgültig geglättet.

730 CC 80, ed. Gundlach 611-614, hier 612: Venientes ad nos fidelissimi missi vestri, scilicet Roro capellanus seu Betto, post vestram optabilem regalem sospitatem adnunciatam sciscitati sunt nobis pro nefandissimo Athalchiso, filio Desiderii tiranni regis: si ita fuisset, quod, Deo sibi contrario, partibus Italie evenisset. Nos vero nuper, quod de ipso protervo Athalchiso audivimus, per fidelissimum missum vestrum Aruinum comitem vobis intimare non obmisimus, quia pro vestra regali victoria Deo auspice tractantes nullum neclectum ex omni parte ponimus, vestrae prefulgide excellentiae indicantes, ut, Domino opitulante atque beato Petro apostolorum principi comitante, precipua vestra regali providentia prudentissimam suamque nostramque salutem procuret. Sic enim de iam dicto nequissimo Athalgiso nobis nunciatum est: quia in veritate, Deo sibi contrario, cum missis inperatoris partibus scilicet Calabriae residet, iuxta confinium ducatui Beneventani, ut de et pro eius invalidum adventum Campulus episcopus civitatis Caietanae per suas nobis significavit syllabas; similiter et de Pentapoli pro eiusdem Athalgisi arrogantia nobis in scriptis intimaverunt. Quatenus ob nimium vestrum amorem infra alios misimus apices tam a Caaeta quamque Pentapoli series nobis destinatas. Nempe quidem scimus, quia ipse iniquus et perfidus Adalgisus pro nulla alia causa in istis declinavit partibus, nisi tantummodo pro vestra nostraque contrariaetate. Unde oportet, ut firmissima vestra scara partibus Beneventanis emittere vestra precelsa regalis excellentia niteat, ut undique per vestrum regale amminiculum inperturbati pariter maneamus.

731 Vgl. CC 82 und 84, ed. Gundlach 615f. und 619f. 


\subsection{Die Wechselfälle der römischen Langobardenpolitik - Versuch einer} Zusammenfassung

Wir haben in dem langen vorangegangen Abschnitt viele unterschiedliche Eindrücke von den Langobarden im achten Jahrhundert bekommen. Es zeigt sich vor allem eines: Die Wahrnehmung und Darstellung der Langobarden unterlag ständigen Schwankungen. Am Beginn des achten Jahrhunderts scheint es aus moderner Sicht zunächst logisch, die Langobarden als Erzfeinde des Papsttums zu betrachten - doch gerade hier lag zunächst eher die Kooperation mit den verschiedenen langobardischen Machthabern näher. Die Politik Gregors II. bezog die Langobarden in die Abwehr der oströmischen Interessen in Italien stark mit ein, auch wenn König Liutprand je nach passender Gelegenheit die Seiten wechselte. Erst unter Gregor III. erreichte die Auseinandersetzung eine neue Ebene, als der Papst sich stark in der Konfrontation zwischen den autonomen Dukaten Spoleto und Benevent und dem König engagierte. Auch unter Zacharias kam es immer wieder zum Konflikt, doch zumindest mit den Königen Liutprand und Ratchis gelang es dem Papst bei mehreren Gelegeheiten, für Rom günstige oder zumindest akzeptable Kompromisse zu erreichen. Klarerweise hing die päpstliche Politik immer von der politischen Situation im langobardischen Bereich und vor allem von der Person des Königs selbst ab. König Liutprand hatte wohl ein Selbstbild als christlicher Herrscher, das es ihm nicht leicht möglich machte, sich allzu offen gegen das Kirchenoberhaupt des Westens zu stellen. ${ }^{732}$ Zudem versuchten sich Liutprand und später Ratchis auch als katholische Herrscher darzustellen, wobei ihnen wiederum vor allem Papst Zacharias als Gegenleistung für eine romfreundliche Politik half. ${ }^{733}$

749 kam mit Aistulf ein König auf den Thron, der in dieser Hinsicht eine neue, härtere Strategie verfolgte. Eine wichtige Variable in der Außenpolitik war daneben auch die Situation der großen südlichen Dukate, die zweitweise von Pavia aus kontrolliert wurden, zeitweise aber auch potenzielle Partner für die Päpste waren. Der Wunsch jedes Langobardenkönigs des achten Jahrhunderts, die duces unter Kontrolle zu haben, führte zur Konfrontation mit dem Papst. Auch die Politik des Lateran in Mittelitalien war ab den 74oer-Jahren um einiges aggressiver geworden: Man engagierte sich, vielleicht vor allem seit den erfolgreichen Interventionen des Zacharias, stärker im Gebiet des untergehenden Exarchats - eine Entwicklung, die die Langobardenkönige mit Recht als bedrohlich einstufen mussten. Auch die zunehmenden Bestrebungen des Papstes, unabhängig vom Kaiserreich zu agieren, berührten immer

732 Delogu, Kingship 267f.

733 Siehe dazu zukünftig: Gantner, The papacy as cultural broker. 
wieder langobardische Interessen. Die Politik beider Seiten, des Papsttums und des langobardischen Königreichs führte somit im achten Jahrhundert zum Konflikt. ${ }^{734}$

Auf diesen Konflikt reagierte das Papsttum auf gleich mehreren Ebenen mit der Entwicklung einer neuen Rhetorik - denn auch der Umgang mit dem Kaiser, seinen Repräsentanten und generell den „Oströmern“wurde ja neu gestaltet. Das vielleicht erfolgreichste Produkt davon war die ausgesprochen antilangobardische Propaganda, die in den Briefen und vor allem im Liber Pontificalis deutliche Spuren hinterließ. Die Vita Stephans II. ist einer der Höhepunkte einer Rhetorik, die sich nun nicht mehr nur gegen den Langobardenkönig oder konkrete Aktionen desselben richtete, sondern auch gegen die Langobarden im Allgemeinen. Die Vita gibt dabei die Stimmung in Rom wieder, wie sie nach dem Ableben des Papstes noch immer vorherrschte - und tatsächlich gab es zumindest am Beginn des Pontifikats Pauls I. durchaus heftige Auseinandersetzungen. Verwunderlich ist daher höchstens, dass König Desiderius in der Vita Stephans so positiv geschildert wird. Doch müssen wir die Vita wohl als durchgeplantes Narrativ verstehen, in dem der positive Abschluss mit Gebietsrückgaben an den Papst, einem nun freundlich gesonnenen Langobardenkönig und einem starken fränkischen Partner ein integraler Bestandteil war. ${ }^{735}$ Die Politik des Papstes sollte logisch und erfolgreich erscheinen, und zwar nicht nur einem römischen Publikum, sondern vor allem einem breiteren Empfängerkreis in Italien und dem fränkischen Reich, den der LP nun auch ansprechen sollte.

Doch die politischen und propagandistischen Ziele der Päpste alleine können die verbalen Attacken auf die Langobarden als gens nicht erklären, die gegen Ende des Pontifikats Stephans II. begannen - hier muss es einen Wandel im Denken und in der Wahrnehmung der entscheidenden Personen im Lateran gegeben haben. Als Grund dafür kann vielleicht ein durchaus nicht unrealistisches Bedrohungsszenario für Rom durch das immer stärker werdende langobardische Königtum verbunden mit dem endgültigen Wegfall der kaiserlichen Macht in Mittelitalien angeführt werden. Dazu wird es noch persönliche Motive der handelnden Personen gegeben haben, die aus den Quellen nur mehr teilweise nachvollziehbar sind. Die Existenz der Langobardischen Rezension der Vita Stephans II. zeigt, dass der neue Umgang des Papsttums mit den Langobarden durchaus nicht ohne Unbehagen erfolgte. Falls die Überarbeitung tatsächlich in Rom erfolgte, wäre es umso mehr ein Zeichen, dass dieser Text auch in Rom als Extremposition aufgefasst wurde, die man Langobarden gegenüber zumindest im Ton mildern musste. ${ }^{736}$ Tatsächlich gab es zwei, möglicher-

734 Siehe dazu Pohl, Papsttum, bes. 159-161.

735 Dazu ausführlich Gantner, Studien 108-115.

736 Gantner, Lombard Recension. 
weise sogar drei Phasen der Zusammenarbeit mit Desiderius: zunächst in den letzten Jahren des Pontifikats Pauls, etwa 762-767 und für kurze Zeit sicher unter Stephan III. (770/77I). Möglicherweise war sogar für Hadrian I. eine Kooperation mit dem Langobardenkönig zunächst eine ernsthafte Option, die Mühe seiner LP-Vita, genau das in Abrede zu stellen, wäre jedenfalls ein Indiz dafür. Die LP-Viten Stephans III. und Hadrians wurden aus der Rückschau nach 774 geschrieben und sind daher vor allem als Rechtfertigung für die Politik des Lateran und insbesondere Hadrians zu verstehen und nicht als Zeugnis einer gegen den Langobardenkönig gerichteten Polemik der Jahre 768-774. Denn für die Zeit ab 77I ist das einzige sicher zuordenbare Textzeugnis, CC 48 von Stephan III., sogar ausnehmend positiv. Inwieweit und wann die Stimmung in Rom sich wieder gegen den Langobardenkönig wendete, kann nur spekuliert werden.

$\mathrm{Zu}$ Beginn des Pontifikats Stephans III. gab es aber noch eine Phase, in die interessanterweise die deutlichsten rhetorischen Ausfälle gegen die Langobarden fallen - sie sind in Brief $\mathrm{CC}_{45} \mathrm{zu}$ finden: Hier werden die Langobarden in davor und danach unübertroffenem Maß auch als Kollektiv verunglimpft, ja sogar der Status einer gens wird ihnen abgesprochen, dafür wird subtil an ihre häretische Vergangenheit erinnert. Mit diesem Höhepunkt endeten aber alle generell auf die Langobarden gemünzten Invektiven, nur noch Desiderius war das Angriffsziel der päpstlichen Texte. Nach 774 war es Hadrian sogar möglich, bestimmte Langobarden aktiv zu unterstützen. Man könnte einwenden, dass das für sich genommen nicht besonders außergewöhnlich war. Die Bedrohung durch das Königreich war weggefallen und mit verhältnismäßig wenig mächtigen Langobarden, die hier unterstützt wurden, hatte das Papsttum nie Probleme gehabt, zumindest keine, von denen die Quellen berichten. Doch es gab nun (wenn auch kurz) die „guten“ Langobarden in Spoleto. Diese waren zwar eher nicht zum peculiaris populus Hadrians zu zählen, doch sie wurden im LP dem Sameing unterzogen. Ein Eintritt dieser mittelitalischen Langobarden in die päpstliche Interessenssphäre hatte stattgefunden, ein Eingang in die römische in-group war vielleicht sogar denkbar.

Zugegebenermaßen kritisierte auch Hadrian in seinen Briefen schon 775 wieder langobardische Machthaber und ab 780 finden wir sogar wieder einige klassische pejorative Adjektive, vor allem für $d u x$ Arichis und für Adelchis. Doch diese Adjektive wurden nun nicht mehr mit den Langobarden oder dem Umstand, dass die betreffenden Personen Langobarden waren, verbunden. Zudem hatte Hadrian einen Gegner, dem es dringender entgegenzutreten galt: die Greci, womit vor allem die Vertreter des Kaisers in Süditalien gemeint waren. ${ }^{737}$

737 Das verhinderte, wie wir in Kap. 4.3 gesehen haben, jedoch nicht eine Zusammenarbeit auf religionspolitischer Ebene mit Kaiser Konstantin VI. beziehungsweise seiner Mutter Eirene. 
Die Langobardenbeziehungen endeten im achten Jahrhundert eher positiv, so wie sie begonnen hatten, dazwischen gab es Konflikte, die aber immer wieder von Phasen der Ruhe, ja sogar der guten Zusammenarbeit unterbrochen waren. Der wechselnde Kurs, in dem die Langobarden beziehungsweise ihr König dabei in Rom standen, gleicht fast einem Wellendiagramm.

Mit Stephan II. kam offenbar ein Mann auf den Papstthron, der bereit war, radikale Rhetorik gegen die Feinde Roms aufzubieten, nicht nur, aber auch gegen die Langobarden. Das führte zumindest in den erhaltenen Texten zu zuvor ungekannten Ausfällen gegen die Langobarden. Spätestens mit dem Pontifikat Hadrians I. kam im Lateran eine neue Führungsgruppe an die Macht, die wieder einen pragmatischeren Zugang zu den Langobarden fand und zumindest von kollektiven Verunglimpfungen gänzlich absah.

Die Langobarden des achten Jahrhunderts unterschieden sich im kulturellen und sprachlichen Bereich kaum von ihren „römischen“ Mitbürgern auf der Apenninenhalbinsel. Hier herrschte zweifellos größere Ähnlichkeit als zwischen griechischen und lateinischen Römern. Im Bereich der Politik und der äußerlichen Repräsentation von Gemeinschaft mag es hingegen Unterschiede gegeben haben. Vor allem die Politik trennte die Päpste von den Langobardenherrschern, auch wenn es Phasen der Kooperation gab. Die Langobarden waren für die analysierten päpstlichen Autoren immer Andere. Aber sie waren vertraute Andere, in vielen Fällen nicht einmal Fremde. Besonders die Oberschicht der südlichen Dukate hatte sogar recht enge Kontakte zu den Greci Süditaliens, den imperialen Amtsträgern und mittelbar somit auch zum Kaiser, was ihnen sicher ähnliche Erfahrungen brachte wie Rom. Die Vertreter der langobardischen Oberschicht waren zum Teil auch in Rom gute Bekannte, als Beispiel zu nennen sind etwa die Könige Liutprand und Desiderius sowie der Spoletiner $d u x$ Transamund. Es ist somit sicher nicht vermessen, im Fall der verschiedenen langobardischen Gruppen von Extimität zu sprechen, von Anderen, die zwar recht klar von den Eigenen abgrenzbar, aber doch „discomfortingly familiar“ waren. ${ }^{738} \mathrm{Im}$ Gegensatz zu den Greci ist das Verhältnis auch ohne großen Aufwand aus einer postkolonialen Perspektive zu verstehen: Die Langobarden waren aus Sicht der Römer Subalterne, kulturell Unterlegene. Sie waren es auch, die sich in Italien assimilierten, auch wenn sie sich militärisch durchgesetzt hatten. Dieses alte Verhältnis der imperialen Römer auf der einen und der subalternen Langobarden auf der anderen Seite spielte in den Beziehungen auch noch nach dem Fall des Langobardenreichs eine Rolle.

Aus dieser Perspektive verwundert es nun nicht, warum gerade die assimilierten Langobarden in den päpstlichen Quellen von Othering betroffen waren. Es war im

738 Siehe oben, Kap. 2., Zitat aus Cohen, Introduction 5. 
Grunde eine konservative Reaktion vonseiten der Romani, die bestrebt waren, den Status quo aufrecht zu erhalten. Bisweilen versuchten sie sogar, ihren Machtbereich in Italien wieder auszubauen, ein Streben, das sich nicht zuletzt am imperialen Erbe Roms orientierte. Die Langobarden konnten also nur dann integriert werden, wenn sie beherrscht werden konnten, wie die Ereignisse rund um den Dukat von Spoleto in den 77oer Jahren deutlich gezeigt haben. Das Papsttum sah sich als Vertretung des römischen Selbstbewusstseins, es war der letzte verbliebene römische Machtfaktor in Mittelitalien, nicht erst seit dem Fall des Exarchats, sondern schon Jahre davor, auch wenn seine Macht nicht militärisch, sondern vor allem kulturell-religiös begründet war. $^{739}$

Das Othering der Langobarden und besonders ihrer Herrscher erfolgte aber nicht nur zum Zweck der eigenen Profilierung des Papsttums, sondern war auch ein wichtiger Faktor in der Kommunikation mit zwei Gruppen von Anderen, den nominellen kaiserlichen Machthabern in Konstantinopel, aber auch mit den Franken, für die aber andere Formen von Othering angewandt wurden, wie das folgende Kapitel 5.8 zeigen wird.

\subsection{Die Franken: Freunde - Verbündete - Andere im achten Jahrhundert}

Die Franken sind eine Gruppe, die methodisch kaum aus der Beschäftigung sowohl mit den „Griechen“ als auch mit den Langobarden herausgehalten werden konnten, ja eine Trennung wurde gar nicht erst versucht. So haben wir in den vorangegangenen Kapiteln über die Langobarden schon sehr viel über die Kommunikation und Kooperation der Päpste mit den Franken erfahren.

Bereits in der Analyse der schriftlichen Quellenzeugnisse in Kapitel I haben wir gesehen, wie groß die Rolle fränkisch geprägten Materials ist. Der Codex Carolinus, die vielleicht bedeutendste Quelle für die diplomatischen Vorgänge des achten Jahrhunderts überhaupt, ist am Karolingerhof kompiliert worden - die wahrscheinlich von den meisten wesentlichen Stücken vorhandenen Kopien der Papstkanzlei hingegen sind verloren. Zwar ist aufgrund der Beschaffenheit des Codex nicht davon auszugehen, dass es sich hierbei um eine absichtliche Auswahl handelt, und somit wurde wahrscheinlich auch nicht absichtlich Einfluss auf die Darstellung genommen. ${ }^{740}$ Doch die Kommunikation richtet sich im Prinzip ausschließlich an die Karolinger ${ }^{741}$,

739 Dazu auch Gantner, Papacy as cultural broker.

740 Siehe dazu oben, Kapitel 1.2.

741 Der Codex enthält außerdem drei Briefe an spanische Bischöfe (im Zuge des Adoptianismusstreits), 
was allein schon unser Bild des achten Jahrhunderts nachhaltig prägt, sind doch so gut wie alle Briefe an den Kaiser in Konstantinopel oder an diverse langobardische Machthaber verloren. Wenn wir bei aller gebotenen Vorsicht das neunte Jahrhundert mit seinem wesentlich differenzierteren Quellenbild als Maßstab heranziehen, wird dieser Eindruck noch verstärkt, denn im neunten Jahrhundert ist ein reger Briefverkehr erhalten, der den gesamten Mittelmeerraum umfasst. Es gibt eigentlich kaum einen Grund, daran zu zweifeln, dass die Kommunikation des Papsttums auch im achten Jahrhundert einen ähnlichen Aktionsradius umfasste. Wenn nun also größtenteils die Korrespondenz mit nur einem Partner vorhanden ist, verwundert es nicht, dass unser Bild dieses Zeitraums allein schon dadurch verzerrt wird.

Die Dominanz dieses Kommunikationssegments hatte auch eine Vorherrschaft der Beziehung der Päpste zu den Franken in der modernen Geschichtsforschung zur Folge, gerade im deutschsprachigen Raum ist die Popularität der Frage des Verhältnisses zwischen Kaiser und Papst ungebrochen. In der Vergangenheit spielten auch oft teleologische Überlegungen mit Blick auf die hochmittelalterliche deutsche Geschichte eine Rolle.

Im folgenden Kapitel sollen diese Themen bei aller Brisanz ausgeklammert werden. Es soll auch eine Nacherzählung der sattsam bekannten Geschichte so weit wie möglich unterbleiben, ein "754 and all that" wird nicht geboten.

Das Kapitel wird sich ausschließlich der Frage widmen, inwiefern die Franken als Andere für die Päpste eine Rolle spielten. Wie in den anderen Fällen auch soll also zunächst die Frage gestellt werden, wie die Anderen grundsätzlich wahrgenommen wurden, aber auch, welches Bild der Anderen in den päpstlichen Quellen konstruiert wurde, wiederum mittels der Mechanismen des Othering, aber auch der symbolischen und sprachlichen Integration.

\subsubsection{Eine Sonderstellung der Franken?}

Im Vergleich mit den oben in Kapitel 3 und 4 bereits ausführlich erörterten Greci war es für das Papsttum verhältnismäßig einfach, die Franken in ihr Weltbild einzuordnen. Die Franken waren am Beginn des achten Jahrhunderts zunächst einfach die Franken. Das bedeutet, dass sie, in diesem Punkt vergleichbar mit den Langobarden, als eine andere gens wahrgenommen wurden und das in allen Lebenslagen. Oben, am Beginn von Kapitel 5.I, haben wir ein sehr anschauliches Beispiel aus der LP-Vita

allein das Vorhandensein von Kopien am Karolingerhof zeigt jedoch, dass sich diese Briefe mindestens ebenso an dieses Umfeld wie an das nordspanische richteten, ja vielleicht sind sie sogar als Gefälligkeit für die Franken zu verstehen. 
Gregors II. kennengelernt, in dem die Langobarden als Brüder der Römer im Glauben bezeichnet werden. Wie wir gesehen haben, wurden sie dennoch auch in dieser allerpositivsten Szene deutlich von den Romani unterschieden, wobei zu den Römern sogar die Antagonisten des Narrativs, die unmittelbaren und mittelbaren Befehlsträger des Kaisers, gezählt wurden. Die Langobarden waren auch in diesem Moment Andere (und wurden bezeichnenderweise auch nicht nach Dukaten getrennt, was die politische Situation eigentlich besser widergespiegelt hätte ${ }^{742}$ ). Am Beginn des achten Jahrhunderts unterschieden sich die Franken also aus päpstlicher Sicht als gens nicht wesentlich von den Langobarden. ${ }^{743}$ Gänzlich anders war jedoch die politische Situation. Wie wir oben gesehen haben, wurden die Langobarden zwischen 700 und 750 in immer stärkerem Ausmaß als Bedrohung wahrgenommen (und zweifellos bisweilen auch aufgebauscht). Die Franken hingegen galten im frühen achten Jahrhundert als potenzielle Verbündete. Bis dahin hatten die Franken schon eine bemerkenswerte Entwicklung hinter sich: Im sechsten Jahrhundert waren sie bei einigen Historiographen des Kaiserreichs noch ausgesprochen negativ in Erscheinung getreten. Ein Einfall der Franken in der Poebene etwa wurde von Prokop mit folgenden Worten kommentiert: „... dieses Volk ist ja, was Treu und Glauben angeht, das unzuverlässigste der Welt ...“.744 In Ticinum, dem späteren Pavia, sollen sie am Beginn ihres Kriegszuges sogar gotische Frauen und Kinder geopfert haben und werden dabei als Kryptoheiden dargestellt. ${ }^{745}$ Zuvor schon waren sie mit der apokalyptisch verbrämten Eroberung Mailands in Verbindung gebracht worden: König Theudebert wurde vorgeworfen, durch burgundische Truppen Hilfe geleistet zu haben. ${ }^{76}$ Wir sehen hier zweifellos ein Stück oströmischer politischer Propaganda, durchsetzt mit Topoi der antiken römischen Ethnographie. Dennoch erhalten wir hier ein sehr negatives Bild der Franken.

Doch bis zum Beginn des achten Jahrhunderts hatten sich die Franken zu einer in der Literatur durchwegs positiv besetzten gens entwickelt, wobei nicht suggeriert werden soll, es habe hier eine lineare Entwicklung über zwei Jahrhunderte gegeben. Die

742 Ein noch extremeres Beispiel des „In-einen-Topf-Werfens“ sind „die“ Sarazenen, siehe unten, Kap. 6.

743 Zur Selbstsicht der Franken in ihren Schriften wird zukünftig Helmut Reimitz, Historiography and Frankish Identity (Cambridge, in Druck) die maßgeblichen Informationen liefern.

744 Prokop, Gotenkrieg VI, 25,2, trans. Otto Veh (Tusculum Bibliothek, Prokop, Werke, Bd. 2, München ${ }^{2}$ 1978) 391.

745 Prokop, Gotenkrieg VI, 25,9f., trans. Veh 392. Ebd., 25,20, wird ein an Vorwürfen reicher Brief Belisars wiedergegeben. Und noch zwei Bücher später, Ebd., VIII, 24,12, trans. Veh 907, wird die Eidbrüchigkeit der Franken aufs Neue aufgegriffen.

746 Prokop, Gotenkrieg VI, 12,38, trans. Veh 305. Es muss aber darauf hingewiesen werden, dass andere Historiker, so etwa Agathias, die Franken als potenzielle Bundesgenossen sehr positiv darstellten. 
Franken galten nun als potenzielle Verbündete Roms und des Papstes. Bemerkenswert ist allerdings, dass sie auch in dieser Hinsicht zunächst keineswegs eine Sonderstellung einnahmen. Wir haben gesehen, dass mit verschiedenen langobardischen Gruppen immer wieder kooperiert wurde. Zudem wurden auch Kontakte zu den agilofinigischen Herzögen der Bayern geknüpft. So weiß der LP zu berichten, dass der dux Theodo sogar selbst Rom aufgesucht habe. Theodo quippe dux gentis Baioariorum cum alios gentis suae ad apostoli beati Petri limina orationis voto primus de gente eadem occurrit. ${ }^{747}$ Theodo scheint aber nicht nur zum Gebet nach Rom gekommen zu sein, es wurden auch politische Kontakte geknüpft. Zumindest im Bereich der Kirchenorganisation waren die so etablierten Beziehungen für beide Seiten erfolgreich. Der $d u x$ konnte wesentliche Fortschritte in der Kirchenorganisation Bayerns verbuchen, während Rom in den Gebieten der Germania stark an Einfluss gewinnen konnte. ${ }^{748}$ Ein wichtiges Zeugnis hierfür ist auch ein Brief Gregors II. an päpstliche Gesandte in Bayern aus dem Jahr 716. ${ }^{749}$ Und später beorderte Rom auch den Kirchenreformer Bonifatius nach Bayern, ein weiteres Zeichen, dass auf die Beziehung zu diesem Dukat viel Wert gelegt wurde. ${ }^{750}$ Die Päpste des frühen achten Jahrhunderts erhofften sich von den Bayern zweifellos auch politische Unterstützung, die aber nicht im erwünschten Ausmaß gewährt werden konnte. Tatsächlich hätte der Agilolfinger Tassilo III. im Jahr 787 umgekehrt auf die Unterstützung des Papstes gehofft, der nun aber seinerseits nicht in der Lage dazu war. ${ }^{751}$ Inwiefern die Bonifatius-Mission im Norden generell auch dazu dienen sollte, weitere gentes auf die Seite des Papstes und des Heiligen Petrus zu ziehen, kann nur spekuliert werden. Klar ist, dass er ab seiner Bestellung zum Mainzer Erzbischof weiterhin auch päpstliche Interessen vertrat, so wie er generell für eine Unterstellung aller Kirchen der gentes unter römische Oberhoheit eintrat.

Kontakte mit Franken gab es aber auch ohne den päpstlichen Legaten und Missionar. In der Vita Gregors II. im LP etwa finden wir einen sehr interessanten Absatz, der in zwei Varianten überliefert ist. Wie in der Edition werden dabei im Folgenden auch die beiden erhaltenen Versionen dieses Textes gegenübergestellt: Links steht

747 LP I, 398 (linke Spalte).

748 Auch der LP berichtet über die Mission des Bonifatius in der Germania, siehe LP I, 397.

749 Gregor II., Brief an Martinianus und Georgius, 15. Mai 716, ed. Johannes Merkel, Leges Baiuwariorum, in: MGH LL III (Hannover 1863) 183-496, hier 451-454. Siehe auch May Spindler, Handbuch der bayrischen Geschichte: Bd. 1. Das Alte Bayern. Das Stammesherzogtum bis zum Ausgang des 12. Jahrhunderts (München 1981) 226.

750 Noble, Republic 64.

751 Noble, Republic 273, geht davon aus, dass der Papst sich absichtlich auf die Seite Karls des Großen stellte, tatsächlich hatte er in der herrschenden politischen Lage aber wahrscheinlich keine Wahl. Schon in den 760ern hatte Paul I. König Pippin versichern müssen, dass er nicht vorhabe Tassilo zu unterstützen, siehe Noble, Republic 109, und CC 36, ed. Gundlach 545 f. 
jene Version, die Anfang der 73oer-Jahre, ganz kurz nach dem Tod Papst Gregors, fertiggestellt wurde. Dieser Text wurde aus unbekannten Gründen einige Zeit später einer grundlegenden Überarbeitung unterzogen. Neuerdings wird in der Forschung davon ausgegangen, dass das schon während des Pontifikats des Zacharias in den 740er-Jahren geschah. ${ }^{752}$ Die Vita wurde dabei sprachlich vollkommen verändert, inhaltlich aber nur in einigen wenigen Punkten, wobei sowohl Informationen eingefügt als auch weggelassen wurden. Die Frankenstelle findet sich eher zu Beginn der Vita, die behandelten Ereignisse werden vom Autor ungefähr ins Jahr 72 I datiert.

Eodem tempore nec dicenda Agarenorum gens a loco eo qui Septem dicitur transfretantes, Spaniam ingressi, maximam occiserunt partem cum eorum rege; reliquos omnes subdiderunt cum suis bonis et ita eandem provinciam annis possiderunt decem. Undecimo vero anno generalis facta Francorum motio contra Sarracenos circumdantes interemerunt. Trecenta enim septuaginta quinque milia uno sunt die interfecti, ut Francorum missa pontificis epistola continebat; mille tantum quingentos ex Francis fuisse mortuos in eodem bello dixerunt, quod anno praemisso in benedictione a praedicto viro eis directis tribus spongiis quibus ad usum mense pontificis apponuntur, intra qua bellum committebatur, Eodo, Aquitanie princeps, populo suo per modicas partes tribuens ad sumendum, ex eis ne unus vulneratus est nec mortuus ex bis qui participati sunt. ${ }^{753}$
Eodem tempore nefanda Agarenorum gens cum iam Spaniarum provinciam per $X$ tenerent annos pervasam, undecimo anno Rodanum conabantur fluvium transire, ${ }^{754}$ Francias occupandum, ubi Eodo praeerat. Qui facta generali Francorum monitione contra Sarracenos, eos circumdantes interemerunt. Trecenta enim septuaginta quinque milia uno sunt die interfecti, ut eiusdem Eodonis Francorum ducis missa pontificis epistola continebat; mille tantum quingentos ex Francis fuisse mortuos in eodem bello dixerunt, adiciens quod anno praemisso in benedictione a praedicto viro eis directis tribus spongiis quibus ad usum mense pontificis apponuntur, in hora qua bellum committebatur, idem Eodo, Aquitaniae princeps, populo suo per modicas partes tribuens ad sumendum, ex eis ne unus vulneratus est nec mortuus ex his qui participati sunt.

In beiden Fällen wird die Schlacht von Toulouse dargestellt. Im Hinblick auf die wesentlichen Interessen des Papsttums unterscheiden sich die beiden Versionen nicht: Der Autor der Vita will vor allem einen Anteil an dem bedeutenden militärischen Erfolg vor Toulouse für Gregor II. reklamieren. In beiden Fällen bleiben am Ende I50o Franken,

752 Siehe oben, Kap. 1.1.3.1 und Bougard, Composition 137f.

753 LP I, 401.

754 Der Überarbeiter der Vita verortet Aquitanien auf der falschen Seite der Rhone, wahrscheinlich vermischte er die Ereignisse 737-39 in der Narbonnensis mit jenen von 721. Siehe dazu Davis, LP 8, 8, Anm. 32. 
aber vor allem 375.00o Sarazenen tot auf dem Schlachtfeld zurück, ${ }^{755}$ in beiden Fällen werden insbesondere die Kämpfer des aquitanischen Herrschers Eudo verschont, weil sie Teile von vom Papst übersandten geweihten Schwammbroten gegessen haben. ${ }^{756}$

In den Zitaten sind jene Stellen markiert, in denen sich die beiden Versionen des LP substanziell unterscheiden. In der späteren Rezension, die sich in den Handschriftenklassen BDE findet und somit sowohl in der Francia als auch in Italien (Handschriftenklasse E!) verbereitet wurde, wurde die Rolle Eudos - je nachdem wie man die ursprüngliche Fassung lesen will - entweder neu definiert oder präzisiert. In der Urfassung aus den frühen 73oern (Klassen ACG) wird Eudo nämlich nicht ausdrücklich als Franke bezeichnet, auch wenn der von ihm befehligte Teil des Aufgebots implizit den Franken zugerechnet wird. Explizit wird Eudo aber konkreter princeps Aquitaniae genannt.

Man kann die Stelle in der Originalfassung auf zwei Arten interpretieren: Man kann davon ausgehen, dass der Autor „die Franken“von Eudo und den Aquitaniern trennt. Somit wären die Aquitanier nur ein Teil der generalis Francorum motio. Interessanterweise wären es auch die aus dieser Sichtweise nicht näher definierten Franken, die im Bericht über die Ereignisse an den Papst die Taten Eudos und die positive Auswirkung der päpstlichen Schwammbrote besonders hervorgehoben hätten. Das macht zumindest eher wahrscheinlich, dass jene Franken, die den Papst informiert hatten, auf der Seite Eudos standen. Ob es sich dabei aber um die Aquitanier selbst oder um etwa neustrische oder burgundische Berichterstatter handelte, kann nicht mehr festgestellt werden. Die Stelle im LP lässt zumindest offen, ob Eudo und die Aquitanier als Franken zu verstehen sind oder nicht.

Ganz anders zeigt sich hier die jüngere Version des Textes: hier steht Eudo zunächst dem Frakenreich vor (Franciae, ubi Eodo praeerat), wenig später ist er es, der den Brief an den Papst sendet. Im Zuge der Erwähnung des Briefs wird er nun ausdrücklich als dux der Franken bezeichnet (Eodonis Francorum ducis missa pontificis epistola). Zugleich bleibt Eudo aber princeps Aquitaniens, ist also weiterhin Träger einer hohen lokalen Würde. ${ }^{757}$

755 Die Zahlen sind zweifellos nicht als exakt aufzufassen. Zur Größe von Armeen im frühen Mittelalter siehe Guy Halsall, Warfare and Society in the Barbarian West, 450-900 (Warfare and History, London/New York 2003) 119-133.

756 Die Schwammbrote hießen so offenbar wegen ihrer Beschaffenheit und Form, vgl. Karl Ernst Georges: Ausführliches lateinisch-deutsches Handwörterbuch (Hannover ${ }^{8} 1918$, Nachdruck Darmstadt 1998), Bd. 2, Sp. 2772f. Von dieser Art Brot berichtet u. a. Isidor von Sevilla, Etymologien XX,2,16, ed. Lindsay: Spungia panis aqua diutius malaxatus similam modicam accipit et fermentum modicum, et habet humectationis plus quam omnis panis; unde et spungiae nomen accepit.

757 Philippe Depreux, Auf der Suche nach dem princeps in Aquitanien (7.-8. Jahrhundert), in: Die Anfänge Bayerns. Von Raetien und Noricum zur frühmittelalterlichen Baiovaria, ed. Hubert Fehr/ 
Es ist kaum zu klären, ob der zweifellos in Rom arbeitende Redaktor hier eine Präzisierung vornahm, das heißt, ob Eudo auch vorher in Rom als Anführer aller Franken in der Schlacht von Toulouse gesehen wurde oder ob der Text absichtsvoll in seinem Sinn verändert wurde. Wahrscheinlich war dem Redaktor selbst nicht klar, wie der ursprüngliche Bericht gemeint war und er erzeugte durch seine Eingriffe einen eindeutigen Text.

Das macht die Stelle nicht leicht zu interpretieren. Es ist fraglich, wer aus der Sicht des Originalautors „die“ Franken waren, auch aus anderen zeitnahen Quellen kann nicht geschlossen werden, aus welchen Teilen des Merowingerreichs Toulouse Unterstützung gewährt wurde. In der Literatur wird aber die Führung des Heeres immer Eudo zugeschrieben. ${ }^{758}$

$\mathrm{Ob}$ Eudo für den Autor der Originalversion der Vita in erster Linie ein Franke war, lässt sich dabei nicht mit Sicherheit sagen, auch wenn eine derartige Interpretation der Stelle zumindest naheliegt. Denn Eudo (oder irgendjemand anderes) wird im LP nicht als Aquitanier bezeichnet, Aquitanien kommt ausschließlich zur Abgrenzung des Herrschaftsgebietes Eudos vor. Aquitanien hatte für ein stadtrömisches Publikum vielleicht auch deshalb eine Bedeutung, weil es sich hierbei um eine seit der Antike bekannte Region Galliens handelte, die aus der alten Literatur durchaus auch bekannt sein hätte können - man denke nur an den Beginn von Caesars De bello Gallico. Insofern könnte die Verortung Eudos in dieser alten Region nicht zuletzt für ein lateinisch gebildetes Publikum in Italien gedacht gewesen sein. Letztlich kann Eudo somit auch in der Originalversion der Vita eher als prominentes Mitglied des fränkischen Aufgebots gesehen werden, auch wenn Zweifel bleiben. Auch für Zeitgenossen in Italien war die genaue Rolle Eudos wahrscheinlich nicht leicht zu deuten.

Es sind also „die Franken“, die bei Toulouse die Christenheit gegen die Sarazenen verteidigen. Als wesentlichster Akteur tritt ausdrücklich Eudo in Erscheinung, der noch dazu seinen Männern (aber nicht dem gesamten Heer!) physischen geistlichen Beistand des Papstes (wahrscheinlich) in Form von kleinen Brotstücken zukommen

Irmtraut Heitmeier (St. Ottilien 2012) 551-566, hier bes. 560-562, hat nachgewiesen, dass der Eintrag im LP die früheste Nennung dieses princeps-Titels ist. Im achten Jahrhundert war der Titel immer nur auf die Region, nicht auf etwaige Aquitanier bezogen. Die Bezeichnung princeps hatte, wie im Folgenden noch gezeigt werden wird, in der Vita Gregors II. zumindest auch eine weitere, andere Funktion. Zu Aquitanien als Sonderfall siehe auch Wolfram, Intitulatio I, 114 mit Anm. 40.

$758 \mathrm{Zu}$ den frühen Quellen siehe Ulrich Nonn, Die Schlacht bei Poitiers 732. Probleme historischer Urteilsbildung, in: Beiträge zur Geschichte des Regnum Francorum, Referate beim Wissenschaftlichen Colloquium zum 75. Geburtstag von Eugen Ewig am 28. Mai 1988, ed. Rudolf Schieffer/ Eugen Ewig (Beihefte der Francia 22, Sigmaringen 1990) 37-56. Die Bedeutung der Schlacht wird auch in spanischen Quellen hervorgehoben, siehe dazu Ann Christies, Christians in Al-Andalus 711-1000 (Surrey 2002) 45-47. 
lassen kann. Daraus können wir schließen, dass Eudo in einer recht engen Beziehung mit dem Papst stand. In der Originalversion ist er dennoch letztlich nicht als alleiniger Vertreter der gens Francorum zu sehen.

Ganz anders verhält es sich in der etwas späteren Fassung, in der Eudo zum Sprecher und Anführer aller Franken wird. Er erhält außerdem den offiziellen Titel eines $d u x$ der Franken, was ihn auf eine Stufe mit seinen karolingischen Zeitgenossen stellt. ${ }^{759}$ Auch hier wird er ausdrücklich als princeps Aquitaniens bezeichnet, man kann aber dennoch von einer wesentlich verstärkten Identifikation Eudos mit den Franken sprechen. Das ist umso bemerkenswerter, als Eudo zum Zeitpunkt der Abfassung dieser Version (nicht der Originalversion) bereits verstorben war und sich Karl Martell im Frankenreich als De-facto-Herrscher weitestgehen durchgesetzt hatte. ${ }^{760} \mathrm{Ob}$ das Papsttum noch in den 740er-Jahren gute Beziehungen nach Aquitanien unterhielt, wissen wir nicht. Sicher ist, dass es dann bereits Kontakte zu den Karolingern gab. Beide Versionen der Vita belegen, dass Kontakt zwischen Rom und den Aquitaniern bestand. Diese wurden nie als solche bezeichnet, sondern sind nur als die Leute Eudos fassbar, welcher wiederum über seinen Herrschaftsbereich identifiziert wird. Die „Aquitanier“ wurden aller Wahrscheinlichkeit nach als Teil der Franken wahrgenommen, implizit sind sie auch in der älteren Version des LP Teil der generalis Francorum motio. Über die Einordnung ihres Anführers Eudo gelten sie aber zugleich innerhalb des Reichs auch als distinkt - was durchaus die politische Situation am Beginn des achten Jahrhunderts abbildet. Ein Jahrzehnt später ordnete sie der LP dann ganz eindeutig den Franken zu, Eudo wird, obwohl er weiterhin Aquitanien zugeordnet wird, zum dux aller bei Toulouse kämpfenden Franken - in der Darstellung Roms somit sogar aller Franken.

Die Episode demonstriert in beiden Versionen, dass die päpstliche Diplomatie im achten Jahrhundert zunächst in alle möglichen Richtungen operierte. Wenn wir noch einmal an Bonifatius denken, können wir sogar davon ausgehen, dass auch nicht ausschließlich Augenmerk auf die früheren Gebiete des Römischen Reichs gelegt wurde - auch wenn dem Papst die Kommunikation mit diesen Gegenden wahrscheinlich wesentlich leichter gefallen sein dürfte. Sicher können wir sagen, dass

759 Zum Titel dux Francorum siehe Wolfram, Intitulatio I, 146-155, und Karl Brunner, Die fränkischen Fürstentitel im neunten und zehnten Jahrhundert, in: Intitulatio II. Lateinische Herrscher- und Fürstentitel im neunten und zehnten Jahrhundert, ed. Herwig Wolfram (MIÖG, Ergänzungsband 24, Wien 1973) 179-340, hier $262 f$.

$760 \mathrm{Zu}$ Herrschaft Karl Martells siehe Andreas Fischer, Karl Martell. Der Beginn karolingischer Herrschaft (Stuttgart 2012), hier bes. 110-122 zur Auseinandersetzung mit Eudo. Siehe auch Paul Fouracre, The Age of Charles Martel (Harlow 2000). 
Kontakte mit Bayern, Angelsachsen ${ }^{761}$, diversen langobardischen Gruppen und eben aquitanischen und karolingischen Franken bestanden oder geknüpft wurden.

Bezeichnenderweise sind es die Aquitanier, die in der frühesten Erwähnung der Franken in einer päpstlichen Quelle des achten Jahrhunderts als heroische Verteidiger der Christenheit auftreten dürften. Zudem kooperieren sie in dieser Hinsicht augenscheinlich voll mit dem Papst, was wiederum Rom veranlasste, sie in noch besserem Licht darzustellen. ${ }^{762}$ Die Franken erscheinen damit bereits in der Vita Gregors II als Retter (wenn auch nicht Roms) - nur wurden sie aus Sicht späterer karolingischer Rezipienten vom falschen Herrscher angeführt. Es ist bemerkenswert, dass die Episode in der jüngeren Version der Vita, die zu einer Zeit als auch für Rom sicherlich schon klar war, dass Karl Martell sich durchgesetzt hatte, Eudo sogar noch viel stärker unter die Franken integrierte. Auch in der noch wesentlich später erstellten sogenannten fränkischen BD-Rezension des LP blieb diese Stelle in der überarbeiteten Fassung der 740er-Jahre enthalten. Das ist umso bemerkenswerter, als der große karolingische Sarazenensieg von Poitiers $73^{763}$ im LP keine Erwähnung fand, was in einem karolingischen Umfeld eigentlich umso mehr auffallen hätte müssen. Man kann spekulieren, ob einfach der antisarazenische Charakter der Passage genügte um sie vor Tilgung zu schützen. Zudem wurde sie wohl auch von einigen Lesern missverstanden und ihrer Eindeutigkeit zum Trotz auf den Sieg Karl Martells bei Poitiers bezogen, so etwa von dem großen langobardischen Gelehrten Paulus Diaconus ${ }^{764}$ und von einem anonymen Glossator in Reims, der wahrscheinlich im zehnten Jahrhundert arbeitete. ${ }^{765}$

Sowohl die Viten Gregors III. als auch jene Zacharias' enthalten keine Hinweise auf Kontakte mit den Franken, ja nicht einmal die Mission des Bonifatius oder die in den fränkischen Quellen als so wichtig und richtungsweisend präsentierte Entschei-

761 Die westsächsischen Könige Caedwalla (im 7. Jahrhundert) und Ine etwa dankten gegen Ende ihres Lebens ab - nur um sich auf eine Reise nach Rom begeben zu können. Siehe dazu Beda, Historia ecclesiastica gentis Anglorum, 5,7 (ed. und trans. Günter Spitzbart, Darmstadt 21997) 450. Neben dem sicherlich wichtigen Ziel der Wallfahrt spielten auch politische und kulturelle Kontakte eine wichtige Rolle. So war auch die Schola Saxonum in Rom eine wichtige Institution um Kontakte aufrechtzuerhalten. Siehe dazu auch Dee Dyas, Pilgrimage in Medieval English Literature (Woodbridge 2001) 100-102.

762 Dass das auch noch einem anderen Zweck diente, werden wir im folgenden Kapitel 6.2 sehen.

763 Zur Schlacht, ihrem Mythos und ihren Nachwirkungen siehe Philippe Sénac, Les carolingiens et alandalus. VIII - -IX ${ }^{e}$ siècles (Paris 2002), Nonn, Schlacht bei Poitiers, sowie Ekkehart Rotter, Abendland und Sarazenen. Das okzidentale Araberbild und seine Entstehung im Frühmittelalter (Studien zur Sprache, Geschichte und Kultur des islamischen Orients, 11, Berlin/New York 1986) 220-224.

764 Siehe Davis, LP 8, 8, Anm. 32.

765 Siehe die Notiz im Codex Leiden, Vossianus Lat Q60, fol. 92v. 
dung des Zacharias zugunsten der Karolinger, dass jener im Frankenreich herrschen solle, der auch tatsächlich die Macht habe, wird im LP nicht erwähnt. Erst mit der Vita Stephans II. erhielten die Karolinger eine Rolle in der päpstlichen Historiographie, immerhin aber gleich eine Hauptrolle. Daneben stieg auch die Bedeutung der Langobarden für das Narrativ stark an, wenn auch als Antagonisten, wie wir bereits gesehen haben. Anderen Gruppen wurden hingegen nicht einmal mehr ihre kleinen Rollen zugestanden, sie waren durch die Zuspitzung auf die große Erzählung völlig marginalisiert. Davon ausgenommen waren die Oströmer, denen aber eine spezielle Rolle zukam, die mit jener der Franken und Langobarden nicht vergleichbar ist. Das Konzept der Vita Stephans II. wurde in jenen seiner Nachfolger zwar nicht ganz konsequent weitergeführt, der Fokus auf Langobarden und Franken blieb jedoch in den Viten Stephans III. und Hadrians I. erhalten. In der Vita Pauls I. fehlt politische Information fast gänzlich und es überrascht daher nicht, dass fränkische Belange nicht enthalten sind.

Man kann nach dem Befund des LP also davon ausgehen, dass sich ab den 750erJahren die Prioritäten des Papsttums in der Kommunikation mit den gentes hin zu den zwei wichtigsten Partnern verschoben. Besonders die Franken, die mittlerweile sicher unter karolingischer Führung standen, nahmen dabei als wichtigste Verbündete der Päpste nun zweifellos eine Sonderstellung ein.

Auch die Briefe des Codex Carolinus belegen diese Entwicklung, stammen doch nur drei Briefe aus der Zeit vor dem Pontifikat Stephans II; obschon wir davon ausgehen müssen, dass ab der Alleinherrschaft König Pippins die Überlieferungschance der Briefe höher war und generell eine größere zeitliche Nähe zum Herstellungszeitpunkt der Sammlung zwischen 79I und 793 ebenfalls die Chance einer Aufnahme in das Corpus erhöhte ${ }^{766}$. Dennoch ist davon auszugehen, dass sich ab dem Pontifikat Stephans II. die Kommunikation wesentlich intensivierte. Zwei der Briefe aus der Zeit vor $75^{2}$ haben wir oben in Kapitel 5.I bereits länger analysiert, es handelt sich um die Hilfegesuche Papst Gregors III. gegen Langobardenkönig Liutprand. Daneben existiert noch ein langer Brief des Zacharias, der sich mit religionspolitischen Themen befasst. Dieser Brief verrät uns nichts über etwaige Vorbereitungen einer engeren Zusammenarbeit, seine Existenz ist aber zumindest ein Hinweis, dass es nach der wahrscheinlich abgelehnten Unterstützung für Gregor III. unter Zacharias wieder eine Annäherung gegeben hatte.

766 So wissen wir, wie bereits erwähnt, von einigen Gelegenheiten, an denen Kommunikation zwischen Karolingern und den Päpsten der ersten Hälfte des achten Jahrhunderts stattfand, die nicht ihren Niederschlag im CC gefunden hat. Siehe dazu Kap. 1.2. Vielleicht lagen auch keine Schriftstücke vor und die Kommunikation fand verbal statt. Es ist außerdem möglich, dass Schriftstücke bis zur Erstellung des CC verloren gegangen waren oder an einem anderen Ort aufbewahrt worden waren. 
Wichtig für den vorliegenden Band ist aber nun die Frage, wie die Franken von den Päpsten wahrgenommen wurden, wie sich diese Wahrnehmung im Laufe des achten Jahrhunderts veränderte und inwiefern der Lateran ein Interesse haben konnte, das Bild der Franken in Rom aktiv zu beeinflussen.

\subsubsection{Die Franken als Andere?}

Kehren wir noch einmal zu den Anfängen zurück, zur Schlacht von Toulouse und der extrem positiven Zeichnung Eudos. Nur einen Absatz später folgt in der Vita Gregors II. eine Stelle, die den antisarazenischen Tenor verstärkt und hilft die Frankenstelle einzuordnen:

In der Zwischenzeit wurde in diesen Tagen Konstantinopel von den unaussprechlichen Hagarenen zwei Jahre lang belagert. Doch Gott war gegen sie und so mussten sie sich, nachdem der größte Teil von ihnen an Hunger und Krieg zugrunde gegangen war, ungeordnet zurückziehen. Leo war damals Kaiser. Und es wird berichtet, dass von der Bevölkerung jener Stadt 300.000 verschiedenen Alters durch Mangel und Krankheit vernichtet wurden. ${ }^{767}$

Wir erfahren also von der Belagerung Konstantinopels 717/7i 8 durch die Truppen des umayyadischen Kalifats. Die oben wiedergegebene Passage ist die gesamte Information, die wir über dieses Ereignis erhalten - mehr als die Hälfte weniger als über die Schlacht von Toulouse. Bezeichend ist auch, dass sich der römische Autor zwar auf die Seite der Oströmer stellte, aber eben auch zu berichten wusste, dass in Konstantinopel etwa 300.000 Menschen ums Leben gekommen waren. Dem Leser wird durch den Aufbau der Erzählung die Frage nahegelegt, wie viele davon durch päpstliche Unterstützung gerettet hätten werden können. Das Problem des Biografen Gregors II. war, dass Kaiser Leon III. seinem Protagonisten im Steuerstreit der

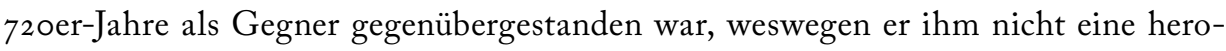
ische Verteidigung der Stadt zugestehen wollte. Ohne die Bedeutung der Franken wesentlich schmälern zu wollen, muss also auch darauf hingewiesen werden, dass diese als dem Papst freundlich gesonnene gens dem später in der Narration deutlich negativ besetzten Kaiser gegenübergestellt wurden.

Es fällt neben dieser Antithese in der Darstellung sogar noch eine weitere auf: Wir haben in Kapitel 4 bereits gesehen, dass in dieser Vita die oströmischen Prota-

767 LP I, 402: Illis interea diebus Constantinopolim biennio est a nec dicendis Agarenis obsessa. Sed Deo eis contrario maxima illic eorum parte fame ac bello interempta confusi recesserunt, Leone principe. Nam et eiusdem civitatis populum trecenta dictum est milia diversae aetatis fuissent necessitate vastatum pestilentiae. 
gonisten, im vorliegenden Fall auch der Kaiser, nie irgendeiner Gruppe zugeordnet werden: Leon wird schlicht als Leo princeps bezeichnet. Ohne Zweifel ermöglichte das dem Leser eine eindeutige Zuordnung. Nirgends aber ist der Kaiser ein Grecus. Damit lag der LP-Autor ganz auf der päpstlichen Linie der ersten Hälfte des achten Jahrhunderts. Umso mehr fällt, wie schon oben im Fall der Langobarden, auf, dass für die Franken eine ethnische Zuordnung als gens erfolgte, wenn auch Eudo ebenfalls mit einem rein funktionalen, nicht ethnischen Herrschaftstitel versehen wird. ${ }^{768}$ Wiederum gleichen die positiven Franken den in der Vita Gregors II. ebenfalls positiv geschilderten Langobarden. Auch sie werden an dieser Stelle zwar positiv hervorgehoben, zugleich aber von den Romani abgegrenzt. Der missliebige Kaiser hingegen, der später in der Vita noch massiver Kritik ausgesetzt ist, ist wohl als Römer zu betrachten und somit Teil der Eigenen, der in-group.

Der römische Autor und sein Redaktor taten sich also nicht schwer, die Aquitanier zu definieren, sie waren aus ihrer Sicht mehr oder weniger den Franken zuzuordnen und unterschieden sich klar von den Römern. Die große antike Tradition der Region wurde offenbar auch in die Erwägungen einbezogen. Eudo wurde sogar als princeps Aquitaniae bezeichnet. Möglicherweise handelte es sich dabei um seine Selbstdefinition, doch ergibt sich im LP auch eine wahrscheinlich beabsichtigte Parallelität zur Darstellung des Kaisers. Der Titel, der Eudo gegeben wird, zeigt, dass es dem Autor nicht schwer fallen hätte müssen, die Aquinanier einzugemeinden. Doch stattdessen entschied sich der Redaktor endgültig für eine Identifikation mit „den“ Franken, die in der jüngeren Fassung der Stelle mehrmals vorkommt. ${ }^{769}$

Es ist davon auszugehen, dass die Bezeichnung Franken, die klare Abgrenzung der Herrscher in Gallien, in Rom einfach als gültige Realität wahrgenommen wurde. Auch wenn die Franken wahrscheinlich in Rom durch Sprache oder Auftreten kaum fremder wirkten als die Menschen aus dem imperialen Osten, ja wahrscheinlich den lateinischen Römern sogar ähnlicher erscheinen konnten, unterschieden sie sich doch in einer Hinsicht ganz eindeutig: sie waren Teil einer anderen Gruppe, einer gens und somit keine Römer. Simpler ausgedrückt: Aus Sicht der Römer waren die Franken einfach Franken, im Frankenreich vorhandene Differenz wurde zwar zumindest für Aquitanien auf der politischen Ebene durchaus anerkannt, auf der kulturellen und ethnischen Ebene aber nicht wahrgenommen oder ignoriert. Jedenfalls war im engeren Sinne kein Prozess des Othering notwendig, auch wenn die geradezu antithetische Darstellung Franken - Kaiser auch für die Franken eine Abgrenzung von den Römern mit sich brachte. Das intendierte Publikum, das, wie wir gesehen haben, im

768 Vgl. oben, Kap. 5.8.

769 LP I, 401, rechte Spalte. 
frühen achten Jahrhundert noch vor allem in Italien zuhause war, sah die Franken aber auf eher emotionslose Weise als Andere, im Gegensatz zu den Greci war eine „Anleitung“ in diese Richtung nicht von Nöten.

Die Haltung der päpstlichen Schriften änderte sich auch nicht wesentlich, als man sich mit Karl Martell und seinen Söhnen in Verbindung setzte, auch wenn die zentralen Angebote, die Papst Gregor III. dem fränkischen Hausmeier machte, auf eine bessere Reputation und engere Integration der Karolinger in der römischen Welt, vor allem aber der Kirche hinauslief:

Du aber, mein Sohn, sollst gegenüber dem Apostelfürsten hier und im kommenden Leben gegenüber unserem allmächtigen Gott in aller Schnelligkeit das erledigen, was Du für seine Kirche und zu unserer Verteidigung geplant und entschieden hast, damit alle Völker Deinen Glauben und Deine Reinheit und Deine Liebe sehen können, welche Du für den Heiligen Apostelfürsten Petrus zeigst, indem Du uns und seinen peculiaris populus unterstützt und verteidigst. Denn das wird Dir Ruhm und das ewige Leben einbringen. ${ }^{770}$

Schon Gregor III. bezog sich also in der Kommunikation mit den Karolingern ausdrücklich auf den Heiligen Petrus. Am Beginn des zitierten Briefes bezeichnet er den Adressaten als amator des wichtigsten römischen Heiligen, ${ }^{771}$ es ist also davon auszugehen, dass der Papst über eine wie auch immer geartete Bevorzugung des Apostels informiert war und danach trachtete, Karl Martell eine „maßgeschneiderte“ Botschaft zu senden.

Angesichts der Tatsache, dass auch das wortreiche Hilfegesuch Gregors in $\mathrm{CC}_{2}{ }^{772}$ nicht zu einer Intervention der Karolinger beim Langobardenkönig Liutprand führte, verwundert es nicht, dass auch in den 73oer-Jahren keine wesentliche Änderung der päpstlichen Wahrnehmung und Darstellung der Franken zu verzeichnen ist. Die LPVita Gregors III. erwähnt die Franken entsprechend mit keinem Wort, erst in der später hinzugefügten Interpolation, die sich nur in der „fränkischen“ Rezension des Textes findet, werden die Versuche, Karl Martell zu einem Eingreifen gegen die Langobarden zu bewegen, erwähnt - der für Rom unbefriedigende Ausgang jedoch verschwiegen. Auch die Auseinandersetzungen mit den Langobarden werden erst in der

770 CC 1, ed. Gundlach 476f., hier 477.: Tu autem, fili, habeas cum ipsi principe apostolorum bic et in futura vita coram omnipotenti Deo nostro, sicut pro eius eclesia et nostra defensione disposueris et decertaveris sub omni velocitate, ut cognoscant omnes gentes tuam fidem et puritatem atque amorem, quae habes erga principem apostolorum beatum Petrum et nos eiusque peculiarem populum zelando et defendendo; ex hoc enim tibi poteris memorialem et aeternam atquirere vitam.

771 CC 1, ed. Gundlach 476.

772 Siehe dazu oben, Kap. 5.1. 
interpolierten Fassung erwähnt. ${ }^{773}$ Während die Langobardenpolitik wahrscheinlich aufgrund ihres Scheiterns nicht ihren Weg in den Text gefunden haben dürfte, wurden die (ja ebenfalls gescheiterten) Verhandlungen mit den Franken in Rom wahrscheinlich nicht als wichtig genug wahrgenommen. Zudem waren die Details der Verhandlungen dem Autor der Vita Gregors III. möglicherweise nicht bekannt.

Auch in der LP-Vita Zacharias' finden sich nur wenige Hinweise auf die Franken und das obwohl es auch unter diesem Papst zu aus fränkischer Sicht wesentlichen Kontakten gekommen war. Aus päpstlicher Sicht werden diese Kontakte mit dem Frankenreich nur durch einen langen Brief belegt. Zacharias kümmerte sich in diesem Schreiben aber vor allem darum, die Herstellung der geistlichen Ordnung im Frankenreich zu unterstützen. Der Brief richtet sich folgerichtig an alle Bischöfe des Fränkischen Reichs und an Pippin, zu dem Zeitpunkt noch Hausmeier. Er enthält eine lange Liste von Auszügen aus der kanonistischen Sammlung des Dionysius Exiguus. ${ }^{774}$ Der Brief zeigt, dass auch schon vor der berühmten Anfrage, wer denn die Franken beherrschen solle, enge Kontakte bestanden. Nichts davon wurde jedoch im LP erwähnt, auch wenn die Vita relativ ausführlich ist. Es ist eher auszuschließen, dass zu diesem Zeitpunkt die Kontakte mit den Franken als zu unwichtig hätten abgetan werden können. Eher möglich ist, dass die Kontakte noch nicht einer breiteren Öffentlichkeit bekannt werden sollten, weil ihre Implikationen zu weitreichend waren und Langobarden und imperiale Offizielle gleichermaßen unter Druck gesetzt hätten. Aus diesem Grund haben wir aus der Zeit Zacharias' lediglich eine einzige klare Einstufung der Franken, nämlich aus Brief Nummer 3 des CC. Hier lesen wir in der Adresse:

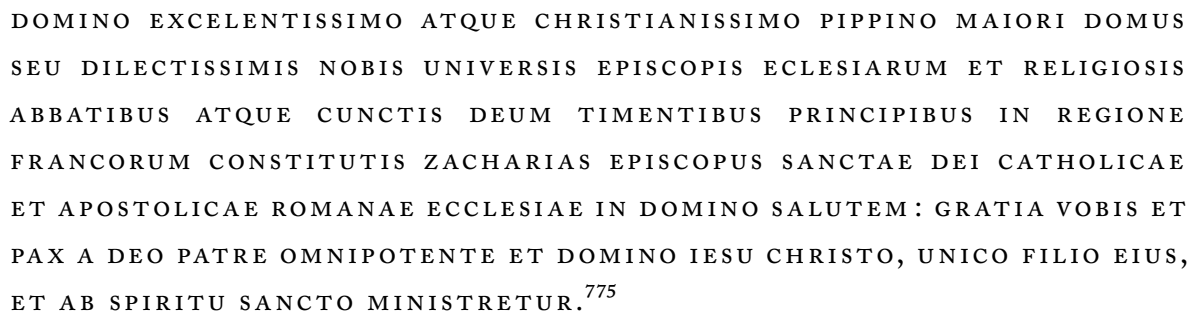

Wir erfahren dann in der Folge noch, dass die Initiative, die zu dem Brief beziehungsweise der Übersendung der ausgewählten Kanones geführt hat, von Pippin

773 LP I, 420, Anm. *.

774 CC 3, ed. Gundlach 479-487. Dionysius' Sammlung des kanonischen Rechts spielte im Karolingerreich eine wichtige Rolle, die Kanones sind in vielen Handschriften überliefert, siehe McKitterick, History 95 und $249-261$.

775 CC 3, ed. Gundlach 479. 
ausgegangen ist, was die Anrede hinreichend erklärt. Interessant ist, dass der Geltungsbereich des Textes mit in Regione Francorum abgesteckt wird. Pippin erhält die Anrede eines hohen weltlichen Würdenträgers (excellentissimus), er wird aber außerdem auch als christianissimus bezeichnet, was wahrscheinlich vonseiten des Papstes verdeutlichen soll, dass die Kirchenreformbemühungen des Herrschers honoriert werden. Im Gegensatz zu einer in späteren Briefen vorhandenen demonstrativen Vertraulichkeit, wird Pippin hier recht förmlich angeschrieben. Die ebenfalls als Adressaten genannten Geistlichen allerdings werden durchaus als zur römischen Kirche gehörig kenntlich gemacht.

Im LP findet nur ein Franke Erwähnung, nämlich Karlmann, der kurzzeitig gemeinsam mit Pippin Hausmeier gewesen war. Nun wird folgendes berichtet:

Zu dieser Zeit ließ Karlmann, Sohn des Frankenkönigs [eigentl. Hausmeier] Karl, weltlichen Ruhm und weltliche Macht hinter sich und kam unterwürfig gemeinsam mit einigen seiner Getreuen zum Heiligen Apostelfürsten Petrus; er präsentierte sich dem Apostel Gottes und wollte im geistlichen Habit verbleiben. Er nahm das Joch des Mönchtums ${ }^{776}$ von demselben allerheiligsten Bischof. Nach einiger Zeit begab er sich zum Kloster des Heiligen Benedikt im Territorium von Aquino [Monte Cassino]; dort legte er den ProfessEid ab und schwor, den Rest seines Lebens dort zu verbringen. ${ }^{777}$

Wir erfahren hier vom Rückzug Karlmanns ins Kloster. Warum wird von allen Kontakten mit den Karolingern genau diese Episode berichtet? Zunächst verblüfft vor allem, dass jener Karolinger, der die Macht abgegeben hatte, in der Vita vorkommt. Sicherlich hatte Karlmann die engeren Kontakte zum päpstlichen Gesandten Bonifatius, der noch immer eine wichtige Informationsquelle aus dem Norden war und der wiederum Karlmann näher gestanden war als seinem Bruder. ${ }^{778}$ Dennoch: Die Vita wurde in den frühen 75oern fertiggestellt, möglicherweise noch zu Lebzeiten Zacharias', und so ist doch interessant, dass der neue Frankenkönig Pippin, der sich bei seinem Staatsstreich unter anderem auch auf die Unterstützung des Papstes berufen hatte, im Gegensatz zu seinem Bruder keine Rolle spielt.

776 clericatus, siehe Davis, LP 8, 47, Anm. 82.

777 LP I, 433: Huius temporibus Carolomannus, filius Caroli Francorum regis, praesentis vite relinquens gloriam atque potestatem terrenam, ad beatum Petrum apostolorum principem devotus cum aliquantis suis advenit fidelibus, seseque eidem Dei contulit apostolo atque in spiritali habitu fore spondens permansurum, clericatus iugum ab eodem sanctissimo suscepit pontifice. Et post aliquantum temporis ad beati Benedicti quod Aquinensium finibus situm est profectus est monasterium, in quo et suam finiri vitam iure professus est iurando.

778 Lutz E. von Padberg, Bonifatius. Missionar und Reformer (München 2003) 80. 
Eine Erklärung können wir vielleicht in der sehr speziellen narrativen Strategie des Autors der Vita finden. Diese ist auf den Protagonisten Zacharias zugeschnitten, der, mit quasiprophetischer geistlicher Autorität ausgestattet, vor allem für seine Bekehrung von ehemals kriegerischen Herrschern gepriesen werden soll. Schon zu Beginn seines Pontifikats gelingt es dem Papst gleich mehrmals den Langobardenkönig Liutprand mittels vor allem religiöser Standfestigkeit auf den richtigen (nämlich für Rom günstigeren) Weg zurückzuführen. Nach der Episode um Karlmann ist es Liutprands mittelbarer Nachfolger Ratchis, der von Zacharias zunächst zu einem sehr günstigen Friedensschluss und danach sogar zu einem Rückzug ins Kloster gebracht werden kann. In dieser Hinsicht fungiert der zum Glaubenshelden stilisierte Karlmann sozusagen als Vorbild und passt somit gut zum Grundtenor der Vita. Zudem sah der Autor der Vita des Zacharias in den Franken noch kein potenzielles Publikum seines Werkes, weshalb er in seinen Text keine auf deren Bedürfnisse abzielenden Elemente aufnahm.

Wesentlich ist, dass auch Karlmann der Ältere ganz eindeutig als Franke gekennzeichnet wurde, hier sehen wir also bis etwa 750 keine Änderung im päpstlichen Material. Gleichbleibend ist auch die Tendenz, die Franken positiv darzustellen schon in der Vita Gregors III. wurde ja die Verweigerung der Unterstützung verschwiegen. Zwar ist nicht klar, in welcher Weise Karl Martell, dem grundsätzlich an Kontakten nach Rom gelegen sein musste, um die eigene Position zu stärken, auf die Briefe Gregors III. reagierte. Dass der Papst kurz nach CC I einen weiteren, ausführlicheren Brief ( $\mathrm{CC}_{2}$ ) schickte, zeigt aber doch, dass zunächst keine Hilfe gewährt wurde. Auch nach dem zweiten Hilfegesuch finden sich keine historischen Spuren eines fränkischen Vermittlungsversuchs, Liutprand führte seine Politik in Mittelitalien fort. Dennoch waren die Franken zwischen etwa 720 und 750 im LP positiv besetzte Andere in den päpstlichen Quellen, ungünstige Ereignisse wurden verschwiegen.

Mit der Reise Stephans II. ins Frankenreich im Jahr 753/54 traten die Beziehungen zwischen Rom und den Franken in eine neue Phase. Der Grund für die Reise war, wie wir gesehen haben, das Ziel des Papstes, Sicherheit für den römischen Dukat zu gewährleisten und, wenn möglich, Ravenna für das Kaiserreich zurückzugewinnen - wobei man einschränken muss, dass die Langobarden nicht vorhatten, den päpstlichen Bereich dauerhaft zu gefährden oder zu besetzen. Zunächst führte die Mission nach Pavia, wo allerdings trotz der Präsenz der fränkischen Gesandten keine Übereinkunft mit König Aistulf gefunden werden konnte. Daraufhin reiste der Papst über die Alpen, um dann im fränkischen Kernbereich mit König Pippin zusammenzutreffen. Die Gespräche führten dazu, dass der Papst den König und die beiden Königssöhne Karl und Karlmann öffentlich salbte und dafür Pippin zu einer 
militärischen Intervention in Italien bewegen konnte. Diese brachte eine langobardische Niederlage, ebenso wie die zweite Intervention im Jahre $756 .^{779}$

Ab 754 arbeiteten also die Franken zumindest für kurze Zeit sehr eng mit dem Papst zusammen, wobei Rom vor allem mit der karolinigischen Königsfamilie und ihr nahestehenden Personen kooperierte. Die wichtigste Kontaktperson des Lateran war auf fränkischer Seite Abt Fulrad von St. Denis, der im Pontifikat Stephans II. jene Verhandlungen leitete, an denen Pippin nicht selbst teilnahm.

Die Frage ist nun, ob und inwieweit diese neue Kooperation Einfluss auf die in Rom vorherrschende Wahrnehmung und Darstellung der Franken als Andere hatte. Hierzu ist zunächst wieder der LP heranzuziehen, vor allem um zu sehen, welches Bild der Lateran offiziell transportieren wollte - und eine genaue Prüfung zeigt, dass Pippin so gut wie nie ohne den Zusatz rex Francorum auskommen muss. Einzig wenn die Franken im selben Kontext als Gruppe genannt werden, verzichtet der Autor des Textes bisweilen auf die Spezifizierung (Pippin bleibt aber rex). Teilweise liegt das sicherlich daran, dass der Autor dieser Vita auch ein fränkisches Publikum mit seinem Text erreichen wollte - eine Neuerung im LP. Es war ihm deshalb sicherlich wichtig, den König möglichst korrekt zu bezeichnen. Abgesehen davon kann der Stil des Textes als weitschweifig bezeichnet werden. ${ }^{780}$

Doch die persistente Bezeichnung Pippins als König der Franken hat zusätzlich auch einen exklusiven Effekt. Es handelt sich hier auch um eine Form von subtilem Othering, denn an der Zugehörigkeit des Karolingerherrschers zu einer externen Gruppe wird kein Zweifel gelassen. Auf den ersten Blick mag das angesichts der engen Zusammenarbeit Pippins mit dem Papst überraschen - doch es war wahrscheinlich gerade diese Kooperation, die diese extrem affimative Darstellungsweise überhaupt notwendig erscheinen ließ. Schließlich war es nur auf diese Weise möglich, die Handlungen des Frankenkönigs effektiv von jenen des Papsttums zu trennen. Das Ziel war, nicht mit den Franken verwechselt zu werden, sondern eine klar erkennbare eigene Linie zu bewahren. Das geschah nicht zuletzt auch im Hinblick auf den Kaiser, der eine zu enge Bindung Roms an die Franken nur als Bedrohung für imperiale Interessen in Italien auffassen konnte. Es geschah aber auch aus dem Bestreben heraus, den Papst von etwaiger Verantwortung für kriegerische Handlungen von vornherein frei zu halten.

Der Eindruck der Abgrenzung von Pippin wird noch dadurch verstärkt, dass der in der Vita Stephans II. ebenfalls häufig genannte Langobardenkönig Aistulf oft nur als rex bezeichnet wird, ohne dass die Langobarden gennannt werden. Das

779 Siehe dazu ausführlich oben, Kapitel 5.3.

780 Siehe dazu oben, Kap. 1.1, bes. Anm. 95. 
mag einerseits daran liegen, dass der Autor Aistulf ähnlich prachtvolle Epitheta wie Pippin verwehren wollte. Andererseits war es aber auch nicht nötig, den Langobardenkönig noch zusätzlich von den Römern zu differenzieren, als deren Feind er in der Erzählung ohnehin bereits zur Genüge aufgebaut war.

Erwähnenswert ist ferner, dass fränkische Geistliche, wie etwa Fulrad, nie als Franken bezeichnet werden. Hier zeigt sich die Vita durchaus konsistent etwa mit dem Brief des Zacharias ( $\mathrm{CC}_{3}$ ), in dem die fränkischen Geistlichen ebenfalls als direkt zu Rom gehörig (nostri!) angesprochen werden. Das freilich liegt an der Stellung des Papstes, der sich konsistent als oberste spirituelle Instanz (zumindest) für das Abendland zu positionieren versuchte. Dass es nicht zuletzt im Frankenreich unter den frühen Karolingern eine frappierende Diskrepanz zwischen päpstlichem Anspruch und Wirklichkeit gab, steht allerdings außer Frage. Dennoch ist aus diesem Blickwinkel die nahezu automatische Integration der Geistlichkeit in päpstlichen Quellen gut verständlich. ${ }^{781}$

Im Gegensatz dazu wurden jedoch Franken aus dem Laienstand, nicht zuletzt die Karolinger selbst, im LP des achten Jahrhunderts als positiv besetzte Andere dargestellt. Auffällig ist allenfalls, dass sie in der Vita Pauls gar nicht erwähnt werden, generell ist dieser Eintrag aber ausgesprochen kurz und möglicherweise auch unvollendet. In der Vita Stephans III., die vor allem den Wirren rund um die Usurpation des Papsttums durch Konstantin (II.) sowie jenen während des Pontifikats Stephans selbst gewidmet ist, ${ }^{782}$ kommen die neuen Karolingerkönige Karl und Karlmann wieder vor, allerdings werden für die Franken eventuell unangenehme Informationen weggelassen, so etwa die angebliche Parteinahme Dodos, eines Gesandten Karlmanns, für die Gegner des Papstes. Auch hier werden sowohl Karl der Große als auch Karlmann immer deutlich als auswärtige Herrscher dargestellt, auch wenn den verbündeten Franken in Rom zweifellos viel Einfluss zugestanden wurde. So folgte etwa gleich nach der Machtübernahme durch Stephan, Christophorus und Sergius eine hochrangige Gesandtschaft ins Frankenreich, die dann wiederum eine Teilnahme einer Reihe von fränkischen Bischöfen an der römischen Synode von 769 zur Folge hatte. ${ }^{783}$ In der Vita von Stephans Nachfolger Hadrian I. kommt den Franken, vor allem Karl dem Großen, eine noch wesentlich herausragendere Rolle zu.

Das bedeutet aber keineswegs, dass das Verhältnis zu den Franken immer als ungetrübt zu sehen ist. Im LP gibt es zwar die Tendenz, vieles zu beschönigen, aber in

$781 \mathrm{Im}$ achten Jahrhundert gibt es mit Waldipert nur einen prominenten Fall eines Priesters, der in der päpstlichen Darstellung ausdrücklich als Anderer, nämlich als Langobarde, dargestellt wurde. $\mathrm{Zu}$ ihm siehe oben, Kap. 5.5.1.

782 Siehe oben, Kap. 5.5.

783 LP I, 473-475. 
manchen Passagen kann man dennoch den Eindruck gewinnen, dass sich das Papsttum weder vollständig an die Karolinger ausliefern wollte noch volles Vertrauen in die Franken hatte. So berichtet der LP zur Ankunft Karls des Großen zu Ostern 774 vor Rom:

Der genannte allerheiligste Papst Hadrian hörte von seiner [Karls d. Gr.] Ankunft (adventus) und war von großer Verblüffung und Aufregung (magno stupore et extasi) erfüllt, dass der König der Franken so unerwartet kam. Er schickte ihm alle iudices bis zur 30. Meile vor der Stadt Rom entgegen, zum Ort, der Novae genannt wird; dort empfingen sie ihn mit ihren Bannern. Und als er sich der Stadt Rom bis auf eine Meile genähert hatte, schickte er alle scholae [Abteilungen] der römischen Miliz zusammen mit den patroni [ihren Vorstehern] und den Kindern, die gerade begonnen hatten, die Buchstaben zu lernen: Sie trugen Palmen- und Olivenzweige und sangen Loblieder auf ihn; mit Hochrufen und Lob begrüßten sie den Frankenkönig. Seine Heiligkeit sandte außerdem verehrungswürdige Kreuze, wie Feldzeichen, auf seinen Weg, so wie auch ein Exarch oder patricius empfangen wird und ließ ihn mit allen Ehren willkommen heißen. ${ }^{784}$

Der vorliegende Absatz berichtet den adventus des Frankenkönigs ${ }^{785}$ Der Bericht ist relativ üblich für solche Anlässe und der LP vergleicht die Vorgehensweise mit dem Zeremoniell beim Eintreffen des Exarchen in Rom. ${ }^{786}$ Allerdings sind einige Auffälligkeiten enthalten. Zunächst verblüfft es, dass der Papst offenbar vom Zug der Franken nach Süden überrascht wurde, ja er wurde in magno stupore et extasi ergriffen, was am ehesten als Verblüffung (beziehungsweise auch Schreck) und Aufregung übersetzt

784 LP I, 496f.: Cuius adventum audiens antedictus beatissimus Adrianus papa quod sic repente ipse Francorum advenisset rex, in magno stupore et extasi deductus, direxit in eius occursum universos iudices ad fere XXX milia ab hac Romana urbe, in loco qui vocatur Nobas: ibi eum cum bandora susceperunt. Et dum adpropinquasset fere unius miliario a Romana urbe, direxit universas scolas militia una cum patronis simulque et pueris qui ad didicendas litteras pergebant, deportantes omnes ramos palmarum adque olivarum, laudesque illi omnes canentes, cum adclamationum earundem laudium vocibus ipsum Francorum susceperunt regem; obviam illi eius sanctitas dirigens venerandas cruces, id est signa, sicut mos est exarchum aut patricium suscipiendum, eum cum ingenti honore suscipi fecit.

785 Zum Zeremoniell siehe Ernst Kantorowicz, Laudes regiae. A Study in Liturgical Acclamations and Mediaeval Ruler Worship (Berkeley/Los Angeles 1946) 75f., sowie 53f. und 102, sowie Michael McCormick, Eternal Victory. Triumphal Rulership in Late Antiquity, Byzantium and the Early Medieval West (Cambridge 1990) 358. Zur Entwicklung des adventus in der Antike siehe Sabine G. Maccormack, Change and Continuity in Late Antiquity: The Ceremony of „Adventus“, in: Historia, 21 (1972) 721-752.

786 LP I, 497: ... sicut mos est exarchum aut patricium suscipiendum ... Auch der adventus der Päpste selbst war im Frühmittelalter jenem spätantiker römischer Amtsträger nachempfunden, vgl. Twyman, $\mathrm{Pa}-$ pal Ceremonial 58f., sowie 74, zu den Vorgängen 774 und ebd. 41-87 zu deren Kontext. 
werden kann. ${ }^{787}$ Beide Quasisynonyme müssen hier also nicht mit positiven Konnotationen gelesen werden - es handelt sich wohl zumindest um versteckte Kritik an der eigenmächtigen Vorgehensweise Karls. Möglicherweise gibt die Stelle sogar eine verunsicherte Reaktion des Papstes vor dem Besuch wieder. Der Empfang selbst wurde mit allen Ehren durchgeführt, ist aber nicht nur ein Akt der Wertschätzung für den König, sondern auch ein ostentatives Zurschaustellen der römischen Stärke. Selbst in einem Moment, der auf den ersten Blick die Harmonie zwischen Papsttum und Frankenkönig fördern müsste, gibt es in der Darstellung leichte Risse und Hinweise auf Missverständnisse in der Kommunikation - und das in einem offiziellen Text, der für ein größeres Publikum gedacht war. In der Vita Hadrians gibt es mehrere solche Stellen, mehrere Ereignisse, in denen das Papsttum sich unzufrieden mit den Franken zeigt. Oben haben wir bereits gesehen, dass der $d u x$ von Spoleto 776 von Rom zum neuen Langobardenkönig Karl dem Großen überging. ${ }^{788}$ Wiederum wurde der Karolinger im LP nicht offen kritisiert, doch die Erzählweise ist auch als Vorwurf an die Franken zu werten, die die päpstliche Oberherrschaft über Spoleto offenbar nicht anerkannt hatten.

Ebenfalls während des Pontifikats Hadrians I. kam es in den Jahren 783/84 zu einer Auseinandersetzung zwischen Rom und Karl um die Abtwürde im Kloster San Vincenzo al Volturno. Diese kann anhand von zwei Briefen des CC gut nachverfolgt werden. ${ }^{789}$ Konkret war die Führungsposition zwischen dem Langobarden Potho und dem Franken Ambrosius Autpertus umstritten und die Auseinandersetzung wurde zwischen dem König und Hadrian zunehmend erbittert kommuniziert. ${ }^{790}$ Bezeichnenderweise ergriff der Papst die Partei des Langobarden, ${ }^{791}$ obwohl Potho ausdrücklich antifränkische Politik vorgeworfen wurde. In Brief CC 67 wird dabei sehr deutlich, dass die Franken im Kloster (auch aus Sicht des Papstes) als Fremde zu betrachten sind. ${ }^{792}$ Der Papst stellte sich in der Sache ganz eindeutig auf die Seite Pothos, konnte sich aber schlussendlich nicht durchsetzen, Karl der Große erhielt dessen Absetzung aufrecht.

Die Episode zeigt jedenfalls, dass die Franken als Gruppe dem Papst auch in den $780 e r-J a h r e n$ noch nicht wesentlich näher gerückt waren, sie wurden immer noch

787 Siehe Lemma „Ecstasis“ in: Albert Blaise, Dictionnaire latin-français des auteurs chrétiens (Turnhout 1954-1967): „peur, effroi, angoisse“. Siehe Lemma „Stupor“ in: Charlton T. Lewis/Charles Short, A Latin Dictionary (Oxford 1891) 1770: u. a. ,astonishment, wonder, amazement“.

788 Siehen oben, Kap. 5.6.1.2.

789 CC 66 und 67, ed. Gundlach, 593-597. Dabei ist CC 66 nach 67 zu datieren, wie Hartmann, Hadrian 235-237, nachweist.

$790 \mathrm{Zu}$ dem Streit siehe ausführlich Hartmann, Hadrian 227-243.

791 Hartmann, Hadrian 237-240.

792 Hartmann, Hadrian 232-235. CC 67, ed. Gundlach 594-597. 
klar als Andere wahrgenommen, in diesem Fall wohl sogar im Verhältnis zu den im nördlichen Beneventer Gebiet ansässigen Langobarden.

Kehren wir noch einmal zurück zum Pontifikat Stephans III. und zum programmatischen Brief CC 45 aus dem Jahr 770, dem oben Kapitel 5.5.2 gewidmet ist. Darin wird die Position der Franken und der Karolinger aus päpstlicher Sicht besonders genau definiert. Den Beginn des Briefes haben wir oben schon analysiert, die Franken werden darin als preclara gens bezeichnet und von den Langobarden abgesetzt, die als übelriechend bezeichnet werden und denen der Status einer gens überhaupt abgesprochen wird. Auch die Rechtgläubigkeit der Franken wird implizit Anspielungen auf die häretische Vergangenheit der Langobarden gegenübergestellt. Der eigentliche Zweck des Schreibens wird aber erst später offenbar, wenn die beiden Adressaten Karl und Karlmann eindringlich vor einer Ehe mit einer Tochter des Langobardenkönigs gewarnt werden, ja mehr noch, bei Zuwiderhandeln wird ihnen sogar das Anathem als Strafe in Aussicht gestellt. ${ }^{793}$ Es wird in diesem Brief, der mit so schmeichelhaften Worten für die Franken beginnt, also mit dem Ausschluss aus der Gemeinschaft der Christen für die Könige dieser gens gedroht. Eine deutlichere Form des Otherings gegen einzelne Christen kannte die Kirche eigentlich nicht.

Auch das Hervorheben der Franken als beste gens setzt diese keineswegs mit den Römern oder dem peculiaris populus des Papstes gleich. Mary Garrison hat die Frage gestellt, ob die Franken vom Papst als auserwähltes Volk im biblischen Sinne gesehen wurden und kommt gerade unter Heranziehung von CC $45 \mathrm{zu}$ dem Schluss „either Ecclesia or the Republic of St. Peter was Israel, the Lombards, the persecutors, and the Franks, the military heroes of Israel. ${ }^{\text {"794 }}$ Biblisch verbrämt trifft es dieser Satz genau: Akte des Sameings oder gar der Integration der Franken waren selten und wären zumeist auch nicht zielführend gewesen. Vielmehr wurde leichtes aber doch explizites Othering angewandt um die Gefahr einer Verwechslung der fränkischen mit der päpstlichen Politik zu vermeiden. Die Päpste brauchten vor allem einen externen Verbündeten. Der Grund dafür ist vor allem in der Position des Papsttums zu suchen, das als oberster Vertreter des Christentums keine eigenen Kriege führen wollte, sondern lieber die für Rom nützlichen Erfolge der Franken als gottgewollt präsentieren wollte.

Bei den im achten Jahrhundert schließlich gefundenen Verbündeten handelte es sich allerdings nicht in erster Linie um „die Franken“ sondern um die Karolinger und ihre Amtsträger. Man sollte daher fragen, ob zumindest die Karolingische Familie

793 CC 45, ed. Gundlach 563: Et si quis, quod non optamus, contra huiusmodi nostrae adiurationis atque exhortationis seriem agere praesumserit, sciat se auctoritate domini mei, beati Petri apostolorum principis, anathematis vinculo esse innodatum et a regno Dei alienum atque cum diabolo et eius atrocissimis pompis et ceteris impiis aeternis incendiis concremandum deputatum; ...

794 Garrison, New Israel 125. 
unterschiedlich behandelt und vom Papsttum absichtlich angeglichen wurde. Die bisher gezeigten Beispiele deuten darauf keineswegs hin, aber einige Briefe des CC enthalten durchaus vertrauliche Anreden, die zweifellos inklusiv wirken sollten. In Brief CC 48 , der einige Zeit nach CC 45 ebenfalls im Namen von Papst Stephan III. verfasst wurde, werden die Empfänger Karl der Große und seine Mutter Bertrada folgendermaßen angesprochen:

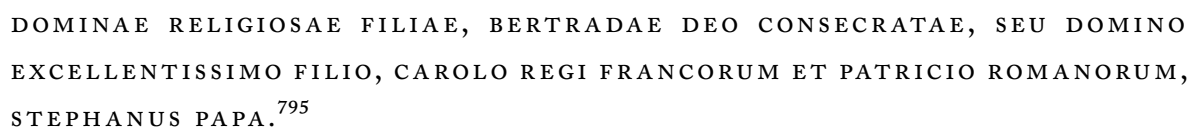

Karl ist excellentissimus filius des Papstes, seine Mutter sogar religiosa filia, Deo consecrata. Trotz der eindeutigen Verortung Karls als rex Francorum wird hier doch eine große Vertraulichkeit suggeriert - und dieser Brief ist bei weitem kein Einzelfall. Einschränkend muss aber bemerkt werden, dass flius noster beziehungsweise filia nostra in der päpstlichen Korrespondenz des Frühmittelalters relativ üblich waren, ja nicht einmal engen Verbündten vorbehalten waren. Allerdings wird an dieser Stelle eine gesteigerte Variante, nämlich mit excellentissimus und religiosa gewählt, die vielleicht doch eine bessere Beziehung zeigen könnte. Im Brieftext selbst findet sich jedoch auch folgende Passage:

Aber der allmächtige Gott, der die Reinheit unseres Herzens kennt, hat, damit uns kein Leid geschehe, uns ihren Händen [der Feinde des Papstes in Rom] entrissen. Während unser vorzüglichster Sohn Desiderius, König der Langobarden, hier bei uns weilte, um uns verschiedene Güter des Heiligen Petrus zu übergeben, haben wir es bei derselben Gelegenheit mit großer Anstrengung gerade so geschafft, mit unserem Klerus bei Eurem Beschützer [St. Peter] Zuflucht zu suchen. ${ }^{796}$

Auch der Langobardenkönig ist also excellentissimus flius noster! Insofern kann man eine besondere Exklusivität dieser Anrede endgültig ausschließen, auch wenn Desiderius zum Zeitpunkt der Abfassung des Briefes kurzzeitig mit dem Papst verbündet war. Noch dazu wird in dem Brief einer Person auffälligerweise diese Anrede ver-

795 CC 48, ed. Gundlach 566f., hier 566.

796 CC 48, ed. Gundlach 566: Sed omnipotens Deus, cernens rectitudinem cordis nostri: quod nulli umquam malum cogitavimus, de eorum nos eripuit manibus. Et vix per multum ingenium, dum hic apud nos excellentissimus filius noster, Desiderius Langobardorum rex, pro faciendis nobis diversis iustitiis beati Petri existeret, per eandem occasionem valuimus cum nostro clero refugium facere ad protectorem vestrum [beatum Petrum]. 
wehrt, nämlich Karlmann, der lediglich als rex bezeichnet wird. Das kommt umso mehr einer Degradierung gleich, als sich Karlmann zweifellos im selben geistlichen Verhältnis zu Stephan III. befand wie sein älterer Bruder. Ja der Papst war wahrscheinlich sogar geistlicher Pate (compater) seines jüngeren Sohnes. ${ }^{797}$ Der Grund für diese zweifellos bewusste Herabsetzung des zweiten Karolingerkönigs ist sicherlich in den Auseinandersetzungen in Rom zu sehen, in denen sich Dodo, der Gesandte Karlmanns, auf die Seite der nunmehrigen Feinde des Papstes gestellt haben dürfte. ${ }^{798}$

Das zeigt zum einen, dass die diplomatischen „Nettigkeiten“ dieser Korrespondenz immer sehr situationsabhängig vergeben wurden, zum anderen, dass die karolingische Familie kein Vorrecht darauf hatte, auch wenn in den Briefen des CC aus begreiflichen Gründen meistens Karolinger mit positiven Anreden bedacht wurden.

Die Anrede des Briefes $\mathrm{CC}_{48}$ enthält aber noch eine weitere Information, die analysiert werden muss: Karl der Große wird, wie in so gut wie allen Briefen des CC, als patricius Romanorum angesprochen, ein Titel, der ihm 754 offenbar im Zuge seiner Salbung zum König der Franken durch Papst Stephan II. gemeinsam mit seinem Vater und seinem Bruder verliehen worden war. Wir haben gesehen, dass dieser Titel möglicherweise in Verbindung mit dem kaiserlichen Ehrentitel

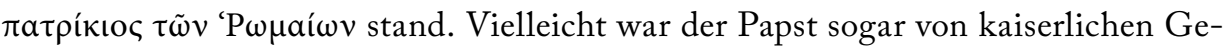
sandten zur Verleihung ermächtigt worden. ${ }^{799}$ Zweifellos wurde der Titel jedenfalls vom Papst als offizielles kaiserliches aber zugleich auch stadtrömisches Amt präsentiert, das den Träger dazu verpflichtete, für das Wohl der Stadt Rom und seiner Bewohner Sorge zu tragen. Aller Wahrscheinlichkeit nach wurde die Würde von den Karolingern auch so verstanden. Schließlich hatten auch die Exarchen von Ravenna zumeist den patricius Titel geführt, wenn auch ohne den Zusatz Romanorum. $^{800}$

Die Verleihung wird allerdings ausschließlich in zwei fränkischen Quellen erwähnt, den Annales Mettenses Priores sowie der sogenannten Clausula de unctione Pippini. ${ }^{801}$ Die päpstlichen Quellen, am ehesten käme hier der LP in Betracht, klammern diesen Teil der Ereignisse hingegen aus. Auf der praktischen Seite sah es zunächst genau anders aus: Die Päpste verwendeten den Titel konsequent in ihren offiziellen Schriftstücken. Pippin hingegen benutzte den Titel öffentlich nicht, zumindest sind keine Spuren mehr davon erhalten. Erst Karl der Große führte den

797 CC 47, ed. Gundlach 565f.

798 Siehe dazu oben, Kap. 5.5.3.

799 Siehe oben, Kap. 3.1, sowie Deér, Patricius-Romanorum-Titel und Noble, Republic 278-280.

800 Helmut Michels, Patricius, Patrikios, I. Westen, in: LMA Bd. 6 (München/Zürich 1993) 1789f.

801 Annales mettenses priores, ed. von Simson 45f.; Clausula de unctione Pippini, ed. Stoclet 2f. 
Titel nachdem er sich zum König der Langobarden gemacht hatte - wahrscheinlich um seine Macht in Italien noch weiter zu legitimieren. ${ }^{802}$

Die Ernennung der drei Karolinger zu patricii Romanorum war ohne Zweifel ein Akt der Einbeziehung sowohl ins imperium als auch in die Stadt Rom. Doch damit war auch eine bestimmte Erwartungshaltung verbunden. Pippin und seine Söhne hatten nun in der Theorie eine offizielle Funktion in Rom, die sowohl zivile als auch militärische Komponenten beinhaltete. Vielleicht aus genau diesem Grund scheinen die Karolinger die neue Würde nicht offensiv verwendet zu haben, ja sogar die eigene Integration in die größere Nähe des Papstes und des Kaisers vermieden zu haben. Dieses Verhalten dürfte trotz des ostentativen Einsatzes des patricius RomanorumTitels auch im Interesse des Papstes gewesen sein, wie die restliche Korrespondenz und der LP hinreichend belegen. Zwar war es aus politischen Gründen sowohl für das Papsttum als auch für die Karolinger notwendig sich gegenseitig anzunähern und in wichtige Entscheidungen und Abläufe einzubeziehen. Pippin und später auch seine Söhne brauchten den Papst vor allem als Lieferanten von Legitimität für ihre Herrschaft, Rom hingegen konnte auf die diplomatische und militärische Unterstützung der Franken nur schwer verzichten. Und für beide Seiten dürfte sich das Bündnis als zweckmäßig und nützlich herausgestellt haben, auch wenn es immer wieder zu Unstimmigkeiten kam. Die gegenseitige Annäherung wurde aber immer wieder gestoppt - wie sich zeigt sogar von beiden Seiten - offenbar spätestens an Punkten an denen eine Seite gezwungen gewesen wäre, sich mit der anderen Seite zu weitreichend zu identifizieren. Beide Seiten waren also bestrebt, eine gewisse Distanz deutlich aufrechtzuerhalten. Aus päpstlicher Sicht blieben die Franken nach 753/4 immer privilegierte Partner aber dennoch Andere. Die Beziehungen waren dabei, wie wir gesehen haben, keineswegs derart harmonisch, wie sie in der Literatur oft dargestellt werden. ${ }^{803}$

Die Franken wurden auch im neunten Jahrhundert kein Teil des päpstlichen peculiaris populus, obwohl die Kaiserkrönung Karls im Jahr 800 sicher eine noch engere Verstrickung der Beziehungen und eine noch klarere Zuständigkeit der Karolinger für Rom nach sich zog. Karl der Große wurde immerhin vom Papst zum Kaiser gekrönt. Schon vor der Kaiserkrönung hatten karolingische Offizielle in Rom ein

802 Siehe Wolfram, Intitulatio 1, $232 \mathrm{f}$.

803 Siehe Noble, Republic 183, für die traditionelle Darstellungsweise. Dagegen hat Hartmann, Hadrian 265, für die Zeit Hadrians I. folgendes festgestellt: „Die offiziöse Darstellung beider Seiten zeigte sich ... stets bemüht, das Bild einträchtiger Kooperation zwischen Papst und König zu erzeugen. Dass sich hinter der Fassade tatsächlich ein vor allem durch Spannungen ausgezeichnetes Verhältnis verbarg, konnte indes nicht vollends versteckt werden." Siehe zu dieser Frage sehr ausführlich ebd., 197-265. 
Gerichtsverfahren abgehalten, bei dem der äußerst umstrittene Papst Leo III. von allen Anschuldigungen freigesprochen wurde. Und schon knapp davor waren im neu gebauten päpstlichen Triclinium im Lateran Leo und Karl der Große zu Füßen des H1. Petrus kniend abgebildet worden, auch wenn der Papst zweifellos zur Rechten des Apostels den bedeutenderen Platz einnimmt. Berechtigterweise kann man sich fragen, ob mit der Rangerhöhung für den Frankenkönig und eigentlich schon mit den Ereignissen seit 798/799 auch eine Inkorporation Roms in dessen Herrschaftsgebiet einherging. Klar ist, dass am Ende des achten Jahrhunderts die Beziehungen des Papstums zu den Karolingern rechtlich auf eine neue Ebene gehoben wurden. Auch in den Briefen redete Leo III. den neuen Kaiser nicht mehr als fränkischen Herrscher an, sondern gestand ihm eine universelle Position durchaus zu. ${ }^{804}$ „Die Franken“ kommen in den Briefen Leos nach 800 gar nicht mehr vor. Sie gehen als Untertanen des Kaisers im Prinzip vollständig im neuen westlichen imperium auf, während die Stadtrömer weiterhin distinkt bleiben. Das zeigt auch der komplizierte Titel Karls des Großen: Serenissimus Augustus a Deo coronatus magnus, pacificus, imperator Romanum gubernans imperium, qui et per misericordiam Dei rex Francorum et Langobardorum. Besonders die Wendung Romanum gubernans imperium ist für uns hier von Interesse. Thomas Noble schreibt dazu in seiner Republic of St. Peter: „The odd phrase ..., which was not a recent invention but a formula taken over from Roman [gemeint im Sinne von ,altrömisch'] documents probably found at Ravenna, was designed to include the Romans in the empire without acknowledging that the empire itself was Roman, that it had been created by the Romans, or that it was centered on them. “805 Abgesehen von den Schwierigkeiten, in die man gerät, wenn man in dem Zitat versucht, festzulegen, von welchen ,Romans' bei welcher Nennung die Rede ist, handelt es sich hierbei um die Einschätzung der eigentümlichen Formulierung, die die wahrscheinliche Intention der Beteiligten am besten auf den Punkt bringt. Rom sollte nicht im Reich Karls des Großen aufgehen, eher handelte es sich bei seiner Herrschaft um eine Art Protektorat - wiederum ist davon auszugehen, dass diese Formulierung die Befindlichkeiten von Karolingern und Papsttum widerspiegelt. Auch die Briefe Leos III. und seiner Nachfolger lesen sich weiterhin wie die einer

804 In den Briefen Leos wurde folgende Adresszeile verwendet: Dom ino pi Is Simo E T SEREnissimo, VICTORI AC TRIUMPHATORI, FILIO AMATORI DEI ET DOMINI NOSTRI IESU CHRISTI, KArolo augusto leo episcopus Servus servorum dei, siehe zum Beispiel: Leo, ep. 2, ed. Hampe 89.

805 Noble, Republic 296. Zu allen Teilen der Titulatur siehe auch Peter Classen, Romanum gubernans imperium. Zur Vorgeschichte der Kaisertitulatur Karls des Großen, in: Deutsches Archiv 9 (1952) 103-121. Classen hebt besonders hervor, dass die meisten Teile der Titulatur aus jener des oströmischen Kaisers entlehnt wurden. 
unabhängigen Instanz. Vom Gefühl her gehörten die Karolinger immer noch nicht zu den eigenen Leuten des Papstes, sie bleiben auch im neunten Jahrhundert Andere, wenn sie auch rechtlich und zeitweise persönlich den jeweiligen Päpsten durchaus nahestehen konnten, ja gemeinhin als Freunde Roms gelten konnten.

Wie „die Franken“ verschwanden im neunten Jahrhundert auch „die Langobarden“ zunehmend aus den päpstlichen Schriften - mit Ausnahme des Prinzipats von Benevent und seiner Nachfolgefürstentümer, die eine eigenständige Entwicklung bis zur normannischen Eroberung nahmen. Dieser Bereich ging auch in der päpstlichen Wahrnehmung im „überethnischen“ Königreich Italien auf. Doch nicht nur in dieser Entwicklung der Wahrnehmung gleichen sich Franken und Langobarden. Zwar fällt im Vergleich der beiden gentes zunächst die deutliche Diskrepanz in der Darstellung auf, die in der Historiographie seit dem achten Jahrhundert bis heute konsistent betont wird. In der päpstlichen Wahrnehmung waren sich die beiden Gruppen aber im Grunde nicht unähnlich. Beide waren als gentes keine Römer, ein Umstand, der besonders im Fall der Franken bisweilen absichtlich herausgestrichen wurde, um eine gewisse Distanz zu betonen. Besonders im Vergleich mit „Griechen“ und Sarazenen (die im folgenden Kapitel 6 analysiert werden) zeigt sich, dass Langobarden und Franken auf ähnliche Weise im Hinblick auf Othering und Sameing trotz aller Probleme und Ungereimtheiten für die Päpste verhältnismäßig einfach zu behandelnde Gruppen waren, bei denen es auch für die Gestaltung des römischen Diskurses über sie nicht sehr viel Aufwand bedurfte. Sie waren einfach von den Romani und dem peculiaris populus zu unterscheiden und ebenso einfach als relativ homogene Gruppen porträtierbar. 


\section{Das neunte Jahrhundert und die sarazenische Bedrohung}

\subsection{Die Päpste und die Sarazenen im achten und neunten Jahrhundert}

Im Lauf des neunten Jahrhunderts begannen die Vorstöße der Sarazenen ${ }^{806}$ im Zuge ihres Fortschreitens rund um das Mittelmeer auch das italienische Festland zu betreffen, nachdem die Halbinsel zuvor lange relativ ruhig geblieben war. ${ }^{807}$ Zunächst griffen verschiedene sarazenische Söldnereinheiten im Auftrag aller lokalen Machthaber - sowohl der langobardischen als auch der nominell dem Oströmischen Reich unterstellten - in die Auseinandersetzungen in Süditalien ein. Da die sarazenischen Gruppen nicht permanent bezahlt werden konnten und sie zudem als Teil der Bedingungen von verschiedensten Friedensschlüssen nicht mehr weiter beschäftigt werden durften, begannen einige von ihnen, auf eigene Rechnung in Süditalien zu operieren - und das bisweilen mit durchschlagendem Erfolg. Im Jahr 847 wurde Bari von einer dieser Sarazenengruppen eingenommen und in der Stadt und ihrem Umland bis weit nach Apulien hinein ein Emirat eingerichtet, das bis $87 \mathrm{I}$ Bestand hatte. ${ }^{808}$

Im Jahr 846 hinterließ ein sarazenischer Raubzug gegen Rom eine Spur der Verwüstung im Dukat von Rom. Dieser Angriff führte zu einem fundamentalen Umdenken des Papsttums in einer Reihe von Fragen. Diese letzte Fallstudie wird also mehr noch als die anderen in der Arbeit enthaltenen das Augenmerk darauf legen, inwiefern die Interaktion mit den Fremden eine Veränderung auch bei den Päpsten selbst bewirkte: Erstens änderte sich die päpstliche Wahrnehmung der Situation des eigenen Machtbereichs und damit verbunden auch der christlichen Umwelt des

806 In der modernsten Forschung wird diese bei weitem häufigste Quellenbezeichnung für die Muslime des Frühmittelalters wieder sehr häufig verwendet. In Italien ist sie auch insofern am Zutreffendsten, da der Begriff auch die in der islamischen Expansion massiv beteiligten Berber miteinbezieht, während sie bei der Verwendung von „Araber“ explizit ausgeschlossen wären. Zur Verwendung des Begriffs siehe Tolan, Saracens und Rotter, Abendland, Einleitung.

807 Einen sehr guten Überblick aus orientalistischer Sicht bietet Hugh Kennedy, The Great Arab Conquests. How the Spread of Islam Changed the World We Live In (Philadelphia 2007).

808 Zur Situation in Süditalien im neunten Jahrhundert siehe Kreutz, Before the Normans 18-74. Zum Emirat von Bari siehe Giosuè Musca, L'emirato di Bari, 847-871 (Bari ${ }^{2} 1978$, 1967). Siehe auch Clemens Gantner, Die Wahrnehmung des Islam und der Sarazenen im frühmittelalterlichen Europa (ungedr. Univ. Dipl., Wien 2005) 77-120. 
Papsttums in Italien. Zweitens änderten die Päpste unter diesem Druck von Außen auch ihre theologische Position zum Krieg gegen Heiden beziehungsweise gegen religiös und kulturell stark unterschiedliche Andere.

Trotzdem soll auch das Bild der Sarazenen von der Warte des Papsttums aus behandelt werden. Schließlich handelt es sich bei den Sarazen um diejenigen der in dieser Arbeit behandelten Anderen, die sich bei weitem am meisten vom Papst und seinem Umfeld abhoben und zwar auf dem Gebiet der Religion und wahrscheinlich auch der Herkunft und der Sprache. Alleine schon die Verwendung der Bezeichnung „Sarazenen“ (und sogar noch mehr der ebenfalls gebräuchlichen biblisch konnotierten Synonyme Agareni und Ismaeliten ${ }^{809}$ ) ist automatisch ein Akt des Otherings, auch wenn die Päpste in dieser Hinsicht an den Diskurs im christlichen Bereich des Mittelmeeres gebunden waren und sich in dieser Hinsicht nicht wesentlich von der Mehrheit der lateinischen Quellen abhoben. ${ }^{810}$ Aber auch die Sarazenen waren im neunten Jahrhundert fraglos im Kulturraum des Mittelmeeres auf der kulturellen Ebene völlig integriert. Auch sie waren nun Erben des Römischen Reichs, ein Faktum, das man bei aller Dämonisierung des Gegners in den Quellen nicht außer Acht lassen darf.

Die erste Nennung von Sarazenen in päpstlichen Quellen des achten Jahrhunderts findet sich in der bereits vielfach besprochenen Vita Gregors II. Hier wird unter anderem über die lange Belagerung Konstantinopels durch Truppen des Kalifats berichtet - für die Bevölkerung der Stadt wird die exorbitante Opferzahl von 300.000 angegeben. Die Befreiung der Stadt durch Kaiser Leon III. wird nicht verschwiegen, aber doch relativ emotionslos referiert, sicherlich deshalb, weil der Kaiser im Zuge des Steuerstreits jeglichen Kredit in Rom verspielte. ${ }^{811}$ Noch davor wird aber kurz der Fall des wisigotischen Spaniens (7 I I, eigentlich vor Gregors Pontifikat) berichtet und im Zuge dessen auch auf die Situation in Aquitanien eingegangen:

Im I . Jahr [der Besatzung Hispaniens durch die Sarazenen] starteten die Franken einen großen Feldzug gegen die Sarazenen, umzingelten sie und vernichteten sie. Denn 375.000 von ihnen wurden an nur einem Tag getötet, wie ein Brief der Franken an den Bischof berichtet; in derselben Schlacht seien auch I500 Franken gestorben. Was die Schwammbrote $^{812}$ betrifft, die ihnen im Jahr zuvor vom genannten Mann als Segnung zum Verzehr an ihrem Tisch geschickt worden waren: bevor der Krieg begann, hatte Eudo, der princeps

809 Vgl. zu diesen Bezeichnungen z. B. Tolan, Saracens 10f., zur Sichtweise Isidors von Sevilla.

810 Zum herrschenden Diskurs über die Sarazenen im lateinischen Westen siehe Tolan, Saracens, und Gantner, Wahrnehmung.

811 LP I, 401f. Zum Steuerstreit mit Kaiser Leon III. siehe oben, Kap. 3.2.2.

812 Siehe dazu oben, Kap. 5.8.1, Anm. 756. 
Aquitaniens, sie seinen Leuten in kleinen Stücken zu Essen gegeben. Von jenen, die daran teilgehabt hatten, wurde weder einer verwundet noch getötet. ${ }^{813}$

Die Sarazenen wurden also in der hier erwähnten Auseinandersetzung, gemeint ist die Schlacht von Toulouse (72r), entscheidend geschlagen. Die Vita Gregors II. überliefert auch den Namen des Anführers der Franken, nämlich Eudo. Dieser ist es auch, der dem Papst in einem Brief von der Schlacht berichtet: Der Sieg fiel unter anderem wegen der vom Papst gesandten geweihten Schwammbrote sehr deutlich aus. All jene, die kleine Stücke der Schwammbrote gegessen hatten, blieben völlig unversehrt, und auch insgesamt sollen nur I500 Franken in der Schlacht gefallen sein, während laut LP 375.00o Sarazenen den Tod fanden. ${ }^{814}$ Schon hier griff der Papst also aus römischer Sicht zugunsten der Franken ins Kriegsgeschehen ein.

Fast nur nebenbei muss auch ein weiterer Umstand kurz erwähnt werden: Eudo war ein ausgewiesener Gegner des Karl Martell - umso bemerkenswerter ist es, dass er im LP die Rolle des Helden einnehmen darf, während der Sieg des Karolingers über zehn Jahre später in der Schlacht von Poitiers keine Erwähnung findet. Das änderte übrigens weder die Überarbeitung der Vita Gregors II. noch jene der Vita Gregors III. Die Passage zeigt uns, dass Papst Gregor II. durchaus gute Kontakte zu den Franken hatte, wenn auch zu einer Gruppe, die sich nicht durchsetzen sollte. Das ist auch ein Indiz, dass die Päpste keineswegs schon damals gezielt auf ein fränkisches Bündnis hinarbeiteten, sondern generell gute Kontakte mit vielen Machthabern im Lateinischen Westen pflegten.

Sowohl in der Belagerung von Konstantinopel als auch in der Schlacht von Toulouse sind die Sarazenen jedenfalls zweifelsfrei die Bösen, deren Niederlage positiv vermerkt werden kann, während ihre Erfolge im LP nur erwähnt werden, um die Rückschläge plausibel erklären zu können.

Es ist interessant, dass sich nach dem Pontifikat Gregors II. lange Zeit keine päpstliche Quelle mehr mit den Sarazenen auseinandersetzt, obwohl sich reichlich Stoff für Kommentar geboten hätte. Im Frankenreich gab es etwa die Schlacht von Poitiers 732 oder die Rückeroberung von Narbonne durch König Pippin im Jahr 759.

813 LP I, 401 (ältere Version zitiert): Undecimo vero anno generalis facta Francorum motio contra Sarracenos circumdantes interemerunt. Trecenta enim septuaginta quinque milia uno sunt die interfecti, ut Francorum missa pontificis epistola continebat; mille tantum quingentos ex Francis fuisse mortuos in eodem bello dixerunt, quod anno praemisso in benedictione a praedicto viro eis directis tribus spongiis quibus ad usum mense pontificis apponuntur, intra qua bellum committebatur, Eodo, Aquitanie princeps, populo suo per modicas partes tribuens ad sumendum, ex eis ne unus vulneratus est nec mortuus ex his qui participati sunt.

814 Die Zahl ist zweifellos weitaus übertrieben. Aber auch spanische Chroniken beschreiben die Schlacht als große Niederlage, siehe Tolan, Saracens 82. 
Und das Kaiserreich hatte im achten Jahrhundert ohnehin einige militärische und diplomatische Erfolge im Osten zu vermelden, die durchaus berichtet hätten werden können.

Doch die nächste Beschäftigung mit Sarazenen, von der wir heute Kenntnis haben, erfolgte erst im Pontifikat Hadrians I., wobei wir hier über einen recht ungewöhnlichen Brief verfügen, von dem an anderer Stelle bereits die Rede war. ${ }^{815}$ Brief CC 59 ist auch für das Sarazenenbild von Relevanz. Es handelt sich um eine Antwort Papst Hadrians auf einen nicht überlieferten Brief Karls des Großen. Die Kommunikation erfolgte ungefähr im Jahr 776, eine genaue Datierung ist aber nicht möglich. ${ }^{816}$ Karl der Große machte in seinem Schreiben dem Papst offenbar Vorwürfe, dass er Sklavenhandel zwischen seinen römischen Untertanen und Sarazenen zumindest dulde. Bei aller nötigen Diplomatie lässt die Antwort Hadrians an Deutlichkeit nichts zu wünschen übrig. Er informierte den Frankenkönig, dass keineswegs Römer, sondern vielmehr Langobarden, die, wie implizit klar wird, aus Tuszien stammen, mit griechischen $^{817}$ Sklavenhändlern Geschäfte machten:

Wir antworten hiermit auf Eure honigsüßen Schreiben betreffend den Verkauf von Sklaven, welche (wie Ihr sagt) von unseren Römern an die unaussprechliche gens der Sarazenen verkauft worden sein sollen. Doch bis jetzt sind wir, was Gott verhindern möge, nicht so tief gesunken, um ein solches Verbrechen zu begehen; und wenn es begangen wurde, so wäre es ohne unsere Zustimmung geschehen. Jedoch segeln immer unaussprechliche Griechen an der langobardischen Küste, die diese familiae dann kauften; sie haben auch einen Vertrag (amicitia) mit den Langobarden [dieser Gegend] geschlossen und von diesen Langobarden die Sklaven erhalten. ${ }^{818}$

Wie wir schon gesehen haben, widersprach der Papst den Vorwürfen des Karolingers. ${ }^{819}$ Doch seine Argumentation ist bemerkenswert: Der Papst verurteilte weder den Sklavenhandel noch widerlegte er in irgendeiner Weise die Vorstellung, dass sarazenische Händler in Rom Handel trieben. ${ }^{820}$ Vielmehr wies er auf die ökono-

$815 \mathrm{Zu}$ CC 59 siehe oben, Kap. 4.3 und 5.6.2.2.

816 Siehe dazu oben, Kap. 5.6.2.2.

$817 \mathrm{Zu}$ den „Griechen“ siehe oben, Kap. 3.2 und 4.

818 CC 59 ( $\mathrm{JE}^{2}$ 2426), ed. Gundlach 585. Ein längeres Zitat des Briefes findet sich sowohl in Kap. 4.3 als auch in Kap. 5.6.2, weswegen das Zitat hier auf das absolut notwendige Minimum beschränkt wurde. In Kapitel 6 werden die $\mathrm{JE}^{2}$ Nummern der Stücke konsequent ausgewiesen, weil es für Teile der Papstforschung zum neunten Jahrhundert die Vergleichbarkeit ganz wesentlich erleichtert.

819 Siehe dazu ausführlich oben, Kap. 5.6.2.2.

820 Und tatsächlich florierte im achten und neunten Jahrhundert der Sklavenhandel zwischen Italien und dem islamischen Bereich der Mittelmeerwelt, siehe Charles Verlinden, L'esclavage dans 
mischen Zwänge hin, denen die Langobarden nördlich von Rom ausgesetzt waren: aufgrund von Hungersnot würden die Langobarden ihre eigenen Leute - der Terminus familia könnte sogar die eigenen Verwandten bedeuten! - an die griechischen Sklavenhändler verkaufen. ${ }^{821}$

Allerdings müssen wir dem Brief gegenüber relativ vorsichtig sein, da Hadrian ja darauf bedacht war, jegliche Schuld von sich zu weisen und wir somit nicht entscheiden können, wie sehr er sich dabei an der Wahrheit orientierte. Aber wir erhalten, wie auch schon über Langobarden und „Griechen“, dennoch wertvolle Informationen über die päpstliche Wahrnehmung der Sarazenen. Letztere werden hier necdicendi genannt, ein Ausdruck, der, wie auch nefandi, im achten Jahrhundert für ausgewiesene Feinde des Papstes verwendet wurde. ${ }^{822}$

Doch wir müssen auch in diesem Fall mit dem Urteil ein wenig zurückhaltend sein, da der Papst in dem Brief offenbar direkt auf ein Schreiben antwortet. Dessen Wortlaut kennen wir nicht, es ist aber durchaus möglich, dass sich der Papst in seiner Formulierung an seiner Vorlage orientierte. Interessant ist auch, dass die „Griechen“ an dieser Stelle sprachlich gespiegelt werden und ebenfalls als necdicendi tituliert werden, wahrscheinlich um sie mit den angeblichen Übeltätern Karls, den Sarazenen, auf eine Stufe zu stellen. So gesehen lässt sich mit dem gewählten Adjektiv nur sehr vorsichtig argumentieren und es kann nicht als signifikant für die päpstliche Wahrnehmung der Sarazenen gelten.

Doch alleine die Formulierungen, in denen der Brief gehalten ist, legen einen bedeutsamen Schluss nahe: Wir können davon ausgehen, dass in Rom Handel mit Sarazenen betrieben wurde, denn sonst wäre es Hadrian ein Leichtes gewesen, diesen Umstand in Abrede zu stellen. Es scheint so, als sei die Präsenz sarazenischer Händler in den römischen Häfen Portus, Ostia und Centumcellae kein sehr außergewöhnliches Phänomen gewesen.

Diese Spekulation wird sogar von einer arabischen Quelle untermauert. Das berühmte Wörterbuch oder Lexikon der Ortsnamen des Jakut (Yāḳūt) aus dem frühen I3. Jahrhundert überliefert ein langes Zitat aus dem verlorenen Werk des al-Walīd ibn Muslim al-Dimashqī, das dieser um 800 verfasste. ${ }^{823}$ Der Bericht lautet in der englischen Übersetzung wie folgt:

l'Europe médiévale, Bd. 2, Italie, colonies italiennes du Levant, Levant latin, Empire byzantin (Gent 1977) 114f. und McCormick, Origins.

821 CC 59, ed. Gundlach 585: Sed a Langobardis, ut praefati sumus, plura familia venundata sunt, dum famis inopia eos constringebat. Siehe oben, Kap. 5.6.2.2.

822 Vgl. oben, Kap. 5.3.1, bes. Anm. 546.

823 Al-Walīd ibn Muslim al Dimashqī (i.e. aus Damaskus) starb im Jahr 810 (AH 194). Er wird als Verfasser einer sogenannten musannaf, einer religiösen Sammlung, angegeben, die leider, wie so viele 
And al-Walīd ibn Muslim al Dimashqī said: One of the merchants (tujjär) told me: We went on a sea voyage and the ship dropped us on the shore of Rome. And we sent to them: ,We have intended [to deal with] you and so send us an escort (rasül).'After this we went out with him. We climbed a mountain on our way and, lo and behold, there was something green like the sea. So we said „God is great!“ The escort said to us: ,Why did you say, God is great?'We said: ,This is the sea and it is our custom to say, God is great' when we see the sea.' So he laughed. And he said: ,These are the roofs (suqüf) of Rome, and all of them are made of lead (murașsașat). He said when we reached the city, ,Lo and behold, its circumference was forty miles.' In each mile of this wall there is an open gate. When we reached the first gate, lo and behold, there was the market (suq) of the veterinaries [or "farriers": bayatira] and something like it. Then we climbed a flight of stairs. Lo and behold, there was the market (suq) of the money changers (șayärifa) and those who sell textiles (bazzāzinn). Then we entered the city and lo and behold, in its midst was a spacious great tower. On one side of it there was a church; the mithrab [presumably the sanctuary] was facing the west while its door faces the east. And in the midst of the tower there was a pool, the floor of which was made of copper out of which gushed forth all the water of the city, and in the midst of the pool there was a stone column. On it there was a statue also of stone and so I asked one of the inhabitants of the city and said,What is this?' He said, ,The one who built this city said to its people: ,Do not fear for your city until a people of this description comes to you, and they will be the ones who capture it. ${ }^{\text {(824 }}$

Der Text beschreibt florierende Märkte in Rom, die auch von weit her gereiste Händler anziehen, anscheinend auch Araber. Rom als Stadt wird - sicherlich übertreibend - als in voller Blüte stehend beschrieben, was einen fast dazu verleiten möchte, hier auch den Einfluss literarischer Topoi, die noch das kaiserzeitliche Rom meinen, zu vermuten. Die Quellen legen aber jedenfalls nahe, dass das Auftreten von Sarazenen in den römischen Häfen nicht als besonders auffällig galt, ebenso wie auch in Süditalien zumindest im neunten Jahrhundert der Handel mit Sarazenen an der Tagesordnung war. ${ }^{825}$ Und sie wurden offenbar nicht als besonders gefährliche Gruppe wahrgenommen.

frühislamische Texte nur in Fragmenten erhalten ist. Siehe G. H. A. Juynboll, Musannaf, in: Encyclopaedia of Islam, 2. Aufl., Bd. 7, ed. C. E. Bosworth/E. van Donzel/W. P. Heinrichs/Ch. Pellat (Leiden 1993) 662f. Zu Yāḳūt ibn 'Abdallāh, siehe Cl. Gilliot, Yākūūt al-Rūmī, in: Encyclopaedia of Islam, Second Edition, Bd. 11, ed. P. Bearman/Th. Bianquis/C. E. Bosworth/E. van Donzel/W. P. Heinrichs (Leiden 2002) 264.

824 Yāḳūt ibn 'Abdallāh, zitiert von McCormick, Origins 622f. Übersetzung von Irfan Shahid, der der Edition in Jacut's geographisches Wörterbuch, 11 Bde., ed. Ferdinand Wüstenfeld (Leipzig 1867), Bd. 2, 868, folgt.

825 Auch die süditalienischen Quellen erwähnen den Handel mit Sarazenen kaum (was auch auf die 
Es könnten Berichte wie eben jener al-Walīds gewesen sein, die die Nachricht vom römischen Reichtum in der muslimischen Welt verbereiteten. ${ }^{826}$ Doch diese Berichte zogen nicht nur Händler, sondern auch Räuber und Plünderer an. Im Jahr 846 griff schließlich eine recht große sarazenische Streitmacht, die wahrscheinlich von Nordafrika aus operierte, Rom an. Es handelte sich zweifellos nicht um eine einfach Piratenbande, doch Peter Partner geht wohl zu weit, wenn er schreibt der Angriff „was not a casual raid, but the operation of a large army which must have been carefully planned by the Aghlabid government. “827 Es ist keineswegs als erwiesen anzusehen, dass die aghlabidischen Herrscher Nordafrikas oder ihre Untergebenen, die auf Sizilien operierten, etwas mit dem Angriff zu tun hatten. ${ }^{828}$ Vielmehr ist es zumindest wahrscheinlich, dass es sich um eine eher privat finanzierte und geplante Aktion handelte, so wie die ein Jahr später erfolgte Eroberung Baris durch Khalfūn, der angeblich sogar berberischer Herkunft war. ${ }^{829}$ Bemerkenswert ist auch, dass Rom vor dem Angriff vom fränkischen marcensis (Markgraf) von Korsika gewarnt wurde ${ }^{830}$, was eigentlich darauf hindeuten könnte, dass die sarazenische Flotte von Westen kam. Doch andererseits berichtet der LP in der Vita Leos IV. ganz ausdrücklich, dass die Schiffe aus Afrika kamen. ${ }^{831}$ Die Sarazenen hatten jedenfalls keine Schwierigkeiten, die Befestigungen der Küstenorte Ostia und Portus zu überwinden, obwohl diese erst einige Jahre zuvor von Papst Gregor IV. ausgebaut worden waren - explizit um einer möglichen Attacke einer sarazenischen Flotte widerstehen zu können. ${ }^{832}$ Einer der

Alltäglichkeit des Phänomens hindeuten könnte), doch das anonyme Chronicon Salernitanum aus dem zehnten Jahrhundert zeigt in einer Episode, wie sehr die Präsenz von Sarazenen im Salerno des neunten Jahrhunderts Teil des täglichen Lebens war: Es wird berichtet, dass ein sarazenischer Händler namens Arrane, der in der Gunst princeps Waifers stand, die entscheidene Warnung übermittelt hatte, die es den Stadtherren ermöglichte, sich gegen den großen, von den Aghlabiden Nordafrikas direkt organisierten und angeführten Feldzug im Jahr 871 zeitgerecht zu wappnen. Siehe Chronicon Salernitanum (ed. Ulla Westerbergh, Acta Universitatis Stockholmensis, Studia Latina Stockholmensia 3, Lund/Stockholm 1956) 122f. und ebd., 99f. zu einer sarazenischen Delegation in Salerno.

$826 \mathrm{Sehr}$ oft wird in der Historiographie übersehen, dass Rom auch eines der bedeutendsten Handelszentren Italiens war: siehe McCormick, Origins 618-627, und Delogu, L'importazione.

827 Peter Partner, The Lands of St Peter. The Papal State in the Middle Ages and the Early Renaissance (Berkeley, California 1972) 56f.

828 Wie es etwa auch Ekkehard Eickhoff, Seekrieg und Seepolitik zwischen Islam und Abendland. Das Mittelmeer unter byzantinischer und arabischer Hegermonie (650-1040) (Berlin 1966) 182f., ohne Angabe weiterer Belege behauptet.

829 Musca, L'emirato di Bari 35-37.

830 LP II, 99 (Vita Sergius II.)

831 LP II, 107.

832 LP II, 81f. (Vita Gregors IV.). 
Versionen der LP-Vita Papst Sergius' II. (844-847) zu Folge verfügten die Verteidiger der Häfen weder über die nötige Ausbildung noch über die notwendige Truppenstärke, um ausreichende Gegenwehr leisten zu können. Die Vita berichtet auch, dass die Sarazenen Rom erreichten, bricht danach jedoch leider ab:

Sie [die Sarazenen] bestiegen mit ihren Fuß- und Reitertruppen die Schiffe und eilten Richtung Rom. Den ganzen Tag fuhren sie mit ihren Schiffen und bei der Dämmerung hatten sie den vereinbarten Ort erreicht; dort strömten die Reiter aus den Schiffen und griffen überraschend die Kirche des Heiligen Apostelfürsten Petrus an und begingen unaussprechliche Missetaten. Daraufhin kamen die anführerlosen Kontingente der Römer auf den campus Neronis, um sich den Bewaffneten zu stellen ... ${ }^{83}$

Die Sarazenen fuhren also mit ihren Schiffen den Tiber hinauf und griffen von ihrem wohl in der Nähe der Stadt gelegenen Lager sofort die Peterskirche an. Die römische Miliz trat ihnen daraufhin in der Vatikangegend entgegen, vom Ausgang des Gefechts erfahren wir im LP jedoch nichts mehr - wir werden aber gleich sehen, dass die Römer offenbar unterlagen. Interessant ist es vielleicht noch, zu sehen, dass die römische Miliz als führerlos bezeichnet wird. Es wird jedoch nicht klar, warum das so ist, sodass vielleicht vermutet werden kann, dass dieser Kommentar gegen den Papst und seine unmittelbaren Getreuen gerichtet war, genauso wie der Rest des Berichts aus dem Codex Farnese im Wesentlichen eine Anklage gegen Sergius darstellt..$^{834}$

Der hier zitierte Bericht ist nur in einem Zusatz zur Vita Sergius II. erhalten, der in einer einzigen Handschrift enthalten war, die jedoch anscheinend noch aus dem neunten Jahrhundert stammte, dem sogenannten Codex Farnese. Diese Handschrift ist jedoch mittlerweile leider verschollen, es existiert nur noch eine Edition aus dem 18. Jahrhundert, die auch Duchesne in seiner Ausgabe verwendet hat. ${ }^{835}$

Auch als die Abschriften des i7. und I8. Jahrhunderts gemacht wurden, war die Handschrift nur noch als Fragment vorhanden, der detailliert beginnende Bericht,

833 Für den ganzen Bericht siehe LP II, 99-101, hier 100f.: Et [Sarraceni] iter assumentes navigio et pedestres simul et equestres coeperunt Romam festinare. Qui tota die simul cum navibus properantes, diluculo venerunt ad loca ubi constituerant; ibique ex navibus examinantes equestres, ecclesiam beati Petri apostolorum principis nefandissimis iniquitatibus praeoccupantes invaserunt. Tunc omnes coetus Romanorum sine capite positi, campo qui dicitur Neronis, armatos obviati .......

834 Denn davor wird im Codex Farnese-Text von den Verfehlungen Sergius' II. und insbesondere seines Bruders Benedikt berichtet, welchem die wahre Macht im Lateran zugeschrieben wird, siehe LP II, 97-99 und auch Pseudo-Liutprand, PL 129, Pseudo-Luitprandi liber de pontificum Romanorum vitis, col. 1149-1256, hier 1244.

835 Duchesne, LP I, CXCIXf. 
den wir oben gesehen haben, bricht deshalb leider genau zu dem Zeitpunkt ab, als die Sarazenen gegen Rom vorrücken. Die weiteren Ereignisse sind uns daher nur aus anderen Quellen überliefert, aus fränkischen Annalen und süditalienischen Chroniken. Offenbar griffen in Mittelitalien stationierte fränkische Kämpfer in die Auseinandersetzung ein. Es ist möglich, dass dieses Heer von Ludwig II., König von Italien und Sohn Kaiser Lothars I., angeführt wurde. Ludwig war erst 844 zum König erhoben worden. ${ }^{836}$ Die Information, dass der König selbst den Entsatz für Rom anführte, ist allerdings erst in der Papstgeschichte des sogenannten Pseudo-Liutprand enthalten. ${ }^{837}$ Dieser Text basiert auf einer Version des LP, die jener des Codex Farnese zumindest für die Päpste des neunten Jahrhunderts sehr ähnlich war, doch der Verfasser des Pseudo-Liutprand hatte sicherlich noch eine vollständige Version vorliegen, was die Überlieferung besonders wertvoll macht. ${ }^{838}$ Allerdings sind leider alle Papstviten sehr stark gekürzt wiedergegeben, sodass sich nur folgendes Epitom erhalten hat:

Und weil es unter den Christen niemand gab, der dieses Übel berichtigen hätten können, schickte die göttliche Macht die Geißel der Heiden um die Sünden der Christen zu strafen. Es kamen nämlich die Sarazenen über sie, die unzählige Menschen töteten und viele Städte und Kastelle einnahmen und, nachdem sie die Beute an sich genommen hatten, niederbrannten: hierauf schlugen die Eroberer den König in die Flucht und zogen sich, nachdem sie viele gefangen und auch getötet hatten, mit vielen Menschen und ihrer gesamten Beute beladen, zurück. ${ }^{839}$

Auch süditalienische Quellen berichten, dass das römische und das karolingische Heer besiegt wurden: Eine sehr detailreiche Schilderung liefern etwa die sogenannten Chronica Sancti Benedicti Casinensis. ${ }^{840}$

836 Prudentius, Annales Bertiniani, a. 846 (ed. Georg Waitz, MGH SS rer. Germ. in us. schol. [5], Hannover 1883) 34, der jedoch eine Beteiligung König Ludwigs II. nicht berichtet. (Siehe auch die Übersetzung The Annals of St-Bertin [trans. Janet L. Nelson, Manchester Medieval Sources, Manchester/New York 1991] 63.)

837 Pseudo-Liutprand, PL 129, col. 1245.

838 Siehe Wilhelm Levison, Die Papstgeschichte des Pseudo-Liudprand und der Codex Farnesianus des Liber Pontificalis, in: Neues Archiv, 36 (1911) 415-438 und Detlef Jasper, Die Papstgeschichte des Pseudo-Liudprand, Deutsches Archiv, 31 (1975) 17-107, hier 54-73.

839 Pseudo-Liutprand, PL 129, col. 1245: Et quia nemo erat Christianorum, per quem hoc malum corrigeretur, misit divina potentia flagellum paganorum ad ulciscenda peccata Christianorum. Nam supervenientes Saraceni innumeros hominum interfecerunt, castella et urbes multas captas accepta praeda igni dederunt: demum regem expugnantes fugaverunt, et, multis captis et interfectis, maxima hominum et omnium rerum praeda onusti reversi sunt.

840 Chronica Sancti Benedicti Casinensis, 6 (ed. Georg Waitz, MGH SS rer. Lang., Hannover 1878) 
Doch trotz ihres militärischen Erfolges gelang es den Sarazenen schlussendlich nicht, Rom einzunehmen, vielleicht, weil sie sich in kleinere Einheiten aufteilten. Sie plünderten allerdings die wesentlichen römischen Kirchen außerhalb der Mauern, insbesondere St. Peter und S. Paolo fuori le Mura. ${ }^{841}$

Es ist jedoch zumindest möglich, dass die sarazenische Flotte auf ihrem Heimweg kurz vor der (afrikanischen?) Küste Schiffbruch erlitt und der Raubzug somit doch noch in einem Desaster endete. Das berichten die päpstlichen und süditalienischen Quellen jedenfalls unisono. ${ }^{842}$

Der Raubzug von 846 führte jedenfalls zu einer fundamentalen Veränderung der päpstlichen Politik. Der neue Papst Leo IV. (847-853) scheint sich als Speerspitze gegen die Feinde definiert zu haben, deren Rückkehr bald erwartet wurde. ${ }^{843}$ Und diese Annahme erwies sich auch als korrekt, denn bereits 849, zweieinhalb Jahre nach seiner Weihe, erhielt der Papst die Gelegenheit sich als Führer einer Koalition der süditalienischen Küstenstädte Neapel, Amalfi und Gaeta gegen einen neuen sarazenischen Angriff zu profilieren. In der Schlacht von Ostia konnte eine sarazenische Flotte, die wahrscheinlich von der Schlagkraft her mit jener von 846 durchaus vergleichbar war ${ }^{844}$, besiegt werden. Der LP schreibt den Sieg jedoch vor allem göttlicher Unterstützung zu, denn eine Sturmfront hatte die feindliche Flotte fast völlig aufgerieben. Das Schlechtwetter war aufgrund des Gebets Leos IV., das im LP als direkte Rede wiedergegeben wird, aufgezogen. ${ }^{845}$

468-488, hier 472f. und (ed. Luigi Andrea Berto, Cronicae Sancti Benedicti Casinensis, Editione nazionale dei testi mediolatini, 15, Florenz 2006) 18f. Zu dem Text siehe Walter Pohl, Werkstätte der Erinnerung. Montecassino und die Gestaltung der langobardischen Vergangenheit (MIÖG, Ergänzungsband 39, Wien 2001) bes. 85-95.

841 Die beste Zusammenfassung der Ereignisse von 846, die auch die fränkischen Quellen stark in Betracht zieht, ist überraschenderweise in Davis, LP 8, 96f., Anm. 92 enthalten. Berichte finden sich in den Annales Bertiniani, den Gesta Episcoporum Neapolitanorum des Johannes Diaconus, den genannten Chronica Sancti Benedicti Casinensis und in der Chronik des Benedikt von Monte Soratte (der jedoch eine sehr konfuse Narration liefert); siehe auch Herbers, Leo IV., 108-112. Der sarazenische Überfall muss auch ein schwerer Schlag für die römische Wirtschaft gewesen sein. Nach den letzten großen Ausgaben im Pontifikat Leos IV. (die zum Teil von den Franken unterstützt wurden) hatten die Päpste bei weitem nicht mehr so viel Geld zur Verfügung wie ihre Vorgänger zwischen 772 und 846. Siehe dazu die Statistik von Delogu, L'importazione, der jedoch den Aufstieg Amalfis zur Handelsgroßmacht im Mittelmeer als wahrscheinlichste Ursache für den Rückgang der römischen Handelseinkünfte sieht.

842 Chronica Sancti Benedicti Casinensis, 6, ed. Waitz 472f. und LP II, 107.

843 Herbers, Leo IV., 105-134: „Leo als Feld- und Kriegsherr“.

844 Allerdings kamen diese Sarazenen nun von Westen, da sie vor ihrem Angriff auf Italien auf einer nahe Sardinien gelegenen Insel namens „Totarum“ Halt gemacht hatten. Siehe LP II, 117 und Davis, LP 9, 132, mit Anm. 78.

845 LP II, 117-119 (Kapitel 47-54), siehe 118 zu Leos Gebet. Herbers, Leo IV. 114-117 hat gezeigt, dass 
Nach dem Pontifikat Leos IV. haben wir für einige Jahre keine Berichte über eine sarazenische Bedrohung für Rom. Die Pause umfasst gleich die drei folgenden Pontifikate Benedikts III. (855-858), Nikolaus' I. (858-867) und Hadrians II. (867-872). Doch diese Lücke könnte durchaus in der Natur des überlieferten Quellenmaterials begründet sein: Die Quellenlage für den etwa zweieinhalbjährigen Pontifikat Benedikts III. ist ohnehin sehr dürftig, die LP-Viten Nikolaus' I. und Hadrians II. sind hingegen zwar umfangreich, konzentrieren sich jedoch völlig auf die Auseinandersetzung mit Konstantinopel im Zuge der Kontroverse um Patriarch Photios. ${ }^{846}$ Die Briefe der beiden letztgenannten wurden zudem nicht in der konzentrierten Form eines Registers oder Registerauszugs überliefert, sondern über die Adressaten oder Dritte (und hier insbesondere kanonistische Autoren des Hochmittelalters). Keiner der erhaltenen Briefe beschäftigt sich mit Süditalien oder ist dort überliefert. ${ }^{847}$ Dazu kommt aber, dass in dieser Phase Kaiser Ludwig II., dessen Machtbereich sich ausschließlich auf Italien beschränkte, auf dem Höhepunkt seiner Macht angekommen war. Das bedeutete, dass er auch im Süden militärisch eingreifen konnte und dadurch die päpstliche res publica bis zu einem gewissen Grad schützen konnte.

Erst nach dem Fall des Emirats von Bari im Jahr 87 I berichten die Quellen wieder von einer größeren Bedrohung Roms durch Sarazenen. Das klingt zunächst paradox, weil das Emirat die wesentliche Operationsbasis für sarazenische Raubzüge in Süditalien gebildet hatte und somit theoretisch auch eine Bedrohung für Rom dargestellt hätte. Doch tatsächlich büßte Ludwig II. just 87I fast seinen gesamten Einfluss im Süden ein, da die lokalen Machthaber nun meinten, seine Dienste nicht mehr zu benötigen. Der Kaiser wurde also von princeps Adelchis von Benevent gefangen genommen und erst freigelassen, als er schwor, nie wieder einen Fuß in die langobardischen Territorien im Süden zu setzen. ${ }^{848}$

Als Johannes VIII. (872-882) also im Jahr 872 den Papstthron bestieg, war die Situation in Süditalien prekärer und verwirrender als jemals zuvor: Es gab drei langobardische Herrschaftsgebiete, die Prinzipate von Benevent und Salerno und die Grafschaft Capua. Dazu kamen die nominell oströmischen Küstenstädte Amalfi,

das Gebet vor allem der Liturgie des Peter-und-Paul-Festes entnommen wurde. Somit wurde die Schlacht mit den beiden wichtigsten Heiligen Roms verbunden, deren Kirchen zudem 846 geplündert worden waren.

846 Siehe Herbers, Papst Nikolaus und ders., Rom und Byzanz, sowie Bougard, Anastase le Biliothécaire ou Jean Diacre?

847 Siehe JE², Nr. 2662 bis 2953, von denen nur JE² 2858 (Urkunde Nikolaus' I. für Monte Cassino, wahrscheinlich eine Fälschung) sich an einen süditalienischen Adressaten richtet.

848 Erchempert, Historia Langobardorum Beneventanorum (ed. Georg Waitz, MGH SS rer. Lang, Hannover 1878) 231-264, hier 247f. und Chronicon Salernitanum, ed. Westerbergh, 121f. Siehe Kreutz, Before the Normans 45-47. 
Neapel und Gaeta. Daneben hatten auch die Widonen, die Machthaber des Dukats von Spoleto, großen Einfluss im Süden. Das spätere neunte Jahrhundert sah zudem ein Wiedererstarken des Oströmischen Reichs, als zunächst 875 Bari eingenommen wurde (nun von den langobardischen Stadtherren) und im Jahr 880 Tarent eingenommen werden konnte. ${ }^{849}$ Dazu kamen schließlich noch die verschiedenen sarazenischen Gruppen, bei denen es sich um kleine Söldnerkontingente, bisweilen aber auch um mittelgroße Gruppen handelte, die jeweils auf eigene Rechnung in der Region operierten..$^{850}$

Insofern überrascht es nicht, dass ein großer Teil der 3I4 erhaltenen Briefe Johannes' VIII., die in der Teilkopie seines Briefregisters für die Jahre 876 bis 882 erhalten sind ${ }^{851}$, sich in der einen oder anderen Weise mit der sarazenischen Bedrohung für Rom beschäftigt. Die Briefe zeigen, dass Johannes VIII. es zu seiner Aufgabe gemacht hatte, Rom und Süditalien von den Sarazenen zu befreien. ${ }^{852}$ Dieses Ziel erwies sich aber als zu schwierig zu erreichen, erst 915 wurde die letzte befestigte Siedlung von Sarazenen auf dem Territorium von Gaeta am Ufer des Flusses Garigliano unter der Ägide von Papst Johannes X. vernichtet. ${ }^{853}$

Im Jahr 878, dem sechsten Jahr seines Pontifikats, war Johannes VIII. sogar gezwungen, einer sarazenischen Gruppe Tributzahlungen zu leisten, wie wir aus seinem Brief an Karlmann, den Sohn des verstorbenen Ludwig des Deutschen und Vater Arnulfs von Kärnten, König von Bayern (876-880) und Italien (877-879), erfahren ${ }^{854}$ : Johannes suchte wie so oft um militärische Unterstützung der Franken gegen die Sarazenen an, denen er einen jährlichen Tribut von beträchtlichen 25000 mancusi zahlen musste.

Ein mancus ist eine kleine, etwa 4,25 Gramm wiegende Goldmünze. Sie ist damit deutlich kleiner als ein römischer/oströmischer solidus, aber das Äquivalent eines arabischen Gold-dinnār. ${ }^{855}$ Johannes schreibt ausdrücklich vom Äquivalent dieses Be-

849 Siehe Vera von Falkenhausen, La dominazione bizantina nell'Italia meridionale dal IX all'XI secolo (Bari 1978) 21f.

850 Siehe Kreutz, Before the Normans, bes. 18-74, wo sie unter Konzentration auf die langobardischen Fürstentümer einen Abriss der Geschichte des neunten Jahrhunderts liefert. Zu Gaeta, Amalfi und Neapel siehe Patricia Skinner, Family Power in Southern Italy. The Duchy of Gaeta and its Neighbours, 850-1139 (Cambridge 1995). Arnold, Johannes VIII., 205-226, liefert eine gute Zusammenfassung der süditalienischen Ereignisse aus Sicht des Papstes.

851 Siehe oben, Kap. 1.3.2.

852 Kreutz, Before the Normans 57-60: „John VIII: A Dream Denied“.

853 Siehe Scholz, Politik 242f. und Regesta Imperii, II, 5, Papstregesten 911-1024 (ed. Johann Friedrich Böhmer/Harald Zimmermann, Köln, Weimar, Wien ${ }^{21998) ~ N r . ~} 37$.

854 Johannes VIII., ep. 89 (JE² 3139) (ed. Erich Caspar, MGH EE 7, Berlin 1928) $85 f$.

855 Grierson/Blackburn, Medieval European Coinage, Bd. 1, $327 f$. 
trags in Silber, nicht in gemünztem Gold, was in Italien bei dieser Einheit meist so gehandhabt wurde. ${ }^{856} 25.000$ mancusi waren in jedem Fall eine beträchtliche Summe, die auch für den Papst sicher sehr schwer zu verkraften gewesen wäre, theoretisch wären es 106,25 Kilogramm Gold beziehungsweise eben das noch wesentlich umfangreichere Äquivalent in Silber.

Dieser Brief Johannes VIII. ist die einzige Quelle, die uns den Papst als einer sarazenischen Gruppe tributpflichtig zeigt. Damit kommen wir zu einem wesentlichen Faktor des päpstlichen Kampfes gegen die Sarazenen im Süden von Rom: den Kosten. ${ }^{857}$ Johannes war dabei nicht nur gezwungen, diesen hohen Tribut zu zahlen (wobei wir nicht wissen, ob und wie oft tatsächlich bezahlt wurde), er musste auch die süditalienischen Machthaber bezahlen, um sie auf seiner Seite zu halten. Diese allerdings nahmen öfters das Geld und stellten dennoch sarazenische Söldner an, wie der gut dokumentierte Fall Amalfi deutlich macht. ${ }^{858}$

$\mathrm{Zu}$ den steigenden finanziellen Belastungen kam aber auch noch der ideologische Preis, den der Papst für die relative Sicherheit Roms bezahlen musste, der möglicherweise aus Sicht des Lateran noch wesentlich schwerer wog: Die einzige Seestreitmacht, die es in größerem Umfang im Mittelmeer mit den sarazenischen Flotten aufnehmen konnte, war die oströmische Marine, die seit den $870 e r-J a h r e n$ auch in Süditalien wieder stärker in Erscheinung trat. ${ }^{859}$ Doch erst hundert Jahre zuvor hatten sich der Papst und Rom vom Oströmischen Reich losgesagt. ${ }^{860}$ Und erst wenige Jahre zuvor hatte Nikolaus I. eine erbitterte diplomatische Auseinanderstzung mit Patriarch Photios und Kaiser Michael III. ausgetragen und Hadrian II. hatte mit Genugtuung die Absetzung Photios' als Erfolg verbuchen können. ${ }^{861}$

856 Paulo Delogu, Il mancoso è ancora un mito?, in: 774. Ipotesi su una transitione, ed. Stefano Gasparri (Seminari internazionali del Centro interuniversitario per la storia e l'archeologia dell'alto medioevo, 1, Turnhout 2008) 139-159.

857 Fred Engreen, Pope John the Eighth and the Arabs, in: Speculum, 20, 3 (1945) 318-330, hier 327-329. 858 Arnold, Johannes VIII. 214-218. Zur Situation in Amalfi siehe Skinner, Family Power 50.

859 Siehe Eickhoff, Seekrieg, und John H. Pryor/Elisabeth M. Jeffreys, The Age of the $\triangle \mathrm{POM} \Omega \mathrm{N}$. The Byzantine Navy ca 500-1204 (The Medieval Mediterranean, 62, Leiden/Boston 2006) bes. 50-76. Entlang der tyrrhenischen Küste verfügten Neapel und vor allem Amalfi sicherlich über einen beträchtlichen Operationsspielraum, doch beide Städte entschieden sich in den 870ern, den Papst nicht zu unterstützen. Das lag zum Teil sicher auch an dem Disput zwischen Amalfi und Rom nach 877, siehe Kreutz, Before the Normans 58f. Auch die Franken verfügten im neunten Jahrhundert zunächst über eine nicht zu unterschätzende Flotte im Mittelmeer, die aber nur bis etwa 840 gut in Erscheinung treten konnte. Danach scheinen die Sarazenen die Oberhand gewonnen zu haben. Siehe dazu John Haywood, Dark Age Naval Power. A Reassessment of Frankish and Anglo-Saxon Activity (London/New York 1991) 113-118.

860 Siehe oben, Kap. 4.3.

861 Siehe Herbers, Papst Nikolaus und ders., Rom und Byzanz. 
Doch aufgrund der präkeren Lage Roms hatte sich die Situation geändert. Johannes VIII. musste 879 widerwillig der Restauration Photios' zustimmen und auch noch die Gleichrangigkeit des Patriarchen von Konstantinopel mit dem Papst anerkennen, nachdem er zuvor den oströmischen strategos von Bari bitten hatte müssen, mit seiner Flotte Rom gegen sarazenische Schiffe zu verteidigen. ${ }^{862}$ Zuvor war ein Vertrag von Amalfi offenbar gebrochen worden. ${ }^{863}$ Nun allerdings erhielt Rom auch tatsächlich Hilfe von der oströmischen Flotte, denn Johannes berichtet in Brief 263 aus dem Jahr 880 dem neuen Kaiser Karl dem Dicken: „Die Schiffe der Griechen haben die Ismaeliten erfolgreich angegriffen und haben sie, wie es Gottes Wille ist, bekämpft. "864

Für die Anerkennung des Patriarchen Photios erhielt Rom zwar theoretisch auch die kirchliche Oberhoheit in Bulgarien, um das auch schon seit Nikolaus I. gestritten wurde, doch in Wirklichkeit hatte sich Konstantinopel dort schon längst durchgesetzt - auch hier erlitt der Papst also eine Niederlage. ${ }^{865}$

\subsection{Veränderung der Wahrnehmung: Das Umfeld des Papstes in Italien}

Wir sehen nach dieser kurzen historischen Einführung, dass die Kontakte zu Sarazenen im achten Jahrhundert tendenziell noch friedlicher, merkantiler Natur waren, wenn auch die Quellenlage so schlecht ist, dass ein allgemeiner Schluss hier letztlich nicht gezogen werden kann. Das neunte Jahrhundert brachte dann ein wesentliches Umdenken auf Seiten des Papsttums, das vor allem durch den Schock von 846 wesentlich beschleunigt wurde und in der Politik Johannes' VIII. gipfelte. Dieses Umdenken betraf zunächst die päpstliche Wahrnehmung der eigenen Umwelt in Italien und es ging mit neuen Konzepten von christlicher Gemeinschaft einher. Der große Angriff von 846 scheint zwar nicht der einzige Grund für diesen Perspektivenwechsel

862 Im Jahr 880 schrieb Johannes einen Brief, der die Verhandlungen der vergangenen Jahre gut zusammenfasst: Johannes VIII., ep. 259 (JE² 3323), ed. Caspar 228f. Der Brief zeigt, dass der Papst zwischen 877 und 880 fast permanent auf die Hilfe der oströmischen Flotte angewiesen war. Siehe Pryor/Jeffreys, Age of the $\triangle \mathrm{POM} \Omega \mathrm{N} 166$.

863 Kreutz, Before the Normans 58.

864 Johannes VIII., ep. 263 (JE22 3327), ed. Caspar 233: Grecorum navigia in mari Hismahelitarum victoriosissime straverunt phalanges et eos, prout Dominus voluit, debellati sunt.

865 Johannes VIII., ep. 259, ed. Caspar 228f. Siehe Daniel Ziemann, Vom Wandervolk zur Großmacht. Die Entstehung Bulgariens im frühen Mittelalter (7.-9. Jh.) (Kölner historische Abhandlungen, 43, Köln/Weimar/Wien 2007) 390-412, bes. 397f. und 408f. zum schon unter Hadrian II. erfolgten Scheitern der päpstlichen Bulgarenmission. Siehe auch Arthur Lapôtre, L'Europe et le Saint-Siège à l'époque carolingienne, 1: Le pape Jean VIII (872-882) (Paris 1895) 47-90, bes. 71f. zu Johannes VIII. und der Bulgarenmission. Siehe auch Engreen, Pope John 324. 
gewesen zu sein, doch er war so etwas wie ein Katalysator, der neue Ideen beschleunigte. Wir müssen nun bedenken, dass Rom seit dem berühmten Überfall durch Alarichs Goten im Jahr 4Io mindestens einmal alle hundert Jahre gefallen war oder zumindest belagert worden war, zuletzt durch die Langobarden im Jahr 773. Warum also erfolgte ein Umdenken erst im neunten Jahrhundert? Die Ursachen lagen offenbar tiefer, in der Natur des Feindes selbst. ${ }^{866}$ Langobarden, Franken und auch die oströmischen Greci waren noch verhältnismäßig einfach als Gruppe zu fassen gewesen, die auch über einen König oder einen anderen hochrangigen Offiziellen, zumindest aber über eine Gruppe von Adeligen angesprochen werden konnte. ${ }^{867}$ Doch die Sarazenen in Italien unterschieden sich völlig davon: Es handelte sich um kleine und mittelgroße Gruppen, die unabhängig von einander operierten und auch keine wesentlichen institutionellen Verbindungen zu den größeren islamischen Machtbereichen in Nordafrika, Sizilien oder Spanien aufwiesen. Diese größeren Machthaber starteten aber dafür selbst bisweilen kleinere militärische Aktionen in Italien. ${ }^{868}$ Süditalienische Quellen, wie Erchemperts Historia Langobardorum Beneventanorum oder das Chronicon Salernitanum, zeigen ein im Vergleich zu den päpstlichen Quellen wesentlich heterogeneres Bild. Im Italien des neunten Jahrhunderts finden wir diesen Quellen zufolge kleine Gruppen von Sarazenen, die weitestgehend alleine operieren, so lange sie nicht als Kämpfer eines lokalen Machthabers engagiert werden. Sogar der Emir von Bari hatte in der Blütezeit des Emirats offenbar nur relativ begrenzte Kontrolle über andere sarazenische Gruppen. ${ }^{869}$

866 An dieser Stelle sei Max Diesenberger besonders für die Diskussion zum Thema gedankt.

867 Zugegebenermaßen gab es auch andere Fremde, die ebenso schwierig anzusprechen waren, was diejenigen, die mit ihnen verhandeln wollten, in Schwierigkeiten bringen konnte, man denke nur an die Situation auf dem Balkan im frühen Mittelalter (siehe Francesco Borri, Gli Istriani e i loro

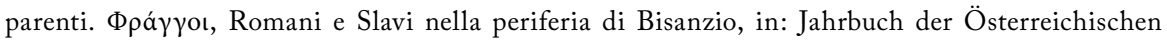
Byzantinistik, 60 [2010] 1-26), an die Probleme auf die Karl der Große in seiner Interaktion mit den Sachsen stieß (siehe Matthias Becher, Non enim habent regem idem Antiqui Saxones. Verfassung und Ethnogenese in Sachsen während des 8. Jahrhunderts, in: Sachsen und Franken in Westfalen. Zur Komplexität der ethnischen Deutung und Abgrenzung zweier frühmittelalterlicher Stämme, ed. Hans-Jürgen Häßler [Studien zur Sachsenforschung, 12, Oldenburg 1999] 1-31) oder an die Schwierigkeiten, die die Franken in der Kommunikation mit den Normannen/Wikingern hatten (siehe zum Beispiel Janet L. Nelson, The Frankish Empire, in: The Oxford illustrated history of the Vikings, ed. Peter Sawyer [Oxford 1997] 19-47). Doch für die Päpste war die sarazenische Bedrohung einzigartig, weil sie sie in Italien direkt betraf.

868 Siehe Kreutz, Before the Normans 48-54, bes. 49, zum sehr heterogenen Background der verschiedenen Sarazenengruppen.

869 Siehe aber Musca, Emirato, zum Status der zweiten sarazenischen Basis Tarent, die in relativ engem Kontakt zu Bari stand. Auch er hat aber keinerlei Hinweis gefunden, der belegt, dass andere sarazenische Gruppen in Konatkt mit Bari oder Tarent standen. 
Diese Situation führte dazu, dass jegliches Übereinkommen mit einer sarazenischen Gruppe keinerlei Effekt auf das eigene Verhältnis zu einer anderen sarazenischen Gruppe gehabt zu haben scheint. Das führte wiederum zu noch ausgeprägteren Reserven auf Seiten der Päpste, als sie ohnehin schon vorhanden waren.

Der päpstliche Gegensatz zu allen Sarazenengruppen hatte zweifellos starken Einfluss auf die Repräsentation von Sarazenen in den römischen Quellen des neunten Jahrhunderts, allerdings auf ein wenig unorthodoxe Weise. Zunächst müssen wir festhalten, dass die vorherrschende Rhetorik der Päpste von pejorativen Attributen geprägt war: Es finden sich beschimpfende Epitheta, biblische Anspielungen und erwartungsgemäß auch Wörter wie nefandissimi, um die Sarazenen als Feinde darzustellen. Die Rhetorik war jedoch schon vor 846 auf diesem Niveau angelangt. In der LP-Vita Papst Gregors IV. (827-844), die wahrscheinlich schon vor den Ereignissen von 846 fertiggestellt wurde, werden die Sarazenen bereits extrem negativ dargestellt:

In der Zeit dieses allerheiligsten Vaters und Papstes erhob sich die gottlose, böse und Gott verhasste gens der Hagarenen aus ihren eigenen Gegenden und umschlossen fast alle Inseln und alle Gegenden des Festlandes und grausam plünderten sie die Menschen aus und verwüsteten Orte. Bis zum heutigen Tag haben sie nicht damit aufgehört. ${ }^{870}$

Die Sarazenen sind hier die "gottlose, böse und Gott verhasste“ gens der Agareni. Diese Art der Darstellung hatte sich also schon vor dem großen Überfall 846 verfestigt. Ihr Gebrauch intensivierte sich allerdings im Lauf des frühen neunten Jahrhunderts, vielleicht aufgrund der steigenden Bedrohung, von der die Vita Gregors II. und zwei Briefe Leos III. berichten. ${ }^{871}$ Man kann allenfalls ein gesteigertes Auftreten der Einstufung der Sarazenen als Heiden in den Briefen Johannes' VIII. bemerken, der den Terminus pagani die meiste Zeit als Synonym für diese benutzte. ${ }^{872}$ Demgegenüber hatten Nikolaus I. und Hadrian II. dieses Wort eher für die Normannen und Heiden im Allgemeinen benutzt, abgesehen von einem Fall, in dem Hadrian sicherlich die Sarazenen meint. ${ }^{873}$

Doch es ist etwas anderes, das an der Darstellung der Sarazenen in den päpstlichen Quellen am erstaunlichsten ist: Sie werden ohne Ausnahme als eine homogene

870 LP II, 81: Et quoniam huius sacratissimi patris ac papae temporibus impia atque nefaria et Deo odibilis Agarenorum gens a finibus suis consurgens pene omnes insulas et omnium regiones terrarum circuiens, depraedationes hominum et locorum desolationes atrociter faciebat et usque actenus facere nullatenus cessat; ...

871 Leo III., ep. 6 und 7 (JE 2524 und 2526), ed. Hampe 96-99, von 812 und 813.

872 Jedoch nicht in ep. 150, siehe unten, Anm. 904.

873 Hadrian II., ep. 6 (JE 22895 ), aus dem Jahr 868, an Ludwig den Deutschen (ed. Ernst Perels, MGH EE 6, Berlin, 1925) 703. 
Gruppe porträtiert, die als Einheit auf der italienischen Halbinsel anzutreffen ist. ${ }^{874}$ Merkwürdigerweise trifft diese Beobachtung auch auf den Großteil der modernen Fachliteratur zu diesem Thema zu. ${ }^{875}$ Wie bereits gezeigt wurde, war das von der Realität sehr weit entfernt.

Doch die Päpste bezeichneten die Sarazenen in ihren Briefen an die karolingischen Kaiser und Könige, die oströmischen Offiziellen in Italien und die süditalienischen lokalen Machthaber stur als eine einizige Einheit. Daher müssen wir fragen, wozu diese Simplifizierung von Nöten war. Die Päpste neigten überhaupt dazu, in ihren Schriften Andere mit generalisierenden Termini zu bezeichnen, wie wir oben in Kapitel 4 über die Greci bereits gesehen haben.

Doch im Fall der Sarazenen wurden die rhetorischen Stilmittel graduell härter eingesetzt. Die Päpste kreierten durch die künstliche Generalisierung ein Feindbild. Diese Strategie benötigten allerdings vor allem die Päpste selbst, um die Sarazenen als koherente Andere in ihr Weltbild eingliedern zu können. Darüber hinaus war ein weiteres Ziel der Rhetorik aber sicherlich, ein Bild der christlichen Einheit gegen die Sarazenen zu vermitteln. Die Sarazenen wurden, neben ihrer Einordnung als religiös differente Feinde (pagani), im Zuge dessen auch konsequent als gens und somit als ethnische Gruppe definiert, obwohl die Muslime der Zeit sich keineswegs als solche sahen. ${ }^{876}$

Wie bereits angedeutet führte die Kombination aus der absoluten Unmöglichkeit regulärer diplomatischer Beziehungen mit den die Stadt Rom selbst massiv bedrohenden Angriffen der zweiten Hälfte der 84oer-Jahre zu (mindestens) zwei entschei-

874 Interessant wäre es, zu erforschen, inwieweit die Darstellung der Sarazenen in den verschiedenen lateinischen und griechischen Quellen der Zeit auf Modelle der lateinischen und griechischen Ethnographie oder der christlichen Exegese zurückgriff. Für ein allgemeines Bild der Sarazenen, das während des gesamten Mittellaters relativ stabil blieb, siehe Tolan, Saracens; Rotter, Abendland und Sarazenen, sowie John Victor Tolan, „A wild man, whose hand will be against all“: Saracens and Ishmaelites in Latin Ethnographical Traditions, from Jerome to Bede, in: Visions of Community in the Post-Roman World. The West, Byzantium and the Islamic World, ed. Walter Pohl/Clemens Gantner/Richard Payne (Aldershot 2012) 513-30.. Zum Einfluss der klassischen Ethnographie auf die päpstliche Wahrnehmung von Anderen siehe Bruno Judic, Gregoire le Grand et les barbares, in: Le barbare, l'étranger. Images de l'autre. Actes du colloque organisé par le CERHI, Saint-Étienne, 14 et 15 mai 2004, ed. Didier Nourisson/Yves Perrin (Saint-Étienne 2005) 137-146.

875 Ein Beispiel ist leider Arnold, Johannes VIII., die zugegebenermaßen die Situation auch von der päpstlichen Warte darstellen möchte. Allerdings wäre ein kritischer Abgleich der Papstbriefe mit den anderen zeitgenössischen Quellen aus Italien wünschenswert gewesen.

876 Die „Sarazenen“ sahen sich als múminin, also Gläubige, hierbei handelt es sich vor allem um eine religiöse und imperiale Identität. Zum Konzept der Gläubigen bis heute siehe Smail Balić, Glaube, islamisch, in: Lexikon religiöser Grundbegriffe, ed. Adel Theodor Khoury (Wiesbaden 2007) Sp. 374-376. Ethnische Unterschiede spielten innerhalb der Gemeinschaft der Gläubigen aber durchaus eine Rolle, in Nordafrika und Italien spielte es etwa eine Rolle, ob jemand arabischer oder berberischer Herkunft war. 
denden Veränderungen in der päpstlichen Selbstwahrnehmung und, damit untrennbar verbunden, auch in der Wahrnehmung von Anderen.

Die erste Veränderung betraf die päpstliche Wahrnehmung der christlichen Nachbarn in Italien, insbesondere der Fürstentümer und Dukate im Süden, die nun mehr in den Fokus der römischen Politik rückten, während die Franken in Norditalien und jenseits der Alpen spätestens seit 774 ein ungebrochen wichtiger Faktor im päpstlichen Weltbild waren. Im Pontifikat Johannes' VIII. wurde bis zu einem gewissen Grad auch das Oströmische Reich wieder stärker auf der Seite des Papstes verortet. ${ }^{877}$

Das war ein wesentlicher Schritt weg von der traditionellen päpstlichen Position, die das achte Jahrhundert und die Zeit davor bestimmt hatte. So waren etwa die Langobarden in päpstlichen Schriften lange Zeit entweder ignoriert oder negativ dargestellt worden, wenn die Beziehungen auch, wie wir gesehen haben, variabler waren als man zunächst denken könnte. Als politische Partner kamen die Langobarden Benevents nach den $730 e r-J a h r e n$ allerdings nicht mehr in Frage. ${ }^{878}$ Auch die Neapolitaner waren in den päpstlichen Schriften ausgesprochen negativ dargestellt worden, wie wir im Zuge der Auseinandersetzung um Terracina bereits gesehen haben. ${ }^{879}$

Doch nun, im Zuge der Ereignisse der 840er-Jahre, veränderte sich die Wahrnehmung des eigenen Patrimoniums im Herzen der Apenninenhalbinsel. Die Konsequenz dieser gewandelten Selbstsicht war auch eine veränderte Sicht der kleinen Fürstentümer Süditaliens, die nun mehr Aufmerksamkeit aus Rom erhielten als jemals zuvor - wobei die Päpste sicherlich auch eine Ausweitung des eigenen Machtbereichs als Ziel hatten ${ }^{80}$ Die Beziehungen zu diesen Herrschaftsgebieten blieben also keineswegs ohne Verstimmungen, das belegen schon die berühmten Auseinandersetzungen Johannes' VIII. mit Amalfi und Neapel. Doch für kurze Zeit schien es in den 77oer-Jahren für Johannes möglich, eine Art Aufsichtsposition, wenn nicht gar Schutzmachtfunktion des Papsttums im Süden (ausgenommen den oströmischen Bereich in Apulien und Kalabrien) zu etablieren. Ganz besonders gilt das für das erste Halbjahr 876, als der Papst in besonders regem Austausch mit süditalienischen Großen stand. ${ }^{81}$ Diese

877 Engreen, Pope John 324 schreibt: „How could a pope, depending on the help of the Greeks, maintain the traditional claims on southern Italy...?" Diese „traditional claims“ gab es jedoch großteils nur im kirchlichen Bereich, während Johannes' VIII. Streben nach politischer Vorherrschaft durchaus als revolutionär betrachtet werden kann, siehe Arnold, Johannes VIII., 205-225. Engreen hat allerdings recht, wenn er die päpstliche Allianz mit dem oströmischen Heer vor allem als Zweckbündnis charakterisiert.

878 Siehe dazu oben, Kap. 5.1 und 5.2.

879 Siehe oben, Kap. 4.3.

880 Siehe, besonders zu Benevent, Bertolini, Relazioni politiche 689-692.

881 Johannes VIII., epp. 3-6 (JE² 3050, 3051, 3045 und 3046), ed. Caspar 2-5, siehe Arnold, Johannes VIII., $209 f$. 
Strategie scheiterte schlussendlich an der Verschiedenartigkeit der Interessen der regionalen Machthaber, der der Papst nicht Herr werden konnte. Dazu kam sicherlich auch eine nicht unbegründete Angst vor einer absoluten Dominanz Roms in der Region - Johannes VIII. scheiterte also an denselben Hindernissen, die schon Ludwig II. wenige Jahre zuvor zum Verhängnis geworden waren.

Das Briefregister zeigt uns jedenfalls einen Papst, der unablässig versuchte, Italien wieder sicherer zu machen. Um dieses Ziels willen appellierte er an christliches Gemeinschaftsgefühl der (süd-)italienischen Herrscher. Das war eine Neuerung für das Papsttum, das sich sonst seit dem achten Jahrhundert eher auf den eigenen Machtbereich, den eigenen peculiaris populus beschränkt hatte. ${ }^{82}$ Diese neue Politik unterschied sich auch von der allgemeinen päpstlichen Rhetorik von der Einheit der Christenheit und der Christianitas, dieses Konzept können wir getrost als Konstante in den päpstlichen Schriften des frühen Mittelalters sehen. ${ }^{883}$ Auch von diesem Konzept wurde weiterhin stark Gebrauch gemacht, vielleicht sogar in erhöhtem Ausmaß nach $846 .{ }^{884}$ Doch dieses Konzept war eben nicht neu, während das Streben nach einer Form der politischen Einheit der Christen in Süditalien sicherlich eine Neuerung in der Politik des Papsttums war.

Den klarsten Ausdruck dieser Politik Johannes' VIII. finden wir in einem Brief an den langobardischen princeps Waifer von Salerno vom Oktober 876. Darin versucht der Papst, eine Koalition unter den süditalienischen Machthabern zu schmieden, namentlich nennt er Waifer und dessen Schwiegersohn Pulchar von Amalfi. Der Zweck

$882 \mathrm{Zu}$ diesem Konzept siehe oben, Kap. 3.1.

883 So dominierte dieses Konzept von Christenheit die päpstlichen Schreiben an Missionare, siehe Lutz E. von Padberg, Unus populus ex diversis gentibus. Gentilismus und Einheit im früheren Mittelalter, in: Der Umgang mit dem Fremden in der Vormoderne: Studien zur Akkulturation in bildungshistorischer Sicht, ed. Christoph Lüth/Rudolf W. Keck/Erhard Wiersing (Beiträge zur historischen Bildungsforschung, 17, Köln, Weimar, Wien 1997) 155-193. Padberg entwickelt seine Argumentation hauptsächlich auf Basis der Mission des H1. Bonifatius in der Germania. Doch sein Versuch, seine Ergebnisse generell für die Päpste des achten Jahrhunderts anzuwenden, ist nicht sehr überzeugend. 884 Siehe hierfür zum Beispiel Johannes VIII., ep. 46 (JE² 3091), ed. Caspar 44, ein Brief an Bischof Aio von Benevento aus dem Jahr 876: Huius rei gratia, quia multis studere loquelis, ne magis multiplicare verba quam gemitus videamur, non expediat, precipue quia tua fraternitas ipsos invisibiles merores nostros, sicut in litteris tuis conspicimus, non ignorat, per illum, qui te sacerdotem suum constituit, tuam reverentiam adiuramus suadentesque modis omnibus deprecamur et auctoritate principum apostolorum fraterno freti amore precipimus, ut omnibus viribus tuis omnique posse tuo labores tam scilicet cum germano fratre quam cum aliis Christicolis in hoc opem ferre valentibus, ut impia Agarenorum fędera, que Neapolitani vel sui consocii cum inimicis Christi nominis inierunt, Christo miserante quantocius destruantur et pax atque concordia fidelium per eundem Christum dominum reformetur, quatenus corpus sancte Dei ecclesię, pro qua sanguis fusus est Christi, in suis membris non laceretur et, que sit vera religio atque perfecta caritas, agnoscatur. (Johannes VIII. verwendete den Terminus Agareni fast genauso häufig wie Saraceni.) 
des Bündnisses ist die liberatione to[ti]us patrię. ${ }^{885}$ Der Begriff patria bezieht sich an dieser Stelle mit Sicherhiet auf die erweiterte Einflusssphäre des Papstes in Italien und eben nicht auf die gesamte Christenheit. ${ }^{886}$ Hier haben wir also ein recht klares Bekenntnis des Papstes dazu, wie er sich eine Ordnung der christlichen Umgebung Roms vorstellte. Leider wird dieses Konzept in den allermeisten Briefen nicht direkt angesprochen, doch wenn man dazu das Vorgehen des Papstes in der zweiten Hälfte seines Pontifikats in Betracht zieht, zeigt sich seine Politik doch sehr klar. ${ }^{87}$

Und diese Tendenz, eine lockere Allianz unter den Christen Italiens zu schaffen, scheint zunächst sogar auf offene Ohren gestoßen zu sein. Bereits 849 im Pontifikat Leos IV. kamen überraschend die süditalienischen Hafenstädte dem Papst zu Hilfe, ausdrücklich übrigens, um die Christenheit zu schützen. Der LP dürfte hier durchaus ein realistisches Bild überliefern, wenn Leo IV. zunächst als überrascht dargestellt wird. Ja, der Papst war sogar skeptisch genug, um zunächst ein Treffen mit nur einigen der Anführer der Flotte zu arrangieren, um auszuloten, ob deren Absichten überhaupt friedlich waren oder ob auch diese Flotte eine Gefahr für Rom darstellte. ${ }^{888}$ Umsomehr dürfte der Grad an Hilfsbereitschaft den Papst beeindruckt haben. Auch etwa dreißig Jahre danach fand Johannes VIII. für seine Pläne einige mächtige Unterstützer unter den süditalienischen Potentaten. ${ }^{889}$ Besonders in den $870 e r-J a h r e n$, aber sicherlich auch schon davor, versuchte das Papsttum, sich in Süditalien Verbündete zu schaffen. Zunächst setzten die Päpste ihre Hoffnungen auf Kaiser Ludwig II., der jedoch keine männlichen Erben hatte und deshalb in seinem Alter jenseits der 40 möglicherweise langsam als wenig zukunftssicher betrachtet werden konnte. ${ }^{890}$ Abgesehen davon war es dem Kaiser auch niemals gelungen, in Süditalien richtig Fuß zu fassen. ${ }^{891}$

Aus diesem Grund nahm sich Johannes VIII. selbst der süditalienischen Fragen an. Sein politisches Projekt scheiterte allerdings, da sich der Papst nicht gegen die schiere Vielfalt an Interessen in der Region behaupten konnte. Am Ende des neunten Jahrhunderts war das Papsttum noch mehr als zuvor auf Rom reduziert - und diese Situation sollte sich auch in den Wirren des zehnten Jahrhunderts nicht ändern, als

885 Johannes VIII., ep. 3, ed. Caspar 3.

886 Anders Arnold, Johannes VIII., 219. Der Begriff patria konnte allerdings bisweilen im neunten Jahrhundert durchaus auch in einem weiteren Sinn verwendet werden. Die von Leo IV. erhaltenen Schriften etwa enthalten beide Varianten, siehe Herbers, Leo IV., 124 und 248. (Das Konzept einer christlichen patria im weiteren Sinn findet sich etwa in Leo IV., ep. 28, siehe dazu unten, Anm. 901.)

887 Kreutz, Before the Normans 57-60.

888 LP II, 118. Siehe Herbers, Leo IV., 112f.

889 Kreutz, Before the Normans 58; Arnold, Johannes VIII., 209-212.

890 Siehe Ludo Moritz Hartmann, Geschichte Italiens im Mittelalter, Bd. 3, 1: Italien und die fränkische Herrschaft (Gotha 1908) 297-301, der die Situation nach 871 sehr treffend beschreibt.

891 Arnold, Johannes VIII., 206. 
die weltlichen Oberhäupter der Familie der Tuskulaner oder Theophylakten Rom dominerten. ${ }^{892}$

\subsection{Veränderung der Wahrnehmung: Krieg gegen Nichtchristen}

Die zweite wesentliche Veränderung im päpstlichen Weltbild, die durch die Angriffe der 840er-Jahre ausgelöst wurde, erwies sich als wesentlich nachhaltiger als die Süditalienpolitik: Die Doktrin der römischen Kirche betreffend die Kriegführung gegen Nichtchristen wurde modifiziert. Diese Veränderung zeigt sich in der Kommunikation mit Christen außerhalb der römischen „in-group“, also mit christlichen Anderen, betreffend der Sarazenen (oder auch anderer Nichtchristen). Demgegenüber haben wir bereits gesehen, dass die für die Sarazenen selbst angewandten Sprachmuster sich nicht entscheidend veränderten.

In früheren Jahrhunderten war die päpstliche Position zum Krieg vor allem defensiv gewesen und zwar sowohl gegenüber Christen als auch Nichtchristen. Carl Erdmann zitiert eine Passage aus einem Brief Gregors des Großen, die er als wesentlich für die Entwicklung einer kriegerischen Theologie der Päpste erachtet, eine Entwicklung, die er auch schon im Werk des Aurelius Augustinus erkennen wollte. ${ }^{893}$ Laut Erdmann soll Gregor den Krieg zum Zwecke der Mission befürwortet haben, doch diesen Eindruck vermittelt der Brief eigentlich nicht. Vielmehr sollte wohl eine militärische Aktion, die Gennadius, der Exarch von Africa, bereits unternommen hatte, ein wenig beschönigt werden. ${ }^{894}$ Denn Gregors Einstellung konnte auch ganz anders formuliert werden. Unter dem Eindruck akuter Gefahr für die Stadt Rom durch Langobarden verfasste er zwischen 593 und 6or eine Predigt über das Buch Ezechiel, in der er die hoffnungslose Situation der Römer betrauerte:

Niemand soll mich also schelten, wenn ich nach dieser Ansprache aufhöre, weil, wie ihr alle wisst, unsere Leiden sich noch verschlimmert haben: Auf allen Seiten sind wir von

892 Siehe das drastische Fazit von John Gilchrist, The Papacy and War against the Saracens, 795-1216, in: The International History Review, 10 (1988) 174-197, hier 183.

893 Carl Erdmann, Die Entstehung des Kreuzzugsgedankens (Stuttgart 1935, ND Darmstadt 1972) 8. Zu Augustinus' Konzept des bellum iustum, das unter den historischen Umständen vor allem als apologetisch gesehen werden kann, siehe Johannes Brachtendorf, Augustinus: Friedensethik und Friedenspolitik, in: Krieg und Christentum. Religiöse Gewalttheorien in der Kriegserfahrung des Westens, ed. Andreas Holzem (Krieg in der Geschichte, 50, Paderborn/München/Wien/Zürich 2009) 234-253, und Jean Flori, La guerre sainte. La formation de l'idée de croisade dans l'Occident chrétien (Paris 2001) 37-39.

894 Gregor I., ep. 1, 73, ed. Norberg, Bd. 1, 81f. 
Schwertern umgeben, überall fürchten wir dauernde Todesgefahr. Einige kommen zu uns mit abgehackten Händen zurück, andere sind gefangen, andere werden für tot erklärt. Schon werde ich gezwungen zu schweigen, den „zum Ekel ist mein Leben mir geworden“ [Hiob ıо, I]. Und niemand soll länger von mir die Beschäftigung mit dem Heiligen Wort verlangen, denn „zur Trauer wurde mein Harfenspiel, mein Flötenspiel zum Klagelied“ [Hiob 30,31]. ${ }^{895}$

Wie wir sehen war die Reaktion Gregors kein Aufruf zum Kampf, sondern, kurz gesagt, Resignation. Der Papst sagte seinen Zuhörern, dass er seine Predigt beenden müsse, da er es nicht mehr ertragen könne, mitanzusehen, wie Römer mit abgehackten Händen in die Stadt zurückkehrten. Andere wiederum seien überhaupt umgekommen oder in Gefangenschaft geraten. Es kann kein Zufall sein, dass in dieser Passage auch gleich zweimal das Buch Hiob zitiert wird.

Und es gibt auch aus späterer Zeit noch Beispiele für die zumindest offiziell pazifistische Haltung des Papsttums: Als Mitte des achten Jahrhunderts Rom von den Truppen des Langobardenkönigs Aistulf bedroht wurde, betont die Vita trotz der massiven antilangobardischen Ausrichtung des Textes ${ }^{896}$ gleich mehrmals, dass Papst Stephan II. den Frankenkönig Pippin gebeten habe, eine diplomatische Lösung anzustreben. ${ }^{897}$ Klarerweise können wir nicht sicher sein, ob Stephan tatsächlich eine friedliche Lösung bevorzugte. Doch offenbar war es zumindest für die Erzählung des LP notwendig, dieses Bild zu vermitteln. Es wurde auch im achten Jahrhundert noch von einem Papst erwartet, Menschen von Kriegen abzuhalten.

Und sogar noch im neunten Jahrhundert, genauer im Jahr 844, rief Papst Sergius II. die Bischöfe im Frankenreich dazu auf, Verfolgungen zu erdulden und nannte Kriegstreiber „Söhne des Teufels“:

,Seelig, die Frieden stiften, denn sie werden Söhne Gottes genannt werden' [Mt 5,9]. Im Gegensatz dazu wird deutlich zu verstehen gegeben, dass jene, die Kriege wollen, Söhne des Teufels sind. Aber wir vertrauen auf jenen, der die Welt besiegt, durch die Fürspra-

895 Gregor I., Homilia in Hezechielem, Buch 2, hom. 10, c. 24 (ed. Marc Adriaen, CC SL 142, Turnhout 1971) 397: Nemo autem me reprehendat, si post haec alocutione cessauero, quia, sicut omnes cernitis, nostrae tribulationes excreuerunt: undique gladiis circumfusi sumus, undique imminens mortis periculum timemus. Alii, detruncatis ad nos manibus redeunt, alii capti, alii interempti nuntiantur. Iam cogor linguam ab expositione retinere, quia taedet animam meam uitae meae. [Iob 10,1] Iam nullus in me sacri eloquii studium requirat, quia uersa est in luctum cithara mea, et organum meum in uocem flentium. [Iob 30,31].

896 Siehe oben, Kap. 5.3.

897 In LP I, 449f., findet sich gleich zweimal die Wendung: ne sanguis effunderetur christianorum. 
che des Heiligen Apostels Petrus, [und darauf] dass eure Autorität durch keine Art von weltlicher Vermessenheit untergeht. Und auch wenn sie sich für einen gewissen Zeitraum durchsetzen sollten, ist es eindeutig, dass sie für die Ewigkeit verdammt werden werden. Aber ihr, auch wenn ihr für die Gerechtigkeit verfolgt werdet, werdet seelig sein. ${ }^{898}$

Erst Leo IV. verknüpfte als erster Papst den Kampf gegen „Ungläubige“ mit einem Heilsversprechen. Der berühmteste Ausdruck davon findet sich in einem Brief an den Fränkischen exercitus. Dieser Brief war bereits den Proponenten der hochmittelalterlichen Kanonistik aufgefallen, die ihn jedoch überinterpretierten. ${ }^{899}$ Der Brief ist deshalb in einer Reihe von Sammlungen fragmentarisch überliefert. Das Schreiben steht in Verbindung mit einer Expedition Ludwigs II. gegen Sarazenen in Süditalien, entweder $847 / 848$ oder $85^{2} \cdot{ }^{900}$ Die wesentliche Passage lautet wie folgt:

Wir wollen, dass die karitas aller Eurer Leute wisse, dass jedem, der in der Auseinandersetzung dieses Krieges sterben sollte (was wir nicht hoffen wollen!), das himmlische Königreich nicht verwehrt werden wird. Denn der Allmächtige weiß, dass, falls irgendjemand der Eurigen stirbt, dieser für die Wahrheit des Glaubens, die Rettung der Seele und die Verteidigung der patria der Christen gestorben ist und somit die erwähnte Belohnung von Gott erhalten wird. ${ }^{901}$

898 Sergius II., ep. 1 (JE² 2586) (ed. Adolph von Hirsch-Greuth, MGH EE 5, Berlin 1899) 584: Beati pacifici, quoniam filii Dei vocabuntur. [Mt 5,9] At contra, qui bella volunt, quia diaboli flii sunt, palam datur intelligi. Sed nos in eo qui vincit mundum, beato Petro apostolo intercedente confidimus quod nullo typo saecularis audaciae vestra succumbit auctoritas: tamen etsi ad tempus praevaluerint, quia in aeternum damnabuntur, ambiguum non est. Vos autem, etsi persecutionem patimini propter iustitiam, beati. Siehe dazu Gilchrist, Papacy and War 182f., der jedoch ein wenig weit geht, wenn er Sergius als „truly pacifist pope" bezeichnet.

899 Vor allem Ivo von Chartres, Decretum X, 87, PL 161, coll. 719f. und ders., Panormia VIII, 30, PL 161, col. 1311; dazu kommt Gratian, Decretum, wo sich Teile in C. 23, qu. 8, c. 9 und C. 23 qu. 5 c. 46 (ed. Emil Friedberg, Corpus Iuris Canonici, 1, Leipzig 1879) col. 944 und 955, finden. Gratian schrieb die Passagen aber Nikolaus I. zu. Siehe die detaillierte Analyse von Herbers, Leo IV., $120-124$.

900 Herbers, Leo IV., 124.

901 Leo IV., ep. 28 (JE² 2642) (ed. Adolph von Hirsch-Greuth, MGH EE 5, Berlin 1899) 601: [O]mnium vestrum nosse volumus karitatem, quoniam quisquis (quod non optantes dicimus) in hoc belli certamine fideliter mortuus fuerit, regna illi cęlestia minime negabuntur. Novit enim omnipotens, si quislibet vestrum morietur, quod pro veritate fidei et salvatione anime ac defensione patrie christianorum mortuus est, ideo ab eo pretitulatum premium consequetur. Der Brief ist in seiner vollständigsten Form in der Collectio Britannica (siehe dazu oben, Kap. 1.3.1) erhalten. Das versale „O“, das als Initiale des Abschnitts zu erwarten wäre, ist in der Handschrift nicht ausgeführt. 
Jedem also, der für die Wahrheit des Glaubens, die Rettung der Seele und die Verteidigung der christlichen patria stirbt, wird das Himmelreich nicht verweigert werden. Auch in den Briefen Johannes VIII. finden wir wieder dieses Argument vor: Im Jahr 878 beantwortete er eine Anfrage westfränkischer Bischöfe, die die geistliche Lage jener betraf, die im Kampf gegen Heiden gefallen waren. Die Anfrage hatte wahrscheinlich den unmittelbaren Hintergrund, dass der westfränkische König Ludwig II. der Stammler, Sohn des verstorbenen Kaisers Karl des Kahlen, gegen normannische Invasionen zu kämpfen hatte. ${ }^{902}$ Der Brief lautet wie folgt:

Weil Eure verehrenswürdige Brüderlichkeit bescheiden nachgefragt hat, ob jene, die für die Verteidigung der Heiligen Kirche Gottes und für das Fortbestehen der christlichen Religion und der res publica neulich im Kampf gefallen sind oder für dieselbe Sache sterben müssen, Vergebung für ihre Verbrechen erlangen können, antworten wir ermutigt durch den Glauben an unseren Gott Christus, dass der Friede des ewigen Lebens jenen zu Teil werden wird, die im Glauben an die katholische Religion im Kampf des Krieges fallen und tüchtig gegen die Heiden und Ungläubigen kämpfen, auf Grund dessen was der Herr uns durch den Propheten gesagt hat: Dem Schuldigen wird, sobald er bekehrt ist, keines der Vergehen, derer er sich schuldig gemacht hat, weiterhin angerechnet werden; ${ }^{903}$ und jener Räuber hat durch ein paar Worte der Beichte am Kreuz das Paradies erlangt; ... ${ }^{904}$

Damit verdeutlicht Johannes VIII. noch einmal das Argument Leos IV. Interessant ist, dass der zentrale Satz sogar den Schluss zuließe, allein der Kampf und nicht der Tod im Kampf gegen die Ungläubigen würde schon den direkten Weg ins Himmelreich ebnen, doch die biblischen Anspielungen, die folgen, machen deutlich, dass der Tod in der Schlacht gegen Heiden mit einer Bekehrung im letzten Moment verglichen werden soll. Einem Sünder, so heißt es in einer aus Ezechielstellen zusammengebauten, sinngemäß zitierenden Stelle, werden unabhängig vom Zeitpunkt seiner

902 Mit diesem Argument wurde der Brief von Engreen, Pope John 320, für irrelevant für italienische Fragen erklärt. Doch der Papst schränkt seine theologische Position in seiner Antwort in keiner Weise ein, durch die Zitierung der Bibel will er seiner Position sogar noch zusätzlich Gewicht verleihen.

903 Zusammengesetzt (und gekürzt) aus Ezechiel 33, 12 und 18,22.

904 Johannes VIII., ep. 150 (JE² 3195), ed. Caspar 126f.: Quia veneranda fraternitas vestra modesta interrogatione sciscitans quęsivit, utrum hi, qui pro defensione sancte Dei ecclesię et pro statu Christiane religionis ac rei publice in bello nuper ceciderunt aut de reliquo pro eadem re casuri sunt, indulgentiam possint consequi delictorum, audenter Christi Dei nostri pietate respondemus, quoniam illi, qui cum pietate catholice religionis in belli certamine cadunt, requies eos ęternę vitę suscipiet contra paganos atque infideles strenue dimicantes, eo quod Dominus per prophetam dignatus est dicere: ,Peccator quacumque hora conversus fuerit, omnium iniquitatum illius non recordabor amplius', et venerabilis ille latro in una confessionis voce de cruce meruit paradysum; ... 
Reue die Sünden vergeben. Als Beispiel dafür wird der gläubige Räuber angeführt, der sich am Kreuz zu Christus bekehrt. Der Kampf gegen Ungläubige wird hier also sogar mit tätiger Reue für vergangene Sünden gleichgesetzt.

Wenn wir die Situation Roms in den späten 87oer-Jahren bedenken - wir erinnern uns: oströmische Schiffe waren zum Schutz der Stadt nötig - verwundert es nicht sehr, dass Johannes die Theologie Leos noch ein wenig zuspitzte. Klar ist jedenfalls, dass jene, die gegen die Sarazenen (oder Normannen) kämpften, mit himmlischer Belohnung rechnen durften.

Diese Argumentation war nicht ohne Vorläufer: Wir haben bereits gesehen, dass schon Augustinus eine Theologie des „gerechten Krieges“ entwarf und damit eine Wendung des Christentums zu aggressiveren Methoden markierte - doch von dort aus war es immer noch ein riesiger Schritt zur Position der Päpste, die wir gerade gesehen haben. ${ }^{905}$ Und Augustins Lehren wurden auch im neunten Jahrhundert noch rezipiert und verbreitet, zum Beispiel von Hinkmar von Reims in De regis persona. ${ }^{906}$ Der Erzbischof von Reims zitierte Augustinus in seiner Schrift ausgiebig, doch als er bei der Frage der im Krieg Gefallenen ankam, bezog er sich nur auf 2 Makabäer 43 und 45 f. und argumentierte, dass für ihr Seelenheil Vorkehrungen getroffen werden müssten ${ }^{907}$ - also völlig konträr zur gleichzeitigen Haltung der Päpste. ${ }^{908}$

Es finden sich im Lateinischen Westen aber schon seit dem frühen achten Jahrhundert auch Texte, die der päpstlichen Linie des neunten Jahrhunderts schon sehr nahekamen. Autoren stilisierten ihre Protagonisten zu Märtyrern, weil sie im Kampf gegen „Ungläubige“ gefallen waren: Beda tat das mit Oswald ebenso wie fränkische Quellen mit Graf Gerold, der gegen die Awaren gefallen war. ${ }^{909}$ Es ist jedoch immer noch ein wesentlicher Unterschied, ob man seinen eigenen Helden als Märtyrer darstellt - oder, wie die Päpste, allen Kämpfern gegen Feinde der Christenheit ewigen Lohn und Vergebung der Süden verspricht. Man muss aber auch einschränkend sagen, dass die Position der Päpste noch nicht mit jener vergleichbar war, die ihre Nachfolger im elften Jahrhundert am Vorabend der Kreuzzüge entwickelten - man

905 Siehe Erdmann, Entstehung 5-8, und Friedrich Wilhelm Graf, Sakralisierung von Kriegen: Begriffs- und problemgeschichtliche Erwägungen, in: Heilige Kriege. Religiöse Begründungen militärischer Gewaltanwendung: Judentum, Christentum und Islam im Vergleich, ed. Klaus Schreiner (Schriften des Historischen Kollegs, Kolloquien, 78, München 2008) 1-30, hier 7-10, bes. 7f.

906 Hinkmar, De Regis persona et regio ministerio, PL 125, col. 833-856.

907 Hinkmar, De Regis persona, col. 844.

908 Zur Fränkischen Perspektive siehe Janet L. Nelson, Violence in the Carolingian world and the ritualization of ninth-century warfare, in: Violence and Society in the Early Medieval West, ed. Guy Halsall (Woodbridge 1998) 90-107, hier 91 zu De regis persona.

909 Albrecht Noth, Heiliger Krieg und Heiliger Kampf in Islam und Christentum. Beiträge zur Vorgeschichte der Kreuzzüge (Bonner historische Forschungen, 28, Bonn 1966) 100-104. 
kann also für Italien im neunten Jahrhundert noch nicht von Kreuzzugsrhetorik sprechen. ${ }^{910}$ Denn in einem Kreuzzug, wenn wir Erdmanns immer noch gültiger Definition folgen wollen, „bildete die Religion eine spezifische Kriegsursache und fiel nicht mit dem Volkswohl, der Landesverteidigung, dem Staatsinteresse oder der nationalen Ehre zusammen“. ${ }^{911}$ Doch im neunten Jahrhundert spielte eben die Verteidigung des päpstlichen Machtbereichs die entscheidende Rolle bei der Entwicklung der neuen theologischen Position. ${ }^{912}$

In jedem Fall aber zeigt sich in den Briefen Leos IV. und Johannes' VIII., dass diese Päpste zumindest für Rom die theologische Position revolutionierten. Diese Position scheint sich unter Johannes VIII. verfestigt zu haben. Ein weiterer Brief dieses Papstes untermauert diese These. In einem Schreiben vom 30. Oktober 880 rief er den ostfränkischen Kaiser Karl III. den Dicken dazu auf, schnell Rom zur Hilfe zu eilen: ut bella Domini vice illius preliemini ad beatorum apostolorum limina Deo pręduce pro Christianorum omnium auxilio properate. Der Karolinger solle also an Stelle des Herrn zum Nutzen der Christen für Rom intervenieren. ${ }^{913}$ Auch dieser Satz passt sehr gut zum Befund der päpstlichen Position, die von Leo IV. wesentlich entwickelt worden war. Auch ein Brief von Johannes' Vorgänger Hadrian II. ist hier von Interesse: Der Papst riet darin dem ostfränkischen König Ludwig dem Deutschen, nicht gegen Christen in den Krieg zu ziehen. Vielmehr solle er wie sein Neffe, der Kaiser Ludwig II., gegen die „Söhne Belials“ kämpfen, mit denen zweifellos die Sarazenen gemeint sind. ${ }^{914}$ Es wird vielleicht nicht sofort deutlich, doch diese Rhetorik unterschied sich wesentlich von den Bitten der Päpste des achten Jahrhunderts an die Karolinger, doch gegen die Langobarden (oder sogar die Oströmer) vorzugehen. Denn hierin wurden die Franken nur gebeten, die römische Kirche sowie den H1. Petrus und seinen Stellvertreter zu verteidigen. Doch Heiden oder eine gemeinsame christliche Sache wurden nie ins Treffen geführt. ${ }^{915}$

910 Das wird im Detail von Flori, Guerre sainte 51-54, sehr schön belegt. Er behauptet allerdings auch, dass es Johannes VIII. ausschließlich um die Verteidigung Roms gegangen sei, zieht jedoch nicht in Betracht, dass der berühmte Brief 150 wahrscheinlich auf normannische Angriffe rekurriert.

911 Erdmann, Entstehung 1.

912 Jean Flori, À propos de la première croisade: Naissance et affirmation de l'idée de guerre sainte dans l'Occident chrétien (XI ${ }^{\mathrm{e}}$ siècle), in: Imaginaires de guerre. L'histoire entre mythe et réalité. Actes du colloque, Louvain-la-Neuve, 3-5 mai 2001, ed. Laurence van Ypersele (Louvain-la-Neuve 2003) 31-43, hier 37f. - Der neue Ansatz des Papstes war jedoch universeller angelegt als Flori zugestehen will. (Siehe auch oben, Anm. 910.)

913 Johannes VIII., ep. 263, ed. Caspar 233.

914 Hadrian II., ep. 6, ed. Perels 703f. Gilchrist, Papacy and war 182, Anm. 45.

915 Siehe oben, Kap. 5. In einem Fall allerdings wurden die Langobarden implizit zu Häretikern erklärt, siehe oben, Kap. 5.5, zu CC 45. 


\subsection{Zusammenfassung: Der Einfluss der Sarazenen auf das Papsttum}

Die Sarazenen waren zunächst Handelspartner Roms, das sich besonders zu Beginn des neunten Jahrhunderts prosperierender Märkte erfreuen konnte. Die Erträge der Märkte in Rom und in den wichtigen Häfen, die ebenfalls der Stadt unterstanden, trugen wesentlich dazu bei, dass das Papsttum ab der zweiten Hälfte des achten Jahrhunderts über beträchtliche finanzielle Mittel verfügen konnte. Dass auch Sarazenen Handelsbeziehungen in Rom hatten, erfahren wir jedoch nur aus arabischen Quellen, dieser Aspekt wird in den lateinischen Quellen fast völlig ausgeblendet. ${ }^{916}$ Doch so sehr man mit den sarazenischen Händlern auf friedlicher Basis verkehren konnte, so sehr zählten die Sarazenen von Beginn der Beziehungen an zu den entferntesten Anderen, von denen in römischen Quellen berichtet wird. Bezeichnend sind hier die kurzen Passagen aus der Vita Gregors II. Die Sarazenen erscheinen fast ausschließlich als Feinde der Kommunikationspartner der Päpste im Speziellen und der Christenheit im Allgemeinen. Ab dem Beginn des neunten Jahrhunderts verdüsterte sich das Sarazenenbild noch ein wenig. Tatsächlich scheint auch die Bedrohung zugenommen zu haben, sodass man sogar versuchte, sich gegen Angriffe zu wappnen. Dennoch hatte man trotz schnell anlaufender fränkischer Hilfe dem Angriff von 846 nichts entgegenzusetzen. Allerdings konnte mithilfe einer süditalienischen Koalition der zweite Versuch 849 zurückgeschlagen werden.

Die eminente sarazenische Bedrohung führte $\mathrm{zu}$ fundamentalen Umwälzungen im päpstlichen Weltbild und Denken. Das Papsttum entwickelte zunächst ein neues Gefühl für die eigene Situation in Mittelitalien. Diese neue Selbstsicht führte zum (allerdings nur teilweise erfolgreichen) Versuch, die lokalen süd- und mittelitalienischen Potentaten stärker ins päpstliche politische System zu integrieren. Dieses Streben entfaltete sich vor allem im Pontifikat Johannes VIII., doch wir können die Wurzeln dieser Politik schon unter Leo IV. erkennen. Allerdings scheiterte das Konzept mit dem Tod Johannes' VIII.

Außerdem änderte das Papsttum unter dem Eindruck seine theologische Position zu Kriegen gegen Heiden oder Andersgläubige, somit also bezüglich der Teilnahme an der Tötung anderer Menschen. Ein solcher Akt hatte bis dahin als verwerflich gegolten und der Buße bedurft, sogar wenn er unter vertretbaren Umständen erfolgt war. $^{917}$ Doch von nun an galt, dass, sobald jemand im Kampf für die Kirche starb,

916 Wir begegnen diesem Phänomen auch in Süditalien, vgl. Gantner, Wahrnehmung des Islam 77-120. 917 Cyrille Vogel, Le Pecheur et pénitance au Moyen Âge (Paris 1969) 73f., zum Beispiel Bedas. Siehe auch Erdmann, Entstehung 13-16, mit Anm. 32, wo er aus Bußtraktaten des ersten Milleniums zitiert. Zur ursprünglichen christlichen Position zu Gewaltanwendung siehe Philippe Buc, Some Thoughts on the Christian Theology of Violence, Medieval and Modern, from the Middle Ages to 
eine Buße nicht mehr benötigt wurde. Die Sünden waren automatisch vergeben. ${ }^{918}$ Mit ecclesia meinten die Päpste übrigens so gut wie immer die römische Kirche.

Das Papsttum hatte somit auch das Rüstzeug für einen religiös begründeten Krieg gegen Andersgläubige vorbereitet. Auf diese Basis konnten die Päpste des elften Jahrhunderts zurückgreifen, als sie den Weg für die Kreuzzüge bereiteten.

the French Revolution, in: Rivista di Storia del Cristianesimo, 5,1 (2008) 9-28, hier 11-13, sowie Flori, À propos, bes. $32-34$.

918 Flori, Guerre sainte 51f., argumentiert auch in diese Richtung, um zu zeigen, dass die Papstbriefe des neunten Jahrhunderts keine verfrühten Kreuzzugsbullen waren, womit er sicherlich recht hat. Allerdings spricht er sich auch dagegen aus, dass ep. 150 Johannes' VIII. automatischen Ablass versprochen habe, bezieht aber die recht eindeutigen Bibelzitate nicht in seine Überlegungen mit ein. 


\section{Conclusio}

In den theoretischen Überlegungen zu Beginn dieser Arbeit wurde vor allem zwischen der „reinen“ Interpretation der eigenen Wahrnehmung von Alterität auf der einen Seite und der Konstruktion von anderen Identitäten durch die im unmittelbaren Umkreis des Papsttums verorteten Sprecher selbst unterschieden. Es ist, wie oben in Kapitel 2.I bemerkt wurde, oft schwer hier eine exakte Unterscheidung zu treffen. Die langobardische Identität mit ihren historischen Assoziationen von Barbarei, Heidentum und Häresie war jedoch leicht als andersartig zu markieren und musste von den Päpsten weniger stark bearbeitet werden. Doch das Beispiel der Franken hat gezeigt, dass es der negativen Stereotype nicht notwendigerweise bedurfte. Auch Verbündete oder Freunde konnten unter bestimmten Veraussetzungen recht einfach von den Eigenen abgegrenzt werden. Auf der anderen Seite dieses Spektrums finden sich der Kaiser und die Vertreter des imperialen Establishments, die um die Mitte des achten Jahrhunderts aus durchaus nachvollziehbaren Gründen ausgiebigem Othering vonseiten der Päpste unterworfen waren. Die Sarazenen schließlich waren wieder Andere, die sehr leicht von einem „Wir“ getrennt werden konnten. Dennoch wurde gerade ihr Bild in den römischen Quellen von den Päpsten auf eine ganz bestimmte Weise konstruiert, indem (zum Teil sicher erhebliche) Unterschiede zwischen einzelnen sarazenischen Gruppen nivelliert wurden und die Sarazenen als Einheit präsentiert wurden (vgl. vor allem Kapitel 6.2). Auch das ist zweifellos als eine Form des Othering zu betrachten.

Auch wenn alle Bilder von Anderen und Fremden in unseren Quellen bis zu einem gewissen Grad durch die Autoren konstruiert waren, können wir graduelle Unterschiede in dieser Konstruiertheit feststellen. Wie immer wenn es um menschliche Identitäten geht, waren auch diese Konstrukte nicht arm an Widersprüchen.

Beim Fall „Ostrom“/Greci (Kapitel 4 ) handelte es sich um jene Anderen, die für die Päpste das wahrscheinlich komplexeste Problem darstellten. In Kapitel 3.2 konnte deutlich gemacht werden, wie sehr Rom und das Papsttum im Frühmittelalter noch mit dem Kaiserreich verbunden waren, auch wenn dieses seit Jahrhunderten vom Osten aus dominiert wurde. Hier handelte es sich um einen klaren Fall einer Anderen Identität, die doch auch „discomfortingly familiar" ${ }^{\text {“19 }}$ war. Zu dieser Problematik trug

919 Siehe dazu oben, Anm. 148. 
sicherlich bei, dass in Rom selbst eine ganze Reihe von Menschen lebte, die trotz ihrer heterogenen Herkunft als kulturell griechisch zu sehen sind.

In Kapitel 4 hat sich der Terminus Greci als hervorragender Indikator für die Beziehungen zwischen Rom und den Vertretern des „oströmischen“ Kaiserreichs erwiesen. In der ersten Hälfte des achten Jahrhunderts ist er als Bezeichnung für ein Kollektiv von Menschen in Rom nicht nachweisbar - eine auffällige Diskrepanz zu anderen lateinischen Quellen des Zeitraums aus dem fränkischen und hispanischen Bereich. Der Unterschied ergab sich vielleicht daraus, dass in Rom dem Begriff gegenüber ein größeres Problembewusstsein herrschte, weil man die vertrauten Anderen aus dem Osten (und Süden) eben wesentlich besser kannte. Diese intimere Kenntnis wurde auch um die Mitte des achten Jahrhunderts nicht geringer. Dennoch entschieden sich die Bruderpäpste Stephan II. und Paul I. dazu, den Terminus Greci als Werkzeug zu verwenden, mit dessen Hilfe der Kern des Imperiums von Rom möglichst klar abgesetzt wurde. Als sich Hadrian I. schließlich dazu durchrang, Rom politisch auch de facto aus dem Römischen Reich herauszulösen, konnte er auf dieses sprachliche Repertoire zurückgreifen - und er machte davon auch vielfach Gebrauch.

In Kapitel 4 konnte somit auch gezeigt werden, wie entscheidend sich die Beziehung zwischen Papsttum und Kaiser/Kern des Reichs durch die politischen Umwälzungen des achten Jahrhunderts veränderte und wie sehr, anders betrachtet, die Veränderung dieser Beziehung auch ebendiese Umwälzungen beschleunigte. Besonders die päpstliche Politik in der zweiten Hälfte des achten Jahrhunderts erwies sich als entscheidend für das Verhältnis zwischen Ost und West und lateinischem und griechischem Kulturbereich. Das ist insofern paradox, als die beiden Kulturen auch weiterhin gerade in Rom sehr stark vertreten waren.

Auch die Langobarden (Kapitel 5) waren für Rom im achten Jahrhundert einer der wichtigsten Kommunikationspartner. Das war allein schon dadurch begünstigt, dass langobardische Herrschaftsgebiete den römischen Dukat fast auf allen Seiten umgaben. Der Befund der Quellen des siebenten Jahrhunderts zeigt zwar, dass auch weitgehend friedliche und unspektakuläre Koexistenz nicht ausgeschlossen war, doch im achten Jahrhundert wechselten sich kurze Phasen engerer Kooperation mit längeren des Konflikts immer wieder ab. Die Langobarden waren dabei von Rom aus gesehen immer Fremde, auch wenn es sich um vertraute Fremde handelte. Die langobardische Identität war immer von der römischen abgesetzt. Das haben wir besonders eindrucksvoll am Beispiel der Kooperationen mit langobardischen Gruppen unter Gregor II. (715-73I) gesehen: Obwohl in der LP Vita die Langobarden „Brüder im Band des Glaubens“ für die Römer sein dürfen, werden sie doch vom Autor in derselben Passage von jenen abgesetzt, indem er sie mehrmals als Langobarden bezeichnet. Die Offiziellen des Kaiserreichs hingegen wurden, obwohl sie eindeutig Feinde des 
Papstes waren, nicht als Andere dargestellt. Wenn wir bedenken, dass sich darunter sicher auch kulturell griechische Personen befanden, wird die Abgrenzung gegenüber den Langobarden noch deutlicher.

Dabei muss offen bleiben, wie die Langobarden überhaupt von den Römern unterschieden werden konnten, zumal im achten Jahrhundert von einer weitgehenden kulturellen Assimilation ausgegangen werden muss. Die Haartrachtstellen des LP aus den Viten Gregors III. (73I-74I) und Hadrians I. (772-795) suggerieren jedoch selbst für die Eliten der beiden Seiten eine klare äußerliche Unterscheidbarkeit, auch wenn die Darstellung nicht besonders konkret wird. Obwohl wir uns also genauere Angaben wünschen würden, belegen die vorgestellten Quellen doch, dass die Differenz zwischen Römern und Langobarden von den Zeitgenossen in vielen Fällen wahrnehmbar war. ${ }^{920}$

Das auffälligste Merkmal des päpstlichen Umgangs mit den Langobarden war die politische Flexibilität, die anderen Gruppen gegenüber nicht in vergleichbarer Weise gezeigt wurde. Schon im Pontifikat Gregors II. oszillierte das Papstum zwischen Kooperation und Konflikt mit Langobarden. Gregor III. schlug sich auf die Seite der südlichen duces, sein Nachfolger Zacharias (74I-752) lieferte Transamund von Spoleto jedoch an Liutprand aus und begründete so eine recht konstruktive $\mathrm{Zu}$ sammenarbeit mit dem Langobardenkönig, im Zuge derer sich der Papst sogar erfolgreich zugunsten Ravennas einsetzen konnte. Doch trotz der Kooperation galten die Langobarden in Rom tendenziell immer als Feinde, wie der überraschend offene Jubel der Vita des Zacharias über den Tod Liutprands deutlich macht. Im Pontifikat Stephans II. könnte man den Eindruck gewinnen, der Papst habe sich nun endgültig in völlige Opposition zu den Langobarden begeben - wäre da nicht der Schluss von Stephans LP-Vita, der nicht nur die Rolle des Papstes bei der Einsetzung des Desiderius als König hervorhebt, sondern den neuen Herrscher auch in einem sehr positiven Licht erscheinen lässt.

Die reichlich überlieferten Quellen zu König Desiderius zeigen, wie schnell zwischen positivem und negativem Fremdbild gewechselt werden konnte, wenn die politische Situation es erforderte. Im Pontifikat Stephans III. (768-772) wurden die Langobarden zunächst in CC 45 im wahrsten Sinne des Wortes verteufelt und zu einer quasihäretischen Nicht-gens erklärt - eine Rhetorik, die sich besonders gegen Desiderius und seine Familie richtete. Wenig später kooperierte der Papst aber wieder vollständig mit dem Langobardenkönig, seinem excellentissimus filius.

Und auch unter Hadrian I. wurden die Langobarden sehr differenziert gesehen. Zunächst scheint sich der Papst zwar für eine Linie gegen König Desiderius ent- 
schieden zu haben (wofür uns allerdings die letzte Sicherheit fehlt), doch nach der Übernahme des langobardischen Königreichs durch Karl den Großen setzte sich Hadrian in mehreren Fällen für Langobarden innerhalb der erweiterten römischen Interessenssphäre ein. Das hielt ihn aber nicht davon ab, gegen die langobardischen Machthaber größerer Dukate inner- und außerhalb des fränkischen Einflussbereichs zu polemisieren und zu intrigieren, insbesondere gegen Arichis von Benevent.

Der Pontifikat Stephans II. markierte einen Wendepunkt in den Langobardenbeziehungen der Päpste. Rom gewann durch das Bündnis mit den Franken neue Handlungsfreiheit und neues Selbstbewusstsein. Zugleich wurde die Beziehung zum langobardischen Königtum aber auch von einer erbitterten Antagonie geprägt, die abgesehen von kurzen Episoden bis 774 anhalten sollte und auch als Folge von Stephans Politik zu sehen ist. ${ }^{921}$

Das ist umso bemerkenswerter, als der Pontifikat Stephans II. auch in der Beziehung zum Kaiser und seinen Offiziellen einen wesentlichen Entwicklungsschub gebracht hatte. Auch hier waren die Zeichen auf Konfrontation gesetzt worden. Der Papst hatte ein Bündnis mit einer auswärtigen Macht geschlossen und das möglicherweise sogar unter Umgehung oder zumindest willkürlicher Umdeutung der Wünsche des Kaisers und seiner missi. Sicherlich hatte Konstantinopel an der Verschlechterung des Verhältnisses auch einen beträchtlichen Anteil, etwa durch die Festschreibung des Ikonoklasmus am Konzil von Hiereia oder durch die konstante Weigerung, in Italien auch nur symbolisch militärisch einzugreifen. Die Entwicklung der mit negativen Konnotationen versehenen Bezeichnung Greci durch Stephan II. und seinen Bruder und Nachfolger Paul (757-767) sollte sich aber als ebenso entscheidend erweisen.

Die Franken, die in Kapitel 5 durchwegs eine wichtige Rolle spielen, wurden im Anschluss noch einzeln analysiert. Dabei zeigten sich viele Parallelen zur grundsätzlichen Disposition des Papsttums den Langobarden gegenüber. Auch hier hatte es Rom mit einer gens zu tun, die sich ohne Aufwand von den Römern unterscheiden ließ. Zwar kam es zu Akten des Sameing, doch diese waren wohldosiert, um immer eine Unterscheidbarkeit der fränkischen Politik von der eigenen zu gewährleisten. Auf fränkischer Seite funktionierte dieser Mechanismus ähnlich. Gegenüber Franken wurde aber auch bisweilen subtiles Othering angewandt, wenn etwa Pippin ostentativ immer wieder als rex Francorum bezeichnet wurde. In diesen Fällen war es den Päpsten und ihren Mitarbeitern offenbar wichtig, eine unabhängige und leicht unterscheidbare politische, religiöse und kulturelle Position gegenüber dem wachsenden Karolingerreich aufrechtzuerhalten.

921 Daneben spielten auch die Ambitionen der Langobardenkönige Aistulf und Desiderius sicher eine wesentliche Rolle. 
Im Fall der Sarazenen (Kapitel 6) war es wichtig, zunächst zu zeigen, dass es trotz des fast vollkommenen Schweigens der Quellen wahrscheinlich ist, dass noch um 800 in den römischen Häfen gute Handelsbeziehungen zu sarazenischen Kaufleuten herrschten. Um 840 galten Sarazenen bereits als so große Bedrohung, dass die Befestigungen der Häfen Portus und Ostia verstärkt wurden. Das konnte jedoch den Überfall von 846 nicht verhindern. Dieser Angriff hatte auf das Papsttum zwei Auwirkungen: Erstens veränderte er die Wahrnehmung der eigenen, weitestgehend christlichen Umwelt in Italien. Es herrschte nun das Streben nach größerer Einheit vor. Besonders Johannes VIII. (872-882) versuchte alles, um diese neue Vision der christlichen Gemeinschaft Italiens Realität werden zu lassen. Die Bemühungen scheiterten jedoch. Die zweite Veränderung, die die sarazenische Bedrohung beim Papsttum auslöste, war jedoch wesentlich dauerhafter. Im Angesicht der großen militärischen Gefahr durch andersgläubige Fremde änderte schon Papst Leo IV. $(847-853)$ und in seiner Nachfolge noch radikaler Johannes VIII. die Position der römischen Kirche zum Krieg gegen „Ungläubige“. Plötzlich wurde im Kampf gegen Sarazenen und andere „Heiden“ gefallenen Kämpfern der direkte Weg ins Himmelreich in Aussicht gestellt. Dabei handelte es sich sicherlich noch nicht um dieselbe Argumentation, wie sie zwei Jahrhunderte später am Vorabend der Kreuzzüge verwendet wurde, dennoch war die Änderung der päpstlichen Position in dieser Frage sehr bedeutend.

Ein wesentliches Ergebnis der Studie zu den Sarazenen war außerdem die Erkenntnis, dass diese Anderen von den Päpsten des neunten Jahrhunderts als eine Einheit dargestellt wurden, obwohl sie genau das in Süditalien nie waren. Viel mehr operierten Gruppen verschiedener Größe unabhängig voneinander. Diese Diversität machte diese Fremden für das Papsttum sehr unberechenbar und daher noch bedrohlicher. Dennoch entschied man sich dazu, die Sarazenen als quasimonolithischen Block zu definieren. Auch das kann man sicherlich als Strategie des Otherings werten, denn umso leichter war es, ein Feindbild dieser Anderen zu kultivieren.

Einen Schluss muss man aus der Zusammenschau der Beispiele ziehen: Die Frage der Andersartigkeit ist niemals absolut zu betrachten, sondern immer im jeweiligen Kontext. Es gibt vereinfachend dargestellt Stufen der Alterität, das wichtigste Beispiel liefert uns hier die Reaktion der Päpste auf die sarazenische Bedrohung. Denn zuvor waren die Langobarden Süditaliens immer sehr deutlich als Andere dargestellt worden, ja sie waren sicherlich auch zu einem gewissen Grad einem aktiven Othering ausgesetzt. Davon ist nach dem Schock von 846 in den Quellen nicht mehr viel übrig, von da an wurde vielmehr versucht, die langobardischen Fürstentümer zu einer A1lianz mit Rom zu überreden. Das hatte zur Folge, dass von da an eine sehr inklusive Rhetorik überwog, die versuchte, alle Christen, vor allem aber jene Süd- und Mit- 
telitaliens, als eine Einheit darzustellen, die eine gemeinsame patria zu verteidigen hatte. Man kann hierin durchaus Akte des Sameing sehen.

Ein sehr ähnliches Ergebnis liefert auch ein Vergleich der beiden anderen Beispiele in Kapitel 4 und 5 (unter Einbeziehung der Ergebnisse von Kapitel 3). Hier hat sich gezeigt, dass zunächst die Oströmer in jedweder Gestalt und Ausprägung als dem Papsttum und Rom näherstehend behandelt wurden als die Langobarden, die immer automatisch als Langobardi oder gens Langobardorum gut kenntlich von den Romani abgesetzt wurden, bei den Franken verhielt es sich ebenso. Für die Oströmer, die Greci der päpstlichen diplomatischen Schreiben seit Stephan II., war der Fall hingegen sehr viel schwieriger gelagert, weshalb es umso entschiedeneren Otherings bedurfte.

Der in Kapitel 2.2 postulierte Unterschied zwischen Fremdheit und Alterität konnte in der vorliegenden Arbeit gut abgebildet werden. Zwar erfolgt in den päpstlichen Quellen niemals ausdrücklich eine Qualifizierung der in der Arbeit behandelten Anderen als Fremde, doch dennoch lassen sich aus dem vorhandenen Material vorsichtige Schlüsse ziehen. Hierfür müssen wir vor allem an die in Kapitel 4.I vorgestellten kaiserlichen Amtsträger (vermutlich östlicher Herkunft) denken. Denn diese Menschen sind aus römischer Sicht fast ausschließlich Andere, doch ob sie auch als Fremde empfunden wurden, wird nicht klar. Im LP werden sie zwar in den meisten Fällen als niederträchtige Feinde des Papstes porträtiert, doch sie zählen auffälligerweise eher zur „in-group“, deren Wahrnehmung wahrscheinlich noch von der Idee des Römischen Reichs geprägt ist. Durch das intensive Othering werden ihre Nachfolger zu Greci ${ }^{922}$ und damit Zugehörige einer als fremd definierten Gruppierung. Im Gegensatz dazu sind hingegen die stadtrömischen Greci zu sehen: Die meisten von ihnen gehören zweifellos zum päpstlichen peculiaris populus, aber einerseits konnten Untergruppen dieser Griechen sicherlich auch als Andere gelten, andererseits waren einige Neuankömmlinge, die von der „lateinischen“ Mehrheit wahrscheinlich dieser Sammelgruppe zugeordnet wurden, auch für die römischen Griechen durchaus Andere, wahrscheinlich auch Fremde.

Ein weiteres Beispiel sind die Langobarden des Spoletiner dux Hildebrand. Diese Langobarden, die zu Römern geschoren wurden, wurden vermutlich weiterhin als Andere wahrgenommen, aber ob sie den Päpsten richtig fremd waren, darf bezweifelt werden. Denn hier hatte man es im Lateran mit Menschen zu tun, mit denen man in sehr häufigem, engem Kontakt stand. Diese Anderen waren somit keine Fremden, sie verband mit den Römern ein jeweils unterschiedliches Maß an Extimität ${ }^{923}$ - eine

922 Man denke nur an den sizilianischen strategos aus der Zeit Hadrians I., vgl. Kap. 4.3.

923 Zum Konzept siehe oben, Kap. 2.1. 
verschwimmende Grenze zwischen Identität und Alterität. Homi K. Bhabha hat eine ähnliche Diskrepanz (in seinen gänzlich unterschiedlichen Texten) mit dem auch hier zutreffenen Ausdruck „almost the same, but not quite“ beschrieben. ${ }^{924}$

Man kann also im Prinzip von fernen und naben Anderen ausgehen, wobei die Kategorie der Fremden irgendwo mitten unter den „nahen“ Anderen beginnt. Die nächsten dieser Anderen werden vom Papst als peculiaris populus eingestuft, sie waren seine Schtuzbefohlenen, diejenigen Menschen, die vom Papsttum und dem Heiligen Petrus direkt beherrscht und verwaltet werden konnten. Allen Formen von Alterität stehen der Papst und sein engstes Umfeld, sein engster Stab gegenüber, die methodisch in der Untersuchung nicht mehr trennbar waren. Durch Othering war es aber möglich, als aus diesem innersten Kreis ausgeschieden gekennzeichnet zu werden, wie der Fall von Paulus Afiarta gezeigt hat.

Um die Komplexität dieser verschiedenen Beziehungsformen zu illustrieren, wurde das Diagramm in Abbildung 2 erstellt. ${ }^{925}$ Mitgedacht muss werden, dass die Grenzen zwischen den Kategorien in der Realität niemals so klar wie in der Abbildung sein können, sondern als fließend zu verstehen sind. Auch ein Wechsel zwischen dem Papst und seinen Schutzbefohlenen näher stehenden und weiter entfernten Anderen war, wie wir ja gehört haben, durchaus möglich. Die erste Stufe der Anderen wird in den für diese Arbeit ausgewählten Beispielen jedenfalls von den oströmischen Mandatsträgern der ersten Hälfte des achten Jahrhunderts repräsentiert, die meiste Zeit sicher auch von vielen Langobarden, die allerdings in der Schnittmenge mit den Fremden zu verorten sind. Ohne Zweifel Fremde und Andere waren alle Sarazenengruppen, die zweifellos der weiter entfernten Kategorie der Anderen zuzuordnen sind. Es ist zur Graphik zu bemerken, dass die äußere Kategorie der Anderen als fast deckungsgleich mit den Fremden zu betrachten ist, was hier soweit wie möglich dargestellt wurde. Die Kategorie der Fremden umfasst außerdem auch Teile der nahen Anderen und wurde deshalb hier leicht transpartent abgebildet.

Das Diagramm soll verdeutlichen, dass es verschiedene Kategorien von Fremden und Anderen gab, die auf verschiedenen Niveaus der Alterität anzusiedeln sind. Diese Kategorien waren allerdings weder trennscharf, noch waren die Grenzen dazwischen unüberwindbar. Mittelitalienische Kollektive konnten aus der römischen Warte etwa relativ leicht zwischen in-group (peculiaris populus) und out-group (Andere) wechseln. Neben den eben erwähnten Spoletiner Langobarden sei hier auch auf die Bewohner

924 Homi K. Bhabha, Of mimicry and man, in: ders., The Location of Culture (London/New York 1994) 121-131, hier 122.

925 Herzlichen Dank an Dagmar Giesriegl für die technische Unterstützung bei der graphischen Verbesserung meiner ursprünglichen Entwürfe. 


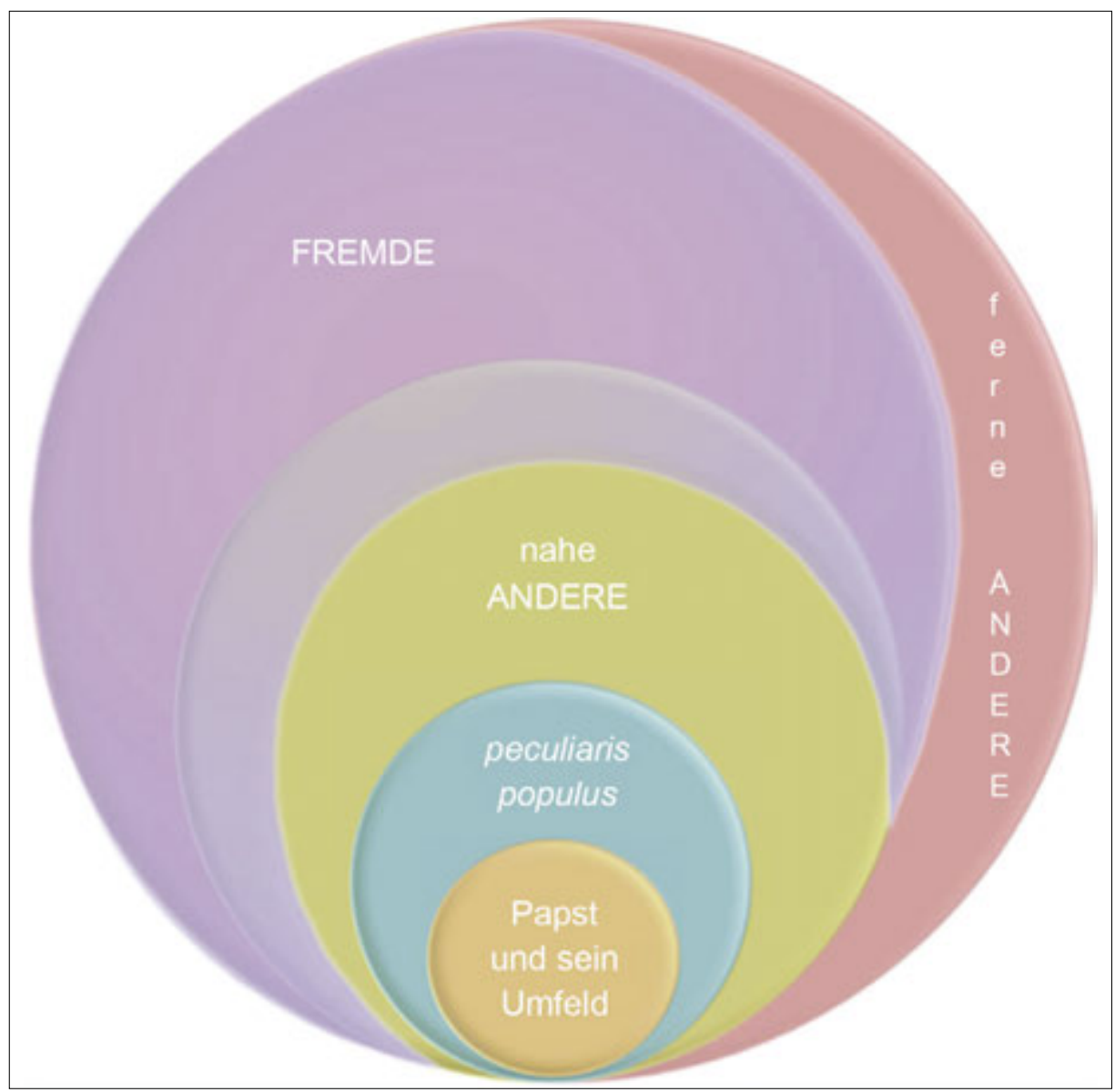

Abbildung 2: Stufen der Alterität

Ravennas verwiesen, die zwar im LP-Eintrag des Zacharias explizit der „Herde“ des als bonus pastor auftretenden Papstes zugerechnet werden und doch aus römischer Sicht oft auch Andere waren - wenn auch dem peculiaris populus sehr nahestehende Andere.

Auch vorher als sehr fremd betrachtete Gruppen hatten unter bestimmten Voraussetzungen das Potential, als durchaus vertraut erscheinen zu können. Dieses Potential können wir ebenfalls am Beispiel der Langobarden demonstrieren. In den Quellen des achten Jahrhunderts konnten durchaus noch Stereotype aus der Frühzeit dieser 
gens in Italien zur Anwendung kommen. Die implizite Darstellung der Langobarden als der Häresie und des Heidentums verdächtige Gruppe war sicherlich ein Akt des zielgerichteten Otherings, zeigt aber auch, dass der Langobardenname als Inbegriff des Fremden eben über dieses Potential verfügte. Entsprechend einfach war es für Hadrian I. noch im ausgehenden achten Jahrhundert, die Beneventaner Langobarden als Feinde zu markieren. Doch im neunten Jahrhundert war es plötzlich möglich, die verbliebenen Langobarden im Süden zu Vertrauten zu erklären, die der eigenen in-group nahestanden. Das war umso leichter, als sich die Langobarden Süditaliens, die ja wie Rom selbst von griechischer und lateinischer Kultur geprägt waren, sehr gut assimiliert hatten. Der Wechsel der Langobarden zu den „nahen“ Anderen vollzog sich unter dem Druck der Sarazenen relativ schnell, war aber abgesehen davon kein außergewöhnlicher Vorgang. So waren die Franken im sechsten Jahrhundert, im Zuge der Gotenkriege, bisweilen als furchterregende Fremde dargestellt worden, bis zum achten Jahrhundert hatten sie sich aber zur wesentlichen Stütze des katholischen Christentums und zum wichtigsten Ansprechpartner der Päpste im Westen entwickelt. Auch bei Auseinandersetzungen mit den karolingischen Verbündeten, wie sie in den Papstbriefen des achten Jahrhunderts nicht selten zu finden sind, wurde die wenig rühmliche Vergangenheit der Franken im Gegensatz zu den Langobarden niemals vorgebracht - ganz im Gegensatz dazu wurden die Vorfahren der Karolinger im Brief CC 45 sogar noch dafür gelobt, ausschließlich fränkische Frauen geheiratet zu haben. Fremde/Andere Identitäten waren dynamisch, sie änderten sich immer wieder, weshalb sich Wahrnehmung und Konstruktion von Alterität ständig neuen Gegebenheiten anpassen mussten.

Die Interaktion der Päpste des achten und neunten Jahrhunderts mit anderen politischen Gruppen hat sich insgesamt als ein äußerst interessantes Forschungsfeld erwiesen. Die Päpste saßen als Bischöfe von Rom nicht nur an einem historisch äußerst bedeutenden Ort, die Ewige Stadt war im Frühmittelalter auch ein Schnittpunkt der mittelmeerischen Kulturen, insbesondere der lateinischen und der griechischen. Obschon man sich von den "Griechen“ aus politischen und religiösen Gründen sehr oft absetzen musste, profitierte Rom und nicht zuletzt das Papsttum doch auf außerordentliche Weise von dieser Situation. Auch die Langobarden spielten in Italien eine wichtige Rolle. Der die meiste Zeit vorherrschende Antagonismus mit den Langobarden war für die Päpste zweifellos bedrohlich, brachte aber auch die Chance mit sich, die Position des Papsttums in Mittelitalien zu stärken - eine Chance, die schließlich auch recht entschlossen ergriffen wurde.

Das politische Gleichgewicht des Mittelmeeraumes wurde durch die militärischen Erfolge der Sarazenen wesentlich verändert. Auch Rom war davon stark betroffen. Zunächst wandelte sich die Bevölkerungsstruktur der Stadt schon ab dem siebenten 
Jahrhundert, im neunten Jahrhundert führte schließlich der direkte feindliche Kontakt mit Sarazenengruppen dazu, dass sich die römische Sicht der Welt ein wenig veränderte. Die Entwicklung des Papsttums selbst wurde durch die Auseinandersetzung und durch die Kooperation mit Anderen ganz wesentlich geprägt. Doch auch das Papsttum prägte durch seine Texte das Bild dieser Anderen oftmals bis in die moderne Historiographie hinein auf entscheidende Weise: Die Sarazenen und bisweilen auch die Langobarden wurden zu Völkern der Finsternis, die Franken hingegen zu Freunden Roms, sie wurden bis in die moderne Historiographie hinein nicht zuletzt durch die Erzählung des Liber Pontificalis zu Helden der Geschichte. 


\section{Tabellen-, Abbildungs-, Quellen- und Literaturverzeichnis}

Verzeichnis der Tabellen und Abbildungen

\section{Tabellen}

Tabelle r: natione-Kategorie des Liber Pontificalis, 625-795 93

Tabelle 2: Codex Carolinus Briefe, die den Terminus Greci enthalten 122

Tabelle 3: Die Verteilung der Textklassen für die einzelnen Papstviten 309-3I3

\section{Abbildungen}

Abbildung I: Variante (49), LP I, 450, 11. 3-I I (entnommen aus Gantner, Studien I 46) 37

Abbildung 2: Stufen der Alterität 279

\section{Verzeichnis der verwendeten Quellen}

Annales Bertiniani (ed. Georg Waitz, MGH SS rer. Germ in us. schol. [5], Hannover I883); (trans. Janet L. Nelson, The Annals of St-Bertin, Manchester Medieval Sources, Manchester/New York 1991).

Annales Fuldenses, a. 876 (ed. Friedrich Kurze, MGH SS rer. Germ. in us. schol. [7], Hannover I891, ND 1993).

Annales Mettenses priores (ed. Bernhard von Simson, MGH SS rer. Germ in us. schol. [ıo], Hannover 1905).

Johannes Aventinus, Annales ducum Boiariae, Buch I-4 (ed. Sigmund von Riezler, Matthias Lexer, Annales ducum Boiariae, Bd. I, München i 882).

Beda, Chronica maiora a. 725 et Chronica minora a. 703 (ed. Theodor Mommsen, MGH AA I3, Chronica minora saec. IV-VII, 3, Berlin I898) 223-354; (trans. Faith Wallis, Bede: The Reckoning of Time, Translated Texts for Historians 29, Liverpool I999) I57-237.

Beda, Historia ecclesiastica gentis Anglorum (ed. und trans. Günter Spitzbart, Darmstadt ${ }^{2}$ I997).

Bonifatius, Epistolae (ed. Michael Tangl, Die Briefe des Heiligen Bonifatius und Lullus, MGH EE sel., I, Berlin i9r6).

Briefe Gregors II. an Leon III. und Patriarch Germanos (ed. Jean Gouillard, Aux origins de l'iconoclasme: Le témoignage de Grégoire II?, in: Traveaux et memoires, Centre de recherché d'histoire et de civilisation byzantines, 3 [1968]) 243-307. 
Chronica Sancti Benedicti Casinensis (ed. Georg Waitz, MGH SS rer. Lang., Hannover I878) 468-488; (ed. Luigi Andrea Berto, Cronicae Sancti Benedicti Casinensis, Editione nazionale dei testi mediolatini, I5, Florenz 2006).

Chronicon Salernitanum (ed. Ulla Westerbergh, Acta Universitatis Stockholmensis, Studia Latina Stockholmensia 3, Lund/Stockholm i956).

Clausula de unctione Pippini (ed. Alain J. Stoclet, La „clausula de unctione Pippini regis“: mises au point et nouvelles hypthèses, in: Francia, 8 [I980]) I-42.

Codex epistolaris Carolinus (ed. Wilhelm Gundlach, MGH EE 3, Epistolae Merovingici et Carolini aevi I, Berlin I892) 469-657.

Codex epistolaris Carolinus, Österreichische Nationalbibliothek Codex 449 (Codices selecti, 3, Graz i962).

Codice diplomatico Longobardo, 5 Bde. (ed. Liugi Schiaparelli/Carlrichard Brühl, Rom 1929-2003).

Concilium Lateranense a. 649 (ed. Rudolf Riedinger, Acta conciliorum oecumenicorum, Series 2 , Bd. I, Berlin 1984 ).

Concilium Quinisextum (ed. Heinz Ohme, Fontes Christiani, 82, Turnhout 2006).

Concilium Romanum a. 76r (ed. Albert Werminghoff, MGH LL Concilia 2, I, Concilia aevi Karolini [742-842], Hannover/Leipzig 1906) 64-7 I.

Concilium Romanum a. 769 (ed. Albert Werminghoff, MGH LL Conc. 2, I, Concilia aevi Karolini [742-842)], Hannover/Leipzig, I906) 74-92.

Continuationes Fredegarii (ed. Bruno Krusch, MGH SS rer. Merov., 2, Fredegarium et aliorum chronica. Vitae sanctorum. Hannover 1888) I68-193.

Ecloga (ed. Ludwig Burgmann, Ecloga: Das Gesetzbuch Leons III. und Konstantinos' V., Forschungen zur byzantinischen Rechtsgeschichte, Io, Frankfurt am Main 1983).

Einhard, Vita Karoli (ed. Georg Waitz, MGH SS rer. Germ. in us. schol. [25], Hannover/ Leipzig I9I I).

Epistolae Langobardicae Collectae, I3 (Gregorius III. papa Antonino Gradensi) (ed. Wilhelm Gundlach, MGH EE, 3 Berlin I892) 69I-715, hier 703.

Epistolae selectae Sergii II, Leonis IV, Benedicti III, pontificum Romanorum (ed. Adolph von Hirsch-Greuth, MGH EE 5, Berlin I899) 58I-6I 4.

Gratian, Decretum (ed. Emil Friedberg, Corpus Iuris Canonici, I, Leipzig 1879).

Gregor I., Epistolae (ed. Dag Norberg, Gregorii magni registrum epistularum, 2 Bde., CC SL I 40 und I40A, Turnhout 1982) (trans. John R. C. Martyn, The Letters of Gregory the Great. Translated, with introduction and Note, 3 Bde., Medieval Sources in Translation, 40, Toronto 2004).

Gregor I., Homilia in Hezechielem, lib. 2 (ed. Marc Adriaen, CC SL I42, Turnhout I97I).

Gregor I., Moralia in Iob I (ed. Marc Adrien, CC SL I 43, Moralia in Iob Libri I-X, Turnhout I979).

Gregor II., Brief an Martinianus und Georgius, I5. Mai 716, ed. Johannes Merkel, Leges Baiuwariorum, in: MGH LL III (Hannover I863) I83-496, hier 45 I-454.

Hadrian I., Hadrianum (ed. Karl Hampe, MGH EE 5, Epistolae selectae pontificum Romanorum Carolo Magno et Ludowico Pio regnantibus scriptae, 2, Berlin I 899) 5-57.

Hadrian II., Epistolae (ed. Ernst Perels, MGH EE 6, Berlin i925) 69I-765. 
Hinkmar, De Regis persona et regio ministerio, PL I25, col. 833-856.

Isidor, Etymologiae (ed. W. M. Lindsay, Oxford I9I I).

Ivo von Chartres, Decretum, PL i6r, col. 9-1036.

Ivo von Chartres, Panormia, PL i6r, col. 1037-I344.

Jacut's geographisches Wörterbuch, I I Bde., ed. Ferdinand Wüstenfeld (Leipzig I 867).

Johannes VIII., Epistolae (ed. Erich Caspar, MGH EE 7, Berlin 1928) XIII-XXII und I-272.

Konstantin Porphyrogennetos, De administrando imperio (ed. Gyula Moravcsik/Romilly J.

H. Jenkins, Corpus Fontium Historiae Byzantinae I, Washington/D. C. I967).

Leo III., Epistolae X (ed. Karl Hampe, MGH EE 5, Berlin I899) 85-104.

Liber Diurnus (ed. Hans Förster, Liber Diurnus Romanorum Pontificum, Bern 1958).

Liber Pontificalis (ed. Louis Duchesne, Le Liber Pontificalis: Texte, introduction et commentaire, 3 Bde. [Bd. 3: Additions et corrections de Mgr L. Duchesne, ed. Cyrille Vogel] Paris ${ }^{2}$ I955-1957); (trans. Raymond Davis, The Book of Pontiffs (Liber Pontificalis): The Ancient Biographies of the First Ninety Roman Bishops to AD 7 I5, Translated Texts for Historians, 6, Liverpool ${ }^{2}$ 200o); (trans. Raymond Davis, The Lives of the Eighth-Century Popes [Liber Pontificalis]: The Ancient Biographies of Nine Popes from AD 715 to AD 817, Translated Texts for Historians, I3, Liverpool I992); (trans. Raymond Davis, The Lives of the NinthCentury Popes [Liber Pontificalis]: The Ancient Biographies of Ten Popes from AD 8I 7 to AD 891, Translated Texts for Historians, 20, Liverpool 1995).

Liber Pontificalis pars prior (ed. Theodor Mommsen, MGH SS Gesta pontificum romanorum I, Berlin I898).

Liber Pontificalis: Anastasii Bibliothecarii historiae de vitis romanorum pontificum, PL I27 und 128.

Liber Pontificalis nella recensione di Pietro Guglielmo e del card. Pandolfo, glossato da Pietro Bohier, vescovo di Orvieto, 3 Bde. (ed. Ulderico Prerovsky, Studia Gratiana 2 I-23, Rom I 978 ).

Martin I., ep. I5 ad Theodorum, PL 87, col. 199-202.

Bronwen Neil, Seventh-Century Popes and Martyrs: The Political Hagiography of Anastasius Bibliothecarius (Studia Antiqua Australiensia, 2, Turnhout 2006).

Nicolaus I., Epistolae (ed. Ernst Perels, MGH EE 6) 257-69o.

Paulus Diaconus, Historia Langobardorum (ed. Ludwig Bethmann/Georg Waitz, MGH SS rer. Lang.) I2-I 87.

Pseudo-Liutprand, PL I29, Pseudo-Luitprandi liber de pontificum Romanorum vitis, col. I $149-$ I 256.

Pseudo-Methodius, Revelationes (ed. Ernst Sackur, Sibyllinische Texte und Forschungen: Pseudo-Methodius, Adso und die Tiburtinische Sibylle, Halle/Saale I898, ${ }^{2}$ 2006) I-96.

Prokop, Gotenkrieg, trans. Otto Veh (Tusculum Bibliothek, Prokop, Werke, Bd. 2, München ${ }^{2}$ I978).

Die Apokalypse des Pseudo-Methodius: Die ältesten griechischen und lateinischen Übersetzungen (ed. Willem J. Aerts/Georg A. A. Kortekaas, 2 Bde., Corpus Scriptorum Christianorum Orientalium; Subsidia, 97 und 98, Louvain 1998).

Die syrische Apokalypse des Pseudo-Methodius (ed. Gerrit J. Reinink, Corpus Scriptorum Christianorum Orientalium, 54I, Scriptores Syri, 22 I [der syrische Text findet sich in den Bänden 540 bzw. 220], Louvain 1993). 
Regesta Imperii, II, 5, Papstregesten 9I I-IO24 (ed. Johann Friedrich Böhmer/Harald Zimmermann, Köln, Weimar, Wien ${ }^{2}$ I998).

Regesten der Kaiserurkunden des oströmischen Reichs, I, I, ed. Franz Dölger/Andres E. Müller (München ${ }^{2} 2009$ ).

Relatio motionis inter Maximum et principes (ed. Pauline Allen/Bronwen Neil, Maximus the Confessor and his companions: documents from exile, Oxford Early Christian Texts, Oxford 2004) 48-74.

Zweites Konzil von Nicäa, Sitzungen I-3 (ed. Erich Lamberz, Concilium Universale Nicaenum secundum, concilii actiones I-III, Acta Conciliorum Oecumenicorum, Series 2, Bd. 3, I, Berlin/New York 2008).

\section{Verzeichnis der verwendeten Literatur}

Urs App, William Jones's Ancient Theology, in: Sino-Platonic Papers, I9I (2009).

Maria Giovanna Arcamone, Die langobardischen Personennamen in Italien: nomen und gens aus der Sicht der linguistischen Analyse, in: Nomen et gens: zur historischen Aussagekraft frühmittelalterlicher Personennamen, ed. Dieter Geuenich/Wolfgang Haubrichs/Jörg Jarnut (RGA Erg. Bd. I6, Berlin/New York 1997) I57-I75.

Girolamo Arnaldi, Anastasio Bibliotecario, in: Dizionario biografico degli Italiani, Bd. 3 (Roma I96I) 25-37.

Girolamo Arnaldi, Come nacque la attribuzione ad Anastasio del Liber Pontificalis, in: Bullettino dell'Istituto Storico Italiano per il Medio Evo e Archivio Muratoriano, 75 (1963) $32 \mathrm{I}-343$.

Girolamo Arnaldi, Anastasio Bibliotecario, antipapa, in: Enciclopedia dei papi, Bd. I (Rom 2000) $735-746$.

Dorothee Arnold, Johannes VIII. Päpstliche Herrschaft in den karolingischen Teilreichen am Ende des 9. Jahrhunderts (Europäische Hochschulschriften, 797, Frankfurt am Main, et al., 2005).

Claudio Azzara, Spoleto e Benevento e il regno longobardo d'Italia, in: I Longobardi dei ducati di Spoleto e Benevento. Atti del XVI Congresso internazionale di studi sull'alto medioevo; Spoleto, 20-23 ottobre 2002, (Spoleto 2003) 105-123.

Smail Balić, Glaube, islamisch, in: Lexikon religiöser Grundbegriffe, ed. Adel Theodor Khoury (Wiesbaden 2007) Sp. 374-376.

Ross Balzaretti, Theodelinda, ,Most Glorious Queen‘. Gender and Power in Lombard Italy, in: The Medieval History Journal, 2 (I999) I 83-207.

Bernard Bavant, Le duché byzantin de Rome: Origine, durée et extension géographique, in: Mélanges de l'École française de Rome: Moyen-Âge, Temps modernes, 9I, I (I979) 4I-88. Matthias Becher, Non enim habent regem idem Antiqui Saxones. Verfassung und Ethnogenese in Sachsen während des 8. Jahrhunderts, in: Sachsen und Franken in Westfalen. Zur Komplexität der ethnischen Deutung und Abgrenzung zweier frühmittelalterlicher Stämme, ed. Hans-Jürgen Häßler (Studien zur Sachsenforschung, I2, Oldenburg 1999) I-3I.

Hans-Georg Beck, Konstantinopel: das neue Rom, in: Gymnasium: Zeitschrift für Kultur der Antike und humanistische Bildung, 7I (1964) I66-I73. 
Walter Berschin, Biographie und Epochenstil im lateinischen Mittelalter r: Von der Passio Perpetuae zu den Dialogi Gregors des Großen (Quellen und Untersuchungen zur lateinischen Philologie des Mittelalters 8, Stuttgart 1986).

Ottorino Bertolini, Roma di fronte a Bisanzio e ai Longobardi (Storia di Roma, 9, Bologna 194I).

Ottorino Bertolini, Il primo "periurium“ di Astolfo verso la chiesa die Roma, in Miscellanea Giovanni Mercati, Studi e testi I25 (Vatikanstadt 1946) I60-205, ND in ders., Scritti Scelti di Storia Medievale, 2 Bde., ed. Ottavio Banti (Livorno 1968) Bd. I, I25-I69.

Ottorino Bertolini, La caduta del primicerio Cristoforo (77 I) nelle versioni dei contemporanei, e le correnti antilongobarde e filolongobarde in Roma alla fine del pontificato di Stefano III (77I-772), in: Rivista di Storia della Chiesa in Italia, I, n. 2-3 (I947) 227-289, ND in ders., Scritti Scelti di Storia Medievale, 2 Bde., ed. Ottavio Banti (Livorno 1968) Bd. 2, 615-677.

Ottorino Bertolini, Le relazioni politiche di Roma con i ducati di Spoleto e di Benevento nel periodo del dominio Longobardo, in: Atti del I congresso internationale di studi longobardi, Spoleto, 27-30 settembre I95 I (Spoleto I952), 37-49, hier 47-49, ND in ders., Scritti Scelti di Storia Medievale, 2 Bde., ed. Ottavio Banti (Livorno r968) Bd. 2, 679-692.

Ottorino Bertolini, Carlomagno e Benevento, in: Karl der Große, Bd. I, Persönlichkeit und Geschichte, ed. Wolfgang Braunfels/Helmut Beumann (Düsseldorf I965) 609-67I.

Ottorino Bertolini, Scritti Scelti di Storia Medievale, 2 Bde., ed. Ottavio Banti (Livorno I968).

Homi K. Bhabha, Of mimicry and man, in: ders., The Location of Culture (London/New York I994) I2I-I3I.

Bernhard Bischoff, Die südostdeutschen Schreibschulen, Bd. 2, Die vorwiegend österreichischen Diözesen (Wiesbaden r980).

Albert Blaise, Dictionnaire latin-français des auteurs chrétiens (Turnhout 1954-1967).

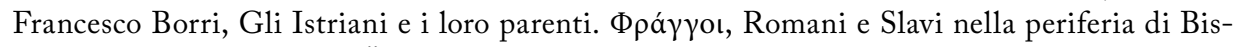
anzio, in: Jahrbuch der Österreichischen Byzantinistik, 6o (2010) I-26.

Francesco Borri, L’Adriatico tra Bizantini, Longobardi e Franchi. Dalla conquista di Ravenna alla pace di Aquisgrana ( $75^{\mathrm{I}-8 \mathrm{I} 2}$ ), in: Bulletino dell'istituto storico italiano per il medioevo, I 22 (2010) I-56.

Francesco Borri, Duces e magistri militum nell'Italia esarcale (VI-VIII secolo), in: RM Reti Medievali Rivista, 6 (2005/2) I-46.

Arno Borst, Der Turmbau von Babel. Geschichte der Meinung über Ursprung und Vielfalt der Sprachen und Völker, Bd. 2, I: Ausbau (München ${ }^{2}$ I995).

François Bougard, Anastase le Bibliothécaire ou Jean Diacre? Qui a réécrit la Vie de Nicolas Ier et pourquoi, in: Vaticana et medievalia. Études en l'honneur de Louis Duval-Arnould, ed. Jean-Marie Martin/Bernadette Martin-Hisard/Agostino Paravicini Bagliani (Millennio Medievale 7r, Strumenti e Studi i4, Florenz 2008) 27-40.

François Bougard, Composition, diffusion et réception des parties tardives du Liber pontificalis romain $\left(\mathrm{VIII}^{\mathrm{e}}-\mathrm{IX}^{\mathrm{e}}\right.$ siècles), in: Liber, Gesta, histoire. Écrire l'histoire des évêques et des papes, de l'Antiquité au XXI' siècle, ed. ders./Michel Sot (Turnhout 2009) I 27-I 52.

Johannes Brachtendorf, Augustinus: Friedensethik und Friedenspolitik, in: Krieg und Christentum. Religiöse Gewalt theorien in der Kriegserfahrung des Westens, ed. Andreas Holzem (Krieg in der Geschichte, 50, Paderborn/München/Wien/Zürich 2009) 234-253. 
Wolfram Brandes, „Juristische“ Krisenbewältigung im 7. Jahrhundert? Die Prozesse gegen Papst Martin I. und Maximos Homologetes, in: Fontes Minores X (Forschungen zur byzantinischen Rechtsgeschichte, 22, 1998) I4I-2I 2.

Wolfram Brandes, Finanzverwaltung in Krisenzeiten: Untersuchungen zur byzantinischen Administration im 6.-9. Jahrhundert (Forschungen zur byzantinischen Rechtsgeschichte 25, Frankfurt am Main 2002).

Wolfram Brandes, Pejorative Phantomnamen im 8. Jahrhundert: Ein Beitrag zur Quellenkritik des Theophanes und deren Konsequenzen für die historische Forschung, in: Zwischen Polis, Provinz und Peripherie. Beiträge zur byzantinischen Geschichte und Kultur, ed. Lars M. Hoffmann/Anuscha Monchizadeh (Mainzer Veröffentlichungen zur Byzantinistik, 7, Wiesbaden 2005) 93-I25.

Wolfram Brandes, Die Belagerung Konstantinopels 717/7r 8 als apokalyptisches Ereignis. Zu einer Interpolation im griechischen Text der Pseudo-Methodios-Apokalypse, in: Byzantina Mediterranea: Festschrift für Johannes Koder, ed. Klaus Belke/Ewald Kislinger/Andreas Külzer/Maria A. Stassinopoulou (Wien/Köln/Weimar 2007) 65-9r.

Wolfram Brandes, Rezension von: Bronwen Neil, Seventh-Century Popes and Martyrs: The Political Hagiography of Anastasius Bibliothecarius (Studia Antiqua Australiensia, 2, Turnhout 2006), in: Byzantinische Zeitschrift, 102, 2 (2010) 794-803

Harry Breslau, Handbuch der Urkundenlehre für Deutschland und Italien, Bd. I (Leipzig ${ }^{2}$ I 9 I 2).

Saul Nathaniel Brody, The Disease of the Soul. Leprosy in Medieval Literature (Ithaca/London 1974).

Thomas S. Brown, Gentlemen and Officers: Imperial Administration and Aristocratic Power in Byzantine Italy, A.D. 554-800 (Hertford I984).

Thomas S. Brown, Lombard religious policy in the late sixth and seventh centuries: The Roman dimension, in: The Langobards Before the Frankish Conquest. An Ethnographic Perspective, Giorgio Ausenda/Paolo Delogu (Woodbridge 2009) 289-308

Leslie Brubaker/John Haldon, Byzantium in the Iconoclast Era, c. 680-850 - A history (Cambridge 20II).

Karl Brunner, Die fränkischen Fürstentitel im neunten und zehnten Jahrhundert, in: Intitulatio II. Lateinische Herrscher- und Fürstentitel im neunten und zehnten Jahrhundert, ed. Herwig Wolfram (MIÖG, Ergänzungsband 24, Wien 1973) I79-340.

Philippe Buc, Some Thoughts on the Christian Theology of Violence, Medieval and Modern, from the Middle Ages to the French Revolution, in: Rivista di Storia del Cristianesimo, 5 , I (2008) 9-28.

Martin Büchsel, Das Christusporträt am Scheideweg des Ikonoklastenstreits im 8. und 9. Jahrhundert, in: Marburger Jahrbuch für Kunstwissenschaft, 25 (I998) 7-52.

Filippo Burgarella, Presenze greche a Roma. Aspetti culturali e religiosi, in: Roma fra oriente a occidente (Settimane di studio del Centro italiano di studi sull'Alto Medioevo, 49, Spoleto 2002) 943-992.

Lidia Capo, Il Liber Pontificalis i Longobardi e la nascita del dominio territoriale della chiesa romana (Spoleto 2009).

Antonio Carile, Roma vista da Constantinopoli, in: Roma fra oriente a occidente (Settimane di studio del Centro italiano di studi sull'Alto Medioevo, 49, Spoleto 2002) 49-99. 
Erich Caspar, Studien zum Register Johanns VIII., in: Neues Archiv, 36 (I9I I) 77-I56.

Erich Caspar, Geschichte des Papsttums von den Anfängen bis zur Höhe der Weltherrschaft, Bd. 2: Das Papsttum unter byzantinischer Herrschaft (Tübingen 1933).

María do Mar Castro Varela/Nikita Dhawan, Postkoloniale Theorie. Eine kritische Einführung (Bielefeld 2005).

Ann Christies, Christians in Al-Andalus 7 I I-1000 (Surrey 2002).

Peter Classen, Romanum gubernans imperium. Zur Vorgeschichte der Kaisertitulatur Karls des Großen, in: Deutsches Archiv 9 (1952) I03-I2 I.

Peter Classen, Karl der Große, das Papsttum und Byzanz, in: Karl der Große. Lebenswerk und Nachleben, Bd. I, ed. Helmut Beumann/Wolfgang Braunfels u.a. (Düsseldorf i965) $537-607$.

Peter Classen, Karl der Große, das Papsttum und Byzanz: Die Begründung des karolingischen Kaisertums (Sigmaringen ${ }^{2}$ I985).

Florence Close, De l'alliance Franco-Lombarde à l'allience Franco-Pontificale, in: Francia. Forschungen zur westeuropäischen Geschichte, 37 (2010) I-24.

Jeffrey Jerome Cohen, Introduction: Midcolonial, in: The Postcolonial Middle Ages, ed. ders. (New York 2000).

Simone M. Collavini, Des Lombards aux Carolingiens: L'évolution des élites locales, in: Le monde Carolingien: Bilan, perspectives, champs de recherche. Actes du colloque international de Poitiers, Centre des Études supérieures de la Civilisation médievale, I8-20 novembre 2004, ed. Wojciech Falkowski/Yves Sassier (Culture et société médievale I8, Turnhout 2009) 263-300.

Roger Collins, The ,Reviser' revisisted. Another look at the alternative version of the Annales regni francorum, in: After Rome's Fall. Narrators and Sources of Early Medieval History. Essays presented to Walter Goffart, ed. Alexander C. Murray (Toronto I998) I9I-2I3.

Demetrios J. Constantelos, Christian Hellenism: Essays and Studies in Continuity and Change (Studies in the social and religious history of the mediaeval Greek world, 3, New Rochelle 1998).

Demetrios J. Constantelos, Christian Hellenism and How the Byzantines Saw Themselves, in: The National Herald, I2. September 2004.

Demetrios J. Constantelos, Liturgy and liturgical daily life in the medieval Greek world - the Byzantine Empire, in: The Liturgy of the Medieval Church. Second edition, ed. Thomas J. Heffernan/E. Ann Matter (Kalamazoo 2005) 97-I28.

Pietro Conte, Regesto delle lettere dei papi del secolo VIII (Milano I984).

Salvatore Cosentino, Prosopografia dell'Italia bizantina (493-804), 2 Bde. (Bologna 19962000,3 . Bd. Noch ausständig).

Salvatore Cosentino, Storia dell'Italia bizantina (VI-XI secolo): Da Giustiniano ai Normanni (Bologna 2008).

Marios Costambeys/Conrad Leyser, To be the Neighbour of St. Stephen: Patronage, Martyr, Cult, and Roman Monasteries, c. 600-c. 900, in: Religion, Dynasty and Patronage in Early Christian Rome, 300-900, ed. Kate Cooper/Julia Hillner (Cambridge 2007) 262-287.

Luciana Cuppo-Csaki, A Seventh-Century List of Patriarchs of Constantinople in The Roman Book of Pontiffs: some considerations, in: Proceedings of the 2 Ist International Con- 
gress of Byzantine Studies London $2 \mathrm{I}-26$ August 2006, 3, Abstracts of Communications, ed. Elizabeth Jeffreys/Fiona K. Haarer/Judith Gilliland (London 2006) $226 f$.

Luciana Cuppo, I pontifices di Costantinopoli nel Liber Pontificalis del settimo secolo: Note sul codice BAV, Vat. Lat. 3764, in: Rivista di storia e letteratura religiosa 44 (2008) 359-371.

Gilbert Dagron, Byzantinische Kirche und byzantinische Christenheit zwischen Invasionen und Ikonoklasmus (von der Mitte des 7. bis zum Beginn des 8. Jahrhunderts), in: Die Geschichte des Christentums, Mittelalter, Bd. r: Bischöfe, Mönche und Kaiser (642-1054), ed. Gilbert Dagron, Pierre Riché und André Vauchez (Freiburg/Basel/Wien 2007) 3-96.

Philip Daileader, One will, one voice and equal love. Papal elections and the Liber Pontificalis, in: Archivum Historiae Pontificiae, 3I (I993) I I-3I.

Josef Deér, Zum Patricius-Romanorum-Titel Karls des Großen, in: Archivum Historiae Pon-

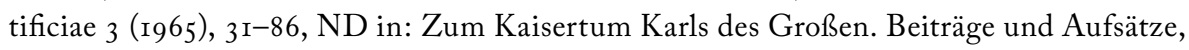
ed. Gunther Wolf (Darmstadt I972) 240-308.

Paulo Delogu, L'importazione di tessuti preziosi e il sistema economico romano nel IX secolo, in: Roma medievale. Aggiornamenti, ed. ders. (Florenz I998) I23-I4I.

Paolo Delogu, Leone III, santo, in: Enciclopedia dei papi, Bd. I (Rom 2000) 695-704.

Paolo Delogu, Paolo I, santo, in: Enciclopedia dei papi, Bd. I (Rom 2000) 665-669.

Paolo Delogu, Zaccaria, santo, in: Enciclopedia dei papi, Bd. I (Rom 200o) 656-659.

Paolo Delogu, Il passaggio dall'antichità al medioevo, in: Storia di Roma dall'antichità a oggi, Bd. 2, Roma medievale, ed. André Vauchez (Rom/Bari 200I) 3-40.

Paulo Delogu, Il mancoso è ancora un mito?, in: 774. Ipotesi su una transitione, ed. Stefano Gasparri (Seminari internazionali del Centro interuniversitario per la storia e l'archeologia dell'alto medioevo, I, Turnhout 2008) I39-I59.

Paolo Delogu, Kingship and the shaping of the Lombard political body, in: The Langobards Before the Frankish Conquest: an Ethnographic Perspective, ed. ders./Giorgio Ausenda (Woodbridge 2009) $25 \mathrm{I}-288$.

Philippe Depreux, Auf der Suche nach dem princeps in Aquitanien (7.-8. Jahrhundert), in: Die Anfänge Bayerns. Von Raetien und Noricum zur frühmittelalterlichen Baiovaria, ed. Hubert Fehr/Irmtraut Heitmeier (St. Ottilien 20I 2) $55 \mathrm{I}^{\mathrm{I}-566 .}$

Maximilian Diesenberger, Hair, sacrality and symbolic capital in the Frankish kingdoms, in: The construction of communities in the early middle ages: Texts, resources and artefacts, ed. ders./Richard Corradini/Helmut Reimitz (Transformation of the Roman World I2, Leiden 2003) I73-2 I2.

Dr. H. Pabst's Reise nach Italien I869/70, ed. Georg Waitz, in: Neues Archiv, 2 (I877) 3I-45.

Michel Dubuisson, GRAECVS, GRAECVLVS, GRAECARI: L'emploi péjoratif du nom des Grecs en latin, in $E \lambda \lambda \varepsilon v ı \mu$ oc. Quelques jalons pour une histoire de l'identité grecque. Actes du Colloque de Strasbourg, 25-27 octobre I989, ed. Suzanne Said (Leiden/New York/ Kopenhagen/Köln I99I) 315-335.

Louis Duchesne, Etude sur le Liber Pontificalis, in: Bibliothèque des Ecoles françaises d'Athènes et de Rome I (Paris I877).

Dee Dyas, Pilgrimage in Medieval English Literature (Woodbridge 20or).

Albert Ehrhard, Überlieferung und Bestand der hagiographischen und homiletischen Litera- 
tur der griechischen Kirche von den Anfängen bis zum Ende des r6. Jahrhunderts, Erster Teil: Die Überlieferung, Bd. I (Texte und Untersuchungen, 50, Leipzig 1937).

Ekkehard Eickhoff, Seekrieg und Seepolitik zwischen Islam und Abendland. Das Mittelmeer unter byzantinischer und arabischer Hegemonie (650-1040) (Berlin 1966).

Andrew J. Ekonomou, Byzantine Rome and the Greek Popes: Eastern Influences on Rome and the Papacy from Gregory the Great to Zacharias, A.D. 590-752 (Lanham, Maryland 2007).

Fred Engreen, Pope John the Eighth and the Arabs, in: Speculum, 20, 3 (1945) 318-330.

Carl Erdmann, Die Entstehung des Kreuzzugsgedankens (Stuttgart 1935, ND Darmstadt 1972).

Dorine van Espelo, A testimony of Carolingian rule? The Codex epistolaris carolinus, its historical context, and the meaning of imperium, in: Early Medieval Europe, 2 I,3 (2013) 254-282.

Anton von Euw, Anmerkungen zu Diözesan- und Dombibliothek Handschrift 103, in: Glaube und Wissen im Mittelalter, Katalogbuch zur Ausstellung (München 1998).

Vera von Falkenhausen, La dominazione bizantina nell'Italia meridionale dal IX all'XI secolo (Bari 1978).

Vera von Falkenhausen, Chiesa greca e chiesa latina in Sicilia prima della conquista Araba, in: Archivio Storico Siracusano, 5 (I978-79/1985) I37-I55.

Stephen C. Fanning, Lombard Arianism Reconsidered, in: Speculum 56,2 (I98I) 24 I-258.

Albrecht Graf Finck von Finckenstein, Rom zwischen Byzanz und den Franken in der ersten Hälfte des 8. Jahrhunderts, in: Festschrift für Eduard Hlawitschka zum 65. Geburtstag, ed. Karl Rudolph Schnith/Roland Pauler (Münchner historische Studien, Abteilung Mittelalterliche Geschichte, 5, München 1993) 23-36.

Andreas Fischer, Karl Martell. Der Beginn karolingischer Herrschaft (Stuttgart 2012).

Jean Flori, La guerre sainte. La formation de l'idée de croisade dans l'Occident chrétien (Paris 200I).

Jean Flori, À propos de la première croisade: Naissance et affirmation de l'idée de guerre sainte dans l'Occident chrétien (XI ${ }^{\mathrm{e}}$ siècle), in: Imaginaires de guerre. L'histoire entre mythe et réalité. Actes du colloque, Louvain-la-Neuve, 3-5 mai 200I, ed. Laurence van Ypersele (Louvain-la-Neuve 2003) 3I-43.

Michel Foucault, L'ordre du discours (Paris 1972).

Paul Fouracre, The Age of Charles Martel (Harlow 2000).

Paul Fournier/Gabriel LeBras, Histoire des collections canoniques en Occident depuis les fausses décrétales jusqu'au Decret de Gratien (2 Bde., Paris I93 I-I932).

Das Fremde im Selbst. Das Andere im Selben. Transformationen der Phänomenologie, ed. Matthias Flatscher/Sophie Loidolt (Orbis Phaenomenologicus Perspektiven, Neue Folge Bd. I9, Würzburg 2010).

Das Fremde und das Andere in der Kinder- und Jugendliteratur, ed. Petra Bükler/Clemens Kammler (Weinheim/München 2003).

Pierluigi Galletti, Del primicero della santa sede apostolica e di altri uffiziali maggiori del sacro palagio lateranese (Rom I 776).

François Louis Ganshof, Note sur les origines byzantines du titre "Patricius Romanorum", in: Annuaire de l'Institut de Philologie et d'Histoire orientales et slaves Io (I950) 26I-282. 
Clemens Gantner, Die Wahrnehmung des Islam und der Sarazenen im frühmittelalterlichen Europa (ungedr. Univ. Dipl., Wien 2005).

Clemens Gantner, Studien zur handschriftlichen Überlieferung des Liber Pontificalis am Beispiel der so genannten Langobardischen Rezension (ungedr. Univ. Mag., Wien 2009).

Clemens Gantner, New Visions of Community in Ninth Century Rome. The Impact of the Saracen Threat on Papal Thought, in: Visions of Community in the Post-Roman World: The Latin West, Byzantium and the Islamic World, 300-I Ioo, ed. Walter Pohl/Clemens Gantner/Richard Payne (Aldershot 2012) 403-42I.

Clemens Gantner, Hoffnung in der Apokalypse? Die Ismaeliten in den älteren lateinischen Fassungen der Revelationes des Pseudo-Methodius, in: Abendländische Apokalyptik. Kompendium zur Genealogie der Endzeit in der europäischen Kultur, ed. Veronika Wieser/ Christian Zolles/Martin Zolles/Leo Schlöndorff/Catherine Feik (Berlin 2013) 52 I-548.

Clemens Gantner, The label „Greeks“ in the papal diplomatic repertoire in the eighth century, in: Strategies of Identification. Ethnicity and Religion in Early Medieval Europe, ed. Walter Pohl/Gerda Heydemann (Cultural Encounters in Late Antiquity and the Middle Ages I3, Turnhout 2013) 303-349.

Clemens Gantner, The Lombard Recension of the Roman Liber Pontificalis, in: Rivista di storia del cristianesimo, Iо, I (2013) 65-I I4.

Clemens Gantner, The papacy as cultural broker in the eighth century, in: ders./Rosamond McKitterick/Sven Meeder, Cultural Memory and the Resources of the Past in the Early Middle Ages (Cambridge, in Vorbereitung).

Stefano Gasparri, I duchi longobardi (Studi Storici Io9, Rom I978).

Stefano Gasparri, Roma e i longobardi, in: Roma nell'alto medioevo. Settimane di studio del centro italiano di studi sull'alto medioevo 48 (200I) 219-253.

Stefano Gasparri, The Fall of the Lombard Kingdom. Facts, Memory and Propaganda, in: 774: ipotesi su una transizione; atti del Seminario di Poggibonsi, I6-18 febbraio 2006, ed. ders (Turnhout 2008) $4 \mathrm{I}-65$.

Stefano Gasparri, Italia longobarda. Il regno, i Franchi, il papato (Rom/Bari 2012).

Herman Geertman, More Veterum. Il Liber Pontificalis e gli edifici ecclesiastici di Roma nella tarda antichità e nell'alto medioevo (Archaeologica Traiectina, Groningen 1975).

Herman Geertman, Documenti, redattori e la formazione del testo del Liber Pontificalis, in: Il Liber Pontificalis e la storia materiale, ed. ders. (Mededelingen van het Nederlands Instituut te Rom, 6o-6r, Assen 2003) 267-284.

Herman Geertman, La genesi del Liber pontificalis romano. Un processo di organizzazione della memoria, in: Liber, Gesta, histoire. Écrire l'histoire des évêques et des papes, de l'Antiquité au XXIe siècle, ed. François Bougard/Michel Sot (Turnhout 2009) 37-Io8.

Karl Ernst Georges, Ausführliches lateinisch-deutsches Handwörterbuch (Hannover ${ }^{8}$ I9r 8, Nachdruck Darmstadt 1998).

Geschichte der katholischen Kirche, ed. Josef Lenzenweger/Peter Stockmeier/Johannes B. Bauer/Karl Amon/Rudolf Zinnhobler (Graz/Wien/Köln ${ }^{3}$ I995).

Dieter Geuenich, Geschichte der Allemannen (Stuttgart/Berlin/Köln 1997).

John Gilchrist, The Papacy and War against the Saracens, 795-I216, in: The International History Review, ro (I988) I74-I97. 
Cl. Gilliot, Yāḳūt al-Rūmī, in: Encyclopaedia of Islam, Second Edition, Bd. II, ed. P. Bearman/Th. Bianquis/C. E. Bosworth/E. van Donzel/W. P. Heinrichs (Leiden 2002) 264.

Matthias Gillner, Bartolomé de las Casas und die Eroberung des indianischen Kontinents. (Theologie und Frieden I2, Stuttgart/Berlin/Köln 1997).

Ignazio Giorgi, Appunti su alcuni manoscritti del Liber Pontificalis, in: Archivio della società romana di storia patria 20 (I897) 247-312.

Hans-Werner Goetz, „Fremdheit“ im frühen Mittelalter, in: Herrschaftspraxis und soziale Ordnung im Mittelalter und in der frühen Neuzeit, ed. Peter Aufgebauer/Christine van der Heuvel (Hannover 2006) 245-265.

Walter Goffart, The supposedly ,Frankish“ Table of Nations: an edition and study, in: ders., Rome's Fall and After (Bristol r989) I33-166.

Jean Gouillard, Aux origins de l'iconoclasme: Le témoignage de Grégoire II ?, in: Traveaux et mémoires (Centre de recherche d'histoire et de civilisation byzantines), 3 (I968), 243-307.

Friedrich Wilhelm Graf, Sakralisierung von Kriegen: Begriffs- und problemgeschichtliche Erwägungen, in: Heilige Kriege. Religiöse Begründungen militärischer Gewaltanwendung: Judentum, Christentum und Islam im Vergleich, ed. Klaus Schreiner (Schriften des Historischen Kollegs, Kolloquien, 78, München 2008) I-30.

Thomas Granier, Les moines "grecs“ de Saints-Serge-et-Bacchus et Saints-Théodore-et-Sébastien dans la société napolitaine des $\mathrm{VII}^{\mathrm{e}}-\mathrm{XII}{ }^{\mathrm{e}}$ siècles, in: Vivre en société au Moyen Âge. Occident chrétien VI ${ }^{\mathrm{e}}-\mathrm{XV}$ e siècle, ed. Claude Carozzi/Daniel Le Blévec/Huguette Taviani-Carozzi (Aix-en-Provence 2008) I97-2 I8.

Ferdinand Gregorovius/Waldemar Kempf, Geschichte der Stadt Rom, Bd. r: Vom Beginn des V. Jahrhunderts bis zum Untergange des westlichen Reichs i. J. 476 (Darmstadt I978).

Philip Grierson/Mark Blackburn, Medieval European Coinage. The Early Middle Ages (500-1000) (Cambridge I986, ${ }^{2} 2007$ ).

Hans Grotz, S. I., Beobachtungen zu den zwei Briefen Papst Gregors II. an Kaiser Leo III., in: Archivum Historiae Pontificiae, I8 (1980) 9-40.

Hans Grotz, S. I., Weitere Beobachtungen zu den zwei Briefen Papst Gregors II. an Kaiser Leo III., in: Archivum Historiae Pontificiae, 24 (1986) 365-375.

Bernard Guenée, Histoire et culture historique dans l'Occident medieval (Paris 1980).

Wilhelm Gundlach, Ueber den Codex Carolinus, in: Neues Archiv, I7 (1892) 525-566.

Nikolaus Gussone, Thron und Inthronisation des Papstes von den Anfängen bis zum I2. Jahrhundert. $\mathrm{Zu}$ Beziehungen zwischen Herrschaftszeichen und bildhaften Begriffen, Recht und Liturgie im christlichen Verständnis von Wort und Wirklichkeit (Bonner historische Forschungen 4I, Bonn 1978).

Achim Thomas Hack, Bildaussendung und Bildeinholung im 7. und 8. Jahrhundert, in: Saeculum, 54 (2003) I 47-I 77 .

Achim Thomas Hack, Codex Carolinus. Päpstliche Epistolographie im 8. Jahrhundert, 2 Bde. (Päpste und Papsttum 35, I-2, Stuttgart 2006-2007).

Othmar Hageneder, Das crimen maiestatis, der Prozeß gegen die Attentäter Papst Leos III. und die Kaiserkrönung Karls des Großen, in: Aus Kirche und Reich. Studien zu Theologie, Politik und Recht im Mittelalter. Festschrift für Friedrich Kempf, ed. Hubert Mordek (Sigmaringen 1983) 55-79. 
Jan T. Hallenbeck, Pavia and Rome. The Lombard Monarchy and the Papacy in the Eighth Century (Transactions of the American Philosophical Society, New Series, 72,4, Philadelphia I982).

Johannes Haller, Quellen zur Geschichte der Entstehung des Kirchenstaates (Quellensammlung zur deutschen Geschichte, Leipzig/Berlin 1907).

Guy Halsall, Warfare and Society in the Barbarian West, 450-900 (Warfare and History, London/New York 2003) i I 9-I33.

Florian Hartmann, Hadrian I. (772-795). Frühmittelalterliches Adelspapsttum und die Lösung Roms vom byzantinischen Kaiser (Päpste und Papsttum 34, Stuttgart 2006).

Ludo Moritz Hartmann, Geschichte Italiens im Mittelalter, Bd. 2, 2 (Gotha I903).

Ludo Moritz Hartmann, Geschichte Italiens im Mittelalter, Bd. 3, r: Italien und die fränkische Herrschaft (Gotha I908).

Wolfgang Haubrichs, Amalgamierung und Identität - Langobardische Personennamen in Mythos und Herrschaft, in: Die Langobarden - Herrschaft und Identität, ed. Walter Pohl/ Peter Erhart (Forschungen zur Geschichte des Mittelalters, 9, Wien 2005) 67-99.

John Haywood, Dark Age Naval Power. A Reassessment of Frankish and Anglo-Saxon Activity (London/New York 1991).

Klaus Herbers, Papst Nikolaus I. und Patriarch Photios. Das Bild des byzantinischen Gegners in lateinischen Quellen, in: Die Begegnung des Westens mit dem Osten. Kongreßakten des 4. Symposions des Mediävistenverbandes in Köln aus Anlaß des rooo. Todesjahres der Kaiserin Theophanu, ed. Odilo Engels/Peter Schreiner (Sigmaringen 1993) $5^{\mathrm{I}}-74$.

Klaus Herbers, Leo IV. und das Papsttum in der Mitte des 9. Jahrhunderts. Möglichkeiten und Grenzen päpstlicher Herrschaft in der späten Karolingerzeit (Päpste und Papsttum 27, Stuttgart 1996).

Klaus Herbers, Zu Mirakeln im Liber Pontificalis des 9. Jahrhunderts, in: Mirakel im Mittelalter. Konzeptionen, Erscheinungsformen, Deutungen, ed. ders./Martin Heinzelmann/ Dieter R. Bauer (Beiträge zur Hagiographie 3, Stuttgart 2002) I I4-I34.

Klaus Herbers, $\mathrm{Zu}$ frühmittelalterlichen Personenbeschreibungen im Liber Pontificalis und in römischen hagiographischen Texten, in: Von Fakten und Fiktionen. Mittelalterliche Geschichtsdarstellungen und ihre kritische Aufarbeitung, ed. Johannes Laudage (Köln/ Weimar/Wien 2003) I65-г9г.

Klaus Herbers, Das Bild Papst Leos III. in der Perspektive des Liber pontificalis, in: Erzbischof Arn von Salzburg, ed. Meta Niederkorn-Bruck/Anton Scharer (Wien/München 2004) I $37-$ I5 5 .

Klaus Herbers, Papst Leo IV. und seine Vita im Liber Pontificalis (um 850), in: Mirakelberichte des frühen und hohen Mittelalters, ed. ders./Lenka Jirouskova/Bernhard Vogel (Freiherr-vom-Stein-Gedächtnisausgabe, Ausgewählte Quellen zur deutschen Geschichte des Mittelalters 43, Darmstadt 2005) I $18-$ - 23.

Klaus Herbers, Rom und Byzanz im Konflikt. Die Jahre 869/87o in der Perspektive der Hadriansvita des Liber Pontificalis, in: Die Faszination der Papstgeschichte. Neue Zugänge zum frühen und hohen Mittelalter, ed. Wilfried Hartmann/Klaus Herbers (Forschungen zur Kaiser- und Papstgeschichte des Mittelalters, Regesta Imperii, Beiheft 28, Köln/Weimar/Wien 2008) 55-70. 
Klaus Herbers, Konkurrenz und Gegnerschaft. „Gegenpäpste“ im 8. und 9. Jahrhundert, in: Gegenpäpste. Ein unerwünschtes mittelalterliches Phänomen, ed. Harald Müller/Brigitte Hotz (Papsttum im mittelalterlichen Europa I, Wien/Köln/Weimar 2012) 55-70.

Judith Herrin, The Formation of Christendom (Princeton, NJ 1987).

Judith Herrin, Constantinople, Rome and the Franks in the seventh and eighth centuries, in: Byzantine Diplomacy: Papers from the Twenty-fourth Spring Symposium of Byzantine Studies, ed. Jonathan Shepard/Simon Franklin (Aldershot, I992) 9I-I07.

Judith Herrin, The Quinisext Council (692) as continuation of Chalcedon, in: Chalcedon in Context. Church Councils 400-700, ed. Richard Pryce/Mary Whitby (Translated Texts for Historians, Contexts I, Liverpool 2009) I 48-168.

Paul Hinschius, Das Kirchenrecht der Protestanten und Katholiken in Deutschland, Bd. I: System des katholischen Kirchenrechts mit besonderer Rücksicht auf Deutschland (Berlin I 869).

Heinz Hofmann, Roma caput mundi? Rom und imperium romanum in der literarischen Diskussion zwischen Spätantike und dem 9. Jahrhundert, in: Roma fra oriente a occidente (Settimane di studio del Centro italiano di studi sull'Alto Medioevo, 49, Spoleto 2002) 493-559.

Robert G. Hoyland, Seeing Islam as Others saw it: A Survey and Evaluation of Christian, Jewish and Zorotastrian Writings on Early Islam (Princeton/NJ 1997).

J. Insley, Septimanien, in: RGA, Bd. 28 (2004) I85-194.

Jörg Jarnut, Nomen et gens. Political and linguistic aspects of names between the third and the eighth century - Presenting an interdisciplinary project from a historical perspective, in: Strategies of Distinction. The Construction of Ethnic Communities, 300-800, ed. Walter Pohl/Helmut Reimitz (The Transformation of the Roman World, 2, Leiden/Boston/Köln I998) II3-Ii6.

Jörg Jarnut, Ein Bruderkampf und seine Folgen. Die Krise des Frankenreiches, in: ders. Herrschaft und Ethnogenese im Frühmittelalter (Münster 2002) 235-246.

Jörg Jarnut, Gens, Rex and Regnum of the Lombards, in: Regna and Gentes. The Relationship between Late Antique and Early Medieval Peoples and Kingdoms in the Transformation of the Roman World, ed. Hans-Werner Goetz/Jörg Jarnut/Walter Pohl (The Transformation of the Roman World, I3, Leiden/Boston 2003) 409-427.

Detlef Jasper, Die Papstgeschichte des Pseudo-Liudprand, Deutsches Archiv, 3I (I975) I7I07.

Bruno Judic, Grégoire le Grand et les barbares, in: Le barbare, l'étranger. Images de l'autre. Actes du colloque organisé par le CERHI, Saint-Étienne, I4 et I5 mai 2004, ed. Didier Nourisson/Yves Perrin (Saint-Étienne 2005) I37-I46.

G. H. A. Juynboll, Musannaf, in: Encyclopaedia of Islam, 2. Aufl., Bd. 7, ed. C. E. Bosworth/E. van Donzel/W. P. Heinrichs/Ch. Pellat (Leiden I993) 662 f.

Mohja Kahf, Western Representations of the Muslim Woman. From Termagant to Odalisque (Austin, Texas 1999).

H. H. Kaminsky, Arichis II., in: LMA, Bd. I, 93of.

Ernst Kantorowicz, Laudes regiae. A Study in Liturgical Acclamations and Mediaeval Ruler Worship (Berkeley/Los Angeles 1946). 
Paul Fridolin Kehr, Rezension von Wilhelm Gundlach (ed.), Codex Carolinus, in: Göttingische Gelehrte Anzeigen 55 (1893) 871-898.

Paul Fridolin Kehr, Über die Chronologie der Briefe Pauls I. im codex Carolinus, in: Nachrichten von der Königlichen Gesellschaft der Wissenschaften zu Göttingen, PhilologischHistorische Klasse, 2 (I896) I03-I57.

Paul Fridolin Kehr, Italia Pontificia, 7, 2 (Berlin 1925).

Matthew Kempshall, Rhetoric and the Writing of History (Manchester 201 I).

Hugh Kennedy, The Great Arab Conquests. How the Spread of Islam Changed the World We Live In (Philadelphia 2007).

Johannes Koder, Rhomaioi, in: LMA, Bd. 7, Sp. 797.

Johannes Koder, Byzanz, die Griechen und die Romaiosyne - eine „Ethnogenese“ der „Römer“?, in: Typen der Ethnogenese unter besonderer Berücksichtigung der Bayern, Berichte des Symposiums der Kommission für Frühmittelalterforschung, 27. Bis 30. Oktober 1986, Stift Zwettl, Niederösterreich, I, ed. Herwig Wolfram/Walter Pohl (Veröffentlichungen der Kommission für Frühmittelalterforschung, I2, Wien I990) Io3-I I I.

Johannes Koder, Griechische Identitäten im Mittelalter. Aspekte einer Entwicklung, in: Byzantium: State and Society: In memory of Nikos Oikonomides, ed. Anna Avramea, Angeliki Laiou and Evangelos Chrysos (Athen 2003) 297-319.

Harald Krahwinkler, Friaul im Frühmittelalter: Geschichte einer Region vom Ende des fünften bis zum Ende des zehnten Jahrhunderts (VIÖG 30, Wien u.a. I992).

Barbara M. Kreutz, Before the Normans. Southern Italy in the Ninth and Tenth Centuries (Philadelphia 199I).

Gerald Krutzler, Die Wahrnehmung fremder Völker in der Merowingerzeit, in: Walter Pohl/ Gerda Heydemann, Post-Roman Transitions. Christian and Barbarian Identities in the Early Medieval West (Cultural Encounters in Late Antiquity and the Middle Ages I4, Turnhout 2013).

Jacques Lacan, Das Werk von Jacques Lacan. Das Seminar: Buch 3 (1955 - 1956). Die Psychosen, ed. Norbert Haas (Berlin/Weinheim 1997).

Erich Lamberz, „Falsata Graecorum more“? Die griechische Version der Briefe Papst Hadrians I. in den Akten des VII. Ökumenischen Konzils, in: Novum Millennium. Studies on Byzantine History and Culture Dedicated to Paul Speck, ed. Claudia Sode/Sarolta Takács (Aldershot 200I) 213-229.

Arthur Lapôtre, L'Europe et le Saint-Siège à l'époque carolingienne, I: Le pape Jean VIII (872-882) (Paris I895).

Wilhelm Levison, Die Papstgeschichte des Pseudo-Liudprand und der Codex Farnesianus des Liber Pontificalis, in: Neues Archiv, 36 (I9II) 4I5-438.

Charlton T. Lewis/Charles Short, A Latin Dictionary (Oxford I891).

Lexikon des Mittelalters (LMA), 9 Bde. (Stuttgart/Weimar 1980-I999).

Dietrich Lohrmann, Das Register Papst Johannes' VIII. (872-882). Neue Studien zur Abschrift Reg. Vat. I, zum verlorenen Originalregister und zum Diktat der Briefe (Bibliothek des Deutschen Historischen Instituts in Rom, 30, Tübingen 1968).

Michael Maas, Roman Imperial Ethnography and the End of Antiquity (in Vorbereitung).

Cyril Mango, L'origine de la minuscule, in: La paléographie greque et Byzantine (Colloques 
Internationales du Centre National de la Recherche Scientifique [CNRS] 559, Paris, I977) I75-I80.

Sabine G. Maccormack, Change and Continuity in Late Antiquity: The Ceremony of „Adventus“, in: Historia, 21 (1972) $72 \mathrm{I}-75^{2}$.

Giorgio S. Marcou, Zaccaria $\left(679-75^{2}\right)$ : L'ultimo papa greco nella storia di Roma altomedievale. Note storico-giuridiche, in: Apollinaris, 50 (1977) 274-289.

Jean-Marie Martin, Greeks in Italy, in: The Papacy: an encyclopedia, Bd. 2, ed. Philippe Levillain, trans. John W. O'Malley (New York/London 2002) 638f. (Originalversion: Dictionnaire historique de la papauté, I994).

Maya Maskarinec, Who were the Romans? Shifting scripts of Romanness in early medieval Italy, in: Walter Pohl/Gerda Heydemann, Post-Roman Transitions. Christian and Barbarian Identities in the Early Medieval West (Cultural Encounters in Late Antiquity and the Middle Ages I 4, Turnhout 2013) 297-363.

Georg May, Kirchenrechtsquellen: Katholische, in: Theologische Realenzyklopädie, Band i9: Kirchenrechtsquellen, ed. Gerhard Krause/Gerhard Müller (Berlin/New York 1990) I-44.

Michael McCormick, Eternal Victory. Triumphal Rulership in Late Antiquity, Byzantium and the Early Medieval West (Cambridge 1990).

Michael McCormick, Textes, images et iconoclasme dans la cadre des relations entre Byzance et l'occident Carolingien, in: Testo e imagine nell'alto medioevo (Settimane di studio del Centro italiano di studi sull'Alto Medioevo, 4I, Spoleto 1994) 95-I62.

Michael McCormick, Origins of the European Economy. Communications and Commerce, AD 300-900 (Cambridge 200I).

Rosamond McKitterick, Political ideology in Carolingian historiography, in: Using the Past in the Early Middle Ages, ed. Yitzhak Hen/Matthew Innes (Cambridge 2000) I62-I74.

Rosamond McKitterick, History and Memory in the Carolingian World (Cambridge 2004).

Rosamond McKitterick, Charlemagne. The Formation of a European Identity (Cambridge 2008).

Rosamond McKitterick, Roman texts and Roman history in the early middle ages, in: Rome Across Time and Space: Cultural Transmission and the Exchange of Ideas, C.500-I400, ed. dies./Claudia Bolgia/John Osborne (Cambridge 20r I) I9-33.

Mischa Meier, Das andere Zeitalter Justinians: Kontingenzerfahrung und Kontingenzbewältigung im 6. Jahrhundert n. Chr. (Göttingen 2003).

Ronald Mellor, Graecia capta. The confrontation between Greek and Roman identity, in: Hellenisms: Culture, Identity, and Ethnicity from Antiquity to Modernity, ed. Katerina Zacharia (Aldershot 2008) 79-I 26.

Helmut Michels, Zur Echtheit der Briefe Papst Gregors II. an Kaiser Leon III., in: Zeitschrift für Kirchengeschichte, 99 (I988) 376-39I.

Helmut Michels, Patricius, Patrikios, I. Westen, in: LMA Bd. 6 (München/Zürich I 993) I $789 f$. Jacques-Alain Miller, Extimité, in: M. Brachner, Lacanian Theory of Discourse: Subject, Structure, Society (New York 1994) 74-87.

Andreas Mohr, Das Wissen über die Anderen: Zur Darstellung fremder Völker in den fränkischen Quellen der Karolingerzeit (Münster/New York/München/Berlin 2005).

Hannes Möhring, Der Weltkaiser der Endzeit: Entstehung, Wandel und Wirkung einer tau- 
sendjährigen Weissagung (Mittelalterforschungen, 3, Stuttgart 2000).

Giosuè Musca, L’emirato di Bari, 847-87i (Bari ${ }^{2}$ 1978, 1967).

Janet L. Nelson, The Frankish Empire, in: The Oxford illustrated history of the Vikings, ed. Peter Sawyer (Oxford 1997) 19-47.

Janet L. Nelson, Making a difference in eighth century politics: The daughters of Desiderius, in: After Rome's Fall: Narrators and Sources of Early Medieval History, ed. Alexander Callander Murray (Toronto I998) i7 I-I9o.

Janet L. Nelson, Violence in the Carolingian world and the ritualization of ninth-century warfare, in: Violence and Society in the Early Medieval West, ed. Guy Halsall (Woodbridge 1998) 90-107.

J. F. Niemeyer/ C. van der Kieft/J. W. J. Burgers, Mediae Latinitatis Lexicon minus, 2 Bde. (Darmstadt ${ }^{2}$ 2002).

Thomas F. X. Noble, The Republic of St. Peter. The Birth of the Papal State, 680-825 (Philadelphia I984).

Thomas F. X. Noble, A new Look at the Liber Pontificalis, in: Archivum historiae pontificiae, 23 (I985) $347-35^{8}$.

Thomas F. X. Noble, The declining knowledge of Greek in eighth and ninth century Papal Rome, in: Byzantinische Zeitschrift, 78 (1985) 56-62.

Thomas F. X. Noble, Topography, Celebration and Power: The Making of Papal Rome in the Eighth and Ninth Centuries, in Topographies of Power in the Early Middle Ages, ed. Frans Theuws/Mayke de Jong (The Transformation of the Roman World 6, Leiden/Boston/ Köln 200I) 45-9I.

Thomas F. X. Noble, Images, Iconoclasm and the Carolingians (Philadelphia 2009).

Ulrich Nonn, Die Schlacht bei Poitiers 732. Probleme historischer Urteilsbildung, in: Beiträge zur Geschichte des Regnum Francorum, Referate beim Wissenschaftlichen Colloquium zum 75. Geburtstag von Eugen Ewig am 28. Mai 1988, ed. Rudolf Schieffer/Eugen Ewig (Beihefte der Francia 22, Sigmaringen 1990) 37-56.

Albrecht Noth, Heiliger Krieg und Heiliger Kampf in Islam und Christentum. Beiträge zur Vorgeschichte der Kreuzzüge (Bonner historische Forschungen, 28, Bonn 1966).

Heinz Ohme, Das Concilium Quinisextum und seine Bischofsliste: Studien zum Konstantinopeler Konzil von 692 (Arbeiten zur Kirchengeschichte 56, Berlin/New York 1990).

Werner Ohnsorge, Der Patricius-Titel Kaiser Karls des Großen, in: Byzantinische Zeitschrift 53 (i 960$) 300-32$ I.

Henri Omont, Inventaire sommaire des manuscrits grecs de la Bibliothèque Nationale, Seconde Partie (Paris I 888).

Georg Ostrogorsky, Geschichte des Byzantinischen Staates (Handbuch der Altertumswissenschaft I2,I,2, München I968).

„Other", in: Post-Colonial Studies. The Key Concepts, ed. Bill Ashcroft/Gareth Griffith/Hellen Tiffin (London/New York ${ }^{2} 2000$ ) I $54-156$.

Lutz E. von Padberg, Unus populus ex diversis gentibus. Gentilismus und Einheit im früheren Mittelalter, in: Der Umgang mit dem Fremden in der Vormoderne: Studien zur Akkulturation in bildungshistorischer Sicht, ed. Christoph Lüth/Rudolf W. Keck/Erhard Wiersing (Beiträge zur historischen Bildungsforschung, I7, Köln, Weimar, Wien 1997) I55-193. 
Lutz E. von Padberg, Bonifatius. Missionar und Reformer (München 2003).

Peter Partner, The Lands of St Peter. The Papal State in the Middle Ages and the Early Renaissance (Berkeley, California 1972).

Walter Pohl, Introduction, in: Strategies of Distinction: The Construction of Ethnic Communities, 300-800, ed. Walter Pohl/Helmut Reimitz (The Transformation of the Roman World 2, Leiden/Boston/Köln I998) I-I5.

Walter Pohl, Telling the difference: Signs of ethnic identity, in: Strategies of Distinction. The Construction of Ethnic Communities, 300-80o, ed. Walter Pohl/Helmut Reimitz (The Transformation of the Roman World, 2, Leiden/Boston/Köln 1998) I7-69.

Walter Pohl, Conceptions of Ethnicity in Early Medieval Studies, in: Debating the Middle Ages - Issues and Readings, ed. Lester K. Little/Barbara H. Rosenwein (Oxford 1998) I5-24.

Walter Pohl, Deliberate ambiguity - the Lombards and Christianity, in: Christianizing Peoples and Converting Individuals, ed. Gyuda Armstrong/Ian N. Wood (Turnhout 2000) 47-58.

Walter Pohl, Werkstätte der Erinnerung. Montecassino und die Gestaltung der langobardischen Vergangenheit (MIÖG, Ergänzungsband 39, Wien 200I).

Walter Pohl, Invasions and Ethnic Identity, in: Italy in the Early Middle Ages, 476-rooo, ed. Cristina La Rocca (Oxford 200I) i I-33.

Walter Pohl, Die Völkerwanderung. Eroberung und Integration (Stuttgart/Berlin/Köln 2002).

Walter Pohl, Das Papsttum und die Langobarden, in: Der Dynastiewechsel von 751. Vorgeschichte, Legitimationsstrategie und Erinnerung, ed. Matthias Becher/Jörg Jarnut (Münster 2004) I45-I6I.

Walter Pohl, Geschichte und Identität im Langobardenreich, in: Die Langobarden - Herrschaft und Identität, ed. ders./Peter Erhard, Forschungen zur Geschichte des Mittelalters 9 (Wien 2004) 555-566.

Walter Pohl, Theodelinde, in: RGA, 2. Aufl, Bd. 30 (2005) 4I $2 \mathrm{f}$.

Walter Pohl, Alienigena coniuga: Bestrebungen zu einem Verbot auswärtiger Heiraten in der Karolingerzeit, in: Die Bibel als politisches Argument: Voraussetzungen und Folgen biblizistischer Herrschaftslegitimation in der Vormoderne, ed. Andreas Pečar/Kai Trampedach (Historische Zeitschrift, Beihefte, Neue Folge, 43, München 2007) I59-I 88.

Walter Pohl, Heresy in Secundus and Paul the Deacon, in: The Crisis of the Oikumene. The Three Chapters and the Failed Quest for Unity in the Sixth-Century Mediterranean, ed. Celia Chazelle/Catherine Cubitt (Studies in the Early Middle Ages I4, Turnhout 2007) 243-264.

Walter Pohl, Gregorio Magno e il regno dei Longobardi, in: Gregorio Magno, l'impero e i regna ed. Claudio Azzara (Florenz 2008) I5-28.

Walter Pohl, Archaeology of Identity: Introduction, in: Archäologie der Identität, ed. ders./ Matthias Mehofer, Forschungen zur Geschichte des Mittelalters i7 (Wien 2010) I-V.

Walter Pohl, Introduction - Strategies of identification: A methodological profile, in: Strategies of Identification. Ethnicity and Religion in Early Medieval Europe, ed. Walter Pohl/ Gerda Heydemann (Cultural Encounters in Late Antiquity and the Middle Ages I3, Turnhout 2013) I-64.

Walter Pohl, Why not marry a foreign woman: Stephen III's letter to Charlemagne, in: Rome 
and Religion in the Early Middle Ages (Festschrift Thomas F. X. Noble), ed. Owen Phelan/Valerie Garver (in Vorbereitung).

Francisco Prado-Villar, The Gothic anamorphic gaze, in: Under the Influence. Questioning the Comparative in Medieval Castile, ed. Cynthia Robinson/Leyla Rouhi (Leiden 2005) 67-roo.

Friedrich Prinz, Europäische Grundlagen deutscher Geschichte (4.-8. Jahrhundert), in: Gebhardt. Handbuch der deutschen Geschichte, ro. Aufl., Bd. I (Stuttgart 2004) I 47-635.

Prosopographie der mittelbyzantinischen Zeit, ed. Ralph Johannes Lilie/Friedhelm Winkelmann, et al., 6 Bde. (Berlin/New York r999-200I).

John H. Pryor/Elisabeth M. Jeffreys, The Age of the $\triangle \mathrm{POM} \Omega \mathrm{N}$. The Byzantine Navy ca $500-$ I 204 (The Medieval Mediterranean, 62, Leiden/Boston 2006).

Paolo Radiciotti, La scrittura del Liber Pontificalis nel codice Bobbiese IV.A.8 della Biblioteca Nazionale di Napoli, in: Parrhasiana II, Atti del II Seminario di Studi su manoscritti Medievali e Umanistici della Biblioteca Nazionale di Napoli (Napoli, 20-2I ottobre 2000), ed. Giancarlo Abbamonte/Lucia Gualdo Rosa/Luigi Munzi (Napoli 2002) 79-ıor.

Claudia Rapp, Hellenic identity, romanitas and Christianity in Byzantium, in: Hellenisms: Culture, Identity, and Ethnicity from Antiquity to Modernity, ed. Katerina Zacharia (A1dershot 2008) I27-I 47 .

Helmut Reimitz, Ein karolingisches Geschichtsbuch aus St. Amand. Der Codex Vindobonensis palat. 473, in: Text - Schrift - Codex. Quellenkundliche Arbeiten aus dem Institut für Österreichische Geschichtsforschung, ed. Christoph Egger/Herwig Weigl (München 2000) 34-90.

Helmut Reimitz, Omnes Franci. Identifications and Identities of the early medieval Franks, in: Franks, Northmen, and Slavs: Identities and State Formation in Early Medieval Europe, ed. Ildar H. Garipzanov/Patrick J. Geary/Przemyslaw Urbanczyk (Cursor Mundi, 5, Turnhout 2008) $5 \mathrm{I}-69$.

Helmut Reimitz, Cultural brokers of a common past: history, identity and ethnicity in Merovingian historiography, in: Strategies of Identification. Ethnicity and Religion in Early Medieval Europe, ed. Walter Pohl/Gerda Heydemann (Cultural Encounters in Late Antiquity and the Middle Ages I3, Turnhout 2013) 257-30r.

Helmut Reimitz, Historiography and Frankish Identity (Cambridge, in Druck).

Bas ter Haar Romeny/Naures Atto/Jan J. van Ginkel/Mat Immerzeel/Bas Snelders, The Formation of a Communal Identity among West Syrian Christians: Results and Conclusions of the Leiden Project, in: Church History and Religious Culture, 89, I-3 (2009) I-52.

Bas ter Haar Romeny, Ethnicity, Ethnogenesis, and the Identity of Syriac Orthodox Christians, in: Visions of Community in the Post-Roman World. The West, Byzantium and the Islamic World, 300-Iıoo, ed. Walter Pohl/Clemens Gantner/Richard Payne (Aldershot 2012) $183-204$.

Ekkehart Rotter, Abendland und Sarazenen. Das okzidentale Araberbild und seine Entstehung im Frühmittelalter (Studien zur Sprache, Geschichte und Kultur des islamischen Orients, II, Berlin/New York 1986).

Elisabeth Roudinesco/Michel Plon, Wörterbuch der Psychoanalyse: Namen, Länder, Werke, Begriffe (Wien 2004, frz. Orig. 1997). 
Johann Baptist Sägmüller, Die Entwicklung des Archipresbyterats und Dekanats bis zum Ende des Karolingerreichs (Tübingen I898).

Edward Said, Orientalism (London/New York 2003, ${ }^{1}$ I978).

Jean-Marie Sansterre, Les moines grecs et orientaux à Rome aux époques byzantine et carolingienne (milieu du VIe s. - fin du IX es.), 2 Bde. (Académie royale de Belgique, Mémoires de la classe des lettres, Collection in $-8^{\circ}, 2^{\mathrm{e}}$ série, 66, I [1983]).

V. Saxer, Petronilla, in: LMA 6, I95 If.

Rudolf Schieffer, Die Karolinger (Stuttgart/Berlin/Köln ${ }^{4}$ 2006).

Stefan Schima, Papsttum, Papstwahl und Nachfolgesouveränität. Oder: Inwiefern kann ein Papst seine Nachfolge beeinflussen?, in: Juridikum 4/2003, I80-183.

Claudia Schnurmann, Europa trifft Amerika: Zwei alte Welten bilden eine neue atlantische Welt, I492-I783 (Münster 2009).

Sebastian Scholz, Politik - Selbstverständnis - Selbstdarstellung: Die Päpste in karolingischer und ottonischer Zeit (Historische Forschungen 26, Stuttgart 2006).

Tobias Schwarz, Bedrohung, Gastrecht, Integrationspflicht: Differenzkonstruktionen im deutschen Ausweisungsdiskurs (Bielefeld 2010).

Hans Martin Schwarzmaier, Lucca und das Reich bis zum Ende des Ir. Jahrhunderts. Studien zur Sozialstruktur einer Herzogsstadt in der Toskana (Bibliothek des Deutschen Historischen Instituts in Rom 4I, Tübingen 1972).

Philippe Sénac, Les carolingiens et al-andalus. VIIIe-IXe siècles (Paris 2002).

Antonio Sennis, Onorio I, in: Enciclopedia dei papi, Bd. I (Rom 2000) 585-589.

Patricia Skinner, Family Power in Southern Italy. The Duchy of Gaeta and its Neighbours, 850-Ir39 (Cambridge 1995).

Michel Sot, Gesta episcopum, gesta abbatum (Typologie des sources du moyen age occidental 37, Turnhout I98I).

Paul Speck, Kaiser Leon III., die Geschichtswerke des Nikephoros und des Theophanes und

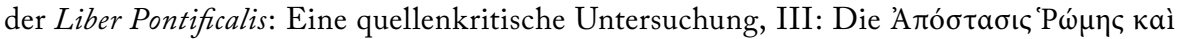

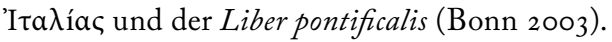

May Spindler, Handbuch der bayrischen Geschichte: Bd. I. Das Alte Bayern. Das Stammesherzogtum bis zum Ausgang des I2. Jahrhunderts (München I98I).

Andreas N. Stratos, The exarch Olympius and the supposed Arab invasion of Sicily in AD 652, in: Jahrbuch der Österreichischen Byzantinistik, 25 (1976) 63-73.

Franz Tinnefeld, Abendland und Byzanz: ein Europa?, in: Byzanz: das andere Europa, ed. Peter Segl, in: Das Mittelalter, 6, 2 (Berlin 200I) 19-38.

Tzvetan Todorov, La conquête de l'Amérique. La question de l'autre (Paris I982).

Klaus-Peter Todt, Theodor von Canterbury, in: Biographisch-bibliographisches Kirchenlexikon, Bd. II (I996) 869-87I.

John Victor Tolan, Saracens. Islam in the Medieval European Imagination (New York 2002). John Victor Tolan, „A wild man, whose hand will be against all“: Saracens and Ishmaelites in Latin Ethnographical Traditions, from Jerome to Bede, in: Visions of Community in the Post-Roman World. The West, Byzantium and the Islamic World, ed. Walter Pohl/ Clemens Gantner/Richard Payne (Aldershot, in Druck).

Warren Treadgold, A History of the Byzantine State and Society (Stanford 1997). 
Warren Treadgold, The prophecies of the patriarch Methodius, in: Revue des études byzantines, 62 (2004) 229-237.

Susan Twyman, Papal Ceremonial at Rome in the Twelfth Century (Henry Bradshaw Society Subsidia IV, London 2002).

Walter Ullmann, The Growth of Papal Government in the Middle Ages (London 1955).

Walter Ullmann, A Short History of the Papacy (London ${ }^{2}$ I 974 ).

Franz Unterkircher, Einleitung, in: Codex epistolaris Carolinus, Österreichische Nationalbibliothek Codex 449 (Codices selecti, 3, Graz I962) I-XXVII.

Charles Verlinden, L'esclavage dans 1'Europe médiévale, Bd. 2, Italie, colonies italiennes du Levant, Levant latin, Empire byzantin (Gent 1977).

Giorgio Vespignani, Costantinopoli Nuova Roma come modello della urbs regia tardoantica, in: Reti Medievali Rivista, XI - 2010/2 (luglio-dicembre), http://www.retimedievali.it (Stand 26.4.2014).

Cyrille Vogel, Le Pecheur et pénitance au Moyen Âge (Paris I969).

Chris Wickham, Framing the Early Middle Ages: Europe and the Mediterranean, 400-800 (Oxford 2005).

Herwig Wolfram, Intitulatio, Bd. r: Lateinische Königs- und Fürstentitel bis zum Ende des achten Jahrhunderts (Graz/Wien/Köln I967).

Ian N. Wood, Where the wild things are, in: Visions of Community in the Post-Roman World. The West, Byzantium and the Islamic World, ed. Walter Pohl/Clemens Gantner/ Richard Payne (Aldershot 2012) 53 I-542.

Greg Woolf, Tales of the Barbarians. Ethnography and Empire in the Roman West (Chichester/Malden, Mass. 2or I).

Helmut Zielinski, Adelchis, r. König der Langobarden, in: LMA, Bd. I, I44f.

Daniel Ziemann, Vom Wandervolk zur Großmacht. Die Entstehung Bulgariens im frühen Mittelalter (7.-9. Jh.) (Kölner historische Abhandlungen, 43, Köln/Weimar/Wien 2007). 


\section{Appendix: Die Textgruppen des Liber Pontificalis ${ }^{926}$}

Die Textklassen und ihre wesentlichen handschriftlichen Textzeugen für das achte Jahrhundert ${ }^{927}$

Der folgende Abschnitt beruht auf den Beschreibungen der Handschriften in den gängigen Editionen. In erster Linie wurde Duchesne, LP I, CLXIV-CCVI herangezogen und durch jüngere Informationen aus der MGH-Edition (Liber Pontificalis pars prior, [ed. Theodor Mommsen, MGH SS Gesta episcopum romanorum I, Berlin I898] IV-VI und LXXIV-CVIII) und den umfassenden Bemerkungen in der Übersetzung von Davis, BP und LP 8 ergänzt. Diese Werke werden hier im Einzelnen nicht mehr zitiert, darüber hinaus herangezogene Literatur aber schon.

Kurz zur Zitierweise der Handschriften: Die Siglen setzen sich aus einem Großbuchstaben und einer hochgestellten Zahl zusammen, der Buchstabe markiert die übergeordnete Textklasse, die Zahl die engere Zugehörigkeit des Textes, wobei die Zahl öfters auch schon für nur eine einzige Handschrift steht. Die hochgestellten Zahlen setzen sich manchmal so zusammen, dass darin mehrere Handschriften genannt sind. So meint „C $\mathrm{C}^{12 “}$ etwa nicht eine Klasse Nummer I 2, die es gar nicht gibt,

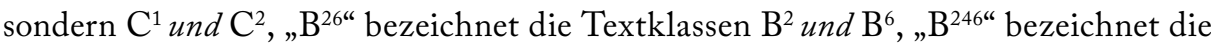
drei Handschriften $\mathrm{B}^{2}, \mathrm{~B}^{4}$ und $\mathrm{B}^{6}$. Die folgende Aufstellung enthält nur jene Handschriften, die Duchesne als für seine Edition relevant eingestuft hat, somit

\section{Klasse $A$}

Die von Duchesne als so wesentlich eingestufte Textklasse A wird für das achte Jahrhundert nur noch von einer Handschrift $\left(\mathrm{A}^{1}\right)$ repräsentiert, nämlich dem Codex 490 der Biblioteca Capitolare in Lucca (Toskana). Alle weiteren Textzeugen dieser Kategorie $\left(\mathrm{A}^{2}-\mathrm{A}^{6}\right)$ enden spätestens mit Konstantin I. Daneben gibt es noch spätere Textzeugen, die aber allesamt von der Handschrift $\mathrm{A}^{1}$ abhängen.

926 Der Appendix basiert auf (überarbeitetem) Text aus Gantner, Studien, 24-35, Kapitel 1.3 (Magisterarbeit aus Geschichtsforschung, Historische Hilfswissenschaften und Archivwissenschaft).

927 Eine ausführliche Aufstellung mit den spezifischen Inhalten der jeweiligen Handschriften findet sich bei Duchesne, LP I, CLXIV-CCVI. 
$A^{1}$ : Die Handschrift ist eine Sammelhandschrift, die den Liber Pontificalis im Volltext bis zu Hadrian I. enthält, dessen Leben auch aufgenommen wurde, jedoch an einigen Stellen unwesentlich gekürzt wurde. Die Entstehungszeit wird meist mit um 800 angegeben. Es handelt sich um einen der wesentlichsten Textzeugen des LP und eine der spannendsten Handschriften Italiens. Der Text verteilt sich auf zwei der drei Handschriftenteile, ab Gregor II. ist er in einer relativ repräsentativen Uniziale gehalten. Der Codex kann hier nicht adäquat repräsentiert werden, verwiesen sei auf Luigi Schiaparelli, Il codice 490 della Biblioteca Capitolare di Lucca e la scuola scrittoria Lucchese, sec. VIII-IX (Studi e testi 36, Roma 1924) und Armando Petrucci, Il codice n. 490 della biblioteca capitolare di Lucca, in: Actum Luce 2 (1973) I59-175. ${ }^{928}$

\section{Klasse $B$}

Die Urfassung dieser Textklasse wird von der Handschrift IV.A.8 der Biblioteca Nationale Vittorio Emanuele III. in Neapel repräsentiert. Der Liber Pontificalis Teil dieser Handschrift ist jedoch nur mehr als Fragment erhalten (bis Anastasius II.) und daher sowie aufgrund einer Behandlung mit Chemikalien im 19. Jahrhundert nur noch mit Einschränkungen zu lesen. Offenbar gibt es auch Schwierigkeiten, das Stück zu datieren, es dürfte jedenfalls dem späten siebenten oder frühen achten Jahrhundert entstammen. ${ }^{929}$ Die Handschrift stammt ursprünglich aus dem norditalienischen Kloster Bobbio. Sie ist nicht nur der erste Textzeuge der Textklasse B, sondern mutatis mutandis auch der Textklasse $\mathrm{C}$, die zu diesem Zeitpunkt B noch fast völlig gleicht. ${ }^{930}$ Von der Klasse B hängt eine Reihe hoch- und spätmittelalterlicher Weiterverarbeitungen des Textes ab, so etwa der Liber Floridus des Lambert von St. Omer.

$\mathrm{B}^{2}$ : Vertreten von den zwei Handschriften Paris BNF 13729 und Laon 342. Beide Handschriften stammen aus dem neunten Jahrhundert und gleichen sich in sehr hohem Maß. Eine gemeinsame Erstellung von einem Schreiber ist wahrscheinlich. Der Text reicht bis zum Leben Hadrians I.

$B^{3}$ : Köln, Dombibliothek I64. Handschrift aus dem neunten Jahrhundert, endet in der Vita Stephans III. vor der Liste der Teilnehmer am Konzil von 769. Aus ihm oder

928 Siehe außerdem Gantner, Studien, bes. 52-62.

929 Paolo Radiciotti, La scrittura del Liber Pontificalis nel codice Bobbiese IV.A.8 della Biblioteca Nazionale di Napoli, in: Parrhasiana II, Atti del II Seminario di Studi su manoscritti Medievali e Umanistici della Biblioteca Nazionale di Napoli (Napoli, 20-21 ottobre 2000), ed. Giancarlo Abbamonte/Lucia Gualdo Rosa/Luigi Munzi (Napoli 2002) 79-101.

930 Siehe die Tabelle weiter unten in diesem Appendix. 
einem weiteren, verlorenen Vertreter der Textklasse wurde der Wolfenbüttler Codex von $\mathrm{C}^{2}$ erweitert.

B4: Universitätsbibliothek Leiden, Vossianus Lat. Q4I. Spätes neuntes Jahrhundert. Endet mit Stephan III., als einzige Handschrift enthält sie die Liste der Teilnehmer am römischen Konzil unter demselben Papst. Von ihr hängen vier spätmittelalterliche Kopien ab. Dieser Textklasse gehören auch noch vier Handschriften des I3.-I5. Jahrhunderts an.

$\mathrm{B}^{5}$ : Bibliothèque royal de Belgique 8380, 9./ro. Jahrhundert. Endet mit dem Leben Stephans II. Es existiert noch eine Kopie aus dem elften Jahrhundert.

$B^{6}$ : Wien, Österreichische Nationalbibliothek (CVP) 473. Endet mit Stephan II. Hier ist der Text allerdings in den Kontext der karolingischen Geschichte gesetzt worden und auch so zu verstehen. Mit ziemlicher Sicherheit stammt die Handschrift aus St. Amand. ${ }^{931}$

$\mathrm{B}^{7}$ : „Zwilling“ von $\mathrm{B}^{6}$. Duchesne hat sich bei der Zuweisung der Siglen als nicht besonders konsequent erwiesen. Diese Handschrift etwa hätte er $\mathrm{B}^{6}$ zurechnen müssen.

Abgesehen vom absoluten Sonderfall $\mathrm{B}^{1}$ sind alle Original-Handschriften der BKlasse ${ }^{932}$ nördlich der Alpen erhalten. Auch der Herstellungsort liegt dort, auffälligerweise sogar jeweils im Gebiet des Frankenreichs des neunten Jahrhunderts.

\section{Klasse C}

$\mathrm{C}^{1}$ : Leithandschrift: Universitätsbibliothek Leiden, Vossianus Lat. Q6o. Endet mit Stephan II. Zu dieser Klasse zählen noch weitere fünf hoch- und spätmittelalterliche Handschriften. Der Codex stammt wahrscheinlich noch aus dem späten achten Jahrhundert und ist der früheste erhaltene Textzeuge der sogenannten Langobardischen Rezension des LP. Er wurde in der Umgebung des Klosters St. Amand verfasst. ${ }^{933}$

931 Vgl. ausführlich Reimitz, Geschichtsbuch, hier besonders 40f. Zur Zuweisung nach St. Amand siehe Rosamond McKitterick, Political ideology in Carolingian historiography, in: Using the Past in the Early Middle Ages, ed. Yitzhak Hen/Matthew Innes (Cambridge 2000) 162-174, bes. 162, die jedoch dort leider ihre Zuweisung nicht begründet oder diskutiert. Eine entsprechende Arbeit McKittericks über das Skriptorium von St. Amand steht bis dato leider noch aus und wäre ein Desiderat.

932 Daneben gibt es auch eine Reihe von textlich abhängigen späteren Kopien.

933 Bischoff, Schreibschulen, Bd. 2, 61-73 und 102, Nr. 43. Siehe auch Gantner, Studien 35-51. 
$\mathrm{C}^{2}$ : Leithandschrift: Herzog August Bibliothek, Wolfenbüttel, ro.r I Aug 4. Die Handschrift endet mit Stephan II. (beziehungsweise Stephan III., in der wenig später verfassten Fortsetzung). Eine Handschrift der Wiener Nationalbibliothek geht auf eine zeitnahe Kopie der Wolfenbüttler Handschrift zurück.

Der Wolfenbüttler Codex enthielt zunächst den LP in der Langobardischen Rezension, die fränkische Rezension wurde aber später teilweise eingefügt, was das Manuskript zu einem hochinteressanten Textzeugen für die Verwendung des LP im neunten Jahrhundert macht. ${ }^{934}$

$\mathrm{C}^{3}$ : Bern, Burgerbibliothek 408, aus dem neunten Jahrhundert. Von Duchesne als wesentlichste Handschrift dieser Klasse eingestuft („incorrect, mais sincère“), bricht im Leben Stephans II. knapp vor dem Ende ab. ${ }^{935}$

$\mathrm{C}^{4}$ : Paris BNF 5 I40, Ir. Jahrhundert. Eine der wesentlichsten Handschriften für die späten Leben des Liber Pontificalis, reicht bis Hadrian II. (unter Auslassung Benedikts III.). Schon vor Stephan II. ist der Text jedoch sehr an die Handschriften der Klasse E angelehnt, was sich danach noch verstärkt.

\section{Klasse D}

Wird von zwei Handschriften aus dem neunten Jahrhundert repräsentiert, die Handschriften Nummer $55 \mathrm{I} 6$ und 2769 der BNF in Paris, respektive aus Tours und Beauvais. Interessant ist, dass sich die beiden Handschriften ab der Vita des Silverus stark voneinander unterscheiden. Beauvais folgt ab da ganz eng dem Text der BHandschriften, Tours jenem von A. Erst mit der Vita Gregors II. schließt auch Tours sich weitestgehend dem Text von B an. Tours bricht im Leben von Leo IV. ab, Beauvais endet mit Stephan II. Diese Variationsbreite alleine belegt einmal mehr, wie viele Handschriften des LP im frühen Mittelalter existiert haben müssen. Trotz des beträchtlichen Unterschieds zwischen den Texten hat Duchesne überraschenderweise keine Untersiglen $\mathrm{D}^{1}$ und $\mathrm{D}^{2}$ vergeben, weswegen diese Arbeit an den wenigen Stellen, an denen eine Unterscheidung notwenig wird, die Hilfsbezeichnung $\mathrm{D}^{\mathrm{B}}$

934 Eine detailreiche Beschreibung findet sich in Gantner, Studien 63-88.

935 Genauer auf LP I, 454, Z. 1. Genau hier beginnt ein neuer Abschnitt der Vita (quasi der Abgesang), insofern ist das Abbrechen des Textes an dieser Stelle vielleicht sogar absichtlich so ausgeführt worden. Der letzte Abschnitt der Vita Stephans II. schildert den späteren Antagonisten der Päpste Desiderius ausgesprochen positiv, was vielleicht in der Rückschau des frühen neunten Jahrhunderts etwas merkwürdig anmutete. Vgl. unten, Kap. 3. 
für die Handschrift aus Beauvais (BNF 2769) verwendet. Der Text der Turonenser Handschrift findet sich auch in einer Leidener Handschrift (zwölftes Jahrhundert), der Text der Handschrift aus Beauvais wiederum wurde im I3. Jahrhundert für eine gekürzte Version des Liber Pontificalis verwendet.

\section{Klasse $E$}

$\mathrm{E}^{1}$ : BAV Vat. Lat. 3764 , aus dem späten Ir. Jahrhundert, mit großer Wahrscheinlichkeit im Kloster Farfa hergestellt. Besonders interessant wird die Handschrift durch eine hinzugefügte Liste der Patriarchen von Konstantinopel, die aber hier nicht behandelt werden kann. ${ }^{936}$ Bemerkenswert ist auch, dass hier die längste bekannte Fassung der Vita Stephans V., des letzten im alten Liber Pontificalis behandelten Papstes, enthalten ist. Es existiert eine Reihe von neuzeitlichen Kopien dieser Handschrift.

$\mathrm{E}^{2}$ : Paris, BNF ${ }_{5143}$, stammt aus dem I4. Jahrhundert und hat einen ähnlichen Text wie $\mathrm{E}^{1}$.

E4: Estensis VI.F.5 der Universitätsbibliothek Modena, spätes elftes Jahrhundert. Der Text reicht bis zum Leben Hadrians, wo er nach der Mitte abbricht. Für das achte Jahrhundert folgt der Text der Handschriftenklasse C (ebenso wie G). ${ }^{937}$

E5: Handschrift aus dem Besitz der Familie Farnese, heute verloren. Im i8. Jahrhundert war sie (beziehungsweise Teile von ihr) noch vorhanden und wurde von Holste und Bianchini kollationiert. Auf diesen Abschriften und einigen Abzeichnungen Bianchinis beruht unser heutiges Wissen über diese Textvariante. Die Handschrift dürfte noch aus dem neunten Jahrhundert gestammt haben, umso bedauerlicher ist der Verlust. Der Codex enthielt auch als einziger ${ }^{938}$ eine extreme Variante der Vita

936 Cuppo[-Csaki], I pontifices di Costantinopoli, sowie Luciana Cuppo-Csaki, A Seventh-Century List of Patriarchs of Constantinople in The Roman Book of Pontiffs: some considerations, Vortrag gehalten bei: 21st International Congress of Byzantine Studies, London 2006, Communications II (VI.3), 23.8.2006. Siehe ein stark gekürztes Abstract: Luciana Cuppo-Csaki, A Seventh-Century List of Patriarchs of Constantinople in The Roman Book of Pontiffs: some considerations, in: Proceedings of the 21st International Congress of Byzantine Studies London 21-26 August 2006, 3, Abstracts of Communications, ed. Elizabeth Jeffreys/Fiona K. Haarer/Judith Gilliland (London 2006) $226 f$.

937 Wobei hier nach dem Leben Stephans II. wohl eher der Umkehrschluss zu gelten hat, die einzige verbliebene Handschrift der Gruppe $\mathrm{C}, \mathrm{C}^{4}$, folgt nun dem Text von E.

938 Von insgesamt nur sechs Handschriften, die dieses Leben überhaupt überliefern, was den Varian- 
Sergius' II., in der dieser massiv angegriffen wird. Schon in der Neuzeit war diese Variante jedoch nur noch ein Fragment. ${ }^{939}$

E6: Ms LXVI, 35 der Biblioteca Medicea Laurenziana in Florenz, aus dem I5. Jahrhundert, ist den Handschriften $\mathrm{E}^{12}$ sehr nahe, enthält aber viele Fehler.

\section{Klasse G}

Diese Handschriftenklasse wird nur durch einen einzigen Textzeugen repräsentiert, nämlich den Codex Vat. Lat. 376r der BAV. Die Handschrift enthält ebenfalls die Langobardische Rezension und stammt aller Wahrscheinlickeit nach aus Farfa, wo sie kurz vor oder um rooo hergestellt wurde. Es handelt sich hierbei am ehesten um eine Arbeitskopie eines Mönchs des Klosters. ${ }^{940}$

\section{Andere Klassen und Rezensionen}

Neben den genannten Handschriftenklassen, die nicht nur für die Edition von Duchesne von besonderer Wichtigkeit waren, sondern auch für die hier angestellten Untersuchungen als Vergleichsmaterial von entscheidender Bedeutung sind, existieren noch weitere Versionen des Liber Pontificalis - aus allen Zeiten.

Zunächst sind besonders die Vatikanfragmente zu nennen, denn darin sind auch Teile von Viten des achten Jahrhunderts enthalten. Eine Auflistung dieser Teile ist in den Editionen recht gut erfolgt. Auch gab es vom Liber Pontificalis schon im Hochmittelalter sowohl Überarbeitungen als auch Kurzfassungen, die zum Teil Eingang in umfassendere Werke, wie etwa den Liber Floridus gefunden haben. ${ }^{941}$

Nicht unerwähnt soll hier auch die erste Fassung des alten Liber Pontificalis bleiben. Diese ist in einigen Handschriften präsent. Duchesne hat sie als „Texte primitif“ bezeichnet und in zwei Redaktionshorizonte gegliedert, einen felizianischen ${ }^{942}$ und

tenstatus wieder ein wenig relativiert, vor allem, wenn man in Betracht zieht, dass hier daneben nur noch die Versionen von D (1 Handschrift) und CE (4 weitere Handschriften) halbwegs eigenständig existieren.

939 Eine genaue Aufarbeitung der bekannten Fakten findet sich bei Levison, Pseudo-Liudprand und der Codex, bes. 433-438. Das aus dem elften Jahrhundert stammende Werk des Pseudo-Liutprand ist unter Verwendung eines Liber Pontificalis derselben Textklasse $\left(\mathrm{E}^{5}\right)$ entstanden.

940 Siehe zu diesem Codex Giorgi, Appunti 247-261, und Gantner, Studien 89-96.

941 Ganz besonders sei hier auf Davis, LP 8, XVIIf. verwiesen, denn dort findet sich eine sehr konzise Zusammenfassung, die den Einstieg in die Materie deutlich erleichtern kann.

942 Felix IV., 526-530. 
einen cononianischen ${ }^{943}$, repräsentiert durch die Siglen F und K. Bei diesen beiden Redaktionen handelt es sich allerdings jeweils um Kurzfassungen, ein Text in voller Länge ist nicht überliefert. ${ }^{944}$

\section{Schematische Darstellung der wesentlichen Entwicklungen der Handschriftenklassen}

Ganz wichtig ist es vorweg festzuhalten: Die Handschriftenklasse D (repräsentiert durch zwei Handschriften, $\mathrm{D}$ für Tours und $\mathrm{D}^{\mathrm{B}}$ für Beauvais ${ }^{945}$ ) gleicht $\mathrm{A}$ immer dann, wenn auch diese Klasse auf die von Duchesne postulierte erste Redaktionsstufe des Liber Pontificalis zurückgreift (Klassen F und K). In D klingen mehr Textvarianten dieser ersten Zusammenstellung durch als in den Klassen ABC. Für E gilt bis zu einem gewissen Grad Ähnliches, auch hier konnte Duchesne noch Teile des ersten Liber Pontificalis identifizieren, und auch hier sind es vor allem diese Stellen, an denen $\mathrm{E}$ mit $\mathrm{A}$ übereinstimmt (siehe Tabelle unten). ${ }^{946}$

Die Tabelle basiert auf den vergleichenden Beobachtungen, die Duchesne in seinem Kapitel „Histoire du Texte - Les Recensions“ angestellt hat, vgl. LP I, CCVIICCXXX (reicht bis exklusive Hadrian I.) und Davis, LP 8 und LP 9, Kommentare zu den jeweiligen Leben, beginnend ab Gregor II. Löcher in der Darstellung rühren daher, dass Duchesne nicht für alle Papstleben die Gruppen angibt und für die vorliegende Arbeit nicht alle Handschriften überprüft werden konnten. Für die Päpste von Petrus bis Alexander I. dürfte ein relativ einheitlicher Text vorhanden sein. Danach dürfte anzunehmen sein, dass die jeweils letzten vorhandenen Gruppen auch für die folgenden Leben Geltung haben.

Kursiv gesetzt sind jene Päpste und „Gegenpäpste“, die im Liber Pontificalis nicht genannt werden. Nicht voll anerkannte Päpste sind mit einem Sternzeichen $\left(^{*}\right)$ versehen, unsichere Gegenpontifikate sind mit Klammern versehen. Die normalerweise für die einzelnen Textklassen verwendeten hochgestellten Zahlen werden in der Tabelle normal in den Text gestellt, da andernfalls die Darstellung zu verwirrend wäre. Für die einzelnen Papstviten gibt es nun bis zu drei verschiedene übergeordnete Text-

943 Conon, 686-687.

944 Duchesne, LP I, XLIX-LXVII und 47.

945 Duchesne hat eigentlich keine Nummerierung eingeführt, schreibt aber je einmal von D1 für Tours und D2 für Beauvais. Diese Ausrutscher können aber nicht als ständige Siglen gewertet werden. Zu dem Zeitpunkt, als $\mathrm{D}^{\mathrm{B}}$ von $\mathrm{D}$ abweicht, wird im Fußnotenapparat der Edition offenbar die Sigle D allein für die Handschrift aus Tours verwendet.

946 Duchesne, LP I, CCXIII-CCXV. Geertman, La genesi, sieht aber einen geringeren Zusammenhang zwischen Textklasse D und den Epitoma F und K. 
versionen, das heißt Texte mit Varianten größeren Ausmaßes. Manchmal überliefern aber auch alle Textklassen im Wesentlichen denselben Text. In die folgende Tabelle wurden nun alle großen Textgruppen eingetragen, die Spalte „Textgruppe I“ beginnt dabei immer mit Textklasse A beziehungsweise ab Leo III. (denn ab hier gibt es die Klasse A nicht mehr) mit jener Sigle, die im Alphabet A am nächsten steht.

Tabelle 3: Die Verteilung der Textklassen für die einzelnen Papstviten ${ }^{947}$

\begin{tabular}{|c|c|c|c|c|}
\hline Päpste & Pontifikatsdaten & Textgruppe I & Textgruppe 2 & Textgruppe 3 \\
\hline Petrus & $+64 ?$ & Alle & & \\
\hline Linus & $64-79 ?$ & Alle & & \\
\hline Kletus & 79-9г? & Alle & & \\
\hline Clemens I. & 9I-IOI? & Alle & & \\
\hline Anacletus = Kletus & & Alle & & \\
\hline Evarist & IOI-IO5? & Alle & & \\
\hline Alexander I. & $105-115 ?$ & Alle & & \\
\hline Xystos (Sixtus) I. & I I5-I25? & A & BCDE & \\
\hline Telesphor & I25-136? & A & $\mathrm{BCDE}$ & \\
\hline Hyginos & I36-I40? & & & \\
\hline Pius I. & I 40-I54? & & & \\
\hline Aniket & I54-I66 & & & \\
\hline Soter & I66-I 75 & & & \\
\hline Eleuther & I $75-189$ & $\mathrm{AE}$ & $\mathrm{BCD}$ & \\
\hline Viktor I. & I 89-I99 & & & \\
\hline Zephyrin & 199-217 & & & \\
\hline Calixt I. & $217-222$ & & & \\
\hline Hippolyt* & $217-235$ & & & \\
\hline Urban I. & $222-230$ & A & $\mathrm{BC}$ & $\mathrm{DE}$ \\
\hline Pontian & $230-236$ & A & BCD & $\mathrm{E}$ \\
\hline Anteros & $235^{-236}$ & A & BCDE & \\
\hline Fabian & $236-250$ & & & \\
\hline Cornelius & $25^{\mathrm{I}-253}$ & A & BCD & $\mathrm{E}$ \\
\hline Novatian* & $25^{I-25^{8}}$ & & & \\
\hline Lucius I. & $253-254$ & & & \\
\hline
\end{tabular}

947 Die folgende Liste basiert auf den Daten aus: Geschichte der katholischen Kirche, ed. Josef Lenzenweger/Peter Stockmeier/Johannes B. Bauer/Karl Amon/Rudolf Zinnhobler (Graz/Wien/Köln ${ }^{31995)}$ 560-563. Sie wurde jedoch vom Autor weiter bearbeitet und an die Liste des römischen Liber Pontificalis angepasst. Die Gegenpäpste wurden, obwohl sie allesamt keinen Eintrag im Liber Pontificalis erhalten haben, in der Liste belassen um einen besseren Überblick zu gewährleisten. Gegenpäpste wurden mit einem Asterisk versehen, Päpste, die keinen Eintrag im LP erhalten haben, sind kursiv gesetzt. 


\begin{tabular}{|c|c|c|c|c|}
\hline Päpste & Pontifikatsdaten & Textgruppe I & Textgruppe 2 & Textgruppe 3 \\
\hline Stephan I. & $254-257$ & & & \\
\hline Xystos (Sixtus) II. & $257-25^{8}$ & & & \\
\hline Dionysius & $259-268$ & & & \\
\hline Felix I. & $269-274$ & & & \\
\hline Eutychian & $275-283$ & & & \\
\hline Gaius & $283-296$ & $\mathrm{AE}$ & $\mathrm{BCD}$ & \\
\hline Marcellin & $296-304$ & A & $\mathrm{BCD}$ & $\mathrm{E}$ \\
\hline Marcellus I. & $308-309$ & & & \\
\hline Eusebios & 309 o. 310 & & & \\
\hline Heraklius* $^{*}$ & 3090.310 & & & \\
\hline Miltiades & $3 \mathrm{II}-3 \mathrm{I} 4$ & & & \\
\hline Silvester I. & $314-335$ & A & $\mathrm{BCD}$ & \\
\hline Markus & $335-336$ & & & \\
\hline Julius I. & $337-35^{2}$ & A & BCDE & \\
\hline Liberius & $35^{2}-366$ & $\mathrm{AE}$ & $\mathrm{BCD}$ & \\
\hline Felix II.* & $355-365$ & A & $\mathrm{BCD}$ & $\mathrm{E}$ \\
\hline Damasus I. & $366-384$ & $\mathrm{AE}$ & $\mathrm{BCD}$ & \\
\hline Ursinus* & $366-367$ & & & \\
\hline Siricius & $384-399$ & A & BCDEG $^{948}$ & \\
\hline Anastasius I. & $399-401$ & & & \\
\hline Innozenz I. & $4 \mathrm{OI}-4 \mathrm{I} 7$ & & & \\
\hline Zosimos & $4 \mathrm{I} 7-4 \mathrm{I} 8$ & & & \\
\hline Bonifatius I. & $418-422$ & & & \\
\hline Eulalius* & $418-419$ & & & \\
\hline Cölestin I. & $422-432$ & & & \\
\hline Xystus (Sixtus) III. & $432-440$ & A & BCDEG & $(\mathrm{E})$ \\
\hline Leo I. & $440-46 \mathrm{I}$ & A & BCDEG & \\
\hline Hilarius & $46 I-468$ & A & BCDEG & \\
\hline Simplicius & $468-483$ & & & \\
\hline Felix III. & $483-492$ & A & BCDEG & \\
\hline Gelasius I. & $492-496$ & A & BCDEG & \\
\hline Anastasius II. & $496-498$ & & & \\
\hline Symmachus & $49^{8}-5 \mathrm{I} 4$ & AD & BCEG & \\
\hline Laurentius* & $498 ; 50 I-507$ & & & \\
\hline Hormisdas & $514-523$ & & & \\
\hline Johannes I. & $523-526$ & $\mathrm{~A}^{949}$ & BCDEG & \\
\hline
\end{tabular}

948 Nach Damasus hat G den Text von E. Duchesne, LP I, CCXVI.

949 Johannes I. bis Agapitus nur geringe Unterschiede. 


\begin{tabular}{|c|c|c|c|c|}
\hline Päpste & Pontifikatsdaten & Textgruppe I & Textgruppe 2 & Textgruppe 3 \\
\hline Felix IV. & $526-530$ & A & BCDEG & \\
\hline Dioskoros* & 530 & & & \\
\hline Bonifatius II. & $530-532$ & A & BCDEG & \\
\hline Johannes II. & $533-535$ & A & BCDEG & \\
\hline Agapitus I. & $535-536$ & A & BCDEG & \\
\hline Silverius & $536-537$ & $\mathrm{AD}^{950}$ & $\mathrm{BCD}^{\mathrm{B}} \mathrm{EG}$ & \\
\hline Vigilius & $537-555$ & $\mathrm{AD}$ & $\mathrm{BCD}^{\mathrm{B}} \mathrm{EG}$ & \\
\hline Pelagius I. & $55^{6-56 I}$ & $\mathrm{AD}$ & $\mathrm{BCD}^{\mathrm{B}} \mathrm{EG}$ & \\
\hline Johannes III. & $56 \mathrm{I}-574$ & $\mathrm{AD}$ & $\mathrm{BCD}^{\mathrm{B}} \mathrm{EG}$ & \\
\hline Benedikt I. & $575-579$ & $\mathrm{AD}$ & $\mathrm{BCD}^{\mathrm{B}} \mathrm{EG}$ & \\
\hline Pelagius II. & $579-590$ & $\mathrm{AD}$ & $\mathrm{BCD}^{\mathrm{B}} \mathrm{EG}$ & \\
\hline Gregor I. & $590-604$ & $\mathrm{AD}$ & $\mathrm{BCD}^{\mathrm{B}} \mathrm{EG}$ & \\
\hline Sabinian & $604-606$ & $\mathrm{AD}$ & $\mathrm{BCD}^{\mathrm{B}} \mathrm{EG}$ & \\
\hline Bonifatius III. & 607 & $\mathrm{AD}$ & $\mathrm{BCD}^{\mathrm{B}} \mathrm{EG}$ & \\
\hline Bonifatius IV. & $608-615$ & $\mathrm{AD}$ & $\mathrm{BCD}^{\mathrm{B}} \mathrm{EG}$ & \\
\hline Deusdedit (Adeodat) I. & $615-618$ & $\mathrm{AD}$ & $\mathrm{BCD}^{\mathrm{B}} \mathrm{EG}$ & \\
\hline Bonifatius V. & $619-625$ & $\mathrm{AD}$ & $\mathrm{BCD}^{\mathrm{B}} \mathrm{EG}$ & \\
\hline Honorius I. & $625-638$ & $\mathrm{AD}$ & $\mathrm{BCD}^{\mathrm{B}} \mathrm{EG}$ & \\
\hline Severin & 640 & $\mathrm{AD}$ & $\mathrm{BCD}^{\mathrm{B}} \mathrm{EG}$ & \\
\hline Johannes IV. & $640-642$ & $\mathrm{AD}$ & $\mathrm{BCD}^{\mathrm{B}} \mathrm{EG}^{951}$ & \\
\hline Theodor I. & $642-649$ & $\mathrm{AD}$ & $\mathrm{BCD}^{\mathrm{B}} \mathrm{EG}$ & \\
\hline Martin I. & $649-655$ & $\mathrm{AD}$ & $\mathrm{BCD}^{\mathrm{B}} \mathrm{EG}$ & \\
\hline Eugen I. & $654 ;(655)-657$ & $\mathrm{AD}$ & $\mathrm{BCD}^{\mathrm{B}} \mathrm{EG}$ & \\
\hline Vitalian & $657-672$ & $\mathrm{AD}$ & $\mathrm{BCD}^{\mathrm{B}} \mathrm{EG}$ & \\
\hline Adeodat (II.) & $672-676$ & $\mathrm{AD}$ & $\mathrm{BCD}^{\mathrm{B}} \mathrm{EG}$ & \\
\hline Donus & $676-678$ & $\mathrm{AD}$ & $\mathrm{BCD}^{\mathrm{B}} \mathrm{EG}$ & \\
\hline Agatho & $678-68 \mathrm{I}$ & $\mathrm{AD}$ & $\mathrm{BCD}^{\mathrm{B}} \mathrm{EG}$ & \\
\hline Leo II. & $682-683$ & $\mathrm{AD}$ & $\mathrm{BCD}^{\mathrm{B}} \mathrm{EG}$ & \\
\hline Benedikt II. & $684-685$ & $\mathrm{AD}$ & $\mathrm{BCD}^{\mathrm{B}} \mathrm{EG}$ & \\
\hline Johannes V. & $685-686$ & $\mathrm{AD}$ & $\mathrm{BCD}^{\mathrm{B}} \mathrm{EG}$ & \\
\hline$\left(\right.$ Peter $\left.^{*}\right)$ & 686 & & & \\
\hline (Theodor*) & 686 & & & \\
\hline Conon & $686-687$ & $\mathrm{AD}$ & $\mathrm{BCD}^{\mathrm{B}} \mathrm{EG}^{952}$ & \\
\hline (Theodor*) & 687 & & & \\
\hline
\end{tabular}

950 D bezeichnet ab der Vita des Silverus nur die Handschrift aus Tours, Beauvais wird mit $\mathrm{D}^{\mathrm{B}}$ wiedergegeben.

951 Bis hierher hat $\mathrm{C}^{1}$ eher den Text der B-Klasse (BC sind generell sehr ähnlich), ab jetzt deutlich jenen der C-Klasse.

$952 \mathrm{C}^{4}$ hat nun den Text von E und bleibt so bis inklusive Gregor II. 


\begin{tabular}{|c|c|c|c|c|}
\hline Päpste & Pontifikatsdaten & Textgruppe I & Textgruppe 2 & Textgruppe 3 \\
\hline Paschal $^{*}$ & $687-692$ & & & \\
\hline Sergius I. & $687-701$ & $\mathrm{AD}$ & $\mathrm{BCD}^{\mathrm{B}} \mathrm{EG}^{953}$ & \\
\hline Johannes VI. & $701-705$ & ACDG & $\mathrm{BE}$ & \\
\hline Johannes VII. & $705-707$ & ACDG & $\mathrm{BE}$ & \\
\hline Sisinnius & 708 & ACDG & $\mathrm{BE}$ & \\
\hline Konstantin I. & $708-715$ & ACDG & $\mathrm{BE}$ & \\
\hline Gregor II. & $7 \mathrm{I} 5-73 \mathrm{I}$ & ACG & $\mathrm{BDEC}_{4}$ & \\
\hline Gregor III. & $73 \mathrm{I}-74 \mathrm{I}$ & ACEG & $\mathrm{BD}$ & \\
\hline Zacharias & $74 \mathrm{I}-75^{2}$ & ACEG & $\mathrm{BD}$ & \\
\hline Stephan (II.) & $75^{2}$ & & & \\
\hline Stephan II. (III.) & $75^{2}-757$ & $\mathrm{AC}_{\mathrm{I} 2} \mathrm{G}$ & $\mathrm{BD}$ & $\mathrm{C}_{34} \mathrm{E}$ \\
\hline Theophylakt* & 757 & & & \\
\hline Paul I. & $757-767$ & $\mathrm{ACDEG}^{954}$ & B & \\
\hline Konstantin II. ${ }^{*}$ & $767-768$ & & & \\
\hline Philipp* & 768 & & & \\
\hline Stephan III. (IV.) & $768-772$ & $\mathrm{ACEG}_{3} \mathrm{~B}_{2}$ & $\mathrm{~B}_{4}{ }^{955}$ & $\mathrm{~B}_{3} \mathrm{C}_{2}{ }^{956}$ \\
\hline Hadrian I. & $772-795$ & $\mathrm{ABCDEG}^{957}$ & & \\
\hline Leo III. & $795-8 \mathrm{I} 6$ & $\mathrm{CDE}$ & & \\
\hline Stephan IV. (V.) & $8 \mathrm{I} 6-8 \mathrm{I} 7$ & $\mathrm{CDE}$ & & \\
\hline Paschalis I. & $817-824$ & CDE & & \\
\hline Eugen II. & $824-827$ & $\mathrm{CDE}$ & & \\
\hline Valentin & 827 & $\mathrm{CE}^{958}$ & & \\
\hline Gregor IV. & $827-844$ & CDE & & \\
\hline (Johannes*) & 844 & & & \\
\hline Sergius II. & $844-847$ & CDE & $\mathrm{E}_{5}{ }^{959}$ & \\
\hline
\end{tabular}

$953 \mathrm{G}$ wechselt vom Text der E-Gruppe zu jenem von $\mathrm{C}$, steht $\mathrm{C}^{1}$ besonders nahe und bleibt so bis inkl. Stephan II.

954 Nach Stephan II. enden viele Handschriften, vorhanden sind nun nur noch: $\mathrm{A}^{1}, \mathrm{~B}^{234}, \mathrm{C}^{4}, \mathrm{D}$ (Tours), $\mathrm{E}$ und G. $\mathrm{C}^{2}$ ist in ihrer Fortsetzung präsent, deren Text $\mathrm{B}^{3}$ sehr nahe steht.

955 Einzige Handschrift, die die Bischoflisten zum römischen Konzil von 769 überliefert. Nach diesem Leben endet sie.

956 Diese Handschriften brechen noch vor der Bischofsliste in Stephan III. ab.

957 Noch in elf Handschriften vertreten, nämlich: $\mathrm{A}^{1}, \mathrm{~B}^{2}$ (zwei Mss.), C ${ }^{4}, \mathrm{D}, \mathrm{E}^{12456}$ und G, wobei der Text in $\mathrm{E}^{45} \mathrm{G}$ abbricht und in $\mathrm{A}^{1}$ leicht gekürzt ist. Während oder nach Hadrian brechen viele Handschriften ab, es verbleiben darüber hinaus nur noch: $\mathrm{C}^{4}, \mathrm{D}, \mathrm{E}^{12(5) 6}$, insgesamt also 5 Handschriften und ein Fragment in $\mathrm{E}^{5}$.

958 D enthält dieses Leben nicht.

959 Hat eine komplette Umarbeitung dieses Lebens, die aber im Text abbricht. 


\begin{tabular}{|l|l|l|l|l|}
\hline Päpste & Pontifikatsdaten & Textgruppe I & Textgruppe 2 & Textgruppe 3 \\
\hline Leo IV. & $847-855$ & CDE & & \\
\hline Benedikt III. & $855-858$ & $\mathrm{E}^{960}$ & & \\
\hline Anastasius* & 855 & & & \\
\hline Nikolaus I. & $858-867$ & $\mathrm{CE}$ & & \\
\hline Hadrian II. & $867-872$ & $\mathrm{CE}$ & & \\
\hline Johannes VIII. & $872-882$ & & & \\
\hline Marinus I. (Martin II.) & $882-884$ & & & \\
\hline Hadrian III. & $884-885$ & & & \\
\hline Stephan V. (VI.) & $885-89 \mathrm{I}$ & Eг26 & & \\
\hline
\end{tabular}

Die Entwicklung der Textklassen von Gregor II. bis Paul I.

Das Ende des Lebens Konstantins (708-715) stellt am Beginn des achten Jahrhunderts eine bemerkenswerte Zäsur dar, hier ändert sich die Zusammengehörigkeit der Klassen recht massiv. ${ }^{961}$ So wie sich der Befund darstellt, könnte hier einer der wesentlichen Horizonte der handschriftlichen Überlieferung liegen. Diese Hypothese [die in der Literatur bislang nicht so stark vertreten wurde] wird zumindest durch den Befund der wesentlichen Liber Pontificalis Handschrift $A^{1}$ (Lucca) untermauert, wo genau an dieser Stelle der erste Teil des Liber Pontificalis abbricht und der nächste Teil beginnt. ${ }^{962}$

Die Teilung des Textes von BC erfolgt mit dem Leben Gregors II., von dessen Vita zwei verschiedene Versionen erhalten sind, die ältere Version, die bereits von Beda benutzt worden ist und die jüngere, die eine spätere Überarbeitung darstellt. ${ }^{963}$ Es gelten hier folgende zwei Gruppen: ACG und BDE (die die wesentlich größere Zahl der erhaltenen Handschriften für dieses Leben stellen). Nach Gregor II. folgt E jedoch ACG. Beim Leben von Stephan II. spaltet sich diese Gruppe jedoch auf,

$960 \mathrm{C}^{4}$ lässt dieses Leben aus, D bricht nach Leo IV. ab. E noch mit 1, 2 und 6 vertreten.

961 Es handelt sich hierbei nicht um die erste Zäsur, die vorangegangenen Zäsuren sollten in der obigen Tabelle ersichtlich werden. Wichtig ist etwa der Bruch nach der Vita Sergius' I.

962 Interessanterweise hat auch Theodor Mommsen seine Edition bis zu diesem Pontifikat erstellt (vgl. oben, Kap. 1.1), was wohl der Grund ist, warum Raymond Davis seine Übersetzung des Liber Pontificalis in ihrer ursprünglichen Fassung bis zu diesem Punkt durchgeführt hat und den Text erst in zwei späteren Ausgaben fortgeführt hat. Vgl. Davis, BP bzw. ders., LP 8 und ders., LP 9.

963 Die Überarbeitung verfolgte offenbar das Ziel, die Vita schärfer gegen eine mögliche Allianz zwischen dem Kaiser und den Langobarden zu positionieren. Siehe Bougard, Composition 137f., der dazu auch die nachträglichen Veränderungen in der Vita des Zacharias in Beziehung setzt. Da diese aber in einer völlig anderen handschriftlichen Tradition stehen, sind diese Änderungen keinesfalls in einem einzigen Redaktionsschritt erfolgt. 
$\mathrm{AC}^{12} \mathrm{G}$ überliefern die Langobardische Rezension, $\mathrm{C}^{34} \mathrm{E}$ die Originalversion und die Klasse BD überliefert eine angereicherte Originalversion, wie schon im Fall des Lebens von Gregor III. In der handschriftlichen Überlieferung ist vor Stephan II. kein Bruch zu sehen, der Textteil dürfte wohl meist in einem Block mit Gregor II. und III. sowie Zacharias überliefert sein. Besonders letzterer, der Vorgänger Stephans II., wurde möglicherweise für das Verständnis des Lebens Stephans II. durchaus auch als notwendig empfunden, da es einige Stellen im Leben des Zacharias gibt, auf die in der Vita Stephans deutlich Bezug genommen wird - wie weiter unten noch genauer gezeigt werden wird.

Einen deutlichen Bruch in der handschriftlichen Überlieferung, vielleicht den deutlichsten überhaupt in der Überlieferungsgeschichte des Liber Pontificalis, gibt es aber nach dem Leben Stephans, mit dem eine ganze Fülle von Handschriften endet. Hier dürfte der Liber Pontificalis offenbar absichtlich stark verbreitet worden sein, sowohl in Italien als auch im Frankenreich finden sich darauf zahlreiche Hinweise, wobei vor allem bei den Franken nun überhaupt das Interesse an dem Text entstanden sein dürfte. ${ }^{964}$ Wieder zeigt sich dieser Bruch auch im Manuskript aus Lucca, wo zwar dieselben Schreiber am Werk blieben und am selben Text weiterarbeiteten, jedoch in der Handschrift eine deutliche Zäsur gesetzt wurde, indem, was sonst in der Handschrift völlig unüblich ist, die Vita Pauls I. auf einem neuen Blatt angesetzt wurde.

964 Die handschriftliche Überlieferung setzt zwar erst etwa 40-50 Jahre später stark ein, dabei dürfte sich aber in den Kopien sehr oft diese Überlieferungsstufe niederschlagen. Siehe Bougard, Composition 137, der auf die zwei durchaus stark abweichenden Varianten in LP I, 407f. (Kap. 22 nach Vignoli) hinweist. 


\section{Register}

\section{Personen, Orte und Sachen}

846, Angriff auf Rom 63, 184, 244, 250-254, 257, 259, 262, 270, 276

acheropsita, Ikone 155

Adelchis, Mit-König (Langobarden) 123f., 127, 132, 180, 192, 208-216

Adelchis, princeps von Benevent 254

Adelperga, Ehefrau Arichis II., Tochter Desiderius' 69

Adeodatus, Papst (615-618) 99

adventus, Zeremonie 156, $236 \mathrm{f}$.

Agilolfinger 221

Agilulf, König (Langobarden) 147, 195

Aistulf, König (Langobarden) 33f., 36, 107, 149, 151-153, 155-164, 167, 180, 190, 204, 213f., 233-235, 265, 275

al-Walīd ibn Muslim al-Dimashqī, arabischer Autor 248-250

Alarich, Gotenkönig 258

Allo, dux von Tuszien 133, 198, 203, $205 f$.

Alpen (auch als Grenze Italiens) 28, 160, 233, 261, 304

Alt-St. Peter 63, 99, 148, 182, 193, 253

Alterität, Stufen (Niveaus) der, Grade des Fremdseins/Anders-seins 48-59, 277-280

Amalfi 253-257, 261f.

Ambrosius, primicerius notariorum 30f., 148

Ambrosius Autpertus, Abt von San Vincenzo al

Volturno 237

Amelia (Ameria) 146f.

Anastasius II., Papst (496-498) 303

Anastasius Bibliothecarius 16f., 25f., 81, $130 \mathrm{f}$.

Anastasius, missus 774/5 198-203

Anathema, Kirchenbann, Exkommunikation 25, 82, 118, 180f., 238

Ancona 166, s. auch Pentapolis

Angelsachsen, England 27, 105, 226

Annales Bertiniani, Prudentius, Hinkmar 26, $252 \mathrm{f}$.
Antoninus, Ebf. von Grado $108 \mathrm{f}$.

Aquino 232

Aquitanien 66, 171, 222-226, 229, $245 \mathrm{f}$.

Arichis II., $d u x /$ princeps von Benevent 69, 124f., 132, 167, 208-212, 216, 275

Armenier, armenische Mönche, Rom 57f., 79, 91, $97 f$.

Arnulf von Kärnten, Kaiser (Frankenreich) 255

Autchar, karolingischer dux 191f.

Awaren 268

Bari 244, 250, 254f., $257 \mathrm{f}$.

Basilius, dux von Rom 84f., 103

Basilius, H1., Regel des Basilius 97

Bayern 160, 221, 226, 255

Beda (Venerabilis), inkl. Werke 27, 55, 226, 268, 270, 313

Benedikt II., Papst (683/684-685) 92

Benedikt III., Papst (855-858) 26, 254, 305

Benedikt, Bruder Sergius II. 251

Benedikt von Monte Soratte, Chronik 253

Benevent, langob. Dukat/Prinzipat 75, 81, 112, 132, 140-146, 152, 162, 165-167, 182, 192, 208-214, 238, 243, 254, 261f., 275, 280

Bertrada, Mutter Karls des Großen 173, 182f., 187f., 239

Homi K. Bhabha 278

Francesco Bianchini (Hg. des LP) 20, 306

Bibel 9, 49, 176, 178, 267f., 271

Altes Testament 177

Buch Ezechiel (Predigt Gregorgs des Großen) $264 f$.

Buch Hiob $264 f$.

2. Brief an die Korinther (Paulus) 11, 174, 176

Blera 146f.

Bologna 166

Bomarzo $146 f$. 
Bonifatius (Winfried), H1. 14, 49, 105, 221, 225f., 232, 262

Byzanz, Byzantinisches Reich s. Oströmisches Reich, s. Griechen

Capua 254

Centumcellae (Civitavecchia) 50, 133f., 205f., 248

Cesena 147, 149f.,

Cherson, Krimregion 78

Chiusi, langob. Dukat 142, $208 \mathrm{f}$.

Christophorus, primicerius notariorum 25, 96, 115, 128f., 169-171, 173, 179, 182, 184-187, 235

Chrodegang, Ebf. von Metz 29

Chronica Sancti Benedicti Cassinensis $252 \mathrm{f}$.

Chronicon Salernitanum 250, 254, 258

Città di Castello 209f.

Clausula de unctione Pippini 66, 240

clusae, Klausen, befestigte Alpentäler 160

Codex epistolaris Carolinus (CC), Sammlung oder

Teile davon 13, 38-43, 107-110, 116, 119, 122, 131, 162, 165, 169f., 172-182, 179 (Anm. 624),

181, 188f., 197-213, 218, 227, 237, $239 f$.

CC ms Faksimile 39f., 179, 202

Briefe des CC

CC 1 144, 230, 233

CC 2 144-146, 230, 233

CC 3 231f., 235

CC 4163

CC 5 66, 163

CC 8162

CC 10 66, 100

CC 11 109-111, 122

CC 12115

CC 13165

CC 15 42, 108, 188

CC 16166

CC 17 112f., 122, 165-168

CC 19169

CC 22 168f.

CC 24122

CC 30 111, 122

CC 32 111, 122

CC 36221

CC 37122

CC38 111, 122

CC 44172
CC 45 11, 116f., 172-182, 184-186, 188, 216, 238f., 269, 274, 280

CC 47 182f., 240

CC 48 182f., 187f., 216, $239 f$.

CC 49188

CC 50 188, 198-202

CC 51 188, 198-202

CC 56 123, 209

CC 57 122-124, 126f., 129, 196, 207-209

CC 58 131, $209 f$.

CC 59 122, 127, 132-134, 204-207, $247 f$.

CC 60131

CC 63 122, 124, 127

CC 64 122, 124-126, $210 f$.

CC 65211

CC 66237

CC 67237

CC 70131

CC 72131

CC 78211

CC 80 122, 132, 212f.

CC 82 122, 131f., 213

CC 83 122, $131 f$.

CC 84 122, 125, 132, 213

CC 98170

CC 99 122, 170

Codex Justinianus/Corpus Iuris Civilis $76 \mathrm{f}$.

Codex Theodosianus 76

Collectio Britannica 13, 44f., 266

Comacchio 190

Conon, Papst (686-687), cononianisches Fragment $17,92,308$

Defensor, röm. Amt 62f.,

Desiderius, König (Langobarden) 63, 69, 112f., 115f., 120, 123, 130, 132, 157, 164-174, 180, 182-193, 204, 208, 210-213, 215-217, 239, 274f., 305

Diakon, archidiaconus, Rom, allgemein 61-63, 170

Diskurs, Diskusanalyse (Michel Foucault) 49, 51-53, 55, 57, 162, 173, 175, 181f., 243, 245

Dionysius Exiguus, Gelehrter, Rom 231,

Droctegang, Abt von Jumièges 163

Louis Duchesne (Hg. des LP) 17, 19-21, 26, 32f., 35, 37f., 154, 194, 251, 302, 304f., $307 f$.

$d u x$, Dukat von Rom 13, 64f., 67, 69, 76, 85, 94, 
103, 114, 120, 126, 141-143, 146f., 155, 163 , $207,233,244,273$

ecclesia, Kirche, Rom (Institution) 29, 50, 52, 61, 63, 65f., 82f., 92, 95, 110, 144f., 147, 149, 178, 185f., 193, 209f., 230-232, 238, 264, 267, 269-271, 276

ecclesia, christliche Ökumene 69, 111, 123

Ecloga, Gesetzbuch Leons III. 77

Ekthesis, Mandat Herakleios' $77 \mathrm{f}$.

Einhard, inkl. Vita Karoli Magni 31, 42, 172

Eirene (Irene) Kaiserin (Ostrom) 88, 130f., 138, 216

Erchempert, Ystoriola 254, 258

Ethnographie, antike 49, 220, 260

Eudo (Odo), dux/princeps von Aquitanien 66, 223-226, 228f., $245 \mathrm{f}$.

Eugenius I., Papst (654-657) 78

Eutychius, patricius, Exarch 85, 103, $141 \mathrm{f}$.

Extimität 50f., 217, 272, 277

excellentissimus filius (Anrede) 40, 183, 188, 232, 239f., 274

Faenza 190

Farnese Codex, Liber Pontificalis ( $\left.\mathrm{E}^{5}\right)$ 20, 251f., 306

Feindbild 150, 159, 178, 260, 276

Felix IV., Papst (526-530), felizinaisches Fragment 17, 307

Ferrara 190

Franken, Frankenreich (allgemein) 11, 13f., 16, 30-32, 36, 41, 49, 58, 66, 75, 100, 102, 109-113, $115,117,122-124,126,131,134,136,145,149$, 153, 155, 157-166, 169, 171f., 175, 177-181, 185f., 191, 193f., 197, 199f., 203f., 218-243, 245f., 253, 255f., 258, 261, 265, 269, 272, 275, 277, 280f., 304, 314

Fulrad, Abt von St. Denis 164, $234 f$.

Gaeta 213, 253, 255

Garigliano (Fluss), sarazenische Siedlung 255

Gausfrid (Gaidifridus) 198-204, $206 f$.

Gennadius, Exarch von Africa 264

Georgius, Abt des Klosters ad Aquas salvias, Rom 79, 97

Gerberga, Ehefrau Karlmanns des Jüngeren 172, $191 f$.
Germanos, Patriarch von Konstantinopel 87

Gerold, Graf 268

Gisela, Schwester Karls des Großen 117, $179 f$.

Graecia Magna, Süditalien 68

Graikoi 71f., 79f., 135

Gratian, Decretum Gartiani 44, 266

Gregor I. (der Große), Papst (590-604) 18, 22, 44, 46, 62, 105, 108, 139f., 147, 158f., 177, 206, $264 f$.

Gregor II., Papst (715-731) 13, 23, 26-28, 65f., 80f., 84-87, 92, 94, 99, 102-104, 108, 119, 140-143, 147, 154f., 158f., 214, 219-226, 228f., 245f., 259, 270, 273f., 303, 305, 308, 313

Gregor III., Papst (731-741) 26f., 29, 40, 87, 99, 103-106, 108f., 114, 119, 140, 143-146, 150f., 155, 158f., 160, 194f., 214, 226f., 230f., 233, 246, 274, 314

Gregor IV., Papst (827-844) 126, 250, 259

Gregor VII., Papst (1073-1085) 21, 44

Gregorios, ksl. Gesandter 166

Gregorius, $d u x$ von Rom 170

Griechen (Greci, Romaioi) 13, 58f., 68-138, 140, 154, 204f., 208, 211, 213, 216-219, 230, 243, 247f., 257f., 260, 272f., 275, 277, 280

Griechische Klöster 88f. (Neapel), 95-100, 108, 130 (Rom)

Griechische Liturgie 90, $96 \mathrm{f}$.

Griechische Päpste 69, 91-94, 96, 98, 108, $145 f$.

Griechische Schrift 88f.

Griechische Sprache, Kultursprache, Bilingualität 71, 73f., 79, 88-90, 97f., 104f., 107, 115, 122

Grimoald, princeps von Benevent 132, 212

Wilhelm Gundlach (Hg. Codex Carolinus) 38-40, 111, 112 (Anm. 379), 122 (Anm. 415), 131 (Anm. 449), 172 (Anm. 600), 179 (Anm. 624), 199, 201, 204

Haartracht, langobardisch/römisch 139, 193-197, 274

Hadrian I., Papst (772-795) 13, 24f., 40f., 43f., $62,64,88,107,116,118-136,138,154,165$, 170, 183-213, 216f., 227, 235-237, 241, 247f., 273-275, 277, 280, 303, 306, 308

Hadrian II., Papst (867-872) 21, 26, 254, 256f., 259, 269, 305

Hadrianum, Brief Hadrians I. 131

Häretiker, Häresie 111, 113f., 121, 177, 181, 216, 238, 269, 272, 274, 280 
Heiden, Heidentum, heidnisches Verhalten 72, 74, 139, 162f., 245, 252, 259, 267, 269f., 272, 276, 280

Heirat, Heiratsallianz, Ehe, inkl. fremde Frauen 116f., 172-174, 177-181, 188, 238, 280

Hellenen, heidnische altgriechische Kultur 68, 71-74

Herakleios, Kaiser (Ostrom) 74, 77

Hieronymus, H1. 16

Hildebrand, dux von Spoleto 124, 193f., 196f., 208, 277

Hildeprand, König (Langobarden) 144f., $150 f$. Hinkmar, Ebf. von Reims, inkl. Werke 26, 268

Honorius I., Papst (625-638) 18, 77, 82

Ignatios, Patriarch von Konstantinopel 101

Ikonoklasmus (Bilderstreit) 78, 84, 86f., 99, 102f., 108-111, 113, 117f., 125f., 128, 131, 142, 275

Illyricum, Provinz 86, 110

Imola 166

Isidor, Bf. von Sevilla 49, 176, 223, 245

Ivo von Chartres, Decretum, Panormia 44, 266

Philipp Jaffé (1819-1870) 39, 45 (Anm. 131), 201

Jakut (Yāḳūt ibn 'Abdallāh) 248f.

Johannes VI., Papst (701-705) 141

Johannes VII., Papst (705-707) 154

Johannes VIII., Papst (872-882) 13, 44-47, 254-257, 259, 261-263, 267-271, 276

Johannes X., Papst (914-928) 255

Johannes, Bruder Stephans III. 189

Johannes, Berater in Spoleto $112 \mathrm{f}$.

Johannes, ksl. Gesandter 156

Johannes, Abt des Sabasklosters bei Jerusalem 79

Johannes Aventinus, frühneuzeitlicher Autor 182

Johannes Diaconus, gen. Hymmonides 22, 26

Johannes Diaconus, Neapel 253

Johannes Lurion, Subdiakon 84f., 103

Johannes Lydos 76

Jordannes, chartularius 84, 103

Justinian I., Kaiser (Ostrom) 64, 76

Justinian II., Kaiser (Ostrom) 73, 82, 84, 94

Kanones, kanonisches Recht, Kanonistik 44f., 82f., 117, 170, 231, 254, 266

Kaiserkrönung, 800 136, 241,

Kalabrien 75, 92, 106, 110, 212, 261
Kampania, Region in Süditalien, Eparchie 80, $142 f$.

Kanzlei (scrinium, Papst) 23-26, 43, 47, 52, 62f., 66, 129, 134, 173, 218

Karl I. (der Große), König/Kaiser (Frankenreich) 11, 25, 40f., 66, 116, 120, 122-125, 131-134, 136, 138, 171f., 178, 179-184, 187-189, 191, 193f., 196-202, 204-213, 221, 233, 235-242, 247f., 258, 275

Karl II. (der Kahle), König/Kaiser (Frankenreich) 267

Karl III. (der Dicke), König/Kaiser (Frankenreich) 75, 257, 269

Karl Martell, Hausmeier (Frankenreich) 40, 143-146, 158f., 225f., 230, 232f., 246

Karlmann der Ältere, Hausmeier (Frankenreich) $157,232 \mathrm{f}$.

Karlmann der Jüngere, König (Frankenreich) 11, 66, 116, 171f., 179-183, 186f., 191f., 233, 235, 238-240

Karlmann, König (Italien) 255

Karolinger (allgemein) 13f., 25, 29, 32, 41, 109, 116f., 124, 145, 149, 160, 164, 170, 173, 177f., $180,207,218,225,227,230-232,235 f ., 238$, 240-243, 269, 275, 280

Kilikier, kilikische Mönche, Rom 79, $97 \mathrm{f}$.

Kleinasien, Kernland des oströmsichen Reichs 68f., 74, 80, 83, 86, 89f., 92, 95, 100, 108, 128f., 137

Konstans II., Kaiser (Ostrom) 77, 80f.

Konstantin I., Papst (708-715) 19, 83f., 94, 147, 154

Konstantin II., nicht anerkannter Papst (767-768) 31, 40, 92, 96, 99, 115, 122, 170f., 235, 302, 313

Konstantin I. (der Große), Kaiser 63

Konstantin IV., Kaiser (Ostrom) 81

Konstantin V., Kaiser (Ostrom) 86f., 109f., 113, 117, 120f., 126f., 138, 157, $179 f$.

Konstantin VI., Kaiser (Ostrom) 130, 216

Konstantin VII. Porphyrogennetos, Kaiser (Ostrom) 106,

Konstantinopel (Byzanz, regia urbs) 24, 69, 71, 73, 78, 80-88, 90f., 94, 104, 108-111, 120f., 123, 129-132, 134, 136, 138, 140, 147, 149, 159, 161, 208, 218f., 228, 245f., 254, 257, 275

Konzil von Hiereia (754) 87, 109, 111, 114f., 123, $128,130,275$ 
Konzil von Nicäa II (VII. ökumenisches Konzil, 787) 87f., 126, $130 f$.

Konzil von Konstantinopel (VI. Ökumenisches Konzil, 680/681) 81f.

Konzil (Synode) von Rom (Lateran, 649) 77-79, 91, 97

Konzil (Synode) von Rom (769) 40, 117f., 120, 128f., 235, 303f.

Kreuzzüge, Kreuzzugsrhetorik 268f., 271, 276

Jacques Lacan 48, 50

Lambert von St. Omer, Liber Floridus 20, 303, 307

Langobarden (allgemein) 11, 13, 26, 29, 32-38, 49, 58, 85, 103, 109f., 112f., 115, 121, 123, 126, 133f., 139-220, 227, 229-231, 233f., 238, 241, 243, 247f., 258, 261, 264, 269, 273-281, 313

Lateran, Papstresidenz, Patriarchat, Verwaltung (Ort) 25f., 30, 63, 65, 82f., 85, 114, 119, 137, 156, 164, 242

Laterankonzil s. Konzil v. Rom, 649

Laurentius, nicht anerkannter Papst (498) 17

Leo III., Papst (795-817) 31, 76, 96, 99, 135f., 154, 242, 259, 309

Leo IV., Papst (847-855) 25, 45, 99, 154, 250, 253f., 263, 266-270, 276, 305

Leon III., Kaiser (Ostrom) 76, 80f., 83f., 103, 109, 142f., 228f., 245

Leon IV., Kaiser (Ostrom) 116f., 121, 126f., $179 f$.

Leo, Ebf. von Ravenna 184

Lepra, Lepröse 174, 177, s. auch Häresie

Liber Diurnus 65, 115

Liber Pontificalis (LP, Gesamtes Werk oder größere Abschnitte) 12-14, 16-38, 41-43, 45, 52, 56, 59, 65, 78, 93, 102-109, 138, 158, 192, 226f., 233, 252, 254, 277, 281, 302-314; der LP wird im gesamten Buch sehr häufig zitiert, Information $z u$ den jeweiligen Viten findet sich bei den Stellen des betreffenden Papstes

Varianten des LP im achten Jahrhundert

„Originalversion“ (C $\left.{ }^{34} \mathrm{E}\right)$ 28-38, 154, 302-314

Fränkische Rezension (BD) 28-32, 143, 194f., 226, 230f., 302-314

Langobardische Rezension $\left(\mathrm{AC}^{12} \mathrm{G}\right) 16$ (Anm. 4), 27 (Anm. 55), 28, 32-38, 157-160, 215, 302-314

Vita Gregors II., zwei Versionen 26f., 223, 226,
$313 f$.

Liberius, Papst (352-366), liberianischer Katalog 17

Liutprand, König (Langobarden) 26f., 66, 85, 141-152, 163, 194, 214, 217, 227, 230, 233, 274

Liutprand, $d u x$ von Benevent 112f., 165

Lothar I., Kaiser (Frankenreich) 252,

Lucca, Toskana 34, 199, 202-204

Ludwig II., Kaiser (Frankenreich, Italien) 25, 252, 254, 262f., 266, 269

Ludwig II., der Deutsche, König (Ostfrankenreich) 255, 259, 269

Ludwig II., der Stammler, König (Westfrankenreich) 267

mancus, Münze, Italien $255 \mathrm{f}$.

Marinus, ksl. spatharius 84f., 103

Martin I., Papst (649-653) 63, 77f., 80f., 83, 87

Maurikios, Kaiser (Ostrom) 69

Maximos Homologetes (Confessor) 72, 78-80, 88,95

Methodios, Patriarch von Konstantinopel $99 \mathrm{f}$.

Michael III., Kaiser (Ostrom) 256

Michael, Ebf. von Ravenna 184

Mittelitalien 61, 65-69, 75, 83, 90, 104, 107, 114, $123,125,127,143,145,152,155,158,160,188$, 193, 199f., 204, 214-216, 218, 233, 252, 270, 278, 280

Theodor Mommsen 17-20, 302, 313

Monotheletismus 77f., 80-82, 84, 95

Monte Cassino 45f., 232, 254

Monte Gargano, Michaels-Heiligtum 212

Monteverdi, Kloster 203

Monumenta Germaniae Historica (MGH) 19, 38-40, 44-45, 112 (Anm. 379), 122, 302

Narbonne, Narbonensis 147, 222, 246

Neapel 75, 88f., 97, 112, 125, 141, 166, 210, 253, 255f., 261, 303

nefandissimi 111, 125, 139, 259

Nikolaus I., Papst (858-867) 14, 21f., 25f., 44, 254, 256f., 259, 266

Nordafrika, römisches/arabisches Afrika 69, 79f., 250, 253, 258, 260, 264

Norditalien, Poebene geogr. 120, 153, 172, 220, 261, s. auch Langobarden

Olympios, Exarch 78 
Orte, Ort im Dukat von Rom $146 f$.

Osimo 166

Ostia 49, 248, 250, 253, 276

Oströmisches Reich, Oströmer (Byzantinisches Reich, „Byzanz“) 14, 59, 70-72, 74, 89, 98, 101, 113f., 123-125, 127, 132, 136f., 143, 155, 166, 168, 179f., 209f., 212, 214f., 220, 227f., 242, 244, 254-258, 260f., 268f., 272f., 277f., s. auch Griechen

Oswald, H1. 268

Othering 48-57, 101f., 115, 122, 126, 136f., 140, 145, 150, 162f., 169, 175, 182, 185, 192, 195f., $213,217-219,229,234,238,243,245,272-281$

Otranto $112,165-167$

Pantheon (Sancta Maria ad Marthyres) 30, 81

Pardus, Abt von S. Saba, Rom 130

Paschalis I., Papst (817-824) 43, 99

patricius Romanorum-Titel 66f., 191, $240 f$.

Patriarchat von Konstantinopel, allgemein 86, 110, 122, 257, 306

Patrologia Latine (Hg. Jacques-Paul Migne) 16, 20

Paul I., Papst (757-767) 31, 40, 53, 87, 92, 96-98, 100, 107, 109, 111-116, 119, 122f., 126, 137f., 155, 164-170, 178f., 181, 184, 188, 191, 195, 209, 215f., 221, 227, 235, 273, 275, 313f.

Paul III., Papst (1534-1549) 49

Paulos, Patriarch v. Konstantinopel 80

Paulus, patricius und Exarch 85, 103

Paulus Afiarta, päpstlicher cubicularius 128f., 182f., 184f., 189-192, 278

Paulus Diaconus 69, 139, 146-148, 195, 226

Pavia (Ticinum), inkl. Frieden von 754 und 756 und Eroberung 774 36, 41, 128, 138, 148f., 152f., 157, 161f., 169, 178, 187, 196f., 201, 214 , 220, 233

peculiaris populus 52, 59, 61, 65f., 114, 144, 207, 216, 230, 238, 241, 243, 262, 277-279

Pentapolis, Region 65, 104, 151, 165, 167f., 213

Peredeo, Bf. von Lucca $203 f$.

Petronilla, H1. 29

Peter- und Pauls-Fest 67, 148-150, 254

Petrus, Apostel 11, 29, 66f., 82, 109f., 120, 123, $125,137,144,148,150,152,163,167,181$, 185f., 193f., 198, 200, 202, 208, 210, 212, 221, 230, 232, 239, 242, 251, 254, 266, 269, 278, 308
Petrus, Abt von S. Saba, Rom 130

Petrus, Erzpriester Roms 130

Philipp, Abt von St. Vitus, nicht anerkannter Papst (768) 156, 171

Philippikos Bardanes, Kaiser (Ostrom) 84

Phokas, Kaiser (Ostrom) 74

Photios, Patriarch von Konstantinopel 90, 101, 254, $256 f$.

Pippin III./I., Hausmeier, König (Frankenreich) $30,34,40,66,109-111,115,117,122,157-159$ 162f., 166f., 170f., 178-180, 191, 193, 221, 227, 231-235, 240f., 246, 265, 275

Poitiers, Schlacht von 226, 246

Portus (Porto), röm. Hafen 50, 248, 250, 276

Postkoloniale Theorie 52-55, 68-70, 217

Potho, Abt von S. Vincenzo al Volturno 237 prefectus urbis 64

Priester (presbyter), Rom 61-63

primicerius notariorum, röm. Amt 52, $62 \mathrm{f}$.

princeps, Titel 209, 223-225, 229

Prokop von Caesarea 220

Pseudo-Liutprand 251f., 307

Pseudo-Methodius, Revelationes 72-74, 163

Pulchar von Amalfi 262

Pyrrhos, Patriarch v. Konstantinopel 80

Quinisextum (Trullanische Synode, 691/692) $82 f$.

Ratchis, König (Langobarden) 145, 150-153, 155, 160, 214, 233

Ravenna, Stadt/Exarchat 64f., 75, 82f., 86, 95, 104, 107, 110, 112f., 129, 141, 143, 147-153, 156f., 159, 164, 166, 182, 184, 187, 190f., 194, 199, 214, 218, 233, 240, 242, 274, 279

Regensburg, karolingische Pfalz 41f., 188, 204

Reginbald (Raginald), $d u x$ von Chiusi $208 \mathrm{f}$.

Register, päpstliche, Frühmittelalter 13, 30, 44-47, 154, 254f., 262

Relatio motionis 79,88

res publica 52, 61, 65, 69, 254, 267

Romaioi 71-74, 90, 97, 114

Romani, Römer 11f., 58f., 64, 68, 70f., 74, 79, 90, 98, 100, 103, 114, 127, 132f., 135f., 138, 141143, 150, 158, 161f., 164, 185, 194f., 205-207, 217f., 220, 229, 235, 238, 242f., 247, 251, 264f., 273-275, 277 
Romuald II., $d u x$ von Benevent 141

Romuald, Sohn Arichis II. 211

Rotcaus, $d u x$ von Friaul (Langobarde) 124, $208 f$.

saccellarius, röm. Amt 61

Edward Said 52-54, 68

Salerno, langob. Prinzipat 250, 254, 262

Sameing 55-57, 143, 153, 194, 196f., 204, 207, 216, 238, 243, 275, $277 \mathrm{f}$.

Santa Severina (Siberena) 106

S. Cecilia, Rom 116

S. Chrysogonus, Kloster 99

S. Giovanni in Laterano (auch S. Salvatore, Lateransbasilika, Constantiniana) 63, 78, 156,

S. Maria Maggiore 30, 156

S. Paolo fuori le mura 253

S. Saba, griech. Kloster, Rom 96, 130

St. Peter, Peterskirche s. Alt-St. Peter

St. Stephan und Cassius, Kloster, Rom 99

Sarazenen (Ismaeliten, Hagarenen, Araber, Berber, Muslime) 12, 14, 49, 55, 58, 78, 84, 126, 132, 134, 146, 163, 205-207, 220, 223-226, 243, 244-272, 276, 278, $280 f$.

schola, Lateran 114

scholae für Auswärtige, Rom 226

Sergios, Patriarch v. Konstantinopel 80

Sergius I., Papst (687-701) 82f., 92, 154,

Sergius II., Papst (844-846) 184, 250f., 265f., 307, 313

Sergius, secundicerius notariorum 96, 115, 129, 170f., 182, 184-186, 189, 235

Silvester I., Papst (314-335) 154

Sizilien 75, 78, 85f., 89, 92, 99, 106, 110, 112, 116, 125, 210f., 250, 258

Sklaven, Sklavenhandel 68, 132-134, 205-207, $247 f$.

Spanien (Hispania), westgotisch, sarazenisch 102, 245, 258,

Gayatri Spivak 52, 68

Spoleto, langob./fränk. Dukat 124, 141-147, 152, 162, 165, 167f., 170, 185, 192-194, 196f., 208, 211, 214, 216, 218, 237, 255

spongia, Schwammbrote 66, 223, $245 \mathrm{f}$.

Stephan (II.), Papstelekt (752) 148, $155 f$.

Stephan II., Papst (752-757) 11, 23f., 26f., 28-38, 40, 53, 64-67, 86f., 92, 98, 107, 109-111, 113f., 117, 119, 122f., 126, 136f., 146, 148f., 151,
153-169, 179, 181, 185, 190f., 194f., 197, 204, 209, 215, 217, 227, 233-235, 240, 265, 273-275, 277, 304-306, 313f.

Stephan III., Papst (768-772) 11, 25, 29, 40, 63, 92, 99, 105, 115-120, 127f., 138, 148, 156, 165, 169-190, 192, 199, 209, 216, 227, 235, 238-240, 274, 303-305

Stephan V., Papst (885-891) 12, 16, 21f., 306

Subdiakon, Rom 62, 170

Süditalien 38, 68f., 75, 78, 106, 124, 166, 211, 216f., 244, 249, 252-258, 260-264, 266, 270, 276, 280

Sutri, Ort im Norden des Dukats von Rom 141 Symmachus, Papst (498-514) 17

Synode, Rom 731 (Gregor III.) 87, 108

Synode, Rom 769, s. Konzil von Rom (769)

Synode, Rom 853 (gegen Anastasius) 26

Syrer, Syrien 58f., 73f., 80, 92-95, 98, 100, 104, 106

Tarasios, Patriarch von Konstantinopel 130f., 138

Tassilo III., dux der Bayern 221

Terni, inkl. Friede von 147-149, 151

Terracina 124f., 127, 132, 138, 210, 261

Thalassios, Abt von St. Renati, Rom 79, 97

Theodelinda, König der Langobarden 140, 195

Theodo, dux der Bayern 221

Theodor I., Papst (642-648) 77, 91

Theodor von Tarsos, H1. 105

Theodor, Abt eines afrikanischen Saba-Klosters 79

Theodotus, dux, primicerius defensorum u. notariorum 62, 118f., 138

Theophylakt, archidiaconus 164

Theophylakten (Tusculaner), mächtige Familie in Rom um 900264

Theudebert, Merowinger, König der Franken 220

Ticinum, s. Pavia

Tochter des Desiderius, anonym („Desiderata“) 116, 172, 174, 180, 188, 191, 238

Toto von Nepi 115f., 165, 170,

Toulouse, Schlacht von 66, 222, 224f., 228, 246

Transamund II., dux von Spoleto 146f., 217, 274

Tricliniumsmosaik Leos III., Lateran, Rom 242

Trullanische Synode (Konzil) s. Quinisextum

Tuszien, langob. Dukat 134, 142, 198-207, 247

Tuszien, römischer Teil der Region 170 
Typos, Mandat Konstans II. 77f.

Tzvetan Todorov 48f.

Vestararium, vestararius (Rom) 24-26, 30, 154

Venedig 67, 75

Vertragsbruch, Meineid, periurium der Langobarden 151, 161, 168f., 185f., 210

Giovanni Vignoli (Hg. des LP) 16, 20, 155, 314

Waifer, princeps von Salerno 250, 262

Waldipert, langobardischer Priester 171, 235
Willibert, Ebf. von Köln 38f.

Zacharias, Papst (741-752) 26f., 40, 64-66, 92, 98f., 105-107, 109, 113f., 119, 134, 145-155, 158-160, 214, 222, 226f., 231-233, 235, 274, 279, 313f.

Zacharias, ksl. spatharius $82 \mathrm{f}$.

Weitere Päpste mit ibren Pontifikatsdaten finden sich auf S. 93 (7./8. Jh.) und im Appendix auf S. 309-313 (1.-9.Jh).

\section{Register der zitierten mittelalterlichen Handschriften}

Bern, Burgerbibliothek 408 35, 305

Brüssel, Bibliotheque royal de Belgique 8380304

Florenz, Biblioteca Medicea Laurenziana, Ms LXVI, 35307

Köln, Dombibliothek 164 303f.

Laon, Codex 342303

Leiden, Universitätsbibliothek, Codex Vossianus Lat. Q. 41 117, 304

Leiden, Universitätsbibliothek, Codex Vossianus Lat. Q. 60 32, 38, 226, 304

London, British Library, Ms. Add. 8873 45, 266

Lucca, Bibiloteca Capitolare, Codex 490 32, 302f., $313 f$.

Modena, Estensis VI.F.5 306

Neapel, Biblioteca Nationale Vittorio Emanuele III., IV.A.8 303

Paris, Bibliothèque Nationale de France, Codex grec. 1470 99f.

Paris, Bibliothèque Nationale de France, Codex grec. $147699 f$.

Paris, Bibliothèque Nationale de France, lat. 2769 305f., 308
Paris, Bibliothèque Nationale de France, lat. 5140 305

Paris, Bibliothèque Nationale de France, lat. 5143 306

Paris, Bibliothèque Nationale de France, lat. 5516 305f., 308

Paris, Bibliothèque Nationale de France, lat. 13729303

Rom, Farnese Codex (verloren) 20, 251f., 306

Vatikan, Biblioteca Apostolica, Vat. lat. 3761307

Vatikan, Biblioteca Apostolica, Vat. lat. 3764 20, 306

Vatikan, Archivio Segreto, Registra Vaticana 1 $45 f$.

Wien, Österreichische Nationalbibliothek, Codex lat. 449 38-40, 133, 179, 201f., 212

Wien, Österreichische Nationalbibliothek, Codex lat. 473 31f., 304

Wolfenbüttel, Herzog August Bibliothek, Codex 10.11 Augusteus $4^{\circ} 33,305$ 
$\frac{5}{10}$
$\frac{1}{0}$
0

PAPSTTUM IM

MITTELALTERLICHEN EUROPA

HERAUSGEGEBEN VON

HARALD MÜLLER UND JOCHEN JOHRENDT

BD.1 | HARALD MÜLLER,

BRIGITTE HOTZ (HG.)

\section{GEGENPÄPSTE}

EIN UNERWÜNSCHTES

MITTELALTERLICHES PHÄNOMEN

2012. 468 S. 4 FARB. ABB. GB.

ISBN 978-3-412-20953-7

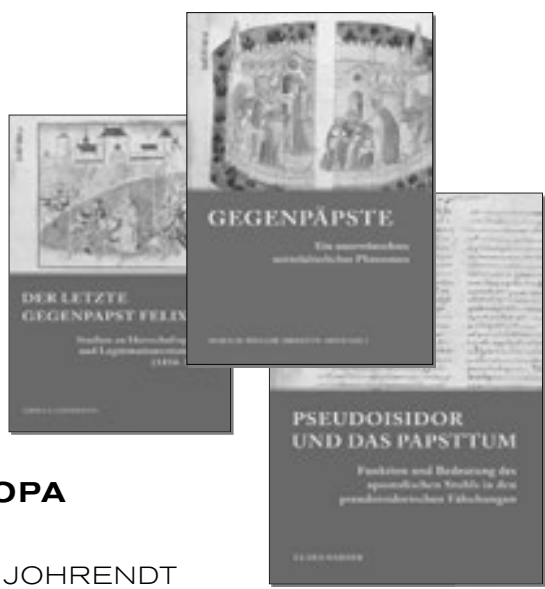

BD. 3 | URSULA GIESSMANN

DER LETZTE GEGENPAPST: FELIX V

STUDIEN ZU HERRSCHAFTSPRAXIS UND LEGITIMATIONSSTRATEGIEN (1434-1451)

2014. CA. 432 S. CA. 5 S/W-ABB. GB

ISBN 978-3-412-22359-5

BD. 2 | CLARA HARDER

PSEUDOISIDOR UND DAS PAPSTTUM

FUNKTION UND BEDEUTUNG DES

APOSTOLISCHEN STUHLS IN DEN

PSEUDOISIDORISCHEN FÄLSCHUNGEN

2014. 290 S. GB.

ISBN 978-3-412-22338-O

BÖHLAU VERLAG, URSULAPLATZ I, D-50668 KÖLN, T: + 49 22I 9I3 90-O INFO@BOEHLAU-VERLAG.COM, WWW.BOEHLAU-VERLAG.COM | WIEN KÖLN WEIMAR 

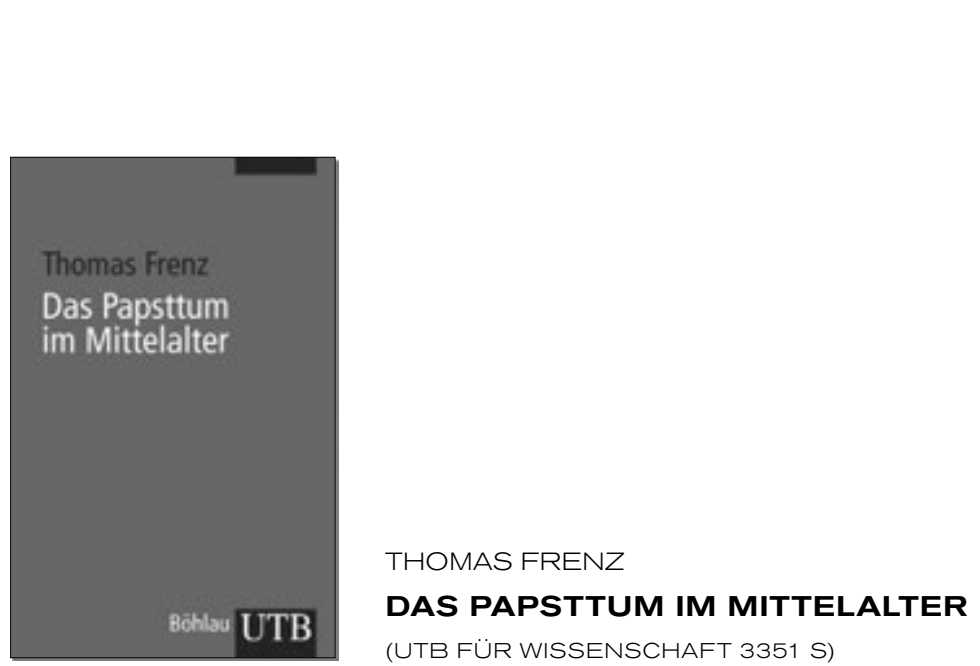

Für die mittelalterliche Geschichte zählt die Geschichte des Papsttums zu den zentralen Inhalten in Studium und Lehre. Dieses Studienbuch vermittelt eine kompakte und anschauliche Übersicht. Auf eine Darstellung der zeitlichen Abläufe folgen vier systematisch gegliederte Teile, in denen nicht nur Standardthemen wie beispielsweise das Verhältnis zwischen Papst und Kaiser behandelt werden, sondern die auch Aspekte wie die Kriegstätigkeit des Papstes und seine Rolle als Kunstmäzen darstellen.

2010. 251 S. MIT 32 S/W-ABB. BR. $120 \times 185$ MM.

ISBN 978-3-8252-3351-8 (BUCH) | 978-3-8385-3351-3 (ЕВOOK)

„Frenz hat eine Geschichte des Papsttums im Mittelalter in Handbuchform verfasst, auf die insbesondere Studierende dankbar zurückgreifen werden $[\ldots$. . Die wahren Stärken des Buches sind [...] in den strukturgeschichtlichen Kapiteln [...] zu finden, die einen überaus gelungenen Überblick über zahlreiche Aspekte des päpstlichen Selbstverständnisses, der Verwaltungstätigkeit, den Aufbau der (spät-)mittelalterlichen Kurie und den gesamtkirchlichen Herrschaftsanspruchs der Bischöfe von Rom bieten.“ H-Soz-u-Kult

BÖHLAU VERLAG, URSULAPLATZ I, D-50668 KÖLN, T:+49 22I 9I3 90-O INFO@BOEHLAU-VERLAG.COM, WWW.BOEHLAU-VERLAG.COM | WIEN KÖLN WEIMAR 
Das Papsttum im 8. und 9. Jahrhundert sah sich unter wechselnden politischen Rahmenbedingungen mit einer Vielzahl von Anderen konfrontiert. Clemens Gantner untersucht in diesem Buch drei Beispiele, die das Papsttum in unterschiedlicher Weise geprägt haben: die Repräsentation des „byzantinischen" oder "griechischen“ Kaiserreichs, jene der Langobarden und Franken im 8. Jahrhundert und der Konflikt mit „Sarazenen“ genannten muslimischen Gruppen im 9. Jahrhundert. 